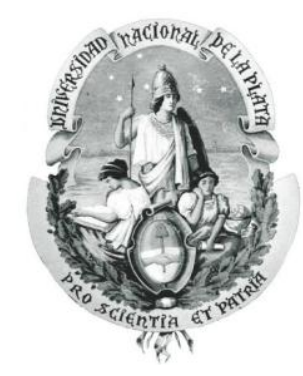

UNIVERSIDAD NACIONAL DE LA PLATA

FACULTAD DE CIENCIAS EXACTAS

Departamento de Química

Trabajo de Tesis Doctoral

\title{
DISEÑO DE PLATAFORMAS SENSIBLES \\ EMPLEANDO GRAFENO Y \\ NANOPARTÍCULAS METÁLICAS
}

María Celeste Dalfovo

Director: Francisco Javier Ibañez

Co-director: Marta Cecilia Yappert 
El presente trabajo se llevó a cabo en el Instituto de Investigaciones Fisicoquímicas Teóricas y Aplicadas (INIFTA) del Departamento de Química de la Facultad de Ciencias Exactas, Universidad Nacional de La Plata, bajo la dirección del Profesor Dr. Francisco Javier Ibañez, y en el Department of Chemistry de la University of Louisville, Kentucky, Estados Unidos, bajo la co-dirección de la Profesora Dra. Marta Cecilia Yappert. El mismo se presenta a consideración de las autoridades de dicha Facultad para acceder al grado académico de Doctor de la Facultad de Ciencias Exactas (UNLP).

\section{Miembros del Jurado:}

Dr. Marcelo R. Ceolín

Dra. Paula C. Angelomé

Dra. Laura C. Estrada

La Plata, Febrero de 2016.

Lic. María Celeste Dalfovo

e-mail: mcdalfovo@,inifta.unlp.edu.ar 
A mis padres, María Elena y Germán A mi hermano, Franco A mi hermano del alma, Jóse En la memoria de Alfredo y Eduardo 


\section{Agradecimientos}

A mis directores Francisco Ibañez y Cecilia Yappert, por haberme transmitido sus conocimientos y brindado las herramientas para poder desarrollar esta Tesis Doctoral.

A Francisco, quien ha sido mi máximo mentor en estos años, por toda su dedicación, empeño constante y sobre todo por la pasión con la que investiga cada día. No tengo palabras para agradecerle tanta ayuda.

A Cecilia y a su marido Donald, quienes han estado siempre dispuestos para ayudarme y brindarme su apoyo, y sobre todo por el cariño con el que me recibieron en cada visita a Louisville.

A Roberto Salvarezza, quien ha sido mi tercer co-director no oficial, con quien a lo largo de estos años he podido aprender, discutir la mayoría de los resultados aquí mostrados, y sobre todo me ha brindado siempre su punto de vista pragmático para resolver cada sistema en estudio.

A todos los integrantes del grupo de Nanoscopías del INIFTA. En especial a Gastón Corthey, Julio Azcárate, Alejandra Floridia, Germán Kürten, Flavia Lobo Maza, Emilia Alberdi, María Ángeles Dolores Manzo, Constanza Flores, Antonieta Daza Millone, Matías Calderón, Emiliano Cortés, Evangelina Pensa, Eduardo Prieto, Agustín Picco, Mariano Fonticelli, Aldo Rubert, Guillermo Benitez, María Elena Vela, Carolina Vericat, Patricia Schilardi, Yamil Chaín, Cecilia Sottile, Alejandro Ramirez, Federico Castez, Bárbara Blum, Laura Arnal, Doris Grumelli y María Ana Huergo.

A Julio, quien me ha brindado su conocimiento y ha estado de manera incondicional para ayudarme, aún en la distancia. Especialmente a Gastón, Alejandra, Germán Ángela, Flavia y Matías, quienes fueron incondicionales para enseñarme cada día, con quienes he compartido buenos y malos momentos científicos. ¡Gracias chicos!

Durante estos años, tuve la fortuna de conocer a muchas personas sin las cuales no hubiera sido posible desarrollar este trabajo. De todos ellos, hay cuatro personas que fueron mis mentores ( $i$ sin ellos saberlo!):

A Mariano Fonticelli, quien me abrió las puertas de su laboratorio y me brindó su valiosa ayuda en estos años. Quien ha estado de manera incondicional para darme sus consejos cada vez que lo necesité.

A Aldo Rubert, quien desde el comienzo de esta Tesis hasta la actualidad ha sido excepcional. Siempre brindándome su conocimiento, por su paciencia cada vez que le pedí ayuda y por su apoyo constante. 
A Lisandro Giovanetti, quien es mi tercer mentor. A quien le agradezco porque si bien no pertenezco a su grupo, siempre ha estado de manera incondicional para ayudarme, para enseñarme, y para brindarme buenos consejos.

A Gabriela Lacconi, a quien admiro profundamente. Con quien tuve la oportunidad de trabajar y aprender.

A Marita Mirífico, José Caram, Mauro Banera, Fernanda Rozas, Esther Svartman, Ethel Flores, por haberme abierto las puertas de sus laboratorios cada vez que lo necesité y por regalarme una sonrisa cada día.

A Javier Amalvi, Leandro Andrini, Matías Rafti, Facundo Herrera, Waldemar Marmisollé, Juan Giusi, Natalia Fagali, quienes en diferentes momentos de esta Tesis han estado para brindarme su ayuda.

A María Elisa Martins, Pablo S. Fernández, Dionisio Posadas, Inés Florit, Jorge Tomas, Miguel Sanservino, Alejandro Bonesi, quienes me abrieron las puertas de sus laboratorios cada vez que lo necesité. A María Elisa, por todos sus consejos. A Pablo, por haberme enseñado tanto, y sobre todo por la linda amistad que surgió luego de trabajar juntos. A Jorge, por su ayuda constante para resolver cada inconveniente que se presentó con el horno tubular.

A Mónica De-Melle y Claudia Grillo, por abrirme las puertas de su laboratorio cada vez que lo necesité. Por las buenas charlas y sobre todo por la energía tan linda que irradian.

A Florencia Álvarez, a quien siempre recordaré con mucho cariño.

A Félix Requejo, José Ramallo-López y Lisandro Giovanetti, por las medidas realizadas empleando luz sincrotrón y especialmente por la ayuda constante a lo largo de estos años.

A Cristián Huck Iriart, por las medidas de SAXS realizadas en el INIFTA. Por su ayuda desinteresada y su paciencia para enseñarme Python.

A Luis A. Pérez, por las medidas de TERS y sobre todo por las buenas discusiones respecto a los resultados obtenidos.

A Luis Foá Torres, quien a lo largo de estos años siempre ha estado dispuesto para brindarme su ayuda.

A Francis P. Zamborini, por las estadías en su grupo de investigación y principalmente por su enorme generosidad.

A Gamini Sumanasekera, por las medidas realizadas en su laboratorio y su ayuda en la interpretación de los resultados obtenidos.

A todo el personal del INIFTA, desde el taller hasta las secretarías. Especialmente a Coco Formoso, Alicia Ledesma, Andrés Curto, Liliana Hernández y a Mabel Antonelli, por la ayuda que siempre me brindaron. 
A Rosana Romano, quien ha estado siempre dispuesta a brindarme su ayuda.

Al Consejo Nacional de Investigaciones en Ciencia y Técnica (CONICET), al Laboratorio Nacional do Luz Sincrotrón (LNLS), al departamento de Química de la Universidad Nacional de La Plata (UNLP), por haberme financiado desde la beca doctoral hasta estadías de investigación que permitieron nutrir esta Tesis.

Al Department of Chemistry, al Conn Center for Renewable Energy, ambos de la University of Louisville, Kentucky, Estados Unidos.

A Dios, por darme salud, fuerzas y una Vida maravillosa para explorar cada día.

A continuación están los agradecimientos a todas aquellas personas externas al ambiente científico, sin las cuales no hubiera podido salir adelante:

A Alejandro Pinto, Quillén Catalán, Lorena Picone, Mónica Moreno, Karina Kornobis, Ayelén Catalán, Kathlyn (Katy) McGrown, Cecilia Bruni, José Giménez (Joselito), Federico (Fechi) Giménez, Lisandro (Lichi) Giménez, Martín (el Oso) Costi, Eduardo Gambino, Esteban Cataña, Juan (el Negro) Castro, Enrique (Quique) Socas Guevara, Demian Slobinsky, Martín Alaniz, Daniel Aguayo, Yoel Quiroga, Claudio Mercado, Valeria y Anabel Bustos, Bernardo y Carlos Sobre-Casas, Juan Basbús, Elif Hilal Soylu. ¡A las familias de todos mis amigos!

A Isabel Sola, Verónica y Luis Sobre-Casas, por cada charla compartida y por todo el cariño que me han brindado.

A mi familia, a mis amados padres Germán y María Elena, sin los cuales no hubiera podido resistir cada adversidad. Quienes me dieron la gran oportunidad de estudiar, y sobre todo que me brindaron los valores más importantes en la Vida.

A mi hermano Franco, quien admiro y quiero profundamente. ¡Gracias hermanito por tanto!

A mis tíos y primos, por tanto apoyo. Especialmente a mis tíos Alicia y Alfredo quienes me han acompañado con tanto cariño.

A mi abuela Elena, quien siempre tuvo las palabras justas cuando más lo necesité.

A Delia Dalla Cia, mi abuela del alma.

En la memoria de Alfredo Fernández y Eduardo Ercoli, mi abuelo y tío, respectivamente. Por todo lo que me enseñaron, por tanto cariño y consejos. A quienes extraño a diario, y sé que hoy estarían muy orgullosos de saber hasta donde llegué.

M.C.D.

La Plata, Febrero de 2016. 


\section{Índice General}

\section{Agradecimientos}

Resumen

Abstract

I. Introducción .1

1.1. Plataformas Sensibles

1.1.1 Definición de Sensor Químico/Biológico/Gases

1.2 Aplicaciones de Nanomateriales en el Diseño de Sensores

1.2.1 Definición de Nanomaterial y Nanotecnología

1.2.2 ¿Porqué usar Nanomateriales?

1.2.3 Dispositivos para el Sensado de Gases

1.3 Nanopartículas (NPs) Metálicas

1.3.1 Dispositivos con Nanopartículas

1.4 Grafeno $(\mathrm{G})$ y Nanocarbones

1.4.1 Grafeno: el Carbono Bidimensional

1.4.2 Métodos de Obtención de Grafeno

1.4.3 Algunas Propiedades de Grafeno con Mayores Implicancias en el Diseño de Dispositivos

\subsubsection{Dispositivos con Grafeno}

1.4.5 Otras Aplicaciones Actuales Utilizando Grafeno

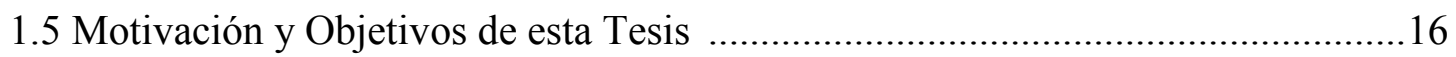

1.6 Lugar de Trabajo y Trabajo en Colaboración .......................................................16

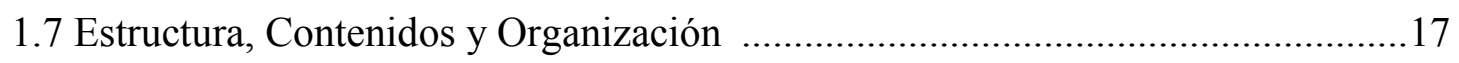

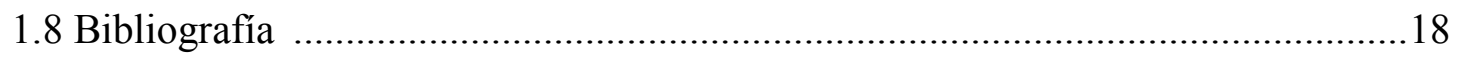

\section{Sección I - Métodos}

II. Métodos Experimentales.

Sección A: Síntesis de Nanomateriales

2.1 Materiales

2.1.1 Agua

2.1.2 Limpieza del Material 
2.1.2.1 Permanganato de Potasio

2.1.2.2 Solución "Piraña"

2.1.2.3 Agua Regia

2.1.3 Reactivos Generales

2.1.3.1 Preparación de Sales de Metales

2.2 Síntesis de Nanopartículas Metálicas Solubles en Medio Orgánico

2.2.1 Nanopartículas de Au Cubiertas con Bromuro de Tetraoctilamonio (Au@TOABr, SNPs)

2.2.2 Nanopartículas Bimetálicas de $\mathrm{Au} / \mathrm{Ag}$ Cubiertas con Bromuro de

Tetraoctilamonio (Au/Ag@TOABr, SNPs)

2.2.3 Nanopartículas de Au Cubiertas con Dodecilamina $\left(\mathrm{Au} @ \mathrm{NH}_{2} \mathrm{C}_{12}\right)$

2.2.4 Nanopartículas de Au Cubiertas con Octilamina $\left(\mathrm{Au} @ \mathrm{NH}_{2} \mathrm{C}_{8}\right)$

2.2.5 Nanopartículas de Au Cubiertas con Dodecanotiol (Au@ $\left.\mathrm{SC}_{12}\right)$

2.2.6 Nanopartículas de Au Cubiertas con Hexanotiol (Au@ $\mathrm{SC}_{6}$ )

2.2.7 Nanopartículas de Pd Cubiertas con Octilamina $\left(\mathrm{Pd} @ \mathrm{NH}_{2} \mathrm{C}_{8}\right)$

2.2.8 Nanopartículas de Pt Cubiertas con Octilamina $\left(\mathrm{Pt} @ \mathrm{NH}_{2} \mathrm{C}_{8}\right)$

2.2.9 Nanopartículas de Pd/Pt Bimetálicas Cubiertas con Octilamina $\left(\mathrm{Pd} @ \mathrm{NH}_{2} \mathrm{C}_{8}\right)$

2.3 Síntesis de Nanopartículas Metálicas Solubles en Medio Acuoso

2.3.1 Nanopartículas de Au Cubiertas con Citrato (Au@citrato, CNPs)

2.3.2 Nanopartículas de Ag Cubiertas con Citrato (Ag@citrato, Ag CNPs)

2.4 Crecimiento de Grafeno por Deposición Química de Vapores (CVD)

2.4.1 Disposición (set-up) experimental

2.4.2 Crecimiento de Grafeno sobre Láminas de $\mathrm{Cu}$

2.4.3 Transferencia de Grafeno a Diferentes Sustratos

2.4.3.1 Transferencia de Grafeno Utilizando Polimetilmetacrilato (PMMA)

2.4.3.2 Transferencia de Grafeno Utilizando Au@TOABr NPs

("Grafeno Libre de PMMA")

2.5 Ensamblado de Nanopartículas sobre Sustratos (películas de NPs)

2.5.1 Películas de NPs para Experimentos y Caracterización por UVvisible

2.5.2 Películas de NPs para Caracterización por Microscopías (TEM,

SEM y AFM)

2.6 Tratamiento de las Películas de NPs

2.6.1 Tratamiento Térmico

2.6.2 Tratamiento con Ozono

2.6.3 Tratamiento con Tioles y Ditioles

2.7 Microelectrodos

2.7.1 Microfabricación de Electrodos de Au sobre $\mathrm{Si} / \mathrm{SiO}_{x}$

2.7.2 Limpieza y Cableado 
Sección B: Caracterización de Nanomateriales

2.8 Voltamperometría Cíclica (CV) y Cronoamperometría (CA)

2.8.1 Medidas de Corriente en Estado Sólido

2.9 Espectroscopía Ultravioleta-visible (UV-vis)

2.9.1 UV-vis de Nanopartículas en Solución

2.9.2 Experimentos de Sensado por UV-vis

2.10 Espectroscopía Infrarroja por Transformada de Fourier (FT-IR)

2.10.1 FT-IR de Películas de Nanopartículas

2.10.2 Experimentos de Sensado por FTIR

2.11 Espectroscopía de Fotoelectrones Generados por Rayos-X (XPS)

2.12 Espectroscopía de Absorción de Rayos X (XAS)

2.13 Dispersión de Rayos-X a Bajo Ángulo (SAXS)

2.14 Dispersión de Rayos-X a Bajo Ángulo con Incidencia Rasante (GISAXS)

2.15 Microscopía Electrónica de Transmisión (TEM)

2.16 Microscopía de Fuerza Atómica (AFM)

2.17 Microscopía Electrónica de Barrido (SEM)

2.18 Microscopía Confocal Raman

2.19 Tip-enhanced Raman spectroscopy (TERS)

2.19.1 Principios Básicos: TERS

2.19.2 Componentes Principales de un Equipo TERS

2.19.3 TERS Acoplado a un Microscopio de AFM

2.20 Análisis Termogravimétrico (TGA)

2.21 Bibliografía

\section{Sección II - Sensado de Compuestos Orgánicos Volátiles (VOCs)}

III. Detección de VOCs Usando Películas con Nanopartículas de Au

3.1. Introducción

3.2. Experimental

3.2.1 Síntesis de Nanopartículas

3.2.2 Preparación de las Películas

3.2.3 Caracterización de las Películas

3.2.4 Experimentos de Sensado

3.3. Resultados

3.3.1 Determinación del Tamaño y Separación de las Nanopartículas

3.3.2 Sensado por LSPR

3.3.3 Hinchamiento de la Película

3.3.4 Teoría de Mie y Compactación de la Película 


\subsubsection{Sensado por FT-IR}

3.3.6 Estabilidad del Sensor Durante Largos Períodos

3.4. Conclusiones

3.5. Bibliografía

IV. Estudio del Mecanismo de Sensado de VOCs por GISAXS

4.1. Introducción

4.2. Experimental

4.2.1 Síntesis de Nanopartículas de Au Protegidas con Surfactante (SNPs)

4.2.2 Ensamblado de las Películas de Nanopartículas para su Caracterización por GISAXS, XANES y UV-vis

4.2.3 Tratamiento de las Películas con Tioles y Ditioles

4.2.4 Sensado de VOCs Utilizando GISAXS in-situ

4.2.5 Otras Técnicas de Caracterización

4.3. Resultados

4.3.1 Ensamblado de las Películas y Correlación

4.3.2 SAXS en Sistemas Isotrópicos Sin Correlación: Ley de Guinier

4.3.3 Distancia Inter-Nanopartículas en Nanopartículas con Correlación

4.3.4 Cambios en las Distancias entre las Nanopartículas y Estructura de la

Película en la presencia de VOCs

4.3.5 Flexibilidad de las Películas

4.3.6 Estudios Químicos y Estructurales de las Cadenas Alquílicas Después del Intercambio con Tioles

4.4. Conclusiones

4.5. Bibliografía

\section{Sección III - Grafeno como Plataforma Sensible}

V. Introducción al Primer Nanomaterial Bidimensional (2D): Grafeno.

5.1. Introducción

5.2. Experimental

5.2.1 Síntesis de NPs de Au y Grafeno

5.2.2 Tratamientos a las Películas Transferidas

5.2.3 Caracterización de las Películas

5.2.4 Experimentos Empleando Espectroscopia Raman

5.2.5 Medidas de Conducción en Estado Sólido y Sensado de Luz UV

5.3. Resultados

5.3.1 Espectroscopia Raman Aplicada a Grafeno

5.3.2 Caracterización Preliminar del Grafeno Obtenido

5.3.3 Formación de las Heterojunciones 
5.3.4 Apagado de la Fotoluminiscencia por Grafeno

5.3.5 Efectos Sinérgicos en las Heterojunciones Conformadas por Grafeno (G) y Grafeno Oxidado (OG)

5.3.6 Sensado de Luz UV

5.4. Conclusiones

5.5. Bibliografía

\section{Sección IV - Implicancias en la Formación de Heterojunciones (Grafeno + NPs} Metálicas)

VI. Diseño de Plataformas Sensibles con Heterojunciones. Caracterización por TERS y SERS.

6.1. Introducción

6.2. Experimental

6.2.1 Síntesis de las Nanopartículas de Au Protegidas con TOABr (Au@TOABr)

6.2.2 Síntesis de Grafeno por CVD

6.2.3 Procedimiento para la Transferencia de Grafeno Libre de PMMA y

Formación de la Heterojunción

6.2.4 Tratamiento Térmico

6.2.5 Caracterización Microscópica

6.2.6 Caracterización Espectroscópica

6.3. Resultados

6.3.1 Transferencia de Grafeno Libre de PMMA

6.3.2 Caracterización por Tip-Enhanced Raman Spectroscopy (TERS)

6.3.3 Actividad SERS Sobre un Único Nanoplate Triangular

6.3.4 Actividad SERS sobre Redes de NPs de Au

6.4. Conclusiones

6.5. Bibliografía

VII. Sensado de Hidrógeno con Nanopartículas de Pd, Pt y aleaciones Pd/Pt 198

7.1. Introducción

7.2. Experimental

7.2.1 Síntesis de los Nanomateriales

7.2.2 Ensamblado de las Películas: Formación de las Heterojunciones sobre Grafeno

7.2.3 Ensamblado de las Películas sobre Si/APTES: Experimentos de Control

7.2.4 Caracterización por SAXS

7.2.5 Caracterización por GISAXS

7.3. Resultados 
7.3.1 Caracterización de las Nanopartículas en Solución por SAXS

7.3.2 Sensado de Hidrógeno con Películas de Grafeno/ $\mathrm{Pd} @ \mathrm{NH}_{2} \mathrm{C}_{8}$

7.3.2 Sensado de Hidrógeno con Películas de Grafeno/Pd/Pt (1:1)@ $\mathrm{NH}_{2} \mathrm{C}_{8}$

7.4. Conclusiones

7.5. Bibliografía

Sección V - Parte final

VIII. Conclusiones Generales y Perspectivas....................................................................220

A.1. Abreviaturas, Siglas y Acrónimos ............................................................................227

A.2. Constantes Físicas .........................................................................................................229

B.1. Cambios Esperados en el Valor de LSPR Calculados Empleando la Teoría de

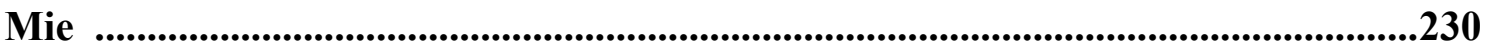

C.1. Trabajos Publicados ...................................................................................................232

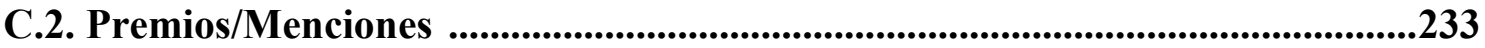




\section{Resumen}

Existe una gran necesidad de detectar analitos en diversas áreas tales como el monitoreo ambiental, el diagnóstico de enfermedades, la seguridad en alimentos, hasta potenciales amenazas químicas y biológicas, las cuales demandan a la ciencia y tecnología a que se desarrollen nuevos materiales (dispositivos) que posean propiedades superlativas.

En este contexto, la presente Tesis aborda el uso de plataformas sensibles las cuales emplean nanopartículas (NPs) protegidas con grupos orgánicos y grafeno (G) en su parte constitutiva. Cabe mencionar que, las obtenciones de los nanomateriales se realizaron íntegramente en el laboratorio a través de métodos de síntesis química y por deposición química de vapores (CVD), respectivamente.

En primer lugar, se desarrollaron sensores ópticos explotando las propiedades plasmónicas de las NPs, los que permitieron la detección de compuestos orgánicos volátiles (VOCs) y una mejora sustancial de la selectividad del sensor. A su vez, en aspectos de ciencia básica, se exploró en el mecanismo de sensado a través de técnicas convencionales tales como FT-IR, como así también con el uso de técnicas más sofisticadas y sensibles como GISAXS y XANES. Lo cual permitió explorar "en tiempo real" cuestiones como la organización de la cadena orgánica que rodea a las NPs (desplazamientos en el numero de onda), los cambios de color (plasmones) a través de cambios en la distancia entre centros metálicos, y la restructuración de la película frente a la presencia de analitos polares y no-polares.

En segundo lugar, conociendo que grafeno presenta una nube de electrones- $\pi$, los cuales están confinados en una superficie bidimensional, se diseñaron plataformas para mejorar técnicas de superficie tales como SERS (surface-enhanced Raman scattering) y TERS (tip-enhanced Raman spectroscopy). Las mismas se construyeron utilizando grafeno $(\mathrm{G})$, NPs metálicas y combinaciones de ambos $(\mathrm{G}+\mathrm{NPs})$ conocidas como heterojunciones, para la detección de bajas concentraciones de analitos de interés. Por último, se emplearon plataformas híbridas en estado sólido conformadas de G y NPs de metales de transición ( $\mathrm{Pd}, \mathrm{Pt}$ y aleaciones entre $\mathrm{Pd} / \mathrm{Pt}$ ) contribuyendo a la compresión en la interacción entre el $\mathrm{H}_{2}$ y los centros metálicos, lo cual permitirá conocer con mayor profundidad cuestiones relacionadas al sensado, catálisis y potenciales usos de este sistema en almacenamiento de energía.

Palabras claves: nanopartículas (NPs), plasmones, grafeno (G), heterojunciones (grafeno + NPs metálicas), sensores/plataformas sensibles, compuestos orgánicos volátiles (VOCs), hidrógeno $\left(\mathrm{H}_{2}\right)$, Fourier transform infrared spectroscopy (FT-IR), grazing-incidence small-angle X-ray scattering (GISAXS), X-ray absorption near edge structure (XANES), surface-enhanced Raman scattering (SERS), tip-enhanced Raman spectroscopy (TERS), chemical vapor deposition (CVD). 


\section{Abstract}

Title: Design of Sensitive Platforms Using Graphene and Metallic Nanoparticles

There is a great need to detect analytes in various areas such as environmental monitoring, medical diagnostics, food safety to potential chemical and biological threats, which demands to science and technology to develop new materials (devices) with superlative properties.

In this context, the present Thesis addresses the use of sensitive platforms which employ nanoparticles (NPs) protected with organic groups and graphene (G) in their constitutive part. It is important to mention that the variety of nanomaterials was entirely made in the laboratory by chemical synthesis methods and chemical vapor deposition (CVD), respectively.

First, optical sensors were developed by exploiting the plasmonic properties of the NPs, which allowed the detection of volatile organic compounds (VOCs) and a substantial improvement in the selectivity of the sensor. Likewise, in basic science aspects, the sensing mechanism was explored through conventional techniques such as FT-IR, as well as the use of more sophisticated and sensitive techniques such as GISAXS and XANES. This permitted us to investigate "in real time" issues like organization of organic ligands surrounding the NPs (by wavenumber shifts), color changes (plasmon) due to changes in the distance between metallic cores, and restructuring of the film in the presence of polar and non-polar analytes.

Second, knowing that graphene has a $\pi$-electron cloud, which are confined in a two-dimensional surface, we designed platforms in order to improve surface techniques such as SERS (surface-enhanced Raman scattering) and TERS (tip-enhancement Raman spectroscopy). These platforms were constructed using graphene $(\mathrm{G})$, metal NPs and a combination of both $(\mathrm{G}+\mathrm{NPs})$ known as heterojunctions to detect low concentrations of analytes. Finally, hybrid platforms in solid state made of $\mathrm{G}$ and transition metal NPs ( $\mathrm{Pd}, \mathrm{Pt}$ and $\mathrm{Pd} / \mathrm{Pt}$ alloys) were used and contributed to a better understanding in the interaction between hydrogen $\left(\mathrm{H}_{2}\right)$ and metallic cores, which shed light onto issues related to sensing, catalysis and potential uses in energy storage systems.

Keywords: nanoparticles (NPs), plasmon, graphene (G), heterojunctions (graphene + metal NPs), sensors/sensitive platforms, volatile organic compounds (VOCs), hydrogen $\left(\mathrm{H}_{2}\right)$, Fourier transform infrared spectroscopy (FT-IR), grazing-incidence small-angle X-ray scattering (GISAXS), X-ray absorption near edge structure (XANES), surfaceenhanced Raman scattering (SERS), tip-enhanced Raman spectroscopy (TERS), chemical vapor deposition (CVD). 
ÍNDICE GENERAL 


\section{Capítulo 1}

\section{Introducción}

Con la creciente demanda de dispositivos que puedan medir y detectar diferentes tipos de analitos y que a su vez posean los atributos de: bajo costo, sensibilidad, robustez, y cortos tiempos de respuesta, entre otros, se están realizado grandes esfuerzos tanto a nivel de ciencia básica como en ciencia aplicada para la obtención de materiales con propiedades acordes a cada necesidad.

La gran ubiquidad de dichos dispositivos abarca áreas tan diversas como el monitoreo ambiental, el diagnóstico de enfermedades, el área forense, la seguridad en alimentos, hasta prevenir amenazas químicas. Así mismo, podemos imaginar en un futuro cercano la posibilidad de emplear dispositivos para diagnósticos médicos noinvasivos y hasta realizar análisis telemétricos (remotos).

Cabe mencionar que el desempeño de los dispositivos empleados como sensores podría mejorarse por ejemplo: a) aumentando la selectividad del mismo frente a analitos de diferente naturaleza; b) mejorando la sensibilidad; y/o c) incrementando la velocidad de respuesta del mismo frente a un analito dado. Es por ello que, uno de los grandes desafíos actuales es el empleo de nuevos materiales, tales como nanomateriales que puedan, debido a que presentan una gran área superficial, incrementar el tiempo de respuesta del sensor.

\subsection{Plataformas Sensibles}

\subsubsection{Definición de Sensor Químico/Biológico/Gases}

Se pueden definir a los sensores químicos, biológicos (biosensores) y de gases como dispositivos de medida, los cuales utilizan reacciones químicas o biológicas para detectar y cuantificar un analito específico o un evento. ${ }^{1}$

Así mismo, es posible diferenciar entre sensores químicos y biosensores de acuerdo a la naturaleza de su superficie activa (material receptor). Mientras que un sensor químico utiliza una membrana polimérica específica o algún otro material nobiológico, un biosensor emplea una biomolécula (ej.: enzima, anticuerpo, etc.) como receptor. Esos materiales empleados como receptores (y ligados al transductor) son los que interactúan y miden el analito, convirtiendo éste evento de reconocimiento en una señal eléctrica o de algún otro tipo. 
En la Figura 1.1 se muestra un esquema de los componentes básicos de un sensor (receptor y transductor) y algunas áreas de aplicación, adaptado según las referencias. ${ }^{1,2}$ Los principales materiales transductores incluyen: a) electrónicos (amperométricos, potenciométricos, impedancia/capacitancia); b) fotométricos (absorción o dispersión de luz, índice de refracción, fluorescencia); c) acústicos/mecánicos (acústicos, densidad, masa); y d) colorimétricos (térmicos, etc.). ${ }^{1,3,4}$ Luego, los cambios inducidos en el transductor debido al evento en la superficie activa, son expresados como una señal específica la cual podría incluir cambios en la impedancia, el voltaje, la intensidad de la luz, la reflectancia, el peso, el color o la temperatura. Finalmente, esta señal es luego detectada, amplificada y registrada en un siguiente módulo (el cual no se muestra en el esquema para una mayor simplicidad).

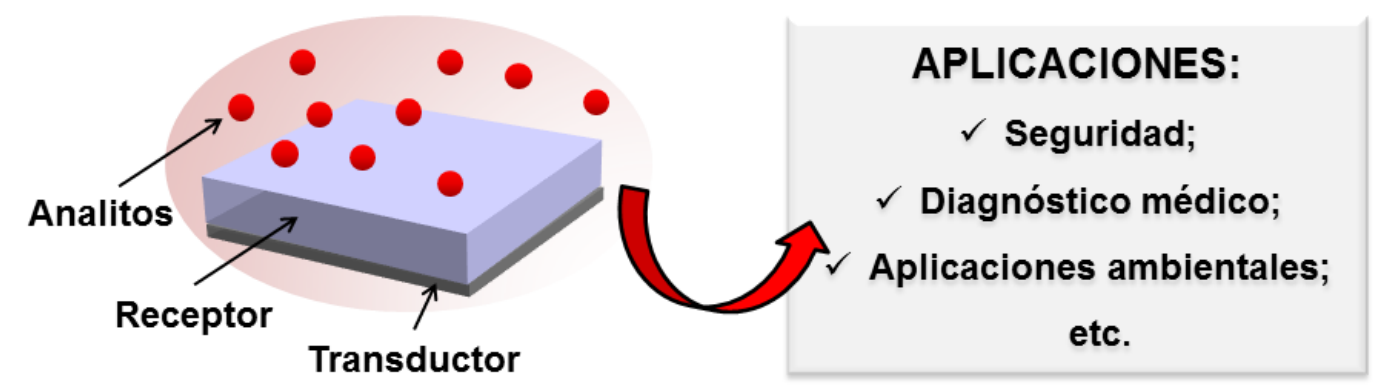

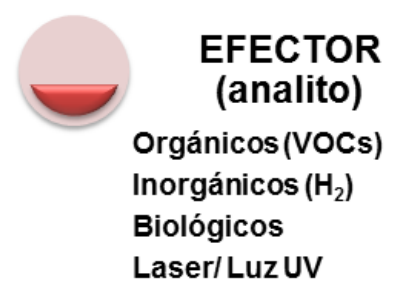

Laser/ Luz UV

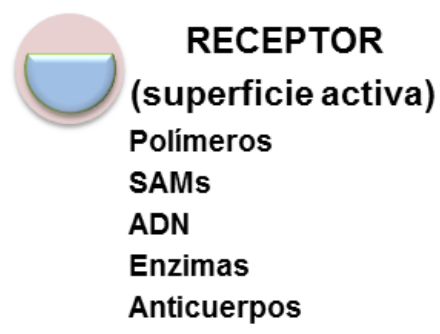

RECEPTOR

(superficie activa)

Polímeros

SAMs

Enzimas

Anticuerpos
TRANSDUCTOR

Electrónico

Fotométrico

Acústico/Mecánico

Colorimétrico

Figura 1.1 Esquema mostrando los componentes básicos de un sensor y algunas áreas de aplicación. Adaptado según las referencias. ${ }^{1,2}$

Como hitos históricos relevantes en el área de sensores, es necesario mencionar el desarrollo en 1922 del primer sensor químico portable para medir el pH de soluciones (pH-metro). ${ }^{5}$ Sin embargo, no fue hasta 1962, gracias a la invención de Clark y Lyons, que se desarrolló el primer sensor para la glucosa, el cual emplea la enzima glucosa oxidasa (GOD) como material activo. ${ }^{6}$ En este dispositivo, la GOD reacciona en la presencia de glucosa y oxígeno, produciendo ácido glucónico y agua oxigenada. De ésta 
manera, la disminución en la concentración de oxígeno es proporcional a la concentración de glucosa en la muestra. Dichos cambios son registrados como cambios de corriente en el sistema, y el dispositivo se calibra por medio del uso de un segundo electrodo (referencia), lo cual mejora la precisión en las medidas.

Uno podría preguntarse: ¿Cuál es el mejor sensor?, y la respuesta es que el mejor sensor es aquel que haga el trabajo de detección y al mismo tiempo que su costo justifique su utilización. Sin embargo, los requisitos son varios, tales como: a) la "robustez", definida como la habilidad de un dispositivo de mantener su rendimiento y utilidad (performance) aún bajo condiciones de operación adversas; y b) la "reversibilidad", en el contexto del sensado químico, significa que la respuesta sigue los cambios de concentración del analito en estudio, que opere en un régimen constante de trabajo, etc. ${ }^{3}$

Por otro lado, los requerimientos más importantes y universales en los sensores son la alta sensibilidad y la especificidad. Es por ello que, los avances en el descubrimiento de nuevos materiales (ej.: polímeros conductores, modificación de enzimas, nanomateriales, etc.) impulsan y demandan el desarrollo en las tecnologías de sensores.

\subsection{Aplicaciones de Nanomateriales en el Diseño de Sensores}

\subsubsection{Definición de Nanomaterial y Nanotecnología}

Recientemente la European Commission brindó la siguiente definición de nanomaterial: "A natural, incidental or manufactured material containing particles, in an unbound state or as an aggregate or as an agglomerate and where, for $50 \%$ or more of the particles in the number size distribution, one or more external dimensions is in the size range $1 \mathrm{~nm}-100 \mathrm{~nm}$ ". Así mismo, el Comité Técnico (TC-229) para la estandarización de las nanotecnologías de la Organización Internacional de Normalización (ISO) define a la nanotecnología como "the application of scientific knowledge to control and utilize matter at the nanoscale, where size-related properties and phenomena can emerge (the nanoscale is the size range from approximately $1 \mathrm{~nm}$ to $100 \mathrm{~nm}) . "{ }^{8-10}$

En éste contexto, es posible definir de manera general a los nanomateriales como aquellos materiales que poseen al menos una de sus dimensiones $\leq 100 \mathrm{~nm}$, siendo un 1 nanómetro $10^{-9} \mathrm{~m}$. Por consiguiente, los mismos pueden ser clasificados de acuerdo a sus dimensiones (D), surgiendo así los nanomateriales 0D, 1D, 2D y 3D.

El principio de la terminología "nano" podría ser establecido a partir de 1959, debido a que en éste año el Dr. en Física Richard Feynman brindó una memorable 
conferencia titulada: "There is a plenity of room at the bottom", durante una reunión de la American Physical Society en el California Institute of Technology (Caltech). ${ }^{11}$ En la misma, Feynman planteó sus hipótesis haciendo alusión en que en un futuro tanto los átomos como las moléculas podrían manipularse para crear diferentes estructuras, destacó la importancia de tener control sobre las pequeñas dimensiones y presentó sus ideas respecto al futuro de la miniaturización de circuitos electrónicos (ley de Moore), entre otros interesantes temas. Con el correr del tiempo y los grandes avances en la nanociencia, se confirmaron las ideas de esta eminencia en física y Premio Nobel.

Como ejemplo de lo expuesto anteriormente, casi 30 años más tarde de las predicciones de Feynman, un grupo de científicos logró manipular 35 átomos de Xenón formando las letras de IBM sobre un sustrato de Níquel, lo cual fue logrado gracias al empleo de un microscopio de efecto túnel (scanning tunneling microscopy, STM) en 1989. ${ }^{12,13}$ El mencionado avance, junto con el descubrimiento en 1991 de los nanotubos

de $\mathrm{C},{ }^{14}$ y el Premio Nobel otorgado por el descubrimiento de los fullerenos, ${ }^{15}$ son hitos suficientes para denotar que la "Era nano" estaba comenzando.

\subsection{2 ¿Por qué Nanomateriales?}

Algunas de las propiedades mencionadas en la sección anterior son asombrosas y están íntimamente asociadas a la variable "tamaño" la cual brinda beneficios tales como: a) la alta relación entre átomos en la superficie con aquellos en el volumen ( $\mathrm{S} / \mathrm{V})$; b) el quantum size effect; y c) los plasmones superficiales, entre otras propiedades.

En primer lugar, la alta relación $\mathrm{S} / \mathrm{V}$, es decir: la predominancia de átomos en la superficie sobre los átomos en el volumen, surgen propiedades físico-químicas tales como una gran adsorción molecular, ${ }^{16}$ aumento de las actividades tanto químicas como biológicas, ${ }^{17}$ grandes actividades y efectos catalíticos, ${ }^{18}$ sólo por mencionar algunas.

En segundo lugar, debido a que los nanomateriales presentan un confinamiento electrónico (quantum size effect) el cual se manifiesta con estructuras de bandas electrónicas discretas, tal como sucede en las moléculas, es posible desarrollar en un futuro cercano dispositivos que sean sensibles por ejemplo a la polarización de la luz. ${ }^{19}$

Por último, en cuanto a los plasmones superficiales, propiedad óptica que desarrollan las nanoestructuras de algunos metales nobles, y la cual adolece su contraparte (materiales masivos o bulk) permite que los primeros puedan ser empleados como plataformas sensibles. Un claro ejemplo de ello es la gran repercusión en nuestra sociedad de los conocidos test de embarazo, desarrollados a fines de los años $60{ }^{20}$ Estos dispositivos contienen nanopartículas de Au protegidas con anticuerpos que son capaces de reconocer a la hormona gonadotropina coriónica humana (hGC), permitiendo así un 99,99\% de exactitud en el resultado. El mecanismo de éste test implica: a) eventos de reconocimiento de la hormona hGG por el anticuerpo del tipo 
llave-cerradura; b) la aglomeración de las NPs; y c) finalmente la lectura de un cambio de color (plasmón) en el dispositivo, el cual es debido al efecto de los cambios en las distancias inter-nanopartículas.

Es importante mencionar que los nanomateriales pueden obtenerse por tres vías: a) "top-down"; b) "bottom-up"; y c) una combinación de ambas. En la primera, se emplean metodologías que permiten reducir alguna de las dimensiones del material hasta la escala del nanómetro. Las ventajas de ésta vía incluyen: parámetros bien controlados y la posibilidad de escalado de los materiales obtenidos. Sin embargo, presenta como desventajas la pérdida de material durante el procesamiento y el relativo alto costo económico en relación a los equipamientos necesarios para tal fin. En la segunda vía, se emplean por lo general rutas de síntesis que implican el ensamblado de las moléculas y átomos para obtener las nanoestructuras requeridas para una aplicación dada. Las ventajas de éste esquema incluyen: procesos bien controlados y la posibilidad de operar en condiciones rápidas y de bajo costo. Por último, en la última vía ambos esquemas "top-down" y "bottom-up" son combinadas para el diseño de nanomateriales más sofisticados. ${ }^{21}$

\subsubsection{Dispositivos para el Sensado de Gases}

Actualmente, existen una gran cantidad de sensores tanto para gases como para compuestos químicos/biológicos que se han visto beneficiados por las propiedades de los nanomateriales. ${ }^{22,21,23}$

A continuación se enumeran algunos ejemplos de analitos detectados. Primeramente, dentro del sensado de Compuestos Orgánicos Volátiles (VOCs), se han detectado analitos tales como: etanol, acetona, metanol, propanol, tolueno, entre otros. En el campo de los gases inflamables, se han detectado gases como: $\mathrm{H}_{2}, \mathrm{CH}_{4}, \mathrm{C}_{2} \mathrm{H}_{2}$ y $\mathrm{C}_{3} \mathrm{H}_{3}$. Por último, en el sensado de gases tóxicos, se pueden mencionar: $\mathrm{NO}_{2}, \mathrm{CO}, \mathrm{SO}_{2}$, $\mathrm{NH}_{3}, \mathrm{O}_{3}$ y $\mathrm{H}_{2} \mathrm{~S}$ como los de mayor relevancia.

Debido a que existe un amplio espectro de nanomateriales empleados en detección, y en esta Tesis se ha trabajado particularmente con nanopartículas de metales nobles y grafeno, a continuación se brindará una breve descripción de los mismos.

\subsection{Nanopartículas Metálicas}

\subsubsection{Dispositivos con Nanopartículas}

Como fue mencionado en la sección de nanomateriales, dentro de las propiedades más importantes para el diseño de dispositivos sensibles empleando 
nanopartículas (NPs), se pueden nombrar: a) los plasmones de metales nobles (propiedad crucial en el diseño de sensores ópticos) y b) la alta relación $\mathrm{S} / \mathrm{V}$.

En este sentido, es necesario destacar la amplia flexibilidad de las NPs cuando se requiere construir un dispositivo, debido a que las mismas pueden ser manipuladas en cuanto a: i) el tamaño; ii) la composición; iii) las diferentes formas; iv) los distintos tipos de ensamblados; y v) hasta la posibilidad de un encapsulado (ej.: aplicaciones en el área medica).

En los últimos años, se ha explorado el uso de nanopartículas (NPs) de Au y Ag en el diseño de nuevos sensores tanto químicos como bioquímicos, ${ }^{24}$ los cuales se construyen y diseñan ensamblando las NPs sobre diferentes plataformas, dependiendo de la señal analítica que se pretenda utilizar y amplificar. Ejemplos de diferentes tipos de sensores empleando NPs incluyen: piezoeléctricos, ${ }^{25}$ chemiresistores, ${ }^{26,27}$ fluorescentes $^{28}$ y colorimétricos. ${ }^{29}$ Este último tipo de sensores conocidos como localized surface plasmon resonance (LSPR) utilizan el plasmón de las NPs como señal frente a los analitos a detectar.

Particularmente, en los trabajos de Haick et al..$^{24,30,31}$ se demuestra la detección de un amplio abanico de VOCs asociados a diferentes tipos de cáncer (pulmón, mama, colon, próstata y ovárico) empleando sensores del tipo chemiresistivos ${ }^{1}$ con NPs metálicas como material sensible. Esto último demuestra los avances actuales en sistemas no invasivos de detección de enfermedades.

Por otro lado, con el fin de lograr obtener dispositivos que puedan ya sea detectar diferentes familias de compuestos químicos o que según el tipo de ensamblado de las NPs se obtengan sistemas con diferentes sensibilidades y/o selectividades frente a un analito en particular, se ha avanzado en el área de los "multisensores". A modo de ejemplo de lo expuesto, en la Figura 1.2A se muestra un esquema de tres películas con nanopartículas (NPs), las cuales fueron ensambladas a partir de un mismo tipo de NPs (mismo batch de síntesis) y dependiendo del tiempo y/o condiciones de ensamblado se obtienen diferentes absorciones en el UV-vis $\left(\lambda_{\text {máx }}\right)$, notar que también esta representado el espectro UV-vis de la solución de las NPs (paneles izquierdo y central), además se muestra una esquema de las películas interactuando con tres analitos diferentes (1, 2 y 3) los cuales generan diferentes respuestas analíticas (panel derecho).

A modo ilustrativo de las diferentes tipos de respuestas que se podrían obtener en un sensor colorimétrico, en la Figura 1.2B se muestran esquemas de los espectros UV-vis correspondientes a dos tipos de películas con NPs antes y después de haber sido expuestas a un analito determinado. Notar que en el panel izquierdo se produce un

\footnotetext{
${ }^{1}$ Un chemiresistor es un tipo de sensor que responde a la presencia de un analito, produciendo cambios de corriente o resistencia eléctrica del sistema.
} 
desplazamiento de la banda plasmónica a mayores longitudes de onda (desplazamiento batocrómico, $\Delta \lambda_{\text {máx }}$ ), en cambio en el panel derecho se produce un incremento en la absorbancia ( $\Delta$ Abs.máx) de la película. De lo expuesto, es posible notar que cada sensor va a interactuar de manera diferente frente a un analito dado, lo cual va a ser expresado por diferentes valores en las cifras de mérito, ${ }^{2}$ siendo éste último valor el que va a determinar la eficiencia o efectividad del dispositivo.

Finalmente, resulta novedoso que de una misma solución de NPs puedan obtenerse películas con NPs con diferentes propiedades ópticas, las que luego probablemente presenten diferentes sensibilidades y/o selectividades frente a un analito dado.

\footnotetext{
${ }^{2}$ Particularmente aquí, el término "cifras de mérito" se refiere a los valores numéricos obtenidos en un sistema durante la exposición a un analito, lo cual en fin va a determinar su eficiencia o efectividad en la detección. Esto puede ser ejemplificado en el caso de que un sistema dado manifieste valores absolutos

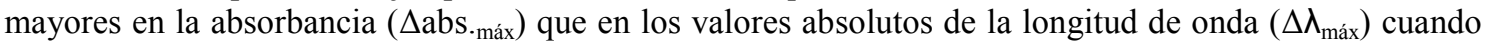
son expuestos a un mismo analito. Luego, para este caso particular se debería escoger la señal de la absorbancia como la cifra de mérito.
} 

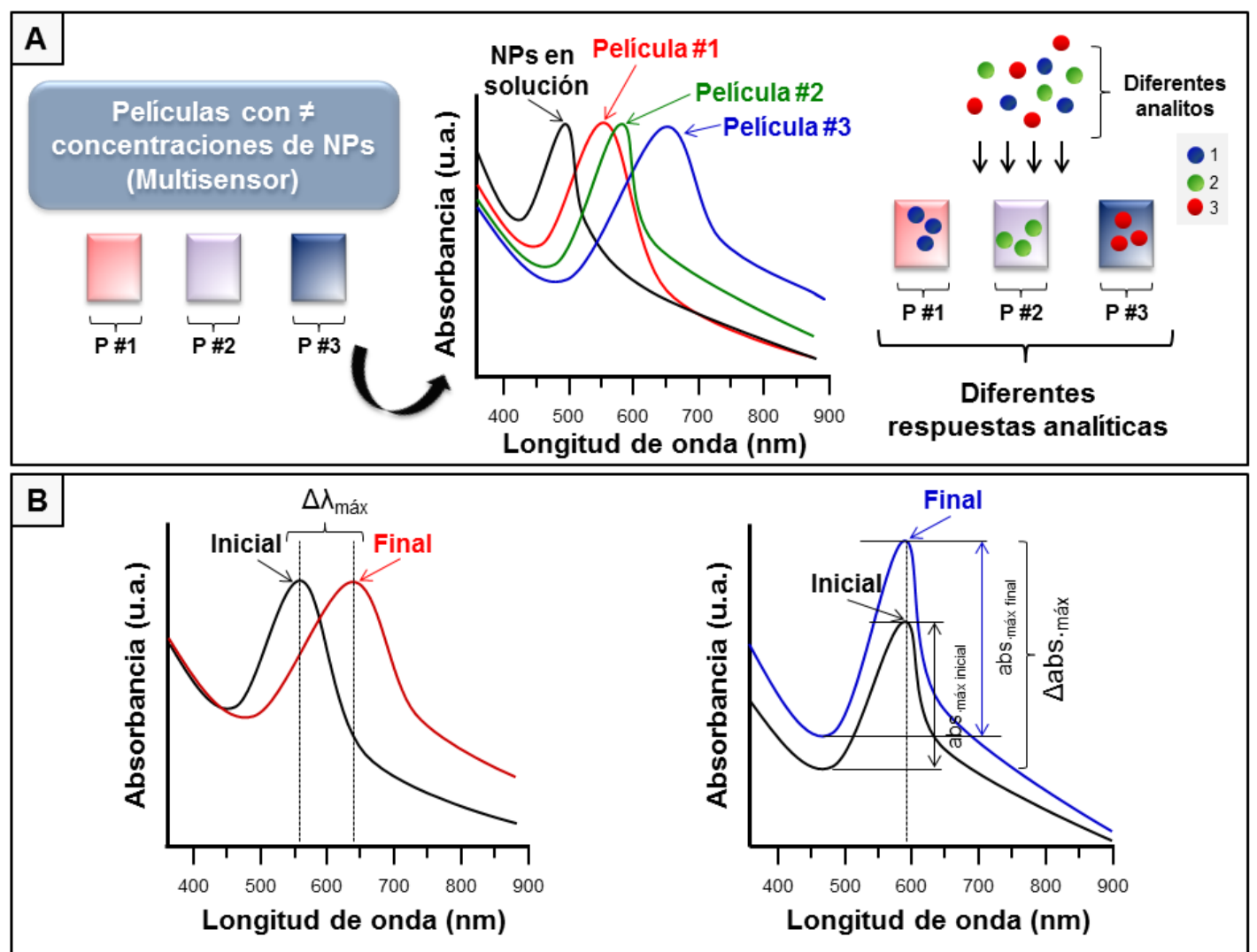

Figura 1.2 Esquema mostrando tres películas con nanopartículas (NPs), las cuales fueron ensambladas a partir de un mismo tipo de NPs (mismo batch de síntesis) y dependiendo del tiempo y/o condiciones de ensamblado se obtienen diferentes absorciones en el UV-vis $\left(\lambda_{\text {máx }}\right)$, por lo tanto diferentes colores, notar que también esta representado el espectro UV-vis de la solución de NPs (paneles izquierdo y central), además se muestra una esquema de las películas interactuando con tres analitos diferentes (1, 2 y 3$)$ los cuales generan diferentes respuestas analíticas (panel derecho) (A). Se muestran ejemplos de los espectros UV-vis correspondientes a dos tipos de películas con NPs antes y después de haber sido expuestas a un analito determinado. Notar que en el panel izquierdo se produce un desplazamiento de la banda plasmónica a mayores longitudes de onda (desplazamiento batocrómico, $\Delta \lambda_{\text {máx }}$ ), en cambio en el panel derecho se produce un incremento en la absorbancia $(\Delta \mathrm{Abs}$.máx $)$ de la película (B). De lo expuesto, cada sensor va a interactuar de manera diferente con un analito dado, lo cual va a ser expresado por diferentes valores en las cifras de mérito, siendo éste último valor el que va a determinar la eficiencia o efectividad del dispositivo. Ver más detalles en la Sección 1.3.1. 


\subsection{Grafeno y Nanocarbones}

Desde el punto de vista de la ciencia de los materiales, es posible anunciar que actualmente estamos transitando la Era del Carbono. Esta declaración tiene fundamentos en el amplio abanico de nuevas propiedades y aplicaciones de los nanocarbones (tales como fullerenos, nanotubos de carbono, y recientemente grafeno). Por ejemplo, se emplean fibras de carbono con el fin de reforzar materiales (ej.: plásticos) y convertirlos en conductores eléctricos, se han producido pantallas táctiles con grafeno $(\mathrm{G})$, se han mejorado celdas solares por el uso de $\mathrm{G}$ en sus ánodos, sumado al amplio espectro de compositos (ej.: pinturas conductoras y coberturas antiestáticas) con diferentes atributos, sólo por citar algunas. ${ }^{32,33}$

\subsubsection{Grafeno: el Carbono Bidimensional}

Grafeno es el primer cristal bidimensional (2D) aislado, donde todos sus átomos se encuentran en superficie, los cuales presentan una hibridación $s p^{2}$ y están organizados en una estructura de tipo panal de abejas. El mismo fue inicialmente aislado por medio de la exfoliación mecánica de grafito, utilizando una cinta Scotch en el 2004, lo que valió el premio Nobel en Física tan sólo 6 años más tarde. ${ }^{34}$

El mayor galardón fue otorgado a los científicos Andre K. Geim y Konstantin S. Novoselov, ambos de la University of Manchester, UK en el año 2010. El éxito de su descubrimiento fue poder aislar y caracterizar el grafeno, lo cual se refleja en la celeridad con que se otorgo tal distincion. ${ }^{35}$

Es conocido que grafeno exhibe propiedades electrónicas inusuales, como por ejemplo es considerado un semiconductor de energía prohibida cero $\left(\mathrm{E}_{\mathrm{g}}=0\right)$, siendo ésta última una propiedad que poseen sólo los metales. Debido a que tales cualidades surgen del confinamiento bidimensional (2D) de sus electrones y de sus peculiares simetrías geométricas, ${ }^{36}$ a continuación se brinda una breve descripción de la estructura electrónica del mismo.

\subsubsection{La Estructura Electrónica del Grafeno: el Concepto de Hibridación $s p^{2}$}

Primeramente es necesario definir el concepto de hibridación, el cual significa la mezcla de estados electrónicos de valencia. El Carbono tiene seis electrones, de los cuales dos están en el estado 1s y los cuatro restantes están ocupando los orbitales 2s y $2 \mathrm{p}$ (constituyendo electrones de valencia). Los orbitales 1 s están en aproximadamente $\mathrm{E}$ $=(-) 285 \mathrm{eV}, \mathrm{y}$ están ocupados por dos electrones (core electrons) los cuales no participan en enlaces químicos. Por otro lado, la segunda capa $(n=2)$ es más flexible, ya que la diferencia en energía entre los orbitales $2 \mathrm{~s}$ y $2 \mathrm{p}$ es menor que la energía ganada a través de la formación de un enlace C-C. Es por ello que, cuando los átomos 
de $\mathrm{C}$ se enlazan unos con otros, sus orbitales $2 \mathrm{~s}$ y $2 \mathrm{p}$ se combinan (mezclan) generando orbitales híbridos $s p^{\mathrm{n}}(\mathrm{n}=1,2,3) .^{10}$

En el caso del diamante, se combinan el orbital $2 \mathrm{~s}$ y tres orbitales $2 \mathrm{p}$ generando cuatro orbitales $s p^{3}$, enlazando cada átomo de $\mathrm{C}$ a cuatro $\mathrm{C}$ vecinos en los vértices de un tetraedro regular. ${ }^{37}$ Por otro lado, en la configuración $s p^{2}$, la cual surge de la combinación del orbital $2 \mathrm{~s}$ y dos orbitales $2 \mathrm{p}$ surgen tres enlaces covalentes en el plano. Aquí, cada átomo de $\mathrm{C}$ tiene tres vecinos, formando así una red hexagonal conocida como grafeno. Por último, la hibridación $s p$, la cual surge de la combinación del orbital 2s y únicamente un 2p, otorga cadenas lineales de átomos de C. En la Figura 1.3 se muestra un esquema de las configuraciones electrónicas del Carbono: estado basal (A), estado excitado (B), hibridación $s p^{3}(\mathrm{C})$, hibridación $s p^{2}$, e hibridación $s p$. Adaptado de la referencia. ${ }^{36}$

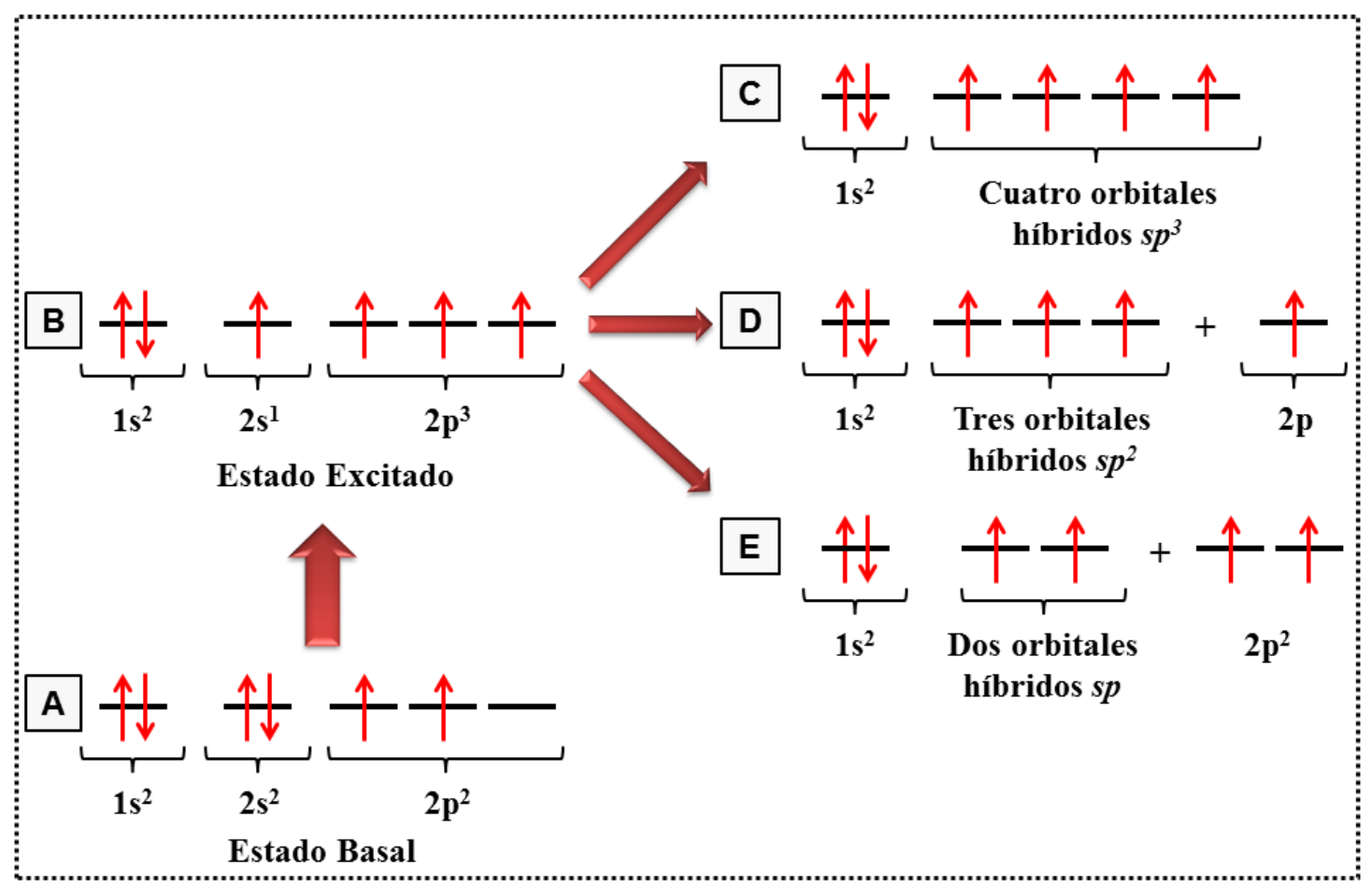

Figura 1.3 Esquema mostrando las configuraciones electrónicas del Carbono: estado basal (A), estado excitado (B), hibridación $s p^{3}$ (C), hibridación $s p^{2}$, e hibridación $s p$. Adaptado de la referencia. ${ }^{36}$ 
En la Figura 1.4 se muestra un esquema de la estructura de bandas de grafeno a lo largo de las direcciones de alta simetría $(\Gamma-K-M)$ en donde los orbitales híbridos $\pi$ y $\sigma$ están señalados cercanos a las bandas electrónicas (adaptado de la referencia). ${ }^{38}$ El nivel de Fermi esta asignado en cero. Dentro de la zona de Brillouin ${ }^{39}$ se da un entrecruzamiento inusual entre las bandas de valencia $\pi$ y de conducción $\pi^{*}$ en el punto de simetría $K$ generando el conocido cono de Dirac, la cual es una zona de alta dispersión de electrones. Es posible notar que las bandas enlazante $\sigma$ y anti-enlazante $\sigma^{*}$, están claramente separadas en energía $(\sim 12 \mathrm{eV}),{ }^{36}$ lo cual justifica que no participen en la mayoría de las propiedades físicas del grafeno.

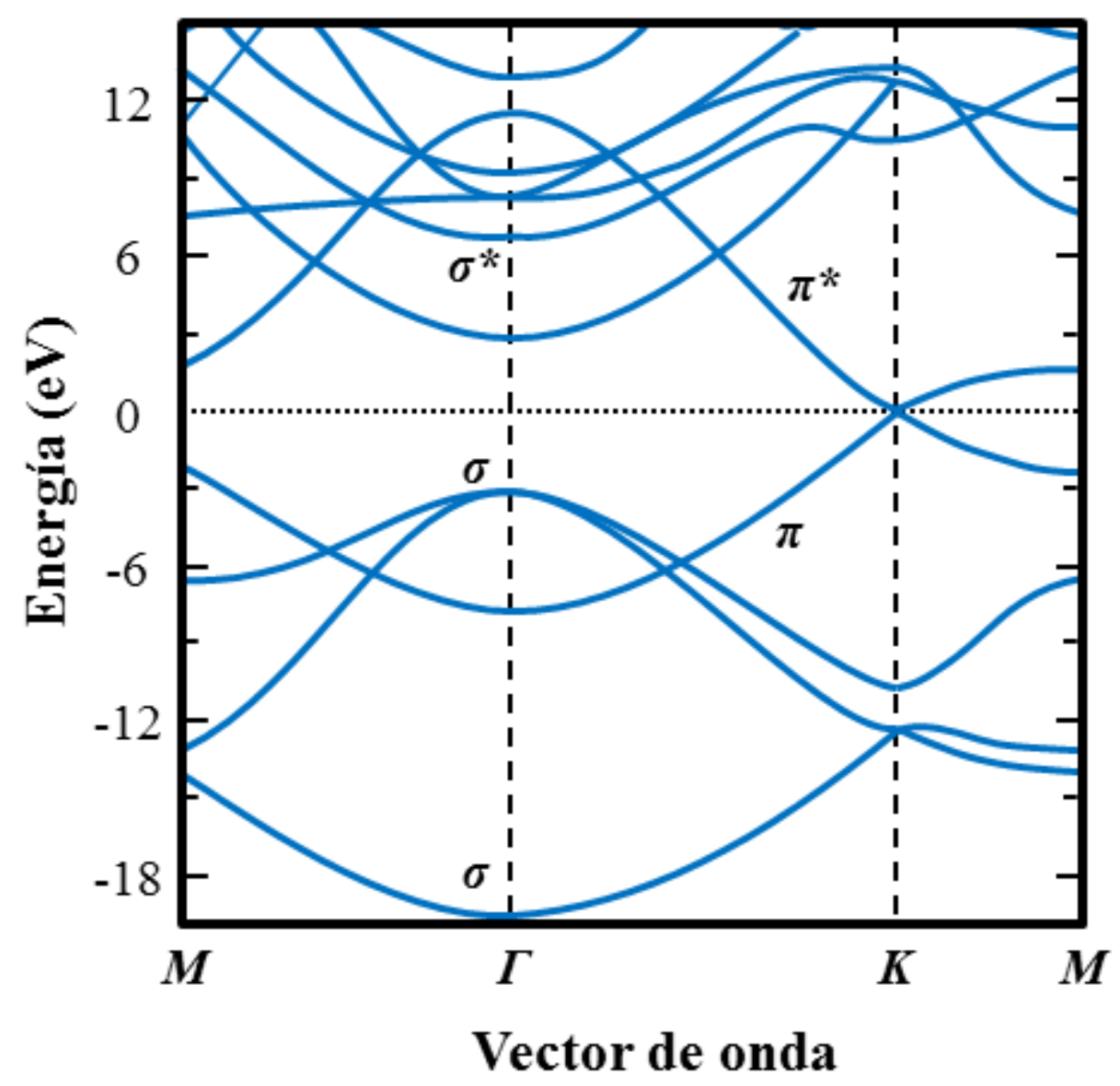

Figura 1.4 Esquema mostrando la estructura de bandas de grafeno. Los orbitales híbridos $\pi$ y $\sigma$ de los estados de valencia 2 s están indicados cercanos a las bandas electrónicas. El nivel de Fermi esta asignado en cero. Adaptado de la referencia. ${ }^{38}$

Finalmente, debido a la singular estructura de bandas de grafeno y por lo tanto a su superficie de Fermi, es que grafeno es un semiconductor con $\mathrm{E}_{\mathrm{g}}=0$ (energy gap). 


\subsubsection{Métodos de Obtención de Grafeno}

Actualmente, existen diferentes vías para la obtención de grafeno. Dentro de las más comúnmente empleadas se encuentran: a) la exfoliación mecánica de grafito; ${ }^{40}$ b) el método de Hummers; ${ }^{41}$ c) la electro-exfoliación (electroquímica) $;{ }^{42}$ d) la exfoliación por ultra-sonicación; y e) la Deposición Química de Vapores (Chemical Vapor Deposition, CVD), ${ }^{43}$ entre otras.

A continuación, se brinda un paneo general de las diferentes metodologías para la obtención de grafeno, haciendo énfasis en el conocido método de Deposición Química de Vapores (CVD), que es el que se ha empleado a lo largo de ésta Tesis.

Es importante mencionar que, dependiendo de la aplicación que se le va a otorgar a éste nanocarbón, es la metodología que se va a escoger.

\subsubsection{Exfoliación Mecánica}

La exfoliación mecánica (también conocida como "clivaje mecánico" o "método de la cinta Scotch") consiste en la exfoliación con una cinta adhesiva ya sea de una pieza de grafito natural o highly oriented pyrolytic graphite (HOPG), hasta lograr obtener una única monocapa de grafeno. Luego, la cinta se presiona sobre el sustrato sobre el cual se quiere transferir el grafeno, y finalmente retira la cinta con cuidado.

Este procedimiento fue reportado por primera vez en el 2004 por el grupo de Geim, en donde el tamaño del flake de grafeno observado fue de $50 \times 20 \mu \mathrm{m}^{40,44} \mathrm{Un}$ dato singular es que, si bien grafeno sólo absorbe $\sim 2,3 \%$ de la intensidad de la luz, se torna visible en el microscopio óptico cuando esta en la superficie de un wafer de $\mathrm{Si} / \mathrm{SiO}_{\mathrm{x}}$ con un espesor en la capa del óxido de $300 \mathrm{~nm}$. Esto último permite que exista un contraste (interferencia) entre el flake y el sustrato. ${ }^{40,45,46}$

Si bien ésta metodología permitió medir las fascinantes propiedades físicas del grafeno (sirve para estudios fundamentales de transporte físico y otras propiedades), presenta la desventaja de que los flakes obtenidos son pequeños (en el orden de las micras), tiene un bajo rendimiento y no es escalable.

\subsubsection{Exfoliación Mecánica por Ultra Sonicación}

Esta exfoliación mecánica se realiza en una solución (generalmente orgánica) conteniendo grafito en polvo o HOPG, la cual se somete a altas intensidades de ultrasonido. Las ondas inducen un proceso de cavitación que conduce a la exfoliación del grafito, mientras que el solvente previene que las capas de grafeno se re-apilen.

Dentro de los solventes orgánicos empleados, se pueden citar: N-metilpirrolidona (NMP), colato de sodio (SD), dodecilbenceno sulfonato de sodio (SDBS), N,N-dimetilacetamida (DMA) y N,N-dimetilformamida (DMF). ${ }^{33}$ Es importante tener 
en cuenta que la elección del solvente es un factor crucial tanto en la calidad del grafeno obtenido como en las aplicaciones en las que se podrá emplear.

Dentro de los usos que se plantean para éste tipo de grafeno son: a) la mejora de pinturas; b) la creación de tintas conductoras; c) la producción de compositos (ej.: supercapacitores); y d) el diseño de cuberturas con nuevas propiedades (ej.: disipadores de calor), entre otras. ${ }^{32}$

Aunque ésta técnica podría ser empleada con facilidad a grandes escalas, presenta las desventajas de que posee un bajo rendimiento, se obtienen flakes con diferentes números de capas de grafeno (few-layers graphene, FLW) y en general los flakes obtenidos son pequeños $(500 \mathrm{~nm}$ a $1 \mu \mathrm{m})$.

\subsubsection{Deposición Química de Vapores (CVD)}

El método de Chemical Vapor Deposition (CVD) consiste en emplear una fuente de Carbono en forma de gas (ej.: metano o etano), la cual es introducida en un reactor operando a altas temperaturas (entre 900 a $1000{ }^{\circ} \mathrm{C}$ ), y en donde se emplea como catalizador un sustrato metálico (metales de transición tales como $\mathrm{Cu}, \mathrm{Ni}, \mathrm{Pt}, \mathrm{Ru}, \mathrm{Ir}$ ). El reactor opera tanto en condiciones inertes $\left(\mathrm{N}_{2} \mathrm{u}\right.$ Ar) como en condiciones de atmósfera reductora $\left(\mathrm{H}_{2}\right)$, siendo éste último el que aporta los electrones para formar los enlaces C-C.

La función del metal catalizador es brindar el medio en el cual las moléculas del gas (fuente de $\mathrm{C}$ ) van a segregarse (en el caso de $\mathrm{Ni}$ ) o adsorberse (en el caso de $\mathrm{Cu}$ ). $\mathrm{Se}$ escogen metales de transición ya que éstos pueden disminuir la energía de las reacciones (precisamente la Energía de activación, EA) al mismo tiempo que presentan orbitales- $d$ parcialmente llenos, lo cual justifica su alta reactividad. ${ }^{47}$ Dependiendo de la solubilidad del $\mathrm{C}$ en el metal empleado como catalizador, se pueden definir dos mecanismos principales de crecimiento por CVD. En primer lugar, en los casos en los que se empleen metales en los cuales el $\mathrm{C}$ tiene alta solubilidad (ej.: $\mathrm{Co}$ y $\mathrm{Ni}$ ) con valores $>0,1 \%$, el mecanismo implica la difusión del $\mathrm{C}$ en el metal durante la temperatura de crecimiento, y finalmente una precipitación del $\mathrm{C}$ fuera del metal masivo durante el proceso de enfriamiento. Lo cual explica porque es más difícil obtener grafeno monocapa sobre Ni. En segundo lugar, en los casos en los que se empleen metales en los cuales la solubilidad del $\mathrm{C}$ es muy baja (ej.: $\mathrm{Cu})<0,001$, lo cual es prácticamente insignificante, el proceso implica una adsorción de las especies de hidrocarburos en la superficie del mismo. Es por ello que, en estos casos se obtienen predominantemente películas de grafeno mono y bicapa comprendiendo grandes áreas superficiales. $^{48}$

Los trabajos pioneros en el desarrollo de ésta metodología fueron desarrollados en diferentes grupos pertenecientes al Massachusetts Institute of Technology (MIT), al 
Brookhaven National Laboratory (BNL) e investigadores de Korea. ${ }^{49-51}$ Para mayores detalles experimentales de la técnica de CVD, se sugiere recurrir al Capítulo 2.

Dentro de las principales ventajas de la obtención de grafeno tanto por CVD como por crecimiento epitaxial, es la alta compatibilidad con la tecnología de los conocidos CMOS (complementary metal-oxide-semiconductor). Debido a que el grafeno obtenido es en general de muy buena calidad (monocapa y con ausencia de defectos) y se puede producir sobre un wafer entero, facilitando de ésta manera la integración de grafeno tanto en dispositivos como en los semiconductores usuales. ${ }^{52,33}$

Otra de las ventajas del Grafeno es su inminente aplicación en pantallas flexibles, tal como se planteó en el reporte de Hong et al., ${ }^{51}$ en donde se reportó la síntesis de G por CVD empleando Ni como catalizador, el cual luego de transferido mostró una resistencia muy baja de $\sim 280 \Omega / \square$, con una transparencia óptica de $\sim 80 \%$.

Finalmente, para brindar un ejemplo de la escalabilidad actual de grafeno, es necesario mencionar el trabajo de Hart et al. ${ }^{53}$ quienes reportaron por primera vez un reactor con un tubo concéntrico que permite la síntesis continua de grafeno por CVD con velocidades comprendidas entre 25 a $500 \mathrm{~mm} / \mathrm{min}$.

\subsubsection{Algunas Propiedades de Grafeno con Mayores Implicancias en el Diseño de Dispositivos}

Densidad: la celda unidad hexagonal de grafeno contiene dos átomos de $\mathrm{C}, \mathrm{y}$ tiene un área de $0,052 \mathrm{~nm}^{2}$. Luego, su densidad puede ser estimada en $0,77 \mathrm{mg} / \mathrm{m}^{2}$.

Transparencia óptica: el grafeno es considerado transparente, debido a que absorbe únicamente 2,3\% de la intensidad de la luz (independientemente de la longitud de onda empleada). ${ }^{54}$ Es por ello que grafeno suspendido carece de color.

Resistencia Mecánica: el grafeno posee una resistencia al rompimiento (breaking strength) de $42 \mathrm{~N} / \mathrm{m}$. Para el caso hipotético en el que se tuviera una lámina de acero bidimensional y del mismo espesor que grafeno, ésta tendría una resistencia al rompimiento entre 0,084 a $0,40 \mathrm{~N} / \mathrm{m}$. Por lo tanto, grafeno sería más de 100 veces más fuerte que el acero. ${ }^{55}$

Conductividad Eléctrica: considerando el espesor de una capa de grafeno, se calcula que la conductividad bulk del mismo es de $0,96 \times 10^{6} \Omega^{-1} \mathrm{~cm}^{-1}$. El mencionado valor es mucho mayor que la conductividad del $\mathrm{Cu}\left(0,60 \times 10^{6} \Omega^{-1} \mathrm{~cm}^{-1}\right)$.

Conductividad Térmica: la conductividad térmica de grafeno es de aproximadamente $5000 \mathrm{Wm}^{-1} \mathrm{~K}^{-1}$, la cual es dominada por fonones. Por otro lado, la conductividad térmica del $\mathrm{Cu}$ a temperatura ambiente es de $401 \mathrm{Wm}^{-1} \mathrm{~K}^{-1}$. Es por ello que grafeno conduce el calor 10 veces mejor que el $\mathrm{Cu}$. 
Propiedades Químicas y Biocompatibilidad: otras de las asombrosas características de grafeno son su alta resistencia química ${ }^{56,57}$ y su biocompatibilidad. ${ }^{58-60}$

\subsubsection{Dispositivos con Grafeno}

En el área de sensores puede mencionarse el reciente desarrollo de un dispositivo que puede determinar el grado de daño en el ojo humano (causado por ejemplo durante un accidente o en un campo de batalla) midiendo los niveles de ácido ascórbico (OcuCheck). ${ }^{61}$

Así mismo, respecto al desarrollo de plataformas sensibles, Duesberg et al. ${ }^{62}$ reportó recientemente un dispositivo conformado por láminas de $\mathrm{Au}$ recubiertas con grafeno obtenido por CVD, demostrando su uso en sensores del tipo surface plasmon resonance (SPR) para la detección de la toxina del cólera. El uso de grafeno en el mencionado sistema tiene dos ventajas, primeramente ayuda a aumentar la señal plasmónica en $\sim 80 \%$, y al mismo tiempo facilita el anclaje de los anticuerpos a la superficie del sensor.

\subsubsection{Otras Aplicaciones Actuales Utilizando Grafeno}

Con el fin de brindar un paneo general de las aplicaciones actuales de grafeno, en el año 2015 la revista Graphene-info elaboró una lista titulada "top 10 graphene applications". 63 En la misma se clasifican según el número de artículos publicados las diferentes áreas en las cuales se ha empleado grafeno para mejorar las propiedades de diferentes materiales. El orden del ranking es el siguiente: 1- Electrónica; 2- Sensores; 3- Baterías; 4- Medicina; 5- Composites; 6- Supercapacitores; 7- Coating; 8- 3D printing; 9-Solar; y 10-Displays.

En el área de la medicina, se pueden citar desde dispositivos que imitan el funcionamiento de una neurona (sinapsis artificial), ${ }^{64}$ dispositivos (nano-compositos) que mejoran la detección de aldehídos en el aliento de pacientes con cáncer de pulmón, ${ }^{65}$ hasta el desarrollo de materiales poliméricos (combinados con grafeno) que actúen como andamios (scaffolds) para el crecimiento de tejidos nerviosos. ${ }^{66}$

En el área de los supercapacitores, es posible ahondar en los microsupercapacitores (MSCs), los cuales si bien no son baterías tienen algunas características en común con éstas últimas. Recientemente, el grupo ${ }^{67}$ de Tour reporto el desarrollo de MSCs empleando grafeno. Estos dispositivos son capaces de: a) cargarse 50 veces más rápido que las baterías; b) descargarse con mayor lentitud que un capacitor tradicional; y c) se parecen a los supercapacitores disponibles en el mercado actual (en cuanto a energía y potencia). Sin embargo, uno de los atributos más importantes de éstos MSCs con grafeno, es que su manufactura es muy barata en comparación a las costosas tecnologías (ej.: litografía) empleadas para la fabricación de los supercapacitores comerciales. Sólo por mencionar algunas áreas. 


\subsection{Motivación y Objetivos de esta Tesis}

La principal motivación de esta Tesis Doctoral fue la síntesis de nanomateriales que actuarán juntos o por separado para el diseño, construcción y mejora de plataformas sensibles para la detección de diferentes analitos.

\subsection{Lugar de Trabajo y Trabajo en Colaboración}

La mayor parte de los resultados presentados en ésta Tesis han sido obtenidos en el Laboratorio de Nanoscopías y Fisicoquímica de Superficies del Instituto de Investigaciones Fisicoquímicas Teóricas y Aplicadas (INIFTA). Así mismo, parte del mismo ha sido producto de colaboraciones con diferentes grupos de investigación tanto Nacionales como Internacionales.

Gracias a un Convenio Marco celebrado entre la Universidad Nacional de La Plata y la University of Louisville, se pudieron estrechar lazos entre investigadores de ambas instituciones. Así mismo, debido a la estrecha colaboración con los Dres. Marta Cecilia Yappert, Francis P. Zamborini, Gamini Sumanasekera y Mahendra Sunkara, los dos primeros pertenecientes al Department of Chemistry y los dos últimos pertenecientes al Department of Physics and Astronomy (Conn Center for Renewable Energy Research) de la University of Louisville, Kentucky, Estados Unidos, fue posible comenzar a trabajar con grafeno.

La síntesis de grafeno por CVD sobre sustratos bidimensionales fue puesta a punto en el INIFTA por el Dr. Pablo S. Fernández y el Ing. Matías Calderón. Cabe mencionar, que el Dr. Jorge Thomas (INIFTA) colaboró durante todos los pasos concernientes a la puesta a punto del mencionado sistema. Luego, junto con el Dr. Fernández se puso a punto la síntesis de G sobre sustratos tridimensionales (espumas de $\mathrm{Ni})$.

Las caracterizaciones empleando Microscopia Raman se realizaron junto con la Dra. Gabriela I. Lacconi, de la Universidad Nacional de Córdoba, Argentina, durante varias estadías en su laboratorio. Las medidas de TERS fueron realizadas por el Dr. Luis Pérez y la Dra. Lacconi, ambos pertenecientes al Instituto de Investigaciones en Fisicoquímica de Córdoba (INFIQC), Córdoba, Argentina.

Las medidas de XPS fueron realizadas por los Dres. Aldo Rubert y Guillermo Benitez, ambos pertenecientes al grupo de Nanoscopías del INIFTA.

Los experimentos de GISAXS, SAXS y XANES se llevaron a cabo en el Laboratório Nacional do Luz Síncrotron (LNLS), Campinas, Brasil. Los mismos fueron 
realizados junto con los Dres. Lisandro J. Giovanetti, José M. Ramallo-López y Félix G. Requejo, pertenecientes al INIFTA, durante varias estadíass breves en el LNLS.

Las caracterizaciones empleando SAXS mostradas a lo largo del Capítulo 7 de esta Tesis, se llevaron a cabo en el INIFTA, en un equipo XENOCS de reciente incorporación. Las mismas fueron realizadas junto con los Dres. Lisandro J. Giovanetti y Cristián Huck Iriart, ambos pertenecientes al INIFTA.

Los microelectrodos utilizados en este trabajo fueron sintetizados por técnicas de litografía en Salas Limpias tanto de la University of Louisville (Kentucky, Estados Unidos) como de los laboratorios del Instituto Nacional de Tecnología Industrial (INTI), Argentina, estando a cargo en ésta última institución por el Lic. Gustavo Giménez.

Las medidas de microscopía electrónica de barrido (SEM) fueron realizadas junto con el Lic. Gustavo Giménez, perteneciente al laboratorio de Microtecnologías y Microsistemas del INTI, Buenos Aires, Argentina, durante una estadía en su laboratorio. Las caracterizaciones empleando microscopía electrónica de transmisión de alta resolución (HRTEM) y microscopía electrónica convencional (TEM) fueron realizadas por el Dr. Horacio Troiani y la Dra. Eugenia Zelaya, respectivamente, ambos pertenecientes al Centro Atómico Bariloche (CAB), Argentina.

\subsection{Estructura, Contenidos y Organización}

Este trabajo se divide en 5 secciones. La primera, Métodos, está compuesta por un capítulo (Capítulo 2) en donde se detallan los métodos experimentales requeridos para las síntesis de los nanomateriales, junto con descripciones breves de las técnicas de caracterización empleadas.

En la segunda sección, Sensado de Compuestos Orgánicos Volátiles (VOCs), se desarrolla el uso de nanopartículas (NPs) de Au protegidas con diferentes grupos orgánicos para el sensado óptico de compuestos orgánicos volátiles (volatile organic compounds, VOCs). En el Capítulo 3 se discuten los aspectos y resultados generales de los mencionados sensores ópticos. En el Capítulo 4, se abarca el estudio del mecanismo de sensado de VOCs empleando técnicas poderosas como GISAXS (grazing-incidence small-angle $X$-ray scattering) y XANES (X-ray absorption near edge structure), entre otras.

En la tercera sección, Grafeno como Plataforma Sensible, se introduce al lector al primer material bidimensional (2D) aislado: el Grafeno. El Capítulo 5, abarca desde la síntesis y aislación de Grafeno, hasta sus aplicaciones en detección de analitos en bajas concentraciones empleando SERS (surface-enhanced Raman scattering), entre otras técnicas. 
En la cuarta sección, Implicancias en la Formación de Heterojunciones (Grafeno + NPs Metálicas), se hace énfasis en la importancia y aplicaciones de sistemas híbridos conformados por grafeno y nanopartículas (NPs) metálicas. El Capítulo 6, se explora en el uso de sistemas híbridos como plataformas TERS (tipenhanced Raman spectroscopy) para la caracterización de grafeno (aumentando la resolución lateral y al mismo tiempo exaltando bandas que por microscopia Raman convencional no pueden definirse). En el Capítulo 7, se aborda el uso de sistemas híbridos, conformados por grafeno y nanopartículas de $\mathrm{Pd}$, Pt y aleaciones entre $\mathrm{Pd} / \mathrm{Pt}$, como sensores de Hidrógeno $\left(\mathrm{H}_{2}\right)$. Se desarrolla un análisis exhaustivo de las mencionadas plataformas por medio de GISAXS y SAXS (small-angle $X$-ray scattering).

En la quinta sección, Parte Final (Capítulo 8), se presentan las conclusiones generales y perspectivas a futuro para todos los sistemas estudiados.

\subsection{Bibliografía}

(1) Taylor, R. F.; Schultz, J. S. Handbook of Chemical and Biological Sensors; CRC Press, 1996.

(2) Ibañez, Francisco J. Doctoral Thesis. Title: Chemiresistive Sensing of Volatile Organic Compounds (VOCs) and Hydrogen $\left(\mathrm{H}_{2}\right)$ Gas with Films of OrganicStabilized Metal and Alloy Nanoparticles. Department of Chemistry, University of Louisville, KY, USA. (2008). Director: Francis Zamborini.

(3) Jiri Janata. Principles of Chemical Sensors, 2nd ed. 2009 edition.; Springer, 2009.

(4) Khanna, V. K. Nanosensors: Physical, Chemical, and Biological; CRC Press, 2011.

(5) Hughes, W. S. The Potential Difference between Glass and Electrolytes in Contact with the Glass. J. Am. Chem. Soc. 1922, 44 (12), 2860-2867.

(6) Clark, L. C.; Lyons, C. Electrode Systems for Continuous Monitoring in Cardiovascular Surgery. Ann. N. Y. Acad. Sci. 1962, 102, $29-45$.

(7) Definition - Nanomaterials - Environment - European Commission http://ec.europa.eu/environment/chemicals/nanotech/faq/definition_en.htm (accessed Jan 23, 2016).

(8) ISO - Technical committees - ISO/TC 229 - Nanotechnologies http://www.iso.org/iso/iso_technical_committee?commid=381983 (accessed Jan 22, 2016).

(9) Sattler, K. D. Handbook of Nanophysics: Nanotubes and Nanowires; CRC Press, 2010.

(10) Jorio, A.; Saito, R.; Dresselhaus, M. S.; Dresselhaus, G. Raman Spectroscopy in Graphene Related Systems; Wiley Vch Verlag Gmbh, 2011.

(11) Feynman, R. P. There's Plenty of Room at the Bottom. Engineering and Science 1960, 23 (5), 22-36.

(12) Eigler, D. M.; Schweizer, E. K. Positioning Single Atoms with a Scanning Tunnelling Microscope. Nature 1990, 344 (6266), 524-526. 
(13) Toumey, C. 35 Atoms That Changed the Nanoworld. Nat Nano 2010, 5 (4), 239241.

(14) Iijima, S. Helical Microtubules of Graphitic Carbon. Nature 1991, 354 (6348), $56-58$.

(15) The Nobel Prize in 1996 http://www.nobelprize.org/nobel_prizes/chemistry/laureates/1996/ (accessed Feb 21, 2016).

(16) Chae, H. K.; Siberio-Perez, D. Y.; Kim, J.; Go, Y.; Eddaoudi, M.; Matzger, A. J.; O'Keeffe, M.; Yaghi, O. M. A Route to High Surface Area, Porosity and Inclusion of Large Molecules in Crystals. Nature 2004, 427 (6974), 523-527.

(17) Flores, Constanza. Tesis Doctoral. Nanopartículas de Plata Con Potenciales Aplicaciones En Materiales Implantables: Síntesis, Caracterización Fisicoquímica Y Actividad Bactericida. Facultad de Ciencias Exactas, Universidad Nacional de La Plata. (2014). Director: Carolina Vericat, CoDirector: Patricia L. Schilardi.

(18) Rioux, R. M.; Song, H.; Hoefelmeyer, J. D.; Yang, P.; Somorjai, G. A. HighSurface-Area Catalyst Design: Synthesis, Characterization, and Reaction Studies of Platinum Nanoparticles in Mesoporous SBA-15 Silica. J. Phys. Chem. B 2005, 109 (6), 2192-2202.

(19) Acharya, S.; Sarma, D. D.; Golan, Y.; Sengupta, S.; Ariga, K. Shape-Dependent Confinement in Ultrasmall Zero-, One-, and Two-Dimensional PbS Nanostructures. J. Am. Chem. Soc. 2009, 131 (32), 11282-11283.

(20) Crane, M. M. Diagnostic Test Device. US3579306 A, May 18, 1971.

(21) Adisorn Tuantranont. Applications of Nanomaterials in Sensors and Diagnostics, 2013 edition.; Springer, 2013.

(22) Gouma, P.; Gouma, P.-I. Nanomaterials for Chemical Sensors and Biotechnology; Pan Stanford Publishing, 2009.

(23) Lvova, L.; Kirsanov, D.; Natale, C. D.; Legin, A. Multisensor Systems for Chemical Analysis: Materials and Sensors; CRC Press, 2014.

(24) Peng, G.; Tisch, U.; Adams, O.; Hakim, M.; Shehada, N.; Broza, Y. Y.; Billan, S.; Abdah-Bortnyak, R.; Kuten, A.; Haick, H. Diagnosing Lung Cancer in Exhaled Breath Using Gold Nanoparticles. Nat Nano 2009, 4 (10), 669-673.

(25) RM Crooks, A. R. New Organic Materials Suitable for Use in Chemical Sensor Arrays. Accounts Chem. Res. 1998, 31, 219-227.

(26) Ibañez, F. J.; Zamborini, F. P. Chemiresistive Sensing of Volatile Organic Compounds with Films of Surfactant-Stabilized Gold and Gold-Silver Alloy Nanoparticles. ACS Nano 2008, 2 (8), 1543-1552.

(27) Ibañez, F. J.; Zamborini, F. P. Chemiresistive Sensing with Chemically Modified Metal and Alloy Nanoparticles. Small 2012, 8 (2), 174-202.

(28) Oh, W.-K.; Jeong, Y. S.; Kim, S.; Jang, J. Fluorescent Polymer Nanoparticle for Selective Sensing of Intracellular Hydrogen Peroxide. ACS Nano 2012, 6 (10), 8516-8524.

(29) Mayer, K. M.; Hafner, J. H. Localized Surface Plasmon Resonance Sensors. Chem. Rev. 2011, 111 (6), 3828-3857.

(30) Peng, G.; Hakim, M.; Broza, Y. Y.; Billan, S.; Abdah-Bortnyak, R.; Kuten, A.; Tisch, U.; Haick, H. Detection of Lung, Breast, Colorectal, and Prostate Cancers 
from Exhaled Breath Using a Single Array of Nanosensors. Br. J. Cancer 2010, 103 (4), 542-551.

(31) Kahn, N.; Lavie, O.; Paz, M.; Segev, Y.; Haick, H. Dynamic Nanoparticle-Based Flexible Sensors: Diagnosis of Ovarian Carcinoma from Exhaled Breath. Nano Lett. 2015, 15 (10), 7023-7028.

(32) Novoselov, K. S.; Falko, V. I.; Colombo, L.; Gellert, P. R.; Schwab, M. G.; Kim, K. A Roadmap for Graphene. Nature 2012, 490 (7419), 192-200.

(33) Subbiah Alwarappan, Ashok Kumar. Graphene-Based Materials: Science and Technology, 1 edition.; CRC Press, 2013.

(34) Ferrari, A. C.; Meyer, J. C.; Scardaci, V.; Casiraghi, C.; Lazzeri, M.; Mauri, F.; Piscanec, S.; Jiang, D.; Novoselov, K. S.; Roth, S.; et al. Raman Spectrum of Graphene and Graphene Layers. Phys. Rev. Lett. 2006, 97 (18), 187401.

(35) The 2010 Nobel Prize in Physics - Press Release http://www.nobelprize.org/nobel_prizes/physics/laureates/2010/press.html (accessed Jan 22, 2016).

(36) Torres, L. E. F. F.; Roche, S.; Charlier, J.-C. Introduction to Graphene-Based Nanomaterials: From Electronic Structure to Quantum Transport; Cambridge University Press, 2014.

(37) Cotton, F. A.; Wilkinson, S. G. Advanced Inorganic Chemistry: A Comprehensive Text, Edición: 3Rev Ed.; John Wiley \& Sons Inc, 1972.

(38) Carbon Nanotubes: Basic Concepts and Physical Properties, 1 edition.; Wiley$\mathrm{VCH}, 2004$.

(39) Ashcroft, N. W.; Mermin, N. Solid State Physics; Brooks/Cole, 1976.

(40) Novoselov, K. S.; Geim, A. K.; Morozov, S. V.; Jiang, D.; Zhang, Y.; Dubonos, S. V.; Grigorieva, I. V.; Firsov, A. A. Electric Field Effect in Atomically Thin Carbon Films. Science 2004, 306 (5696), 666-669.

(41) Hummers, W. S.; Offeman, R. E. Preparation of Graphitic Oxide. J. Am. Chem. Soc. 1958, 80 (6), 1339-1339.

(42) Sidorov, A. N.; Sławiński, G. W.; Jayatissa, A. H.; Zamborini, F. P.; Sumanasekera, G. U. A Surface-Enhanced Raman Spectroscopy Study of Thin Graphene Sheets Functionalized with Gold and Silver Nanostructures by SeedMediated Growth. Carbon 2012, 50 (2), 699-705.

(43) Li, X.; Zhu, Y.; Cai, W.; Borysiak, M.; Han, B.; Chen, D.; Piner, R. D.; Colombo, L.; Ruoff, R. S. Transfer of Large-Area Graphene Films for HighPerformance Transparent Conductive Electrodes. Nano Lett. 2009, 9 (12), 43594363.

(44) Novoselov, K. S.; Jiang, D.; Schedin, F.; Booth, T. J.; Khotkevich, V. V.; Morozov, S. V.; Geim, A. K. Two-Dimensional Atomic Crystals. Proceedings of the National Academy of Sciences of the United States of America 2005, 102 (30), 10451-10453.

(45) Roddaro, S.; Pingue, P.; Piazza, V.; Pellegrini, V.; Beltram, F. The Optical Visibility of Graphene: Interference Colors of Ultrathin Graphite on $\mathrm{SiO}_{2}$. Nano Lett. 2007, 7 (9), 2707-2710.

(46) Blake, P.; Novoselov, K. S.; Neto, A. H. C.; Jiang, D.; Yang, R.; Booth, T. J.; Geim, A. K.; Hill, E. W. Making Graphene Visible. Appl. Phys. Lett. 2007, 91 (6), 063124. 
(47) Mattevi, C.; Kim, H.; Chhowalla, M. A Review of Chemical Vapour Deposition of Graphene on Copper. J. Mater. Chem. 2011, 21 (10), 3324-3334.

(48) Li, X.; Cai, W.; Colombo, L.; Ruoff, R. S. Evolution of Graphene Growth on Ni and $\mathrm{Cu}$ by Carbon Isotope Labeling. Nano Lett. 2009, 9 (12), 4268-4272.

(49) Reina, A.; Jia, X.; Ho, J.; Nezich, D.; Son, H.; Bulovic, V.; Dresselhaus, M. S.; Kong, J. Large Area, Few-Layer Graphene Films on Arbitrary Substrates by Chemical Vapor Deposition. Nano Lett. 2008, 9 (1), 30-35.

(50) Sutter, P. W.; Flege, J.-I.; Sutter, E. A. Epitaxial Graphene on Ruthenium. Nat Mater 2008, 7 (5), 406-411.

(51) Kim, K. S.; Zhao, Y.; Jang, H.; Lee, S. Y.; Kim, J. M.; Kim, K. S.; Ahn, J.-H.; Kim, P.; Choi, J.-Y.; Hong, B. H. Large-Scale Pattern Growth of Graphene Films for Stretchable Transparent Electrodes. Nature 2009, 457 (7230), 706-710.

(52) Avouris; Xia, FN. Graphene Applications in Electronics and Photonics. MRS Bulletin 2012, 37 (12), 1225-1234.

(53) Polsen, E. S.; McNerny, D. Q.; Viswanath, B.; Pattinson, S. W.; John Hart, A. High-Speed Roll-to-Roll Manufacturing of Graphene Using a Concentric Tube CVD Reactor. Sci. Rep. 2015, 5.

(54) Nair, R. R.; Blake, P.; Grigorenko, A. N.; Novoselov, K. S.; Booth, T. J.; Stauber, T.; Peres, N. M. R.; Geim, A. K. Fine Structure Constant Defines Visual Transparency of Graphene. Science 2008, 320 (5881), 1308-1308.

(55) Tsoukleri, G.; Parthenios, J.; Papagelis, K.; Jalil, R.; Ferrari, A. C.; Geim, A. K.; Novoselov, K. S.; Galiotis, C. Subjecting a Graphene Monolayer to Tension and Compression. Small 2009, 5 (21), 2397-2402.

(56) Chen, S.; Brown, L.; Levendorf, M.; Cai, W.; Ju, S.-Y.; Edgeworth, J.; Li, X.; Magnuson, C. W.; Velamakanni, A.; Piner, R. D.; et al. Oxidation Resistance of Graphene-Coated $\mathrm{Cu}$ and $\mathrm{Cu} / \mathrm{Ni}$ Alloy. ACS Nano 2011, 5 (2), 1321-1327.

(57) Nine, M. J.; Cole, M. A.; Tran, D. N. H.; Losic, D. Graphene: A Multipurpose Material for Protective Coatings. J. Mater. Chem. A 2015, 3 (24), 12580-12602.

(58) Sanchez, V. C.; Jachak, A.; Hurt, R. H.; Kane, A. B. Biological Interactions of Graphene-Family Nanomaterials: An Interdisciplinary Review. Chem. Res. Toxicol. 2012, 25 (1), 15-34.

(59) Chung, C.; Kim, Y.-K.; Shin, D.; Ryoo, S.-R.; Hong, B. H.; Min, D.-H. Biomedical Applications of Graphene and Graphene Oxide. Acc. Chem. Res. 2013.

(60) Pinto, A. M.; Gonçalves, I. C.; Magalhães, F. D. Graphene-Based Materials Biocompatibility: A Review. Colloids and Surfaces B: Biointerfaces 2013, 111, 188-202.

(61) Gartia, M. R.; Misra, S. K.; Ye, M.; Schwartz-Duval, A.; Plucinski, L.; Zhou, X.; Kellner, D.; Labriola, L. T.; Pan, D. Point-of-Service, Quantitative Analysis of Ascorbic Acid in Aqueous Humor for Evaluating Anterior Globe Integrity. Scientific Reports 2015, 5, 16011.

(62) Singh, M.; Holzinger, M.; Tabrizian, M.; Winters, S.; Berner, N. C.; Cosnier, S.; Duesberg, G. S. Noncovalently Functionalized Monolayer Graphene for Sensitivity Enhancement of Surface Plasmon Resonance Immunosensors. J. Am. Chem. Soc. 2015, 137 (8), 2800-2803. 
(63) Graphene-Info's top 10 graphene applications of 2015 | Graphene-Info http://www.graphene-info.com/graphene-infos-top-10-graphene-applications2015 (accessed Jan 9, 2016).

(64) Tian, H.; Mi, W.; Wang, X.-F.; Zhao, H.; Xie, Q.-Y.; Li, C.; Li, Y.-X.; Yang, Y.; Ren, T.-L. Graphene Dynamic Synapse with Modulatable Plasticity. Nano Lett. 2015, 15 (12), 8013-8019.

(65) Wang, S.; Hu, S.; Xu, H. Analysis of Aldehydes in Human Exhaled Breath Condensates by in-Tube SPME-HPLC. Analytica Chimica Acta 2015, 900, 6775.

(66) Printing Nerve Tissue in 3D Using Polymers and Graphene | Medgadget http://www.medgadget.com/2015/05/printing-nerve-tissue-in-3d-using-polymersand-graphene.html (accessed Jan 25, 2016).

(67) Li, L.; Zhang, J.; Peng, Z.; Li, Y.; Gao, C.; Ji, Y.; Ye, R.; Kim, N. D.; Zhong, Q.; Yang, Y.; et al. High-Performance Pseudocapacitive Microsupercapacitors from Laser-Induced Graphene. Adv. Mater. Weinheim 2015. 
Sección I

Métodos 


\section{Capítulo 2}

\section{Métodos Experimentales}

\section{Parte I - Métodos Experimentales}

Este capítulo incluye dos secciones experimentales principales:

Sección A - Síntesis de los Nanomateriales

Sección B - Caracterización de los Nanomateriales

\section{Sección A - Síntesis de los Nanomateriales}

En ésta sección se detallan las condiciones experimentales para la síntesis de todos los nanomateriales estudiados. Primeramente, se describen los protocolos generales de limpieza del material de trabajo y los reactivos generales utilizados. Finalmente, se detallan cada una de las síntesis realizadas.

\subsection{Materiales}

\subsubsection{Agua}

Se empleó agua ultra pura Milli-Q (Millipore) tanto para el lavado final del material de trabajo, las medidas realizadas y para la síntesis de los nanomateriales. La misma se utilizó con un valor de resistividad de $\geq 18 \mathrm{M} \Omega \mathrm{cm}$ a $25{ }^{\circ} \mathrm{C}$.

\subsubsection{Limpieza del Material}

Para los casos en los que se utilizó material de vidrio, dependiendo de que sustancias estuvieron previamente en contacto con los mismos, se realizó el lavado siguiendo las metodologías que aquí se detallan.

\subsubsection{Permanganato de Potasio}

El tratamiento en permanganato de Potasio $\left(\mathrm{KMnO}_{4}\right)$ se realiza para oxidar toda la materia orgánica que está presente en el material de trabajo. Brevemente, se coloca 
todo el material dentro de un recipiente de vidrio grande y se sumergen en una solución saturada de $\mathrm{KMnO}_{4}$ (en medio básico), el cual se lleva a ebullición y se mantiene en ésta condición por $\sim 20$ minutos. Seguidamente, se enjuaga con agua destilada y luego con una solución de $\mathrm{H}_{2} \mathrm{O}_{2}$ acidificada (lo que permite remover todos los restos de $\mathrm{MnO}_{2}$, resultantes de la oxidación del paso anterior). Finalmente, se enjuga todo el material con agua Milli-Q y se seca en estufa a $100^{\circ} \mathrm{C}$.

\subsubsection{Solución "Piraña"}

La solución "piraña" fue empleada en todos los casos en los cuales era necesario oxidar la materia orgánica, pero el material no podía exponerse a Permanganato de Potasio caliente (el cual se detalló en la sub-sección anterior). Brevemente, para la preparación de ésta solución se mezclan cuidadosamente $\mathrm{H}_{2} \mathrm{SO}_{4}$ concentrado y $\mathrm{H}_{2} \mathrm{O}_{2}$ 100 vol, en una relación volumétrica de 3:1, respectivamente, empleando un baño de hielo.

\subsubsection{Agua Regia}

El agua regia fue empleada en los casos en los cuales el material estuvo ya sea expuesto o en contacto directo con nanopartículas. La misma se prepara mezclando $\mathrm{HCl}$ y $\mathrm{HNO}_{3}$ en una relación volumétrica de 3:1, respectivamente. Luego del lavado con agua regia, el material es enjuagado con agua Milli-Q.

\subsubsection{Reactivos Generales}

Los solventes empleados en éste trabajo fueron de grado analítico o HPLC. Los reactivos utilizados fueron adquiridos de Aldrich Chemical Co. Las sales de $\mathrm{HAuCl}_{4}$, $\mathrm{AgNO}_{3}, \mathrm{AgC}_{2} \mathrm{~F}_{3} \mathrm{O}_{2}, \mathrm{~K}_{3} \mathrm{PdCl}_{4}$ y $\mathrm{H}_{2} \mathrm{PtCl}_{6}$ utilizadas fueron de $99,99 \%$ de pureza (Aldrich).

\subsubsection{Preparación de las Sales de Metales}

La disolución de la sal $\mathrm{HAuCl}_{4}$ fue realizada en $\mathrm{HCl} 0,1 \mathrm{M}$, y se mantuvo siempre en heladera al abrigo de la luz. La concentración final de la solución fue determinada por espectroscopía ultravioleta, realizando curvas de calibración. ${ }^{1}$

Las sales de $\mathrm{AgNO}_{3}, \mathrm{~K}_{3} \mathrm{PdCl}_{4} \mathrm{y} \mathrm{H}_{2} \mathrm{PtCl}_{6}$, fueron disueltas agua Milli-Q con una resistividad de $\geq 18 \mathrm{M} \Omega . \mathrm{cm}$ a $25^{\circ} \mathrm{C}$. 


\subsection{Síntesis de Nanopartículas Metálicas Solubles en Medio Orgánico}

\subsubsection{Nanopartículas de Au Cubiertas con Bromuro de Tetraoctilamonio (Au@TOABr, SNPs)}

Las nanopartículas de $\mathrm{Au}$ protegidas con TOABr (SNPs, surfactant nanoparticles) fueron sintetizadas siguiendo todos los pasos de la reacción de síntesis bifásica de Brust-Schiffrin, aunque sin el agregado de tioles. ${ }^{2,3}$

Brevemente, en un balón de vidrio con agitación magnética se colocaron 0,71 $\mathrm{mL}$ de $\mathrm{HAuCl}_{4} 25 \mathrm{mM}$ en $25 \mathrm{~mL}$ de agua, y $0,012 \mathrm{~g}$ de TOABr fueron disueltos en 50 $\mathrm{mL}$ de tolueno. Las dos soluciones fueron combinadas y agitadas hasta que todo el ion $\mathrm{AuCl}_{4}{ }^{-}$fue transferido a la fase orgánica (tolueno). Luego, se descartó la fase acuosa (translúcida) y el balón se colocó en un baño de hielo. La razón de utilizar baños de hielo en las síntesis de NPs radica en que las mismas van a ser más reproducibles cuando se comparen síntesis realizadas en diferentes épocas de año. Se agregó $\mathrm{NaBH}_{4}$ disuelto en agua, en un exceso de 10 veces la molaridad de la sal de $\mathrm{Au}$ (III). Rápidamente la solución se tornó de color rojo vino (muy oscuro) indicando la formación de Au NPs. Se dejó la mezcla en agitación por $\sim 2$ horas, para permitir que los tamaños de las NPs sean homogéneos. Luego, se descartó la fase acuosa y se tomó una alícuota de la fase orgánica $(500 \mu \mathrm{L})$ y se la disolvió en $2,5 \mathrm{~mL}$ de tolueno. Esta dilución fue utilizada en el UV-vis para evaluar la calidad de la síntesis. Finalmente, la solución de $\mathrm{Au} @ \mathrm{TOABr}$ NPs fue almacenada en la heladera $\left(\sim 4^{\circ} \mathrm{C}\right)$ para su uso.

\subsubsection{Nanopartículas Bimetálicas de Au/Ag Cubiertas con Bromuro de Tetraoctilamonio (Au/Ag@TOABr, SNPs)}

Se sintetizaron nanopartículas bimetálicas de $\mathrm{Au} / \mathrm{Ag}$ utilizando las siguientes relaciones molares: $\mathrm{Au}: \mathrm{Ag}$ (3:1); $\mathrm{Au}: \mathrm{Ag}$ (1:1); y Au:Ag (1:3), siguiendo el reporte de Ibañez et $a l^{3}$ Para las mencionadas síntesis, se empleó el mismo protocolo descrito en la sección 2.2.1, pero adicionando las concentraciones apropiadas de las sales de $\mathrm{HAuCl}_{4}$ y $\mathrm{AgC}_{2} \mathrm{~F}_{3} \mathrm{O}_{2}$ (disuelta en tolueno en el momento de su uso) para obtener las relaciones molares requeridas.

\subsubsection{Nanopartículas de Au Cubiertas con Dodecilamina $\left(\mathrm{Au} @ \mathrm{NH}_{2} \mathrm{C}_{12}\right)$}

Las nanopartículas de Au protegidas con dodecilamina $\left(\mathrm{Au} @ \mathrm{NH}_{2} \mathrm{C}_{12}\right)$ fueron sintetizadas siguiendo el método de Leff $e t$ al. ${ }^{4}$ En el mencionado reporte, se realiza la síntesis con y sin el agregado del agente de transferencia TOABr. En nuestro caso, decidimos emplear el protocolo sin la utilización del detergente TOABr, ya que presenta dos beneficios: a) las nanopartículas son más estables; y b) se evita el uso excesivo de 
cadenas alquílicas, las cuales presentan la desventaja de disminuir la corriente del sistema en chemiresistores y/o hacer que el sistema tienda a presentar corrientes de carácter iónico en vez de Óhmico, entre otras desventajas que podrían traer aparejado el exceso de material orgánico.

Brevemente, en un balón de vidrio con agitación magnética se colocaron 9,65 $\mathrm{mL}$ de $\mathrm{HAuCl} 4$ 29,4 $\mathrm{mM}$ en 15,4 $\mathrm{mL}$ de agua. Luego, 0,5882 $\mathrm{g}$ de $\mathrm{NH}_{2} \mathrm{C}_{12}$ fueron disueltos en $50 \mathrm{~mL}$ de tolueno, correspondiente a una relación molar de (11:1) aminas:Au. Las dos soluciones fueron combinadas y agitadas. En éste momento se formó una emulsión color naranja/blanquecina. Se cubrió el balón con una lámina de Aluminio, para mantener la reacción al abrigo de la luz. Toda la síntesis fue realizada a temperatura ambiente. Transcurridos los 40 minutos de agitación, se agregó $\mathrm{NaBH}_{4}$ disuelto en agua, en un exceso de 15 veces la molaridad de la sal de $\mathrm{Au}$ (III). Gradualmente la solución orgánica se tornó de color violeta oscuro, mientras que en la solución acuosa comenzaron a aparecer algunos precipitados. La reacción se dejó en agitación por $\sim 12$ horas, para permitir que los tamaños de las NPs sean homogéneos. Luego, la fase acuosa fue descartada y la fase orgánica fue filtrada empleando un filtro de 0,2 $\mu \mathrm{m}$ PTFE (Acrodisc). Seguidamente, al volumen filtrado se le agregó etanol en $\sim 5$ veces el volumen de tolueno y se centrifugó por 10 minutos a $2500 \mathrm{rpm}$. Este paso permite que las NPs precipiten y que en la fase alcohólica permanezcan todos los restos orgánicos que pretenden ser eliminados. Luego, se procede a descartar la fase alcohólica y se vuelven a repetir los pasos de lavado 3 veces más. Finalmente, la solución de NPs de $\mathrm{Au} @ \mathrm{NH}_{2} \mathrm{C}_{12}$ fue almacenada en la heladera $\left(\sim 4^{\circ} \mathrm{C}\right)$ para su uso.

\subsubsection{Nanopartículas de Au Cubiertas con Octilamina $\left(\mathrm{Au} @ \mathrm{NH}_{2} \mathrm{C}_{8}\right)$}

Las nanopartículas de $\mathrm{Au}$ protegidas con octilamina $\left(\mathrm{Au} @ \mathrm{NH}_{2} \mathrm{C}_{8}\right)$ fueron sintetizadas siguiendo el método de Leff et al., ${ }^{4}$ con algunas modificaciones, como aquí se detallan.

Para la mencionada síntesis, se empleó el mismo protocolo descrito en la sección 2.2.3, pero empleando las siguientes relaciones molares: a) $\mathrm{NH}_{2} \mathrm{C}_{8}: \mathrm{Au}=18: 1$; y b) $\mathrm{NaBH}_{4}: \mathrm{Au}=16: 1$. La razón de aumentar la concentración de aminas respecto al método de Leff, radica en que las cadenas alquílicas de menor longitud $\left(\mathrm{C}_{8}\right.$ versus $\left.\mathrm{C}_{12}\right)$ le otorgan menor estabilidad a las nanopartículas que las cadenas de mayor longitud. Las nanopartículas obtenidas fueron limpiadas siguiendo las mismas condiciones anteriormente detalladas. Finalmente, la solución de $\mathrm{NPs}$ de $\mathrm{Au} @ \mathrm{NH}_{2} \mathrm{C}_{8}$ fue almacenada en la heladera $\left(\sim 4^{\circ} \mathrm{C}\right)$ para su uso.

\subsubsection{Nanopartículas de Au Cubiertas con Dodecanotiol (Au@SC $\left.\mathrm{SC}_{12}\right)$}


Las nanopartículas de $\mathrm{Au}$ protegidas con dodecanotiolato ( $\mathrm{Au} @ \mathrm{SC}_{12} \mathrm{MPCs}$, monolayer-protected clusters) fueron sintetizadas siguiendo la síntesis reportada por Hostetler et al. ${ }^{5}$ para obtener nanopartículas de $\sim 2,4 \mathrm{~nm}$ de diámetro. Brevemente, en un balón de vidrio con agitación magnética se colocaron $1 \mathrm{~mL}$ de $\mathrm{HAuCl}_{4}\left(1,47 \times 10^{-5}\right.$ $\mathrm{mol} / \mathrm{mL}$ ) en $25 \mathrm{~mL}$ de agua, y 35,66 mg de TOABr fueron disueltos en $20 \mathrm{~mL}$ de tolueno. Las dos soluciones fueron combinadas y agitadas hasta que todo el $\mathrm{AuCl}_{4}{ }^{-}$fue transferido a la fase orgánica (tolueno). Luego se descartó la fase acuosa (translúcida) y se agregaron $1,56 \mu \mathrm{L}$ de 1 -dodecanotiol, correspondiente a una relación molar de $(0,5: 1)$ tiol:Au a la mencionada fase. La solución se agitó vigorosamente. Luego de 20 minutos en agitación, se agregó $\mathrm{NaBH}_{4}$ disuelto en agua, en un exceso de 10 veces la molaridad de la sal de Au (III). Rápidamente la solución se tornó de color marrón indicando la formación de NPs de Au. Se dejó la mezcla en agitación por $\sim 3$ horas, para permitir que los tamaños de las NPs sean homogéneos. Luego, se descartó la fase acuosa y se redujo el volumen de la fase orgánica mediante evaporación rotatoria, empleando siempre un baño de agua por debajo de $\operatorname{los} 30^{\circ} \mathrm{C}$, para evitar el crecimiento de las NPs. El sólido marrón obtenido se re suspendió en un mínimo volumen de tolueno y se le agregó etanol en $\sim 5$ veces el volumen de tolueno empleado en éste paso. Luego, dichas muestras se sometieron a ultrasonido por 30", para favorecer la disolución de las moléculas tanto de $\mathrm{HSC}_{12}$ y TOABr libres (que se no están unidas al centro metálico) y luego se centrifugaron a $2500 \mathrm{rpm}$ por 20 minutos. Este paso permite que las NPs precipiten y que en la fase alcohólica permanezcan todos los restos orgánicos que pretender ser eliminados. Luego, se procede a descartar la fase alcohólica y se vuelven a repetir los pasos de lavado 3 veces más. Finalmente, el sólido orgánico (NPs) se secaron con $\mathrm{N}_{2}$ y se re suspendieron en tolueno. La solución de $\mathrm{Au} @ \mathrm{SC}_{12}$ fue almacenada en la heladera $\left(\sim 4^{\circ} \mathrm{C}\right)$ para su uso. Es importante mencionar, que si bien en el trabajo de Murray et al..$^{5}$ éstas NPs deberían tener $\sim 2,4 \mathrm{~nm}$, en nuestras condiciones experimentales se obtuvieron NPs de $\sim 3,4 \mathrm{~nm}$ de diámetro.

\subsubsection{Nanopartículas de Au Cubiertas con Hexanotiol (Au@SC}

Las nanopartículas de $\mathrm{Au}$ protegidas con hexanotiol ( $\mathrm{Au} @ \mathrm{SC}_{6} \mathrm{MPCs}$, monolayer-protected clusters) fueron sintetizadas siguiendo la síntesis reportada por Brust et al. ${ }^{6}$ Brevemente, en un balón de vidrio con agitación magnética se colocaron 24 $\mathrm{mL}$ de $\mathrm{HAuCl}_{4}(50,73 \mathrm{mM})$ y se le agregó $1 \mathrm{~mL}$ de agua. Por otro lado, 0,98 g de $\mathrm{TOABr}$ fueron disueltos en $30 \mathrm{~mL}$ de tolueno. Las dos soluciones fueron combinadas y agitadas hasta que todo el $\mathrm{AuCl}_{4}{ }^{-}$fue transferido a la fase orgánica (tolueno). Luego se descartó la fase acuosa (translúcida) y se agregaron 0,52 $\mathrm{mL}$ de 1-hexanotiol, correspondiente a una relación molar de (3:1) tiol:Au a la mencionada fase. La solución se agitó vigorosamente, mientras la misma fue decolorándose rápidamente. Luego de 20 minutos en agitación, se agregó $\mathrm{NaBH}_{4}$ disuelto en agua, en un exceso de 10 veces la molaridad de la sal de Au (III). Rápidamente la solución se tornó de color marrón 
oscuro indicando la formación de NPs de Au. Se dejó la mezcla en agitación por $\sim 3$ horas. Luego, se descartó la fase acuosa y se redujo el volumen de la fase orgánica mediante evaporación rotatoria, empleando siempre un baño de agua por debajo de los $30^{\circ} \mathrm{C}$, para evitar el crecimiento de las NPs. El sólido marrón obtenido se re suspendió en un mínimo volumen de tolueno y se le agregó etanol en $\sim 5$ veces el volumen de tolueno empleado en éste paso. Luego, dichas muestras se sometieron a ultrasonido por 30", para favorecer la disolución de las moléculas tanto de $\mathrm{HSC}_{6}$ y $\mathrm{TOABr}$ libres (que se no están unidas al centro metálico) y luego se centrifugaron a $2500 \mathrm{rpm}$ por 20 minutos. Este paso permite que las NPs precipiten y que en la fase alcohólica permanezcan todos los restos orgánicos que pretender ser eliminados. Luego, se descarta la fase alcohólica y se vuelven a repetir los pasos de lavado 3 veces más. Finalmente, el sólido orgánico (NPs) se secó con $\mathrm{N}_{2}$ y se re suspendió en tolueno. La solución de $\mathrm{Au} @ \mathrm{SC}_{6}$ fue almacenada en la heladera $\left(\sim 4^{\circ} \mathrm{C}\right)$ para su uso.

\subsubsection{Nanopartículas de Pd Cubiertas con Octilamina $\left(\mathrm{Pd} @ \mathrm{NH}_{2} \mathrm{C}_{8}\right)$}

Las nanopartículas de $\mathrm{Pd}$ protegidas con octilamina $\left(\mathrm{Pd} @ \mathrm{NH}_{2} \mathrm{C}_{8}\right)$ fueron sintetizadas siguiendo el método de Leff et al. ${ }^{4}$ (el cual fue descrito originalmente para la síntesis de NPs de $\mathrm{Au}$ ) adaptado ${ }^{7,8}$ para la síntesis de NPs de Pd, y con algunas modificaciones que aquí de detallan.

Brevemente, en un balón de vidrio con agitación magnética se colocaron $10 \mathrm{~mL}$ de $\mathrm{K}_{2} \mathrm{PdCl}_{4} 56,37 \mathrm{mM}$ en $40 \mathrm{~mL}$ de agua, y 0,7106 g de TOABr fueron disueltos en 50 $\mathrm{mL}$ de tolueno, correspondiente a una relación molar TOABr:Pd $=2,35: 1$. Las dos soluciones fueron combinadas y agitadas hasta que todo el $\mathrm{PdCl}_{4}{ }^{-}$fue transferido a la fase orgánica (tolueno). Seguidamente, sin quitar la fase acuosa, se agregó 1,033 mL de octilamina (relación molar $\mathrm{NH}_{2} \mathrm{C}_{8}: \mathrm{Pd}=11: 1$ ). Luego de 1 hora en agitación a temperatura ambiente, se agregaron $50 \mathrm{~mL}$ de una solución $\mathrm{NaBH}_{4}(0,322 \mathrm{~g})$, correspondiente a una relación molar $\mathrm{NaBH}_{4}: \mathrm{Pd}=15: 1$. Gradualmente la solución se tornó de marrón oscuro, indicando la formación de nanopartículas de Pd. Se dejó la reacción en agitación por $\sim 24$ horas, para permitir que los tamaños de las NPs sean homogéneos. Finalmente, la solución de NPs fue concentrada mediante evaporación rotatoria. Luego, se procedió a la limpieza de las NPs, realizando los mismos pasos de limpieza detallados en la sección 2.2.5, pero sin el uso de ultrasonido.

\subsubsection{Nanopartículas de Pt Cubiertas con Octilamina $\left(\operatorname{Pt} @ \mathrm{NH}_{2} \mathrm{C}_{8}\right)$}

Las nanopartículas de $\mathrm{Pt}$ protegidas con octilamina $\left(\mathrm{Pt} @ \mathrm{NH}_{2} \mathrm{C}_{8}\right)$ fueron sintetizadas según el protocolo descrito en la sección anterior (2.2.7). Es importante mencionar que este tipo de NPs aún no han sido reportadas en la literatura. Como precursor metálico se empleó una sal de $\mathrm{K}_{2} \mathrm{PtCl}_{6}$ 19,54 mM ( $\mathrm{HCl} \mathrm{0,1} \mathrm{M).}$ 


\subsubsection{Nanopartículas de Pd/Pt Bimetálicas Cubiertas con Octilamina $\left(\mathrm{Pd} @ \mathrm{NH}_{2} \mathrm{C}_{8}\right)$}

Se sintetizaron nanopartículas bimetálicas de $\mathrm{Pd} / \mathrm{Pt}$ utilizando las siguientes relaciones molares: Pd:Pt (3:1); Pd:Pt (1:1); y Pd:Pt (1:3). Para las mencionadas síntesis, se empleó el mismo protocolo descrito en la sección 2.2.7, pero adicionando las concentraciones apropiadas de las sales de $\mathrm{K}_{2} \mathrm{PdCl}_{4}$ y $\mathrm{K}_{2} \mathrm{PtCl}_{6}$, para obtener las relaciones molares requeridas.

\subsection{Síntesis de Nanopartículas Metálicas Solubles en Medio Acuoso}

\subsubsection{Nanopartículas de Au cubiertas con Citrato (Au@citrato, CNPs)}

Para la síntesis de las nanopartículas de Au estabilizadas (recubiertas) con citrato (Au@citrato, Au CNPs), se utilizó el protocolo descrito por Murphy et al. ${ }^{9}$, pero con la diferencia en que se llevó a cabo en un baño de hielo para mantener la temperatura constante durante toda la síntesis.

Brevemente, en un balón de vidrio con agitación magnética se colocó $0,5 \mathrm{~mL}$ de sal de citrato trisódico $(0,01 \mathrm{M})$ y $0,5 \mathrm{~mL}$ de $\mathrm{HAuCl}_{4}(0,01 \mathrm{M})$ en $19 \mathrm{~mL}$ de agua, y luego de 15 minutos de agitación constante, se adicionó $0,6 \mathrm{~mL}$ de $\mathrm{NaBH}_{4}(0,01 \mathrm{M})$ frío para completar la síntesis. La mencionada síntesis permite la obtención de nanopartículas de diámetros entre 3 a $5 \mathrm{~nm}$ (tal como fue informado por Zamborini et $\left.a l .{ }^{10}\right)$.

\subsubsection{Nanopartículas de Ag Cubiertas con Citrato (Ag@citrato, Ag CNPs)}

Para la síntesis de las nanopartículas de Ag recubiertas con citrato (Ag@citrato, Ag CNPs), se utilizó el protocolo descrito por Murphy et al. ${ }^{11}$ (permite obtener NPs de Ag con un diámetro entre 8 a $12 \mathrm{~nm}$ ), pero con la diferencia en que se llevó a cabo en un baño de hielo para mantener la temperatura constante durante toda la síntesis.

Brevemente, en un balón de vidrio con agitación magnética se colocaron $0,5 \mathrm{~mL}$ de sal de citrato trisódico $(0,01 \mathrm{M})$ y $0,5 \mathrm{~mL}$ de $\operatorname{AgNO}_{3}(0,01 \mathrm{M})$ en $19 \mathrm{~mL}$ de agua, y luego de 15 minutos de agitación constante, se adicionó 0,6 $\mathrm{mL}$ de $\mathrm{NaBH}_{4}(0,01 \mathrm{M})$ frío para completar la síntesis. Se mantuvo en agitación por 2 horas, antes de su uso. Al principio la solución es incolora, pero luego del agregado del reductor débil $\mathrm{NaBH}_{4}$, la solución se tornó inmediatamente color amarilla, indicando la reducción de $\mathrm{Ag}^{+1} \mathrm{a} \mathrm{Ag}^{\mathrm{o}}$. 
La Tabla 2.1 resume todas las diferentes síntesis de nanopartículas estudiadas a lo largo esta tesis. En la misma se detallan las sales metálicas empleadas, el agente de transferencia empleado (en el caso de NPs en medio orgánico), tipos de agentes estabilizantes (capping agent), el agente reductor, los solventes, las relaciones molares entre los reactivos y las referencias en donde pueden encontrarse los protocolos originales.

Tabla 2.1 Resumen de Todas las Diferentes Síntesis de Nanopartículas Estudiadas a lo Largo esta Tesis.

\begin{tabular}{|c|c|c|c|c|c|c|c|c|c|}
\hline \multirow{2}{*}{$\begin{array}{l}\text { Precursor } \\
\text { Metálico }\end{array}$} & \multicolumn{2}{|c|}{ Agente Estabilizante } & \multirow{2}{*}{$\begin{array}{c}\text { Relación Metal: } \\
\text { Agente de } \\
\text { Transferencia }\end{array}$} & \multirow{2}{*}{$\begin{array}{c}\text { Relación } \\
\text { Metal: } \\
\text { Estabilizante }\end{array}$} & \multirow{2}{*}{\begin{tabular}{|c|} 
Relación \\
Metal: Metal \\
(aleaciones)
\end{tabular}} & \multirow{2}{*}{$\begin{array}{l}\text { Agente } \\
\text { Reductor }\end{array}$} & \multirow{2}{*}{ Solvente } & \multirow{2}{*}{ Nomeclatura } & \multirow{2}{*}{ Referencias } \\
\hline & No polar & Polar & & & & & & & \\
\hline $\mathrm{HAuCl}_{4}$ & $\mathrm{TOABr}$ & III & $1: 1,7$ & $1: 1,7$ & III & $\mathrm{NaBH}_{4}$ & Tolueno & $\underline{\mathrm{Au} @ \mathrm{TOABr}}$ & $\begin{array}{l}\text { Brust et al. }{ }^{2} \text { I } \\
\text { lbañez et al. }\end{array}$ \\
\hline $\begin{array}{c}\mathrm{HAuCl}_{4} / \\
\mathrm{AgC}_{2} \mathrm{~F}_{3} \mathrm{O}_{2}\end{array}$ & $\mathrm{TOABr}$ & III & $1: 1,7$ & $1: 1,7$ & $\begin{array}{c}(3: 1) ;(1: 1) \\
(1: 3)\end{array}$ & $\mathrm{NaBH}_{4}$ & Tolueno & AuAg@.TOABr & Ibañez et al. ${ }^{3}$ \\
\hline $\mathrm{HAuCl}_{4}$ & $\mathrm{NH}_{2} \mathrm{C}_{12}$ & III & III & $1: 11$ & III & $\mathrm{NaBH}_{4}$ & Tolueno & $\mathrm{Au} @ \mathrm{NH}_{2} \mathrm{C}_{12}$ & Leff et al. ${ }^{4}$ \\
\hline & & & & & & & & & \\
\hline $\mathrm{HAuCl}_{4}$ & $\mathrm{NH}_{2} \mathrm{C}_{8}$ & III & III & $1: 18$ & III & $\mathrm{NaBH}_{4}$ & Tolueno & $\underline{\mathrm{Au} @ \mathrm{NH}_{2} \mathrm{C}_{8}}$ & $\begin{array}{l}\text { Leff et al. } \\
\text { modificado }\end{array}$ \\
\hline $\mathrm{HAuCl}_{4}$ & $\mathrm{HSC}_{12}$ & III & $1: 4,0$ & $1: 0,5$ & III & $\mathrm{NaBH}_{4}$ & Tolueno & $\underline{\mathrm{Au} @ \mathrm{SC}_{12}}$ & $\begin{array}{l}\text { Hostetler et al. } \\
\text { lbañez et al. }\end{array}$ \\
\hline $\mathrm{HAuCl}_{4}$ & $\mathrm{HSC}_{6}$ & III & $1: 1,5$ & $1: 3$ & III & $\mathrm{NaBH}_{4}$ & Tolueno & $\underline{\mathrm{Au} @ \mathrm{SC}_{8}}$ & $\begin{array}{l}\text { Brust et al }{ }^{8} / \\
\text { lbañez et al. }\end{array}$ \\
\hline & & & & & & & & & \\
\hline $\mathrm{K}_{3} \mathrm{PdCl}_{4}$ & $\mathrm{NH}_{2} \mathrm{C}_{8}$ & III & $1: 2,35$ & $1: 11$ & III & $\mathrm{NaBH}_{4}$ & Tolueno & $\underline{\mathrm{Pd} @ \mathrm{NH}_{2} \mathrm{C}_{8}}$ & \begin{tabular}{|c|} 
Leff et al. ${ }^{4} /$ \\
Moreno et al. ${ }^{7} /$ \\
Corthey et al. \\
\end{tabular} \\
\hline $\mathrm{H}_{2} \mathrm{PtCl}_{6}$ & $\mathrm{NH}_{2} \mathrm{C}_{8}$ & III & $1: 2,35$ & $1: 11$ & III & $\mathrm{NaBH}_{4}$ & Tolueno & $\underline{\mathrm{Pt} @ \mathrm{NH}_{2} \mathrm{C}_{8}}$ & $\begin{array}{c}\text { Reportadas en } \\
\text { esta Tesis }\end{array}$ \\
\hline & & & & & & & & & \\
\hline $\begin{array}{l}\mathrm{K}_{3} \mathrm{PdCl}_{4} / \\
\mathrm{H}_{2} \mathrm{PtCl}_{6} \\
\end{array}$ & $\mathrm{NH}_{2} \mathrm{C}_{8}$ & III & $1: 2,35$ & $1: 11$ & $\begin{array}{c}(3: 1) ;(1: 1) \\
(1: 3)\end{array}$ & $\mathrm{NaBH}_{4}$ & Tolueno & PdPt@ $\mathrm{NH}_{2} \mathrm{C}_{8}$ & $\begin{array}{c}\begin{array}{c}\text { Reportadas en } \\
\text { esta Tesis }\end{array} \\
\end{array}$ \\
\hline & & & & & & & & & \\
\hline $\mathrm{HAuCl}_{4}$ & III & Citrato & III & $1: 1$ & III & $\mathrm{NaBH}_{4}$ & Agua MQ & $\underline{\text { Au @ citrato }}$ & $\begin{array}{c}\text { Murphy et al. } .^{9} / \\
\text { Zamborini et } \\
\text { al. }{ }^{10}\end{array}$ \\
\hline $\mathrm{AgNO}_{3}$ & III & Citrato & III & $1: 1$ & III & $\mathrm{NaBH}_{4}$ & Agua MQ & Ag@ citrato & Murphy et al. ${ }^{11}$ \\
\hline
\end{tabular}

Nota: en la misma se detallan las sales metálicas empleadas, el agente de transferencia empleado (en el caso de NPs en medio orgánico), tipos de agentes estabilizantes (capping agent), el agente reductor, los solventes, las relaciones molares entre los reactivos y las referencias en donde pueden encontrarse los protocolos originales. 


\subsection{Crecimiento de Grafeno por Deposición Química de Vapores (CVD)}

El crecimiento de monocapas de grafeno fue realizado por la técnica de síntesis química de vapores, conocida como "CVD" por sus siglas del inglés Chemical Vapor Deposition. Actualmente, la técnica de CVD permite obtener grafeno con los siguientes atributos: a) posee alta calidad (monocapa versus varias capas); b) baja presencia de imperfecciones y defectos (determinadas por la presencia de la banda D en $\sim 1350 \mathrm{~cm}^{-1}$ por espectroscopia Raman, ver los Capítulos 5 y 6 para más detalles); y c) posibilidad de escalar su obtención.

En este contexto, se ha reportado en la literatura la obtención de grafeno sobre láminas de $\mathrm{Cu}$ por $\mathrm{CVD}$ con un tamaño máximo de $75 \mathrm{~cm}$ (medido en dirección diagonal). ${ }^{12} \mathrm{~A}$ su vez, en una reciente publicación de Hart et al. ${ }^{13}$ se presentó por primera vez un reactor con un tubo concéntrico que permite la síntesis continua de grafeno por CVD (en velocidades comprendidas entre 25 a $500 \mathrm{~mm} / \mathrm{min}$ ). En éste sistema la velocidad de obtención del grafeno es el factor más importante en la calidad del nanocarbón obtenido.

\subsubsection{Disposición Experimental (set-up)}

El crecimiento de grafeno se realizó en un horno tubular (O.R.L. Hornos Eléctricos S.A.) equipado con un tubo de cuarzo de 7,5 $\mathrm{cm}$ de diámetro y una bomba de vacío. Los sustratos catalíticos empleados fueron láminas de $\mathrm{Cu}(25 \mu \mathrm{m}$ de espesor) y espumas de $\mathrm{Ni}((2,0 \mathrm{~mm} \pm 0,1 \mathrm{~mm}$ de espesor, 95\% de porosidad y $40 \mathrm{ppcm}$ (100 ppi) de diámetro de poro), ver el detalles en las siguientes secciones. Los precursores para dicho crecimiento fueron: $\mathrm{N}_{2}$ (gas inerte); $\mathrm{CH}_{4}$ (fuente de C); e $\mathrm{H}_{2}$ (agente reductor). En la Figura 2.1 se muestra el set-up experimental para la síntesis de grafeno.

\subsubsection{Crecimiento de Grafeno sobre Láminas de Cu}


Las láminas de $\mathrm{Cu}$ (25 $\mu \mathrm{m}$ de espesor, > 99,99\% de pureza) fueron adquiridas de la empresa MTI corp., Estados Unidos. Antes de su uso, las mismas fueron cortadas en rectángulos de $\sim 4 \mathrm{~cm} \times 8 \mathrm{~cm}$ y tratadas con acetona (tres pasos de sonicación por 20') para remover impurezas. Luego, fueron colocadas (de a una lámina por síntesis) dentro del tubo de cuarzo. Brevemente el proceso de crecimiento de grafeno implica los siguientes pasos: a) generación de vacío dentro del tubo de cuarzo; b) después de alcanzado un nivel de vacío estable, se permite el ingreso de $\mathrm{H}_{2}(24 \mathrm{~mL} / \mathrm{min})$ el cual está presente durante todo el proceso de síntesis; c) luego, se enciende el horno y
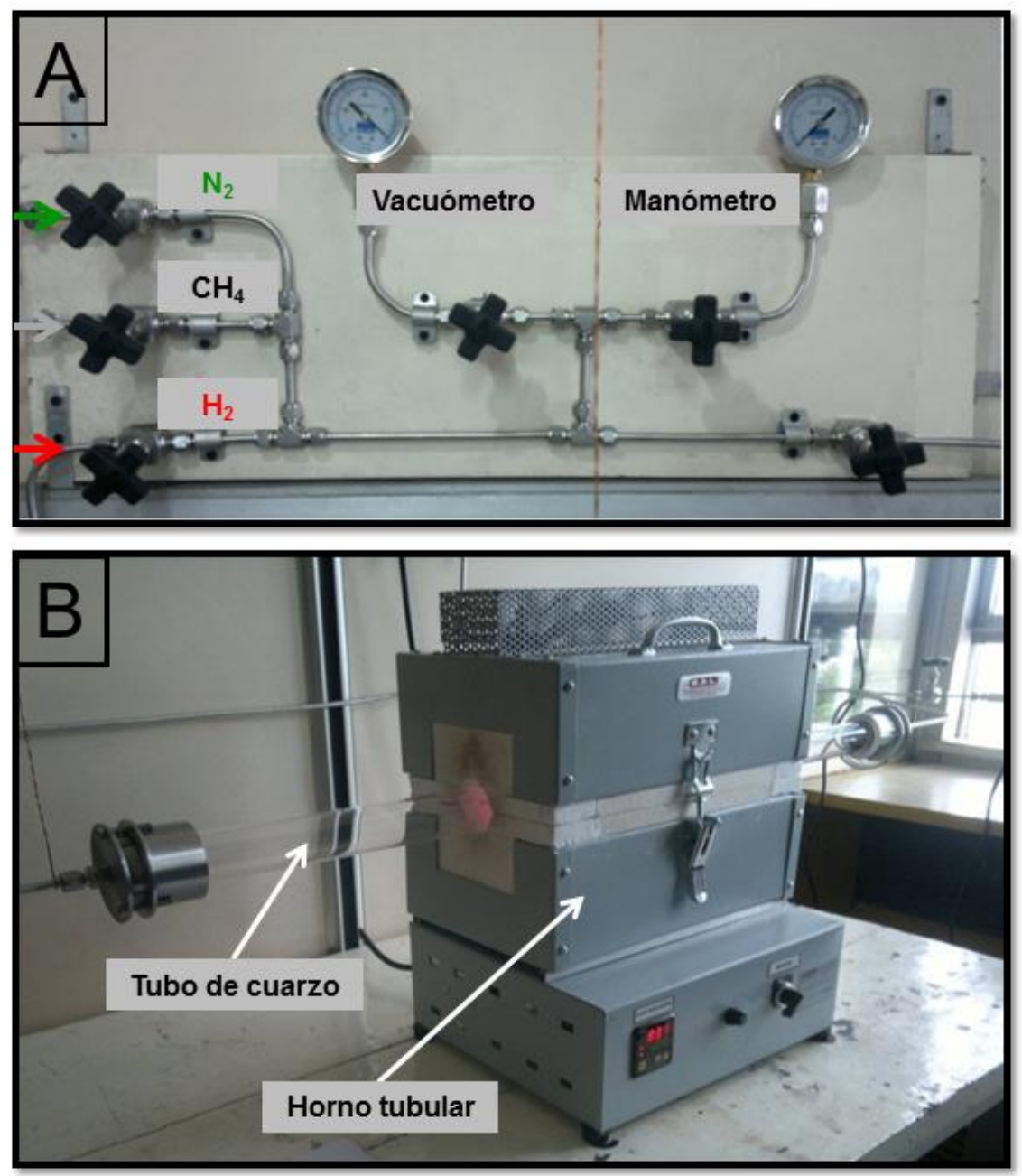

Figura 2.1 Fotografías mostrando el panel de gases (A) y el horno tubular empleado para la síntesis de grafeno por CVD (B). Las flechas de colores en la fotografía $\mathrm{A}$ indican las entradas de gases $\left(\mathrm{N}_{2}, \mathrm{CH}_{4}\right.$ e $\left.\mathrm{H}_{2}\right)$. 
cuando el sistema alcanza los $1000^{\circ} \mathrm{C}$ se procede al ingreso de $\mathrm{CH}_{4}(75 \mathrm{~mL} / \mathrm{min})$ por 5 minutos; d) finalmente se apaga el horno y una vez alcanzada una temperatura menor a los $100^{\circ} \mathrm{C}$ se procede a ingresar $\mathrm{N}_{2}$ y se cierra la entrada de $\mathrm{H}_{2}$. Una vez que el sistema alcanzó la presión atmosférica, es posible abrir las bridas del tubo y sacar la muestra. El aspecto de la lámina de $\mathrm{Cu}$ luego del crecimiento de grafeno es más brillante que en su estado inicial. Dicho brillo radica en que durante el proceso de síntesis, antes del ingreso de $\mathrm{CH}_{4}$, se produce un annealing que permite la remoción de las especies oxidadas presentes en la superficie del $\mathrm{Cu}$. La Figura 2.2 muestra una curva de temperatura $\left({ }^{\circ} \mathrm{C}\right)$ versus tiempo (minutos) obtenida de datos experimentales correspondientes a la síntesis de grafeno sobre una lámina de $\mathrm{Cu}$. Los pasos incluyen: $\mathrm{I}=$ ingreso de $\mathrm{H}_{2}$; $\mathrm{II}=$ annealing en atmósfera de $\mathrm{H}_{2}$; III= síntesis de grafeno / ingreso de $\mathrm{CH}_{4} ; \mathrm{IV}=$ enfriamiento en atmósfera de $\mathrm{N}_{2}$.

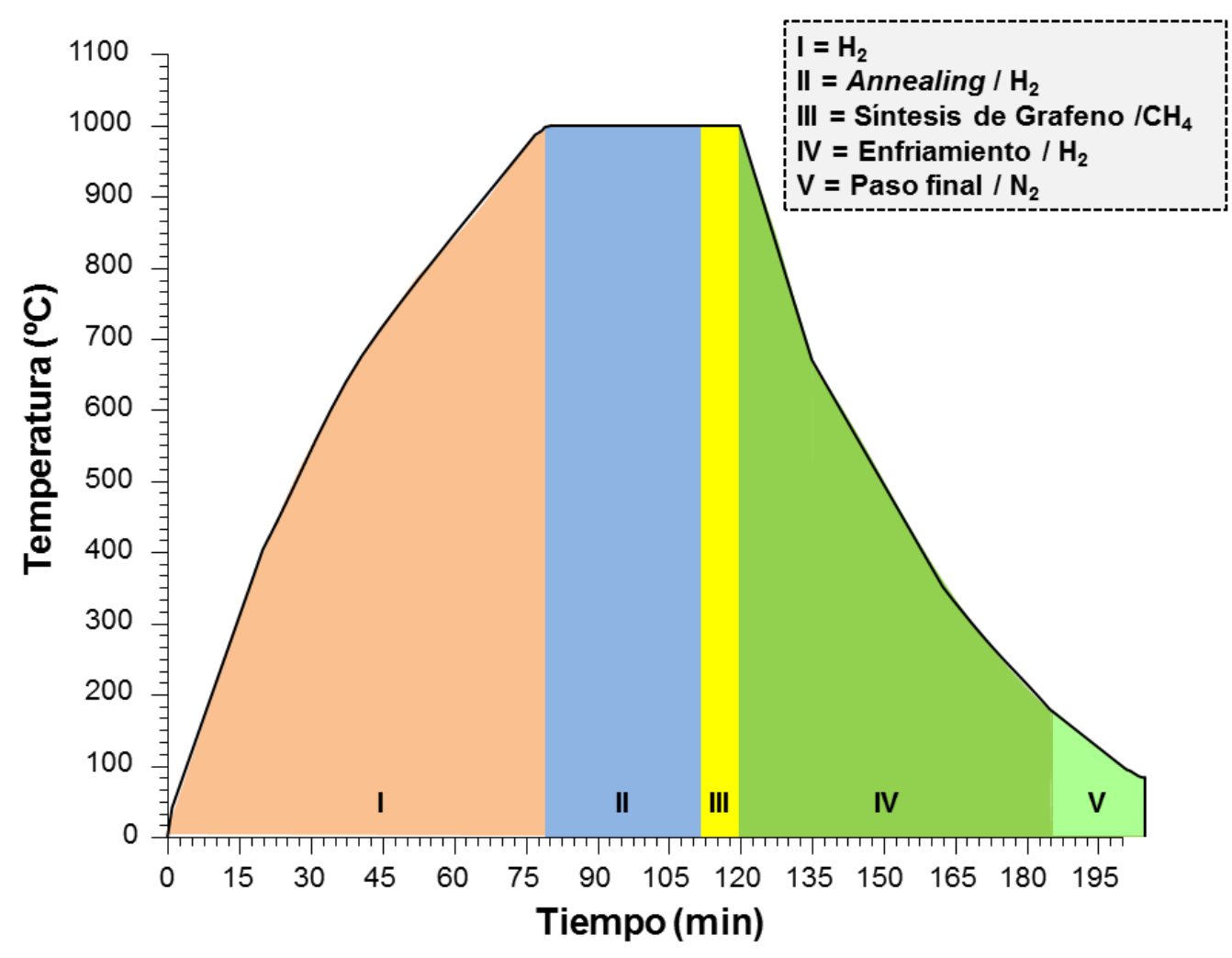

Figura 2.2 Curva de Temperatura $\left({ }^{\circ} \mathrm{C}\right.$ ) versus Tiempo (minutos) obtenida de datos experimentales correspondientes a la síntesis de grafeno por CVD sobre una lámina de $\mathrm{Cu}$. Los pasos incluyen; $\mathrm{I}=\mathrm{H}_{2} ; \mathrm{II}=$ annealing en atmósfera de $\mathrm{H}_{2} ; \mathrm{III}=$ síntesis de grafeno / ingreso de $\mathrm{CH}_{4} ; \mathrm{IV}=$ enfriamiento en atmósfera de $\mathrm{H}_{2} . \mathrm{V}=$ paso final en atmósfera de $\mathrm{N}_{2}$. Ver detalles en la Sección 2.4.2. 


\subsubsection{Transferencia de Grafeno a Diferentes Sustratos}

En el caso del grafeno obtenido sobre láminas de $\mathrm{Cu}$, para su uso se requiere que el grafeno sea transferido a otros sustratos. Los mismos incluyen vidrio, Silicio (100) y microelectrodos, dependiendo de la aplicación y caracterización que se vaya a realizar. En esta tesis se emplearon dos métodos para la transferencia de grafeno, los cuales difieren tanto en "agente de transferencia (andamio)" como en la solución de disolución del $\mathrm{Cu}$. Los detalles de las mismas son dados a continuación.

\subsubsection{Transferencia de Grafeno Utilizando Polimetilmetacrilato (PMMA)}

Para la transferencia del grafeno $(\mathrm{G})$ obtenido, se empleó la metodología reportada por Reina et al. ${ }^{14}$ con algunas modificaciones en el protocolo. ${ }^{15}$ La misma consiste básicamente en emplear un polímero de alto peso molecular, el cual asiste la transferencia de G. Para soportar al $\mathrm{G}$ durante la disolución del $\mathrm{Cu}$, se empleó polimetilmetacrilato (PMMA) de $950 \mathrm{kDa}$, el cual al ser hidrofóbico y de alto peso molecular permite que el $\mathrm{G}$ flote en la solución de etching al mismo tiempo que le otorga robustez, respectivamente. El PMMA se adquirió de la empresa MicroChem, Estados Unidos. Como agente oxidante (etching) del $\mathrm{Cu}$ se empleó una solución de Nitrato Férrico (Sigma Aldrich).

Los pasos para la transferencia de $\mathrm{G}$ implican: a) cortar las láminas de $\mathrm{Cu} /$ grafeno en cuadrados de $1 \mathrm{~cm} \times 1 \mathrm{~cm}$ (el tamaño puede variarse según la aplicación o sustrato al que va a transferirse); b) adición de $20 \mu \mathrm{L}$ de una solución de PMMA en anisol (46 mg/mL) y el recocido ("curado") del polímero en horno a $180{ }^{\circ} \mathrm{C}$ por 1 minuto; c) debido a que el grafeno crece en ambas caras de la lámina de $\mathrm{Cu}$, es necesario remover el grafeno de la cara en la que no se colocó PMMA. Para ello, se colocaron las muestras en una placa de Petri con una solución de $\mathrm{HNO}_{3} 4,14 \mathrm{M}$ por 3 minutos, teniendo cuidado de que dicha solución oxidante no entre en contacto con la superficie de la muestra (para evitar que se dañe); d) seguidamente, se procede a descartar la solución ácida y se lava repetidas veces con agua Milli-Q; e) para remover la lámina de $\mathrm{Cu}$, se colocan las muestras dentro de una placa de Petri contiendo una solución de $\mathrm{Fe}\left(\mathrm{NO}_{3}\right)_{3}(0,5 \mathrm{~g} / \mathrm{mL})$ y se deja en contacto por $\sim 3-4$ horas; f) luego, cuando se observa que el $\mathrm{Cu}$ ha sido disuelto completamente (se evidencia porque se observan las láminas de grafeno translucidas flotando en la solución color marrón/naranja) se procede a efectuar repetidos lavados con agua Milli-Q para remover los residuos de $\mathrm{CuCl}_{2} ; \mathrm{g}$ ) se prepara una solución de $\mathrm{HCl}$ al $12 \%$ (v/v) en agua Milli-Q, y se deja en contacto con las muestras por 10 minutos (lo cual permite la remoción de restos de partículas de Fe; h) se realizan 10 lavados con agua Milli-Q; y i) finalmente, se procede a la transferencia de las películas de grafeno sobre los sustratos ( $\mathrm{Si}$, vidrio, microelectrodos), previamente limpiados con piraña, agua y solventes (acetona, isopropanol y etanol). 
En la Figura 2.3 se muestra un esquema representativo de los pasos requeridos para: i) la síntesis de grafeno por CVD empleando una lámina de $\mathrm{Cu}$ como catalizador (A); ii) la adición del polímero PMMA como andamio para el grafeno y la disolución de $\mathrm{Cu}$ (etching) (B); y iii) la transferencia del grafeno a diferentes sustratos (C), como es indicado. Adaptado según la referencia. ${ }^{16}$

A
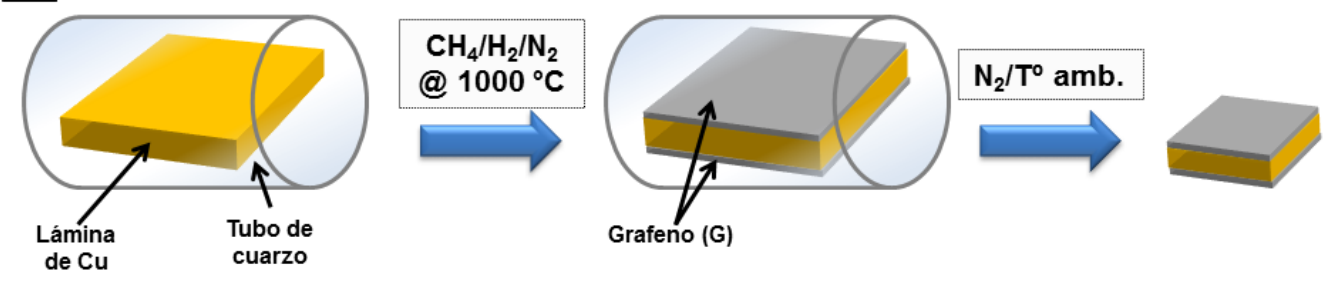

B

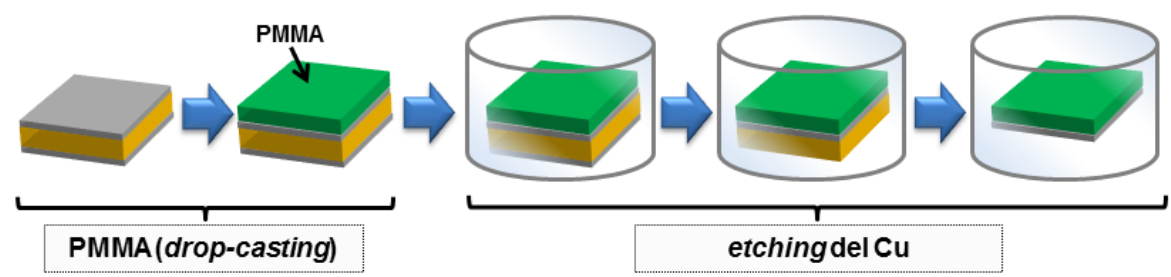

C
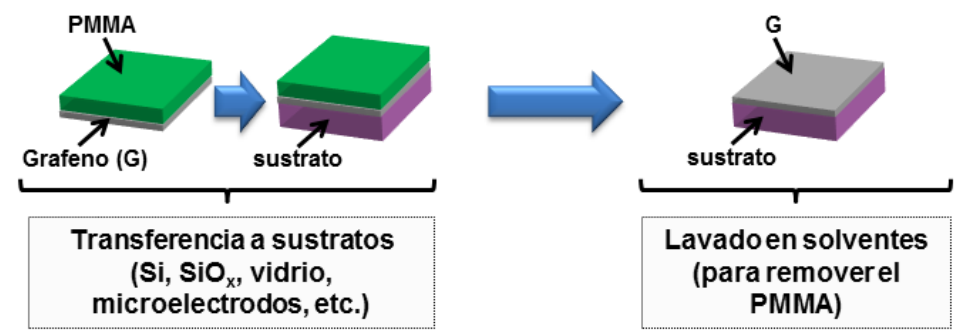

Figura 2.3 Esquema representativo de los pasos requeridos para: i) la síntesis de grafeno por CVD empleando una lámina de $\mathrm{Cu}$ como catalizador (A); ii) la adición del polímero PMMA como andamio para el grafeno y la disolución de $\mathrm{Cu}$ (etching) (B); y iii) la transferencia del grafeno a diferentes sustratos (C), como es indicado. Adaptado según la referencia. ${ }^{16}$ Más detalles pueden encontrarse en la Sección 2.4.3.1.

En la Figura 2.4 se muestran las fotografías de los sustratos de $\mathrm{Cu} /$ grafeno/PMMA dentro de una placa de Petri, en contacto con la solución de $\mathrm{HNO}_{3}$ (A), las mismas muestras en contacto con la solución de $\mathrm{Fe}\left(\mathrm{NO}_{3}\right)_{3}$ (B), y finalmente, las muestras que se observan translucidas flotando en la solución corresponden a láminas de grafeno/PMMA (C). Asimismo, se muestra un esquema general de los pasos comprendidos en éste protocolo. 

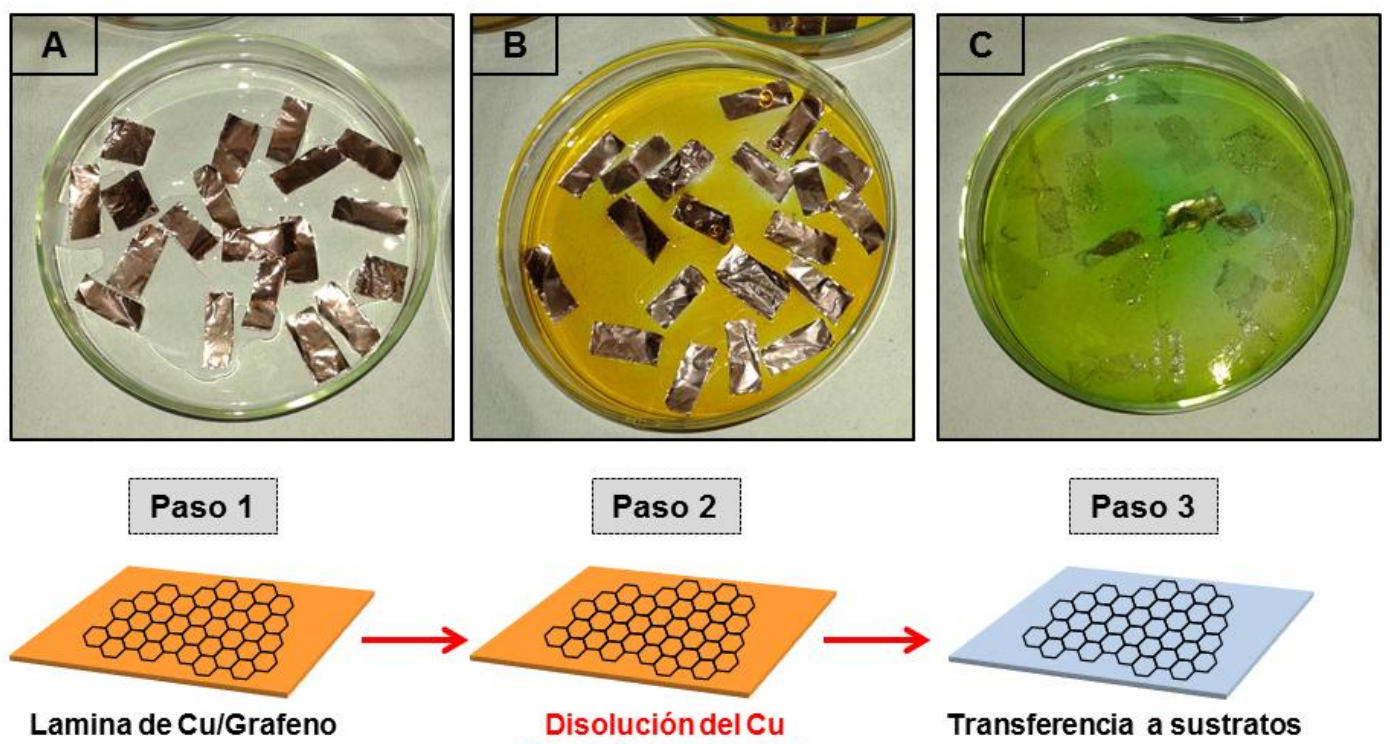

Lamina de Cu/Grafeno
Paso 2

Paso 3

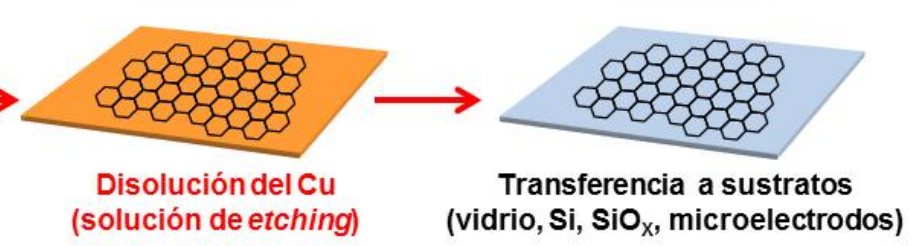

Figura 2.4 Fotografías mostrando los sustratos de $\mathrm{Cu}$ /grafeno/PMMA dentro de una placa de Petri, en contacto con la solución de $\mathrm{HNO}_{3}$ (A), las mismas muestras en contacto con la solución de $\mathrm{Fe}\left(\mathrm{NO}_{3}\right)_{3}(\mathrm{~B})$, y finalmente las muestras que se observan translucidas flotando en la solución corresponden a láminas de grafeno/PMMA (C). Se muestra un esquema representativo de las fotografías en mostradas. Más detalles pueden encontrarse en la Sección 2.4.3.1.

\subsubsection{Transferencia de Grafeno Utilizando Au@TOABr NPs ("Grafeno Libre de PMMA")}

El grafeno crecido sobre láminas de $\mathrm{Cu}$ fue cortado en pequeñas piezas $(1 \mathrm{~cm} \mathrm{x}$ $1 \mathrm{~cm}$ ) y colocado dentro de placas de Petri. Luego, a dichas piezas de $\mathrm{Cu} /$ grafeno se les depositó, por la metodología de drop-casting (gota a gota), $40 \mu \mathrm{L}$ de una solución concentrada de NPs de Au@TOABr. Las muestras se secaron al aire, y las láminas de $\mathrm{Cu}$ fueron disueltas empleando $\sim 5 \mathrm{~mL}$ de una solución de etching compuesta de $\mathrm{CuCl}_{2}$ 2,0 M (28\% p/v) en $\mathrm{HCl} 6 \mathrm{M}$ mezclado con alcohol isopropílico (10\% v/v). La solución de etching fue cuidadosamente adicionada a las placas de Petri, evitando que la misma entre en contacto con la capa superior de NPs metálicas. Las láminas de $\mathrm{Cu}$ se disolvieron por completo en $\sim 6$ horas. Finalmente, la solución de etching fue removida y remplazada con una mezcla de alcohol isopropílico (IPA) en agua Milli-Q al 10\% v/v, la cual permite remover los residuos de $\mathrm{CuCl}_{2}$. Dicha metodología permite la obtención de heterojunciones conformadas por películas de NPs de Au@TOABr en la superficie de grafeno. Las muestras fueron luego transferidas a diferentes sustratos tales como Si, 
vidrio y grillas de $\mathrm{Cu}$. Los sustratos limpios (embebidos previamente en una solución de IPA en agua Milli-Q al 10\% (v/v)) fueron cuidadosamente colocados debajo de las heterojunciones (flakes de Au NPs/grafeno) y retirados de la solución, para finalmente obtener las heterojunciones.

\subsection{Ensamblado de Nanopartículas sobre Sustratos (Películas con Nanopartículas)}

Las nanopartículas (NPs) metálicas as-synthesized fueron ensambladas sobre diferentes sustratos (dependiendo de la aplicación y/o caracterización) previamente funcionalizados con 3-aminopropil-trietoxisilano (APTES), por inmersión del sustrato/APTES en una solución conteniendo las NPs. Ver las siguientes secciones para más detalles en la preparación de las películas.

\subsubsection{Películas con Nanopartículas para Experimentos y Caracterización por UV-visible}

Los sustratos de vidrio $\left(1 \times 2,5 \mathrm{~cm}^{2}\right)$ fueron lavados con solución piraña por 20 minutos, enjuagados con agua Milli-Q y etanol, y finalmente secados con $\mathrm{N}_{2}$. Dichos sustratos fueron luego funcionalizados con 3-aminopropil-trietoxisilano (APTES), colocando los vidrios en una solución conteniendo $10 \mathrm{~mL}$ de etanol, $100 \mu \mathrm{L}$ de APTES y $100 \mu \mathrm{L}$ de agua Milli-Q. Seguidamente, la solución fue calentada a $70{ }^{\circ} \mathrm{C}$ por 10 minutos, y luego los sustratos fueron incubados a temperatura ambiente por 1 hora. Finalmente, las muestras fueron lavadas repetidas veces en etanol, secadas con flujo de $\mathrm{N}_{2}$, y sumergidas en una solución de NPs recién sintetizadas (freshly-prepared) en los tiempos indicados en cada Capitulo. Los sustratos decorados con las NPs por 20 horas desarrollaron diferentes colores dependiendo de las NPs utilizadas. Los mismos fueron lila-púrpura para las películas con $\mathrm{Au} @ \mathrm{TOABr}$, rosado claro para las películas con $\mathrm{Au} @ \mathrm{SC}_{12} \mathrm{MPCs}$, rosado para las películas con $\mathrm{Au}$ CNPs y amarillo claro para las películas con Ag CNPs.

\subsubsection{Películas con Nanopartículas para la Caracterización por Microscopías (TEM, SEM y AFM)}

Para las muestras para microscopía electrónica de transmisión (TEM), las NPs de $\mathrm{Au} @ \mathrm{TOABr}$ fueron depositadas gota a gota (drop-casting) sobre grillas recubiertas con HOPG (highly oriented pyrolitic graphite). Las muestras usadas para microscopía electrónica de barrido (SEM) fueron depositadas siguiendo dos procedimientos diferentes que aquí se detallan: 1) películas formadas por la inmersión de sustratos de Si funcionalizados con APTES dentro de una solución conteniendo las NPs; o 2) 
películas formadas por la deposición por drop-casting de una solución de NPs contenidas en una mezcla de tolueno + agua Milli-Q como se detalla: a $10 \mu \mathrm{L}$ de una solución de nanopartículas $(1,4-1,6 \mathrm{mg} / \mathrm{mL})$ se le adicionaron $30 \mu \mathrm{L}$ de tolueno y 120 $\mu \mathrm{L}$ de agua Milli-Q, la cual fue agitada vigorosamente dentro de un tubo eppendorf. A continuación, se dejó reposar la mezcla, lo cual permitió que las fases se separaran (orgánica y polar). Luego, se tomó una alícuota de las NPs desde el sobrenadante (fase orgánica) y se depositaron por drop-casting sobre sustratos de Si limpios, para luego ser utilizados en la caracterización por SEM. Las muestras usadas para microscopía de fuerza atómica (AFM) fueron ensambladas por inmersión de los sustratos dentro de la solución de nanopartículas en los tiempos indicados (del mismo modo que las muestras utilizadas para los experimentos de UV-visible).

\subsection{Tratamiento de las películas de NPs}

\subsubsection{Tratamiento Térmico}

Los tratamientos térmicos fueron realizados con el fin de facilitar la remoción del material orgánico, tanto de las NPs metálicas como de las muestras de grafeno (transferidas con PMMA o NPs). Las mismas se realizaron en un horno modelo Barnstead/Thermolyne Small Benchtop Muffle Furnaces Type 1300 (Thermo Scientific) a $200{ }^{\circ} \mathrm{C}$ por $30 \mathrm{~min}$.

\subsubsection{Tratamiento con Ozono}

Los tratamientos con ozono fueron realizados con el fin de limpiar las muestras de Grafeno (G) as-transferred, las cuales contienen un exceso del polímero PMMA (ver sección 2.4.3.1 para más detalles). Como paso preliminar, las mismas fueron inmersas en acetona tibia (debajo de su punto de ebullición) para que ocurra la solvatación del PMMA y sea más fácil su desprendimiento de la superficie del grafeno. A continuación, se realizaron lavados con varios solventes y finalmente un secado con flujo de $\mathrm{N}_{2}$. La oxidación de grafeno fue llevada a cabo en un generador de ozono modelo UVO ozone cleaner (Jelight Company Inc., Irvine, CA).

\subsubsection{Tratamiento con Tioles y Ditioles}

Los tratamientos con tioles y ditioles fueron realizados con el fin de ahondar en el rol de la cubierta orgánica en el sensado de compuestos orgánicos volátiles (VOCs). Particularmente, estas muestras fueron empleadas como controles en los experimentos mostrados en el Capítulo 4 de la presente Tesis (mayores detalles son presentados a lo largo de éste Capítulo). 


\subsection{Microelectrodos}

\subsubsection{Microfabricación de Electrodos de Au sobre Sustratos de $\mathrm{Si} / \mathrm{SiO}_{\mathrm{x}}$}

Dos electrodos de Au separados por un espacio comprendido entre 5 a $25 \mu \mathrm{m}$ (dependiendo de la máscara utilizada en el proceso litográfico) se utilizaron como sustratos para el depósito tanto de las nanopartículas (NPs) metálicas como de las películas de grafeno $(\mathrm{G})$. El empleo de microelectrodos permite realizar las medidas de corriente convencionales (cyclic voltammetry, CV) y los ensayos de sensado en el tiempo (chronoamperometry, CA) de una manera reproducible (ya que todos los electrodos son iguales y poseen la misma distancia entre ellos).

Los electrodos de Au fueron fabricados en Salas Limpias (Clean Room) tanto en los laboratorios de la University of Louisville (Kentucky, Estados Unidos) como en los del Instituto Nacional de Tecnología Industrial (INTI, Argentina). Durante el proceso de sputtering, una fuente de iones de Argón $\left(\mathrm{Ar}^{+}\right)$fue empleada para eyectar los sustratos targets $(\mathrm{Cr}$, Ti o Ni) empleados como capas de adhesión, seguido por un depósito de $\mathrm{Au}$ para formar los electrodos de éste material. El espesor de la capa de adhesión fue de 10 $\AA$, y la capa de Au fue de $100 \mathrm{~nm}$.

La Figura 2.5 muestra un esquema de un microelectrodo genérico señalando los electrodos de $\mathrm{Au}\left(\mathrm{E}_{1}, \mathrm{E}_{2}\right)$ y un recuadro mostrando la zona en la cual los electrodos poseen una separación entre 5 a $25 \mu \mathrm{m}$ (dependiendo de la máscara empleada en el proceso de fotolitografía) (A). Se muestran imágenes de microscopia óptica correspondientes a una región equivalente a la remarcada en el esquema exhibido en A, mostrando los diferentes extremos que pueden tener los electrodos (B-E). 


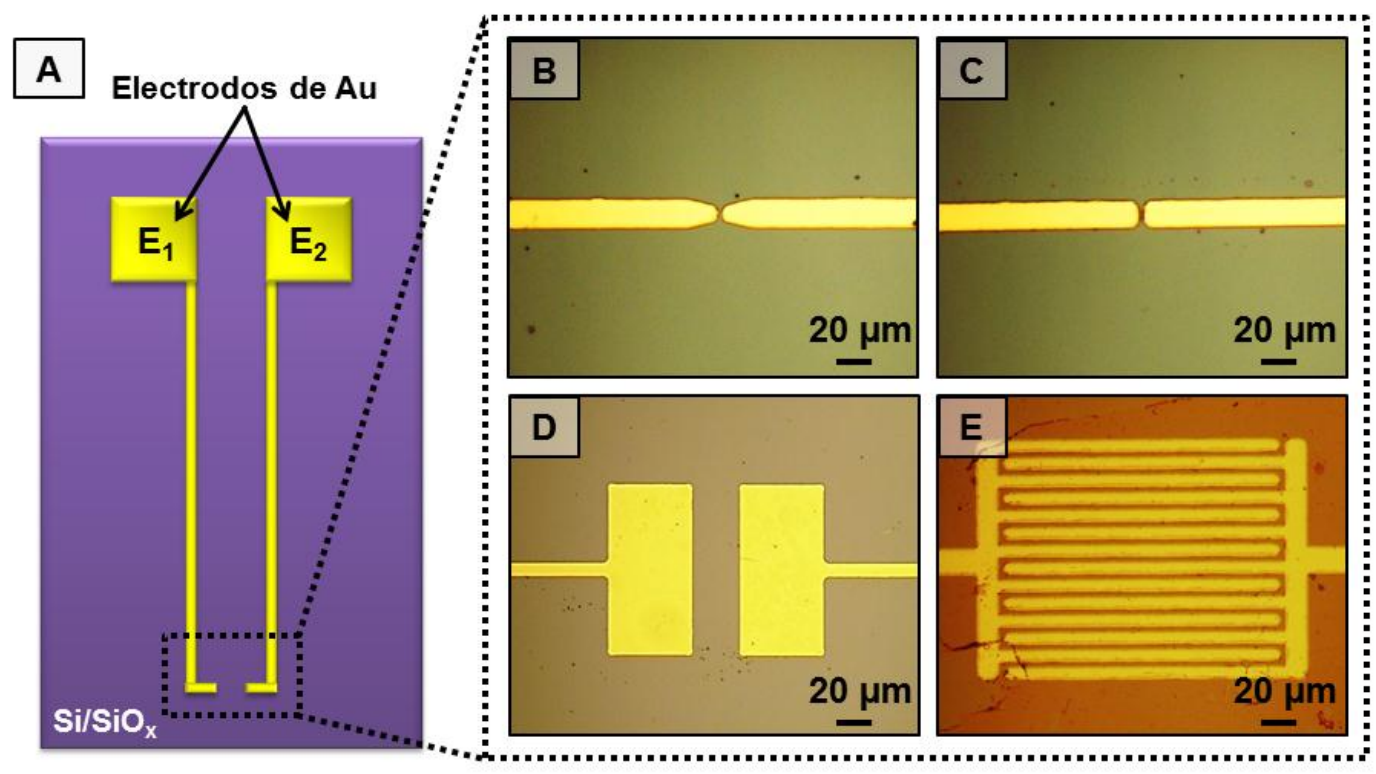

Figura 2.5 Esquema de un microelectrodo genérico mostrando los electrodos de $\mathrm{Au}$ $\left(E_{1}, E_{2}\right)$ y un recuadro mostrando la zona en la cual los electrodos poseen una separación entre $5-25 \mu \mathrm{m}$ (dependiendo de la máscara empleada en el proceso de fotolitografía) (A). Imágenes de microscopia óptica correspondientes a una región equivalente a la remarcada en el esquema exhibido en $\mathrm{A}$, mostrando los diferentes extremos que pueden tener los electrodos (B-E).

\subsubsection{Limpieza y Cableado de los Microelectrodos}

Como primer paso, se deben limpiar cuidadosamente los electrodos de $\mathrm{Au}$ con solventes (diclorometano, tolueno, acetona, etanol e isopropanol) y secarlos con $\mathrm{N}_{2}$, con el fin de remover los residuos de los polímeros utilizados en el proceso litográfico (por lo general de emplea PMMA). Segundo, se colocan cables de $\mathrm{Cu}$ (recubiertos por una vaina plástica) permitiendo el contacto con los pads de $\mathrm{Au}$, lo cual se logra con el empleo de pintura de Ag. Luego, se secan en estufa por $\sim 12$ horas a $80^{\circ} \mathrm{C}$. Tercero, se protegen los contactos realizados en el paso anterior con una capa de torr-seal epoxy, la cual se debe curar en estufa por $\sim 12$ horas a $80^{\circ} \mathrm{C}$. Finalmente, antes de su uso, cada electrodo es lavado nuevamente con los solventes descriptos y secados con $\mathrm{N}_{2}$, para luego ser colocados en una lámpara generadora de ozono por 10 minutos, con el fin de remover todos los restos orgánicos que puedan interferir en siguientes medidas. 
La Figura 2.6 corresponde a una fotografía de una oblea (wafer) de $\mathrm{Si} / \mathrm{SiO}_{\mathrm{x}}$ con arreglos de electrodos (microelectrodos) de $\mathrm{Au}$ depositados como películas delgadas empleando métodos convencionales de fotolitografía, deposición de metales (sputtering) y desprendimiento de los polímeros (lift-off) (A) y una fotografía de un microelectrodo después de que se le colocaron los cables de $\mathrm{Cu}$ y una pintura aislante (Torr-seal epoxy) (B), como es indicado.
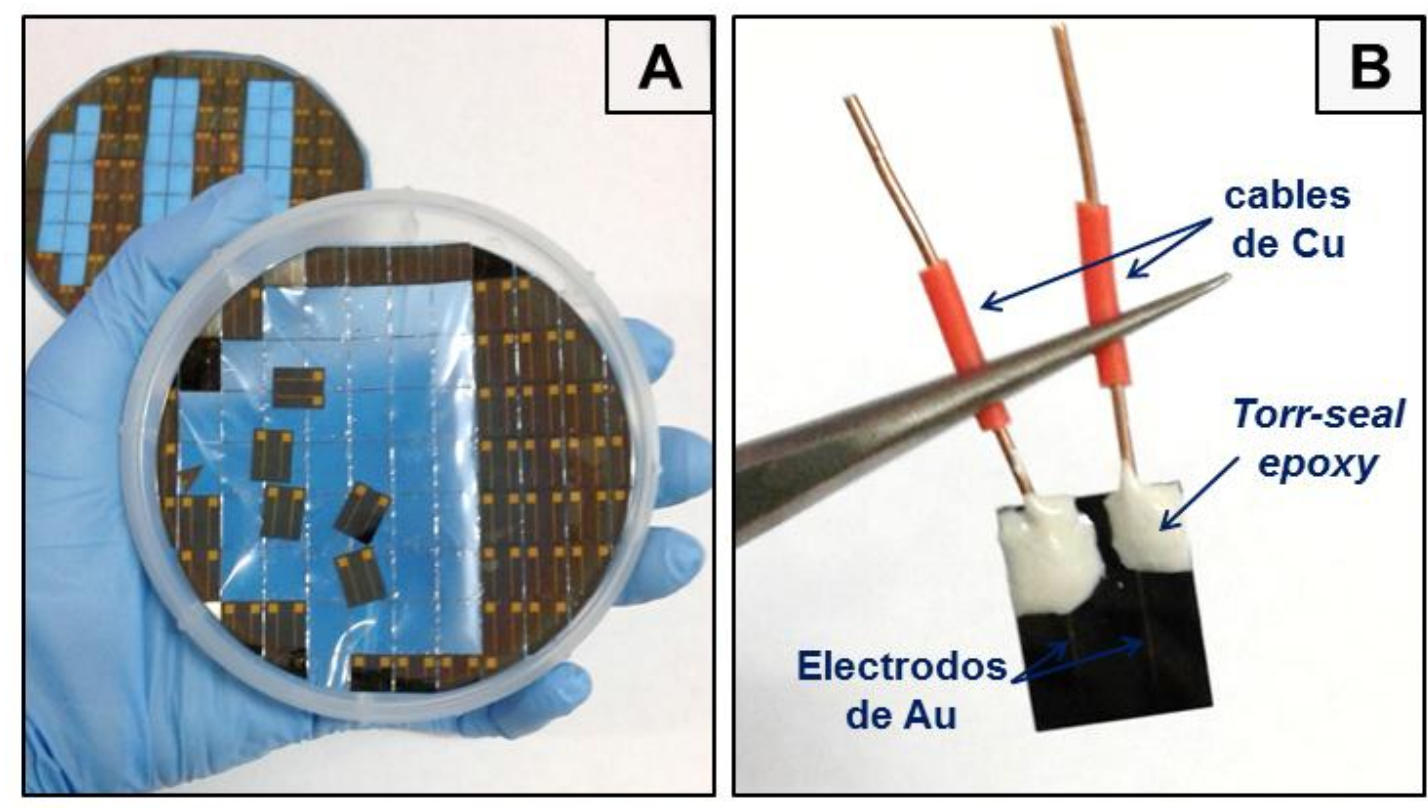

Figura 2.6 Fotografía mostrando una oblea (wafer) de $\mathrm{Si} / \mathrm{SiO}_{\mathrm{x}}$ con arreglos de electrodos (microelectrodos) de Au depositados como películas delgadas empleando fotolitografía (A). Fotografía de un microelectrodo después de que se le colocaron los cables de $\mathrm{Cu}$ y una pintura aislante (Torr-seal epoxy) (B), como es indicado. Ver Sección 2.7.2 para más detalles. 


\section{Sección B - Caracterización de los Nanomateriales}

En ésta sección se especifican las técnicas para la caracterización de los nanomateriales y las condiciones experimentales generales de las mismas. Así mismo, para brindarle al lector mayor claridad, se decidió colocar una sección experimental en cada Capítulo en donde se detallan las condiciones particulares empleadas.

\subsection{Voltamperometría Cíclica y Cronoamperometría}

\subsubsection{Medidas de Corriente en Estado Sólido}

Las medidas de corriente en estado sólido fueron llevadas a cabo en una estación electroquímica (CH Instruments, INC., Model 600D) operando en modo de ciclo voltametría $(\mathrm{CV})$. Este modo permite obtener gráficos de corriente del sistema versus el potencial (voltaje) aplicado (I-V). Las muestras fueron colocadas dentro de una jaula de Faraday que dispone de un amplificador de pico amperes (picoamperometer booster), con tres electrodos terminales. Estos electrodos terminales corresponden a: i) un electrodo de referencia (RE), ii) un electrodo de trabajo (WE), y iii) un electrodo de conteo (CE), los cuales se diferencian por los colores verde, blanco y rojo, respectivamente. Para el caso de las medidas empleando microelectrodos (los cuales poseen dos electrodos de $\mathrm{Au}$ ), un cable del dispositivo se conectó al electrodo de trabajo y el otro cable se conectó al mismo tiempo a los electrodos de referencia y de conteo. ${ }^{17}$

\subsubsection{Cronoamperometría}

Los experimentos de sensado (tanto de luz UV como de $\mathrm{H}_{2}$ ) se realizaron en una estación electroquímica operada en modo de Cronoamperometría (CA), la cual permite realizar estudios de la corriente del sistema versus el tiempo. La corriente fue monitoreada en el tiempo empleando un potencial constante de (-) 0,3V, mientras que el dispositivo fue expuesto al analito (luz $\mathrm{UV} \mathrm{o}_{2}$ ) en ciclos alternantes.

\subsection{Espectroscopia Ultravioleta-visible (UV-vis)}

\subsubsection{UV-vis de Nanopartículas en Solución}


Los espectros ultravioleta-visible (UV-vis) fueron medidos con un espectrómetro Perkin Elmer Lambda 35, equipado con doble haz. Como referencia se utilizó tolueno, acetona, etanol o agua, dependiendo de la muestra. En todos los casos en los que se caracterizaron películas de NPs depositadas sobre vidrios (vidrios decorados con NPs) se utilizó como blanco un vidrio limpio.

\subsubsection{Experimentos de Sensado por UV-vis}

Los experimentos de sensado de compuestos orgánicos volátiles (VOCs) fueron llevados a cabo tanto en atmósfera húmeda como en atmósfera seca (empleando gel de sílice). Los espectros fueron adquiridos en un espectrofotómetro UV-vis Perkin Elmer Lambda 35TM en un rango de longitud de onda comprendido entre 300 a $900 \mathrm{~nm}$. Los mismos se detallan en el Capítulo 3 de la presente Tesis.

\subsection{Espectroscopia Infrarroja por Transformada de Fourier (FTIR)}

La espectroscopia infrarroja por transformada de Fourier (Fourier transform infrared spectroscopy, FT-IR) fue empleada principalmente para caracterizar el material orgánico que protege a las nanopartículas (capping orgánico). ${ }^{18-21}$

Asimismo, en el Capítulo 3 se explorará en la restructuración de la capa orgánica, ${ }^{22}$ por medio de los cambios en la vibración del stretching del $\mathrm{CH}_{2}$ asimétrico (d), cuando las películas se encuentran en la presencia de analitos en fase vapor.

\subsubsection{FT-IR de Películas con Nanopartículas}

Para la caracterización de las nanopartículas por FT-IR, las mismas se depositaron en forma de películas.

Los experimentos mostrados a lo largo del Capítulo 3 fueron llevados a cabo en un espectrómetro PIKE MiracleTM Varian 600 Instrument en modo de transmisión. Mayores detalles se brindan en el citado Capítulo.

Los experimentos mostrados a lo largo del Capítulo 4, fueron realizados llevados a cabo en un equipo Nicolet (380) USA, en modo transmisión. Como sustratos se emplearon discos de $\mathrm{KBr}$, los cuales fueron cuidadosamente lavados con tolueno y secados con $\mathrm{N}_{2}$, a los cuales luego se les depositaron las nanopartículas. Mayores detalles se brindan en el citado Capítulo.

\subsubsection{Experimentos de Sensado por FTIR}


Los experimentos de sensado de compuestos orgánicos volátiles (VOCs) empleando FT-IR fueron llevados a cabo en un espectrómetro PIKE MiracleTM Varian 600 Instrument en modo de transmisión, siguiendo la misma metodología de preparación de las muestras detallada para UV-vis. Los mismos se detallan en el Capítulo 3 de la presente Tesis.

\subsection{Espectroscopia de Fotoelectrones Generados por Rayos $\mathrm{X}$ (XPS)}

La espectroscopia de fotoelectrones generados por rayos X (X-ray photoelectron spectroscopy, XPS) también conocida como espectroscopia de electrones para el análisis químico (electron spectroscopy for chemical analysis, ESCA) esta fundamentada en el efecto fotoeléctrico. En XPS se bombardea la superficie de una muestra con un haz de rayos-X blandos $(<1500 \mathrm{eV})$, causando la eyección un electrón (fotoelectrón). La identificación de la muestra puede hacerse directamente midiendo la energía cinética (KE) de los fotoelectrones. De éste modo, es posible identificar el estado químico de los elementos presentes en la muestra, aún con pequeñas variaciones en la energía cinética. Además, pueden determinarse las concentraciones relativas de los elementos midiendo las intensidades de los fotoelectrones.

En general, con XPS se pueden analizar entre 2 a 20 capas atómicas de espesor. Dicho valor depende del material, la energía del fotoelectrón, y el ángulo (con respecto a la superficie) en el cual se realiza la medida. Así mismo, esta espectroscopia puede detectar todos los elementos, con excepción del Hidrógeno y el Helio. ${ }^{19,23}$ Por otro lado, las muestras pueden ser gaseosas, líquidas o sólidas, aunque la mayoría de los instrumentos de XPS están diseñados para la caracterización de sólidos.

Brevemente, asumiendo que un fotón de alta energía puede ionizar un átomo produciendo un electrón libre eyectado (fotoelectrón), luego la energía cinética (kinetic energy, KE) del fotoelectrón depende de la energía del fotón $h \mathrm{v}$, el cual es expresado por la ley del efecto fotoeléctrico de Einstein como:

$$
\mathrm{KE}=h \mathrm{v}-\mathrm{BE}
$$

donde, "BE" es la energía de enlace (binding energy, BE) de un electrón particular en un átomo particular. De la ecuación 2.1 se denota que, conociendo $h \mathrm{v}$ y midiendo experimentalmente el valor de $\mathrm{KE}$, es posible determinar el valor de la BE. 
Los principales componentes de un XPS incluyen: a) una fuente de radiación (en general monocromática); b) un dispositivo para contener la muestra; c) un sistema analizador (por lo general hemisféricos), el cual el haz de electrones es desviado por un campo magnético electroestático, permitiendo que los electrones se muevan siguiendo una trayectoria curva; d) un detector multicanal (channeltron), en el cual al aplicar un potencial de varios kilovoltios se produce una cascada de $\sim 10^{8}$ electrones secundarios por cada electrón incidente; e) un procesador de la señal junto con un dispositivo de lectura. En la Figura 2.7 A se muestra un esquema de los principales componentes de un equipo de XPS, el cual fue adaptado según las referencias. ${ }^{18,19}$ En la Figura 2.7 B, se

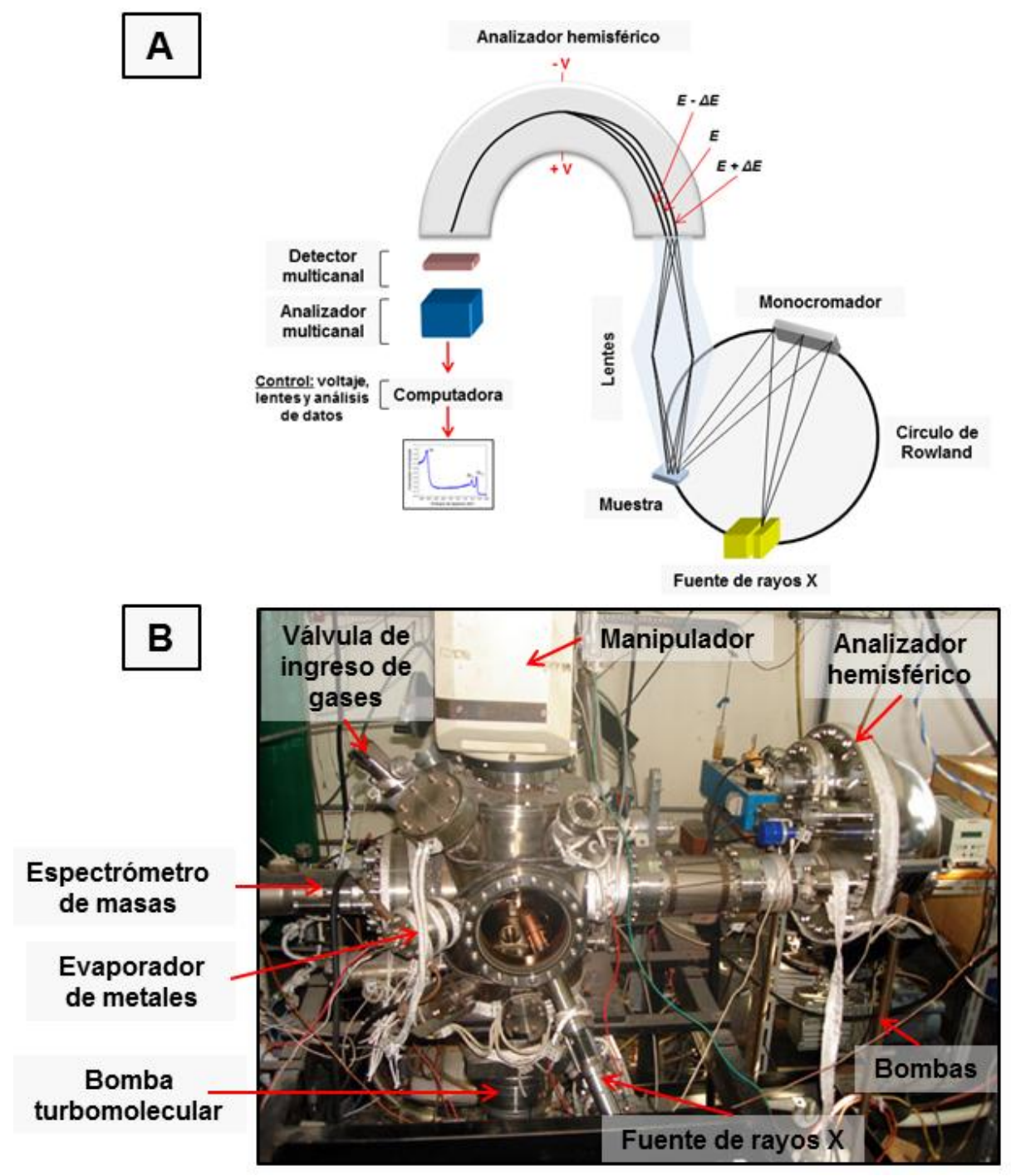

Figura 2.7 Esquema de los principales componentes de un equipo de XPS, el cual fue adaptado según las referencias ${ }^{18,19}$ (A). Componentes del equipo de XPS empleado en esta tesis. Fotografía del equipo de XPS empleado en ésta tesis, gentileza del grupo de Nanoscopías-INIFTA (B). 
muestra una fotografía del equipo de XPS empleado en ésta Tesis, donde se marcan los componentes principales según las referencias. ${ }^{24,25}$ La fotografía fue gentileza del grupo de Nanoscopías (INIFTA). ${ }^{26}$

Es importante mencionar, que todas las medidas se realizan en condiciones de ultra alto vacío (ultra high vacuum, UHV) operando en presiones del orden de $10^{-10}$ Torr. Las razones de ello son: facilitar la trayectoria de los electrones hasta el detector ( $\sim$ un metro) y al mismo tiempo evitar las contaminaciones de moléculas ambientales en las paredes del instrumento (acero inoxidable).

Particularmente, en esta Tesis la espectroscopia XPS fue empleada para caracterizar la calidad del grafeno obtenido por CVD (determinando la cantidad de residuos de $\mathrm{Fe}$ y $\mathrm{Cu}$ remanentes después del procedimiento de transferencia). Los mismos son exhibidos en el Capítulo $\mathrm{V}$, y fueron colectados y analizados por los Dres. Aldo Rubert y Guillermo Benitez, ambos pertenecientes al INIFTA.

Finalmente, valiosa información relacionada a la técnica de XPS puede encontrarse en las siguientes referencias. ${ }^{19,27-29}$

\subsection{Espectroscopia de Absorción de Rayos X (XAS)}

Las espectroscopia de absorción de rayos X (X-ray absortion spectroscopy, XAS) se basa en el cambio de la respuesta de un sistema en función de la energía del fotón incidente. En general, un electrón del core es excitado a un estado de valencia desocupado.

Considerando un haz de rayos-X monocromático pasando a través un material de espesor $(t)$, la intensidad transmitida $(I)$ va a ser reducida con respecto al haz incidente $\left(I_{o}\right)$, lo cual es ejemplificado en la siguiente ecuación:

$$
I=I_{o} e^{-\mu \mathrm{t}}
$$

Donde " $\mu$ " es el coeficiente de absorción, el cual depende de: i) la energía del fotón; ii) la densidad atómica; y iii) las especies atómicas que componen la muestra. En el caso de que se empleen rayos-X duros $(>1000 \mathrm{eV})$ el efecto fotoeléctrico domina, en el cual la absorción de un fotón produce la eyección de un electrón del core del átomo.

La tendencia general es que a medida que incrementa la energía del fotón empleado, el valor de $\mu$ decrece gradualmente hasta que se alcanza una energía crítica, en la cual se produce un cambio abrupto. Esta discontinuidad es conocida como el 
"borde de absorción" y es producida cuando la energía del fotón se corresponde con la energía de excitación del electrón del core. Esta energía es específica de cada elemento químico y se corresponde con la energía de enlace del mismo. Por ende, por ejemplo, a medida que crece el número atómico $(Z)$ se observan bordes de energía, los cuales se corresponden a una especie atómica bien definida. A continuación, después del proceso de absorción de los rayos-X, un átomo aislado puede sufrir dos procesos: a) ser excitado, en el caso de que la energía del fotón se corresponda con la diferencia de energía entre el nivel del core y un nivel superficial desocupado; o b) ser ionizado, en el caso de que la energía del fotón supere la energía del enlace, produciendo un fotoelectrón, el cual va a ser eyectado del átomo.

En correspondencia con el borde, el coeficiente de absorción presenta oscilaciones conocidas como X-Ray Absortion Fine Structure (XAFS). De lo expuesto, surge que en los espectros de absorción se denotan dos regiones principales:

- La región cercana al borde (near edge region), la cual esta extendida unos pocos décimos de eV por encima del borde. Esta es la región X-Ray Absortion Near Edge Structure (XANES) la cual es dominada por múltiples procesos de dispersión de los fotoelectrones emitidos con baja energía cinética. Por consiguiente, XANES contiene la información de la estructura electrónica de la muestra y la simetría geométrica del sitio de la molécula que esta produciendo la absorción;

- La región extendida (extended region), la cual comienza en $\sim 40$ a $50 \mathrm{eV}$ por encima del borde. La misma es denominada Extended X-Ray Absortion Fine Structure (EXAFS) y provee información de la estructura atómica local que rodea al átomo que absorbió inicialmente los rayos-X, tales como números de coordinación y distancias inter-atómicas.

En relación a lo expuesto, en la Figura 2.8 se muestra un esquema de las regiones (pre-borde, XANES y EXAFS) más importantes de un típico espectro de XAS entorno a un borde de absorción de un electrón del core, el cual fue adaptado según la referencia. $^{30}$

Es importante mencionar que XANES permite estudiar el estado químico de un elemento dado de acuerdo a la posición del borde de absorción. Siendo dicha información similar a la que se puede obtener por XPS. Sin embargo, XANES presenta la desventaja en relación a XPS, de no ser una técnica cuantitativa. 


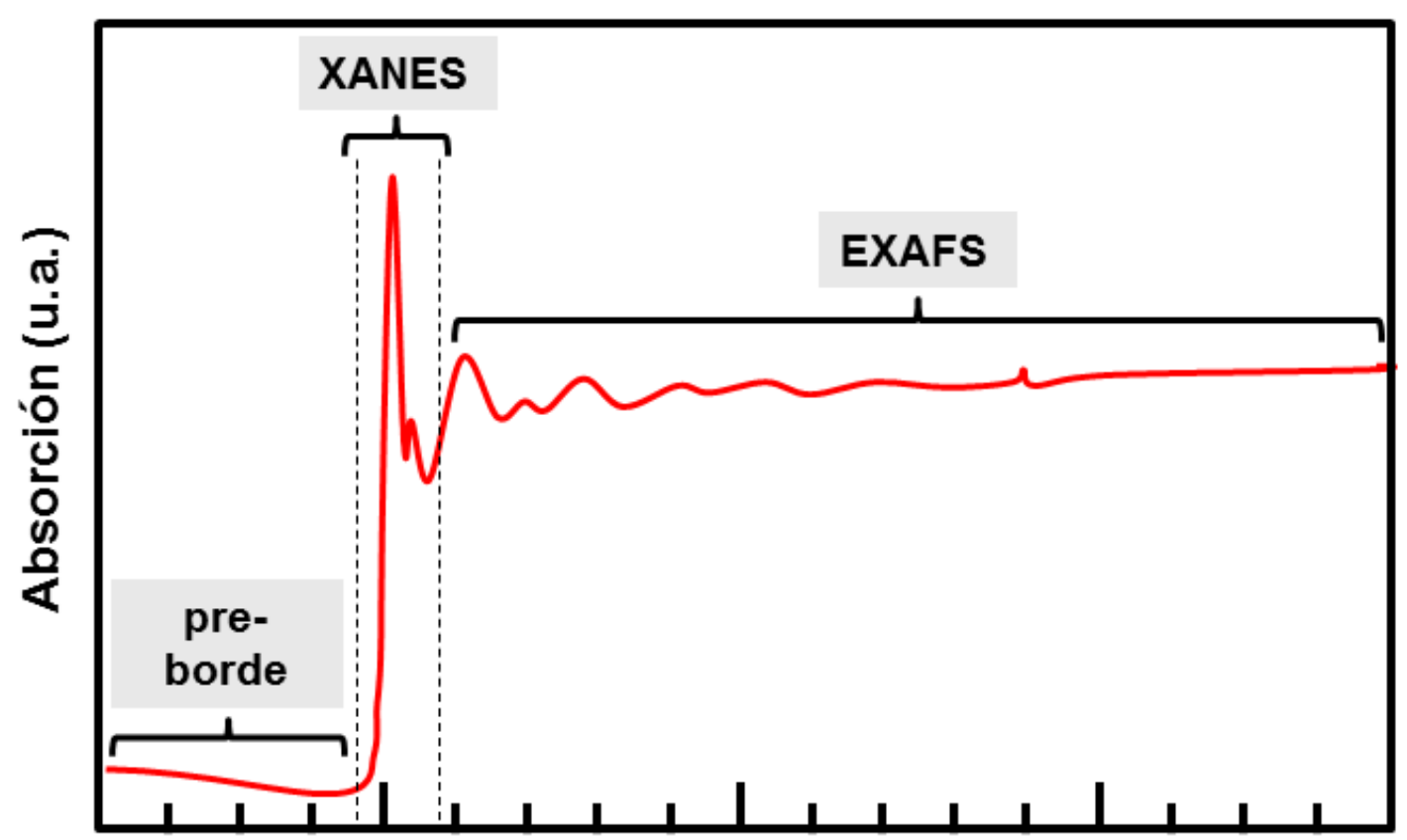

\section{Energía del fotón relativa (eV)}

Figura 2.8 Esquema representando las regiones más importantes de un típico espectro de XAS ( $x$-ray absortion spectroscopy). El mismo fue adaptado según la referencia. ${ }^{30}$

De una manera ilustrativa, en la Figura 2.9 se muestra un esquema de las diferencias esenciales entre las espectroscopías XAS, XPS y Ultraviolet photoelectron spectroscopy (UPS). Notar que mientras que en XAS se promueve un electrón desde el core hasta estados desocupados, en XPS y UPS los electrones son promovidos hasta el vacío. Esquema adaptado según la referencia. ${ }^{30}$ Cabe mencionar que, otra de las grandes diferencias entre XANES y las técnicas tradicionales de fotoemisión es que en la primera ya sea el fotón fluorescente, el electrón Auger o el fotoelectrón dispersado elásticamente son registrados, mientras que en las últimas los fotoelectrones son medidos. Esto implica que en XANES se puede medir el estado final de los fotoelectrones enlazados, ya que el fotoelectrón en sí mismo no necesita ser detectado. En cambio, en técnicas como XPS y UPS, el fotoelectrón es el detectado (ver Sección 2.11 para más detalles). 


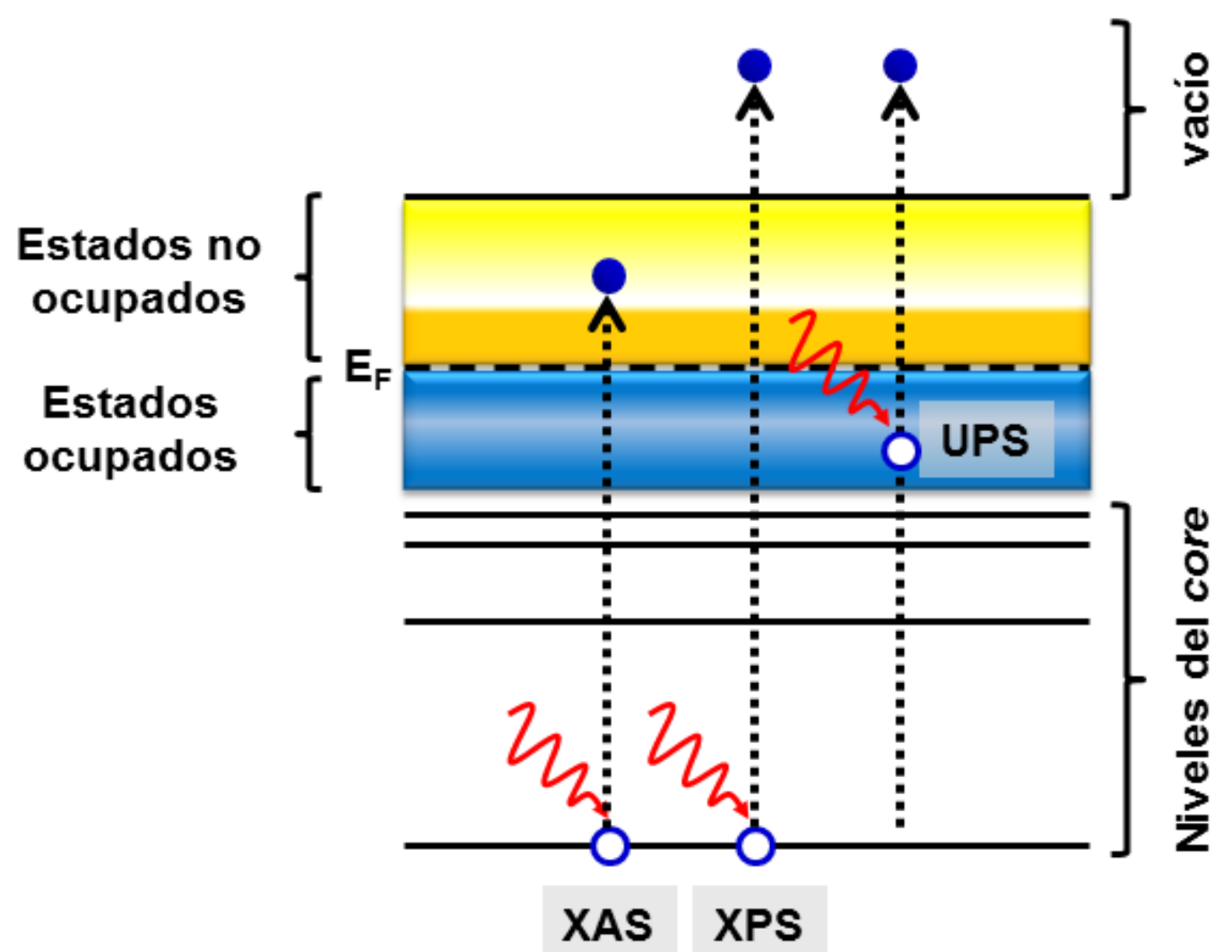

Figura 2.9 Esquema mostrando las diferencias esenciales entre XAS, XPS y UPS. Notar que mientras que en XAS se promueven un electrones desde el core hasta estados no-ocupados, en XPS y UPS los electrones son promovidos hasta el vacío. Esquema adaptado según la referencia. ${ }^{30}$

La espectroscopia XANES fue empleada para caracterizar películas conformas por nanopartículas metálicas cubiertas con tioles y ditioles. Estos datos son mostrados en el Capítulo 4 de la presente Tesis. Los mismos fueron colectados en la línea XAFS-1 del LNLS, por los Dres. Lisandro Giovanetti y José Ramallo-López, como parte de una colaboración existente. En la Figura 2.10 se muestra un esquema de los principales componentes XANES en modo de fluorescencia (XAFS-1, LSNLS). El mismo fue

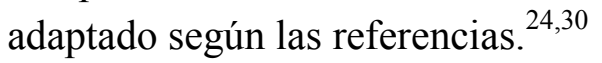

Por último, valiosa información relacionada a la técnica de XANES puede encontrarse en las siguientes referencias. ${ }^{19,30-33}$ 


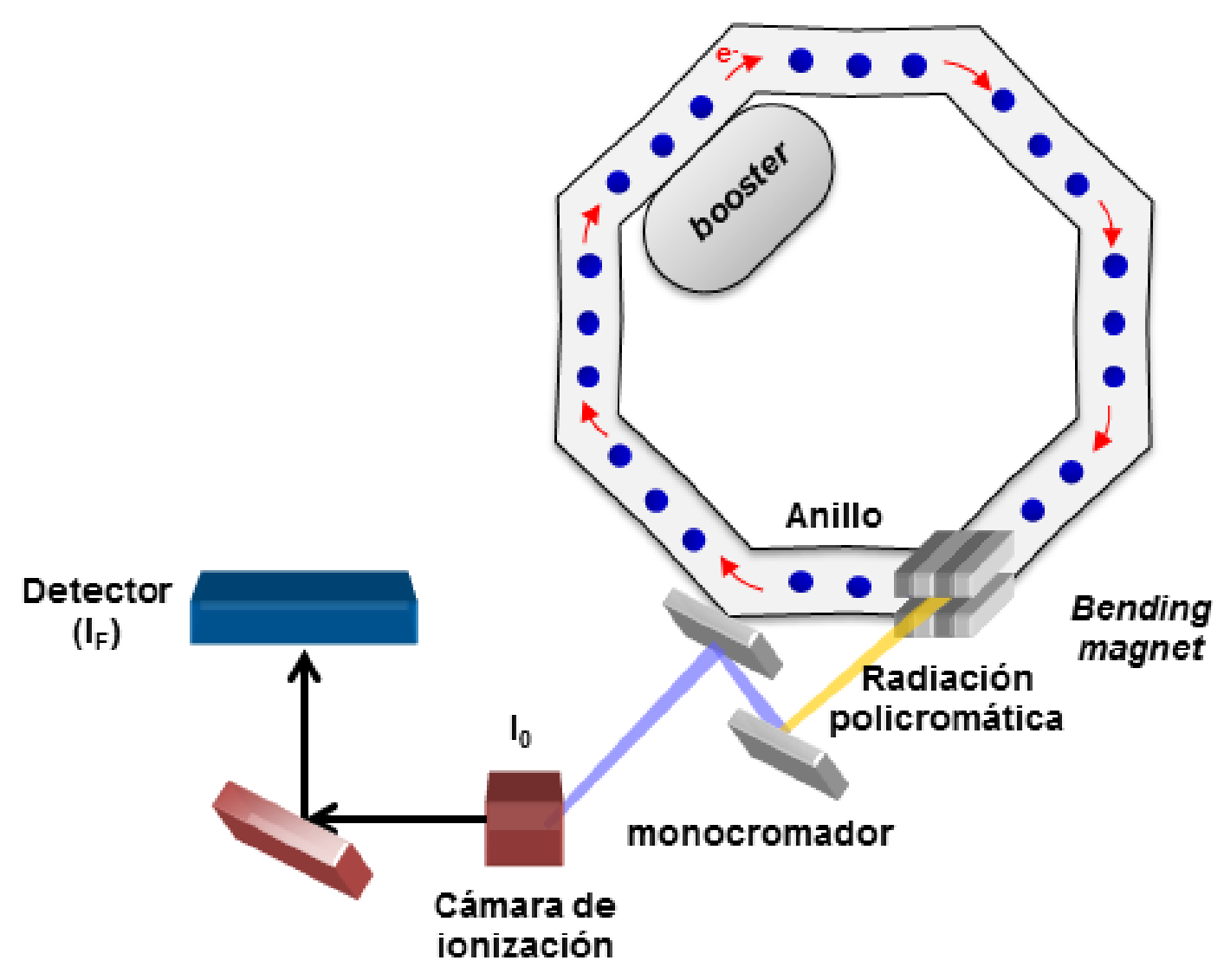

Figura 2.10 Esquema de los principales componentes XANES en modo de fluorescencia (XAFS-1, LSNLS). El mismo fue adaptado según las referencias. ${ }^{24,30}$

\subsection{Dispersión de Rayos X a Bajo Ángulo (SAXS)}

La dispersión de rayos X a bajo ángulo (small-angle X-ray scattering, SAXS) es una técnica que permite monitorear los rayos-X dispersados elásticamente producidos por una muestra dada. En SAXS, dicha dispersión está directamente asociada tanto a las in in-homogeneidades en la densidad electrónica de la muestra como a las dimensiones de la misma (rango desde varios Å hasta décimas del nm).

La técnica se denomina de bajo ángulo, ya que se trabaja por lo general en rangos comprendidos entre $\sim 0,1^{\circ}$ a $10^{\circ}$, pudiendo resolver diferencias en la densidad electrónica de una muestra en rangos de tamaños de $\sim 0,5$ a $50 \mathrm{~nm}$. 
Cabe mencionar que, en SAXS la información obtenida no está asociada a la estructura atómica del material en estudio. En los casos que se requiera resolver las fases cristalinas en una muestra, se debe operar en modos de difracción de rayos-X (Xray diffraction, XRD) y wide-angle X-ray scattering (WAXS).

En este trabajo Doctoral, SAXS fue empleado como un herramienta tanto para determinar el tamaño de las nanopartículas en solución, como para caracterizar cualitativamente la estructura de películas conformadas por nanopartículas.

En el Capítulo 4, los experimentos empleando SAXS fueron llevados a cabo en la línea SAXS-1 del LNLS, Campinas, Brasil. La mencionada caracterización fue realizada por los Dres. Lisandro Giovanetti y José Ramallo-López, ambos pertenecientes al INIFTA-CONICET.

Por otro lado, en el Capítulo 7, los experimentos empleando SAXS fueron realizados en una línea SAXS, XENOCS, perteneciente al INIFTA. Los datos fueron colectados y analizados junto con los Dres. Lisandro Giovanetti y Cristián Huck Iriart (INIFTA-CONICET) como parte de una colaboración existente.

Finalmente, valiosa información relacionada a la técnica de SAXS puede encontrarse en las siguientes referencias. ${ }^{30,34-38}$

\subsection{Dispersión de Rayos $X$ a Bajo Ángulo con Incidencia Rasante (GISAXS)}

La dispersión de rayos $\mathrm{X}$ a bajo ángulo con incidencia rasante (grazing incidence small-angle X-ray scattering, GISAXS) es una herramienta crucial para la caracterización de superficies desde el punto de vista estructural. Esta técnica permite estudiar tanto sistemas ordenados (con correlación) como aquellos sistemas sin orden. Asimismo, debido a que las condiciones experimentales implican el uso de ángulos rasantes muy bajos, y por consiguiente los ángulos dispersados también lo son, se obtienen intensidades de dispersión que son sensibles al tamaño de los nano-objetos en rangos comprendidos entre unos pocos $\mathrm{nm}$ hasta $\sim 1 \mu \mathrm{m}{ }^{39}$

Otra de las ventajas asociadas a GISAXS, es que ésta permite obtener imágenes que se corresponden con prácticamente la totalidad de la muestra (dependiendo del área del spot del haz de rayos-X empleado), por lo tanto son altamente representativas del sistema en estudio.

En el contexto de lo expuesto, por ejemplo en aquellos casos en los que se requiera caracterizar una película con nanopartículas, es posible determinar el tamaño y 
la morfología general de las mismas con el uso de microscopías tales como TEM y AFM. Sin embargo, las mencionadas técnicas si bien brindan una excelente resolución, traen aparejado que sólo se esta observando una porción pequeña de las muestras, lo cual en la mayoría de los casos no es del todo representativo del sistema. En estas situaciones, el uso de GISAXS va a ser esencial para resolver la estructura del sistema en los tres ejes cartesianos ( $\mathrm{x}, \mathrm{y}, \mathrm{z})$.

En la Figura 2.11 se muestra un esquema de la geometría experimental empleada en los experimentos de GISAXS, adaptado según las referencias. ${ }^{30,39}$ Brevemente, el haz de rayos-X incide sobre la superficie de la muestra con un ángulo rasante $\left(\alpha_{i}\right)$ respecto a la misma. La intensidad de dispersión es registrada en un detector bidimensional, como una función del ángulo de salida $\left(\alpha_{\mathrm{i}}\right)$ con respecto a la superficie del plano y al ángulo en el plano $(\theta)$. Asimismo, la muestra puede ser rotada respecto al ángulo azimutal $(\omega)$. La imagen GISAXS corresponde a una película conformada por nanopartículas de Au protegidas con una cubierta orgánica, las cuales fueron depositadas sobre un sustrato de

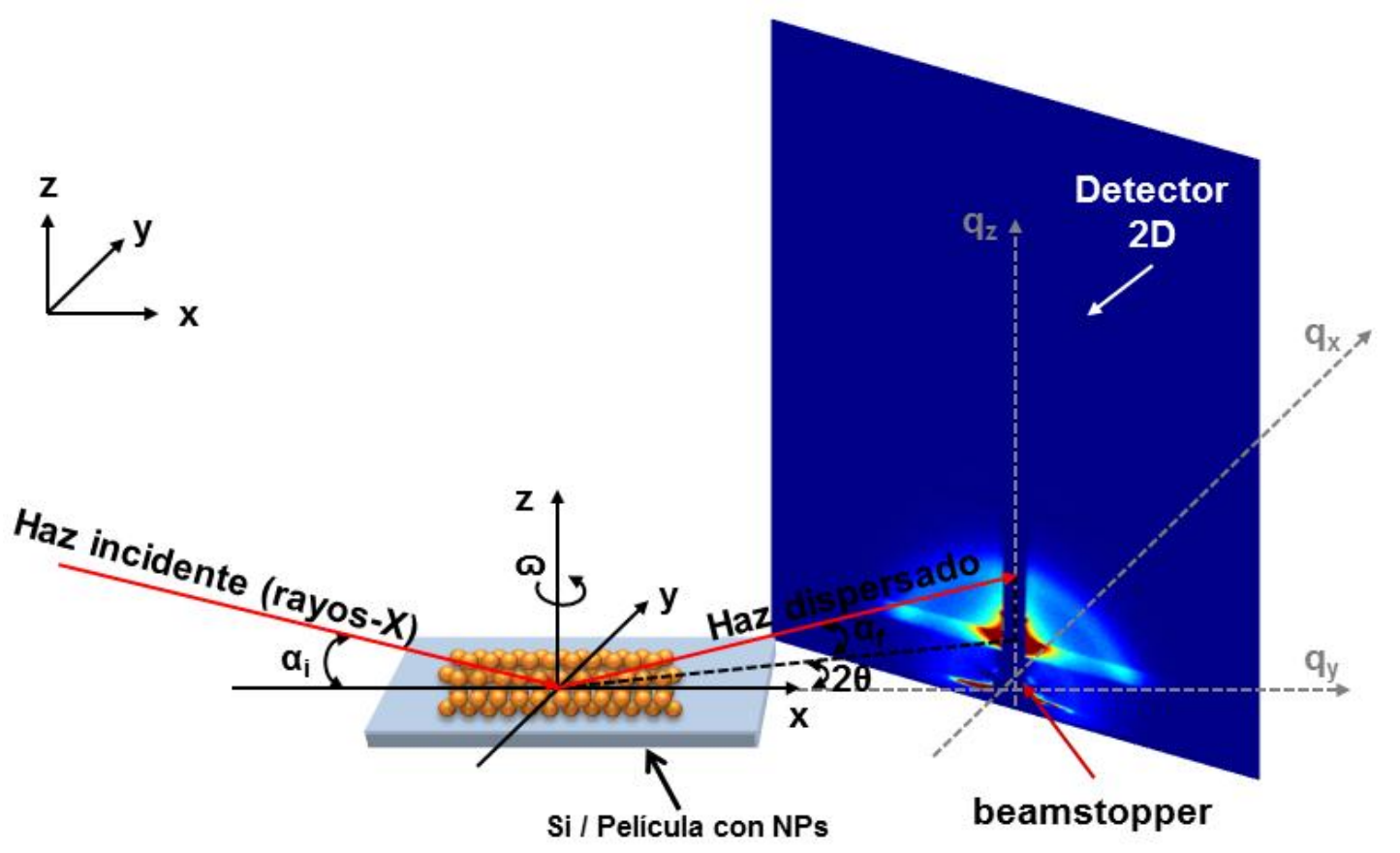

Figura 2.11 Esquema representativo de la geometría empleada en los experimentos de GISAXS. El haz de rayos-X incide sobre la superficie de la muestra con un ángulo rasante $\left(\alpha_{i}\right)$ respecto a la misma. La intensidad de dispersión es registrada en un detector bidimensional, como una función del ángulo de salida $\left(\alpha_{\mathrm{i}}\right)$ con respecto a la superficie del plano y al ángulo en el plano $(\theta)$. Adaptado según las referencias. ${ }^{30,39}$ Ver detalles en la Sección 2.14. 
Si (100).

En la Figura 2.12 se muestra una fotografía panorámica del Laboratorio Nacional de Luz Sincrotrón (LNLS) Campinas, Brasil (A). Fotografías de la línea XRD 2 (LNLS) mostrando el set-up experimental (B-E) empleado durante los ensayos de sensado de $\mathrm{H}_{2}$, junto con la fotografía del panel empleado mostrando los caudalímetros electrónicos, tanques de gases y el sensor de $\mathrm{H}_{2}$ empleados durante los mencionados ensayos $(\mathrm{F})$.
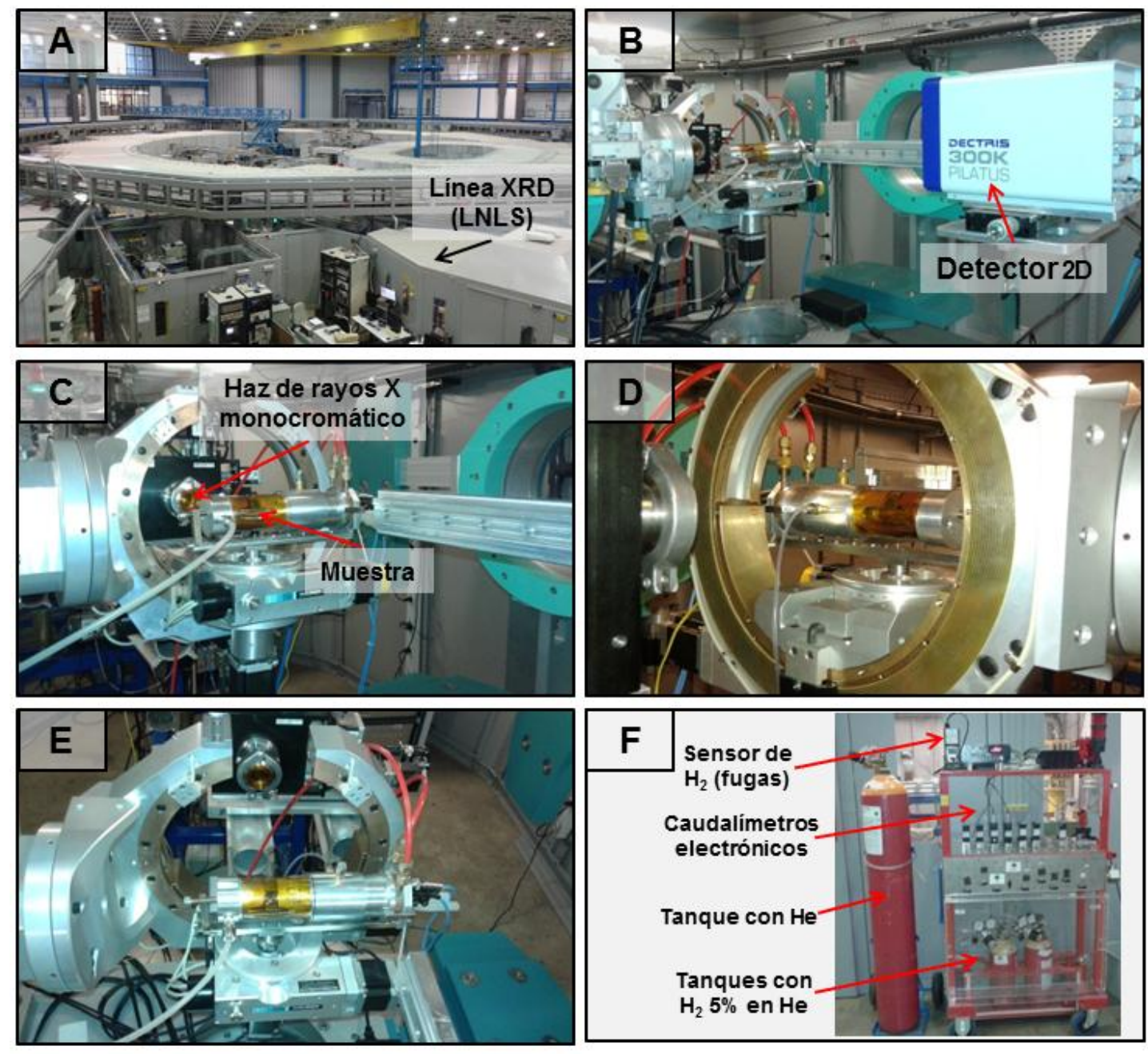

Figura 2.12 Fotografía panorámica mostrando el Laboratorio Nacional de Luz Sincrotrón (LNLS) Campinas, Brasil (A). Fotografías de la línea XRD 2 (LNLS) mostrando el set-up experimental (B-E) empleado durante los ensayos de sensado de $\mathrm{H}_{2}$. Fotografía del panel empleado mostrando los caudalímetros electrónicos, tanques de gases y el sensor de $\mathrm{H}_{2}$ empleados durante los mencionados ensayos (F). 
Finalmente, valiosa información relacionada a la técnica de GISAXS puede encontrarse en las siguientes referencias. ${ }^{30,34,39}$

\subsection{Microscopía Electrónica de Transmisión (TEM)}

En microscopía electrónica de transmisión (Transmission electron microscopy, TEM) una muestra sólida de bajo espesor $(\leq 200 \mathrm{~nm})$ es bombardeada en el vacío con un haz de electrones mono-energético y coherente (altamente enfocado). El mencionado haz tiene la energía suficiente para propagarse a través de la muestra. Por consiguiente, de la interacción ente el haz de electrones y los átomos de la muestra, se generan electrones dispersados, los que finalmente van a ser colectados en un detector para construir una imagen bi-dimensional. El microscopio dispone de una serie de lentes electromagnéticas que magnifican la señal electrónica transmitida. Como consecuencia de lo expuesto, los electrones difractados son observados en la forma de un patrón de difracción (el cual esta debajo de la muestra). Finalmente, la información obtenida permite determinar tanto la estructura atómica como los defectos presentes en el material que constituye la misma. ${ }^{19}$

TEM es una técnica muy poderosa para la caracterización de nanomateriales, debido a que otorga una imagen espacial real correspondiente a la distribución atómica de una muestra dada. La versatilidad de esta microscopía puede notarse cuando de un mismo análisis se obtienen imágenes con resolución atómica junto con la información química (resoluciones espaciales por debajo de $1 \mathrm{~nm}$ ) de la muestra.

Básicamente, un TEM esta constituido por: un sistema de iluminación, una plataforma para la muestra, una lente objetivo, un sistema de magnificación y un sistema de recolección de datos. Todos los componentes están ensamblados en una columna vertical, la cual opera en condiciones de alto vacío $\left(10^{-3}\right.$ a $10^{-7}$ Torr $)$. La fuente de electrones es la parte principal del sistema de iluminación, empleando por lo general fuentes de emisión termiónicas de $\mathrm{LaB}_{6} \mathrm{O}$ un cañón de emisión de campo. Otro de los componentes principales de un TEM son las lentes condensadores, ya que determinan el límite de resolución de las imágenes colectadas. Por otro lado, el sistema de magnificación esta conformado por lentes intermedias y de proyección, las cuales otorgan magnificaciones mayores a los 1,5 millones. Finalmente los datos son colectados en una cámara, por lo general del tipo charge coupled device (CCD).

Simultáneamente, se puede obtener información del estado químico de la muestra a través de las técnicas complementarias llamadas energy dispersive $x$-ray spectroscopy (EDS) y electron-energy loss spectroscopy (EELS), para finalmente poder cuantificar la composición química de la muestra. En la Figura 2.13 se muestra un esquema de la estructura general de un microscopio electrónico de transmisión (TEM), adaptado según la referencia. ${ }^{32}$ 
En este trabajo Doctoral, la microscopía TEM fue empleada para caracterizar diferentes nanomateriales. Todas las imágenes aquí mostradas fueron adquiridas empleando un microscopio Phillips CM 200 UT operado a $200 \mathrm{keV}$.

Particularmente, en el Capítulo 3, las imágenes de TEM se emplearon para determinar el tamaño (diámetro promedio) y las distancias inter-nanopartículas. Las mismas fueron colectadas por los Dres. Eugenia Zelaya (CAB, Bariloche) y Gastón Corthey.

Por otro lado, en el Capítulo 6 se caracterizaron heterojunciones conformadas por grafeno y nanopartículas metálicas. Las mismas fueron colectadas por el Dr. Horacio Troiani, como parte de una colaboración existente.

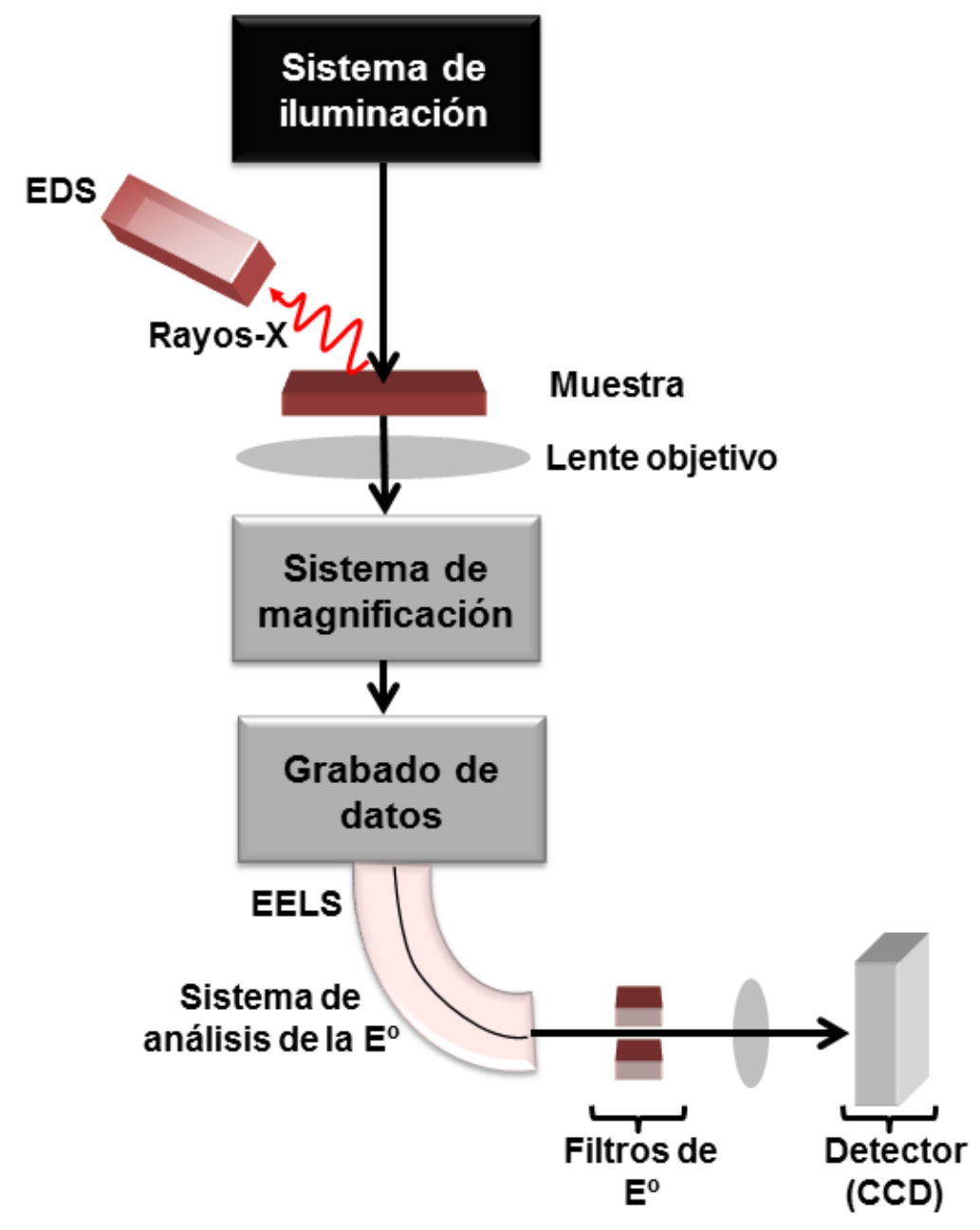

Figura 2.13 Esquema de la estructura general de un microscopio electrónico de transmisión (TEM). El mismo fue adaptado según la referencia. ${ }^{32}$ 


\subsection{Microscopía de Fuerza Atómica (AFM)}

La Microscopía de Fuerza Atómica (Atomic force microscopy, AFM) es una técnica de microscopía por sonda (scanning probe microscopy, SPM) que permite obtener imágenes topográficas (información en los tres ejes espaciales) con resolución nanométrica de una muestra dada. Uno de los aspectos más importantes de ésta técnica radica en que la misma puede analizar diferentes tipos de muestras, desde conductoras, semiconductoras hasta aislantes. Siendo esto último muchas veces un factor limitante en otros tipos de microscopias, tales como scanning electron microscopy (SEM) y scanning tunneling microscopy (STM). Otra de las ventajas de AFM es que las muestras por lo general no requieren de un tratamiento previo (ej., en SEM, si la muestra es no conductora, la misma debe de ser recubierta con una capa metálica) lo cual cambia parcialmente la estructura topológica de la misma. ${ }^{40}$

Los componentes básicos de un AFM incluyen: una punta, un fleje o cantiléver, un detector piezoeléctrico (scanner), un sistema óptico de detección y un sistema de retroalimentación. En la Figura 2.14 se muestra un esquema general de un microscopio de AFM, adaptado de la referencia. ${ }^{41}$

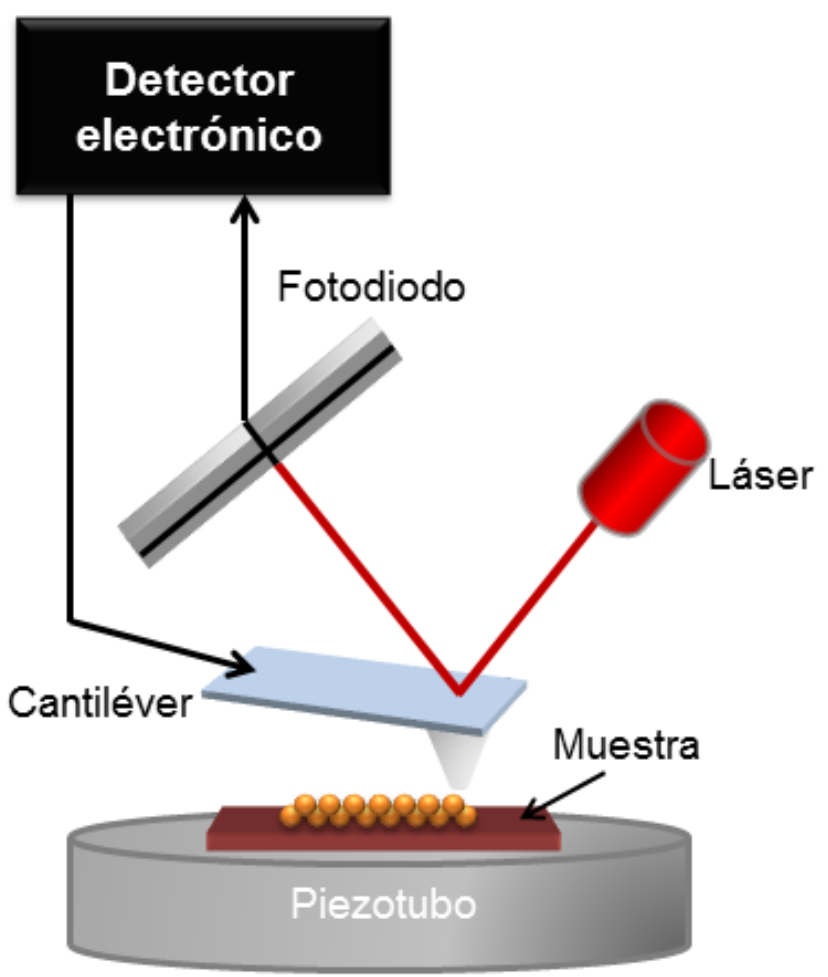

Figura 2.14 Esquema general de un microscopio de AFM. El mismo fue adaptado según la referencia. ${ }^{41}$ 
Concisamente, del barrido de la superficie de la muestra con la punta (la cual es del orden de los nanómetros, y suele ser de $\mathrm{Si}$ o $\mathrm{Si}_{3} \mathrm{~N}_{4}$ ) se obtiene una imagen topográfica. Cada vez que la punta encuentra pequeños cambios de altura en la muestra, se produce una deflexión del cantiléver, lo cual es detectado por el sistema del fotodiodo y finalmente registrado en el detector electrónico. El cantiléver esta recubierto por lo general con materiales que facilitan la deflexión del láser (lo cual le otorga mayor sensibilidad al sistema). Es importante mencionar que el detector piezoeléctrico, debido a que es sensible a los cambios en el voltaje que se le aplica, permite controlar la posición de la punta respecto a la muestra.

A lo largo de ésta Tesis, se emplearon dos equipos diferentes para las imágenes de AFM, los cuales aquí se detallan.

Las imágenes mostradas a en el Capítulo 3, fueron colectadas en un microscopio Veeco Digital Instruments Nanoscope V (Santa Barbara, CA) usando una punta de Si (Si tip) operando en modo tapping. El mismo pertenece al Laboratorio de Nanoscopias, CONICET-UNLP.

Por otro lado, las imágenes mostradas a en el Capítulo 6, fueron adquiridas en microscopio Nanonics Imaging Ltd. Multiview 2000TM Scan Head Assembly (el mismo equipo que se empleó para la caracterización por TERS) operando en modo tapping. El mismo pertenece al Laboratorio de Nanoscopias y Nanofotónica, de la Universidad Nacional de Córdoba (UNC). En éste caso las medidas fueron realizadas junto con los Dres. Gabriela I. Lacconi y Luis A. Pérez, ambos pertenecientes a los organismos UNC-CONICET, a través de una colaboración científica existente.

\subsection{Microscopía Electrónica de Barrido (SEM)}

En la Microscopía Electrónica de Barrido (Scanning electron microscopy, SEM) un haz de electrones es enfocado sobre una pequeña sonda, la cual luego es capaz de rastrear (scanning) una pequeña área de la muestra. De la interacción entre el haz y la muestra, se producen varias señales, tales como electrones secundarios, corrientes internas, emisión de fotones, entre otras. Luego, todas estas señales son debidamente detectadas. Finalmente, las imágenes obtenidas por SEM poseen una alta magnificación, al mismo tiempo que otorgan información de la muestra con mayor profundidad (espesor), cuando se las compara con las obtenidas por un microscopio óptico convencional. $^{19}$

En el presente Trabajo de Tesis se utilizaron dos microscopios de barrido electrónico. 
Las imágenes mostradas a lo largo del Capítulo 3, fueron colectadas en un microscopio FEI QUANTA 200, operando entre 15-20 keV. El mismo pertenece al Laboratorio de Investigaciones de Metalurgia Física (LIMF) de la Facultad de Ingeniería de la UNLP, operado por el personal técnico a cargo del servicio.

Por otro lado, las imágenes mostradas a lo largo del Capítulo 5, fueron colectadas en un microscopio FEI Helios NanoLab 650, operando entre 15-20 keV. El mismo pertenece al Centro de Investigación y Desarrollo en Micro y Nanoelectrónica del Bicentenario, del Instituto Nacional de Tecnología Industrial (INTI). En éste caso las medidas fueron realizadas por el Lic. Gustavo Giménez, perteneciente a la mencionada institución.

\subsection{Microscopía Confocal Raman}

Particularmente, cuando un material es iluminado (ya sea una molécula o un sólido) parte de la energía pasa simplemente a través de la muestra por un proceso de transmisión, mientras que los fotones remanentes pueden interactuar con el sistema a través de otros procesos tales como la absorción de la luz, la reflexión, la fotoluminiscencia o la dispersión de la luz. Como consecuencia del fenómeno de la interacción de la luz con la materia en conjunto con la cantidad de luz transmitida, es posible determinar las propiedades tanto electrónicas como vibracionales de un material dado.

Dentro de los fascinantes procesos ópticos, las técnicas de dispersión de la luz son una herramienta fundamental para el estudio de materiales, debido a que la luz puede ser dispersada inelásticamente de tal forma que los fotones incidentes y los fotones dispersados poseen diferentes frecuencias. Luego, las diferencias en esas frecuencias están directamente relacionadas a la naturaleza de cada material. Particularmente, la dispersión inelástica de la luz recibe el nombre de "efecto Raman". El mencionado fenómeno fue nombrado así en honor al Sir Chandrasekhara Venkata Raman, por el descubrimiento del mismo en 1927. Extraordinariamente, sólo tres años más tarde, el premio Nobel de Física galardonó a Raman por su trabajo titulado "the scattering of light" ${ }^{42}$ Por otro lado, la luz también puede dispersarse de manera elástica, lo cual se denomina dispersión Rayleigh y se caracteriza por que la energía de la luz dispersada es la misma que energía de la luz incidente. Es importante mencionar que, la dispersión Rayleigh es la dominante, mientras que la dispersión Raman involucra sólo 1 de cada $10^{6}-10^{8}$ fotones.

La adquisición de un espectro Raman de un cristal, es una de los principales métodos con los cuales se puede obtener de manera simple y rápida información 
relacionada a su estructura cristalina. Brevemente, la luz incidente de energía $E_{i}$ interactúa con el cristal para crear o destruir una o más vibraciones quanta (fonones) de energía $\mathrm{E}_{\mathrm{v}}$. Luego, la energía ganada (proceso Stokes, $\mathrm{S}$ ) o perdida (proceso anti-Stokes, aS) por el fonón de la red cristalina, es compensada por ya sea un decrecimiento o un incremento de la energía del fotón dispersado $\left(E_{1} \pm E_{v}\right)$. Consecuentemente, la medida de la energía de los fotones Raman dispersados va a otorgar información de la frecuencia de vibración de la estructura cristalina. Esto último puede correlacionarse con el ordenamiento a escala atómica en el material en estudio.

De acuerdo a la ley de distribución de Maxwell-Boltzmann, a temperatura ambiente gran parte de la población de moléculas se encuentran en el nivel vibracional de menor energía $(v=0)$, lo cual justifica que las líneas $\mathrm{S}\left(\mathrm{E}=h \mathrm{v}_{\mathrm{ex}}-\Delta \mathrm{E}\right)$ son más intensas que las líneas aS $\left(\mathrm{E}=h \mathrm{v}_{\mathrm{ex}}+\Delta \mathrm{E}\right)$. En la Figura 2.15 se muestran los Diagramas de Jablonski simplificados, ejemplificando los fenómenos de las dispersiones Rayleigh, Raman-Stokes y Raman -Anti-Stokes.

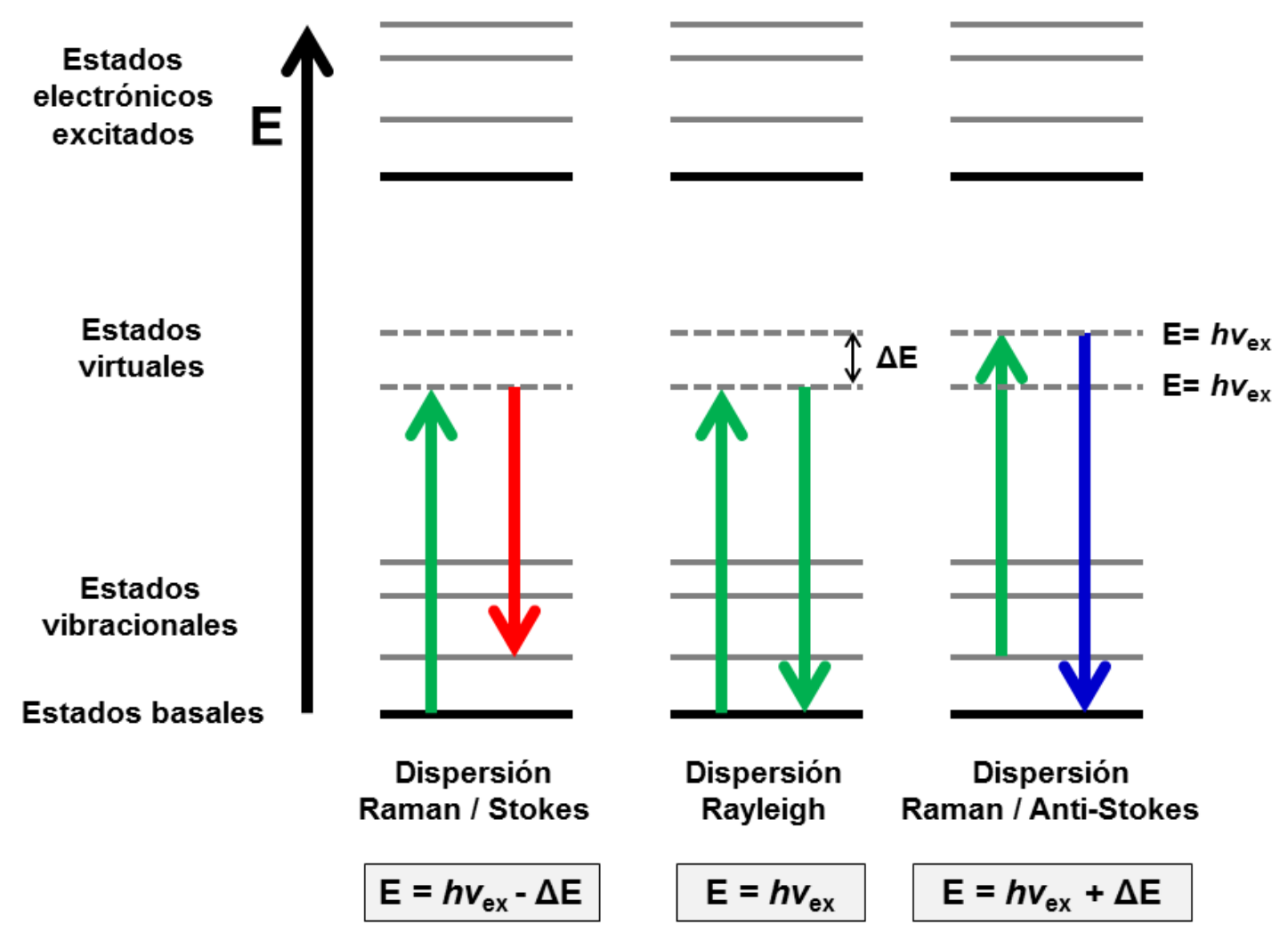

Figura 2.15 Diagramas de Jablonski simplificados, mostrando las dispersiones Rayleigh, Raman-Stokes y Raman -Anti-Stokes. 
Cabe mencionar que, si bien la espectroscopia Raman es una herramienta muy poderosa para la caracterización de diferentes materiales, tiene algunas desventajas tales como una muy baja sección eficaz (cross-section) en el orden de $\sim 10^{-31} \mathrm{~cm}^{2}$ por molécula, sumado a la baja polarización de las moléculas, lo cual limita sus aplicaciones. Como ejemplos de lo expuesto puede nombrarse el caso de la fluorescencia de moléculas, la cual esta comprendida en el rango de $10^{-14}-10^{-16} \mathrm{~cm}^{2}$, mientras que la sección eficaz Raman de la rodamina $6 \mathrm{G}$ está en el orden de $10^{-27} \mathrm{~cm}^{2}$, pudiendo ser aún menor para el caso de moléculas no-resonantes $\left(\sim 10^{-30} \mathrm{~cm}^{2}\right)$.

Si bien la baja polarización de las moléculas ha sido mejorada por la espectroscopia Raman intensificada por superficie (surface Raman enhanced spectroscopy, SERS) sumado a los grandes esfuerzos realizados para el diseño de nuevos nanomateriales con actividad SERS, aún subyacen otras desventajas relacionadas a la resolución lateral de los espectros obtenidos cuando se emplea un microscopio Raman, como se verá mas adelante.

En éste contexto, grandes avances en la ciencia de los materiales se han alcanzado al acoplar al espectrómetro Raman un microscopio confocal, lo cual permite mejorar la resolución lateral de los espectros adquiridos. Además, la microscopía confocal en estos instrumentos permite obtener información tanto química como estructural, por medio de un mapeo (mapping) de las muestras.

De lo expuesto anteriormente, es importante mencionar que en la microscopía Raman confocal la resolución espacial en el rango de la luz visible va a ser del orden de $\sim 250 \mathrm{~nm}$. Sin embargo, este valor es demasiado grande cuando se requieren caracterizar nanomateriales. Las mejoras en estos aspectos van a ser discutidas a continuación en la Sección 2.19 .

Todos los espectros Raman mostrados a lo largo de esta Tesis, fueron adquiridos en un sistema Raman con un microscopio confocal LABRAM-HR Horiba Jobin-Yvon. El mismo pertenece al Laboratorio de Nanoscopias y Nanofotónica, de la Universidad Nacional de Córdoba (UNC) y fueron realizados junto con la Dra. Gabriela I. Lacconi (UNC-CONICET).

Así mismo, valiosa información relacionada a la espectroscopia Raman puede encontrarse en las siguientes referencias. ${ }^{18,19,43-46}$ 


\subsection{Tip-enhanced Raman spectroscopy (TERS)}

\subsubsection{Principios Básicos}

En el contexto de lo expuesto en la sección anterior enfocada a la espectroscopia Raman, es importante mencionar que las resoluciones de ésta van a estar dadas por el límite de difracción de la luz. Particularmente, en un microscopio óptico la resolución lateral va a estar limitada por la difracción óptica. Lo cual puede explicarse con la siguiente ecuación:

$$
\Delta \mathrm{x}=0,61 \lambda / \mathrm{NA}
$$

Siendo, " $\Delta x$ " la resolución lateral, " $\lambda$ " la longitud de onda de la luz empleada para la excitación, y "NA" la apertura numérica de las lentes objetivos. Asimismo, puede darse una ecuación simplificada:

$$
\Delta \mathrm{x} \approx \lambda / 2
$$

De la ecuación 2.4, se denota que en el caso de microscopios trabajando con luz visible, la resolución obtenida va a estar en un rango comprendido entre $200-400 \mathrm{~nm}^{47}$

Cuando la espectroscopia Raman se une con las tecnologías empleadas en Scanning Probe Microscopy (SPM), surge la técnica nombrada como Tip-Enhancement Raman Spectroscopy (TERS). La técnica TERS es tan sensible que permite obtener información de una única molécula, con tan sólo unos pocos nanómetros de resolución espacial. Dichos atributos son logrados gracias a la presencia de una nanopartícula metálica que se encuentra dispuesta en el extremo de la punta de sondeo. Un ejemplo de la sensibilidad fue reportado por el grupo de Raschke et al. ${ }^{48}$ quienes demostraron un incremento de la señal de SWNTs por encima de $\sim 10^{7}$. Por otro lado, como ejemplos de las resoluciones espaciales pueden citarse las de 15 y $\sim 25$ nanómetros obtenidas para el colorante $\mathrm{BCB}^{49}$ y nanotubos de carbono, ${ }^{50}$ respectivamente.

Básicamente, en TERS una punta metálica ya sea de un AFM (Atomic Force Microcopy) o un STM (Scanning Tunneling Microscopy) pueden inducir un campo electromagnético altamente enfocado en un área dada, lo cual finalmente conlleva a un 
enorme aumento de la intensidad de campo en la vecindad de la punta debido al efecto de la resonancia de los plasmones superficiales de ésta última.

Otra de las ventajas de TERS, es que al estar ligada la espectroscopia Raman con las técnicas de SPM, es posible recorrer la superficie de la muestra con la punta (mapeo) permitiendo así tanto un análisis físico como químico.

\subsubsection{Componentes Principales de un Equipo TERS}

Dentro de los componentes principales de un equipo TERS se encuentran: a) un láser colimado, el cual va a ser enfocado principalmente en el área comprendida por la punta de SPM (pudiendo ser una punta de AFM o una punta de STM); b) un sistema óptico para la colectar y analizar la luz emitida por el sistema. Siendo éste último el determinante en la geometría óptica empleada, como se verá más adelante; c) un campo de polarización (field polarization), el cual permite polarizar la luz incidente; d) un sistema de SPM feedback, pudiendo ser ya sea un microscopio AFM, un STM o un shear force, con el fin de controlar la posición de la punta; y finalmente e) una punta TERS.

Las geometrías ópticas disponibles incluyen: iluminación inferior (bottom); iluminación de costado (side) e iluminación superior (top). Luego, de acuerdo a la configuración elegida van a surgir tanto ventajas como desventajas respecto a los tipos de muestras que van a poder caracterizarse.

Cabe mencionar que, el elemento crucial en un sistema TERS es la punta. La misma puede ser ya sea completamente metálica o recubierta parcialmente con un metal, lo cual le permite confinar la energía del láser en un campo electromagnético (EM) en el ápice de la punta. Permitiendo de éste modo excitar a las moléculas en estudio y transformar la información del campo cercano (near-field) en una radiación de campo lejano (far-field) propagante por dispersión. Finalmente, de acuerdo a las propiedades tanto químicas como mecánicas y al tamaño de la punta escogida, van a ser los factores que determinarán las posibilidades de uso y reutilización (tiempo de vida) de la misma.

\subsubsection{TERS Acoplado a un Microscopio de AFM}

En el caso particular en que el instrumento TERS este compuesto de un espectrómetro Raman y un microscopio de AFM, el mismo va a ser denominado como TERS-AFM ${ }^{51,52}$ Este sistema permite operar en dos modos: i) modo contacto (donde la punta interactúa con la muestra); y ii) modo de semi-contacto (en donde la punta esta oscilando en las cercanías de la superficie). 
Una de las ventajas del sistema TERS-AFM, es que la muestra no requiere de tratamientos específicos y puede trabajar en casi cualquier tipo de superficie (con rugosidades $>$ a varios micrones).

Particularmente, en el arreglo de "botton illumunation", si bien en esta configuración la resolución obtenida es mejor, ${ }^{51}$ ya que pueden emplearse aperturas numéricas grandes ( $\geq 1,4 \mathrm{NA}$ ), presenta la desventaja de que sólo pueden emplearse como sustratos vidrios u otros materiales transparentes como ITO (indium tin oxide). Sin embargo, este arreglo es muy conveniente cuando se analizan muestras biológicas.

Por otro lado, en el arreglo de "top illumination" reportado por Anderson et al., si bien deben emplearse objetivos con una apertura numérica menor, este tiene el beneficio de que se pueden caracterizar una amplia variedad de muestras, tales como sustratos opacos, metales y no metales, vidrios, etc. Esta última configuración es la que posee el equipo con el que se trabajó a lo largo del Capítulo 6 de la presente Tesis.

La Figura 2.16 muestra un esquema del arreglo experimental utilizado para los experimentos de TERS. Notar que la iluminación con el láser es superior y la punta para

\section{Arreglo experimental TERS / iluminación superior}
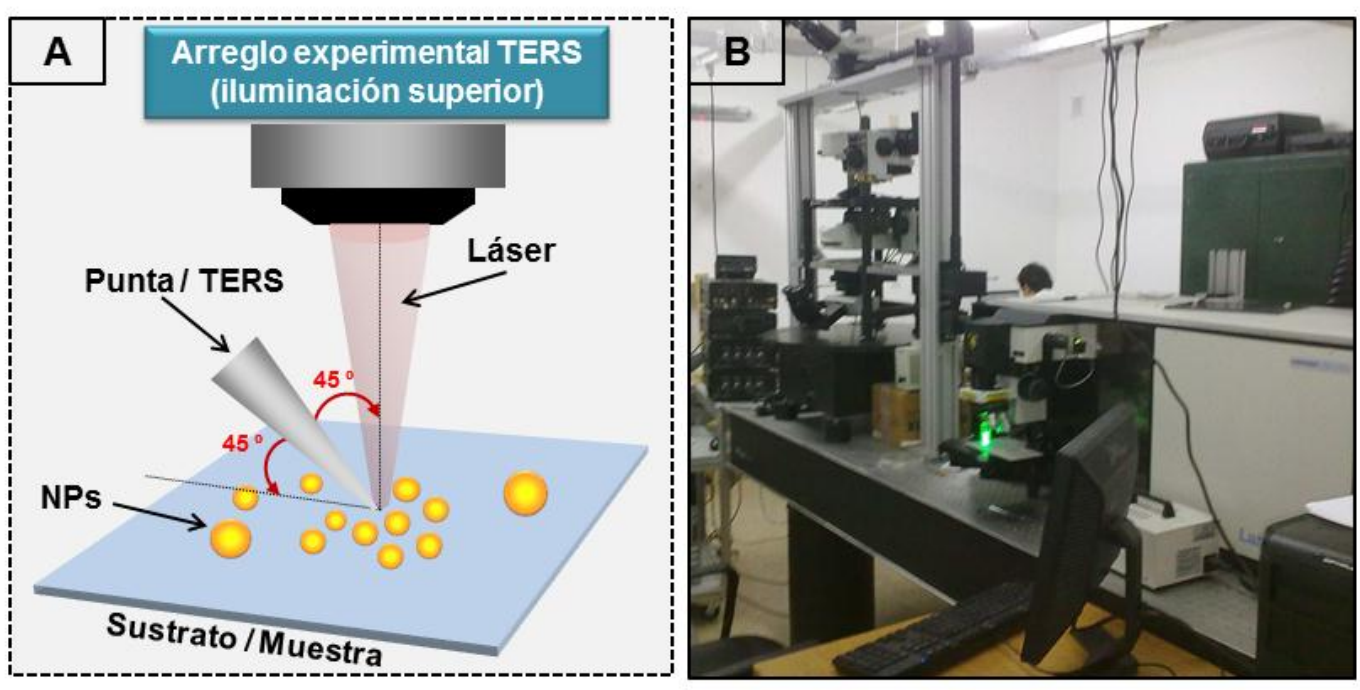

Figura 2.16 Esquema del arreglo experimental utilizado para los experimentos de TERS (tip-enhanced Raman spectroscopy) (A). Fotografía del Microscopio Nanonics Imaging Ltd. Modelo Multiview 2000TM ((NSOM/SPM) Scan Head Assembly) perteneciente al INFIQC, UNC, Córdoba (B). 
TERS esta a $45^{\circ}$ tanto respecto al sustrato (muestra) como al láser incidente (A). Fotografía del Microscopio Nanonics Imaging Ltd. Modelo Multiview 2000TM ((NSOM/SPM) Scan Head Assembly) perteneciente al INFIQC, UNC, Córdoba. Fotografía gentileza de la Dra. Lacconi (B).

Los espectros de TERS mostrados a lo largo del Capítulo 6, fueron colectados en microscopio antes mencionado. En éste caso las medidas fueron realizadas junto con los Dres. Gabriela I. Lacconi y Luis A. Pérez, ambos pertenecientes a los organismos UNC-CONICET, a través de una colaboración científica existente.

Finalmente, valiosa información relacionada a la espectroscopia TERS puede encontrarse en las siguientes referencias. ${ }^{47,53-59}$

\subsection{Análisis Termogravimétrico (TGA)}

Los análisis de termogravimetría (de sus siglas del inglés thermogravimetric analysis, TGA), fueron realizados para examinar la composición de la cubierta orgánica de las nanopartículas (NPs). Dicha caracterización permite conocer la estabilidad térmica de las NPs, debido a que se analiza la temperatura a la cual se despega el material orgánico de la superficie del centro metálico de las NPs. ${ }^{19,60}$

\subsection{Bibliografía}

(1) Mironov, I. V.; Makotchenko, E. V. The Hydrolysis of AuCl 4 - and the Stability of Aquachlorohydroxocomplexes of Gold(III) in Aqueous Solution. J. Solut. Chem. 2009, 38 (6), 725-737.

(2) Fink, J.; Kiely, C. J.; Bethell, D.; Schiffrin, D. J. Self-Organization of Nanosized Gold Particles. Chem. Mater. 1998, 10 (3), 922-926.

(3) Ibañez, F. J.; Zamborini, F. P. Chemiresistive Sensing of Volatile Organic Compounds with Films of Surfactant-Stabilized Gold and Gold-Silver Alloy Nanoparticles. ACS Nano 2008, 2 (8), 1543-1552.

(4) Leff, D. V.; Brandt, L.; Heath, J. R. Synthesis and Characterization of Hydrophobic, Organically-Soluble Gold Nanocrystals Functionalized with Primary Amines. Langmuir 1996, 12 (20), 4723-4730.

(5) Hostetler, M. J.; Wingate, J. E.; Zhong, C.-J.; Harris, J. E.; Vachet, R. W.; Clark, M. R.; Londono, J. D.; Green, S. J.; Stokes, J. J.; Wignall, G. D.; et al. Alkanethiolate Gold Cluster Molecules with Core Diameters from 1.5 to $5.2 \mathrm{Nm}$ : Core and Monolayer Properties as a Function of Core Size. Langmuir 1998, 14 (1), $17-30$. 
(6) Brust, M.; Walker, M.; Bethell, D.; Schiffrin, D. J.; Whyman, R. Synthesis of Thiol-Derivatised Gold Nanoparticles in a Two-Phase Liquid-Liquid System. $J$. Chem. Soc. Chem. Commun. 1994, No. 7.

(7) Moreno, M.; Ibañez, F. J.; Jasinski, J. B.; Zamborini, F. P. Hydrogen Reactivity of Palladium Nanoparticles Coated with Mixed Monolayers of Alkyl Thiols and Alkyl Amines for Sensing and Catalysis Applications. J. Am. Chem. Soc. 2011, 133 (12), 4389-4397.

(8) Corthey, G.; Olmos-Asar, J. A.; Casillas, G.; Mariscal, M. M.; Mejía-Rosales, S.; Azcárate, J. C.; Larios, E.; José-Yacamán, M.; Salvarezza, R. C.; Fonticelli, M. H. Influence of Capping on the Atomistic Arrangement in Palladium Nanoparticles at Room Temperature. J. Phys. Chem. C 2014, 118 (42), 24641-24647.

(9) Murphy, C. J.; Sau, T. K.; Gole, A. M.; Orendorff, C. J.; Gao, J.; Gou, L.; Hunyadi, S. E.; Li, T. Anisotropic Metal Nanoparticles: Synthesis, Assembly, and Optical Applications. J. Phys. Chem. B 2005, 109 (29), 13857-13870.

(10) Beeram, S. R.; Zamborini, F. P. Selective Attachment of Antibodies to the Edges of Gold Nanostructures for Enhanced Localized Surface Plasmon Resonance Biosensing. J. Am. Chem. Soc. 2009, 131 (33), 11689-11691.

(11) Jana, N. R.; Gearheart, L.; Murphy, C. J. Wet Chemical Synthesis of Silver Nanorods and Nanowires of Controllable Aspect Ratio. Chem. Commun. 2001, No. 7, 617-618.

(12) Bae, S.; Kim, H.; Lee, Y.; Xu, X.; Park, J.-S.; Zheng, Y.; Balakrishnan, J.; Lei, T.; Ri Kim, H.; Song, Y. I.; et al. Roll-to-Roll Production of 30-Inch Graphene Films for Transparent Electrodes. Nat. Nanotechnol. 2010, 5 (8), 574-578.

(13) Polsen, E. S.; McNerny, D. Q.; Viswanath, B.; Pattinson, S. W.; John Hart, A. High-Speed Roll-to-Roll Manufacturing of Graphene Using a Concentric Tube CVD Reactor. Sci Rep 2015, 5.

(14) Li, X.; Cai, W.; An, J.; Kim, S.; Nah, J.; Yang, D.; Piner, R.; Velamakanni, A.; Jung, I.; Tutuc, E.; et al. Large-Area Synthesis of High-Quality and Uniform Graphene Films on Copper Foils. Science 2009, 324 (5932), 1312-1314.

(15) Ghoneim, M. Efficient Transfer of Graphene -Physical and Electrical Performance Perspective. 2012.

(16) Huh, S.; Park, J.; Kim, Y. S.; Kim, K. S.; Hong, B. H.; Nam, J.-M. UV/OzoneOxidized Large-Scale Graphene Platform with Large Chemical Enhancement in Surface-Enhanced Raman Scattering. ACS Nano 2011, 5 (12), 9799-9806.

(17) Allen J. Bard, Larry R. Faulker. Electrochemical Methods: Fundamentals and Applications, 2 edition.; Wiley, 2000.

(18) Douglas A. Skoog, F. James Holler, Stanley R. Crouch. Principles of Instrumental Analysis, 6 edition.; Brooks Cole, 2006.

(19) Evans, C.; Brundle, R.; Wilson. Encyclopedia of Materials Characterization: Surfaces, Interfaces, Thin Films, Edición: Braille edition.; ButterworthHeinemann, 1992.

(20) Pavia, D.; Lampman, G.; Kriz, G.; Vyvyan, J. Introduction to Spectroscopy; Cengage Learning, 2008.

(21) Silverstein, R. M.; Webster, F. X.; Kiemle, D. Spectrometric Identification of Organic Compounds, Edición: 0007.; John Wiley \& Sons, 2005. 
(22) Snyder, R. G.; Strauss, H. L.; Elliger, C. A. Carbon-Hydrogen Stretching Modes and the Structure of N-Alkyl Chains. 1. Long, Disordered Chains. J. Phys. Chem. 1982, 86 (26), 5145-5150.

(23) Surface Analysis of Polymers by XPS and Static SIMS, 1 edition.; Cambridge University Press, 1998.

(24) Corthey, Gastón. Tesis Doctoral: Estudio de Interfases Metal-Tiol En Superficies Planas Y Nanopartículas. Facultad de Ciencias Exactas, Universidad Nacional de La Plata. (2012). Director: Mariano H. Fonticelli, Co-Director: Roberto C. Salvarezza.

(25) Azcárate, Julio C. Tesis Doctoral: Estudio Sobre La Modificación de Nanopartículas Metálicas Para El Desarrollo de Sensores Fluorescentes Fotomodulables. Facultad de Ciencias Exactas, Universidad Nacional de La Plata. (2014). Director: Mariano H. Fonticelli, Co-Director: Elizabeth JaresErijman.

(26) SPM and Surface Physical Chemistry Group - Facilities http://nano.quimica.unlp.edu.ar/facilities.php (accessed Jan 30, 2016).

(27) Heide, P. van der. X-Ray Photoelectron Spectroscopy: An Introduction to Principles and Practices, 1 edition.; Wiley, 2011.

(28) J. Michael Hollas. Modern Spectroscopy, 4 edition.; Wiley, 2004.

(29) Wagner, C. D. Handbook of X-Ray Photoelectron Spectroscopy: A Reference Book of Standard Data for Use in X-Ray Photoelectron Spectroscopy; Physical Electronics Division, Perkin-Elmer Corp., 1979.

(30) P. Willmont. An Introduction to Synchrotron Radiation: Techniques and Applications, 1 edition.; Wiley, 2011.

(31) R.Z. Bachrach. Synchrotron Radiation Research, 1 edition.; Springer, 1992.

(32) Wang, Z. L. Characterization of Nanophase Materials. Part. Part. Syst. Charact. 2001, 18 (3), 142-165.

(33) Liscio, Fabiola. Doctoral Thesis. Title: Nanostructures Magnetiques AutoAssemblees Sur Des Surfaces a Faible Energie Par Epitaxie Par Jets Moleculaires. Chimie. Institut National Polytechnique de Grenoble -INPG, France. (2009). Director: Maret Mireille. Co-Director: Mobilio Settimio.

(34) Sakka, S. Handbook of Sol-Gel Science and Technology: Processing, Characterization and Applications, V. I - Sol-Gel Processing/Hiromitsu Kozuka, Editor, V. II - Characterization of Sol-Gel Materials and Products/Rui M. Almeida, Editor, V. III - Applications of Sol-Gel Technology/Sumio Sakka, Editor; Springer, 2004.

(35) Rice, S. A. Small Angle Scattering of X-Rays. A. Guinier and G. Fournet. Translated by C. B. Wilson and with a Bibliographical Appendix by K. L. Yudowitch. Wiley, New York, 1955. 268 Pp. \$7.50. J. Polym. Sci. 1956, 19 (93), 594-594.

(36) Anton Paar GmbH. www.saxspace.com:: SAXS http://www.saxspace.com/ (accessed Jan 22, 2016).

(37) Giovanetti, Lisandro. Tesis Doctoral: Efectos de Superficies En Nanoparticulas Metálicas Estudiados Mediante Técnicas de Luz Síncrotron. Facultad de Ciencias Exactas, Universidad Nacional de La Plata. (2008). Director: Félix G. Requejo. 
(38) Picco, Agustín S. Tesis Doctoral. Macromoléculas Anfifilicas Derivadas de La Polietilenimina Hiperramificada: Caracterización Estructural Y Aplicaciones En Nanociencias. Facultad de Ciencias Exactas, Universidad Nacional de La Plata. (2014). Director: Marcelo Ceolín, Co-Director: Omar Azzaroni.

(39) Renaud, G.; Lazzari, R.; Leroy, F. Probing Surface and Interface Morphology with Grazing Incidence Small Angle X-Ray Scattering. Surf. Sci. Rep. 2009, 64 (8), 255-380.

(40) Nan Yao, Zhong Lin Wang. Handbook of Microscopy for Nanotechnology, 2005 edition.; Springer, 2005.

(41) Flores, Constanza. Tesis Doctoral. Nanopartículas de Plata Con Potenciales Aplicaciones En Materiales Implantables: Síntesis, Caracterización Fisicoquímica Y Actividad Bactericida. Facultad de Ciencias Exactas, Universidad Nacional de La Plata. (2014). Director: Carolina Vericat, Co-Director: Patricia L. Schilardi.

(42) The Nobel Prize in Physics 1930 http://www.nobelprize.org/nobel_prizes/physics/laureates/1930/ (accessed Feb 17, 2016).

(43) Derek A. Long. The Raman Effect: A Unified Treatment of the Theory of Raman Scattering by Molecules, 1 edition.; Wiley, 2001.

(44) Dennis P. Strommen; Kazuo Nakamoto. Laboratory Raman Spectroscopy; John Wiley \& Sons Inc, 1985.

(45) Smith, E.; Dent, G. Modern Raman Spectroscopy: A Practical Approach, 1 edition.; Wiley: Hoboken, NJ, 2005.

(46) Jorio, A.; Saito, R.; Dresselhaus, M. S.; Dresselhaus, G. Raman Spectroscopy in Graphene Related Systems; Wiley Vch Verlag Gmbh, 2011.

(47) Stadler, J.; Schmid, T.; Zenobi, R. Developments in and Practical Guidelines for Tip-Enhanced Raman Spectroscopy. Nanoscale 2012, 4 (6), 1856-1870.

(48) Roth, R. M.; Panoiu, N. C.; Adams, M. M.; Osgood, R. M.; Neacsu, C. C.; Raschke, M. B. Resonant-Plasmon Field Enhancement from Asymmetrically Illuminated Conical Metallic-Probe Tips. Opt. Express 2006, 14 (7), 2921-2931.

(49) Steidtner, J.; Pettinger, B. Tip-Enhanced Raman Spectroscopy and Microscopy on Single Dye Molecules with 15 Nm Resolution. Phys. Rev. Lett. 2008, 100 (23), 236101.

(50) Hartschuh, A.; Sánchez, E. J.; Xie, X. S.; Novotny, L. High-Resolution near-Field Raman Microscopy of Single-Walled Carbon Nanotubes. Phys. Rev. Lett. 2003, 90 (9), 095503.

(51) Anderson, M. S. Anderson, M. S. Locally Enhanced Raman Spectroscopy with an Atomic Force Microscope. Appl. Phys. Lett. 76, 3130-3132. Appl. Phys. Lett. 2000, 76 (21), 3130-3132.

(52) Mark S. Anderson; William T. Pike. A Raman-Atomic Force Microscope for Apertureless-near-Field Spectroscopy and Optical Trapping. Rev. Sci. Instrum 2002, 73, 1198.

(53) Bharat Chushan. Scanning Probe Microscopy in Nanoscience and Nanotechnology 2, 2011 edition.; Springer, 2011.

(54) Sebastian Schlulcker, Wolfgangang Kiefer. Surface Enhanced Raman Spectroscopy: Analytical, Biophysical and Life Science Applications, 1 edition.; Wiley-VCH, 2010. 
(55) Eric Le Ru, Pablo Etchegoin. Principles of Surface-Enhanced Raman Spectroscopy: And Related Plasmonic Effects, 1 edition.; Elsevier Science, 2008.

(56) Blum, C.; Opilik, L.; Atkin, J. M.; Braun, K.; Kämmer, S. B.; Kravtsov, V.; Kumar, N.; Lemeshko, S.; Li, J.-F.; Luszcz, K.; et al. Tip-Enhanced Raman Spectroscopy - an Interlaboratory Reproducibility and Comparison Study. $J$. Raman Spectrosc. 2014, 45 (1), 22-31.

(57) Schultz, Z. D.; Marr, J. M.; Wang, H. Tip Enhanced Raman Scattering: Plasmonic Enhancements for Nanoscale Chemical Analysis. Nanophotonics 2014, 3 (1-2), 91-104.

(58) Schmid, T.; Opilik, L.; Blum, C.; Zenobi, R. Nanoscale Chemical Imaging Using Tip-Enhanced Raman Spectroscopy: A Critical Review. Angew. Chem. Int. Ed. 2013, 52 (23), 5940-5954.

(59) Hartschuh, A. Tip-Enhanced near-Field Optical Microscopy. Angew. Chem. Int. Ed Engl. 2008, 47 (43), 8178-8191.

(60) Moreno, Monica. Doctoral Thesis. Title: Hydrogen $\left(\mathrm{H}_{2}\right)$ Sensing and Catalysis with Organic-Stabilized Pd and Pd Alloy Nanoparticles. Department of Chemistry, University of Louisville, KY, USA. (2013). Director: Francis Zamborini. 
Sección II

Sensado de Compuestos Orgánicos Volátiles

(VOCs) 


\section{Capítulo 3}

\section{Detección de VOCs Usando Películas con Nanopartículas de Au}

\subsection{Introducción}

Tal como fue mencionado en el Capítulo 1, es posible construir sensores ensamblando en forma de películas a nanopartículas (NPs) metálicas protegidas o no con una cubierta orgánica. En dichos sistemas se emplea como señal analítica el plasmón generado por el centro metálico, y en los casos en los que se empleen NPs protegidas, el principal rol de la cubierta orgánica va a ser interactuar directamente con el analito en cuestión, otorgándole así una afinidad para uno o más compuestos.

Para poder comprender mejor como funcionan estos dispositivos, es necesario definir el significado de plasmón. En líneas generales, en el caso de una superficie metálica, los electrones libres de éste material se mueven respecto a un fondo de iones positivos fijos, lo cual por definición es conocido como plasma o free-electron plasma. Por lo tanto, la respuesta óptica de éstos free-electron plasma es la que va a regir las características de un metal dado. En éste contexto, un plasmón ${ }^{*}$ es una oscilación colectiva de los electrones libres en un metal noble. Luego, en la presencia de un campo eléctrico externo esas oscilaciones plasmónicas pueden ser perturbadas, causando el desplazamiento de los electrones dentro del gas respecto a los iones fijos. Para el caso de plasmones masivos $(b u l k)^{\dagger}$ dichas oscilaciones van a ocurrir en la frecuencia plasma de un metal dado. ${ }^{1}$

De este modo, en la superficie de un metal, los plasmones se denominan como surface plasmon polaritons (SPP) o polaritones superficiales, el cual es un termino más apropiado ya que incluye aquellos efectos entre la onda electromagnética propagándose

\footnotetext{
" Cabe mencionar que el sufijo "on" denota el carácter de cuasi-partícula que poseen los plasmones. Además, por su naturaleza, los plasmones presentan una energía específica y un momento, lo cual es considerado en el contexto de la mecánica cuántica. ${ }^{\dagger}$ Notar que masivo se refiere a materiales los cuales presenten dimensiones mayores a la longitud de onda
de la luz incidente.
} 
en el espacio e interactuando con el medio. Sin embargo, para una mayor simplicidad se los nombra como plasmones superficiales. ${ }^{2}$

En el caso de nanopartículas (NPs), las cuales poseen dimensiones que son comparables a la longitud de onda de la luz incidente, los centros metálicos de éstas ejercen fuerzas atractivas sobre los electrones libres que se encuentran en sus superficies, tal que una resonancia puede surgir. Esta resonancia es conocida como localized surface plasmon (LSP) o localized surface plasmon resonance (LSPR). ${ }^{3,4}$ Cabe mencionar que, los LSP poseen dos efectos importantes, a saber: a) los campos eléctricos cercanos a la superficie de la NP son fuertemente intensificados y se encuentran confinados en la superficie de la misma (los cuales decrecen rápidamente con la distancia a la superficie de la NP); y b) la extinción óptica de la NP presenta un máximo en la frecuencia de resonancia del plasmón.

En el contexto de lo expuesto, el fenómeno superficial conocido como LSPR es inducido por la luz incidente sobre la frecuencia oscilante de los electrones confinados en una nanoestructura metálica. Cuando la frecuencia de la luz incidente coincide con la del plasmon, surge un pico máximo de extinción (absorbancia + dispersión), el cual ocurre a una longitud de onda $\left(\lambda_{\text {máx }}\right)$ característica de la composición del metal. ${ }^{5} \mathrm{El}$ pico de extinción es sensible a ambos: a) los cambios en el índice de refracción (refractive index, RI ${ }^{6}$ masivos (bulk); y/o b) al enlace local de moléculas sobre sitios superficiales específicos conocidos como "hot-spots". 7,8 Una gran cantidad de trabajos han sido reportados demostrando el uso de nanoestructuras metálicas para el sensado por LSPR tanto de moléculas como de biomoléculas. ${ }^{2,9,10}$ Grandes esfuerzos se han realizado en el área científica para la mejora de la sensibilidad en sensores del tipo LSPR, como es demostrado por el tamaño, ${ }^{11}$ la composición metálica (esferas de $\mathrm{Au}^{12}$ versus esferas de $\mathrm{Ag}^{13}$ ), la conformación de la nanoestructura (core-shell o hollow), ${ }^{12}$ la relación de aspecto, ${ }^{13-15}$ y la forma. ${ }^{13,16}$ Asimismo, desde el desarrollo de metodologías para la síntesis de nanobastones (nanorods) ${ }^{17}$ o estructuras elongadas, ${ }^{18}$ los investigadores han demostrado que los plasmones longitudinales son más sensibles que los transversales. ${ }^{14}$ Otros grupos han anclado selectivamente biomoléculas, ${ }^{19}$ demostrando así que la sensibilidad depende de la distancia entre el analito y la superficie plasmónica. ${ }^{20,21}$

Particularmente, los estudios de LSPR basados en los efectos de acoplamiento dependientes de la distancia inter-nanopartículas han sido poco explorados. ${ }^{22-26}$ Basados en la distancia entre las nanoestructuras y la polarización de la luz, ${ }^{25}$ los acoplamientos electromagnéticos (interacciones dipolo-dipolo) pueden ser atractivos o repulsivos manifestándose como aumentos o disminuciones en la energía, dependiendo del caso. ${ }^{23}$ Algunos ejemplos de ello incluyen NPs de $\mathrm{Au}$ recubiertas con $\mathrm{Si}^{22}$ NPs de $\mathrm{Au}$

\footnotetext{
$\$$ En el caso de nanopartículas de algunos metales nobles ( $\mathrm{Au}, \mathrm{Ag}$ y $\mathrm{Cu}$ ) y metales alcalinos, el plasmón ocurre en longitudes de onda correspondientes al visible.
} 
separadas por litografia, ${ }^{25}$ nanodiscos de $\mathrm{Au}^{23}$ y películas delgadas de NPs de Au que luego de ser funcionalizadas con varios alcanotioles de diferentes longitudes de cadena, forman las conocidas monocapas autoensambladas, del inglés self-assembled monolayers (SAMs). ${ }^{26} \mathrm{Ha}$ sido demostrado que a medida que la distancia entre las nanopartículas disminuye, se produce un notable desplazamiento de la banda plasmónica hacia altos valores de longitud de onda (baja energía) y viceversa. Los desplazamientos de la banda plasmónica a los rojos o a los azules permiten indirectamente caracterizar tanto la distancia inter-nanopartículas como las interacciones entre las mismas. ${ }^{27}$ Sin embargo, la mayoría de estos experimentos requieren de síntesis tediosas e instrumentación costosa, tales como el uso de salas limpias (Clean Room Facility) para realizar fotolitografía.

La detección de moléculas tanto en fase gaseosa ${ }^{28,29}$ como en fase vapor $^{30,31}$ es importante en áreas que se extienden desde lo ambiental hasta el diagnóstico médico. Recientemente, Liu et al. ${ }^{28}$ reportaron la detección de $\mathrm{H}_{2}$ gaseoso por una metodología muy original, en donde colocaron una única nanoantena de Au en la proximidad de una nanoestructura de $\mathrm{Pd}$. En el mencionado sensor, la formación de $\mathrm{PdH}_{\mathrm{x}}$ fue detectada por los cambios en la longitud de onda plasmónica del Au. Asimismo, Van Duyne et al. ${ }^{29}$ detectaron extremadamente bajas concentraciones de un gas inerte y aire húmedo con películas conformadas por nanoesferas de $\mathrm{Ag}$ y Au. Ellos demostraron que las películas son capaces de discriminar diferencias del orden de 1/10.000 en el valor del índice de refracción entre los gases de Ar y He. Lu et al. ${ }^{31}$ construyeron sensores de LSPR compuestos por un arreglo de NPs de Ag y Au, y películas con nanoshells de Au que luego fueron funcionalizadas con decanotiol, naftaleno-tiol, y 2-mercaptobenzotiolato, con el fin de mejorar la selectividad frente a diferentes compuestos orgánicos volátiles (volatile organic compounds, VOCs). ${ }^{31}$ Otros grupos fueron capaces de mejorar la selectividad colocando polímeros hidrofóbicos e hidrofílicos en la superficie de películas de NPs de Au, cuyos índices de refracción (RI) cambiaron basados en la afinidad entre los analitos en fase vapor y el polímero. ${ }^{32}$ Hasta el momento, la mayoría de los sensores están enfocados en la sensibilidad, mientras que la selectividad y la estabilidad permanecen como desafíos debido a que el pico de extinción usualmente se desplaza a los rojos en la presencia de diferentes analitos ${ }^{30}$ y las nanopartículas desnudas (sin cubierta orgánica) son propensas a la oxidación ambiental. ${ }^{33}$

Las NPs metálicas modificadas químicamente y luego ensambladas como películas, han sido escasamente utilizadas como sensores del tipo LSPR. ${ }^{30,34}$ Es conocido que ligandos fuertes tales como los alcanotioles modifican el índice de refracción $(\mathrm{RI})$ y que drásticamente disminuyen la señal plasmónica por un mecanismo de captura (withdrawing) de los electrones de la superficie metálica. ${ }^{35}$ Este problema podría limitar el uso de películas de NPs metálicas protegidas con grupos orgánicos en sensores del tipo LSPR. Lo opuesto ocurre en chemiresistores, ${ }^{36,37}$ en donde las NPs metálicas protegidas con grupos orgánicos son requeridas para detectar los cambios en 
la resistencia de la película cuando éstas son expuestas a analitos en fase vapor ${ }^{38,39}$ mediante cambios en la corriente de las películas, producidos por el mecanismo de salto de electrones (electron hopping). ${ }^{40}$ Para éstos últimos sistemas, ha sido demostrado que las películas chemiresistivas se hinchan (swell) en la presencia de vapores donde ellas son solubles y en unos pocos casos, las películas se contraen frente a vapores de diferente polaridad conduciendo a un incremento ${ }^{38,41}$ o disminución ${ }^{41}$ en la distancia entre las NPs, respectivamente.

Como fue mencionado al comienzo de este Capítulo, el material orgánico que rodea a las nanopartículas no únicamente les provee de estabilidad a la película sino que además, funciona como un elemento receptor para las moléculas del vapor ingresante. Hasta el momento, los cambios inducidos por el ingreso o presencia de analitos en fase vapor caracterizados por espectroscopia infrarroja por transformada de Fourier (Fourier Transform Infrared Spectroscopy, FT-IR), han sido poco explorados. Un desplazamiento en la frecuencia de vibración a bajas o altas energías, observado en experimentos de FT-IR, otorga información cualitativa acerca de la organización de las cadenas alquílicas alrededor de las nanopartículas. ${ }^{42}$ La organización depende de unas pocas variables incluyendo la naturaleza química de los ligandos, ${ }^{43,44}$ el tamaño y la composición de las nanopartículas, y el valor del dieléctrico del medio. En éste contexto, ha sido demostrado que las cadenas alquílicas largas y fuertemente ${ }^{43,45}$ enlazadas (ej., alcanotioles) se ensamblan sobre la superficie del Au de una manera bien organizada, mejor que en el caso de ligandos de cadenas cortas, los cuales están adsorbidos físicamente a través de una interacción débil. ${ }^{44}$ Por consiguiente, el alto grado de ordenamiento alcanzado por las cadenas alquílicas es generalmente atribuido a las interacciones del tipo van der Waals.

En este contexto, este Capítulo presenta el uso de películas constituidas con NPs de Au protegidas con un surfactante (SNPs) como sensores de compuestos orgánicos volátiles (VOCs). En el mencionado sensor, los centros metálicos de Au brindan la señal plasmónica, mientras que la cubierta orgánica tiene dos funciones principales: a) la de material receptor (brindándole sensibilidad a una familia de compuestos); y b) le otorga estabilidad en el tiempo (previniendo la oxidación del centro metálico). A su vez, como sistemas de control se emplearon otros tipos de NPs.

\subsection{Experimental}

\subsubsection{Síntesis de Nanopartículas}

Las NPs de $\mathrm{Au}$ protegidas con el surfactante bromuro de tetraoctilamonio (Au@TOABr, SNPs) fueron sintetizadas de acuerdo al protocolo de síntesis bifásico de Brust-Schiffrin, pero sin la adición de tioles. ${ }^{46}$ Las SNPs preparadas por ésta vía tienen 
un diámetro de 4,39 \pm 1,25 $\mathrm{nm}$ basados en las imágenes de Transmission Electron Microscopy (TEM) (Figura 3.1). Las nanopartículas de $\mathrm{Au}^{47}$ recubiertas con citrato (citrate- coated $\mathrm{Au}, \mathrm{CNPs}$ ), las NPs de Ag recubiertas con citrato (Ag CNPs), y las monolayer-protected clusters de Au protegidas con dodecanotiol (C12 Au MPCs) ${ }^{48}$ fueron sintetizadas usando los protocolos conocidos y usados como sistemas de control en para éste trabajo. En el Capítulo 2 se brindan los detalles de las mencionadas síntesis.

\subsubsection{Preparación de las Películas}

\subsubsection{Para las Espectroscopias UV-vis y FT-IR}

Las NPs as-synthesized fueron ensambladas sobre sustratos de vidrio funcionalizados previamente con aminopropil-trietoxisilano (APTES), por inmersión del vidrio/APTES en una solución conteniendo las SNPs por 20 horas. Los experimentos de UV-vis y FT-IR fueron llevados a cabo sobre películas en estado sólido, exponiendo las mismas a vapores en modo headspace ${ }^{\S}$ de tolueno (Tol) y etanol $(\mathrm{EtOH})$ en una atmósfera de aire seco (background), y en aire ambiental.

\subsubsection{Para las Microscopias: AFM, TEM y SEM}

En la siguiente sección se explica cómo fueron preparadas las muestras para las diferentes microscopias.

Para las muestras para AFM, sustratos de Si/APTES fueron sumergidos por 20 horas en una solución contenido NPs, de la misma forma en la cual se prepararon las muestras para UV-vis.

Para las muestras de TEM, las SNPs fueron depositadas por la metodología de drop-casting (gota a gota) sobre una grilla de $\mathrm{Cu}$ recubierta con highly oriented pyrolitic graphite (HOPG).

Para las muestras de SEM, primeramente las SNPs (suspendidas en tolueno) se mezclaron con agua Milli-Q, como aquí se detalla: en un tubo eppendorf se colocaron $10 \mu \mathrm{L}$ de la solución de nanopartículas $(1,4-1,6 \mathrm{mg} / \mathrm{mL})$, se les adicionó $30 \mu \mathrm{L}$ de tolueno y $120 \mu \mathrm{L}$ de agua Milli-Q. Luego, el tubo se agitó vigorosamente (para facilitar el contacto entre ambas fases). Finalmente, las nanopartículas fueron extraídas del sobrenadante (fase orgánica) y depositadas por drop-casting sobre sustratos limpios. Luego, las mismas se depositaron como películas por dos metodologías: a) los sustratos de silicio (previamente funcionalizados con APTES) se sumergieron en una solución

\footnotetext{
$\S$ El término "headspace" se refiere a una metodología simple de generar gases a partir de un compuesto volátil dado. Brevemente, se coloca en un recipiente pequeño el solvente (analito) en estudio y luego de trascurrido un tiempo, parte de las moléculas del mismo van a difundir a la fase gaseosa, formando así el gas en headspace.
} 
conteniendo NPs; y b) las películas se formaron por drop-casting de una solución contenido las NPs.

\subsubsection{Caracterización de las Películas}

Las imágenes de AFM, TEM, y SEM fueron adquiridas en un microscopio Veeco Digital Instruments Nanoscope V (Santa Barbara, CA) usando una punta de Si (Si tip) operando en modo tapping, un FEI CM200 UT operando a $200 \mathrm{keV}$, y un FEI QUANTA 200 entre 15-20 keV, respectivamente.

\subsubsection{Experimentos de Sensado}

\subsubsection{UV-vis}

Las medidas de LSPR fueron llevadas a cabo tanto en atmósfera húmeda como en atmósfera seca (gel de sílice), y adquiridos en un espectrofotómetro UV-vis Perkin Elmer Lambda $35^{\mathrm{TM}}$ en un rango de longitud de onda comprendido entre 300 a $900 \mathrm{~nm}$. Debido a que los cambios plasmónicos son pequeños, esto tornó difícil analizar los gráficos de UV-vis directamente. Por lo tanto, todas las muestras involucradas en éste estudio fueron analizadas por comparación de los datos de UV-vis (empleando el software del equipo para determinar los máximos) y luego comparando los datos crudos exportados (determinando los máximos con el software Origin). En todos los casos, los valores obtenidos coincidieron.

Debido a que las películas con SNPs son bastante sensibles a la humedad presente en las condiciones ambientales (como se discutirá más adelante en la Tabla 3.1), se decidió que todos los ensayos se realizaran en aire seco como background. Esto último fue conseguido colocando gel de sílice dentro del compartimento del UV-vis, durante todas las medidas realizadas. Brevemente, las muestras se colocaron dentro del compartimento del equipo junto con el gel de sílice 10 minutos antes de que se colocaran los viales conteniendo los solventes de interés (fuente de vapor, headspace). Las medidas fueron tomadas cada 90 segundos durante un total de 15 minutos de exposición al vapor. Luego de éste tiempo de exposición, el vial conteniendo el solvente fue removido y la puerta del compartimento se abrió al ambiente por 450 segundos, mientras que se mantuvo el agente desecante en el interior del mismo. El valor del cambio plasmónico máximo ( $\lambda_{\text {máx }}$ ) reportado aquí es obtenido de 10 medidas durante la exposición al vapor.

\subsubsection{FT-IR}

Las medidas de FT-IR fueron llevadas a cabo en un espectrómetro PIKE Miracle $^{\mathrm{TM}}$ Varian 600 Instrument en modo de transmisión siguiendo la misma metodología de preparación de las muestras empleadas en UV-vis. Sin embargo, debido a que la señal analítica en éste instrumento es menor que la señal obtenida en el UV-vis, 
fue necesario aumentar el espesor de las películas con NPs. Para ello, a las películas luego de ser ensambladas, se les agregó por drop-casting 3 gotas (de $5 \mu \mathrm{L}$ cada una) de una solución de NPs con una concentración de 1,4-1,6 mg/mL.

\subsection{Resultados}

\subsubsection{Determinación del Tamaño y Separación de las Nanopartículas}

En la Figura 3.1 se muestran las imágenes de microscopía electrónica de transmisión (TEM) de las nanopartículas de Au@TOABr (SNPs) depositadas sobre una grilla de TEM (A y B), junto con los histogramas indicando el diámetro de las NPs (C) y la distancia inter-nanopartículas (calculada de edge-to-edge) (D), obtenidos desde un conjunto de medidas involucrando 100 y 50 unidades, respectivamente. Del mencionado análisis, se terminó que el tamaño de las NPs es de 4,35 $\pm 1,25 \mathrm{~nm}$, y la separación entre

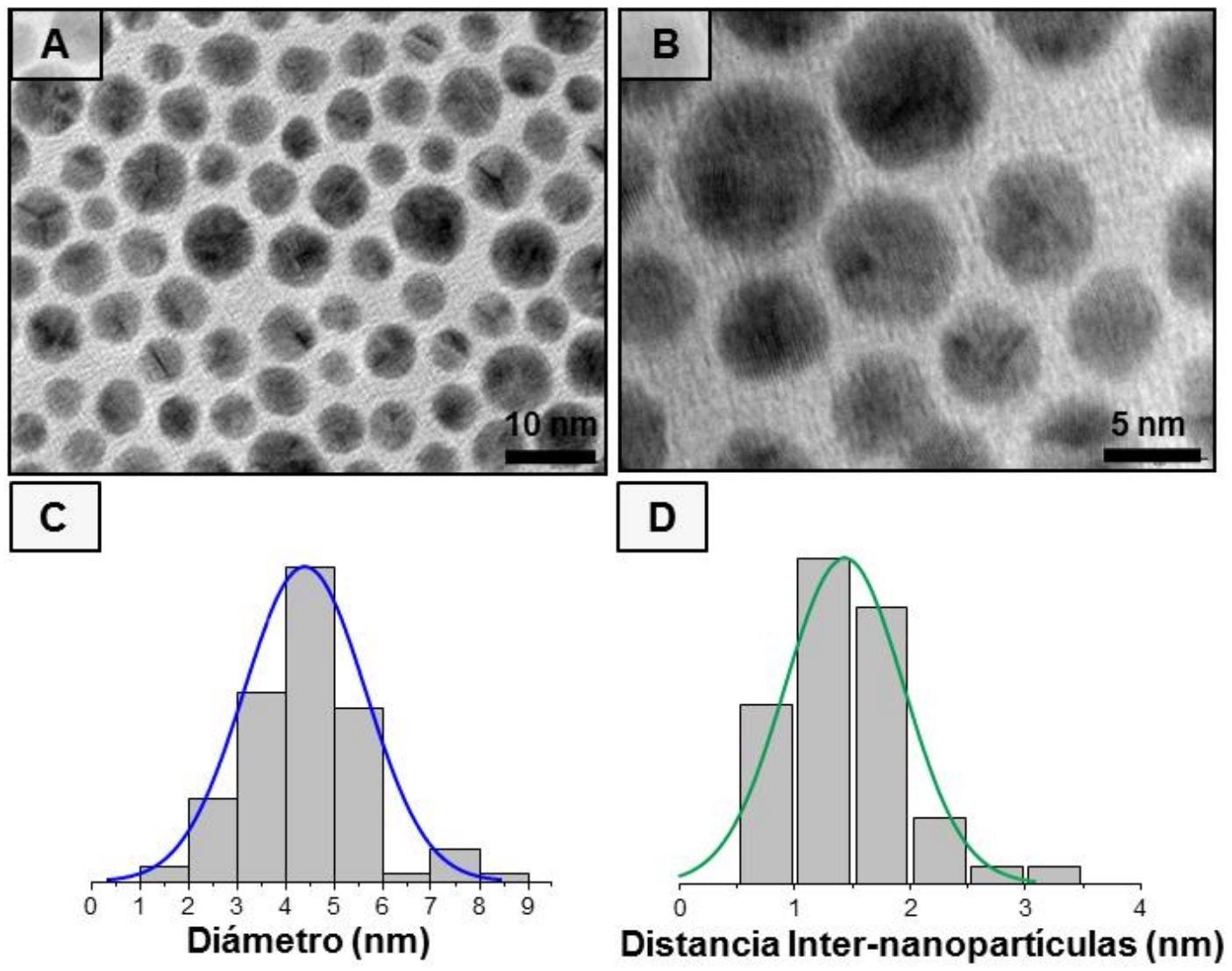

Figura 3.1 Imágenes de microscopía electrónica de transmisión (TEM) de las nanopartículas de Au@TOABr (SNPs) depositadas sobre una grilla de TEM (A y B). Los histogramas muestran que el diámetro de las nanopartículas es 4,35 $\pm 1,25 \mathrm{~nm}$ (C) y la distancia inter-nanopartículas es $1,4 \pm 0,5 \mathrm{~nm}$ (D). 
las mismas es de 1,4 $\pm 0,5 \mathrm{~nm}$. Ambos resultados son consistentes con la literatura. ${ }^{49}$

Es necesario mencionar, que la metodología que se empleó para preparar las muestras para TEM difiere de la metodología empleada para las muestras de UV-vis y FT-IR (comparar las Secciones 3.2.2.1 y 3.2.2.2).

\subsubsection{Sensado por LSPR}

La Figura 3.2A muestra un gráfico de UV-vis de una película de SNPs selecta, la cual se expuso a aire seco, y a los vapores (headspace) de EtOH y Tol como es indicado. La Figura 3.2B muestra el máximo cambio plasmónico $\left(\lambda_{\text {máx }}\right)$ tomado desde un conjunto de tres películas de SNPs expuestas a los mismos vapores en headspace, corridos en aire seco (empleado como línea de base o background) por 270 segundos. La Figura revela que las películas responden con un desplazamiento en el valor del $\lambda_{\text {máx }}$ a los azules y los rojos desde 547 a $543 \mathrm{~nm}$ y desde 551 a $559 \mathrm{~nm}$, respectivamente y que escasamente responden al aire seco durante todo el tiempo de adquisición de las medidas. Finalmente, las películas retornan casi a su línea de base $\left(\lambda_{\text {baseline }}\right)$ después de 450 segundos en aire seco. La Figura 3.2B también muestra que la película requiere de un cierto tiempo para alcanzar el máximo desplazamiento plasmónico (180 seg), y luego el valor del mismo fluctúa durante la exposición al vapor. Uno de los motivos de estas fluctuaciones y del tiempo necesario para observar cambios en los valores de $\lambda_{\text {máx }}$, puede estar relacionado al tiempo que necesita el vapor (analito) para logra embeberse (partición) en la película orgánica, desplazarse a través de las cadenas alquílicas, para finalmente residir cercano a la superficie del centro metálico e inducir el cambio plasmónico. En éste contexto, es razonable pensar que la movilidad de las nanopartículas juega un rol fundamental en el mecanismo de sensado. Esto último podría involucrar reordenamientos o restructuraciones de la película durante la exposición a vapores, conduciendo a cambios constantes en los efectos de acoplamiento plasmónicos (coupling effects). A modo de prueba de concepto, en la Figura 3.3 se muestran gráficos con los cambios plasmónicos máximos $\left(\lambda_{\text {máx }}\right)$ tomados cada 90 seg en un período extendido de tiempo (15 min) para las películas de SNPs y CNPs inmersas en los solventes de EtOH (A) y Tol (B). La Figura muestra que la respuesta plasmónica de las SNPs también fluctúa en el tiempo. Por el contrario, las películas de CNPs muestran un desplazamiento en el valor del $\lambda_{\text {máx }}$ más estable durante todo el tiempo analizado. Si bien hasta el momento permanece incierta la razón de las fluctuaciones observadas en las películas de SNPs, pensamos que las mismas pueden tener su origen en la presencia de la cubierta orgánica. En relación a lo expuesto, en el Capítulo 4 se estudiarán los cambios inducidos en las distancias inter-nanopartículas (por GISAXS) para las películas conformadas con SNPs, cuando se encuentran en la presencia de los vapores de Tol y EtOH. 

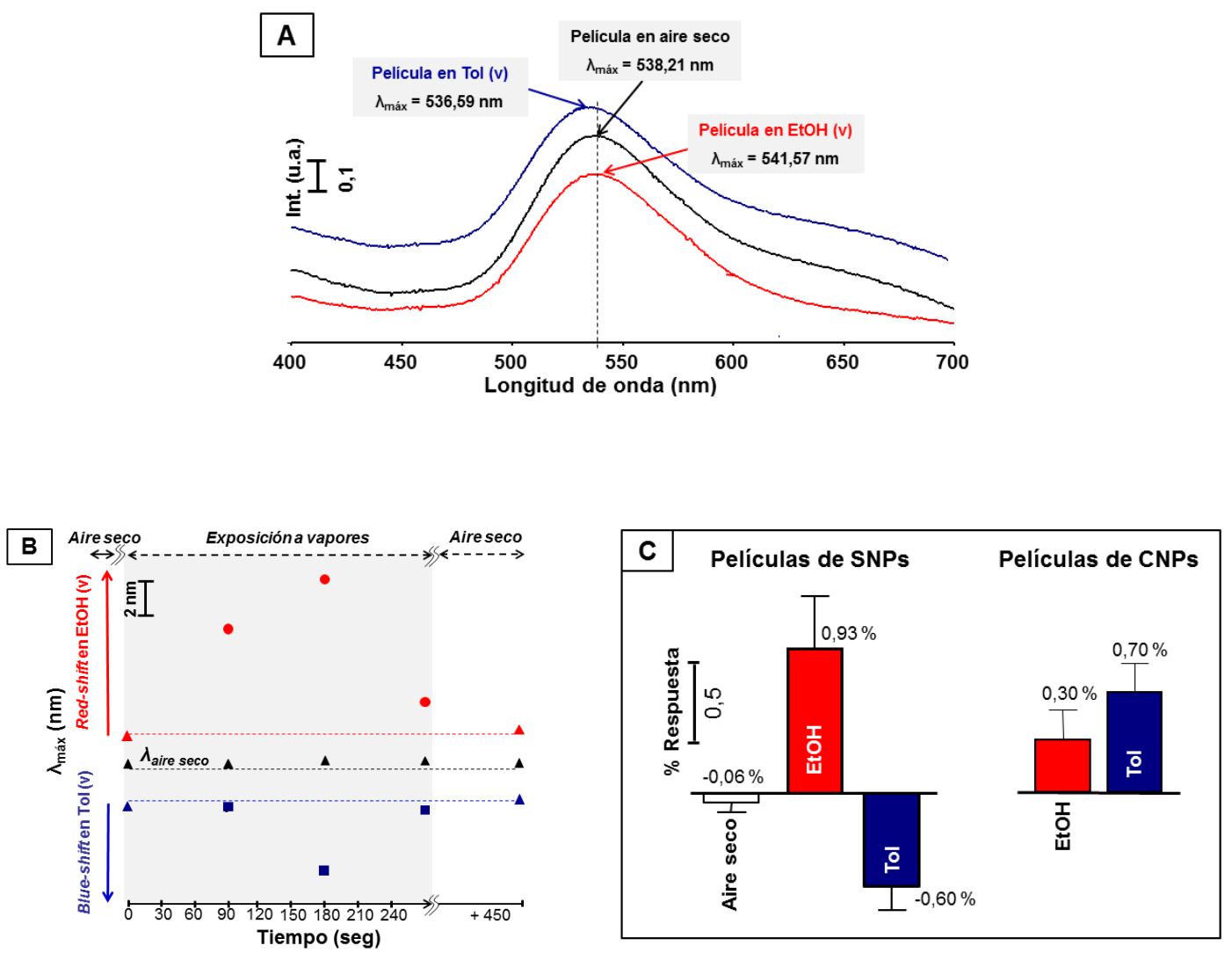

Figura 3.2 Gráfico de UV-vis mostrando los máximos cambios en el plasmón $\left(\lambda_{\text {máx }}\right)$ de una película de SNPs selecta (A), gráfico del máximo cambio plasmónico $\left(\lambda_{\text {máx }}\right)$ versus el tiempo (seg) de las muestras de SNPs (B), y gráfico de barras mostrando el promedio del porcentaje de respuesta con las barras de error para las películas de SNPs y CNPs en aire seco y expuestas a los vapores de Tol y EtOH, como es indicado (C). Notar que el aire seco fue corrido como línea de base (background). Los gráficos de UV en el panel A están en offset para una mejor comparación. 
Por otro lado, es particularmente llamativo que el desplazamiento plasmónico sigue una tendencia general, con desplazamiento en el valor del $\lambda_{\text {máx }}$ hacia los rojos o a los azules, indicando la selectividad de las películas. La Figura 3.2C muestra un gráfico de barras con el porcentaje de respuesta ( $\%$ R) obtenido de tres dispositivos (películas de NPs) junto con su análisis estadístico basado en los cambios en $\lambda_{\text {máx }}$ para las películas de SNPs y CNPs expuestas a los valores, como es indicado. El porcentaje de Respuesta (\% R) fue calculado de la siguiente manera,

$$
\% \mathrm{R}=\left[\left(\lambda_{\mathrm{r}}-\lambda_{\mathrm{b}}\right) / \lambda_{\mathrm{b}}\right] \times 100 \%
$$

donde $\lambda_{b}$ es el valor del plasmon en su "línea de base" (medido para la película en aire seco) y $\lambda_{\mathrm{r}}$ es la respuesta máxima del plasmón en la presencia del vapor en estudio.
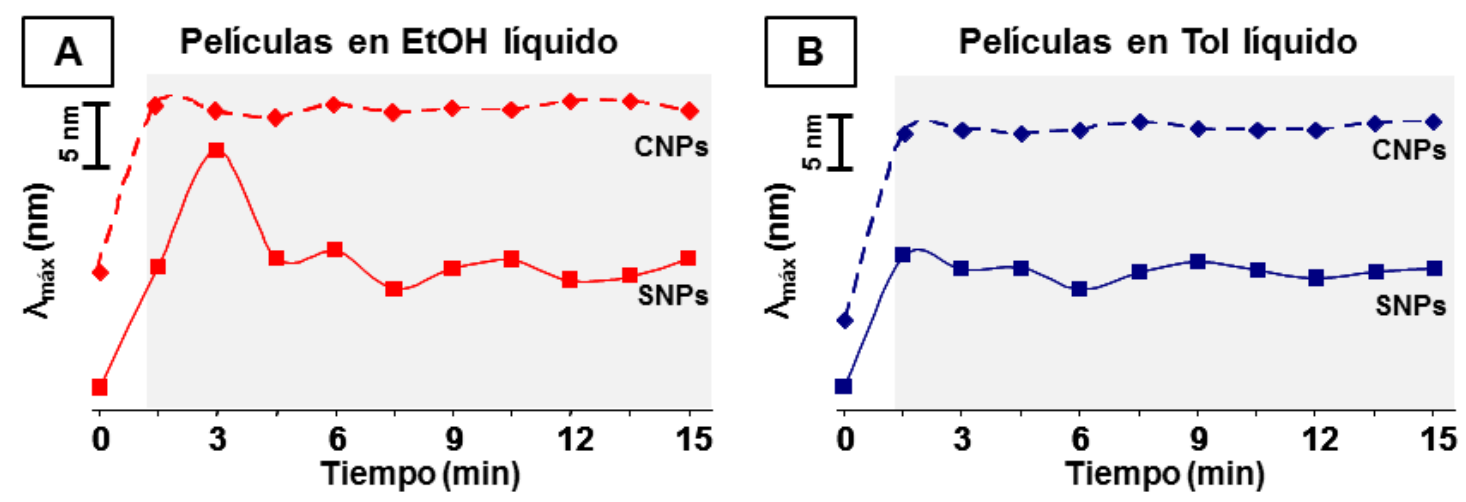

Figura 3.3 Cambios en la respuesta plasmónica de las películas de SNPs y CNPs inmersas en los solventes de EtOH (A) y Tol (B), durante los tiempos indicados.

La Tabla 3.1 muestra los datos estadísticos para todos los dispositivos (SNPs y CNPs) involucrados en éste estudio. Nuestros resultados mostraron un desplazamiento plasmónico diferente a los rojos $(\% \mathrm{R}=0,93)$ y a los azules $(\% \mathrm{R}=-0,60)$ para las mismas películas de SNPs cuando se las expuso a los vapores de EtOH y Tol, respectivamente. De los resultados mostrados en el gráfico, se denotan tres características principales: i) el $\lambda_{\text {máx }}$ de las películas de SNPs se desplaza a los azules en la presencia del vapor de Tol; ii) las películas de SNPs presentan mayor respuesta al vapor de EtOH que al vapor de Tol, aunque el último tiene un mayor índice de refracción (RI); y iii) las películas de SNPs son $\sim 3$ veces más sensibles que las películas de CNPs cuando son expuestas a los vapores de EtOH. 
Tabla 3.1 Datos Mostrando los Porcentajes (\%) de Respuesta de Todos los Dispositivos Analizados, Junto son sus Datos Estadísticos.

Películas de SNPs (surfactant-coated Au NPs)

\begin{tabular}{|c|c|c|c|c|c|c|c|c|c|}
\hline \multicolumn{5}{|c|}{ En atmósfera húmeda (ambiente) } & \multicolumn{5}{|c|}{ En aire seco } \\
\hline Muestra & $\Lambda_{\operatorname{máx}}$,inicial & $\Lambda_{\text {máx }}$,final & $\Delta \Lambda_{\operatorname{máx}}$ & $\%$ Resp & Muestra & $\Lambda_{\text {máx, inicial }}$ & $\lambda_{\operatorname{máx}}$,final & $\Delta \Lambda_{\operatorname{máx}}$ & $\%$ Resp \\
\hline 1 & 553,03 & 559,15 & 6,1 & 1,11 & 1 & 551,02 & 550,99 & 0,0 & $-0,01$ \\
\hline 2 & 589,39 & 598,01 & 8,6 & 1,46 & 2 & 560,98 & 559,99 & $-1,0$ & $-0,18$ \\
\hline 3 & 567,98 & 583,99 & 16,0 & 2,82 & 3 & 559,01 & 559,01 & 0,0 & 0,00 \\
\hline Prom. & & & 10,2 & 1,80 & Prom. & & & $-0,3$ & $-0,06$ \\
\hline STD & & & $\pm 4,20$ & $\pm 0,9$ & STD & & & $\pm 0,58$ & $\pm 0,1$ \\
\hline \multicolumn{5}{|c|}{ En EtOH (vapor) } & \multicolumn{5}{|c|}{ En Tol (vapor) } \\
\hline Muestra & $\lambda_{\max }$, inicial & $\lambda_{\text {máx }}$,final & $\Delta \Lambda_{\operatorname{máx}}$ & $\%$ Resp & Muestra & $\Lambda_{\text {máx }}$,inicial & $\lambda_{\max }$, final & $\Delta \Lambda_{\max }$ & $\%$ Resp \\
\hline 1 & 537,87 & 541,57 & 3,7 & 0,69 & 1 & 538,21 & 536,59 & $-1,6$ & $-0,30$ \\
\hline 2 & 536,46 & 539,15 & 2,7 & 0,50 & 2 & 547,21 & 543,32 & $-3,9$ & $-0,71$ \\
\hline 3 & 551,44 & 560,22 & 8,8 & 1,59 & 3 & 563,98 & 559,54 & $-4,4$ & $-0,79$ \\
\hline Prom. & & & 5,1 & 0,93 & Prom. & & & $-3,3$ & $-0,60$ \\
\hline STD & & & $\pm 3,27$ & $\pm 0,58$ & STD & & & $\pm 1,49$ & $\pm 0,26$ \\
\hline
\end{tabular}

Películas de CNPs (citrate-coated Au NPs)

\begin{tabular}{|c|c|c|c|c|c|c|c|c|c|}
\hline \multicolumn{5}{|c|}{ En EtOH (vapor) } & \multicolumn{5}{|c|}{ En Tol (vapor) } \\
\hline Muestra & $\lambda_{\text {máx, inicial }}$ & $\lambda_{\text {máx }}$,final & $\Delta \Lambda_{\text {máx }}$ & $\%$ Resp & Muestra & $\lambda_{\text {máx, inicial }}$ & $\lambda_{\text {máx }}$ final & $\Delta \Lambda_{\text {máx }}$ & \%Resp \\
\hline 1 & 533,89 & 533,94 & 0,1 & 0,01 & 1 & 529,79 & 533,92 & 4,1 & 0,78 \\
\hline 2 & 524,40 & 526,07 & 1,7 & 0,32 & 2 & 524,38 & 525,80 & 1,4 & 0,27 \\
\hline 3 & 524,08 & 527,57 & 3,5 & 0,67 & 3 & 524,31 & 528,81 & 4,5 & 0,86 \\
\hline Prom. & & & 1,8 & 0,33 & Prom. & & & 3,3 & 0,67 \\
\hline STD & & & $\pm 1,7$ & $\pm 0,4$ & STD & & & $\pm 1,7$ & $\pm 0,3$ \\
\hline
\end{tabular}

Sin embargo, los cambios a los azules en sensores de vapor del tipo LSPR han sido raramente observados. ${ }^{32}$ Por ejemplo, Rubinstein et al. ${ }^{32}$ prepararon películas de $\mathrm{Au}$ cubiertas con polímeros hidrofóbicos e hidrofílicos, y las expusieron a varios analitos en fase vapor incluyendo cloroformo, Tol, agua y metanol. Ellos observaron un desplazamiento de la banda plasmónica a los azules en la presencia de vapores que tienen la misma polaridad que el polímero que protege a las mencionadas películas de $\mathrm{Au}, \mathrm{y}$ por consiguiente sugirieron que el polímero sufre un hinchamiento (film swelling) que provoca que la película disminuya su espesor, atenuando al mismo tiempo el valor del RI. Hasta el momento, sólo unas pocas publicaciones asocian los cambios plasmónicos con la separación de las nanopartículas (ver supra). Asimismo, es complicado poder correlacionar la separación de las nanopartículas con los cambios 
plasmónicos debido a que es difícil predecir con exactitud la extensión de las cadenas orgánicas cuando el vapor se particiona dentro de la película.

Sin embargo, si consideramos que cada SNP esta rodeada por una única monocapa de $\mathrm{TOABr}$, luego la distancia entre dos nanopartículas con cadenas de $\mathrm{TOA}^{+}$ completamente extendida podría ser de $\sim 1,9 \mathrm{~nm}\left(0,12 \mathrm{~nm}\right.$ para un enlace C-C simple) ${ }^{40}$ De los resultados obtenidos por TEM (Figura 3.1) para nuestro sistema, los cuales son consistentes con otros resultados informados, ${ }^{49}$ indican una separación de $\sim 1,4 \mathrm{~nm}$ entre las nanopartículas de Au. Una distancia más corta que 1,9 nm entre las nanopartículas es coherente con cadenas alquílicas pobremente organizadas ${ }^{44}$ (ver infra) y hasta algún grado de interdigitación. ${ }^{40}$ En relación a esto, Rechberger et al. ${ }^{25}$ observaron un corrimiento plasmónico $\left(\lambda_{\text {máx }}\right)$ de $1 \mathrm{~nm}$ a los azules para nanopartículas de Au desnudas (sin cubierta orgánica) separadas por $0,9 \mathrm{~nm}$ expuestas a luz ortogonal polarizada.

En este contexto, de acuerdo a los resultados obtenidos por el grupo ${ }^{25}$ de Rechberger, y considerando los desplazamientos plasmónicos experimentales observados a los azules $\lambda_{\text {máx }}=\sim(-)$ 2,5 nm en nuestro sistema, estimamos que las NPs se podrían separar $\sim 2,2 \mathrm{~nm}$ cuando están en presencia del vapor de Tol, conduciendo a una separación total de $\sim 3,6 \mathrm{~nm}$ (inicial 1,4 + swelling 2,2 $\mathrm{nm}$ ). Asimismo, el desplazamiento plasmónico a los azules ha sido atribuido al hinchamiento de la película (film swelling) en el plano con respecto al sustrato, cuando la misma es expuesta a vapores que causan una disminución en el espesor del polímero observado para tanto sistemas de $\mathrm{Au}^{32}$ como en islas de $\mathrm{Cu}^{50}$ cubiertas con películas poliméricas. Sin embargo, es evidente que la separación entre las nanopartículas junto con la disminución en el espesor de la película superan los cambios plasmónicos esperados a los rojos causados por el Tol, cuyo RI es mayor al del EtOH.

\subsubsection{Hinchamiento de la Película}

Con el fin de explorar en los cambios morfológicos que se puedan producir en las películas por la presencia de los analitos, se decidió exponer una película de SNPs a Tol en fase vapor, de manera similar a lo reportado por Ibañez et al. ${ }^{51}$ La Figura 3.4 muestra una película de SNPs as-deposited sobre un sustrato de Si antes y después de la exposición a vapor de Tol por 240 segundos. La Figura muestra una película poco homogénea compuesta de algunas islas grandes y gruesas, con bordes brillantes y áreas menos pobladas consistentes con nuestras imágenes de SEM mostradas en la Figura 3.5 (más detalles serán brindados en la siguiente sección) y otros reportes. ${ }^{46}$ Los círculos denotan áreas en donde la película cambió su estructura produciendo bordes más redondeados, junto con el promedio de las cross-sections y la root mean square roughness $(w)$ que muestran los cambios inducidos en la película después de la exposición al vapor de Tol. Las cross-sections fueron medidas tres veces en la misma zona (spot) (indicado con un ${ }^{*}$ ) antes y después de la exposición a Tol en fase vapor (headspace). El valor de $w$ fue medido en tres áreas diferentes dentro de la isla central 
mostrada en la Figura. En la presencia de Tol, tanto el espesor promedio de la película como el valor promedio de $w$ decrecen desde 141,0 a $115,3 \mathrm{~nm}$ y desde 90,33 a 60,9 $\mathrm{nm}$ después de la exposición a Tol, respectivamente.
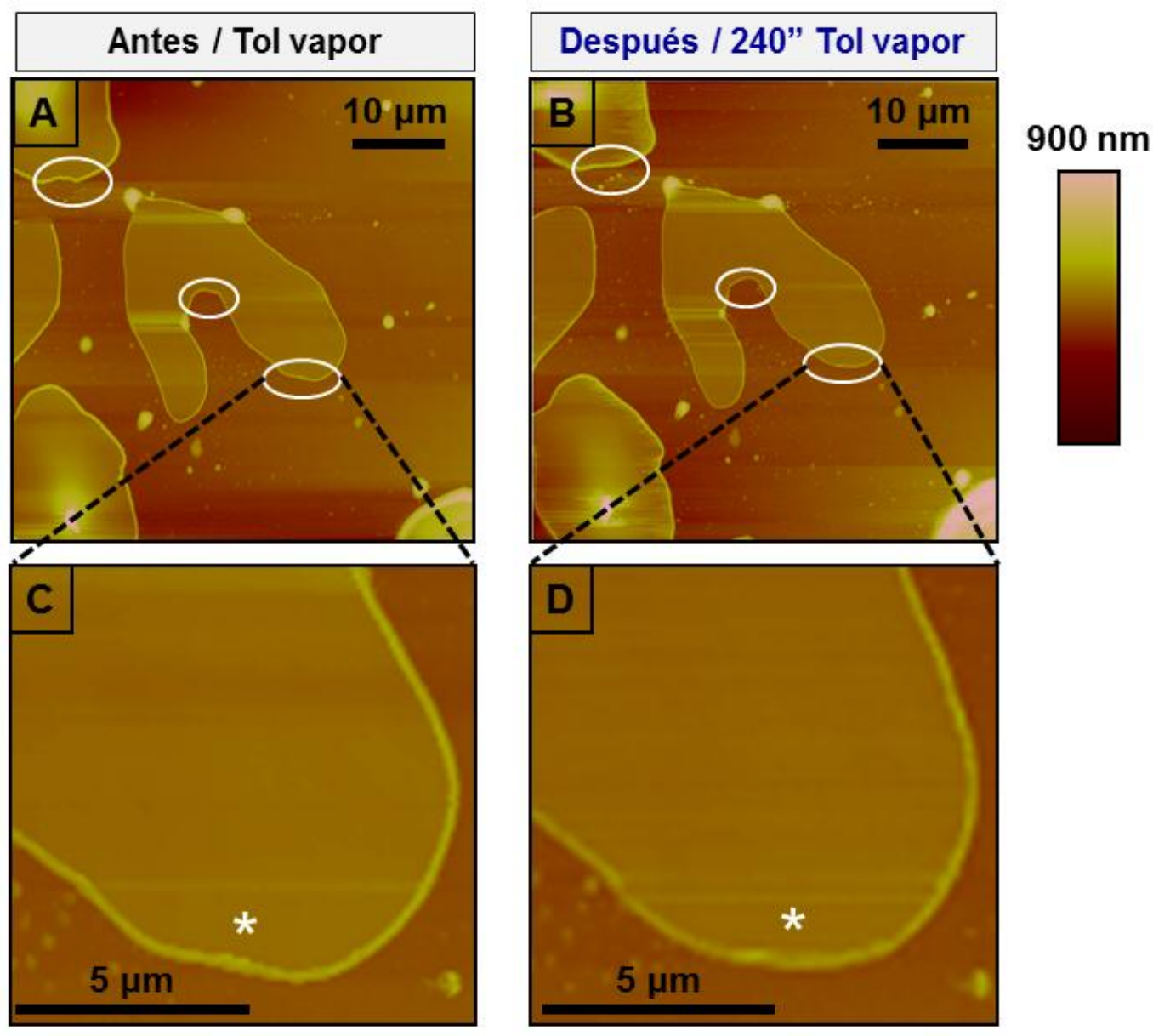

Figura 3.4 Imágenes de AFM de las películas de SNPs film sobre Si (100) antes $(A, C)$ y después $(B, D)$ de una exposición a vapor de Tol por 240 segundos. Ver Sección 3.3.3 para más detalles. 

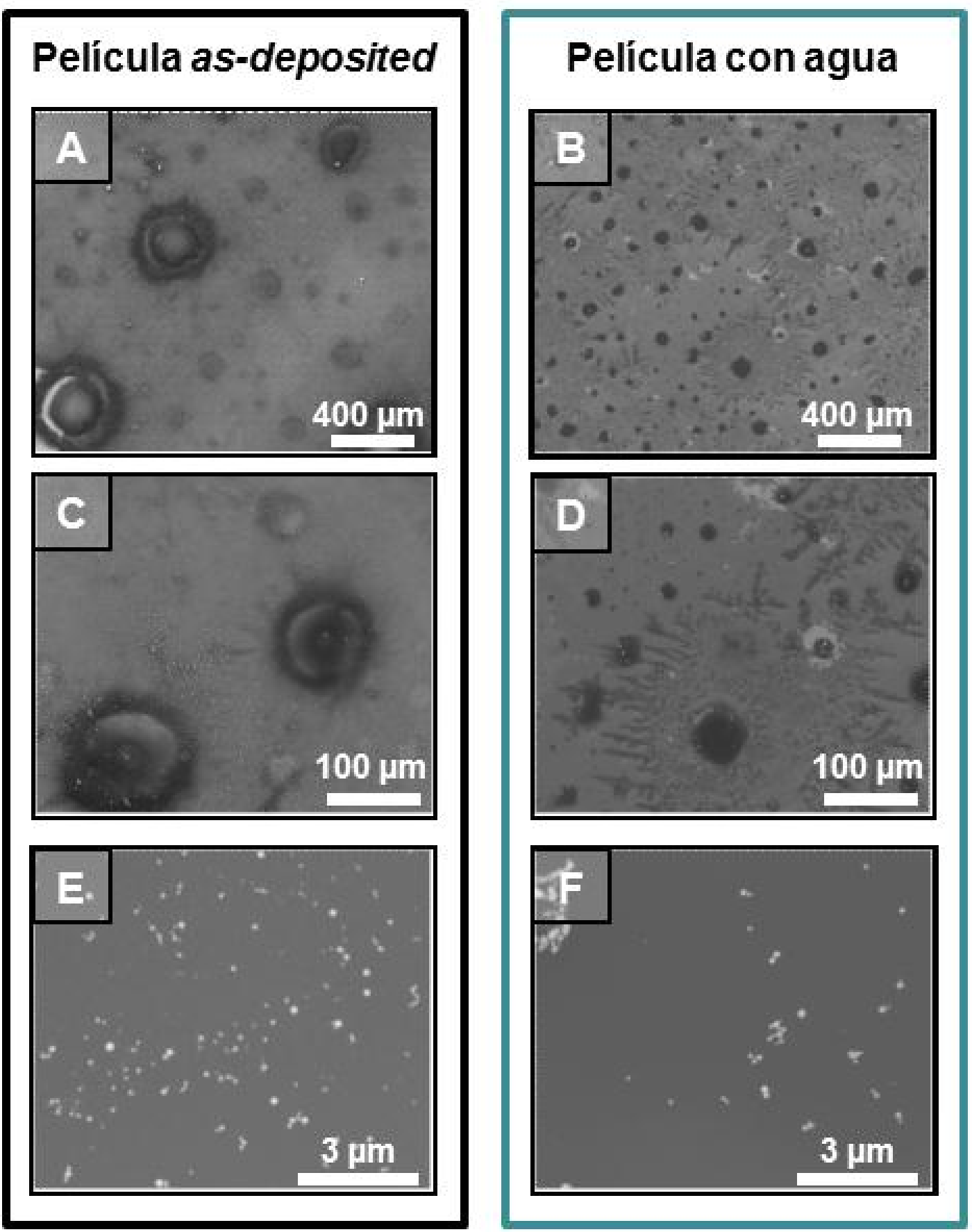

Figura 3.5 Imágenes de SEM de las películas de SNPs a diferentes magnificaciones correspondientes a las as-deposited (A, C, E) y a las que se les adicionó agua (B, D, F), como es indicado. 


\subsubsection{Teoría de Mie y Compactación de la Película}

\subsubsection{Teoría de Mie}

Si bien, desde el Siglo IV DC los romanos empleaban coloides de Au y Ag para para otorgarle colores a los vidrios y murales, para ellos era un misterio el fenómeno observado. ${ }^{52}$ Sin embargo, no fue hasta 1857, cuando Michael Faraday brindó una conferencia en la que describió las propiedades ópticas inusuales de los coloides de Au, argumentando que los diferentes colores observados no son más que una mera variación de los tamaños de las partículas que los componen (coloides). ${ }^{53}$

Más tarde, en 1908, estos hallazgos pioneros realizados por Faraday fueron los que inspiraron a Gustav Mie en la aplicación de las ecuaciones de Maxwell a los mencionados sistemas. Particularmente, Mie resolvió las ecuaciones de Maxwell para el caso de una partícula esférica en la presencia de un campo monocromático incidente. ${ }^{54}$ Sin embargo, cabe mencionar que en las ecuaciones planteadas por Mie, no se contemplan los efectos de dispersión (scattering) producidos por las partículas vecinas. En estos casos, el campo incidente sobre cada partícula va a tener dos componentes: a) uno es el propio campo incidente sobre el sistema; y b) la correspondiente suma de los campos dispersados por el resto de las partículas que forman el agregado o película. Para estos sistemas, la Teoría de Mie debe de contemplar estas condiciones, y es por ello que se la nombra como Teoría de Mie Generalizada (GMM, Generalized Multiparticle Mie-solution). Una clara descripción y aplicación de la misma esta dada en la Tesis del Dr. Luis Pérez. ${ }^{55}$

$$
\varepsilon_{\mathrm{c}}=\varepsilon^{\infty}-\left(\lambda^{2} / \lambda_{\mathrm{p}}^{2}\right)
$$

" $\lambda_{\mathrm{p}}$ " es la longitud de onda correspondiente a la frecuencia plasma del metal masivo (para el Au es, $131 \mathrm{~nm}$ ), " $\varepsilon^{\infty}$ " es la función dieléctrica óptica del metal $(12,2), \mathrm{y}$ " $\varepsilon_{\mathrm{m}}$ " es la función dieléctrica óptica del medio. Siendo $\lambda_{\mathrm{p}}$,

$$
\lambda_{\mathrm{p}}=2 \pi \mathrm{c} / \omega_{\mathrm{p}}
$$

donde "c" es la velocidad de la luz en el vacío, “ $\omega_{\mathrm{p}}$ " es la frecuencia plasma del metal masivo (bulk), el cual es definido por la siguiente ecuación: 


$$
\omega_{\mathrm{p}}=\left(N \mathrm{e}^{2} / \mathrm{m} \varepsilon_{\mathrm{o}}\right)^{1 / 2}
$$

donde, "N" es la concentración de electrones libres, y "m" corresponde a la masa del electrón.

Finalmente, de la combinación de las ecuaciones anteriores, surge la siguiente expresión:

$$
\lambda_{\text {máx }}^{2}=\lambda_{\mathrm{p}}^{2}\left(\varepsilon^{\infty}+2 \varepsilon_{\mathrm{m}}\right)
$$

donde " $\lambda_{\text {máx }}$ " es la posición del pico del plasmón superficial.

Luego, debe de considerarse la siguiente relación entre el índice de refracción (n) y el dieléctrico,

$$
\varepsilon_{\mathrm{m}}=\mathrm{n}^{2}
$$

Es conocido, que la mayoría de los sensores del tipo LSPR presentan cambios o desplazamientos en la banda plasmónica a los rojos cuando se encuentran en la presencia de un analito. Esto es debido a que existe una dependencia casi lineal entre el valor del $\lambda_{\text {máx }}$ con el índice de refracción (RI) del medio circundante, el cual esta basado en el modelo de Drude, ${ }^{2}$ lo cual es claramente notado en la ecuación 3.5

Sin embargo, en la ecuación antes mencionada, no se considera la posibilidad de una compactación entre las partículas. Un ejemplo de ello se daría en el caso de que las películas se contraigan en la presencia de vapores polares. Por lo tanto, resulta muy interesante ahondar en otros posibles factores que contribuyan a los cambios en el $\lambda_{\text {máx }}$, más que el RI por sí mismo.

\subsubsection{Compactación de la Película}

Como fue estudiado anteriormente en este Capítulo, en el gráfico en la Figura 3.2C se mostró un cambio a los rojos significativo para las películas de SNPs $(\% \mathrm{R}=$ $0,93)$ en comparación a las películas de CNPs $(\% \mathrm{R}=0,30)$, sugiriendo que las mismas presentan un mecanismo de sensado diferente. En la Figura 3.6A,B se comparan los 
cambios medidos experimentalmente en el pico del plasmón $\left(\lambda_{\text {máx }}\right)$ versus el índice de refracción (RI) para películas de SNPs y CNPs de similar tamaño, medidos en aire y expuestos a $\mathrm{EtOH}$ en fase vapor y en estado líquido, respectivamente. Como es esperado, las películas de SNPs expuestas a líquidos exhiben una alta sensibilidad. ${ }^{56}$ Es llamativo que, la pendiente $\left(m_{\mathrm{SNP}}\right)$ para las películas de NPs de Au cubiertas con material orgánico es mayor que la pendiente $\left(m_{\mathrm{CNP}}\right)$ para las películas de CNPs débilmente estabilizadas (cubierta con citrato). Si bien estos resultados son consistentes con la Figura 3.2C, caen fuera de lo esperado por la Teoría de Mie, la cual indica un decrecimiento de $\sim 5 \mathrm{~nm}$ en el desplazamiento plasmónico para las SNPs cuando son comparadas a las CNPs dispersas en EtOH (Ver el Apéndice B de esta Tesis, en donde se detallan los cálculos de LSPR de los cambios esperados según la Teoría de Mie). Sin embargo, nuestros resultados experimentales muestran que las películas de SNPs presentan mayor respuesta que las películas de CNPs en la presencia de vapor de EtOH, sugiriendo un decrecimiento en la distancia inter-nanopartículas (compactación de la película), lo cual es conocido que produce desplazamientos a mayores valores de longitud de onda.
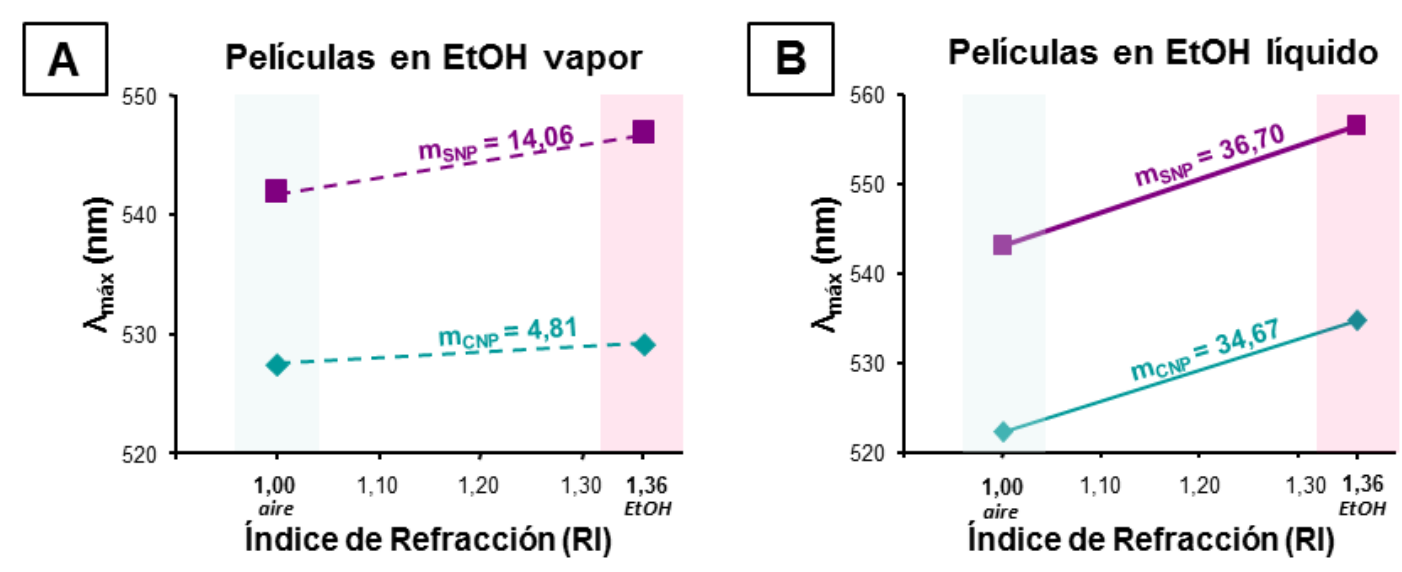

Figura 3.6 Medidas experimentales correspondientes a los cambios máximos observados en el pico plasmónico $\left(\lambda_{\text {máx }}\right)$ con el índice de refracción (RI) para las películas de SNPs y CNPs expuestas a aire (aire seco) y EtOH tanto en fase vapor (A) como en estado líquido (B).

Con el fin de explorar en la posibilidad de que la película se contraiga en la presencia de un solvente polar, se realizó una caracterización por SEM de las películas de SNPs as-prepared y otras conteniendo agua. Escogimos agua en vez de etanol considerando su alta polaridad y la baja probabilidad de que las nanopartículas se aglomeren. ${ }^{57}$ Las películas de SNPs as-deposited mostraron "anillos" (o-rings) concéntricos a lo largo de la superficie ${ }^{46}$ atribuidos a la formación de micelas. Resulta interesante que las películas conteniendo agua mostraron la formación de patrones 
fractales con la apariencia de huecos uniformes, y a altas magnificaciones se observó algún grado de aglomeración, tal como se puede observar en la Figura 3.5. El incremento en el tamaño de los huecos con el agua indica la compactación de la película en algunas áreas, consistente con la formación irreversible de grietas (cracks $)^{41}$ y el decrecimiento $^{58}$ en la distancia inter-nanopartículas reportado en la literatura. En un contexto similar, Pileni et al. ${ }^{58}$ observaron un decrecimiento en la distancia entre C12S $\mathrm{Au}$ MPCs desde 2,2 a $\sim 1,1 \mathrm{~nm}$ por la adición de agua. Ellos sugirieron que existen fuerzas atractivas entre las nanopartículas causadas por medio de las interacciones moleculares agua-agua en la superficie del $\mathrm{Au},{ }^{58}$ lo que daría lugar a la compactación de la película.

\subsubsection{Sensado por FT-IR}

Esta sección esta enfocada en el estudio de la importancia de la cubierta orgánica y sus efectos en el sensado. Para ello, se realizaron experimentos empleando espectroscopia FT-IR para explorar en la restructuración de la capa orgánica, ${ }^{42}$ por medio de los cambios en la vibración del stretching del $\mathrm{CH}_{2}$ asimétrico (d`).

La Tabla 3.2 compara los valores del $\mathrm{CH}_{2} \mathrm{~d}^{-}$antes $(\mathrm{t}=0)$, durante, y después de la exposición al analito en fase vapor para películas seleccionadas de SNPs y C12 Au MPC. Una comparación entre las películas de SNPs as-deposited y las C12S Au MPC muestra que el stretching de los $\mathrm{CH}_{2}$ para los primeros aparece a altas frecuencias, indicando una alta densidad de defectos gauche. ${ }^{42}$ Llamativamente, las películas de C12S Au MPC muestran un desplazamiento plasmónico en la presencia de vapor de EtOH menos prominente que en las películas de SNPs, y ocurre lo opuesto en la presencia de Tol. Estos datos indican que las películas de SNPs y C12S Au MPC son más sensibles a la presencia de vapores polares y no-polares, respectivamente, lo cual es similar a lo que ocurre en chemiresistores compuestos de películas de NPs de Au protegidas con surfactantes y con tioles. ${ }^{46}$ Pensamos que los vapores polares se embeben (partición) más fácilmente sobre las nanopartículas protegidas con surfactante que sobre aquellas que están protegidas con alcanotioles bien organizados, causando grandes restructuraciones en las primeras. A través de estos experimentos es posible correlacionar el orden de la película con la separación inter-nanopartículas, y predecir así los cambios subsiguientes en los sensores del tipo LSPR. 
Tabla 3.2 Cambios en la frecuencia del $\mathrm{CH}_{2}$ asimétrico $\left(\mathrm{d}^{-}\right)$para las películas de SNPs y C12S Au MPCs antes (aire seco), durante, y después (abierto a la atmósfera) de la exposición a vapores.

\begin{tabular}{|c|c|c|c|}
\cline { 2 - 4 } \multicolumn{1}{c|}{} & \multicolumn{3}{c|}{ Películas de SNPs } \\
\cline { 2 - 4 } & $(\mathrm{d}-) \mathrm{t}=\mathbf{0}$ aire seco & (d-) vapor (máx) & (d-) abierto al ambiente \\
\hline EtOH & 2923,46 & 2920,59 & 2922,96 \\
\hline Tol & & 2929,59 & 2923,28 \\
\hline
\end{tabular}

\begin{tabular}{|c|c|c|c|}
\cline { 2 - 4 } \multicolumn{1}{c|}{} & \multicolumn{3}{c|}{ Películas de Au@SC $_{12}$ MPCs } \\
\cline { 2 - 4 } & (d) t=0 aire seco & (d-) vapor (máx) & (d-) abierto al ambiente \\
\hline EtOH & 2917,63 & 2918,22 & 2918,49 \\
\hline Tol & & 2935,39 & 2918,81 \\
\hline
\end{tabular}

La Figura 3.7A muestra un gráfico de FT-IR de una película de SNPs selecta expuesta a los analitos en fase vapor, como es indicado. La Figura 3.7B muestra los desplazamientos en la frecuencia para los $\mathrm{CH}_{2} \mathrm{~d}^{-}$versus el tiempo (segundos), para una película de SNPs selecta expuesta a vapores de EtOH y Tol corridos en aire seco (línea de base) como es indicado. La Figura muestra un incremento en la frecuencia para la película expuesta a Tol, mientras que en aire y EtOH la misma no presenta cambios y se desplaza a bajas frecuencias, respectivamente. Estos resultados claramente demuestran que las cadenas orgánicas se reestructuran en la presencia de vapores, alcanzan una saturación en el vapor, y retornan a su frecuencia después de la remoción del vapor (Tabla 3.2). Se analizaron los efectos de otros vapores incluyendo: hexano, acetona, butanol, isopropanol, metanol y agua, como es mostrado en la Figura 3.8. La Figura muestra el máximo cambio en la frecuencia $\left(\Delta \mathrm{f}_{\text {máx }}\right)$ versus la polaridad para películas de SNPs expuestas a vapores de varios analitos, como es indicado. El gráfico de barras muestra el promedio del porcentaje de respuesta en la frecuencia (Prom. \% $\mathrm{R}_{\mathrm{f}}{ }^{59}$ junto con los valores de los dieléctricos $(\varepsilon)$ para cada analito involucrado en éste estudio. La Figura 3.8 demuestra que los cambios en la frecuencia no pueden ser solamente atribuidos a los cambios en $\varepsilon$, sino que es una combinación de diferentes factores que podrían incluir la presión de vapor, la forma de la molécula (planar o lineal), el coeficiente de partición, la polaridad, y la presencia o ausencia de grupos aromáticos. 

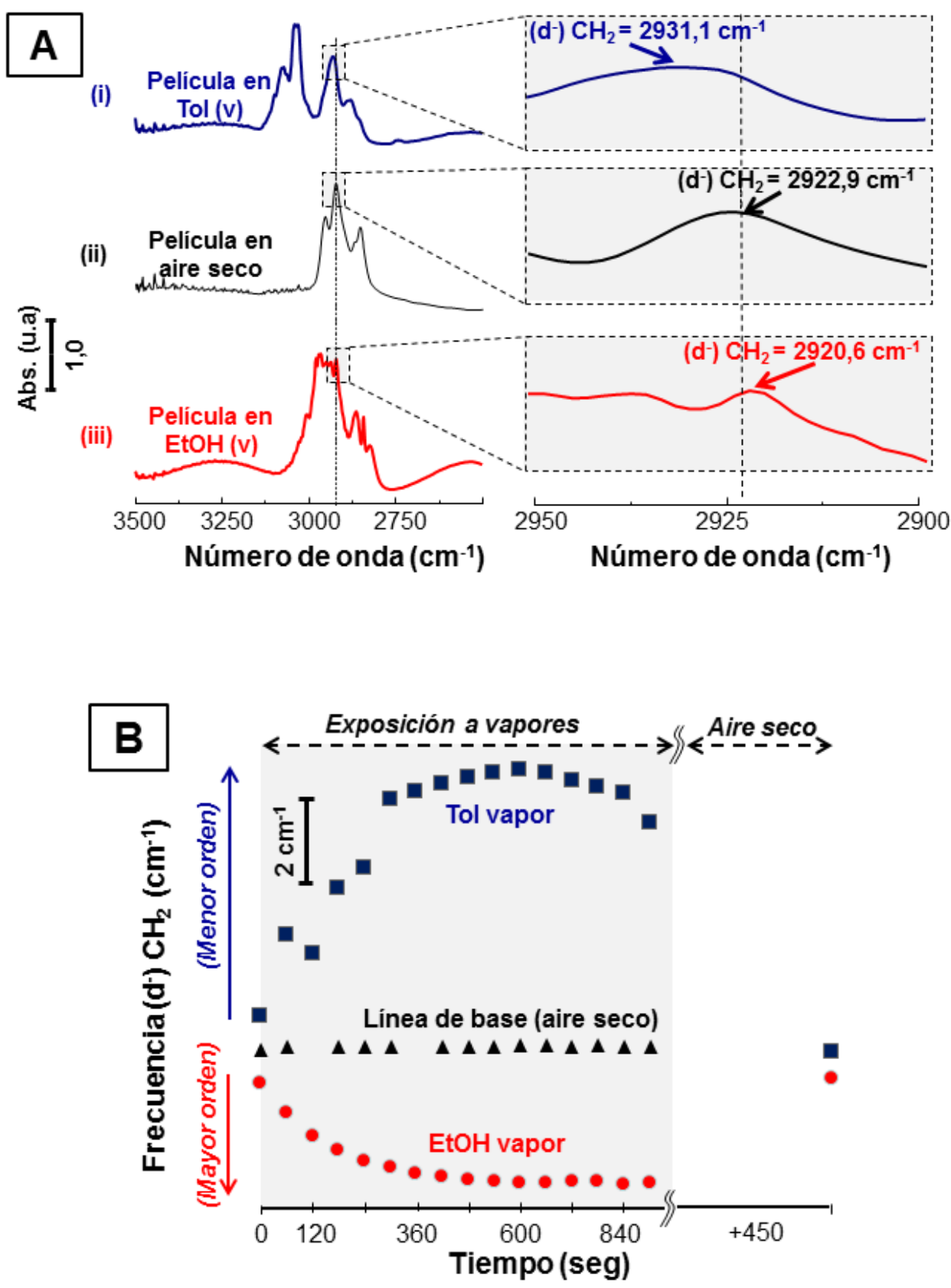

Figura 3.7 Gráficos de FT-IR para una película de SNPs as-deposited en aire seco (línea de base/background gas) (A, ii) y expuesto a vapores de Tol (i) y EtOH (iii), y vibraciones del stretching del $\mathrm{CH}_{2}$ asimétrico (d') correspondientes a una película de SNPs selecta, en los tiempos indicados (B). 
Como consecuencia de ello, las películas de SNPs expuestas a EtOH se comportan de manera diferente, con desplazamientos de sus cadenas orgánicas hacia estados más organizados. Estos resultados podrían ayudar a comprender la importancia de la solubilidad de los vapores en la película orgánica. Por ejemplo, el EtOH induce un comportamiento diferente cuando es comparado a vapores de cadenas más cortas (ej., metanol), sugiriendo que las moléculas de EtOH podrían tener una mayor probabilidad de alcanzar la superficie del $\mathrm{Au}$, conduciendo a la formación de potenciales enlaces de H. Esto último podría favorecer el empaquetamiento de las cadenas alquílicas, resultando en una compactación de la película como fue observado en las imágenes de SEM.

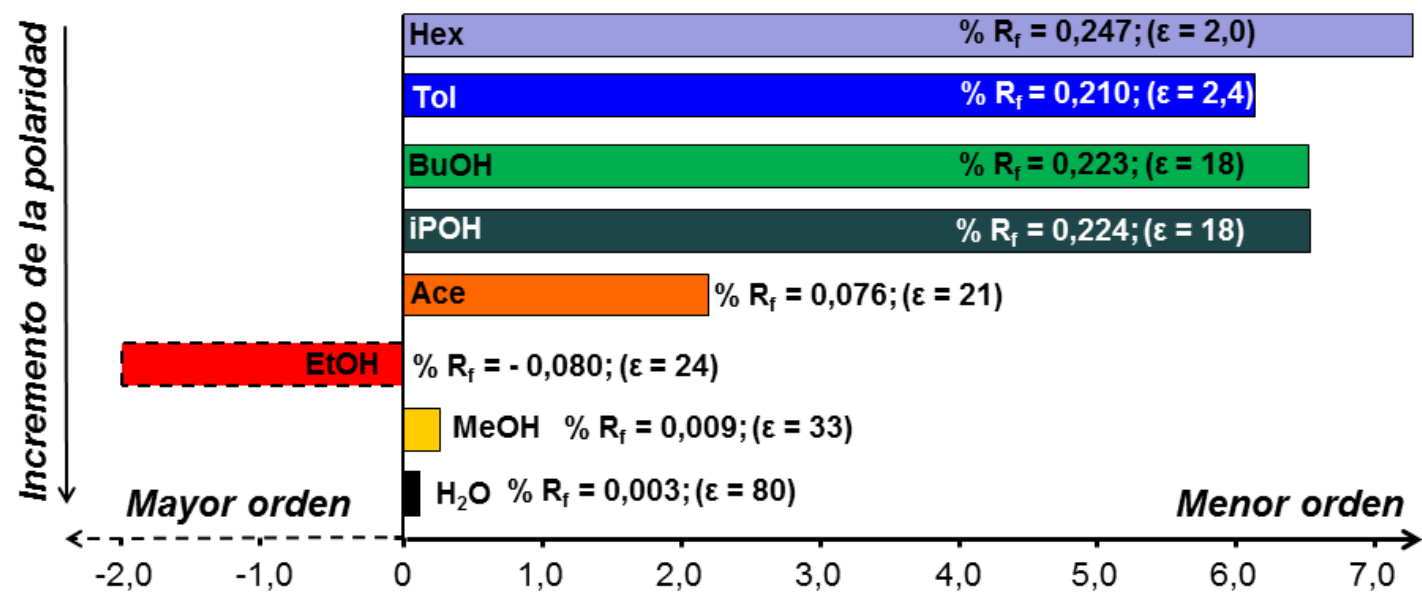

Cambio máximo en la frecuencia $\left(\Delta f_{\text {máx }}\right)$ del estiramiento (d-) $\mathrm{CH}_{2}\left(\mathrm{~cm}^{-1}\right)$

Figura 3.8 Cambios máximos en la frecuencia $\left(\Delta \mathrm{f}_{\text {máx }}\right)$ para la vibración del estiramiento (stretching) del $\mathrm{CH}_{2}$ asimétrico versus la polaridad obtenida de 2 películas de SNPs expuestas a varios VOCs, como es indicado. El gráfico de barras muestra el porcentaje de respuesta $\left(\% \mathrm{R}_{\mathrm{f}}\right)$ y los valores de los dieléctricos $(\varepsilon)$. Nota: Hex = hexano, Tol = tolueno, $\mathrm{BuOH}=1$-butanol, $\mathrm{iPOH}=$ isopropanol, Ace $=$ acetona, $\mathrm{y}$ $\mathrm{EtOH}=$ etanol.

En general, las películas expuestas a vapores orgánicos responden con un desplazamiento de sus cadenas orgánicas hacia altas frecuencias (alta energía) indicando una desorganización, mientras que en la presencia de vapores con relativamente altos valores de dieléctrico $(\varepsilon)$, la película se organiza a una estructura menos extendida o responde con desplazamientos hacia bajas frecuencias (bajas energías) (ej., $\varepsilon_{\mathrm{EtOH}}=24$ ). La organización puede ser atribuida a las interacciones del tipo van der Waals entre las cadenas alquílicas causadas por los vapores polares, mientras que la desorganización esta asociada con el grado de solubilidad entre el analito en fase vapor y el material orgánico de la película. 


\subsubsection{Estabilidad del Sensor Durante Largos Períodos}

La Tabla 3.3 y la Figura 3.9 muestran el porcentaje (\%) de respuesta junto con los valores estadísticos correspondientes a tres películas de SNPs y CNPs almacenadas en condiciones ambientales durante 30 y 12 días, respectivamente. Resulta interesante que los dispositivos con SNPs añejados por un mes respondieron de manera similar que las mismas películas preparadas frescas, asimismo mostraron una pequeña mejora en su respuesta al vapor de Tol desde $0,6 \%$ a $0,7 \%$. Este incremento en la sensibilidad cae dentro de la desviación estándar (standard deviation, STD) para las muestras asprepared (Figura 3.2C). Sin embargo, las películas de CNPs respondieron pobremente en la presencia de los vapores, y en algunos casos los desplazamientos producidos a los azules indicaron el deterioro de las mismas. Por otro lado, se trató de comparar la estabilidad entre las películas de SNPs con un mes de añejamiento con las películas de NPs de Ag protegidas con citrato (CNPs Ag), pero éstas últimas sufrieron la pérdida del plasmón al mes de preparadas, tal como fuera reportado. ${ }^{60}$

Tabla 3.3 Datos Mostrando el \% de Respuesta Junto con los Valores Estadísticos para las Películas de SNPs y CNPs Añejadas.

\section{Películas de SNPs / 1 mes de preparadas}

\begin{tabular}{|ccccc|ccccc|}
\hline \multicolumn{5}{|c|}{ En EtOH (vapor) } & \multicolumn{5}{c|}{ En Tol (vapor) } \\
\hline Muestra & $\lambda_{\text {máx }, \text { inicial }}$ & $\lambda_{\text {máx,final }}$ & $\Delta \Lambda_{\text {máx }}$ & \%Resp & Muestra & $\lambda_{\text {máx, } \text {,inicial }}$ & $\lambda_{\text {máx,final }}$ & $\Delta \Lambda_{\text {máx }}$ & $\%$ Resp \\
1 & 533,99 & 537,99 & 4,0 & 0,75 & 1 & 537,01 & 533,65 & $-3,4$ & $-0,63$ \\
2 & 537,78 & 538,99 & 1,2 & 0,22 & 2 & 537,58 & 533,19 & $-4,4$ & $-0,82$ \\
3 & 554,57 & 560,40 & 5,8 & 1,05 & 3 & 552,85 & 549,18 & $-3,7$ & $-0,66$ \\
& & & & & & & & & \\
Prom. & & & 2,6 & 0,68 & Prom. & & & $-3,9$ & $-0,70$ \\
STD & & & $\pm 1,4$ & $\pm 0,45$ & STD & & & $\pm 0,5$ & $\pm 0,1$ \\
\hline
\end{tabular}

Películas de CNPs / 12 días de preparadas

\begin{tabular}{|c|c|c|c|c|c|c|c|c|c|}
\hline \multicolumn{5}{|c|}{ En EtOH (vapor) } & \multicolumn{5}{|c|}{ En Tol (vapor) } \\
\hline Muestra & $\lambda_{\text {máx }}$,inicial & $\lambda_{\text {máx }}$, final & $\Delta \Lambda_{\text {máx }}$ & $\%$ Resp & Muestra & $\lambda_{\text {máx }}$,inicial & $\lambda_{\text {máx }}$,final & $\Delta \Lambda_{\operatorname{máx}}$ & \%Resp \\
\hline 1 & 541,12 & 532,03 & $-9,1$ & $-1,68$ & 1 & 532,18 & 532,22 & 0,0 & 0,01 \\
\hline 2 & 523,40 & 526,50 & 3,1 & 0,59 & 2 & 526,47 & 523,60 & $-2,9$ & $-0,55$ \\
\hline 3 & 526,15 & 527,59 & 1,4 & 0,27 & 3 & 526,04 & 527,62 & 1,6 & 0,30 \\
\hline Prom. & & & $-1,5$ & $-0,27$ & Prom. & & & $-0,4$ & $-0,08$ \\
\hline STD & & & $\pm 6,6$ & $\pm 1,2$ & STD & & & $\pm 2,3$ & $\pm 0,4$ \\
\hline
\end{tabular}




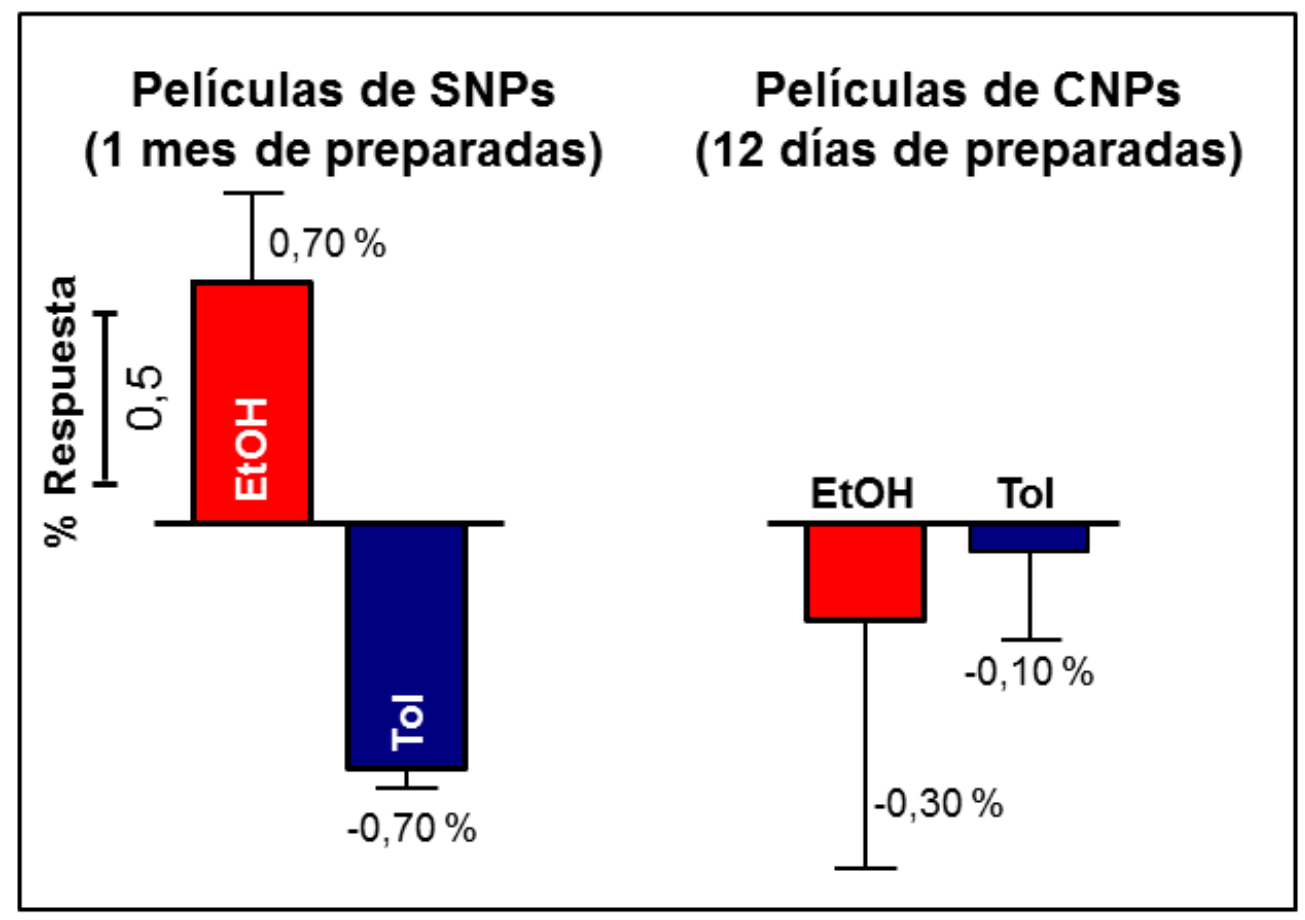

Figura 3.9 Gráfico de barras mostrando el \% de respuesta y la estadística para películas añejadas de NPs de Au protegidas con TOABr (TOABr-coated Au, SNPs) y NPs de Au protegidas con citrato (citrate-coated Au NPs, CNPs) expuestas a vapores de Tol y EtOH, como es indicado.

\subsection{Conclusiones}

En resumen, se realizaron experimentos de sensado de vapores por LSPR basados en las distancias inter-nanopartículas, empleando NPs de Au protegidas con un surfactante. Dicho sistema fue comparado con ligandos débiles y fuertes rodeando a las nanopartículas. En el presente trabajo, la movilidad de las nanopartículas en la película inducida por los analitos en fase vapor, juega un rol crucial en el mecanismo de sensado por LSPR. La presencia de Tol desorganiza la porción orgánica, consistente con el hinchamiento de la película y la separación de las nanopartículas. En sensores del tipo LSPR, esto conduce a una competencia entre el desplazamiento plasmónico esperado a los rojos (causado por un incremento en el RI) y un desplazamiento plasmónico total predominantemente a los azules, siendo éste último inducido por el hinchamiento de la película. Como es de esperar, se observó un desplazamiento en el valor del $\lambda_{\text {máx }}$ a los rojos cuando las películas fueron expuestas a vapores polares, aunque éstas responden de manera más prominente que las películas de CNPs, lo cual indica algún grado de 
cooperación entre la disminución en las distancias inter-nanopartículas junto con el incremento en el RI. Se demostró que las películas que contienen agua tienden a la compactación de la misma, y que los vapores polares (ej., EtOH) tienden a organizar a las cadenas alquílicas. Cabe mencionar que la movilidad de las nanopartículas en la película influencia los cambios observados en los plasmones, sobre los cambios en el RI. Nuestros resultados demostraron que, las películas en estado sólido de Au@TOABr son fácilmente ensambladas sobre sustratos transparentes, son selectivas a vapores tanto polares como no-polares, son sensores de LSPR más sensibles que las nanopartículas de Au protegidas con citrato, y son más estables que las NPs de Au y Ag protegidas con citrato.

Finalmente, de acuerdo a los resultados mostrados a lo largo de éste Capítulo, se plantean futuros experimentos para explorar la aplicación de nanopartículas de $\mathrm{Ag} @ \mathrm{TOABr}$ y aleaciones Ag/Au@TOABr para mantener la estabilidad y al mismo tiempo mejorar la sensibilidad de los sensores de LSPR.

\subsection{Bibliografía}

(1) Eric Le $\mathrm{Ru}$, Pablo Etchegoin. Principles of Surface-Enhanced Raman Spectroscopy: And Related Plasmonic Effects, 1 edition.; Elsevier Science, 2008.

(2) Mayer, K. M.; Hafner, J. H. Localized Surface Plasmon Resonance Sensors. Chem. Rev. 2011, 111 (6), 3828-3857.

(3) Maier, S. A. Plasmonics: Fundamentals and Applications, Edición: 2007.; Springer, 2007.

(4) Dror Sarid, William Challener. Modern Introduction to Surface Plasmons: Theory, Mathematica Modeling, and Applications, 1 edition.; Cambridge University Press, 2010.

(5) Johnson, P. B.; Christy, R. W. Optical Constants of the Noble Metals. Phys. Rev. $B$ 1972, 6 (12), 4370-4379.

(6) Chen, H.; Kou, X.; Yang, Z.; Ni, W.; Wang, J. Shape- and Size-Dependent Refractive Index Sensitivity of Gold Nanoparticles. Langmuir 2008, 24 (10), 5233-5237.

(7) Haes, A. J.; Hall, W. P.; Chang, L.; Klein, W. L.; Van Duyne, R. P. A Localized Surface Plasmon Resonance Biosensor: First Steps toward an Assay for Alzheimer's Disease. Nano Lett. 2004, 4 (6), 1029-1034.

(8) Beeram, S. R.; Zamborini, F. P. Selective Attachment of Antibodies to the Edges of Gold Nanostructures for Enhanced Localized Surface Plasmon Resonance Biosensing. J. Am. Chem. Soc. 2009, 131 (33), 11689-11691.

(9) Willets, K. A.; Van Duyne, R. P. Localized Surface Plasmon Resonance Spectroscopy and Sensing. Annu. Rev. Phys. Chem. 2007, 58 (1), 267-297.

(10) J., Satija, R., Bharadwaj; V.V.R., Sai, S., Mukherji. Emerging Use of Nanostructure Films Containing Capped Gold Nanoparticles in Biosensors. Dovepress 2010, 171-188. 
(11) Nath, N.; Chilkoti, A. Label-Free Biosensing by Surface Plasmon Resonance of Nanoparticles on Glass: Optimization of Nanoparticle Size. Analytical Chemistry 2004, 76 (18), 5370-5378.

(12) Sun, Y.; Xia, Y. Increased Sensitivity of Surface Plasmon Resonance of Gold Nanoshells Compared to That of Gold Solid Colloids in Response to Environmental Changes. Anal. Chem. 2002, 74 (20), 5297-5305.

(13) Mock, J. J.; Barbic, M.; Smith, D. R.; Schultz, D. A.; Schultz, S. Shape Effects in Plasmon Resonance of Individual Colloidal Silver Nanoparticles. J. Chem. Phys. 2002, $116(15), 6755-6759$.

(14) M.A.; Link, S.; Mohamed, M.B. El-Sayed,. Simulation of the Optical Absorption Spectra of Gold Nanorods as a Function of Their Aspect Ratio and the Effect of the Medium Dielectric Constant. J. Phys. Chem. B 1999, 103 (16), 3073-3077.

(15) Henry, A.-I.; Bingham, J. M.; Ringe, E.; Marks, L. D.; Schatz, G. C.; Van Duyne, R. P. Correlated Structure and Optical Property Studies of Plasmonic Nanoparticles. J. Phys. Chem. C 2011, 115 (19), 9291-9305.

(16) Kwon, M. J.; Lee, J.; Wark, A. W.; Lee, H. J. Nanoparticle-Enhanced Surface Plasmon Resonance Detection of Proteins at Attomolar Concentrations: Comparing Different Nanoparticle Shapes and Sizes. Anal. Chem. 2012, 84 (3), 1702-1707.

(17) Sau, T. K.; Murphy, C. J. Seeded High Yield Synthesis of Short Au Nanorods in Aqueous Solution. Langmuir 2004, 20 (15), 6414-6420.

(18) Li, Z.; Tao, J.; Lu, X.; Zhu, Y.; Xia, Y. Facile Synthesis of Ultrathin Au Nanorods by Aging the AuCl(oleylamine) Complex with Amorphous $\mathrm{Fe}$ Nanoparticles in Chloroform. Nano Lett. 2008, 8 (9), 3052-3055.

(19) Hall, W. P.; Modica, J.; Anker, J.; Lin, Y.; Mrksich, M.; Van Duyne, R. P. A Conformation- and Ion-Sensitive Plasmonic Biosensor. Nano Lett. 2011, 11 (3), 1098-1105.

(20) Sannomiya, T.; Hafner, C.; Voros, J. In Situ Sensing of Single Binding Events by Localized Surface Plasmon Resonance. Nano Lett. 2008, 8 (10), 3450-3455.

(21) Beeram, S. R.; Zamborini, F. P. Effect of Protein Binding Coverage, Location, and Distance on the Localized Surface Plasmon Resonance Response of Purified $\mathrm{Au}$ Nanoplates Grown Directly on Surfaces. J. Phys. Chem. C 2011, 115 (15), 7364-7371.

(22) Liz-Marzán, L. M.; Giersig, M.; Mulvaney, P. Synthesis of Nanosized Gold-Silica Core-Shell Particles. Langmuir 1996, 12 (18), 4329-4335.

(23) Jain, P. K.; Huang, W.; El-Sayed, M. A. On the Universal Scaling Behavior of the Distance Decay of Plasmon Coupling in Metal Nanoparticle Pairs: A Plasmon Ruler Equation. Nano Lett. 2007, 7 (7), 2080-2088.

(24) Su, K.-H.; Wei, Q.-H.; Zhang, X.; Mock, J. J.; Smith, D. R.; Schultz, S. Interparticle Coupling Effects on Plasmon Resonances of Nanogold Particles. Nano Lett. 2003, 3 (8), 1087-1090.

(25) Rechberger, W.; Hohenau, A.; Leitner, A.; Krenn, J. R.; Lamprecht, B.; Aussenegg, F. R. Optical Properties of Two Interacting Gold Nanoparticles. Opt. Commun. 2003, 220 (1-3), 137-141.

(26) Agrawal, V. V.; Varghese, N.; Kulkarni, G. U.; Rao, C. N. R. Effects of Changes in the Interparticle Separation Induced by Alkanethiols on the Surface Plasmon 
Band and Other Properties of Nanocrystalline Gold Films. Langmuir 2008, 24 (6), 2494-2500.

(27) Ni, I.-C.; Yang, S.-C.; Jiang, C.-W.; Luo, C.-S.; Kuo, W.; Lin, K.-J.; Tzeng, S.-D. Formation Mechanism, Patterning, and Physical Properties of Gold-Nanoparticle Films Assembled by an Interaction-Controlled Centrifugal Method. J. Phys. Chem. C 2012, 116 (14), 8095-8101.

(28) Liu, N.; Tang, M. L.; Hentschel, M.; Giessen, H.; Alivisatos, A. P. NanoantennaEnhanced Gas Sensing in a Single Tailored Nanofocus. Nat Mater 2011, 10 (8), 631-636.

(29) Bingham, J. M.; Anker, J. N.; Kreno, L. E.; Van Duyne, R. P. Gas Sensing with High-Resolution Localized Surface Plasmon Resonance Spectroscopy. J. Am. Chem. Soc. 2010, 132 (49), 17358-17359.

(30) Chen, Y.-Q.; Lu, C.-J. Surface Modification on Silver Nanoparticles for Enhancing Vapor Selectivity of Localized Surface Plasmon Resonance Sensors. Sens. Actuators, B 2009, 135 (2), 492-498.

(31) Chen, K.-J.; Lu, C.-J. A Vapor Sensor Array Using Multiple Localized Surface Plasmon Resonance Bands in a Single UV-vis Spectrum. Talanta 2010, 81 (4-5), $1670-1675$.

(32) Karakouz, T.; Vaskevich, A.; Rubinstein, I. Polymer-Coated Gold Island Films as Localized Plasmon Transducers for Gas Sensing. J. Phys. Chem. B 2008, 112 (46), 14530-14538.

(33) Malinsky, M. D.; Kelly, K. L.; Schatz, G. C.; Van Duyne, R. P. Chain Length Dependence and Sensing Capabilities of the Localized Surface Plasmon Resonance of Silver Nanoparticles Chemically Modified with Alkanethiol SelfAssembled Monolayers. J. Am. Chem. Soc. 2001, 123 (7), 1471-1482.

(34) Cheng, C.-S.; Chen, Y.-Q.; Lu, C.-J. Organic Vapour Sensing Using Localized Surface Plasmon Resonance Spectrum of Metallic Nanoparticles Self Assemble Monolayer. Talanta 2007, 73 (2), 358-365.

(35) Templeton, A. C.; Pietron, J. J.; Murray, R. W.; Mulvaney, P. Solvent Refractive Index and Core Charge Influences on the Surface Plasmon Absorbance of Alkanethiolate Monolayer-Protected Gold Clusters. J. Phys. Chem. B 1999, 104 (3), 564-570.

(36) Steinecker, W. H.; Rowe, M. P.; Zellers, E. T. Model of Vapor-Induced Resistivity Changes in Gold-Thiolate Monolayer-Protected Nanoparticle Sensor Films. Anal. Chem. 2007, 79 (13), 4977-4986.

(37) Ibañez, F. J.; Zamborini, F. P. Chemiresistive Sensing with Chemically Modified Metal and Alloy Nanoparticles. Small 2012, 8 (2), 174-202.

(38) Wohltjen, H.; Snow, A. W. Colloidal Metal-Insulator-Metal Ensemble Chemiresistor Sensor. Anal. Chem. 1998, 70 (14), 2856-2859.

(39) Joseph, Y.; Guse, B.; Vossmeyer, T.; Yasuda, A. Gold Nanoparticle/Organic Networks as Chemiresistor Coatings: The Effect of Film Morphology on Vapor Sensitivity. J. Phys. Chem. C 2008, 112 (32), 12507-12514.

(40) Terrill, R. H.; Postlethwaite, T. A.; Chen, C.; Poon, C.-D.; Terzis, A.; Chen, A.; Hutchison, J. E.; Clark, M. R.; Wignall, G. Monolayers in Three Dimensions: NMR, SAXS, Thermal, and Electron Hopping Studies of Alkanethiol Stabilized Gold Clusters. J. Am. Chem. Soc. 1995, 117 (50), 12537-12548. 
(41) García-Berríos, E.; Gao, T.; Woodka, M. D.; Maldonado, S.; Brunschwig, B. S.; Ellsworth, M. W.; Lewis, N. S. Response versus Chain Length of AlkanethiolCapped $\mathrm{Au}$ Nanoparticle Chemiresistive Chemical Vapor Sensors. J. Phys. Chem. C 2010, 114 (50), 21914-21920.

(42) Snyder, R. G.; Strauss, H. L.; Elliger, C. A. Carbon-Hydrogen Stretching Modes and the Structure of N-Alkyl Chains. 1. Long, Disordered Chains. J. Phys. Chem. 1982, 86 (26), 5145-5150.

(43) Hostetler, M. J.; Stokes, J. J.; Murray, R. W. Infrared Spectroscopy of ThreeDimensional Self-Assembled Monolayers: N-Alkanethiolate Monolayers on Gold Cluster Compounds. Langmuir 1996, 12 (15), 3604-3612.

(44) Cheng, W.; Dong, S.; Wang, E. Synthesis and Self-Assembly of Cetyltrimethylammonium Bromide-Capped Gold Nanoparticles. Langmuir 2003, 19 (22), 9434-9439.

(45) Grumelli, D.; Méndez De Leo, L. P.; Bonazzola, C.; Zamlynny, V.; Calvo, E. J.; Salvarezza, R. C. Methylene Blue Incorporation into Alkanethiol SAMs on $\mathrm{Au}(111)$ : Effect of Hydrocarbon Chain Ordering. Langmuir 2010, 26 (11), 82268232.

(46) Ibañez, F. J.; Zamborini, F. P. Chemiresistive Sensing of Volatile Organic Compounds with Films of Surfactant-Stabilized Gold and Gold-Silver Alloy Nanoparticles. ACS Nano 2008, 2 (8), 1543-1552.

(47) Murphy, C. J.; Sau, T. K.; Gole, A. M.; Orendorff, C. J.; Gao, J.; Gou, L.; Hunyadi, S. E.; Li, T. Anisotropic Metal Nanoparticles: Synthesis, Assembly, and Optical Applications. J. of Phys. Chem. B 2005, 109 (29), 13857-13870.

(48) Brust, M.; Walker, M.; Bethell, D.; Schiffrin, D. J.; Whyman, R. Synthesis of Thiol-Derivatised Gold Nanoparticles in a Two-Phase Liquid-Liquid System. $J$. Chem. Soc., Chem. Commun. 1994, No. 7.

(49) Fink, J.; Kiely, C. J.; Bethell, D.; Schiffrin, D. J. Self-Organization of Nanosized Gold Particles. Chem. Mater. 1998, 10 (3), 922-926.

(50) Luechinger, N. A.; Loher, S.; Athanassiou, E. K.; Grass, R. N.; Stark, W. J. Highly Sensitive Optical Detection of Humidity on Polymer/Metal Nanoparticle Hybrid Films. Langmuir 2007, 23 (6), 3473-3477.

(51) Ibañez, F. J.; Gowrishetty, U.; Crain, M. M.; Walsh, K. M.; Zamborini, F. P. Chemiresistive Vapor Sensing with Microscale Films of Gold Monolayer Protected Clusters. Anal. Chem. 2005, 78 (3), 753-761.

(52) Wagner, F. E.; Haslbeck, S.; Stievano, L.; Calogero, S.; Pankhurst, Q. A.; Martinek, K. P. Before Striking Gold in Gold-Ruby Glass. Nature 2000, 407 (6805), 691-692.

(53) Faraday, M. The Bakerian Lecture: Experimental Relations of Gold (and Other Metals) to Light. Phil. Trans. R. Soc. 1857, 147, 145-181.

(54) Mie, G. Ann. Phys. 1908, 25, 377-445.

(55) Pérez, Luis A. Tesis Doctoral: Optica En La Nanoescala: Diseño de Nanoestructuras Plasmónicas Con Aplicación a La Detección Espectroscópica Ultrasensible de Moléculas. Facultad Ciencias Químicas, UNC (2015). Director: Eduardo A. Coronado; Codirector: Gabriela I. Lacconi.

(56) Thomas, K. G.; Zajicek, J.; Kamat, P. V. Surface Binding Properties of Tetraoctylammonium Bromide-Capped Gold Nanoparticles. Langmuir 2002, 18 (9), 3722-3727. 
(57) Como fue observado en el procedimiento de limpieza reportado para la síntesis de Brust-Schiffrin.

(58) Salzemann, C.; Zhai, W.; Goubet, N.; Pileni, M.-P. How to Tune the Au Internanocrystal Distance in Two-Dimensional Self-Ordered Superlattices. $J$. Phys. Chem. Lett. 2009, 1 (1), 149-154.

(59) $\%$ Respuesta $(\% R f)=[(f r-f b) / f b] \times 100 \%$. Donde $f b$ es la frecuencia de base inicial, fr es la frecuencia de respuesta.

(60) Dalfovo, M. C.; Salvarezza, R. C.; Ibañez, F. J. Improved Vapor Selectivity and Stability of Localized Surface Plasmon Resonance with a Surfactant-Coated $\mathrm{Au}$ Nanoparticles Film. Anal. Chem. 2012, 84 (11), 4886-4892. 


\section{Capítulo 4}

\section{Estudio del Mecanismo de Sensado de VOCs por GISAXS}

\subsection{Introducción}

La razón de correlacionar los cambios en la distancia entre nanopartículas con la conducción por salto de electrones y los efectos de acoplamiento en chemiresistores y sensores del tipo LSPR, respectivamente, es fundamentalmente importante para una mejor comprensión de algunos fenómenos que ocurren en la nanoescala. En el campo de las aplicaciones, es relevante poder controlar la distancia inter-nanopartículas (interNPd) entre los centros metálicos para producir mejoras en celdas solares, ${ }^{1}$ espectroscopia Raman intensificada por superficies (SERS, de sus siglas del inglés surface enhanced Raman scattering), ${ }^{2}$ y la detección de compuestos orgánicos volátiles (VOCs, volatile organic compounds) o gases con el uso de sensores del tipo chemiresistores, ${ }^{3}$ sólo por mencionar algunas.

En este sentido, tal como fue estudiado a lo largo del Capítulo 3, una película de nanopartículas (NPs) metálicas protegidas con una cubierta orgánica podría ser una plataforma ideal debido a que los centros metálicos proveen la señal analítica mientras que la matriz orgánica actúa como un receptor para los analitos en fase vapor/gas que están ingresando. La presencia de VOCs podría alterar ya sea una o ambas de las principales variables en una película metal-orgánica: la distancia centro-a-centro y/o el dieléctrico del medio circundante (o índice de refracción, IR). En la mayoría de los casos se asume que el primer parámetro mencionado es el que domina el mecanismo de detección, sin embargo nunca se determinó con certeza cuales eran las variables que predominaban.

Es importante mencionar que cuando se diseñan sensores, la sensibilidad en la cual las señales cambian depende del método de transducción elegido (ej.: cambios en la resistencia o cambios en la señal plasmónica). Tal como fue indicado en los Capítulos 
anteriores, un chemiresistor ${ }^{*}$ es un tipo de película sensible que varía exponencialmente su resistividad debido ya sea a cambios en la distancia entre NPs y/o cambios en la energía de activación por el mecanismo de salto de electrones (electron hopping). ${ }^{6-8}$ Por otro lado, los sensores del tipo plasmónicos son linealmente dependientes a los cambios en la banda plasmónica y al IR del medio de acuerdo a la Teoría de Mie. ${ }^{9}$ La dependencia exponencial entre la distancia de los centros metálicos con respecto a la resistencia de las películas explica porque los sensores chemiresistivos han sido extensivamente usados para la detección de VOCs. ${ }^{10-15}$ Sin embargo, si bien es cierto que los chemiresistores son relativamente más sensibles, los mismos presentan la desventaja de ser poco selectivos debido a que los cambios en la resistencia de la película generalmente ocurren en la misma dirección (aumenta o disminuye) independientemente de la naturaleza del analito en fase vapor. ${ }^{3,8,16,17}$

Actualmente, los sensores plasmónicos construidos con películas de NPs recubiertas con material orgánico han ganado un lugar importante en el área de detección de analitos en fase vapor. ${ }^{18-22}$ Nuestro grupo reportó un sensor construido con este tipo de películas, el cual produce distintos desplazamientos en la banda plasmónica (plasmon band) hacia el azul y el rojo en la presencia del vapor no-polar Tolueno (Tol) y del vapor polar Etanol $(\mathrm{EtOH})$, respectivamente, ambos en ensayos del tipo headspace. ${ }^{20 \dagger} \mathrm{El}$ observado desplazamiento a los azules de la banda plasmónica fue

* La conductividad en películas tridimensionales conformadas por nanopartículas protegidas con material orgánico ocurre por un mecanismo de electron hopping, tal como es evidenciado por la siguiente ecuación:

$$
\sigma_{\mathrm{EL}}=\sigma_{0} \exp \left[-\beta_{\mathrm{d}} \delta_{\mathrm{d}}\right] \exp \left[-E_{\mathrm{A}} / R T\right]
$$

donde " $\sigma_{\mathrm{EL}}$ " es la conductividad electrónica $\left(\Omega^{-1} \mathrm{~cm}^{-1}\right)$, “ $\sigma_{0}$ " es una constante pre exponencial, " $\delta_{\mathrm{d}}$ " es la distancia edge-to-edge entre los centros metálicos, " $\beta_{\mathrm{d}}$ " es el coeficiente de electron tunneling $\left(\AA^{-1}\right)$, " $E_{\mathrm{A}}$ " es la energía de activación $\left(\mathrm{kJ} \mathrm{mol}^{-1}\right)$, " $R$ " es la constante de los gases, " $T$ " es la temperatura $(\mathrm{K})$. Notar que la conductividad depende principalmente de dos parámetros: a) la distancia inter-partículas $\left(\delta_{\mathrm{d}}\right)$; y b) el material dieléctrico.

Asimismo, la energía de activación del mencionado mecanismo esta fuertemente ligado al dieléctrico del medio (ej.: en la presencia de un analito dado), lo es ejemplificado en la siguiente ecuación:

$$
E_{\mathrm{A}} \approx \mathrm{e}^{2} / 4 \pi \varepsilon_{\mathrm{r}} \varepsilon_{\mathrm{o}} \mathrm{r},
$$

donde " $\varepsilon_{\mathrm{r}}$ " " " $\varepsilon_{\mathrm{o}}$ " corresponden a las permitividades en el vacío y relativa del medio dieléctrico alrededor de los centros metálicos, respectivamente, y " $\mathrm{r}$ " corresponde al radio del centro metálico (core). Como es claramente evidenciado en ésta ecuación, la constante dieléctrica es inversamente proporcional a la energía de activación, y por ende la constante dieléctrica es directamente proporcional a la conductividad electrónica. Finalmente, valiosa información relacionada a sensores chemiresistivos puede encontrarse en las siguientes referencias. ${ }^{4,5}$

†El término "headspace" se refiere a una metodología simple de generar gases a partir de un compuesto volátil dado. Brevemente, se coloca en un recipiente pequeño el solvente (analito) en estudio y luego de trascurrido un tiempo, parte de las moléculas del mismo van a difundir a la fase gaseosa, formando así el gas en headspace. 
atribuido al hinchamiento de la película (film swelling) ${ }^{20,21}$ producido por una separación de las NPs que predomina al esperado desplazamiento plasmónico a los rojos causado por un incremento en el IR (índice de refracción) que genera el ingreso de Tol al sistema. Asimismo, más tarde el grupo de Scholten et al. ${ }^{21}$ demostró un desplazamiento de la banda plasmónica diferente a los azules en películas de NPs de Au cubiertas con n-octanotiolato en la presencia tanto de vapores de tolueno como de nheptano. ${ }^{21}$ Mientras que los desplazamientos plasmónicos a los azules fueron atribuidos al hinchamiento de la película que contrarrestan el incremento en el IR, el significativo desplazamiento a los rojos observado cuando se expuso el mismo sistema a vapores de $\mathrm{EtOH}^{20}$ fue atribuido a una cooperación entre la compactación de la película (acercamiento de las NPs) y el incremento en el IR. En éste contexto, tanto en nuestro trabajo $^{20}$ como en otras publicaciones,,$^{10,21,23,24}$ ha sido usualmente especulado que un hinchamiento o compactación son los mecanismos predominantes, sin embargo medidas in-situ de los cambios en las inter-NPd cuando son expuestas a vapores tanto polares como no-polares aún permanecen como desafíos para las microscopias actuales. ${ }^{\ddagger}$

Tal como fue mencionado en el Capítulo 2, la dispersión de rayos $\mathrm{X}$ a bajo ángulo con incidencia rasante (por sus siglas del inglés grazing incidence small-angle $X$-ray scattering, GISAXS) es una herramienta fundamental para la caracterización de superficies desde el punto de vista estructural. Algunas de las ventajas de la mencionada técnica incluyen: i) su alta sensibilidad a pequeños cambios que puedan ocurrir en un superficie; ii) es no destructiva; iii) es posible obtener información estadística de una gran fracción de la superficie de la muestra (rangos $\sim 100 \mu \mathrm{m}^{2}$ hasta varios $\mathrm{mm}^{2}$ ); y iv) provee información morfológica de la muestra desde la escala del nanómetro hasta la de los micrómetros; sólo por mencionar algunas. ${ }^{25}$ Asimismo, GISAXS es capaz de brindar información en "tiempo real" tanto de las inter-NPd y como de la estructura de las películas. En una reciente publicación de Goodfellow y Korgel, ${ }^{26}$ en la revista $A C S$ Nano perspective, se enfatizó en la importancia de explorar las fuerzas que controlan tanto el auto-ensamblado, las estructuras supercristalinas como los cambios estructurales en películas de NPs durante procesos de annealing ${ }^{\S}$ con solventes y vapores. En éste sentido, ya sea la auto-organización de las cadenas alquílicas orgánicas o la total restructuración de la película en la presencia de solventes o vapores ocurre gracias a la presencia de cadenas orgánicas que rodean y protegen a los centros

\footnotetext{
* En general, es posible determinar el tamaño y la morfología de películas conformadas por nanopartículas con el uso de microscopías tales como TEM y AFM. Sin embargo, las mencionadas técnicas si bien brindan una excelente resolución, traen aparejada la limitación de que sólo se esta observando una porción pequeña de las muestras, lo cual en la mayoría de los casos no es representativo del sistema en estudio.

$\S$ Particularmente en éste caso, el término "annealing" hace referencia a que el solvente o el vapor se evapora de la estructura de la película de nanopartículas.
} 
metálicos, como fue demostrado por nuestro grupo con experimentos de FT-IR, ${ }^{20}$ los cuales fueron estudiados en el Capítulo 3 de esta Tesis.

En el contexto de lo expuesto, hasta el momento sólo un grupo ha realizado experimentos de evolución GISAXS in-situ para estudiar cambios estructurales en películas de NPs de $\mathrm{Pt}_{2} \mathrm{Cu}_{3}$ cubiertas tanto con ácido oleico como con oleilamina (depositadas por el método de drop-casting) durante el secado de vapores (vapor drying). ${ }^{27}$ Ellos demostraron que la calidad (homogeneidad) de las películas puede ser significativamente mejorada si se controla la cinética de evaporación del hexano (secado de la película) en comparación a otras películas cuya evaporación ocurre de una manera mucho más rápida. En muchos casos, en la literatura se ha reportado que pueden obtenerse películas cristalinas 3D (tridimensionales) después de la evaporación del solvente ${ }^{28}$ como ha sido demostrado por experimentos empleando GISAXS, ${ }^{28-31}$ como por dispersión de rayos-X a bajo ángulo (SAXS, de sus siglas del inglés small angle $X$ ray scattering). ${ }^{30,32} \mathrm{El}$ grupo de Hanrath et al. ${ }^{33}$ observó que la concentración de ligandos también juega un rol fundamental en el orden de las películas. Ellos determinaron que, a medida que la densidad de ligandos decrece, la película se torna más desordenada restructurándose desde una fase cúbica centrada en el cuerpo (bcc, body-centered cubic) a una fase cúbica centrada en la cara (fcc, face-centered cubic). Otras variables tales como la temperatura y la irradiación UV han sido demostrados que decrecen el orden de las películas y la distancia en 3,5 nm en NPs de PdS cubiertas con material orgánico ${ }^{34}$ y NPs de $\mathrm{Pt}_{2} \mathrm{Cu}_{3}$ cubiertas con oleilamina, respectivamente. ${ }^{27}$ Asimismo, Pileni et al. ${ }^{32}$ reportaron cambios reversibles en la inter-NPd con el uso de in-situ SAXRD, de sus siglas del inglés small-angle $X$-ray diffraction. Ellos demostraron que se produce un incremento de $\sim 1,0 \mathrm{~nm}$ en la inter-NPd de $\mathrm{Au} @ \mathrm{SC}_{12}$ MPCs (monolayer-protected clusters de Au protegidos con dodecanotiol) cuando fueron expuestos a una concentración del $75 \%$ de Tol en fase vapor. La correlación de las películas (orden estructural) ha sido usualmente conseguida con MPCs donde las cadenas orgánicas permanecen bien ensambladas rodeando la superficie de los centros metálicos y la distancia entre los mismos es precisamente controlada por la longitud de los ligandos orgánicos.

En el presente trabajo, se demostró por primera vez el mecanismo de sensado de nanopartículas de $\mathrm{Au}$ protegidas tanto con surfactante (SNPs) como con nonanoditiol (NDT) expuestas a concentraciones conocidas de vapores polares y no-polares, a través del uso de GISAXS en tiempo real (real time GISAXS). Con el fin de obtener correlación, un sustrato de Si funcionalizado con APTES fue inmerso en una solución de SNPs (tolueno). Esta metodología experimental mostró correlación a corto alcance y diferentes comportamientos frente a los vapores de tolueno (Tol) y etanol (EtOH), similar a lo recientemente reportado para este sistema empleando sensores plasmónicos. ${ }^{20} \mathrm{Se}$ emplearon técnicas complementarias tales como XANES (X-ray absortion near-edge structure), FT-IR, UV-vis, y voltamperometría cíclica (cyclic 
voltammetry, CV) con motivo de ahondar en la interacción Au-SR. Estos resultados contribuyen a enriquecer aspectos fundamentales del sensado de VOCs tales como: i) el rol de la cubierta orgánica; ii) la deposición y el orden de la película; iii) la distancia inter-nanopartículas; iv) la flexibilidad de la película; y v) la conformación de las cadenas alquílicas alrededor del centro metálico.

\subsection{Experimental}

\subsubsection{Síntesis de las Nanopartículas de Au Protegidas con Surfactante (SNPs)}

Las nanopartículas de Au protegidas con TOABr $(\mathrm{Au} @ \mathrm{TOABr}$, aquí llamadas SNPs) fueron sintetizadas acorde a la reacción bifásica de Brust-Schiffrin pero sin la adición de alcanotioles, como previamente fue reportado. ${ }^{35}$ Más detalles respecto a la mencionada síntesis pueden encontrarse en el Capítulo 2 de la presente Tesis. Las SNPs sintetizadas con el citado protocolo tienen un diámetro de 2,9 $\pm 0,6 \mathrm{~nm}$ por dispersión de rayos-X a bajo ángulo (SAXS). Dicho valor se obtuvo del ajuste de las curvas de las SNPs dispersas en una solución de tolueno (ver Figura 4.1 más adelante).

\subsubsection{Ensamblado de las Películas de Nanopartículas para su Caracterización por GISAXS, XANES y UV-vis}

Las películas de nanopartículas fueron ensambladas utilizando dos metodologías diferentes. Los sustratos de Silicio (100) fueron limpiados con solución piraña, lavados con agua Milli-Q y etanol, y finalmente se secaron con $\mathrm{N}_{2}$. Esos sustratos fueron luego funcionalizados con 3-aminopropiltrietoxisilano (APTES) colocando las muestras en una solución conteniendo $10 \mathrm{~mL}$ de etanol, $100 \mu \mathrm{L}$ de APTES, y 2-3 gotas de agua Milli-Q. La solución fue calentada a $70{ }^{\circ} \mathrm{C}$ por 10 minutos y luego los sustratos fueron incubados por 1 hora a temperatura ambiente. Los sustratos de Si funcionalizados fueron sonicados en etanol y secados con $\mathrm{N}_{2}$.

La deposición de las películas fue llevada a cabo utilizando dos metodologías: a) la primera consiste en el goteo (drop-casting) de $30 \mu \mathrm{L}$ de una solución de NPs $(1,1$ $\mathrm{mg} / \mathrm{mL}$ ) sobre un sustrato de Si funcionalizado con APTES (Si-APTES); y b) la segunda consiste en la inmersión de un sustrato de Si-APTES dentro de una solución fresca de SNPs por 37 horas. La última metodología exhibe correlación por GISAXS, lo cual permite que pueda emplearse dicho sistema en los siguientes análisis (cinéticas en tiempo real).

\subsubsection{Tratamiento de las Películas con Tioles y Ditioles}


Con motivo de tener películas conformadas por NPs en las cuales se restrinja el movimiento inter-nanopartículas y al mismo tiempo posean una cubierta orgánica, se utilizaron películas tratadas con alcanotioles ("as-treated") para todas las técnicas de caracterización mostradas a lo largo de éste Capítulo. Particularmente, se utilizaron dos metodologías para realizar el intercambio de ligandos, como se describe más abajo:

- Intercambio de ligandos en fase líquida: una película de NPs nombrada como "as-formed" fue sometida a un intercambio de ligandos en fase líquida (liquidphase place-exchange) por inmersión dentro de una solución de alcanotioles en una concentración de $20 \mathrm{mM}$ en hexano por 2 horas (1,9-nonanoditiol (NDT) y 1-nonanotiol (NT)) excepto para las películas utilizadas en los experimentos de FT-IR.

- Intercambio de ligandos en fase vapor: el intercambio de ligandos en fase vapor (vapor-phase place-exchange) fue realizado colocando $1 \mathrm{~mL}$ del alcanotiol en estudio (NDT o NT) en un pesa filtro junto con la película de SNPs por 2 horas, evitando que el líquido entre en contacto directo con la muestra. Luego, las muestras fueron copiosamente lavadas con hexano y secadas con $\mathrm{N}_{2}$.

\subsubsection{Sensado de VOCs Utilizando GISAXS in-situ}

Los experimentos de GISAXS fueron llevados a cabo en la línea de difracción de rayos-X XRD2 del Laboratorio Nacional de Luz Sincrotrón (LNLS), Campinas, Brasil. La longitud de onda $(\lambda)$ y el ángulo de incidencia $\left(\alpha_{i}\right)$ escogidos fueron 0,1550 $\mathrm{nm}$ y $0,3^{\circ}$, respectivamente. Los fotones dispersados fueron registrados (100 segundos/frame) usando un detector Pilatus 2D (bidimensional) sensible a la posición. Las películas de nanopartículas fueron colocadas en una cámara de gases ad-hoc y expuestas a flujos alternantes de $\mathrm{N}_{2}$ puro, y diferentes concentraciones de Tol y EtOH fueron obtenidas mezclando el $\mathrm{N}_{2}$ con los vapores ya mencionados. Las concentraciones variadas de vapores fueron obtenidas con el uso de dos caudalímetros electrónicos (mass flow controllers, MFCs) modelo SLA5850, Brooks Instruments Secondary Electronics, con un rango de flujo entre 50 a $500 \mathrm{~mL} / \mathrm{min}$. Los MFCs fueron colocados entre el cilindro con $\mathrm{N}_{2}$ y la cámara de gases (ver la Figura 4.2 más adelante, en donde se muestra un esquema de la disposición experimental empleada). Una línea contuvo el $\mathrm{N}_{2}$ puro, mientras que en la otra línea se burbujeó el solvente de interés. Las películas de SNPs as-formed fueron expuestas a concentraciones de 20, 40, 80 y $100 \%$ de los vapores en estudio, empleando un flujo total de $50 \mathrm{~mL} / \mathrm{min}$. Los vapores saturados de Tol y EtOH fueron corridos en los siguientes flujos totales: bajo $(50 \mathrm{~mL} / \mathrm{min})$; mediobajo $(100 \mathrm{~mL} / \mathrm{min})$, medio $(200 \mathrm{~mL} / \mathrm{min})$; y alto $(500 \mathrm{~mL} / \mathrm{min})$. Cada paso corresponde al promedio de 5 frames medidos, escogidos antes de que el ingreso del vapor sea cerrado ("off"). 


\subsubsection{Otras Técnicas de Caracterización}

\subsubsection{SAXS}

Los experimentos de dispersión de rayos-X a bajo ángulo (small-angle X-ray scattering) fueron llevados a cabo en la línea SAXS-1 del LNLS, Campinas, Brasil. La intensidad de las curvas de SAXS fue determinada usando un detector Pilatus 2D como función del módulo del vector de dispersión (scattering) $q=4 \pi \sin \theta / \lambda$, siendo $\theta$ la mitad del ángulo de dispersión y la longitud de onda $(\lambda)$ de los rayos-X empleada fue $\lambda=1,61$ $\AA$. Las curvas de SAXS fueron normalizadas a la intensidad del haz de rayos-X directo para compensar el continuo decrecimiento en la emisión de la fuente sincrotrón. Las películas en estado sólido en estudio fueron colocadas dentro de una celda con dos ventanas de mica finas y paralelas entre si, lo cual permitió llevar a cabo las medidas de SAXS en modo de transmisión tanto en aire como en solventes (EtOH y Tol).

Con el fin de reproducir las curvas de SAXS obtenidas experimentalmente, se propuso un simple modelo consistiendo de una solución diluida de objetos esféricos. ${ }^{36}$ Una pequeña dispersión en el radio de las NPs (descripto por una función Log Normal) es permitido en el modelo y es cuantificado por la varianza en la distribución $(\sigma)$ y el diámetro promedio (D) de las mismas. El ajuste fue llevado a cabo utilizando el programa SASfit.

\subsubsection{XANES}

La espectroscopia de absorción de rayos X (X-ray absorption near-edge structure) fue realizada en la línea SXS del LNLS, Campinas, Brasil. Los espectros de XANES fueron obtenidos en el borde K del S (2472 eV). Los detalles del arreglo experimental empleado en la línea SXS pueden ser encontrados en la publicación de Tolentino et $a l .^{37}$ El espectro de absorción de rayos-X fue registrado en modo de fluorescencia siguiendo las líneas de emisión de fluorescencia del Sulfuro $K \alpha_{1}(2309,5$ eV) y $\mathrm{Ka}_{2}(2308,4 \mathrm{eV})$ en función de la energía de los fotones incidentes. A todos los espectros de XANES se les sustrajo el background y se normalizaron a la intensidad de la región post-borde.

\subsubsection{FT-IR}

Los experimentos de FT-IR fueron llevados a cabo en un equipo Nicolet (380) USA, en modo transmisión. Los discos de $\mathrm{KBr}$ fueron cuidadosamente lavados con tolueno y secados con $\mathrm{N}_{2}$. Luego, se depositaron sobre los mismos $60 \mu \mathrm{L}$ de una solución de NPs $(1,1 \mathrm{mg} / \mathrm{mL})$ por la metodología de drop-casting. Las películas así obtenidas se nombraron como "as-deposited".

Para las muestras tratadas con alcanotioles (NDT y NT) en fase vapor, las películas “as-deposited" fueron expuestas a los mencionados alcanotioles por 2 horas, $\mathrm{y}$ 
luego se lavaron copiosamente con hexano (a menos que sea indicado) y se secaron con $\mathrm{N}_{2}$. Cada espectro fue normalizado respecto a la intensidad del pico umbrella (U) en $\sim 1377 \mathrm{~cm}^{-1}$, el cual es usado como un yardstick interno. ${ }^{38}$

\subsubsection{UV-vis}

Los experimentos de UV-vis fueron llevados a cabo en un espectrofotómetro Perkin-Elmer Lambda 35 en un rango de longitud de onda desde 300 a $900 \mathrm{~nm}$. Las películas analizadas por UV-vis en aire seco fueron conseguidas colocando silica gel en el gabinete del mencionado equipo, lo cual permite absorber parte de la humedad tanto del sistema como del ambiente en el cual se realizaron las medidas. Los sustratos de vidrio tratados de la misma manera que los sustratos preparados para GISAXS.

\subsection{Resultados}

\subsubsection{Ensamblado de las Películas y Correlación}

Con el fin de determinar el tamaño de las nanopartículas empleadas en éste trabajo, se realizaron experimentos empleando SAXS. Brevemente, las NPs de $\mathrm{Au}$ protegidas con TOABr ( $\mathrm{Au} @ \mathrm{TOABr}$, aquí llamadas SNPs) se dispersaron en tolueno (Tol) y se analizaron mediante SAXS. Luego del ajuste de las curvas obtenidas, las NPs presentaron un diámetro de $2,9 \pm 0,6 \mathrm{~nm}$, y no mostraron correlación espacial, ${ }^{* *}$ tal como puede verse en la Figura 4.1. Es importante mencionar que, la falta de correlación como es esperado para NPs diluidas en solución, implica que la mayoría de las SNPs están erráticamente separadas y/o distribuidas.

\footnotetext{
** El término "correlación" se refiere a la probabilidad de encontrar una distribución espacial de objetos en un volumen dado. La distancia entre los objetos (vecino-a-vecino) es definida como "d". Como resultado de lo expuesto, a medida que incrementa la cantidad de objetos separados por una distancia "d", se produce un incremento en la intensidad del vector de dispersión q (scattering), produciendo así un incremento en la correlación del sistema.
} 


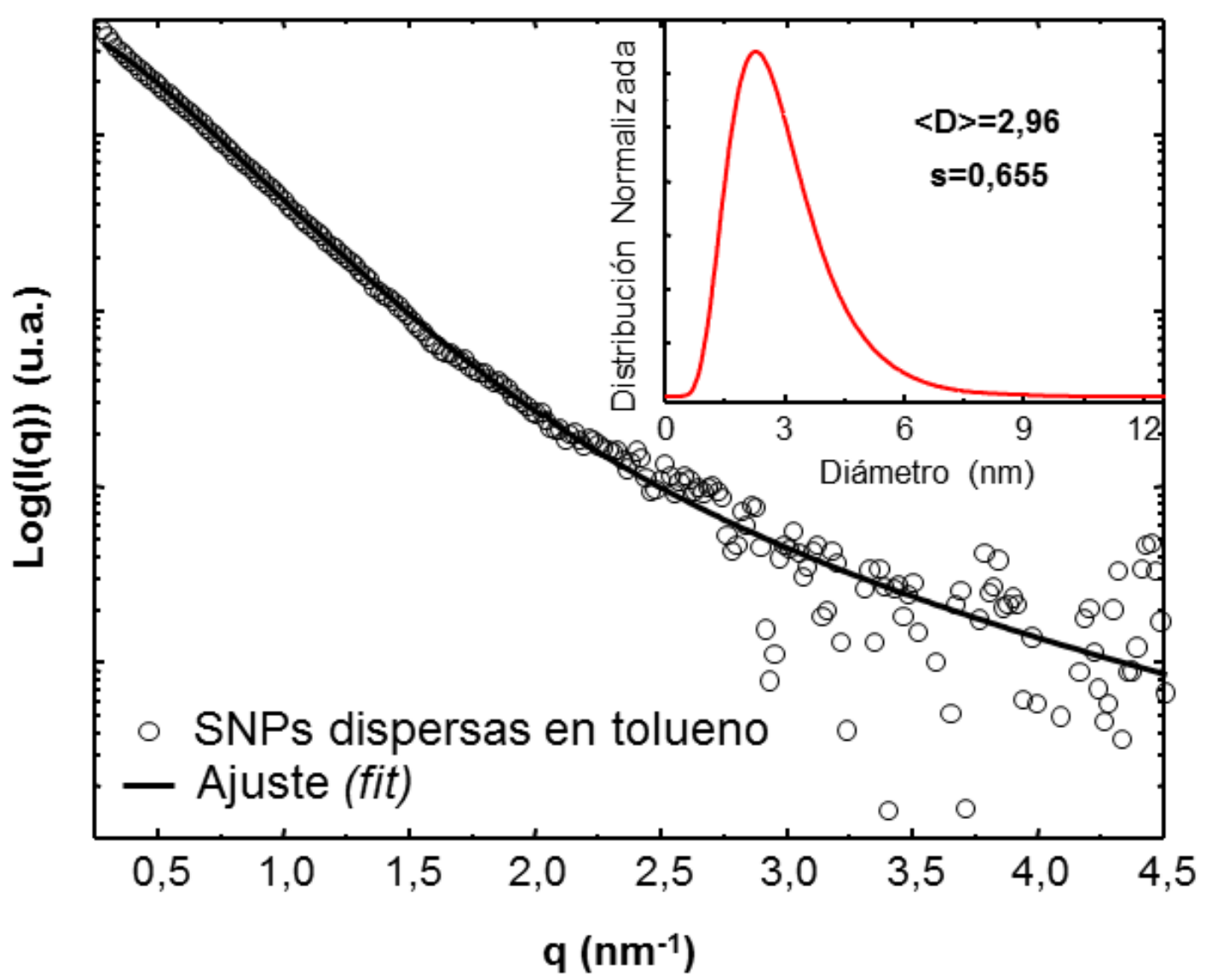

Figura 4.1 Distribución SAXS (recuadro) y perfil sin correlación obtenido de las NPs de Au protegidas con surfactante (surfactant-coated NPs, SNPs) suspendidas en una solución de tolueno. 


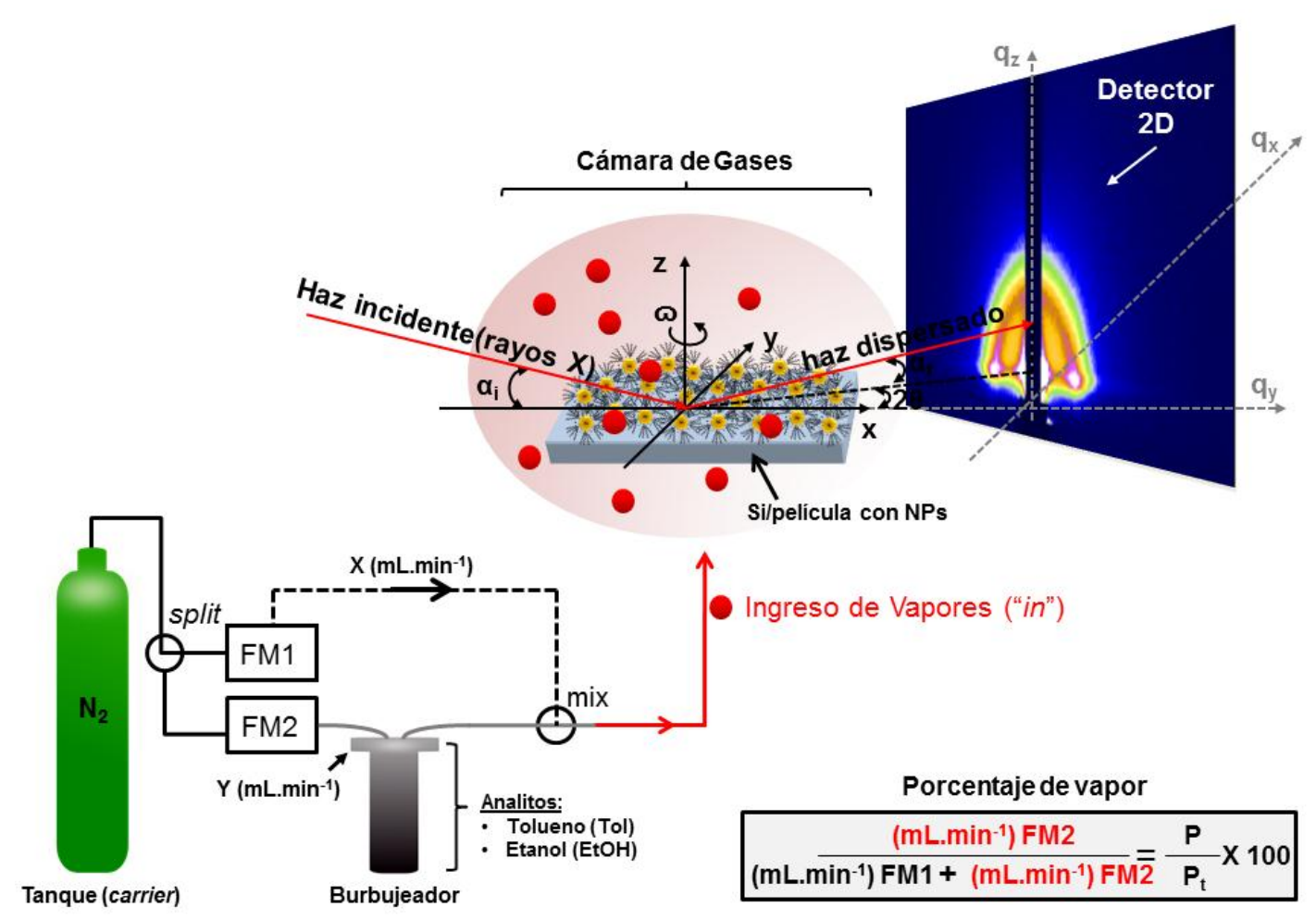

Figura 4.2 Esquema del arreglo experimental empleado para los ensayos de GISAXS in-situ, llevados a cabo sobre una película de SNPs expuesta a diferentes concentraciones de vapores (EtOH y Tol), lo cuales fueron previamente mezclados con $\mathrm{N}_{2}$ (gas de transporte, carrier). La concentración del vapor en la mezcla es controlado por un caudalímetro electrónico (flow meter, FM) y su concentración en porcentaje de vapor fue calculado por la ecuación aquí mostrada, como es indicado. 
Con el fin de obtener correlación y luego poder realizar experimentos de cinética (sensing) por GISAXS, las SNPs fueron ensambladas como películas en estado sólido por dos metodologías (deposición por drop-casting y por inmersión). La Figura 4.3 A, B muestra los patrones de GISAXS, los perfiles de GISAXS (cortes a lo largo $q_{z}$ ), y unos esquemas representando el estado de las películas obtenidas por ambas metodologías de deposición. La correlación en GISAXS permite explorar tanto en las distancias inter-nanopartículas (inter-NPd) como en la organización total de la película. El fundamento de la correlación se basa en que exista un ordenamiento espacial de las NPs, que va a poder ser explorado por ésta técnica tanto a lo largo del eje paralelo $\left(q_{y}\right)$ como del eje perpendicular $\left(q_{z}\right)$ respecto a la superficie del sustrato.

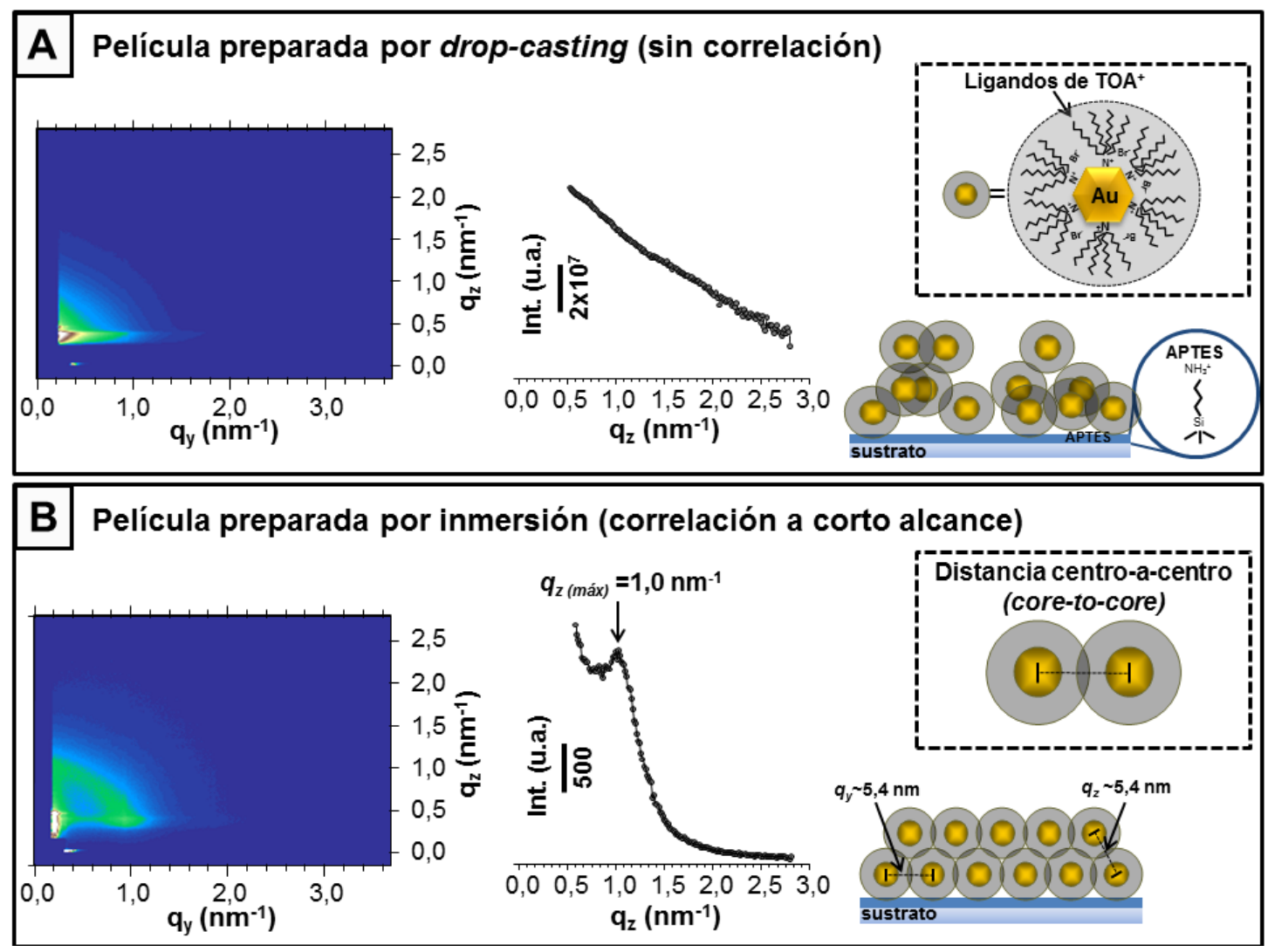

Figura 4.3 Patrón GISAXS y perfiles de intensidad (cortes a lo largo de $q_{z}$ ) de las NPs de $\mathrm{Au}$ cubiertas con surfactante (SNPs) sobre sustratos de $\mathrm{Si}$ funcionalizados con APTES, preparados por drop-coasting (A) y por inmersión (B) junto con los esquemas representando los resultados obtenidos de ambas metodologías de ensamblado. 
Es particularmente llamativo que, la metodología de deposición por drop-casting no exhibe correlación espacial entre las SNPs (ver Figura 4.3A). Por otro lado, la Figura 4.3B exhibe un pico de correlación, el cual es evidenciado por un estrecho halo angular en su correspondiente patrón de GISAXS. La ausencia de correlación podría estar asociada con algún grado de desorden causado por la presencia de una gran cantidad de detergente y por el método de deposición elegido. En éste sentido, una significativa segregación de fases o límites en las películas de SNPs obtenidas por drop-casting ha sido observado por microscopia $\mathrm{SEM}^{8}$ y luego confirmado por experimentos de FT$\mathrm{IR}^{20}{ }^{20}$ las cuales exhiben estructuras tipo micelas y una significativa cantidad de defectos gauche en las cadenas alquílicas, respectivamente, en comparación con los alcanotioles bien organizados y fuertemente enlazados por uniones químicas a la superficie de los centros metálicos (ej., $\left.\mathrm{Au} @ \mathrm{SC}_{6} \mathrm{MPCs}\right)$.

Asimismo, la falta de correlación podría ser atribuida a la cinética de formación de la película (ritmo de evaporación del solvente) ${ }^{27}$ Mientras que las películas obtenidas por drop-casting fueron preparadas en pocos minutos, los sustratos de $\mathrm{Si}$ /APTES se sumergieron en la solución de SNPs en tolueno por $\sim 37$ horas. Consistente con los datos obtenidos por GISAXS, las nanopartículas desordenadas (pobre correlación) han sido también observadas en experimentos de SAXS empleando películas de SNPs preparadas por drop-casting, como es evidenciado en la Figura 4.4. Tal como puede observarse, la curva de SAXS obtenida es ancha y el vector de dispersión $(q)$ está poco definido, lo cual torna difícil poder estimar la distancia entre las SNPs (inter-NPd). Estos resultados se oponen a aquellos reportados en la literatura para películas de NPs preparadas por drop-casting. Por ejemplo, películas de $\mathrm{C} 12 \mathrm{~S} \mathrm{Ag}^{30}$ y $\mathrm{Au} \mathrm{MPCs}^{39}$ mostraron una estructura cristalina en cuanto el solvente se evaporó de las películas como fue determinado por experimentos de SAXS y SAXRD (small-angle $X$ ray diffraction), respectivamente. Existen algunas discrepancias respecto a las técnicas empleadas para medir el tamaño de las NPs y las distancias entre las mismas. Como un ejemplo de ello, se pueden mencionar los experimentos de SAXS y de microscopia TEM realizados sobre películas de $\mathrm{C} 12 \mathrm{~S}$ Ag MPCs sobre mica preparadas por dropcasting, los cuales exhibieron $\sim 2,1 \mathrm{~nm}$ y $1,6 \mathrm{~nm}$ de distancia de borde-a-borde (edge-toedge), respectivamente. ${ }^{30}$ Del mismo modo, en nuestros resultados obtenidos tanto por SAXS (Figura 4.4) como por $\mathrm{TEM}^{20}$ de las películas de SNPs sobre sustratos de mica y grillas de $\mathrm{Cu}$, respectivamente, también se observaron con la última técnica relativamente menores distancias inter-NPd. Por consiguiente, existen unas pocas variables que podrían afectar la inter-NPd y la estructura de la película, ${ }^{31}$ y éstas podrían incluir: i) la naturaleza de los ligandos orgánicos; ii) el tipo de sustrato; iii) el método de deposición; y iv) la técnica de caracterización empleada en esos experimentos. ${ }^{29,34,40,41}$ 


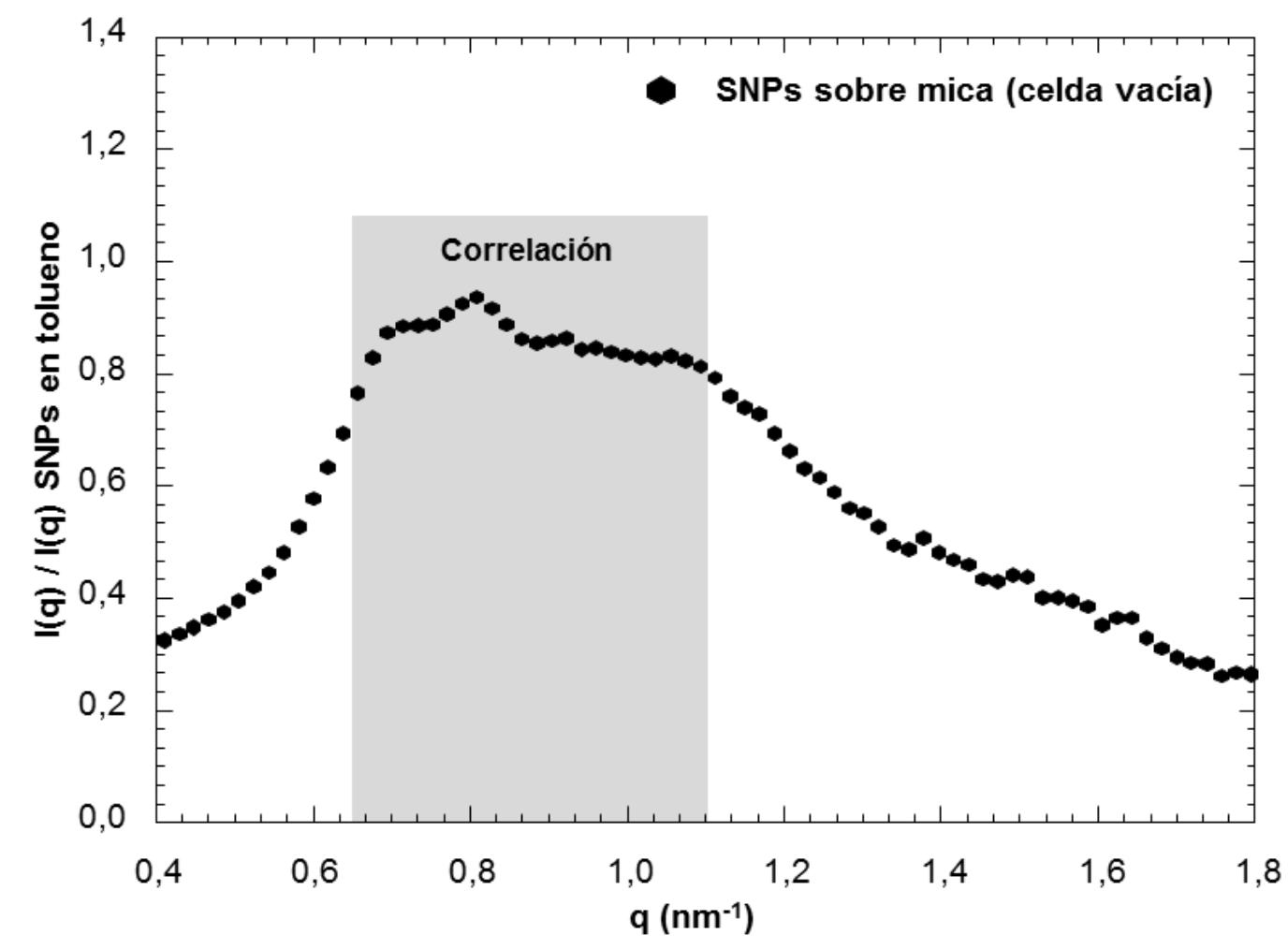

Figura 4.4 Gráfico de SAXS obtenido de las SNPs ensambladas por dropcasting sobre un disco de mica.

Sin embargo, si bien las películas ensambladas por inmersión mostraron correlación a corto alcance, el mismo fue suficiente para continuar con los análisis de sensado de VOCs por GISAXS.

\subsubsection{SAXS en Sistemas Isotrópicos Sin Correlación: Ley de Guinier}

En los casos en los cuales el sistema en estudio se encuentre lo suficientemente diluido y los nano-objetos no presenten correlación, la dispersión del mismo no va a ser influida por los nano-objetos vecinos (sin interferencias). Dadas estas condiciones y considerando un sistema ideal en el cual todos los objetos son idénticos y se encuentran azarosamente orientados, la intensidad total de dispersión del sistema es expresada como: 


$$
I(q)=N . I_{1}(q)
$$

siendo, $I(q)$ la intensidad total de dispersión; y $N$ denota la cantidad (concentración) del objeto en estudio. ${ }^{36}$

\subsubsection{Distancia Inter-Nanopartículas en Nanopartículas con Correlación}

Diferente es el comportamiento de aquellos sistemas en los cuales los nanoobjetos que lo componen estén ya sea concentrados u embebidos en una matriz. En estos casos el proceso de dispersión de rayos-X a bajo ángulo va a ser influido por las interferencias causadas por los nano-objetos vecinos. Un caso particular se da cuando los nano-objetos presentan correlación espacial. La correlación se refiere a la probabilidad de encontrar entidades (ej., NPs) con una distribución espacial en un cierto volumen. Para los casos en los cuales el sistema presente correlación, la ecuación (4.1) no va a poder ser empleada. Luego, para sistemas con correlación, la $I(q)$ puede expresarse con la siguiente ecuación:

$$
I(q)=N . I_{1}(q) . S(q)
$$

Donde $S(q)$ es una función de estructura la cual tiene en cuenta los efectos de la correlación espacial. Existe una función de estructura semi-empírica que describe la correlación espacial de objetos coloidales esféricos embebidos en una matriz, la cual es derivada de la aproximación de Born-Green y fue descripta por Guinier. ${ }^{42}$ Como consecuencia de lo expresado anteriormente, es posible estimar el promedio de distancias $(d)$ centro-a-centro (core-to-core) entre los objetos usando la siguiente expresión:

$$
d=5,6 / q_{\operatorname{máx}}
$$

$q_{\text {máx }}$ corresponde al valor de $q$ en su máximo de intensidad. Utilizando esta aproximación, se calculó que para el sistema en estudio el promedio de separación centro-a-centro (core-to-core) entre las SNPs a lo largo de ambos ejes $\left(q_{z}\right.$ and $\left.q_{y}\right)$ es de $\sim 5,4 \mathrm{~nm}$. Considerando que el radio de una nanopartícula es de $\sim 1,5 \mathrm{~nm}$, de acuerdo a los datos de SAXS, y empleando el valor de separación de centro-a-centro obtenido por 
GISAXS, luego la inter-NPd de borde-a-borde (edge-to-edge) podría ser de $2,4 \mathrm{~nm}$. Esto sugiere que cada centro (core) de $\mathrm{Au}$ está rodeado por un poco más que 1 monocapa de $\mathrm{TOA}^{+}$considerando que la configuración de las cadenas alquílicas es completamente extendida en modo all-trans $\left(0,11-0,13 \mathrm{~nm} \text { entre } \operatorname{los} \mathrm{CH}_{2}\right)^{43}$, y por ende cada cadena alquílica de $\mathrm{C}_{8}$ tendría una longitud de $\sim 1,0 \mathrm{~nm}$. Sin embargo, esta es una estimación exigua, ya que las cadenas de $\mathrm{TOA}^{+}$están abiertas y no se encuentran bien empaquetadas como en las MPCs.

Asimismo, en experimentos empleando SAXRD (small-angle X-ray diffraction) sobre Au MPCs de varios tamaños y diferentes longitudes de cadenas alquílicas, se demostró que la separación de borde-a-borde es de $\sim 1,7 \mathrm{~nm}$ para una película en estado sólido de $\mathrm{Au} @ \mathrm{SC}_{10}$ (1-decanotiol) MPCs. ${ }^{39}$ Siendo ésta una distancia más corta $(\sim 1,7$ $\mathrm{nm})$ que la suma de dos cadenas de $\mathrm{SC}_{10}(\sim 2,0 \mathrm{~nm})$ permitiendo así inferir en que existe algún grado de interdigitación entre las cadenas alquílicas. ${ }^{44}$ Particularmente, la distancia entre las SNPs excede la longitud de dos cadenas de surfactante $(\sim 2,4 \mathrm{~nm})$, sugiriendo de ésta manera la presencia de una tercera cadena de $\mathrm{TOA}^{+}$. Esta configuración se ajusta bien sólo si existe algún grado de interdigitación entre las tres cadenas de $\mathrm{TOA}^{+}$.

\subsubsection{Cambios en las Distancias entre las Nanopartículas y Estructura de la Película en la Presencia de VOCs}

La Figura 4.5A muestra los gráficos las cinéticas (evoluciones) de GISAXS insitu correspondientes a los cortes realizados a lo largo del eje-z (perpendicular a la muestra/sustrato) de una película de SNPs "as-formed" expuesta a $\mathrm{N}_{2}$ y a concentraciones crecientes de tolueno (Tol) y etanol (EtOH), como es indicado. La Figura 4.5B muestra un gráfico de un promedio de las inter-NPd centro-a-centro versus un promedio de la intensidad máxima $\left(q_{\text {máx }}\right)$ junto con la desviación estándar obtenida de cada paso, como fue detallado en la sección experimental. En la Figura 4.2, como fue mencionado anteriormente, se muestra un esquema del arreglo experimental usado en los experimentos de sensado de VOCs. Ambos, la posición del pico y la intensidad del mismo aportan información cuantitativa y cualitativa de las inter-NPd y la estructura de la película, respectivamente. Resulta interesante que, los datos de la evolución GISAXS denotan que la película de SNPs presenta un comportamiento diferente cuando es expuesta a vapores no-polares y polares. El incremento en la concentración de vapor de Tol causa un incremento tanto en las distancias entre las SNPs y como en la intensidad del vector de dispersión $\left(q_{\text {máx }}\right)$. Por otro lado, cuando la misma película fue expuesta al vapor de EtOH, la misma no es capaz de volver a su estado estructural inicial y las interNPd no fueron afectadas notoriamente.

En este contexto, de acuerdo a Guinier ${ }^{45}$ y asumiendo una película compuesta de NPs esféricas con correlación espacial, dos variables pueden incrementar la intensidad 
del $q_{\text {máx }}:$ a) un incremento en el factor de empaquetamiento (cuando el vapor de $q$ permanece fijo); y b) un incremento en las distancia entre las NPs. Particularmente, nuestros resultados experimentales mostraron solo un aumento del $\sim 0,4 \mathrm{~nm}$ en la separación entre las SNPs y un gran incremento de $\sim 30 \%$ en la intensidad del $q_{\text {máx }}$, cuando la película se expuso a un $80 \%$ de Tol en fase vapor. Esto sugiere que el incremento en la intensidad podría estar más asociado con un incremento en la densidad de empaquetamiento (packing factor, $k$ ) que con un incremento en las inter-NPd. ${ }^{36}$ Estos resultados de alguna manera se oponen al comportamiento observado para las NPs de $\mathrm{Pt}_{2} \mathrm{Cu}_{3}$ protegidas con una cubierta orgánica, ${ }^{27}$ las cuales cuando son expuestas a hexano en fase vapor la intensidad del $q_{\text {máx }}$ decrece (se torna más ancho) y retorna a su posición inicial una vez que todo el vapor se evaporó del sistema. En conclusión, nuestro sistema en estudio cambia desde una estructura con correlación a una con mayor correlación (más ordenada) tan pronto como el vapor de Tol se particiona en la película. Es importante mencionar que solo un $\sim 0,4 \mathrm{~nm}$ de incremento en la inter-NPd a altas concentraciones de Tol es un resultado intrigante, ya que por ejemplo Wan et al. ${ }^{39}$ mostraron un incremento 3 veces $(3 \mathrm{x})$ mayor, correspondiente a $\sim 1,5 \mathrm{~nm}$, en la separación de borde-a-borde para una película de $\mathrm{Au} @ \mathrm{SC}_{12} \mathrm{MPCs}$ expuesta a similares concentraciones de vapor de Tol (75\%). Una vez más, diferencias notables son encontradas entre las películas compuestas de NPs de Au protegidas con surfactante en comparación al mismo centro metálico pero protegidas con monocapas orgánicas. Las NPs protegidas con surfactante "as-formed" inicialmente exhibieron pobre correlación, la cual fue mejorada a medida que el Tol comenzó a interactuar con este sistema. En la ausencia de Tol $\left(100 \% \mathrm{~N}_{2}\right)$ la película lentamente se re-estructura y las SNPs tienden a volver a sus posiciones iniciales.

Un paradigma diferente fue observado cuando la película se expuso a EtOH. Primeramente, es casi imperceptible el cambio en la inter-NPd entre el estado inicial en una atmósfera de $\mathrm{N}_{2}$ al 100\% (antes de Tol, paso 9) y la película a altas concentraciones de vapor de EtOH (pasos 13-16) considerando que los cambios caen dentro de la desviación estándar. Segundo, hay una pequeña contracción entre las SNPs $(\sim 0,1-0,2$ $\mathrm{nm}$ ) a vapor de EtOH saturado respecto al estado anterior al ingreso de $\mathrm{EtOH}$ (paso 9). Es importante mencionar que estos datos corresponden a una misma película que fue expuesta a alternantes ciclos de $\mathrm{N}_{2}$, Tol, y EtOH. Finalmente, si se comparan el paso 1 con el paso 17 , la distancia ente las SNPs $\left(q_{z}\right)$ y la intensidad $\left(q_{z, \text { máx }}\right)$ nunca retornan a sus posiciones iniciales, indicando la irreversibilidad de la película. El aparente decrecimiento en la intensidad de $q_{z}$ (ver la Tabla 4.1) podría estar asociado con la perdida de correlación entre las SNPs dentro de la película. Si bien no fue discutido por Fang et al., ${ }^{27}$ en el mencionado trabajo hay un notable tanto ensanchamiento como decrecimiento en la intensidad del pico durante la exposición a vapores, lo cual corresponde a un estado donde la película está perdiendo un poco de correlación. 


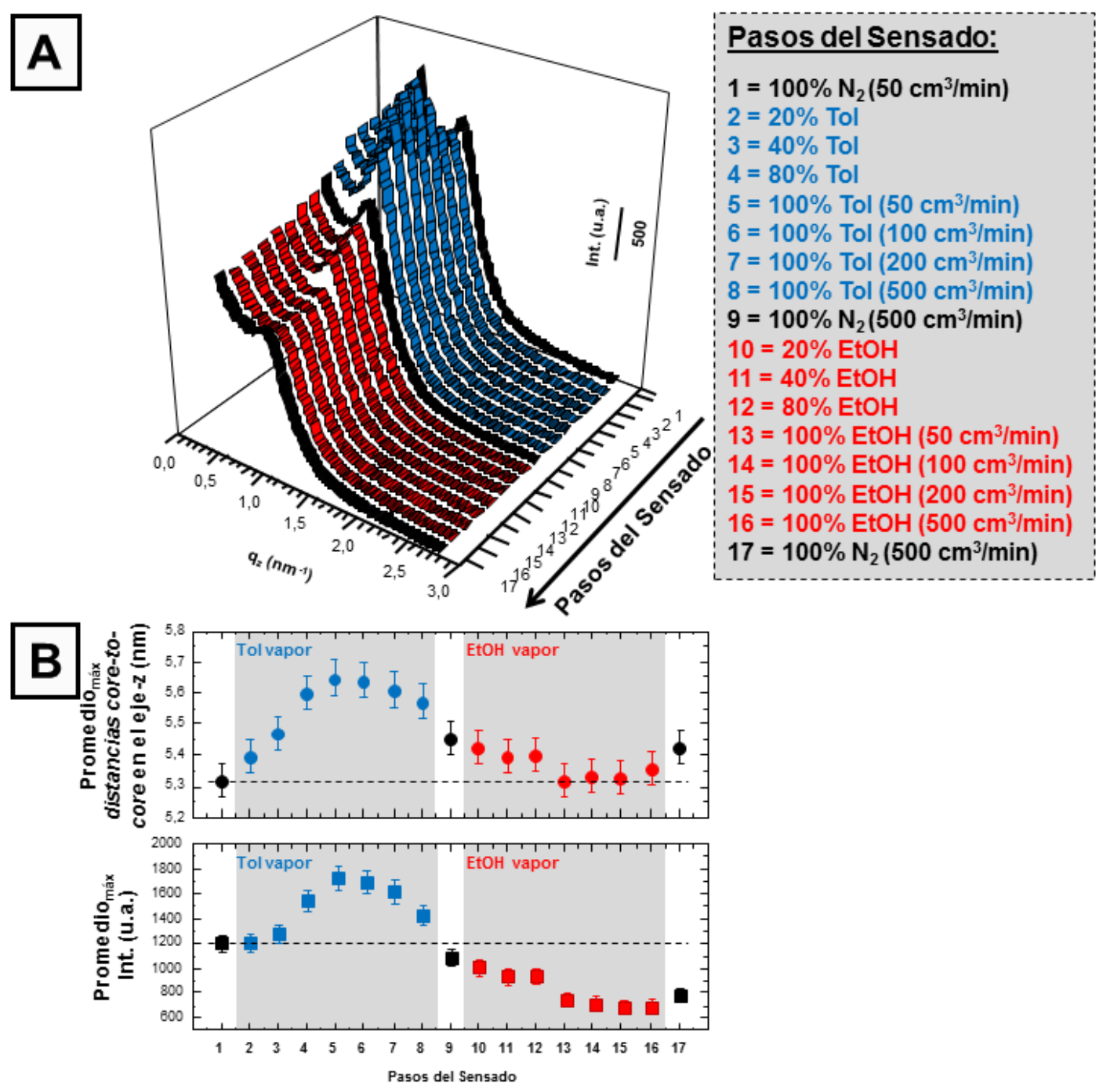

Figura 4.5 GISAXS in-situ ( $q_{z}$ versus intensidad) llevado a cabo sobre una película selecta de SNPs "as-formed" sujeta a concentraciones crecientes de Tol y EtOH como es indicado en cada paso (A). El gráfico inferior muestra el promedio de los máximos (Prom.máx) de intensidad y las distancias de core-to-core a lo largo del eje-z (derivado desde los valores de $q_{z}$ ) de los cambios observados en cada paso, como es indicado en (B). 

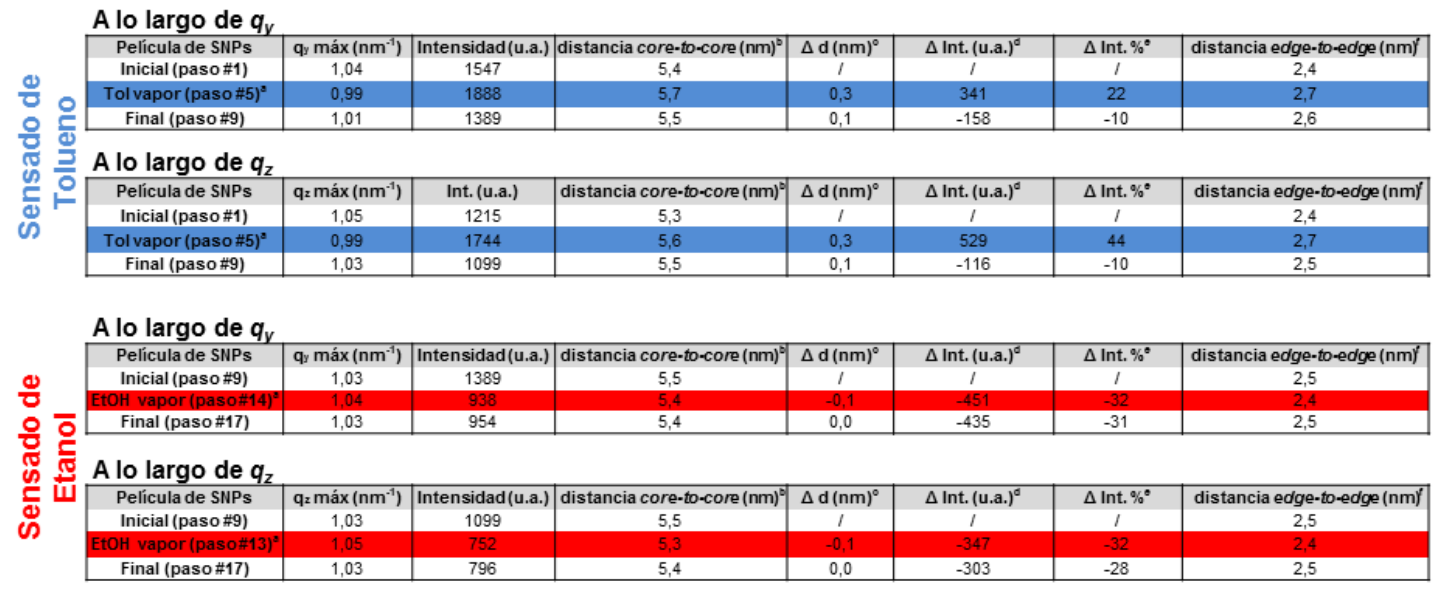

Tabla 4.1 Datos obtenidos por GISAXS correspondientes a una película de SNPs asformed durante el sensado de Tolueno (Tol) y Etanol $(\mathrm{EtOH})$. Ver las Figuras 4.5 y 4.6 para comparar los comportamientos entre los vectores de dispersión $q_{z}$ y $q_{y}$, los que corresponden a los ejes $\mathrm{z}$ e y de la película, respectivamente. ${ }^{\mathrm{a}}$ Corresponde al máximo cambio en $q$ observado durante el sensado de vapores. ${ }^{\mathrm{b}}$ Corresponde a la distancia centro-a-centro (core-to-core) entre las nanopartículas usando la ecuación \#3. ${ }^{c}$ Diferencia en la distancia entre este estadio con respecto a el estadio inicial. ${ }^{d}$ Diferencia en la intensidad entre este estadio con respecto al estadio inicial. ${ }^{\text {e }}$ Porcentaje de cambio en la intensidad en este estadio con respecto a la intensidad del estadio inicial. ${ }^{\mathrm{f}} \mathrm{La}$ distancia borde-a-borde (edge-to-edge) fue calculada de acuerdo al radio de una SNP $(\sim 1,5 \mathrm{~nm})$, el cual fue obtenido del ajuste de los datos obtenidos por SAXS (ver Figura 4.1).

En resumen, el decrecimiento en la intensidad junto con el ensanchamiento del pico es consistente con una disminución en la densidad de empaquetamiento $(k)$, y como consecuencia de ello, decrece la correlación de las SNPs. Por otro lado, la irreversibilidad del comportamiento de la película podría estar asociada a fuerzas moleculares persistentes entre las cadenas alquílicas ${ }^{38}$ y/o a potenciales enlaces por puente de $\mathrm{H}$ entre los centros metálicos. La Figura 4.6 muestra los gráficos de las cinéticas (evoluciones) de GISAXS in-situ correspondientes a los cortes realizados a lo largo del eje-y (paralelo a la muestra/sustrato), mostrando un comportamiento de sensado similar frente a los vapores de Tol y EtOH. La Tabla 4.1 resume todos los resultados obtenidos de la muestra "as-formed" mostrada en las Figuras 4.5 y 4.6. Así mimo, los experimentos de SAXS llevados a cabo sobre películas de SNPs preparadas por drop-casting, que fueron expuestas a los solventes de Tol y EtOH exhiben comportamientos cualitativamente similares a los obtenidos por GISAXS, como es demostrado en la Figura 4.7. 


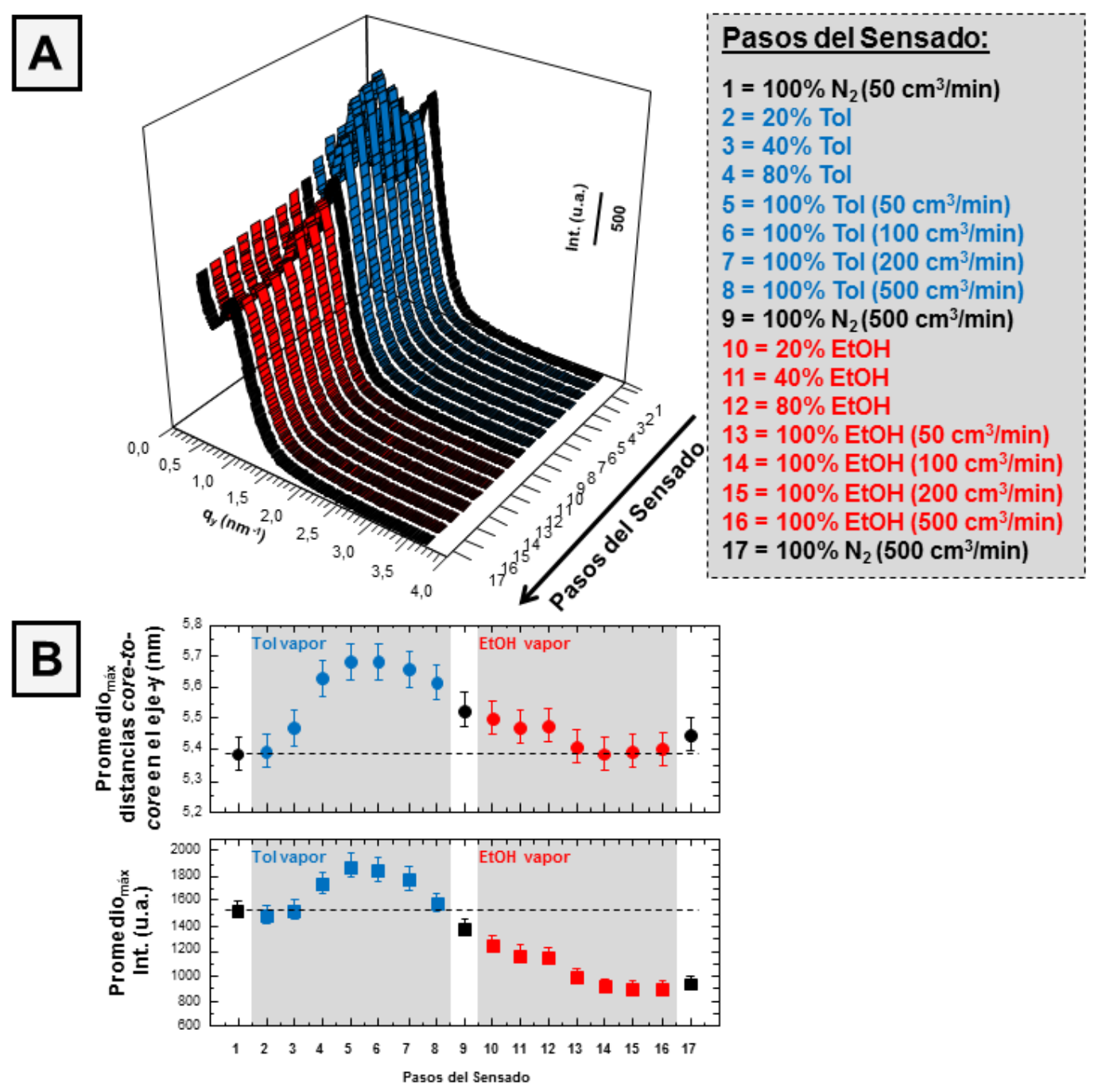

Figura 4.6 GISAXS in-situ ( $q_{y}$ versus intensidad) llevado a cabo sobre una película selecta de SNPs "as-formed" sujeta a concentraciones crecientes de Tol y EtOH como es indicado en cada paso (A). El gráfico inferior muestra el promedio de los máximos (Prom.máx) de intensidad y las distancias centro-a-centro (core-to-core) a lo largo del eje-y (derivado desde los valores de $q_{y}$ ) de los cambios observados en cada paso, como es indicado (B). 


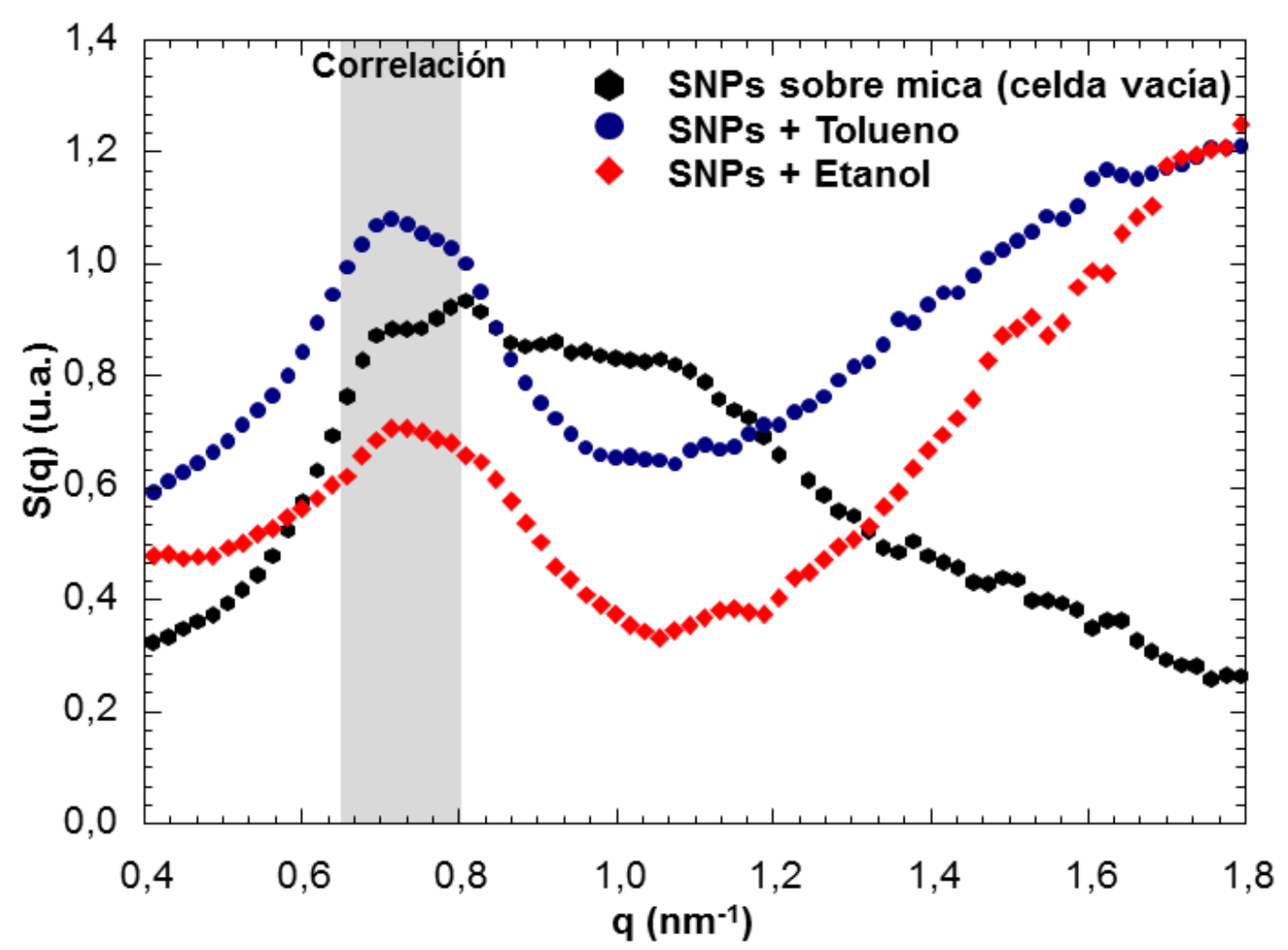

Figura 4.7 Gráficos de SAXS correspondientes a una película de SNPs antes (en aire, hexágonos negros) y después de la exposición a los solventes de Tol (círculos azules) y EtOH (rombos rojos).

\subsubsection{Flexibilidad de las Películas}

Con motivo de explorar tanto en la importancia y como en el rol de la composición de la cubierta orgánica en la flexibilidad de la película frente al sensado de VOCs, una película de SNPs "as-formed" fue sometida a un intercambio de ligandos en fase líquida (liquid-phase place-exchange) con 1,9-nonanoditiol (C9S2H2) (NDT). Luego, dicha muestra fue expuesta a vapor de Tol saturado (100\%). La Figura 4.8 muestra los gráficos de la cinética de GISAXS in-situ a lo largo del eje-z correspondientes a una película "as-treated" expuesta a Tol, como es indicado. La Tabla 4.2 muestra los resultados a lo largo de ambos ejes (y, z) de la muestra analizada en la Figura 4.8. Los gráficos de GISAXS y la tabla muestran que no se perciben cambios ni en las distancias ni en la estructura de la película cuando la misma es expuesta a vapor de Tol saturado, sugiriendo que los ditioles restringen la movilidad entre las NPs y así previenen que la película se re-estructure. 


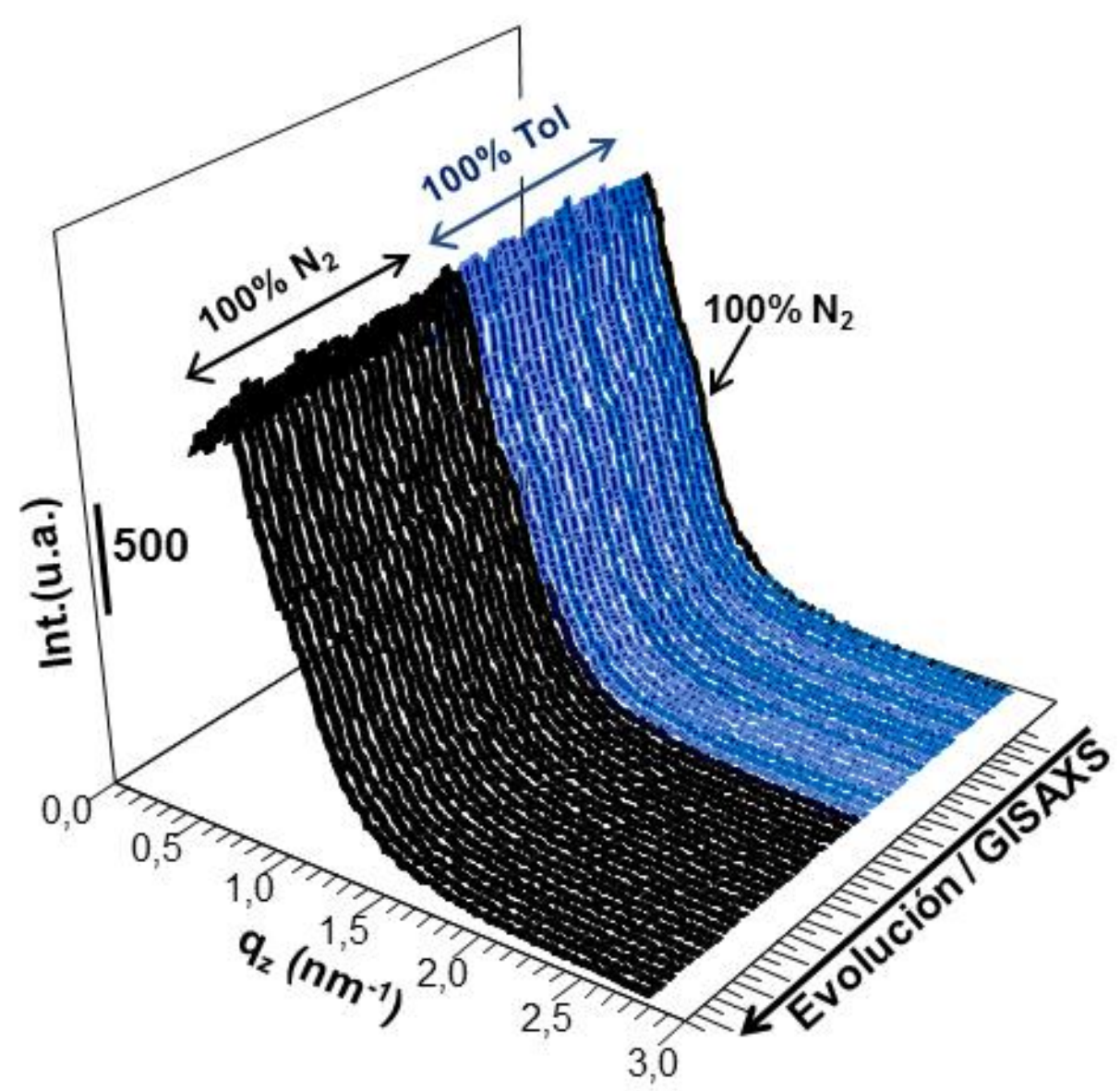

Figura 4.8 GISAXS in-situ ( $q_{z}$ versus intensidad) llevado a cabo sobre una película selecta de SNPs tratada con NDT "as-treated", expuesta a concentraciones alternantes de $\mathrm{N}_{2}$ al $100 \%$, vapor de Tol al $100 \%$ y regreso a una atmósfera de $\mathrm{N}_{2}$, como es indicado. Notar que todas las exposiciones se hicieron al máximo flujo posible para el caudalímetro empleado, que corresponden a $500 \mathrm{~cm}^{3} \cdot \mathrm{min}^{-1}$.

Es particularmente llamativo, tal como se muestra en la Tabla 4.2, que se produjo un incremento en la distancia entre las NPs a lo largo de ambos ejes luego del tratamiento con NDT. En la interfase (paralelo al sustrato) la inter-NPd incrementó desde $\sim 5,4 \mathrm{~nm}$ to $\sim 6,7 \mathrm{~nm}(\sim 1,3 \mathrm{~nm})$, mientras que a lo largo del eje-z el incremento fue relativamente mayor $\sim 2,0 \mathrm{~nm}$, conduciendo a una separación final de core-to-core de $\sim 7,4 \mathrm{~nm}$. Asimismo, es notorio que durante los experimentos de SAXS también se revelaron similares incrementos en la inter-NPd ( 7,5 nm, ver la Tabla 4.3) después del tratamiento con NDT. Estos resultados sugieren que los ligandos de NDT se 
intercambian e interactúan más efectivamente a lo largo del eje perpendicular al sustrato (alejado de la superficie). Esto es coherente, si se asume que aquellas SNPs pertenecientes a la película que estén ubicadas en capas más alejadas al sustrato, van a ser las más propensas a interactuar con los ligandos (en éste caso con el NDT). El enlace de los grupos de HS-(R) $)_{n}-\mathrm{SH}$ a la superficie de dos centros metálicos de $\mathrm{Au}$ adyacentes causaría un entrecruzamiento (cross-linkage) únicamente si la separación entre éstos es similar a la longitud de la cadena alquílica ingresante. Debido a que la distancia inicial entre las SNPs es muy grande $(\sim 2,4 \mathrm{~nm})$, en relación a la longitud de una molécula de NDT $(\sim 1,0 \mathrm{~nm})$, y sumado a esto que la incorporación del NDT incrementó aún más la inter-NPd, se descarta que pueda existir un entrecruzamiento entre los centros metálicos. Sin embargo, si bien se observó que el tratamiento con NDT redujo ampliamente la flexibilidad de la película, ${ }^{17,46}$ la razón de esta limitación en la movilidad aún es desconocida. Es posible que la composición orgánica y la estructura que adoptan las cadenas alquílicas alrededor del centro metálico de Au podrían jugar un rol determinante tanto en la flexibilidad de la película como en la separación entre las NPs (ver las secciones siguientes).

\begin{tabular}{|c|c|c|c|c|c|c|c|c|}
\hline \multirow{4}{*}{$\begin{array}{c}\text { A lo largo } \\
\text { de } q_{y}\end{array}$} & Película tratada con & q máx $\left(\mathrm{nm}^{-1}\right)$ & Intensidad(u.a.) & distancia core-to-core $(\mathrm{nm})$ & $\Delta d(n m)^{\circ}$ & $\Delta$ Int. (u.a.) ${ }^{\natural}$ & $\Delta$ Int. \% ${ }^{\circ}$ & distancia edge-to-edge $(\mathrm{nm})^{\prime}$ \\
\hline & Inicial & 0,84 & 1218 & 6,7 & 1 & 1 & 1 & 3,7 \\
\hline & Tol vapor (paso \#15)" & 0,82 & 1258 & 6,8 & 0,1 & 40 & 3 & 3,8 \\
\hline & Final & 0,84 & 1109 & 6,7 & 0,0 & -109 & -9 & 3,7 \\
\hline \multirow{3}{*}{$\begin{array}{c}\text { A lo largo } \\
\text { de } q_{z}\end{array}$} & Inicial & 0,75 & 1382 & 7,5 & 1 & 1 & 1 & 4,5 \\
\hline & Tolvapor (paso \#15) & 0,75 & 1416 & 7,5 & 0,0 & 34 & 2 & 4,5 \\
\hline & Final & 0,75 & 1322 & 7,5 & 0,0 & -60 & -4 & 4,5 \\
\hline
\end{tabular}

Tabla 4.2 Resumen de los datos de GISAXS obtenidos de la muestra "as-treated" mostrada en la Figura 4.8. ${ }^{\text {a }}$ Máximo cambio en $q$ durante el sensado de vapores. ${ }^{\mathrm{b}}$ Corresponde a la distancia core-to-core entre las nanopartículas usando la ecuación 4.3. ${ }^{\mathrm{c}}$ Diferencia en la distancia entre este paso con respecto al paso inicial. Diferencia en la intensidad entre este paso con respecto al paso inicial. ${ }^{\text {e }}$ Porcentaje de cambio en la intensidad en este paso con respecto al paso inicial. ${ }^{\mathrm{f}} \mathrm{La}$ distancia bordea-borde (edge-to-edge) fue calculada de acuerdo al radio de una SNP $(\sim 1,5 \mathrm{~nm})$, el cual fue obtenido del ajuste de los datos obtenidos por SAXS (ver Figura 4.1). 


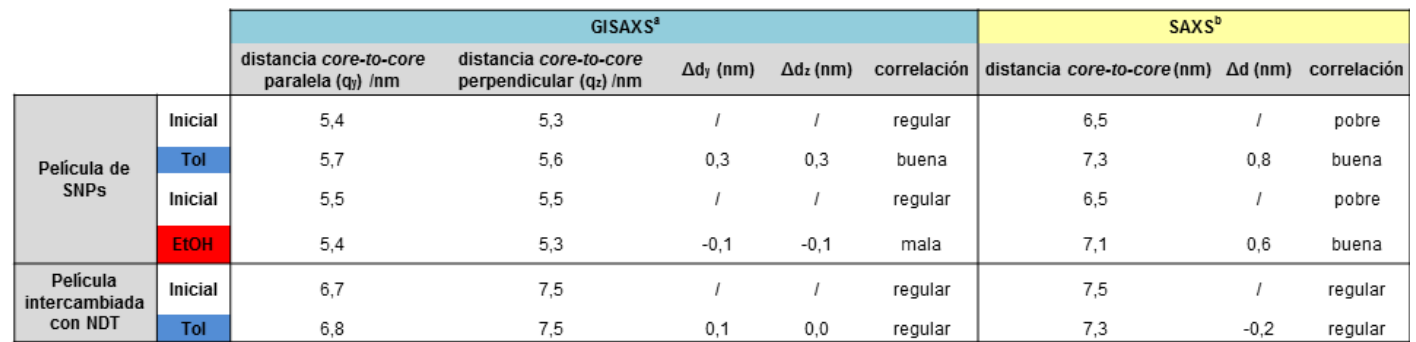

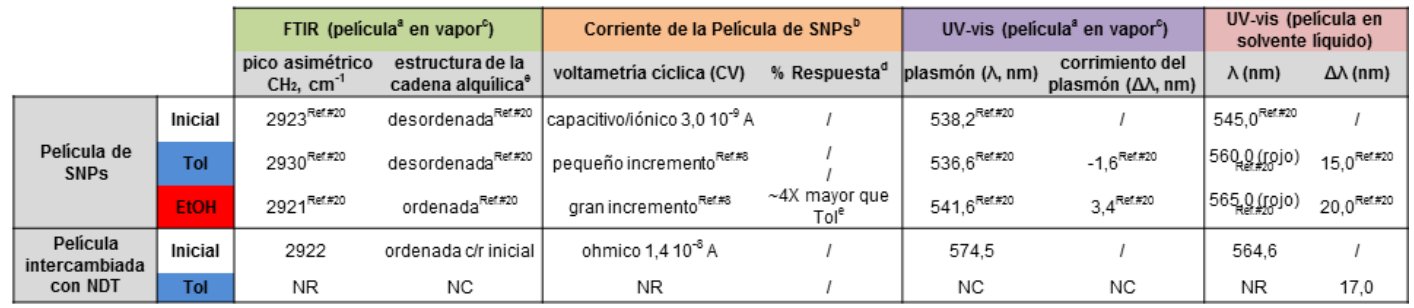

Tabla 4.3 Resultados cualitativos y cuantitativos obtenidos desde las películas de SNPs as-formed y as-treated-NDT expuestas a los solventes Tol y EtOH tanto en estado gaseoso (vapor) como en líquido. Las medidas fueron obtenidas por varias técnicas incluyendo GISAXS, SAXS, FT-IR, UV-vis (plasmón), y voltamperometría cíclica (CV) indicada como la corriente de la película (ver la Figura 4.11). Nota: (a) = películas as-formed, (b) = película de SNPs depositada por drop-casting, (c) película expuesta a vapores en modo headspace, (d) valor sugerido debido a la pobre correlación observada por SAXS, (e) el orden de la película es basado en los defectos gauche determinados por la posición de la banda correspondiente al stretching asimétrico de los $\mathrm{CH}_{2}\left(\mathrm{CH}_{2}\right.$ asym. stretching band $),(\mathrm{c} / \mathrm{r})=$ con respecto a, $(\mathrm{NC})=$ no cambia, $(\mathrm{NR})=$ no corrido $\left(\right.$ not run). ${ }^{*}$ Notar que el valor de las incrementa en la presencia del solvente EtOH. La fuente de dicho comportamiento es desconocida. 


\subsubsection{Estudios Químicos y Estructurales de las Cadenas Alquílicas después del Intercambio con Tioles}

Como una primera aproximación al entorno químico de los sistemas en estudio, se llevaron a cabo experimentos de XPS usando una fuente de $\mathrm{Mg} \mathrm{K} \alpha$ sobre una película "as-treated", pero desafortunadamente la atenuación causada por la gran cantidad de detergente $\left(\mathrm{TOA}^{+}\right)$y la relativa baja sensibilidad del nivel $2 \mathrm{p}$ del $\mathrm{S}$ a ésta energía de excitación, no permitieron poder explorar dicho sistema. Para superar estos impedimentos, se caracterizaron las muestras empleando XANES ( $X$-ray absorption near-edge structure) en el borde-K del S (empleando la señal de fluorescencia de rayos$\mathrm{X} \mathrm{K} \alpha$ del S) para ambas películas tratadas con tioles.

La Figura 4.9 muestra los espectros de XANES obtenidos de las películas de SNPs tratadas con NDT y con NT (C9SH). La película tratada con NDT exhibe dos bandas anchas en $\sim 2480$ y $\sim 2472 \mathrm{eV}$ correspondientes a las resonancias del S-Au y S-C, respectivamente. Sin embargo, la película tratada con NT exhibe solo una banda intensa correspondiente a la interacción S-C. Estudios previos realizados por Giovanetti et al. ${ }^{47}$ en donde caracterizaron por XANES Au@SC 6 MPCs de diferentes tamaños, sugirieron dos posibles razones para explicar las diferencias en las intensidades observadas. Una es atribuida a las distorsiones moleculares que cambian el estado orbital final, mientras que la otra causa podría estar asociada con el tamaño de las NPs y a la habilidad de la superficie del Au de ser ya sea enriquecida o empobrecida con átomos de S. A fin de ahondar más en estas películas tratadas con tioles, se llevaron a cabo experimentos de

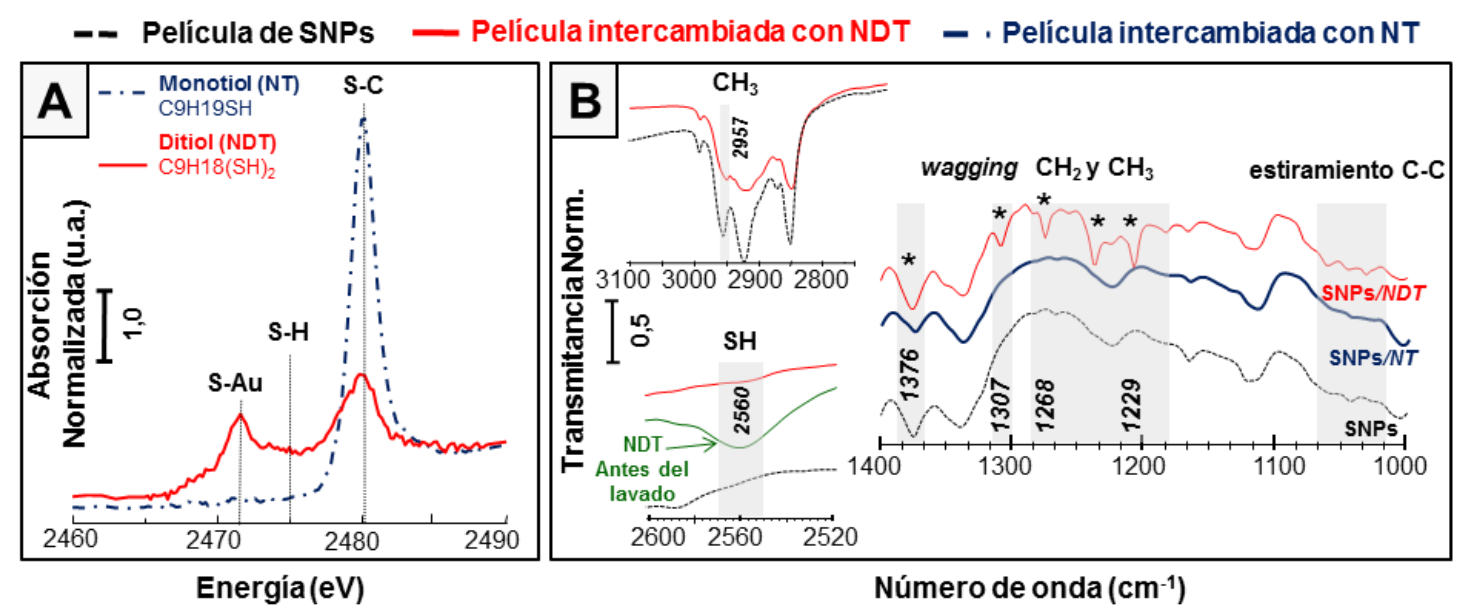

Figura 4.9 Espectros de XANES (A) y FT-IR (B) obtenidos desde las películas de SNPs tratadas con NDT y NT, y lavadas con hexano a menos que sea indicado. Las películas de SNPs caracterizadas por FT-IR, fueron intercambiadas por tioles en fase vapor para evitar que las nanopartículas se despeguen de la película. Todos los gráficos están en off-set para una mejor comparación. 
fluorescencia para medir la relación atómica del S:Au. Nuestros resultados indicaron al menos 2 ordenes de magnitud menor en la relación $\mathrm{S}: \mathrm{Au}(0,0046)$ con respecto a las $\mathrm{Au} @ \mathrm{SC}_{6} \mathrm{MPCs}$ (de similar tamaño) sintetizadas químicamente, las cuales exhibieron $\sim 2$ átomos de Au por cada átomo simple de $\mathrm{S}$ (relación $\sim 0,47$ ). ${ }^{47}$ El pequeño número de átomos de $\mathrm{S}$ sugiere que la gran cantidad de surfactante, probablemente en la forma de micelas, prevenga a los centros metálicos de la interacción R-S-Au. Además, las distorsiones moleculares podrían tener un rol determinante en los mencionados sistemas. Hasta el momento, no es posible determinar cual de las contribuciones es la predominante, sin embargo, la desaparición y la ausencia de los picos en $2560 \mathrm{~cm}^{-1} \mathrm{y}$ $\sim 2475 \mathrm{eV}$ observados en los datos de FT-IR (ver la siguiente sección) y XANES, respectivamente, indican que los tioles libres han sido realmente removidos después del lavado con hexano. Dado que XANES muestra la presencia de los grupos S-C después del lavado, es razonable pensar que las distorsiones moleculares podrían ser las responsables de la ausencia del pico correspondiente al S-Au. Finalmente, es importante mencionar que las posiciones de los picos de Au-S y Au-C de la película tratada con NDT no se modificaron (en posición), lo cual excluye tanto la formación de nuevos enlaces (ej., dimerización S-S) como la ruptura de enlaces (ej., enlace C-S).

La Figura 4.9B muestra tres diferentes espectros de FT-IR tomados entre 30002800, 2600-2500, and 1400-1100 $\mathrm{cm}^{-1}$ asignados a: i) el stretching $\mathrm{C}-\mathrm{H}$; ii) el stretching $\mathrm{S}-\mathrm{H}$; iii) las vibraciones wagging de los $\mathrm{CH}_{2}$ y $\mathrm{CH}_{3}$; y iv) el stretching $\mathrm{C}-\mathrm{C}$, respectivamente. Todas las bandas de FT-IR fueron normalizadas con respecto a la intensidad del pico en $\sim 1375 \mathrm{~cm}^{-1}$ nombrado modo umbrella $(U)$, el cual es usado como un yardstick debido a que es esencialmente insensible a cualquier cambio estructural sufrido por cualquier otro grupo-CH de las cadenas alquílicas. ${ }^{38}$ Las películas de SNPs fueron intercambiadas/expuestas a vapores de NT y NDT, seguido de un lavado copioso con hexano (a menos que sea indicado). Es importante mencionar que los intercambios con NT y NDT fueron llevados a cabo en fase vapor (vapor-phase place-exchange), con el fin de evitar que las SNPs se despeguen de la superficie de las películas durante el proceso de intercambio con alcanotioles. Con los experimentos de FT-IR es posible explorar en la aparición/desaparición, el incremento/decrecimiento de la intensidad, y los corrimientos en el número de onda de las cadenas alquílicas conteniendo grupos. $^{20,44,48} \mathrm{El}$ primer cambio aparente es indicado por un significativo decrecimiento del $\mathrm{CH}_{3}$ asimétrico y el $\mathrm{CH}_{2}$ asimétrico correspondientes a las bandas de stretching en 2957 y $\sim 2929 \mathrm{~cm}^{-1}$, respectivamente, indicando que algunas cabezas de los grupos $\mathrm{CH}_{3}$ y algunos ligandos de $\mathrm{TOA}^{+}$fueron re-emplazados y removidos, respectivamente, por el alcanotiol ingresante. ${ }^{48}$ Es particularmente interesante la aparición de nuevos picos (marcados con un * en la figura) entre 1180 y $1380 \mathrm{~cm}^{-1}$ asignados a twisting-rocking y wagging progression bands para las películas tratadas con NDT. En éste sentido, Snyder ${ }^{49}$ determinó dos tipos diferentes de defectos en la región comprendida entre 1300 y $1400 \mathrm{~cm}^{-1}$ correspondientes a: a) C-H gauche-defects en el extremo y la raíz de las cadenas alquílicas; y b) un defecto interno nombrado como "kink" o torcedura, 
localizado en el centro. Curiosamente, es posible asumir la existencia de un "kink" interno debido a la presencia de una banda en $1307 \mathrm{~cm}^{-1}$, la cual es acompañada por otra banda en $1337 \mathrm{~cm}^{-1}$ de similar intensidad. ${ }^{38}$ Finalmente, las bandas entre 1020 y 1080 $\mathrm{cm}^{-1}$ pueden ser asignadas a los modos de stretching de los C-C, los cuales ligeramente cambian después del tratamiento con NDT.

De lo expuesto, estos resultados claramente sugieren que un pequeño número de cadenas de ditioles (que se intercambiaron dentro de la película) adoptaron una estructura particular en la superficie del Au. Por otro lado, ha sido demostrado en la literatura que los ditioles de cadenas largas tienden a oxidarse en la forma de disulfuros (S-S) entre dos o más cadenas alquílicas. ${ }^{50}$ Por lo tanto, se podrían considerar dos posibles conformaciones para las cadenas alquílicas: a) dos o más cadenas de ditioles ligadas por un fuerte enlace S-S; o que b) ambos grupos R-SH, pertenecientes a una misma, formen tiolatos en la en la superficie de una misma NP de Au. Debido a que los espectros de XANES excluyen tanto la ruptura como la formación de nuevos enlaces, es posible descartar la primer estructura propuesta. Asimismo, los resultados de UV-vis, mostrados en la Figura 4.10, de las películas de SNPs intercambiadas con NT y NDT en fase vapor, excluyen la posibilidad de un cross-linking entre las NPs de Au. Finalmente, consistente con los resultados de XANES, el pico en $2560 \mathrm{~cm}^{-1}$, correspondiente a los tioles libres, desapareció después de un lavado copioso con hexano.

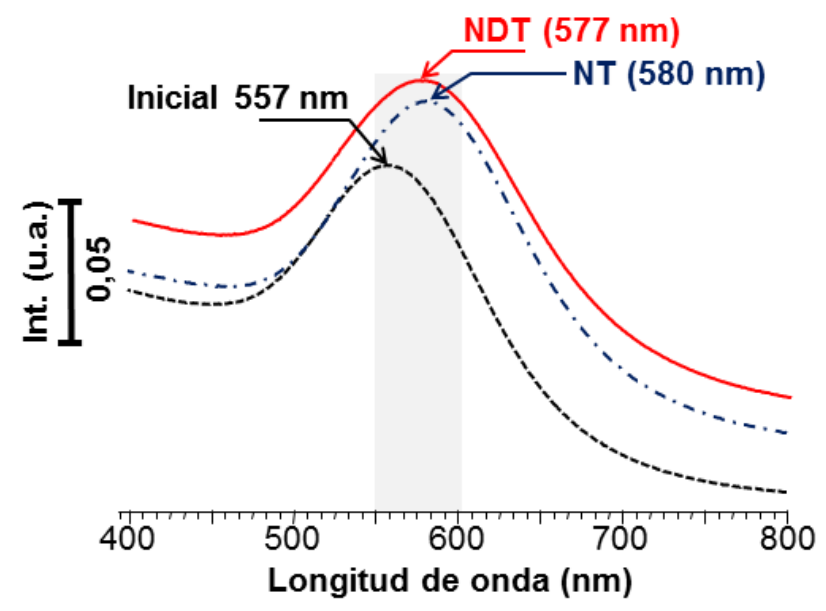

Figura 4.10 Gráficos de UV-vis indicando similares valores en los desplazamientos plasmónicos a los rojos $(570$ y $580 \mathrm{~nm})$ después del intercambio con NT y NDT. Dichos valores/comportamientos sugieren que no existe un entrecruzamiento (cross-linking) entre los centros metálicos (cores) adyacentes, lo cual es a su vez consistente con las inter-NPd obtenidas por GISAXS. 
En resumen, los resultados obtenidos enriquecieron los conocimientos sobre: a) la importancia de la composición de la cubierta orgánica; b) la conformación de la misma alrededor del centro de $\mathrm{Au}$; c) permitieron ahondar en la flexibilidad de la película y las inter-NPd. El Esquema 4.1 representa un pequeño número de moléculas de NDT alcanzaron la superficie del Au y adoptaron una conformación de tipo "loop" o curvada, la cual es consistente con los datos de XANES y FT-IR, respectivamente. La Tabla 4.3 muestra un resumen de todos los resultados obtenidos en éste trabajo junto

\section{Película as-prepared}
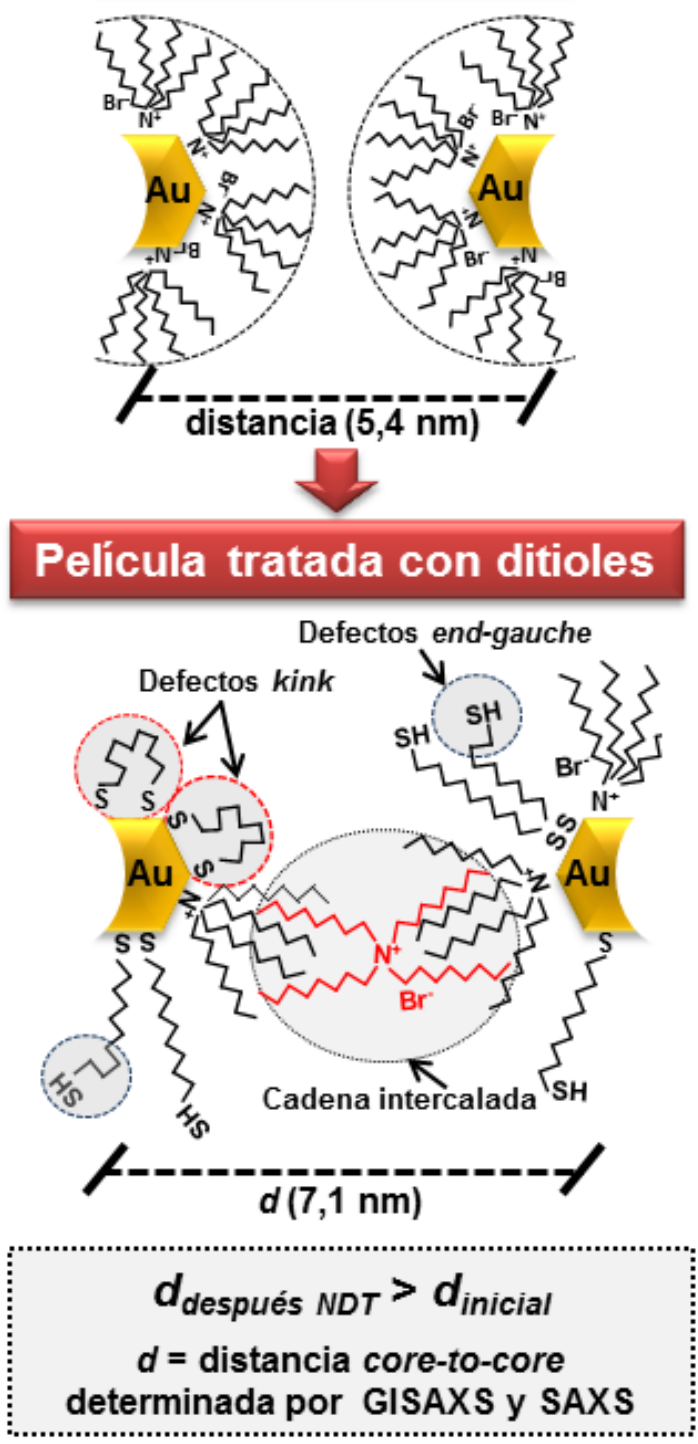

Esquema 4.1 Representación de un ligando de $\mathrm{TOA}^{+}$intercalado entre dos monocapas, basados en los resultados de las inter-NPd obtenidos por GISAXS. Los ligandos de NDT adoptan una conformación en forma de rulo/curvado (loop) de acuerdo a los kink defects observados por FT-IR. 
con los resultados informados en la literarura, ${ }^{8,20}$ para las películas de SNPs "asprepared" y "as-treated" expuestas a vapores y solventes, como es indicado. Las columnas muestran todas las técnicas complementarias a GISAXS, que se emplearon para estudiar todas las películas informadas a lo largo de éste Capítulo.

\subsection{Conclusiones}

En conclusión, las películas de SNPs preparadas por inmersión mostraron correlación a corto alcance y una separación de centro-a-centro de 5,4 nm, la cual es más grande que la distancia observada en sistemas bien ensamblados de MPCs de similares tamaños (tanto del centro metálico como el grupo orgánico que las protege). La gran separación entre las SNPs fue atribuida a un exceso en la cantidad de los ligandos de $\mathrm{TOA}^{+}$, los cuales se encuentran débilmente coordinados alrededor de la nanopartícula de Au. Resulta interesante que, los experimentos de GISAXS determinaron un incremento en las inter-NPd y una mejora en la correlación de la película durante la exposición a concentraciones de vapor de Tol. El incremento en las distancias es consistente con los efectos de acoplamiento (coupling effects) en sensores de LSPR como es indicado por el desplazamiento a los azules del máximo del plasmón (ver la Tabla 4.3). Por otro lado, la misma película expuesta a EtOH exhibió un ligero decrecimiento en la distancia entre las SNPs y una pérdida de la estructura de la película, como es notado por el decrecimiento en la intensidad del vector $q_{\text {máx }}$. El mencionado ligero decrecimiento en la distancia podría estar asociado con el significativo desplazamiento plasmónico a los rojos y la re-estructuración de las cadenas alquílicas, como es indicado por los datos de LSPR y FT-IR, respectivamente. ${ }^{20}$ Asimismo, Ibañez y Zamborini ${ }^{8}$ sugirieron que el transporte de electrones en películas de NPs protegidas con surfactante ocurre primariamente por corrientes de tipo iónicas, las cuales son favorecidas por la presencia de vapores polares (ej., EtOH) sobre los nopolares, lo cual es notado por el gran incremento en la corriente (Tabla 4.3). Consistente con todo lo expuesto, la respuesta de la corriente al Tol es 4x menor en relación al EtOH en la misma concentración de vapores, indicando que los dos mecanismos de sensado podrían competir uno con el otro: corrientes iónicas versus salto de electrones (electron hopping). Mientras que la primera muestra un significativo incremento en la corriente, la última comúnmente muestra un decrecimiento en la corriente (incremento en la resistencia) debido a un incremento en la distancia entre las SNPs (film swelling). Los cambios en las inter-NPd fueron mayormente atribuidos a la flexibilidad de la película provista por la gran cantidad de ligandos del surfactante $\left(\mathrm{TOA}^{+}\right)$. Una vez que las moléculas de ditioles re-emplazaron o removieron algunos de los grupos de $\mathrm{TOA}^{+}$, la flexibilidad de la película fue severamente disminuida, limitando tanto la movilidad entre las NPs como la restructuración de la película. Después del tratamiento con ditioles se observaron dos aspectos interesantes: a) un incremento en las inter-NPd; y 
que b) los ditioles interactúan más favorablemente con las SNPs localizadas alejadas de la interface de la película. Los datos de FT-IR demostraron defectos de tipo "kink" sugiriendo una conformación curvada de las cadenas alquílicas alrededor de los centros de $\mathrm{Au}$, lo cual podría ser el causal de la gran separación inter-NPd observada. La falta de respuesta de la película tratada con ditioles frente al vapor de Tol saturado, permanece desconocida. Sin embargo, estimamos que la significativa remoción de los ligandos débiles (ej., $\mathrm{TOA}^{+}$) limita la flexibilidad de la película. Es particularmente llamativo que las curvas de CV (corriente versus voltaje) de las películas exhiben un cambio desde corriente iónica a corriente óhmica después del intercambio con ditioles (Figura 4.11).

De acuerdo a lo expuesto, planteamos realizar experimentos utilizando RMN en estado sólido (solid-state NMR) con el fin de poder explorar en mayor detalle cada carbón a lo largo de la cadena del ditiol.

Finalmente, este trabajo demostró que una película protegida con grupos orgánicos, es una plataforma interesante para explorar: a) el rol de la cubierta orgánica y sus efectos sobre las distancias entre las nanopartículas; y b) ahondar en la estructura de la película durante el sensado de compuestos orgánicos volátiles (VOCs) tanto polares como no polares.

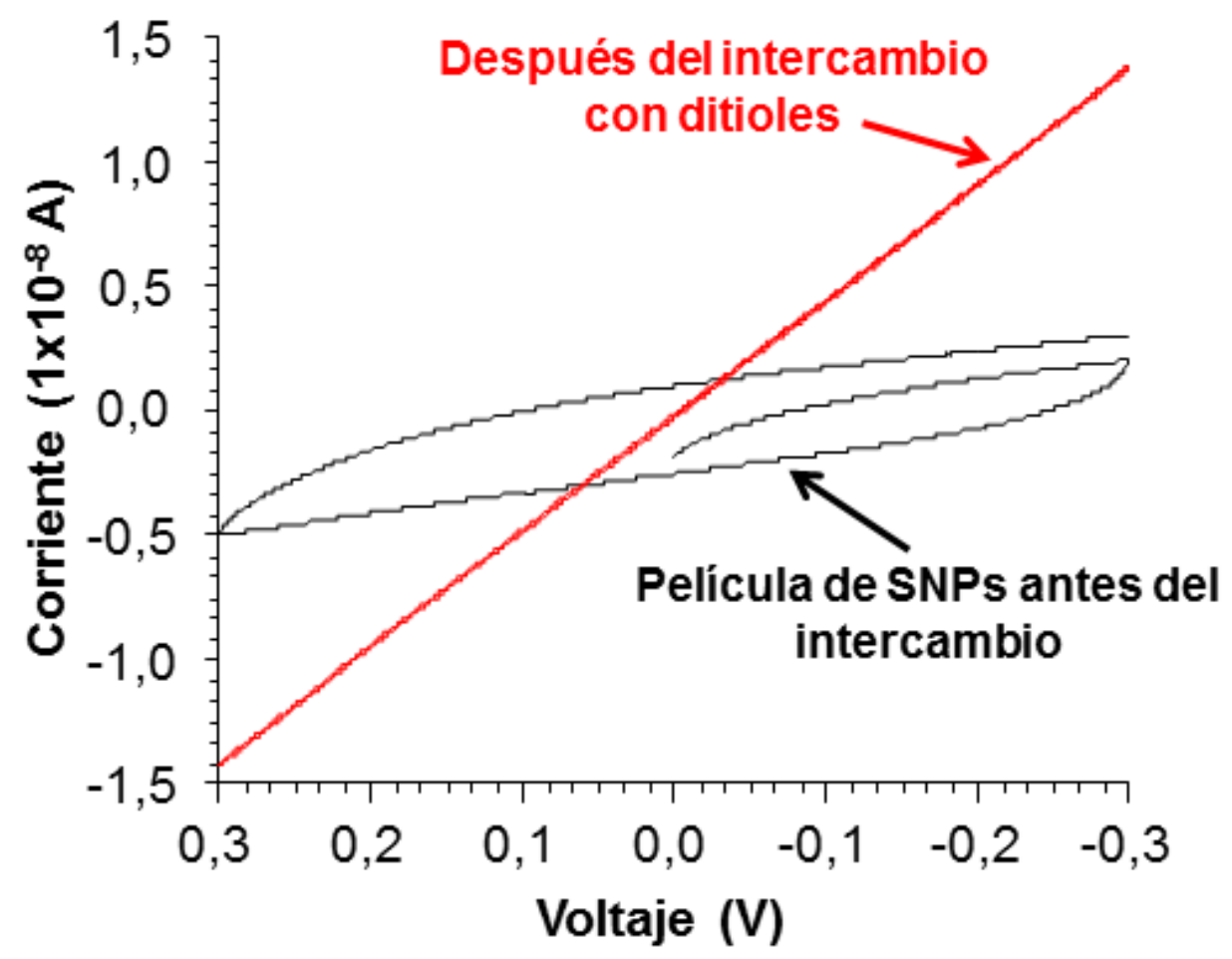

Figura 4.11 Gráfico de voltamperometría cíclica $(\mathbf{C V}, I$ versus $V)$ de una película de SNPs depositada sobre un microelectrodo, antes y después del intercambio con nonanoditiol (NDT) en fase líquida. 


\subsection{Bibliografía}

(1) Liao, H.-C.; Tsao, C.-S.; Lin, T.-H.; Jao, M.-H.; Chuang, C.-M.; Chang, S.-Y.; Huang, Y.-C.; Shao, Y.-T.; Chen, C.-Y.; Su, C.-J.; et al. Nanoparticle-Tuned Self-Organization of a Bulk Heterojunction Hybrid Solar Cell with Enhanced Performance. ACS Nano 2012, 6 (2), 1657-1666.

(2) Lee, K.; Irudayaraj, J. Correct Spectral Conversion between Surface-Enhanced Raman and Plasmon Resonance Scattering from Nanoparticle Dimers for SingleMolecule Detection. Small 2013, 9 (7), 1106-1115.

(3) Ibañez, F. J.; Zamborini, F. P. Chemiresistive Sensing with Chemically Modified Metal and Alloy Nanoparticles. Small 2012, 8 (2), 174-202.

(4) Ibañez, Francisco J. Doctoral Thesis. Title: Chemiresistive Sensing of Volatile Organic Compounds (VOCs) and Hydrogen $\left(\mathrm{H}_{2}\right)$ Gas with Films of OrganicStabilized Metal and Alloy Nanoparticles. Department of Chemistry, University of Louisville, KY, USA. (2008). Director: Francis Zamborini.

(5) Ibañez, F. J.; Zamborini, F. P. Chemiresistive Sensing with Chemically Modified Metal and Alloy Nanoparticles. Small 2012, 8 (2), 174-202.

(6) Zamborini, F. P.; Leopold, M. C.; Hicks, J. F.; Kulesza, P. J.; Malik, M. A.; Murray, R. W. Electron Hopping Conductivity and Vapor Sensing Properties of Flexible Network Polymer Films of Metal Nanoparticles. J. Am. Chem. Soc. 2002, 124 (30), 8958-8964.

(7) Zamborini, F. P.; Smart, L. E.; Leopold, M. C.; Murray, R. W. DistanceDependent Electron Hopping Conductivity and Nanoscale Lithography of Chemically-Linked Gold Monolayer Protected Cluster Films. Anal. Chim. Acta 2003, 496 (1-2), 3-16.

(8) Ibañez, F. J.; Zamborini, F. P. Chemiresistive Sensing of Volatile Organic Compounds with Films of Surfactant-Stabilized Gold and Gold-Silver Alloy Nanoparticles. ACS Nano 2008, 2 (8), 1543-1552.

(9) Mie, G. Beiträge Zur Optik Trüber Medien, Speziell Kolloidaler Metallösungen. Ann. Phys. 1908, 330 (3), 377-445.

(10) Wohltjen, H.; Snow, A. W. Colloidal Metal-Insulator-Metal Ensemble Chemiresistor Sensor. Anal. Chem. 1998, 70 (14), 2856-2859.

(11) Snow, A. W.; Ancona, M. G.; Park, D. Nanodimensionally Driven Analyte Response Reversal in Gold Nanocluster Chemiresistor Sensing. Langmuir 2012, 28 (44), 15438-15443.

(12) Steinecker, W. H.; Rowe, M. P.; Zellers, E. T. Model of Vapor-Induced Resistivity Changes in Gold-Thiolate Monolayer-Protected Nanoparticle Sensor Films. Anal. Chem. 2007, 79 (13), 4977-4986.

(13) Krasteva, N.; Besnard, I.; Guse, B.; Bauer, R. E.; Müllen, K.; Yasuda, A.; Vossmeyer, T. Self-Assembled Gold Nanoparticle/Dendrimer Composite Films for Vapor Sensing Applications. Nano Lett. 2002, 2 (5), 551-555.

(14) Wang, L.; Luo, J.; Yin, J.; Zhang, H.; Wu, J.; Shi, X.; Crew, E.; Xu, Z.; Rendeng, Q.; Lu, S.; et al. Flexible Chemiresistor Sensors: Thin Film Assemblies of Nanoparticles on a Polyethylene Terephthalate Substrate. J. Mater. Chem. 2010, 20 (5), 907-915. 
(15) Leopold, M. C.; Donkers, R. L.; Georganopoulou, D.; Fisher, M.; Zamborini, F. P.; Murray, R. W. Growth, Conductivity, and Vapor Response Properties of Metal Ion-Carboxylate Linked Nanoparticle Films. Faraday Discuss. 2004, 125, 63-76.

(16) Joseph, Y. ; Besnard, I. ; Rosenberger, M. ; Guse, B ; Nothofer, H. G. ; Wessels, J. M. ; Wild, U. ; Knop-Gericke, A. ; Su, D. ; Robert Schlögl, R. ; Yasuda, A. ; Vossmeyer, T.. Self-Assembled Gold Nanoparticle/Alkanedithiol Films: Preparation, Electron Microscopy, XPS-Analysis, Charge Transport, and VaporSensing Properties. J. Phys. Chem. B, 2003, 107 (30), pp 7406-7413

(17) Joseph, Y.; Peie, A.; Chen, X.; Michl, J.; Vossmeyer, T.; Yasuda, A. Vapor Sensitivity of Networked Gold Nanoparticle Chemiresistors: Importance of Flexibility and Resistivity of the Interlinkage. J. Phys. Chem. C 2007, 111 (34), 12855-12859.

(18) Chen, Y.-Q.; Lu, C.-J. Surface Modification on Silver Nanoparticles for Enhancing Vapor Selectivity of Localized Surface Plasmon Resonance Sensors. Sens. Actuators B Chem. 2009, 135 (2), 492-498.

(19) Cheng, C.-S.; Chen, Y.-Q.; Lu, C.-J. Organic Vapour Sensing Using Localized Surface Plasmon Resonance Spectrum of Metallic Nanoparticles Self Assemble Monolayer. Talanta 2007, 73 (2), 358-365.

(20) Dalfovo, M. C.; Salvarezza, R. C.; Ibañez, F. J. Improved Vapor Selectivity and Stability of Localized Surface Plasmon Resonance with a Surfactant-Coated $\mathrm{Au}$ Nanoparticles Film. Anal. Chem. 2012, 84 (11), 4886-4892.

(21) Scholten, K.; Reddy, K.; Fan, X.; Zellers, E. T. Vapor Discrimination by DualLaser Reflectance Sensing of a Single Functionalized Nanoparticle Film. Anal. Methods 2013, 5 (16), 4268-4272.

(22) Potyrailo, R. A.; Larsen, M.; Riccobono, O. Detection of Individual Vapors and Their Mixtures Using a Selectivity-Tunable Three-Dimensional Network of Plasmonic Nanoparticles. Angew. Chem. - Int. Ed. 2013, 52 (39), 10360-10364.

(23) García-Berríos, E.; Gao, T.; Woodka, M. D.; Maldonado, S.; Brunschwig, B. S.; Ellsworth, M. W.; Lewis, N. S. Response versus Chain Length of AlkanethiolCapped Au Nanoparticle Chemiresistive Chemical Vapor Sensors. J. Phys. Chem. C 2010, 114 (50), 21914-21920.

(24) Zhang, H.-L.; Evans, S. D.; Henderson, J. R.; Miles, R. E.; Shen, T.-H. Vapour Sensing Using Surface Functionalized Gold Nanoparticles. Nanotechnology 2002, 13 (3), 439-444.

(25) Renaud, G.; Lazzari, R.; Leroy, F. Probing Surface and Interface Morphology with Grazing Incidence Small Angle X-Ray Scattering. Surf. Sci. Rep. 2009, 64 (8), 255-380.

(26) Goodfellow, B. W.; Korgel, B. A. Reversible Solvent Vapor-Mediated Phase Changes in Nanocrystal Superlattices. ACS Nano 2011, 5 (4), 2419-2424.

(27) Zhang, J.; Luo, Z.; Martens, B.; Quan, Z.; Kumbhar, A.; Porter, N.; Wang, Y.; Smilgies, D.-M.; Fang, J. Reversible Kirkwood-Alder Transition Observed in $\mathrm{Pt} 3 \mathrm{Cu} 2$ Nanoctahedron Assemblies under Controlled Solvent Annealing/Drying Conditions. J. Am. Chem. Soc. 2012, 134 (34), 14043-14049.

(28) Wan, Y.; Portalès, H.; Goubet, N.; Mermet, A.; Pileni, M.-P. Impact of Nanocrystallinity Segregation on the Growth and Morphology of Nanocrystal Superlattices. Nano Res. 2013, 6 (8), 611-618. 
(29) Bian, K.; Choi, J. J.; Kaushik, A.; Clancy, P.; Smilgies, D.-M.; Hanrath, T. Shape-Anisotropy Driven Symmetry Transformations in Nanocrystal Superlattice Polymorphs. ACS Nano 2011, 5 (4), 2815-2823.

(30) Connolly, S.; Fullam, S.; Korgel, B.; Fitzmaurice, D. Time-Resolved SmallAngle X-Ray Scattering Studies of Nanocrystal Superlattice Self-Assembly. J. Am. Chem. Soc. 1998, 120 (12), 2969-2970.

(31) Corricelli, M.; Depalo, N.; Fanizza, E.; Altamura, D.; Giannini, C.; Siliqi, D.; Di Mundo, R.; Palumbo, F.; Kravets, V. G.; Grigorenko, A. N.; et al. TwoDimensional Plasmonic Superlattice Based on Au Nanoparticles Self-Assembling onto a Functionalized Substrate. J. Phys. Chem. C 2014, 118 (14), 7579-7590.

(32) Wan, Y. F.; Goubet, N.; Albouy, P. A.; Pileni, M. P. Hierarchy in Au Nanocrystal Ordering in Supracrystals: A Potential Approach to Detect New Physical Properties. Langmuir 2013, 29 (24), 7456-7463.

(33) Choi, J. J.; Bealing, C. R.; Bian, K.; Hughes, K. J.; Zhang, W.; Smilgies, D.-M.; Hennig, R. G.; Engstrom, J. R.; Hanrath, T. Controlling Nanocrystal Superlattice Symmetry and Shape-Anisotropic Interactions through Variable Ligand Surface Coverage. J. Am. Chem. Soc. 2011, 133 (9), 3131-3138.

(34) Wang, Z.; Schliehe, C.; Bian, K.; Dale, D.; Bassett, W. A.; Hanrath, T.; Klinke, C.; Weller, H. Correlating Superlattice Polymorphs to Internanoparticle Distance, Packing Density, and Surface Lattice in Assemblies of PbS Nanoparticles. Nano Lett. 2013, 13 (3), 1303-1311.

(35) Fink, J.; Kiely, C. J.; Bethell, D.; Schiffrin, D. J. Self-Organization of Nanosized Gold Particles. Chem. Mater. 1998, 10 (3), 922-926.

(36) Sakka, S. Handbook of Sol-Gel Science and Technology: Processing, Characterization and Applications, V. I - Sol-Gel Processing/Hiromitsu Kozuka, Editor, V. II - Characterization of Sol-Gel Materials and Products/Rui M. Almeida, Editor, V. III - Applications of Sol-Gel Technology/Sumio Sakka, Editor; Springer, 2004.

(37) Abbate, M.; Vicentin, F. C.; Compagnon-Cailhol, V.; Rocha, M. C.; Tolentino, H. The Soft X-Ray Spectroscopy Beamline at the LNLS: Technical Description and Commissioning Results. J. Synchrotron Radiat. 1999, 6 (5), 964-972.

(38) Hostetler, M. J.; Stokes, J. J.; Murray, R. W. Infrared Spectroscopy of ThreeDimensional Self-Assembled Monolayers: N-Alkanethiolate Monolayers on Gold Cluster Compounds. Langmuir 1996, 12 (15), 3604-3612.

(39) Wan, Y.; Goubet, N.; Albouy, P.-A.; Schaeffer, N.; Pileni, M.-P. Hierarchy in Au Nanocrystal Ordering in a Supracrystal: II. Control of Interparticle Distances. Langmuir 2013, 29 (44), 13576-13581.

(40) Salzemann, C.; Zhai, W.; Goubet, N.; Pileni, M.-P. How to Tune the Au Internanocrystal Distance in Two Dimensional Self-Ordered Superlattices. $J$. Phys. Chem. Lett. 2010, 1 (1), 149-154.

(41) Klecha, E.; Ingert, D.; Pileni, M. P. How the Level of Ordering of $2 d$ Nanocrystal Superlattices Is Controlled by Their Deposition Mode. J. Phys. Chem. Lett. 2010, 1 (10), 1616-1622.

(42) Guinier, A. Small-Angle Scattering of X-rays.; John Wiley: New York, 1955.

(43) Porter, M. D.; Bright, T. B.; Allara, D. L.; Chidsey, C. E. D. Spontaneously Organized Molecular Assemblies. 4. Structural Characterization of N-Alkyl Thiol 
Monolayers on Gold by Optical Ellipsometry, Infrared Spectroscopy, and Electrochemistry. J. Am. Chem. Soc. 1987, 109 (12), 3559-3568.

(44) Terrill, R. H.; Postlethwaite, T. A.; Chen, C.-H.; Poon, C.-D.; Terzis, A.; Chen, A.; Hutchison, J. E.; Clark, M. R.; Wignall, G.; Londono, J. D.; et al. Monolayers in Three Dimensions: NMR, SAXS, Thermal, and Electron Hopping Studies of Alkanethiol Stabilized Gold Clusters. J. Am. Chem. Soc. 1995, 117 (50), $12537-$ 12548.

(45) Rice, S. A. Small Angle Scattering of X-Rays. A. Guinier and G. Fournet. Translated by C. B. Wilson and with a Bibliographical Appendix by K. L. Yudowitch. Wiley, New York, 1955. 268. J. Polym. Sci. 1956, 19 (93), 594-594.

(46) Ibañez, F. J.; Gowrishetty, U.; Crain, M. M.; Walsh, K. M.; Zamborini, F. P. Chemiresistive Vapor Sensing with Microscale Films of Gold Monolayer Protected Clusters. Anal. Chem. 2006, 78 (3), 753-761.

(47) Ramallo-López, J. M.; Giovanetti, L. J.; Requejo, F. G.; Isaacs, S. R.; Shon, Y. S.; Salmeron, M. Molecular Conformation Changes in Alkylthiol Ligands as a Function of Size in Gold Nanoparticles: X-Ray Absorption Studies. Phys. Rev. B 2006, 74 (7), 073410.

(48) Choo, H.; Cutler, E.; Shon, Y.-S. Synthesis of Mixed Monolayer-Protected Gold Clusters from Thiol Mixtures: Variation in the Tail Group, Chain Length, and Solvent. Langmuir 2003, 19 (20), 8555-8559.

(49) Snyder, R. G. Vibrational Study of the Chain Conformation of the Liquid NParaffins and Molten Polyethylene. J. Chem. Phys. 1967, 47 (4), 1316-1360.

(50) Millone, M. A. D.; Hamoudi, H.; Rodríguez, L.; Rubert, A.; Benítez, G. A.; Vela, M. E.; Salvarezza, R. C.; Gayone, J. E.; Sánchez, E. A.; Grizzi, O.; et al. SelfAssembly of Alkanedithiols on Au(111) from Solution: Effect of Chain Length and Self-Assembly Conditions. Langmuir 2009, 25 (22), 12945-12953. 
Sección III

Grafeno como Plataforma Sensible 


\section{Capítulo 5}

\section{Introducción al Primer Nanomaterial}

\section{Bidimensional (2D): Grafeno}

\subsection{Introducción}

Grafeno es un material compuesto de únicamente átomos de carbono superficiales, los cuales presentan una hibridación $s p^{2}$ y se encuentran organizados en una estructura de tipo panal de abejas. Las singulares propiedades tanto químicas como electrónicas de grafeno $(\mathrm{G})$ han generado un impacto directo en áreas tales como: i) sensores; ${ }^{1}$ ii) fotónica y optoelectrónica; ${ }^{2}$ y ii) espectroscopia Raman intensificada por superficies (surface-enhanced Raman scattering, SERS); ${ }^{3}$ sólo por mencionar algunas.

El grafeno fue inicialmente aislado por medio de la exfoliación mecánica de grafito, utilizando simplemente una cinta Scotch. ${ }^{4}$ Luego, otros métodos fueron desarrollados para obtener G, los cuales incluyen: el método de Hummers; ${ }^{5}$ la electroexfoliación (electroquímica); ${ }^{6}$ y la deposición química de vapores (Chemical Vapor Deposition, CVD) ${ }^{7}$, tal como fue mencionado en el Capítulo 1. Particularmente, la metodología por CVD es simple y permite tener control en el tamaño del G sintetizado, ${ }^{7}$ sin embargo el protocolo de transferencia involucra el uso del polímero polimetilmetacrilato (PMMA). El PMMA es un polímero utilizado frecuentemente en laboratorios de salas limpias (clean room laboratories) durante los procesos de fotolitografía y para la construcción de transistores, como los graphene field-effect transistors (G-FET). ${ }^{8}$ Además, se ha reportado el uso del PMMA como una capa protectora frente a la oxidación generada por el ozono $\left(\mathrm{O}_{3}\right)^{9}$ y en el diseño de sensores para la detección de compuestos orgánicos volátiles (volatile organic compounds, VOCs). ${ }^{10}$ A pesar de las mencionadas ventajas en algunas áreas, el PMMA usualmente permanece como un residuo o impureza en la película de G.

En este contexto, Ruoff et. $a l^{11}$ demostraron la presencia de PMMA sobre grafeno crecido por CVD empleando XPS (X-ray photoelectron spectroscopy). Ellos compararon los espectros de grafeno crecido sobre $\mathrm{Cu}$ ( $\sin$ PMMA), grafeno transferido (utilizando PMMA) y a ésta última muestra luego de un tratamiento térmico para remover el mencionado polímero. Ellos demostraron que en ambos casos, tanto después de la transferencia como después del tratamiento térmico (annealing), el pico del $\mathrm{C} 1 \mathrm{~s}$ nunca retorna a su configuración $s p^{2}$ original, indicando la presencia de residuos del 
PMMA sobre la película de G. Asimismo, otros grupos emplearon diferentes metodologías para remover completamente el PMMA sobre muestras de $\mathrm{G}$ transferido a diferentes sustratos. ${ }^{12-14}$ Respecto a lo expuesto anteriormente, nosotros confirmamos que el PMMA disminuye la corriente de las películas de G, alterando de éste modo sus propiedades electrónicas. La presencia del PMMA sobre la película de G no es trivial, y debería ser considerada tanto en la fabricación de dispositivos como en el diseño de plataformas para sensado ${ }^{8}$ y detección de analitos por SERS. ${ }^{14}$

La dispersión Raman (Raman scattering) tiene una muy baja sección eficaz, alrededor de $\sim 10^{-31} \mathrm{~cm}^{2}$ por molécula, la cual compite desigualmente con la fluorescencia (FL) cuya probabilidad de ocurrencia es mucho mayor $\left(\sim 10^{-16} \mathrm{~cm}^{2}\right.$ por molécula). La baja polarización de las moléculas por la dispersión Raman ha sido superada por un fenómeno de superficie conocido como Espectroscopia Raman intensificada por Superficies, de sus siglas del inglés SERS, surface-enhanced Raman scattering. ${ }^{15}$ Esto significa que cuando una molécula Raman activa se sitúa cercana o en las inmediaciones de partículas o zonas con campos electromagnéticos altamente confinados, puede ocurrir un aumento de su señal analítica (tan alta como $10^{14}$ ) por los mecanismos electromagnéticos ${ }^{16} \mathrm{y} / \mathrm{o}$ químicos. ${ }^{17}$

Desde el descubrimiento en 1970 del fenómeno SERS, ${ }^{15}$ grandes esfuerzos se han realizado para el desarrollo de nuevos nanomateriales para mejorar su actividad. Por ejemplo, concentraciones extremadamente bajas de analitos han sido detectadas, ${ }^{18}$ hasta el punto de la detección de una única molécula. ${ }^{19}$ Nanoestructuras metálicas de variadas composiciones, tamaños, y formas han sido empleadas como plataformas SERS, las cuales son usualmente obtenidas por técnicas de electrodeposición, ${ }^{20,21}$ fotolitografía y sputtering, ${ }^{22}$ y por síntesis química (bench-top chemical synthesis). ${ }^{23}$ Aunque los mecanismos aún están siendo explorados, se ha observado que la composición, la forma y el tamaño juegan un rol crucial en la actividad SERS. Con respecto a la forma, en conocido que las nanopartículas (NPs) anisotrópicas presentan un gran aumento de la señal analítica en comparación a NPs esféricas, por ejemplo Xia et al. ${ }^{24}$ reportaron estos comportamientos en sistemas conformados por nanocubos puntiagudos y truncados de Ag. Además, la composición juega un rol crítico, lo cual justifica en muchos casos el uso de nanoestructuras de Ag en vez de Au. Sin embargo, existen algunas desventajas asociadas al uso de nanoestructuras de Ag como plataformas SERS, debido a que ésta es propensa a la oxidación en condiciones ambientales. Como es esperado, la oxidación de nanoestructuras metálicas que poseen terminaciones puntiagudas (sharp tips) no cambia únicamente su composición sino que además conduce a la perdida de los conocidos hotspots, ${ }^{*}$ debido a la formación de terminaciones redondeadas (ej., desde nanoplates a

\footnotetext{
*El término "hot-spot" se refiere a la interacción entre dos nanoestructuras, las cuales generan un campo electromagnético altamente concentrado en la unión entre ambas. Como un ejemplo de ello puede
} 
nanopartículas esféricas). ${ }^{26}$ Por otro lado, es conocido que puede mejorarse la actividad SERS de grafeno por la incorporación de nanopartículas (NPs) metálicas. Sin embargo, se ha demostrado que la intensidad de la fotoluminiscencia (photoluminescence, PL) comienza a ser un problema cuando las nanopartículas de Au presentan un tamaño de $\sim 5 \mathrm{~nm}^{27}$ Sumado a esto, algunas moléculas Raman activas pueden presentar fluorescencia (fluorescence, FL) durante la excitación con el láser Raman. ${ }^{28}$ Todos estos efectos no deseados (ej., la oxidación de las nanoestructuras metálicas, y la presencia de PL y FL), causan el detrimento de la señal SERS debido a la pérdida de los hot-spots y el solapamiento de la señal analítica buscada.

A primera vista, parece que el G satisfice todos los requerimientos para SERS debido a su vasta área superficial, a sus electrones deslocalizados, a su habilidad para transferir cargas, y a su bio-compatibilidad. ${ }^{\dagger}$ Si bien todos estos atributos son ciertos, el G sintetizado por CVD ha demostrado que aumenta débilmente la señal Raman de varios analitos. ${ }^{9}$ En una publicación reciente, Hou et al. ${ }^{29}$ compararon grafeno obtenido por exfoliación mecánica con óxido de grafeno reducido (reduced graphene oxide, rGO). Ellos demostraron que controlando el grado de reducción del rGO, es posible obtener un aumento de 1 orden de magnitud en la actividad SERS de Rodamina B (RhB). Luego, Nam et al. ${ }^{9}$ expusieron G obtenido por CVD a una lámpara de luz ultravioleta (UV), la cual genera ozono, y observaron una mejora de $\sim 1$ orden de magnitud en la actividad SERS de los analitos RhB, Rh6G y cristal violeta. Más tarde, Liu et al. fueron los primeros en reportar la formación de una heterojunción conformada por NPs de $\mathrm{Cu}$ y $\mathrm{G}$ exfoliado, la cual luego de construida es sometida a un procedimiento para la disolución de las NPs de $\mathrm{Cu}$ con el fin de construir una nanomalla (nanomesh). Esta metodología permite la creación de varios defectos en la estructura de G (hot-spots), permitiendo luego una mejora en la señal de RhB con un factor de incremento de $\sim 1,8$ (enhancement factor, EF). ${ }^{30}$ Asimismo, algunos grupos han mejorado la actividad SERS incorporando nanopartículas metálicas como copotenciadores. ${ }^{31-34}$ Por ejemplo, Murphy et al. ${ }^{31}$ redujeron $\mathrm{Ag}^{+}$en la presencia de óxido de grafeno (GO), con el fin de formar compositos entre ambos nanomateriales (GOnanopartículas de $\mathrm{Ag}$ ). Esta elegante metodología permitió la obtención de derivados de porfirinas en concentraciones tan bajas como $140 \mathrm{nM}$. Siguiendo un procedimiento

mencionarse el caso en el que dos nanocristales de $\mathrm{Ag}$ de $30 \mathrm{~nm}$ de radio cada uno, se encuentren separados por una distancia de $1 \mathrm{~nm}$. Luego, las polarizaciones mutuas van a transformar completamente la naturaleza de los estados electrónicos excitados del metal. Particularmente, las partículas únicas poseen un estado excitado uniformemente distribuido en su interior, mientras que en el caso de los dímeros de nanocristales poseen un estado excitado localizado en la superficie del metal exactamente en la unión entre ambas partículas, creando así las regiones conocidas como "hot-spots". ${ }^{25}$

$\dagger$ Es importante mencionar que recientemente se ha acuñado el término Graphene-enhanced Raman scattering (GERS) en analogía con el término SERS, para referirse a todos los casos en los que grafeno es capaz de incrementar la señal Raman de un analito dado. ${ }^{3}$ 
similar, Dutta et al. ${ }^{32}$ redujeron iones de Ag en la presencia de GO, y lograron un límite de detección (limit of detection, LOD) de $10 \mathrm{nM}$ para acetato de uranilo. Asimismo, otros grupos adsorbieron nanopartículas bimetálicas de $\mathrm{Ag} / \mathrm{Au}$ sobre $\mathrm{GO}$ funcionalizado, en donde las heterojunciones produjeron un incremento en la actividad SERS de Alexa flúor 488 de $\sim 1,5$ ordenes de magnitud en comparación al GO sólo. ${ }^{33}$ Recientemente, Min et al. construyeron plataformas SERS del tipo sándwich entre nanopartículas de Au protegidas con una cubierta orgánica y grafeno. En el diseño de las mismas, las películas de rGO (óxido de grafeno reducido) se colocaron en la base, el GO (óxido de grafeno) en la superficie, con las NPs de Ag en el medio de ambas películas. Esta metodología produjo dos ventajas al sistema, por un lado previno de la oxidación a las NPs de Ag por más de dos meses, y a su vez produjo un incremento en la actividad SERS de Rh6G de $\sim 1,6$ veces. $^{34}$

En éste contexto, este Capítulo presenta el desarrollo de un método simple para obtener heterojunciones compuestas de grafeno (G) y nanopartículas (NPs) de Au protegidas con un grupo orgánico, las cuales se ensamblaron por medio de interacciones hidrofóbicas entre ambos nanomateriales. Aunque el uso de una cubierta orgánica alrededor de los centros metálicos de Au les confiere estabilidad y permite la formación de las heterojunciones, las cadenas alquílicas tienen que ser removidas por tratamientos térmicos. Asimismo, se exploró en la corriente y la actividad Raman (SERS) de películas de grafeno (G) as-tranferred; grafeno oxidado (aquí nombrado como OG, para evitar la confusión con el GO que es obtenido por otra metodología); y las heterojunciones (NPs de $\mathrm{Au}$ tanto sobre G o como sobre OG). Se observó una importante sinergia entre ambas películas frente al apagamiento (quenching) de la PL y la FL, y sumado a ésto se consiguió un aumento en la actividad SERS. Se encontró que el grafeno as-transferred suprime la mayor parte de las señales no deseadas de PL y FL, mientras que las NPs de Au son las que actúan como co-potenciadores de la actividad Raman de RhB. Sabiendo que los electrones- $\pi$ en nanocarbones son los encargados de conferirle conductividad, surgió la curiosidad de explorar en los efectos de las diferentes energías de luz UV sobre las propiedades electrónicas de grafeno. ${ }^{35}$ Estos resultados podrían tener implicancias en la construcción de transistores del tipo G-FET, en el diseño de plataformas SERS, y en aplicaciones en paneles solares.

\subsection{Experimental}

\subsubsection{Síntesis de NPs de Au y Grafeno}

Las NPs de Au recubiertas con TOABr (Au@TOABr), fueron sintetizadas de acuerdo a la síntesis bifásica de Brust-Schiffrin pero sin la adición de alcanotioles, como ha sido reportado. ${ }^{36}$ Las NPs preparadas por éste protocolo tienen un diámetro de $4,9 \pm$ 
1,2 $\mathrm{nm}$ de acuerdo a la caracterización por $\mathrm{TEM}^{37}$ El grafeno fue crecido (sintetizado) sobre una lamina de $\mathrm{Cu}$, y luego transferido a varios sustratos siguiendo el protocolo reportado por Sumanasekera et al. ${ }^{38}$ Las muestras fueron transferidas a microelectrodos de Au separados ya sea por $5 \mu \mathrm{m}$ (electrodos de Au interdigitados, IDA mostrado en el recuadro de la Figura 5.5A) o por $23 \mu \mathrm{m}$ para las medidas de corriente (cyclic voltammetry, CV y Cronoamperometría cíclica, CA). Los sustratos de vidrio y Si fueron empleados en los experimentos de LSPR y SERS, respectivamente. Mayores detalles respecto a las síntesis mencionadas pueden encontrarse en el Capítulo 2.

\subsubsection{Tratamientos a las Películas Transferidas}

Con el fin de limpiar las muestras de Grafeno (G) as-transferred, las mismas fueron inmersas en acetona tibia (debajo de su punto de ebullición) para remover el PMMA, seguido de un lavado con varios solventes y finalmente un secado con flujo de $\mathrm{N}_{2}$. La oxidación de grafeno fue llevada a cabo en un generador de ozono modelo UVO ozone cleaner (Jelight Company Inc., Irvine, CA). Las heterojunciones fueron formadas tanto sobre películas de grafeno como sobre grafeno oxidado, realizados por una inmersión de ambas películas en una solución de NPs de Au por 1 hora y 12 horas. Para el caso de las películas de NPs de Au sobre sustratos de $\mathrm{Si}$ y $\mathrm{SiO}_{\mathrm{x}}$, las mismas fueron depositadas por la metodología de drop-casting (gota a gota) colocando $10 \mu \mathrm{L}$ de una suspensión de NPs de Au en tolueno (correspondiente a una concentración de 1,4-1,6 $\mathrm{mg} / \mathrm{mL}$ ). Los tratamientos térmicos fueron realizados en un horno modelo Barnstead/Thermolyne Small Benchtop Muffle Furnaces Type 1300 (Thermo Scientific) a $200{ }^{\circ} \mathrm{C}$ por $30 \mathrm{~min}$. Mayores detalles experimentales pueden encontrarse en el Capítulo 2.

\subsubsection{Caracterización de las Películas}

Las películas fueron caracterizadas por XPS usando una fuente de $\mathrm{Mg} \mathrm{KR}$ (XR50, Specs $\mathrm{GmbH}$ ) acoplada a un analizador para la energía de electrones hemisférico (PHOIBOS 100, Specs GmbH). Los espectros de UV-vis fueron realizados en un espectrofotómetro Perkin-Elmer Lambda 35 Spec. (Rango comprendido entre 300 y $900 \mathrm{~nm}$ ). Las heterojunciones fueron formadas sobre sustratos de vidrio, y las películas fueron medidas en condiciones ambientales. Los espectros de FTIR fueron realizados en un espectrómetro PIKE Miracle Varian 600 Instrument, operando en modo de transmisión. Las mencionadas medidas se realizaron sobre sustratos de vidrio limpios antes y después de la adición de unas gotas del polímero PMMA diluido en tolueno. Las imágenes de SEM de las heterojunciones fueron adquiridas en un microscopio FEI Helios NanoLab 650, operando entre 15-20 keV. Las imágenes de AFM fueron adquiridas en un microscopio Veeco Digital Instruments Nanoscope V (Santa Barbara, CA) usando una punta de Si (Si tip) operando en modo tapping. Las muestras utilizadas para la caracterización por AFM fueron ensambladas y tratadas 
térmicamente siguiendo el mismo protocolo descripto más abajo en éste Capítulo. Los análisis por termogravimetría (thermogravimetric analysis, TGA) fueron realizados en un NETZSCH STA 409C, operando en un rango de temperaturas comprendido entre 30-500 ${ }^{\circ} \mathrm{C}$. Para la mencionada técnica, $50 \mathrm{mg}$ of nanopartículas secas (polvo) fueron colocadas en un crisol de alúmina, el cual fue sometido a un incremento de la temperatura en intervalos de $10{ }^{\circ} \mathrm{C}$ cada 10 minutos (realizado en una atmósfera oxidante, aire).

\subsubsection{Experimentos Empleando Espectroscopia Raman}

Los espectros Raman fueron adquiridos en un sistema Raman con un microscopio confocal LABRAM-HR Horiba Jobin-Yvon, empleando un objetivo de $100 x$, y lentes con una apertura numérica de (numerical aperture, NA) de 0,9. El láser de excitación y la fuente empleada fueron de 632,8 nm (He-Ne) y 1,7 mW, respectivamente. Los espectros se adquirieron empleando una baja potencia del láser, para evitar el calentamiento y el daño en las muestras inducidos por el éste. Para los experimentos de SERS, $20 \mu \mathrm{L}\left(2,0 \times 10^{-5} \mathrm{M}\right)$ de una solución acuosa de rodamina $\mathrm{B}$ $(\mathrm{RhB})(\mathrm{pH}=5)$ fue goteada (drop-casting) sobre sustratos de $\mathrm{Si}, \mathrm{SiO}_{\mathrm{x}}, \mathrm{G}$ as-transferred, y OG, y se permitió que las películas se secaran por 1 hora.

\subsubsection{Medidas de Conducción en Estado Sólido y Sensado de Luz UV}

Todas las medidas de corriente en estado sólido y experimentos de sensado fueron realizadas en una estación electroquímica de trabajo $\mathrm{CH}$ Instruments 700D Bipotentiostat (Austin, TX). La corriente fue medida en las películas de grafeno empleando electrodos interdigitados (interdigitated electrodes, IDA) y/o electrodos con espaciado de 5 a $23 \mu \mathrm{m}$. Los electrodos fueron fabricados en una sala limpia para fotolitografía sobre sustratos de $\mathrm{Si} / \mathrm{SiO}_{\mathrm{x}}$ (INTI, Argentina). El cableado de los microelectrodos fue realizado utilizando cables de $\mathrm{Cu}$ (con un recubrimiento plástico), los cuales se unieron a los pads de los electrodos por medio de pintura de Ag (curada por $12 \mathrm{hs} \mathrm{a} 80^{\circ} \mathrm{C}$ ), la cual luego fue aislada y protegida con una capa de torr-seal epoxy (curado por $12 \mathrm{hs}$ a $80^{\circ} \mathrm{C}$ ). Los electrodos fueron limpiados por inmersión en anisol y dicloroetano, seguidos de lavados en acetona, etanol, isopropanol y secado bajo flujo de $\mathrm{N}_{2}$. Un electrodo fue conectado a los cables de los electrodos de referencia y de conteo, mientras que el otro electrodo fue conectado al cable correspondiente al electrodo de trabajo. Los experimentos de sensado fueron realizados en modo de Cronoamperometría (chronoamperometry mode, CA). La corriente fue monitoreada en el tiempo mientras que un potencial de $0,3 \mathrm{~V}$ fue aplicado entre los dos electrodos y la muestra fue expuesta a ciclos de encendido/apagado ("on/off") de luz UV empleando diferentes longitudes de onda (diferentes energías). La mayor energía de luz UV empleada fue conseguida utilizando un generador de ozono UVO cleaner operando a $180 \mathrm{~nm}$ (para generar especies altamente reactivas) y $254 \mathrm{~nm}$ para la oxidación del material orgánico. 
Asimismo, se utilizaron otras dos lámparas de $\mathrm{Hg}$ operando a 254 y $365 \mathrm{~nm}$ (intensidad de la fuente de $6 \mathrm{~W} / \mathrm{cm}^{2}$ ), para comparar los perfiles de sensado de UV obtenidos a diferentes energías. Todas las lámparas de iluminación Ultravioleta (UV) fueron colocadas a $15 \mathrm{~cm}$ de las muestras y todos los experimentos fueron realizados en condiciones ambientales.

\subsection{Resultados}

\subsubsection{Espectroscopia Raman Aplicada a Grafeno}

Es conocido que la espectroscopia Raman aplicada a la caracterización de grafeno y otros nanocarbones permite explorar en aspectos tan diversos como: a) el tamaño de los cristales (cristalitas); b) el carácter de las hibridaciones ( $s p^{2}$ versus $s p^{3}$ ); c) la presencia de impurezas químicas; d) permite asignar el número de capas; e) descubrir posibles torsiones en la película (strains); f) determinar la energía de la banda prohibida $\left(\mathrm{E}_{\mathrm{g}}\right)$; g) determinar el grado de dopado (doping) y defectos; y h) la densidad de masa, sólo por mencionar algunos.

La Figura 5.1 muestra los espectros Raman correspondientes a grafito (A) y a grafeno (B), los cuales fueron adquiridos empleando un láser a 632,8 nm. En los mismos están asignadas las bandas $\mathrm{G}\left(\sim 1580 \mathrm{~cm}^{-1}\right)$ y $2 \mathrm{D}\left(\sim 2700 \mathrm{~cm}^{-1}\right)$ (también llamada $\mathrm{G}^{\prime}$, por ser la segunda más prominente después de la banda $\mathrm{G}$ característica de grafito). Puede notarse, con una intensidad muy baja, la presencia de una banda situada en $\sim 1350$ $\mathrm{cm}^{-1}$, denominada D en el espectro de grafeno. Esta última banda está asociada al grado de desorden en la película y una breve descripción de la misma es dada en la Sección 5.3.1.4.

A continuación se bridarán algunos ejemplos de aportes en la caracterización de grafeno empleando espectroscopia Raman, los cuales demuestran que ésta última es una herramienta ideal para el estudio de nanocarbones.

\subsubsection{Proceso de Doble Resonancia en Grafeno}

Particularmente, la banda 2D es empleada como una huella dactilar en la determinación del número de capas de grafeno. La misma está presente tanto en grafeno como en HOPG (highly oriented pyrolytic graphite) con defectos. La naturaleza de esta banda es regida por un proceso de Doble Resonancia (DR), como se explica más abajo. 
Existe una fuerte correlación entre las bandas electrónicas de grafito y grafeno con el fenómeno Raman. La mencionada relación permite explicar porque por ejemplo, grafeno posee una única banda 2D (ver Sección 5.3.1.2 para más detalles) y porque grafeno bicapa posee una banda $2 \mathrm{D}$ que se resuelve en cuatro picos. La Figura 5.2 muestra un esquema del proceso de DR tanto para grafeno (A) como para grafeno bicapa (B), el cual fue adaptado según la referencia. ${ }^{4}$ Tal como fue rigurosamente explicado por Ferrari et al., ${ }^{4}$ la banda 2D en grafeno es producida por dos fonones con momentos opuestos, en la zona de alta simetría cercana a los puntos $\mathrm{K}$ y K'. Notar que estos puntos de simetría están situados en el medio de los conos de Dirac (puntos de Dirac).

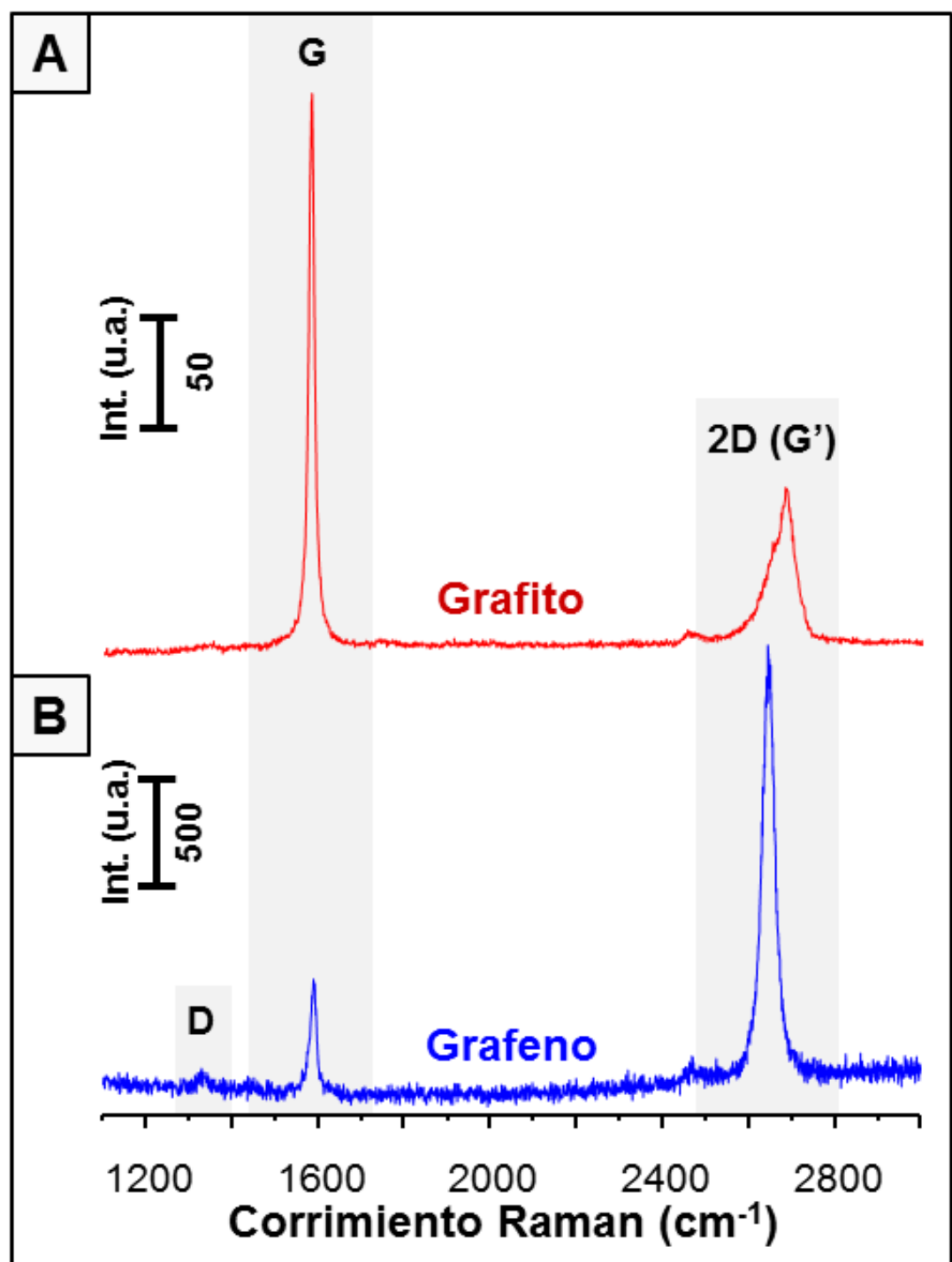

Figura 5.1 Espectros Raman de grafito (A) y grafeno (B). Las bandas características están marcadas con una banda gris. Ver el texto para más detalles. 
La dispersión Raman (dentro del proceso de DR) implica cuatro transiciones virtuales, es por ello que es un proceso de cuarto orden. Las transiciones virtuales implican: i) la excitación de un par hueco-electrón, la cual es inducida por el láser (transición vertical desde $\mathrm{a} \rightarrow \mathrm{b}$ ); ii) la dispersión del electrón-fonón con un momento de intercambio q, el cual es cercano al punto $\mathbf{K}(\mathrm{b} \rightarrow \mathrm{c})$; iii) la dispersión del electrón-fonón con un momento de intercambio $-\mathbf{q}(\mathrm{c} \rightarrow \mathrm{b})$; y finalmente iv) la recombinación del par electrón-hueco $(\mathrm{b} \rightarrow \mathrm{a})$. Por consiguiente, el proceso de DR es alcanzado sólo cuando la energía es conservada en esas transiciones, ${ }^{4}$ ver la Figura 5.2A.
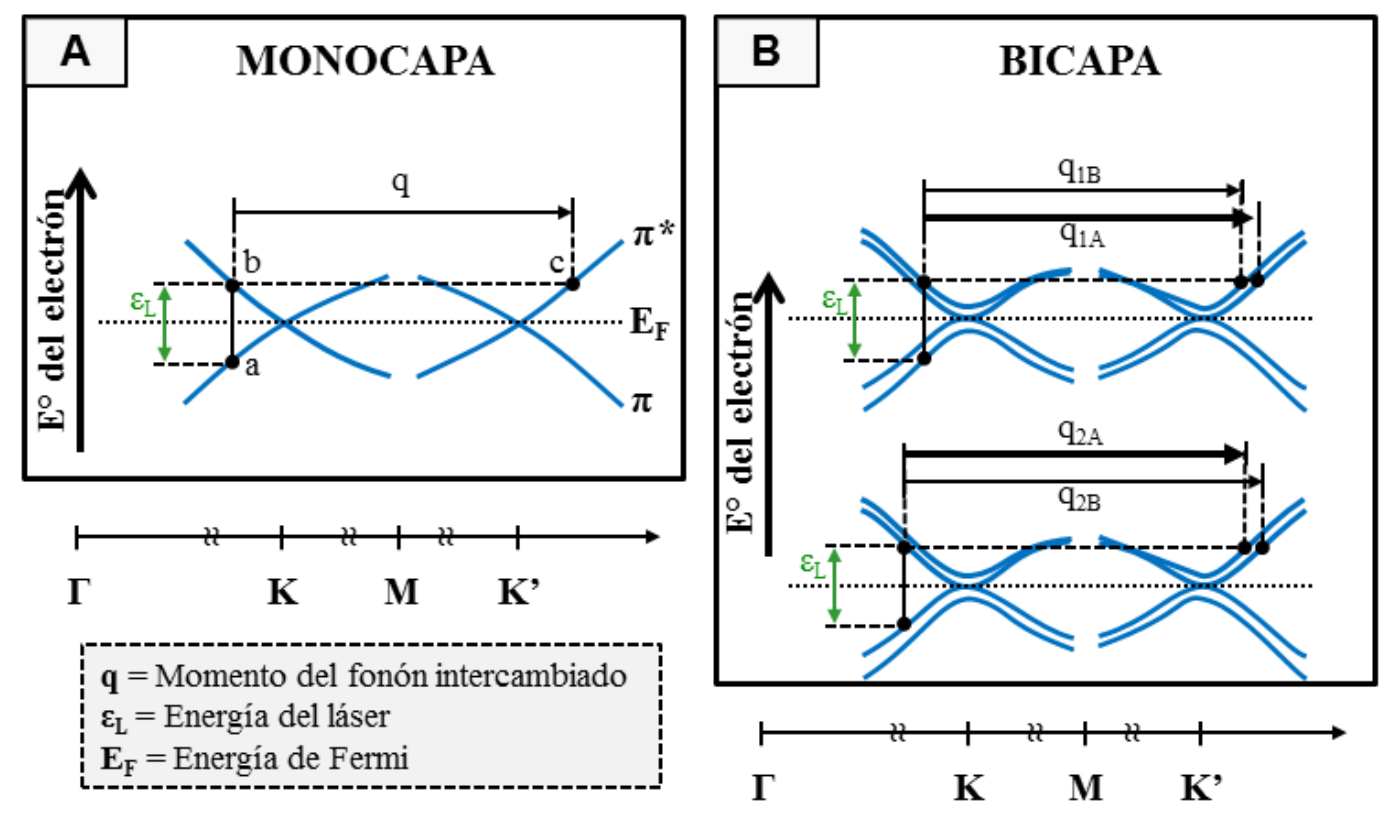

Figura 5.2 Esquema mostrando el proceso de Doble Resonancia (DR) para grafeno monocapa (A) y para grafeno bicapa (B). Adaptado de la referencia. ${ }^{4}$

Por otro lado, para el caso de grafeno bicapa con un apilamiento tipo AB, la interacción en el eje $\mathrm{z}$ de las capas causa que las bandas $\pi$ y $\pi^{*}$ se dividan en cuatro bandas. Como resultado de ello, se observan cuatro picos (dos con mayor intensidad y dos con menor intensidad) los cuales corresponden a los cuatro fonones implicados en el proceso. En la Figura 5.2B, las flechas más gruesas denotan aquellos momentos que al ser más probables $\left(\mathrm{q}_{1 \mathrm{~A}} \mathrm{y} \mathrm{q}_{2 \mathrm{~A}}\right)$ dan origen a los dos picos más intensos. Lo contrario sucede para los otros dos momentos $\left(\mathrm{q}_{1 \mathrm{~B}}\right.$ y $\left.\mathrm{q}_{2 \mathrm{~B}}\right)$ que originan dos picos de menor intensidad. ${ }^{4}$

\subsubsection{Dependencia de la Banda 2D con el Número de capas de Grafeno}

Como es de esperar, las propiedades electrónicas (particularmente la estructura electrónica) de grafeno se ven notoriamente influencias tanto por el número de capas 
como por el tipo de apilamiento entre las mismas. Notar que en el caso de grafito, la única configuración entre las capas es del tipo $\mathrm{AB}$, pero en grafeno pueden producirse otros modos de apilamiento.

Como se estudió en la sección anterior, el proceso Raman de doble resonancia (DR) para el caso de una bicapa de grafeno con un apilamiento tipo AB (en donde existen dos bandas de valencia y dos bandas de conducción) da lugar a una banda 2D que debe ajustarse con cuatro picos Lorentzianos (Lorentz fit). Es por ello que la evolución desde un grafeno monocapa hasta multicapas (partiendo desde un sistema bidimensional a uno tridimensional) va produciendo un ensanchamiento de la banda 2D al mismo tiempo que la intensidad de la misma va decreciendo.

Empleando los criterios mencionados respecto a los incrementos en el ancho a la altura media del pico (FWHM) de la banda 2D, se ha determinado cuantitativamente que por encima de 5 capas de grafeno, el espectro Raman del mismo comienza a ser casi indistinguible del de grafito. ${ }^{4}$

Es importante mencionar que, en general en el grafeno obtenido por CVD el apilamiento de las capas de grafeno no es del tipo AB (Bernal stacking), tal como ocurre en grafito. ${ }^{39}$ Estos cambios en la orientación entre las capas de grafeno producen una disminución en la simetría de la banda $2 \mathrm{D}$, que finalmente tienden a ensancharla. Considerando lo antes expuesto, cuando se requiera determinar el número de capas de grafeno en una muestra dada, deben considerarse estos fenómenos que producen cambios en el FWHM de la banda 2D. ${ }^{40}$

\subsubsection{Dependencia de la Frecuencia de la Banda 2D con la Energía del Láser}

Como se verá más adelante en éste Capítulo, la posición e intensidad de la banda 2D está estrechamente ligada a la energía del láser empleado durante los experimentos Raman.

Como un ejemplo de ello, cabe mencionar la reciente publicación del grupo de Ruoff, quienes emplearon espectroscopia Raman para caracterizar muestras de grafeno crecido sobre Cobre, las cuales fueron expuestas a láseres con diferentes energías. El objetivo del mencionado trabajo fue explorar la influencia de la energía del láser de excitación (entre $\sim 2 \mathrm{a} \sim 4 \mathrm{eV}$ ) en el ancho, la intensidad, y la forma de la banda 2D de grafeno. $^{41}$

\subsubsection{Determinación de Defectos en Grafeno}

Existen dos bandas en grafeno asociadas al grado de desorden en el mismo, nombradas como D y D'. Ambas son bandas Raman prohibidas. 
La banda D (nombrada así por su relación con el desorden) está presente solamente en zonas de grafeno en los que existen imperfecciones en la película ${ }^{42}$ o bien que se esté adquiriendo el espectro Raman en un borde de la misma. ${ }^{43}$ Por otro lado, dependiendo de que tan defectuosa sea la muestra, puede aparecer la banda D', la cual es de menor intensidad que la primera.

El mecanismo por el cual se generan dichas bandas implica un proceso de dispersión inter-valle (banda D) e intra-valle (banda D') mediado por un único fonón (single-phonon intravalley scattering process). ${ }^{44,45,42}$ Asimismo, la aparición de la banda D + D' implica la combinación de ambos modos Raman (sobre-tono). ${ }^{42}$

Como se verá más adelante en el Capítulo 6 de la presente Tesis, las mencionadas bandas pueden ser estudiadas empleando la espectroscopia TERS (tipenhancement Raman spectroscopy) debido a que ésta técnica permite mejorar la resolución de las bandas características de grafeno.

\subsubsection{Sensibilidad de la Banda G a los Portadores de Cargas}

Recientemente, ha sido demostrada la sensibilidad de las bandas G y 2D a la concentración de portadores de cargas (carriers) en una muestra dada. Particularmente, la banda $\mathrm{G}$ es la que muestra mayores cambios tanto en la frecuencia como en el ancho de banda (FWHM) dependiendo del voltaje aplicado al sistema, como fue demostrado por Das et al. ${ }^{46}$ Cabe mencionar que estos resultados fueron primeramente predichos teóricamente, $\mathrm{y}$ finalmente demostrados experimentalmente. ${ }^{40}$

\subsubsection{Caracterización Preliminar del Grafeno Obtenido}

Con el fin de determinar la calidad del grafeno obtenido, luego de que el mismo fue transferido a diferentes sustratos empleando PMMA, se realizó su caracterización empleando espectroscopia Raman y XPS.

La Figura 5.3 muestra los espectros Raman correspondientes a grafeno astransferred sobre sustratos de Si tomados en diferentes áreas de la misma muestra (desde la zona 1 a la zona 3). Las bandas 2D fueron ajustadas con una línea Lorentziana, resultando un promedio de un FWHM de $\sim 34,2 \mathrm{~cm}^{-1}$, evidenciando que el grafeno obtenido es monocapa y no presenta defectos (ausencia de las bandas D y D'). Además, mostró una relación de intensidades entre las bandas $\mathrm{G}: 2 \mathrm{D}$ de $1: 3$.

En la Figura 5.4 se muestran los espectros de XPS de alta resolución de grafeno as-transferred sobre un sustrato de $\mathrm{SiO}_{\mathrm{x}}$. Los espectros muestran un contenido mínimo esperado tanto de $\mathrm{Cu}(0,007 \%)$ (A) como de $\mathrm{Fe}(0,10 \%)$ presentes después de la disolución (etching) de la lámina de $\mathrm{Cu}$ en una solución de nitrato férrico (B). 

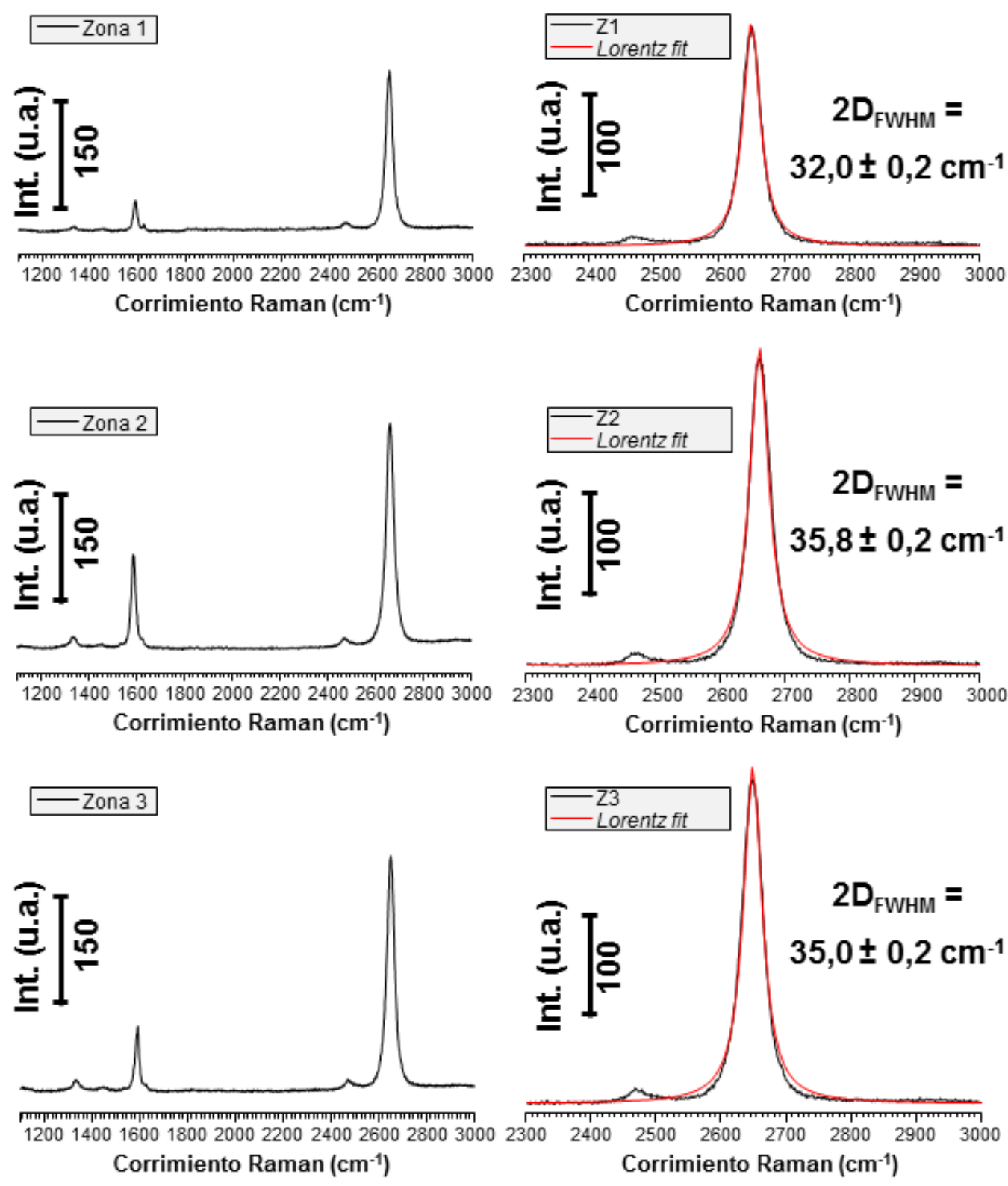

Figura 5.3 Espectros Raman de $\mathrm{G}$ as-transferred sobre sustratos de Si tomados en diferentes áreas (desde la Z1 a la Z3). Los espectros demostraron que el grafeno obtenido es monocapa de alta calidad, con una relación entre las bandas $G: 2 D$ de $1: 3$. Las bandas 2D fueron ajustadas con una línea Lorentziana resultando un promedio de un full width at half maximum (FWHM) de $\sim 34,2 \mathrm{~cm}^{-1}$. 


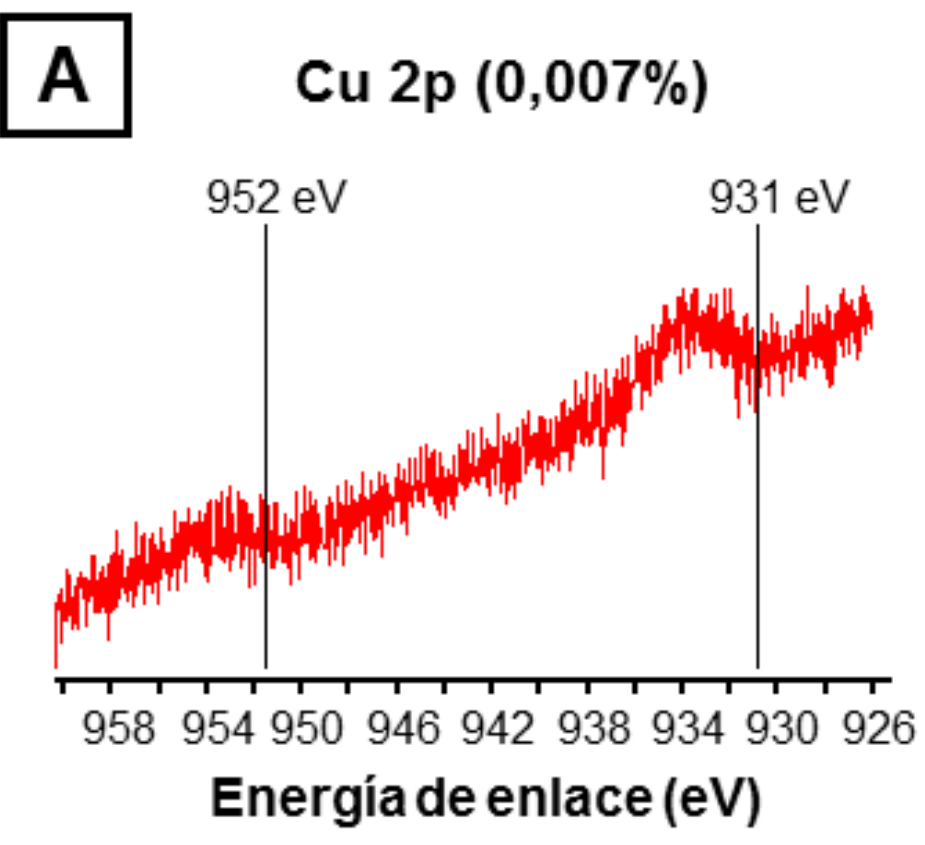

\section{B $\quad F e 2 p(0,10 \%)$}

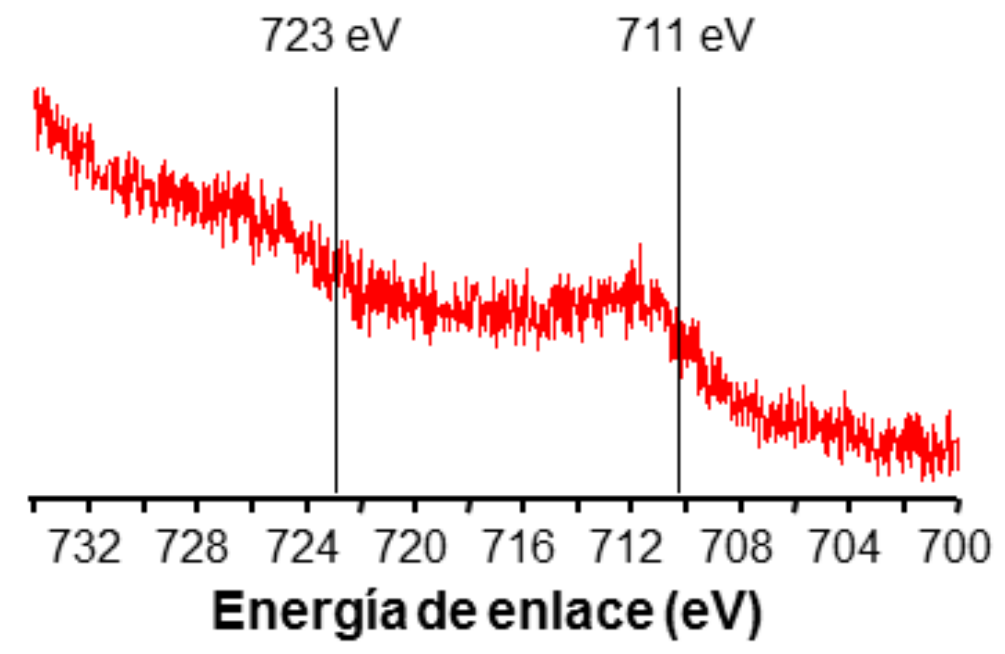

Figura 5.4 Espectros de XPS de alta resolución de grafeno (G) as-transferred sobre un sustrato de $\mathrm{SiO}_{\mathrm{x}}$. Los espectros muestran un contenido mínimo esperado de $\mathrm{Cu}(0,007 \%)(\mathrm{A})$ y de $\mathrm{Fe}(0,10 \%)$ presentes después de la disolución (etching) de la lámina de $\mathrm{Cu}$ en una solución de nitrato férrico (B). 


\subsubsection{Formación de las Heterojunciones}

Las heterojunciones fueron formadas colocando los sustratos de Grafeno (G) astransferred dentro de una solución de tolueno conteniendo las NPs de Au protegidas con surfactante (Au@TOABr). La Figura 5.5A muestra un grafico de corriente en función del voltaje aplicado (curvas $I-V$ ) antes y después de formar una heterojunción sobre un electrodo de $\mathrm{Au}$ interdigitado (IDA), indicando pequeños cambios en la corriente inducidos por la deposición de las NPs de Au sobre la película de grafeno. La ventana de potencial aplicada para todas las muestras que se estudiaron fue desde -300 a $300 \mathrm{mV}$. El G monocapa de alta calidad (ver Sección 5.3.2) exhibe corriente óhmica de $\sim 9,7 \times 10^{-5}$ A (a $300 \mathrm{mV}$ ), la cual está en cercana proximidad con los valores de corriente reportados en la literatura. ${ }^{8}$ Sobre las bases de la conductividad del grafito $(\sigma$ $\sim 5,3 \times 10^{-5}$ ohm.cm) reportadas por Wallace, ${ }^{39}$ nosotros calculamos ${ }^{47}$ la corriente de la película a través de un espacio de $5 \mu \mathrm{m}$ sobre un microelectrodo de Au IDA, mostrado en el recuadro en la Figura 5.3A. La corriente calculada exhibió un valor de $\sim 0,4 \mathrm{~A}$, la cual es generalmente entre 4 a 5 -veces mayor que la corriente medida en nuestros dispositivos. De acuerdo a lo expuesto, pensamos que los residuos remanentes del polímero PMMA, junto con los defectos a lo largo de la película de grafeno (grietas o huecos observados en la Fig. 5.3A) son los responsables del decrecimiento en la corriente observada en la película. En la Figura 5.6 se muestra una completa caracterización por medio de XPS, espectroscopia Raman, conducción, imágenes ópticas (índice de refracción, RI), y FTIR de películas de G as-transferred y posttreated. 


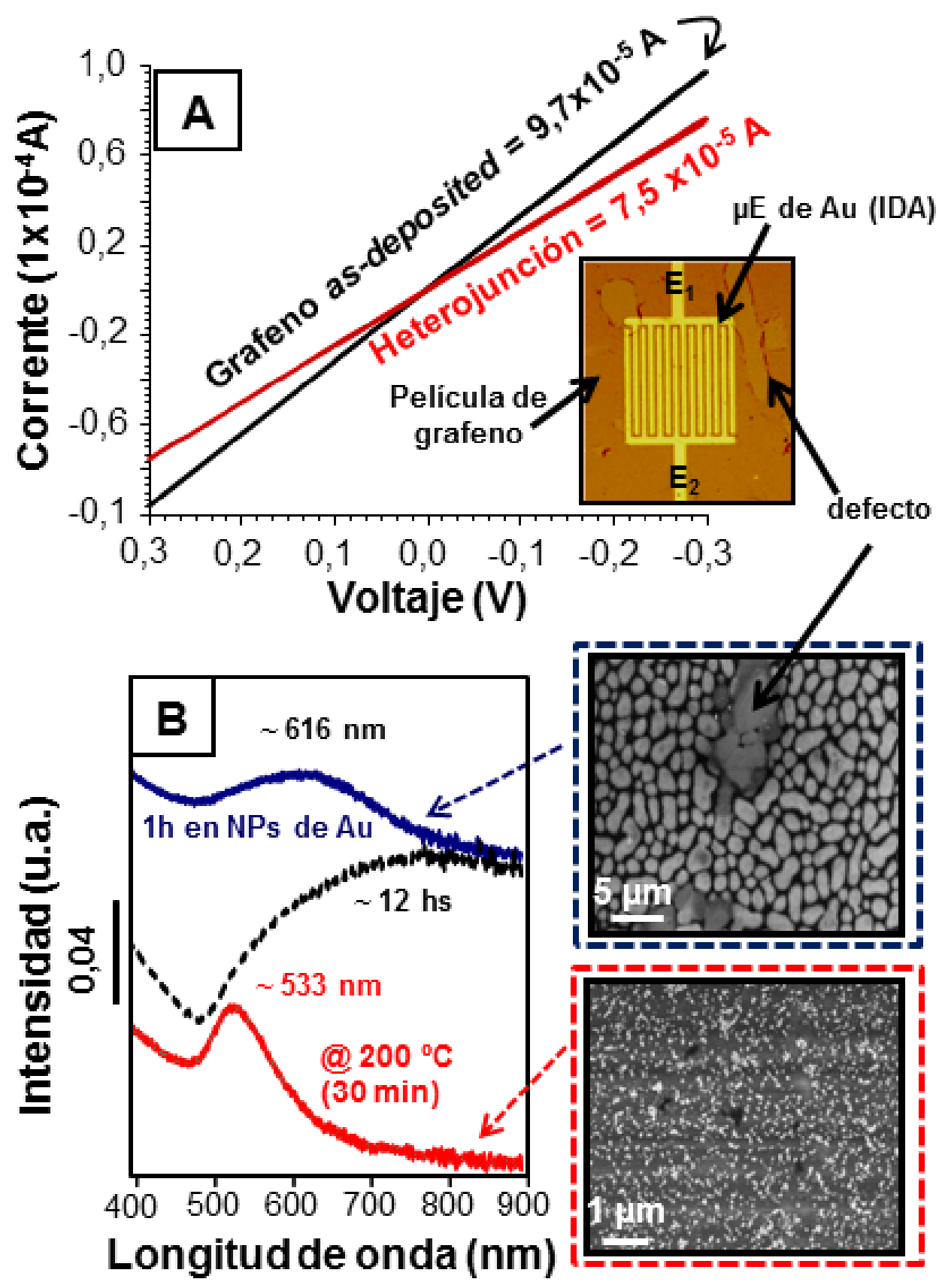

Figura 5.5 Curvas de corriente versus potencial (curvas $I-V$ ) para grafeno $(\mathrm{G})$ as-transferred sobre microelectrodos y después de 1 hora de inmersión en una solución conteniendo nanopartículas de $\mathrm{Au} @ \mathrm{TOABr}(\mathrm{A})$. Espectros de UV-vis de $\mathrm{G}$ as-transferred sobre vidrio inmerso en una solución de nanopartículas de Au@TOABr por 1 y 12 hs, y después del calentamiento de la película a $200{ }^{\circ} \mathrm{C}$ junto con imágenes de SEM tomadas en los tiempos indicados (B). 

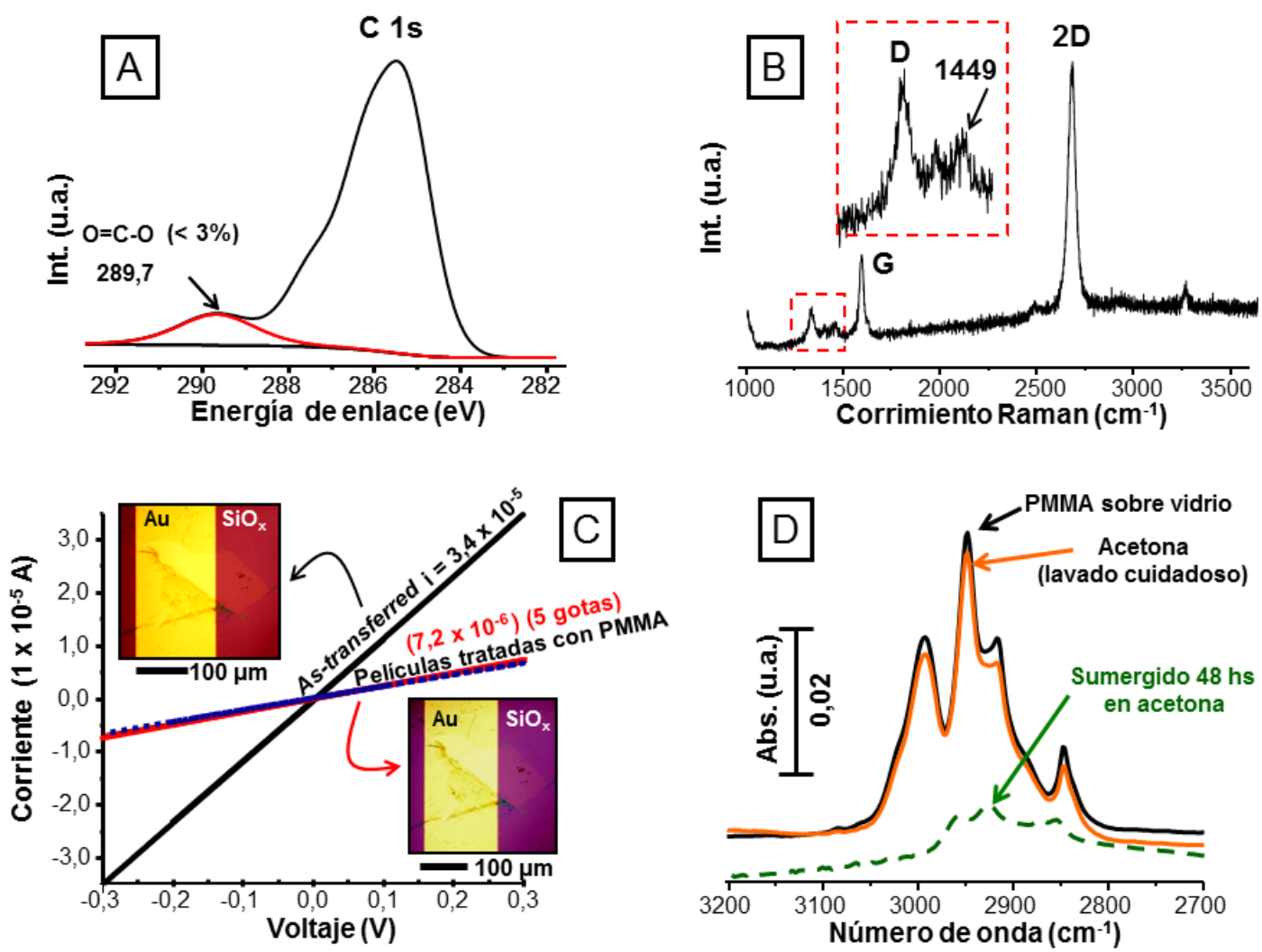

Figura 5.6 Espectros de XPS de C1s (A) y Raman (B) de muestras de G astransferred después de un lavado con acetona. Ambos espectros indican la potencial presencia de PMMA en $\sim 289 \mathrm{eV}$ y $1449 \mathrm{~cm}^{-1}$, respectivamente. Los gráficos de corriente versus voltaje (curvas $I-V$ ) para $\mathrm{G}$ as-transferred y después de la adición de 3 a 5 gotas de PMMA junto con las imágenes ópticas indicando los cambios en el índice de refracción (refractive index, RI) (C) y los espectros de FTIR del PMMA depositado sobre vidrio antes y después de un lavado cuidadoso y una inmersión por 48 hs en acetona, como es indicado (D), sugiriendo una incompleta remoción del PMMA.

La Figura 5.5B incluye los espectros de UV-vis de una heterojunción seleccionada (Au@TOABr y $\mathrm{G}$ ) formada sobre un sustrato de vidrio limpio. Después de 1 hora de inmersión de la película de grafeno en la solución conteniendo NPs de Au, la banda plasmónica correspondiente a las NPs aparece ancha y está desplazada a los rojos (en $\sim 80 \mathrm{~nm}$ ) en comparación a las mismas NPs ensambladas sobre vidrio, ${ }^{37}$ mientras que la inmersión durante toda la noche $(\sim 12 \mathrm{hs})$ resultó en una absorbancia en donde no se define el plasmón del $\mathrm{Au}$, lo cual es consistente con la aglomeración de las NPs (la 
película luce al ojo humano color púrpura, datos no mostrados). Resulta particularmente llamativo que, sólo con 1 hora de inmersión se observaron islas compuestas de NPs aglomeradas en la forma de micelas, ${ }^{48}$ las cuales están presentes en la imagen entera salvo en las zonas con defectos. Después del tratamiento térmico, la banda plasmónica situada en los azules se desplazó desde $\sim 620$ a $\sim 530$ nm y se tornó más aguda. Además, la película se tornó color rojiza (no mostrado) consistente con las imágenes de SEM, las cuales exhiben una configuración más separada entre las NPs de Au o islas. Ambos,

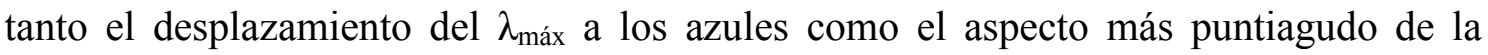
banda plasmónica son atribuidos a la combinación entre la restructuración de la película (separación entre las NPs) ${ }^{49}$ y la pérdida del material orgánico. El ultimo efecto conduce a disminuir el índice de refracción (refractive index, $\mathrm{RI})^{50}$ provocando un corrimiento a los azules y un incremento en la intensidad del plasmón, ${ }^{51}$ como es claramente notado en la Figura 5.5 B.

Con el fin de comparar la influencia del sustrato en los mencionados comportamientos, se realizaron experimentos utilizando indium tin oxide (ITO), el cual es un electrodo transparente y conductor. A diferencia de la películas de $\mathrm{G}$, el electrodo de ITO requiere de una funcionalización (en éste caso se empleó APTES), de extensos tiempos de inmersión en la solución de NPs $(\sim 12 \mathrm{hs})$, y el tratamiento térmico ligeramente mejora la intensidad del plasmón, como es mostrado en la Figura 5.7.

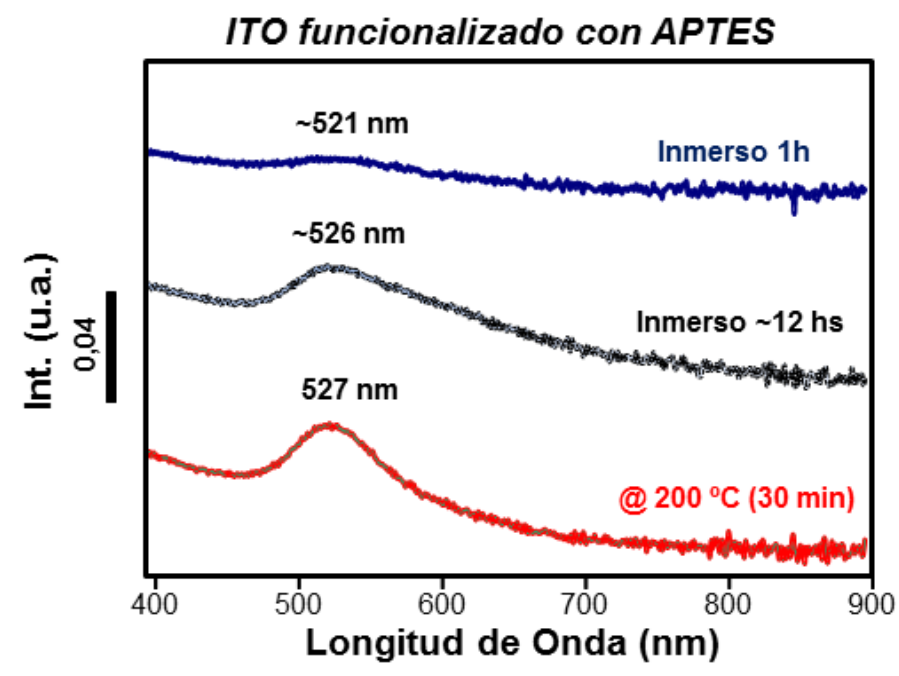

Figura 5.7 Espectros de UV-vis de un sustrato de ITO (Indium tin oxide) funcionalizado con APTES, seguido de una inmersión en una solución conteniendo las NPs de Au protegidas con surfactante por 1 y 12 horas, y luego del tratamiento térmico en el tiempo y temperatura indicados. Todos los gráficos están en offset para una mejor comparación. 


\subsubsection{Apagado de la Fotoluminiscencia por Grafeno}

Uno de los grandes inconvenientes cuando se emplean metales (ej.: $\mathrm{Cu}, \mathrm{Ag} \mathrm{u}$ $\mathrm{Au}$ ) para aumentar la señal Raman de un analito por medio de SERS, es la presencia de fotoluminiscencia (photoluminescence, PL) por parte de los primeros. Este fenómeno, muchas veces puede desde ocultar parcial o totalmente la señal del analito en estudio, hasta saturar el detector empleado en los experimentos de espectroscopia Raman. Es por ello que es crucial poder apagar la PL proveniente de estas plataformas metálicas, para disminuir así los tiempos de adquisición de los espectros y mejorar la relación señal/ruido del analito en cuestión.

La fotoluminiscencia (PL) en metales nobles puede explicarse como un proceso en el cual se produce una excitación de un electrón desde las bandas $d$ ocupadas hacia los estados comprendidos por encima del nivel de Fermi $\left(E_{F}\right)$. Luego, ocurre un proceso de dispersión de los pares electron-fonón y huecos-fonón, conduciendo a la pérdida de la energía y la generación de la fotoluminiscencia (la cual surge de la recombinación de un electrón desde una banda $s p$ ocupada con el hueco antes generado en la banda $d$ ). En la Figura 5.8 se muestra un esquema de la estructura de bandas de un metal noble,

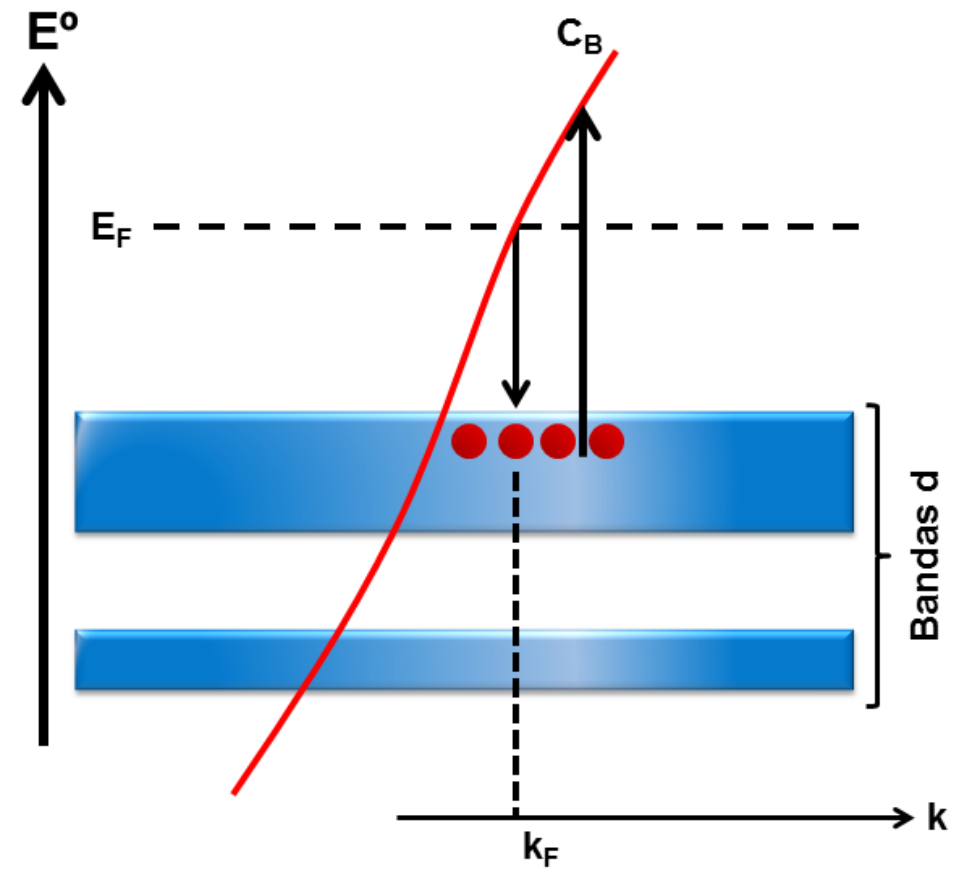

Figura 5.8 Esquema de la estructura de bandas de un metal noble, mostrando las transiciones de excitación y recombinación. Adaptado según la referencia. ${ }^{51}$ Siendo: $\mathrm{E}^{\mathrm{o}}$, energía; $\mathrm{E}_{\mathrm{F}}=$ Energía de Fermi; $\mathrm{C}_{\mathrm{B}}=$ banda de conducción; $\mathrm{k}_{\mathrm{F}}=$ momento de Fermi; $\mathrm{y} k=$ punto de simetría (espacio k). Ver la Sección 5.3.4 para mayores detalles. 
mostrando las transiciones de excitación y recombinación, el cual fue adaptado de la referencia. ${ }^{52}$ Definiendo: $\mathrm{E}^{\mathrm{o}}$, energía; $\mathrm{E}_{\mathrm{F}}=$ Energía de Fermi; $\mathrm{C}_{\mathrm{B}}=$ banda de conducción; $\mathrm{k}_{\mathrm{F}}=$ momento de Fermi; $\mathrm{y} \mathrm{k}=$ punto de simetría (espacio $\mathrm{k}$ ). Respecto a éste fenómeno, mayores detalles pueden encontrarse en los siguiente trabajos. ${ }^{27,52}$

Debido a lo anteriormente expuesto y como paso previo a los experimentos de SERS de Rodamina B (RhB), se caracterizó la heterojunción por medio de espectroscopia Raman. En la Figura 5.9A y 5.9B se comparan los espectros Raman de las NPs de Au sobre Si (100) y sobre G (heterojunción) antes y después del tratamiento térmico, respectivamente. Algunos aspectos interesantes observados incluyen: a) la banda del Si situada en $\sim 958 \mathrm{~cm}^{-1}$ (marcada con un *) comienza a ser completamente apantallada por un ancho e intenso espectro de las películas de NPs de Au sobre $\mathrm{Si}(\mathrm{Si} /$ Au NPs) que surge después del tratamiento térmico (Figura 5.9B). El área sombreada debajo del espectro indica la fotoluminiscencia (photoluminescence, PL) calculada como la diferencia entre el área integrada debajo del espectro y el área de todos los picos después de una corrección con una línea de base (en la Figura 5.10 se muestra un ejemplo del cálculo realizado para obtener el valor del área de la PL); b) la banda situada en $\sim 2885 \mathrm{~cm}^{-1}$ atribuida al stretching simétrico de los enlaces C-H mostró que luego del tratamiento térmico se produce un incremento mayor a 1 orden de magnitud debido a la actividad SERS de las NPs; y c) es necesario mencionar la notable habilidad de grafeno para suprimir en un 93\% la PL, como es indicado en el gráfico de barras mostrado en la Figura 5.9C.

Aunque la capa orgánica alrededor de las NPs de Au les otorga estabilidad y a su vez les permite la formación de la heterojunción por medio de interacciones hidrofóbicas con el grafeno, es conocido que las cadenas alquílicas pueden disminuir la señal SERS. ${ }^{53}$ De acuerdo a lo expuesto, ambas muestras fueron tratadas térmicamente con el objetivo de remover la cubierta orgánica. La Figura 5.11 muestra los experimentos de TGA y FT-IR indicando que los ligandos de $\mathrm{TOA}^{+}$comienzan a desprenderse alrededor de los $\sim 150^{\circ} \mathrm{C}$ y la mayoría del material orgánico fue removido ( 98\%) a los $200{ }^{\circ} \mathrm{C}$ después del tiempo indicado, respectivamente. Sin embargo, la remoción de la cubierta orgánica trae aparejado algunas consideraciones que aquí se detallan. 

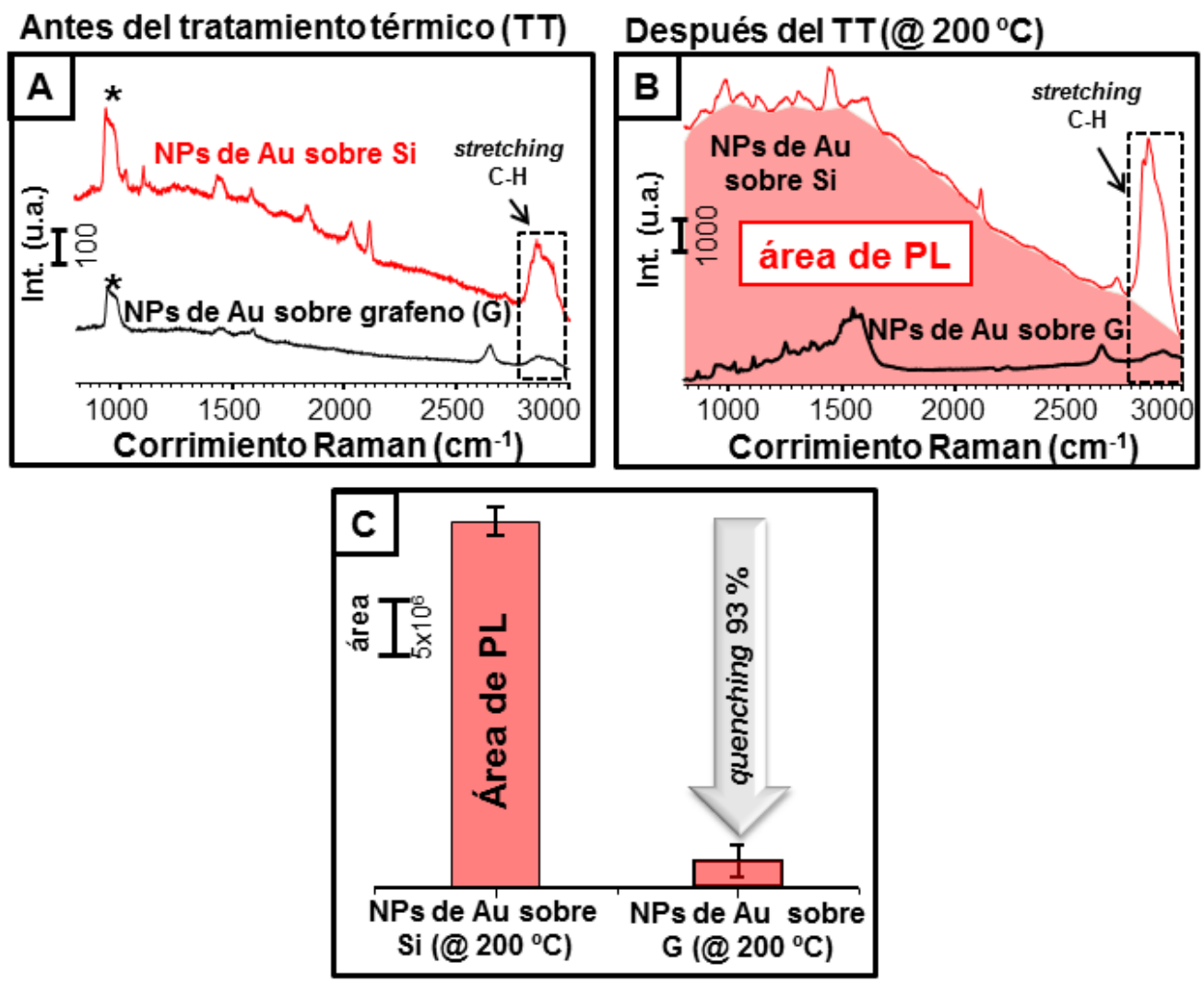

Figura 5.9 Espectros Raman correspondientes a las NPs de $\mathrm{Au} @ \mathrm{TOABr}$ decorando los sustratos de $\mathrm{Si}$ (100) y G (heterojunción) antes (A) y después (B) del calentamiento a $200^{\circ} \mathrm{C}$ por $30 \mathrm{~min}$, y los gráficos de barras indicando el porcentaje de apagado de la fotolumiscencia (photoluminescence, PL) por G calculado por el área bajo la curva de dos muestras preparadas en las mismas condiciones (C). Todos los espectros Raman mostrados en el panel A están en offset para una mejor comparación. 


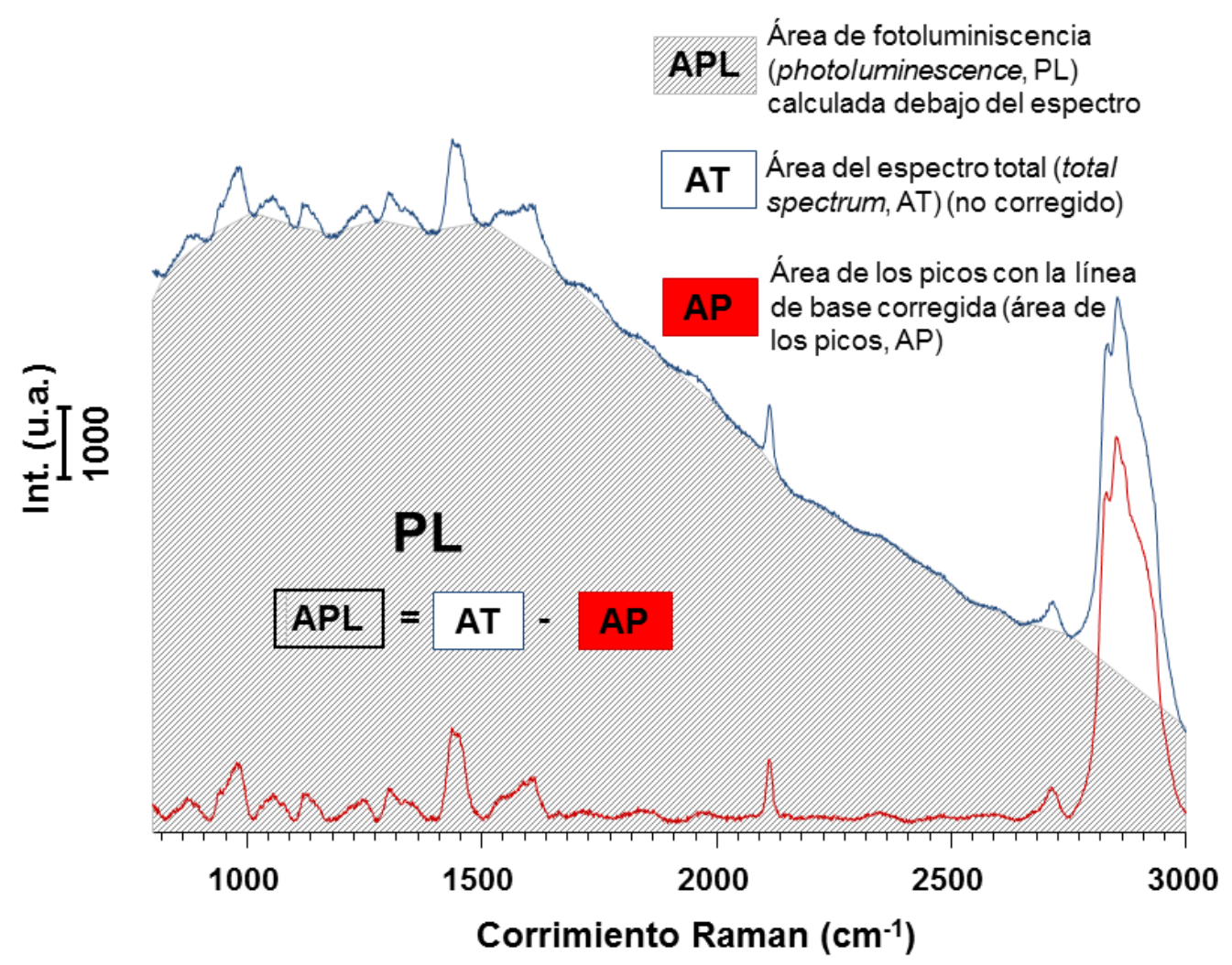

Figura 5.10 El área de la fotoluminiscencia (photoluminescence area, APL) fue calculada por la diferencia entre el área total del espectro (AT) (NPs de Au NPs sobre $\mathrm{Si}$ ) y el área de los picos (AP) después de la corrección de la línea de base, como es indicado. 


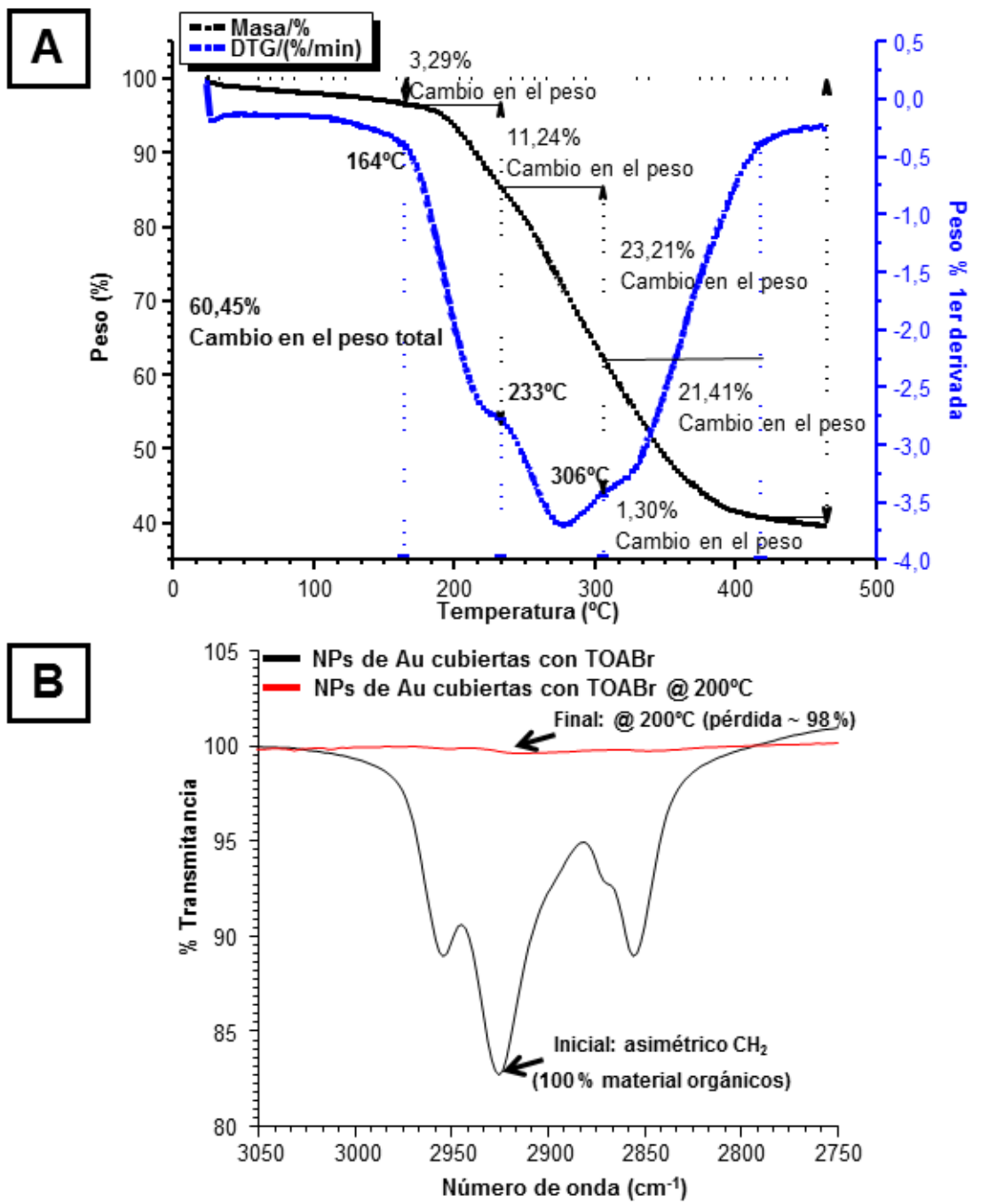

Figura 5.11 Análisis termogravimétrico (TGA), primera derivada (A) y espectros de FT-IR (B) correspondientes a las nanopartículas de $\mathrm{Au} @ \mathrm{TOABr}$ tratadas térmicamente, como es indicado.

Como fue mencionado anteriormente, la iluminación tanto de Au desnudo como de películas de Ag podría causar fotoluminiscencia (PL) ${ }^{52}$ Este fenómeno ha sido previamente reportado en películas delgadas de $\mathrm{Au}^{54}$ y nanopartículas ${ }^{27}$ durante experimentos empleando espectroscopia Raman. En nuestro sistema, la PL aparece después de que la muestra fue calentada, como es claramente notado por la gran intensidad mostrada en la Figura 5.9B. Una razón para explicar la gran intensidad de la 
PL podría estar asociada con la pérdida de las cadenas alquílicas y el annealing entre las nanopartículas. ${ }^{55,56}$

De carácter coherente con lo expresado anteriormente, se observó un incremento en la roughness (root mean square, RMS) desde $\sim 4$ a $8 \mathrm{~nm}$ después del tratamiento térmico de la heterojunción. Las imágenes de AFM (Figura 5.12) exhiben grandes y bien definidas NPs o islas después del tratamiento térmico, consistentes con las
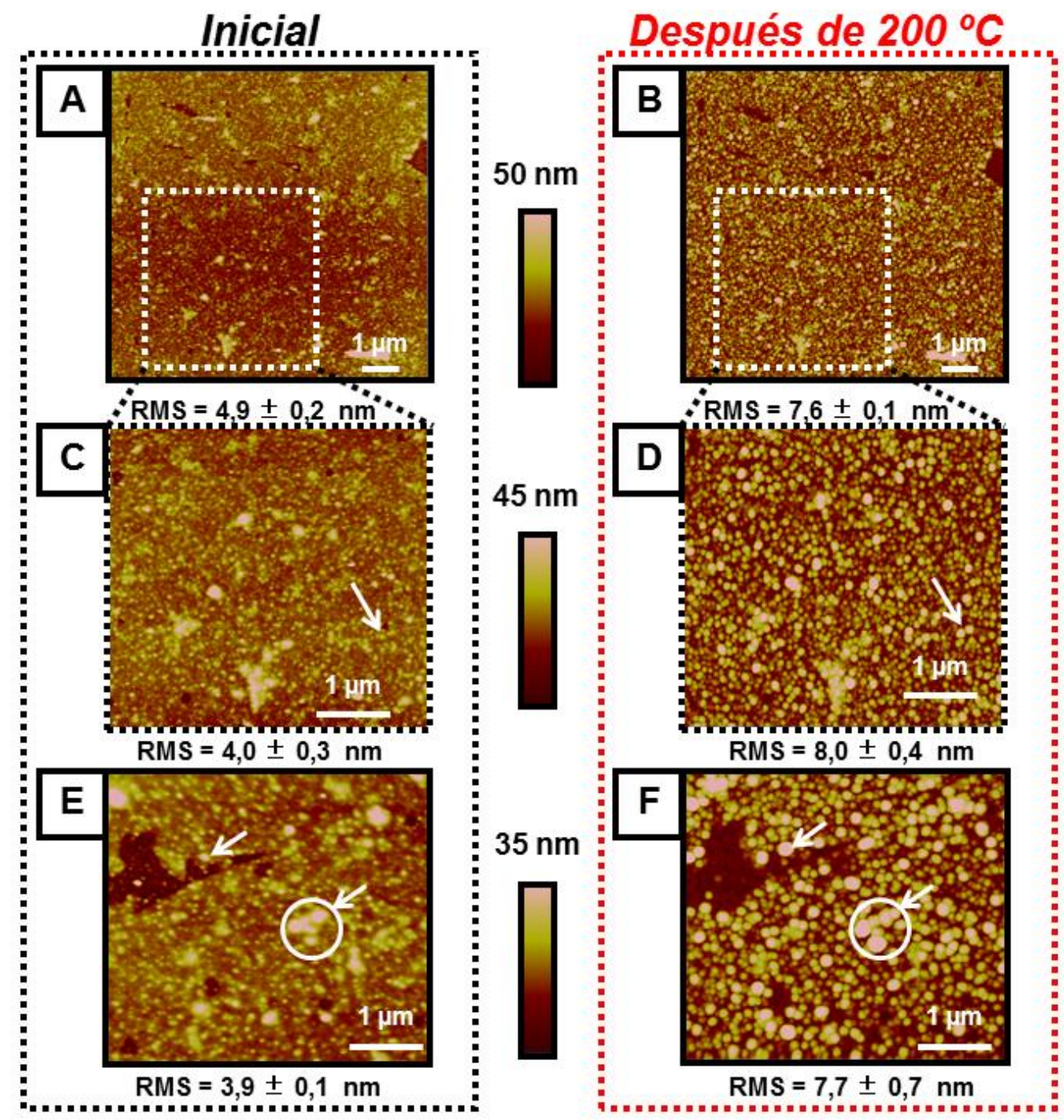

Figura 5.12 Imágenes de AFM de la heterojunción antes (A, C, D) y después (B, D, E) del tratamiento térmico realizado a $200{ }^{\circ} \mathrm{C}$ por 30 minutos. El valor de la roughness (root mean square, RMS) es mostrado debajo de cada imagen y obtenido del promedio del análisis de 4 diferentes áreas por imagen. Notar que la RMS duplica su valor desde $\sim 4$ a $8 \mathrm{~nm}$ después del tratamiento térmico. Las flechas blancas indican nanopartículas e islas antes y después del annealing. 
imágenes de SEM mostradas en la Figura 5.5B. Debe ser notado que la energía del láser utilizado $(\sim 633 \mathrm{~nm})$ cae dentro del rango de absorción del plasmón de las NPs $(\sim 530$ a $620 \mathrm{~nm})$ como es mostrado en la Figura 5.5B. Por lo tanto, la significativa supresión de la PL podría ser atribuida a una transferencia de la energía de resonancia desde las NPs de Au a el G en la heterojunción, como recientemente ha sido reportado que ocurre en nanobastones de Au. ${ }^{57}$

\subsubsection{Efectos Sinérgicos de las Heterojunciones Conformadas por Grafeno (G) y Grafeno Oxidado (OG)}

En esta sección se van a explorar los comportamientos sinérgicos de las heterojunciones respecto a la actividad SERS de la RhB. El Esquema 5.1 representa todos los pasos a los cuales tanto el $\mathrm{G}$ como el grafeno oxidado (OG) fueron sujetos durante los experimentos de espectroscopia Raman. Los sustratos de $\mathrm{SiO}_{\mathrm{x}}$ fueron empleados como control.

Esquema 5.1 Experimentos Raman llevados a cabo durante la construcción de las heterojunciones

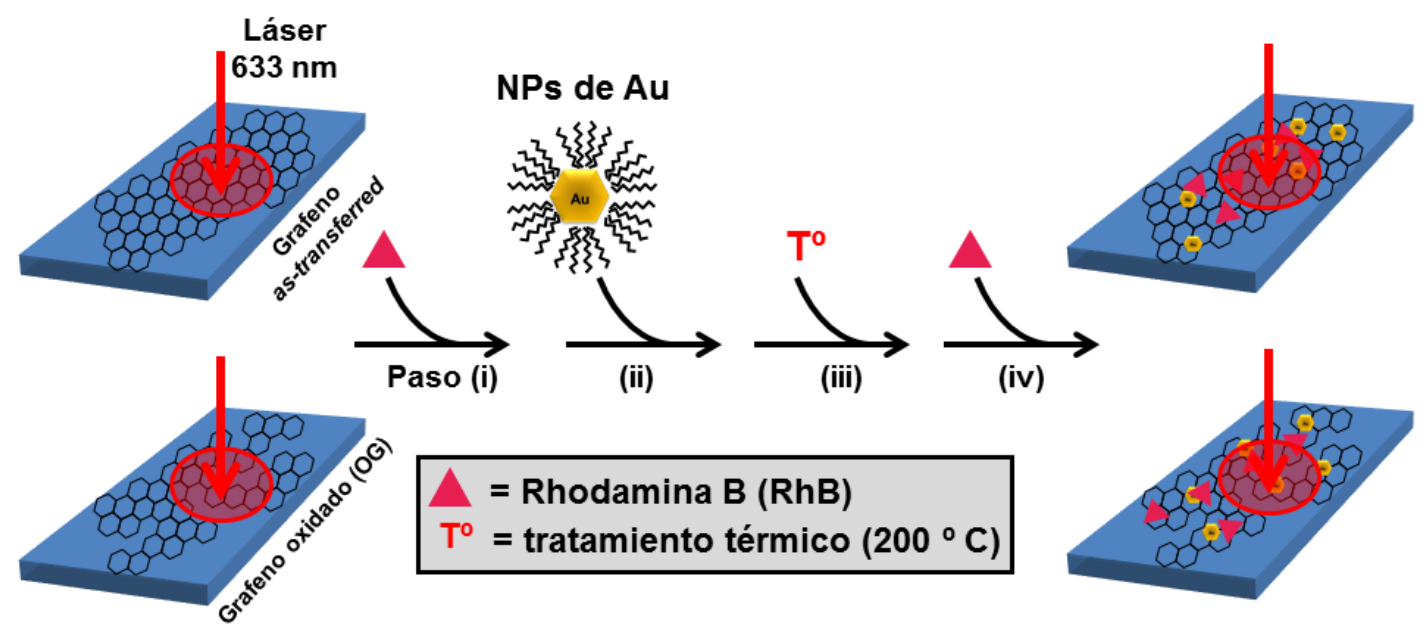

Experimentos Raman llevados a cabo sobre grafeno (G) y grafeno oxidado (OG) sujetos a diferentes tratamientos, como es indicado. Notar que la Rodamina $\mathrm{B}(\mathrm{RhB})$ es adicionada dos veces, debido a la desorción del analito después del tratamiento térmico.

En la Figura 5.13A se comparan los espectros Raman de la $\mathrm{RhB}$ adsorbida sobre $\mathrm{SiO}_{\mathrm{x}}$ y G. Los picos de la $\mathrm{RhB}$ están indicados con (*) y aparecen montados sobre un intenso espectro. El área sombreada debajo del espectro corresponde a la fluorescencia (fluorescence, FL) que surge de la $\mathrm{RhB}$, y fue calculada de la misma manera que la PL mostrada en la Figura 5.9B (ver la Figura 5.10 para mayores detalles). 
En el recuadro de la Figura 5.13A se muestra un aumento del espectro de la RhB sobre $\mathrm{G}$ en un rango comprendido entre 1100 y $1800 \mathrm{~cm}^{-1}$. Además, en el recuadro se muestran dos picos Raman que corresponden a la banda $G$ del grafeno y a la presencia del polímero PMMA (ver Figura 5.6). Esto indica que al G as-transferred le falta actividad SERS debido a la ausencia de las bandas de la RhB, las cuales deberían haber aparecido a pesar de la gran intensidad de la FL. La Figura 5.13B exhibe los espectros correspondientes a la FL (desde la Figura 5.13A) y la PL (desde la Figura 5.9B) de la RhB y las Au NPs, respectivamente, junto con un espectro de la RhB adsorbida sobre la heterojunción. Ambos espectros, el de la PL y el de la FL son mostrados juntos para enfatizar en la habilidad de $\mathrm{G}$ para suprimir ambos efectos. Es necesario mencionar que, aunque los picos característicos de la $\mathrm{RhB}$ sobre la heterojunción no están bien

\section{Grafeno apaga la $F L$}

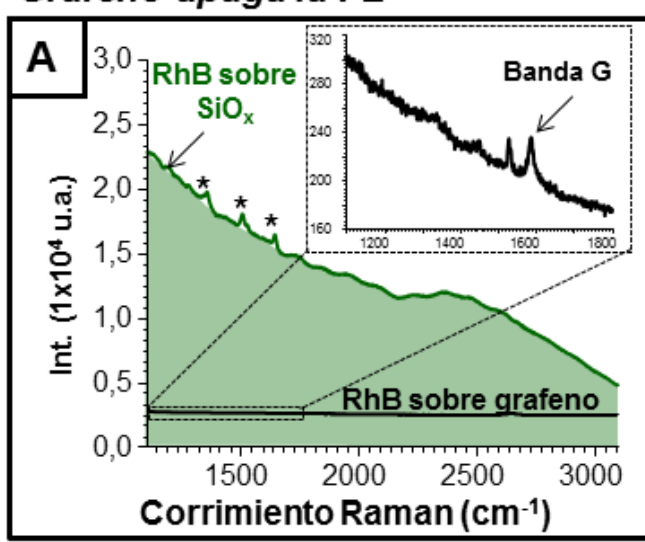

Grafeno apaga $F L+P L$

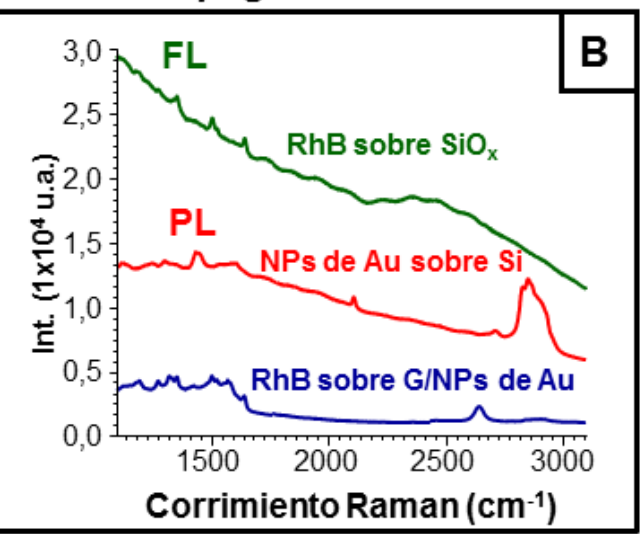

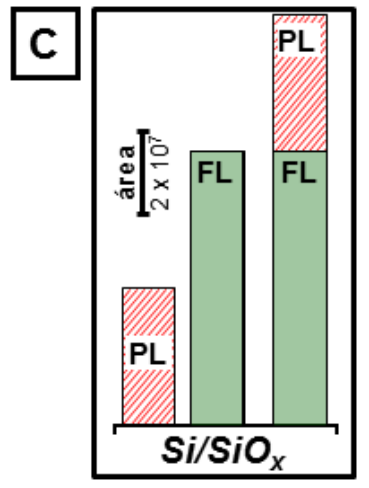

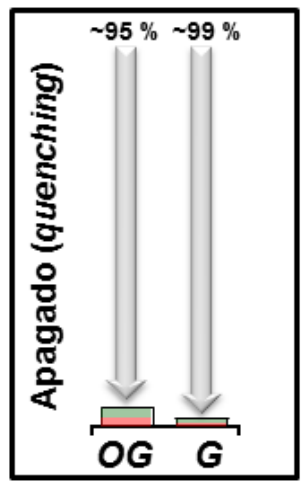

Figura 5.13 Espectros Raman de la Rodamina $\mathrm{B}(\mathrm{RhB})$ sobre $\mathrm{SiO}_{\mathrm{x}}$ y sobre $\mathrm{G}$ as transferred (A), $\mathrm{RhB}$ sobre $\mathrm{SiO}_{\mathrm{x}}$, espectro de la PL tomado de la Figura 5.9B, y la $\mathrm{RhB}$ sobre la heterojunción (NPs de Au y G) como es indicado (B), y gráficos de barra indicando el apagamiento de la PL y la FL por el OG y el G (C). Las bandas características de la $\mathrm{RhB}$ son indicadas con (*). Todos los espectros en el panel B están en offset para una mejor comparación. 
definidos, tanto la FL como la PL fueron notoriamente disminuidas por el grafeno. El gráfico de barras muestra el apagamiento de un $95 \%$ y un $99 \%$ por OG y $G$ en las heterojunciones, respectivamente. El espectro Raman correspondiente al OG no es mostrado en ésta figura, con el propósito de mayor claridad.

La Figura 5.14A muestra un espectro Raman seleccionado de RhB obtenido en la misma área de la muestra durante cada paso realizado, como es indicado en el Esquema 5.1. Los espectros fueron separados en dos paneles para mayor claridad. Los paneles izquierdo y derecho muestran la actividad SERS y la caracterización de las películas analizando las bandas 2D y el stretching del enlace $\mathrm{C}-\mathrm{H}$, respectivamente. Del análisis de la mencionada figura, se desprenden los siguientes comportamientos. Primeramente, en el panel izquierdo el G as-transferred (i) es un potenciador Raman débil, lo cual es notado por la ausencia de las bandas características de RhB en 1195, 1507, y $1646 \mathrm{~cm}^{-1}$ (ver supra). Segundo, después de la incorporación de las NPs de Au al G (ii), la actividad SERS fue incrementada en al menos 2 órdenes de magnitud. Como ha sido reportado recientemente, la oxidación de G obtenido por CVD dramáticamente mejora la señal Raman de varios analitos. ${ }^{9}$ De acuerdo a lo mencionado, se expusieron las películas $\mathrm{G}$ a una lámpara UV generadora de ozono $\left(\mathrm{O}_{3}\right)$ (ver la Sección 5.2.2 para mayores detalles respecto al tratamiento con ozono). Asimismo, en la Figura 5.15 se muestra un gráfico de corriente versus voltaje $(I-V)$ correspondiente a una película de grafeno expuesta a Ozono $\left(\mathrm{O}_{3}\right)$ en diferentes tiempos. Dicho experimento fue realizado para conocer el tiempo requerido para producir la oxidación, y por ende la disminución en la corriente, de las películas de grafeno obtenidas por CVD.

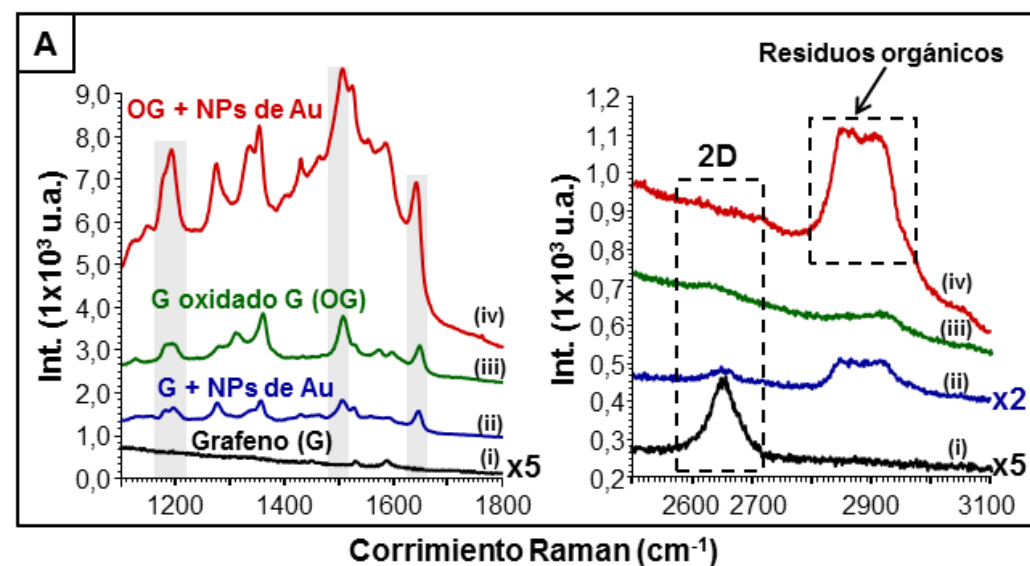

Corrimiento Raman $\left(\mathrm{cm}^{-1}\right)$

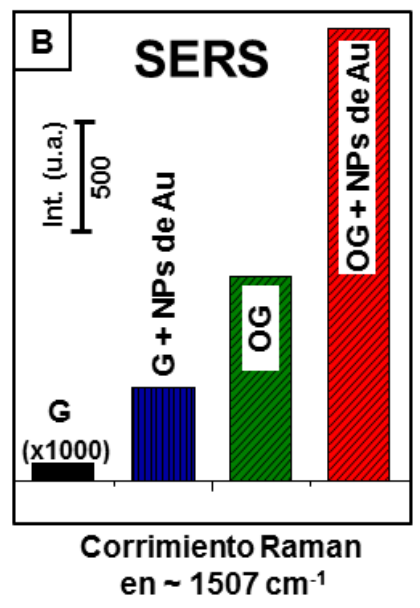

Figura 5.14 Espectros Raman seleccionados de RhB sobre el $\mathrm{G}$ as-transferred (i), la heterojunción formada con NPs de Au sobre G(ii), el grafeno oxidado (OG) (iii), y la heterojunción formada con NPs de Au sobre OG (iv) (A), junto con un gráfico de barras indicando la actividad SERS de la $\operatorname{RhB}\left(\mathrm{a} \sim 1507 \mathrm{~cm}^{-1}\right)$ en cada paso, como es descripto (B). Todos los gráficos están en off set para una mejor comparación. 


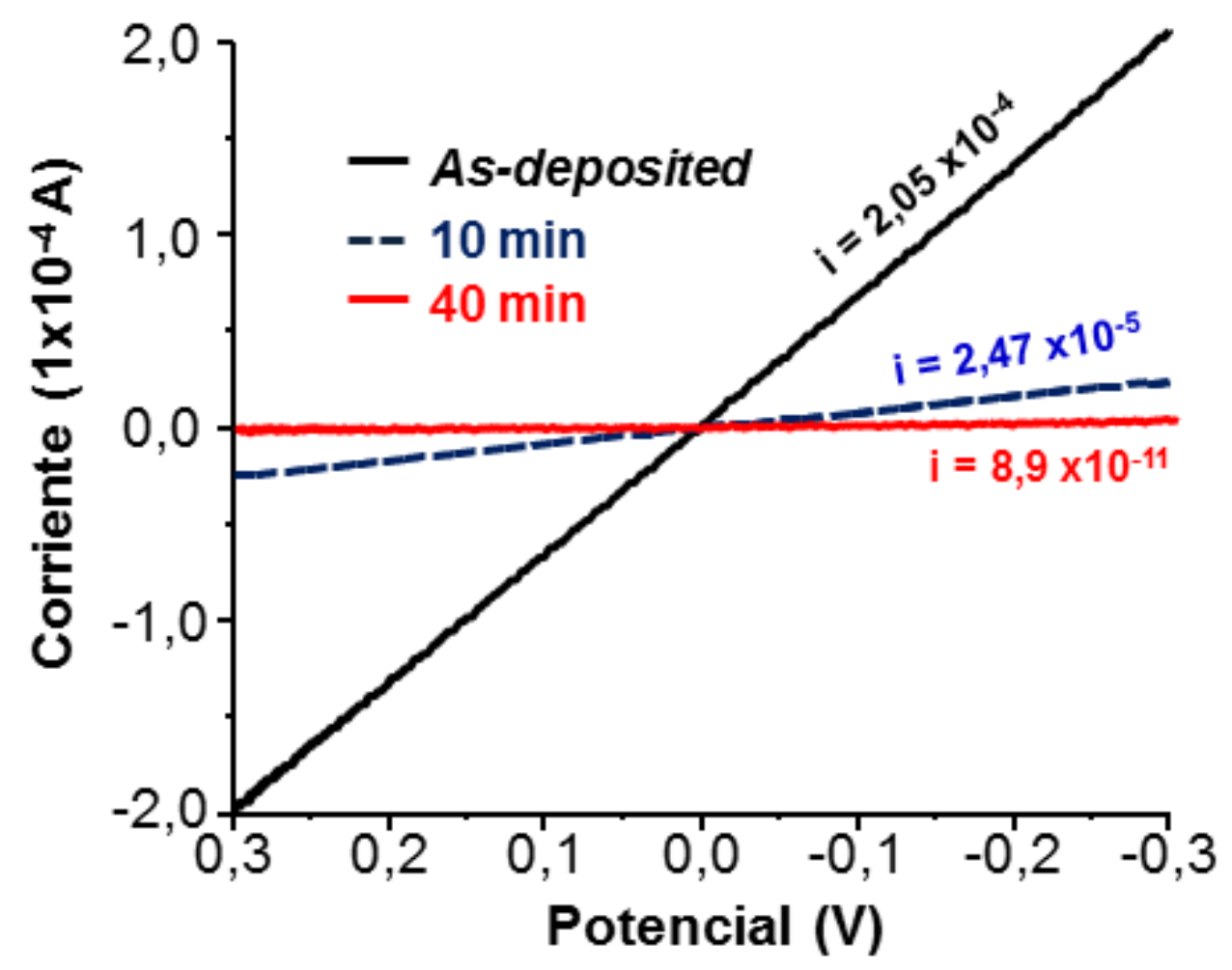

Figura 5.15 Corriente versus voltaje (curvas $I-V$ ) de una muestra de $\mathrm{G}$ astransferred seleccionada, expuesta a $\mathrm{O}_{3}$ en varios tiempos como es indicado. El gráfico muestra un decrecimiento drástico en la corriente ( 6 órdenes de magnitud) obtenido cuando se expuso la muestra a $\mathrm{O}_{3}$ por sólo por 40 minutos.

Como ha sido reportado previamente, el grafeno oxidado presenta mayor actividad Raman que el grafeno pristine. ${ }^{\ddagger}$ Particularmente, en nuestro sistema el OG solo (sin NPs) (iii) exhibió mayor actividad SERS que las nanopartículas de Au sobre G as-transferred (ii), ver la Figura 5.14B. Finalmente, una vez que la película de OG es decorada con NPs de Au (iv) se observó un incremento de más de 3 veces en la intensidad de $\mathrm{RhB}$ con respecto al $\mathrm{G}$ as-transferred sólo (i), medidos para la banda situada en $1507 \mathrm{~cm}^{-1}$. Sobre el panel derecho, como es esperado después de los tratamientos de oxidación y de calentamiento, no se observa la banda $2 \mathrm{D}$ y la banda correspondiente a los $\mathrm{C}-\mathrm{H}$ asimétricos es notoriamente incrementada, respectivamente.

* El término "pristine" se refiere a que el grafeno no ha sido sometido a ningún tratamiento lo suficientemente agresivo como para haber cambiado sus propiedades tanto físicas como químicas. 
Estos resultados son consistentes tanto con lo reportado en la literatura, ${ }^{9}$ como en nuestros datos experimentales. En resumen, si bien las NPs de Au mejoran la actividad SERS de $\mathrm{RhB}$, el incremento óptimo de la misma fue conseguido empleando la heterojunción formada con OG (iv).

El gráfico de barras de la Figura 5.14B muestra los valores de actividad SERS de la $\mathrm{RhB}$ a $\sim 1507 \mathrm{~cm}^{-1}$ de la misma muestra seleccionada antes y después de cada paso, como es indicado en el Esquema 5.1. La Tabla 5.1 muestra los datos estadísticos obtenidos de dos diferentes zonas (spots) dentro de la misma muestra, medidos para las tres bandas características de la $\mathrm{RhB}$, como es indicado. La Tabla muestra los factores de incremento (enhancement factor, EF) y la contribución actual a la señal SERS de cada película involucrada en éste estudio. La Tabla indica que en la heterojunción formada con G as-transferred, las NPs de Au son las que mayormente contribuyen a la actividad SERS. Sin embargo, cuando la heterojunción es formada con OG, la presencia de las NPs de Au jugó un rol menor, ya que contribuyeron con $\sim 28 \%$ a la señal SERS total. En conclusión, existe una interesante sinergia entre ambas películas frente a la actividad SERS, y el grado de incremento depende de si están presentes las NPs de Au y si el G está oxidado.

Tabla 5.1 Promedio de la intensidad relativa de $\mathrm{RhB}$, el factor de incremento (enhancement factor, EF), y el porcentaje (\%) en la contribución SERS de cada nanomaterial.

\begin{tabular}{|c|c|c|c|c|c|c|c|}
\hline \multirow[b]{2}{*}{ Películas } & \multicolumn{4}{|c|}{ Intensidad relativa promedio y desviación estándar de la $\mathrm{RhB}$ a } & \multirow[t]{2}{*}{$\mathrm{EF}^{(\mathrm{d})}$} & \multicolumn{2}{|c|}{$\%$ de contribución SERS } \\
\hline & $\sim 1195 \mathrm{~cm}^{-1}$ & $\sim 1507 \mathrm{~cm}^{-1}$ & $\sim 1646 \mathrm{~cm}^{-1}$ & Promedio/picos ${ }^{(\mathrm{c})}$ & & NPs de $\mathrm{Au}$ & Grafeno \\
\hline Grafeno (G)(a) & $0,067^{*}$ & $0,092^{*}$ & $0,074^{*}$ & 0,077 & $0 \mathrm{x}$ & - & 100 \\
\hline$G+N P s$ de $A u^{(b)}$ & $3,5 \pm 0,6$ & $3,1 \pm 0,2$ & $2,4 \pm 0,1$ & 3,0 & $41 x$ & 97 & 3 \\
\hline G Oxidado $(O G)^{(a)}$ & $2,3 \pm 0,1$ & $6,4 \pm 1,5$ & $3,9 \pm 0,9$ & 4,2 & $57 x$ & - & 100 \\
\hline OG + NPs de $A u^{(b)}$ & $5,5 \pm 0,6$ & $6,1 \pm 0,7$ & $5,8 \pm 1,0$ & 5,8 & $78 x$ & 28 & 72 \\
\hline
\end{tabular}

Nota: promedio de la intensidad Raman relativa de la $\mathrm{RhB}$ tomada en dos áreas diferentes dentro de la misma muestra y medidas a 1195,1507 y $1646 \mathrm{~cm}^{-1}$, el factor de incremento (enhancement factor, EF), y el porcentaje en la contribución SERS de cada película involucrada en éste estudio. Notar que (a) y (b) corresponden a la intensidad Raman relativa a las bandas de la RhB situadas en $\sim 1589 \mathrm{~cm}^{-1}$ y en $\sim 1128 \mathrm{~cm}^{-1}$, respectivamente, tomadas del mismo espectro; (c) = promedio de todos las bandas de la RhB; y (d) = factor de incremento (enhancement factor, EF) indica cuantas veces la intensidad de la $\mathrm{RhB}$ fue incrementada con respecto al $\mathrm{G}$ as-transferred. (*) Indica el valor de la intensidad promedio sin la desviación estándar debido que el $\mathrm{G}$ as-transferred exhibió sólo una señal observable de $\mathrm{RhB}$ de un conjunto de 7 muestras. 


\subsubsection{Sensado de Luz UV}

Finalmente quisimos explorar los efectos de la luz ultravioleta (UV) sobre G. Como ha sido demostrado en la literatura $^{41}$ y luego corroborado en nuestros experimentos (Figura 5.16), las bandas D y 2D se desplazan, y el grado de cambio varía dependiendo de la energía del láser utilizado durante los experimentos Raman (ver Sección 5.3.1.3).

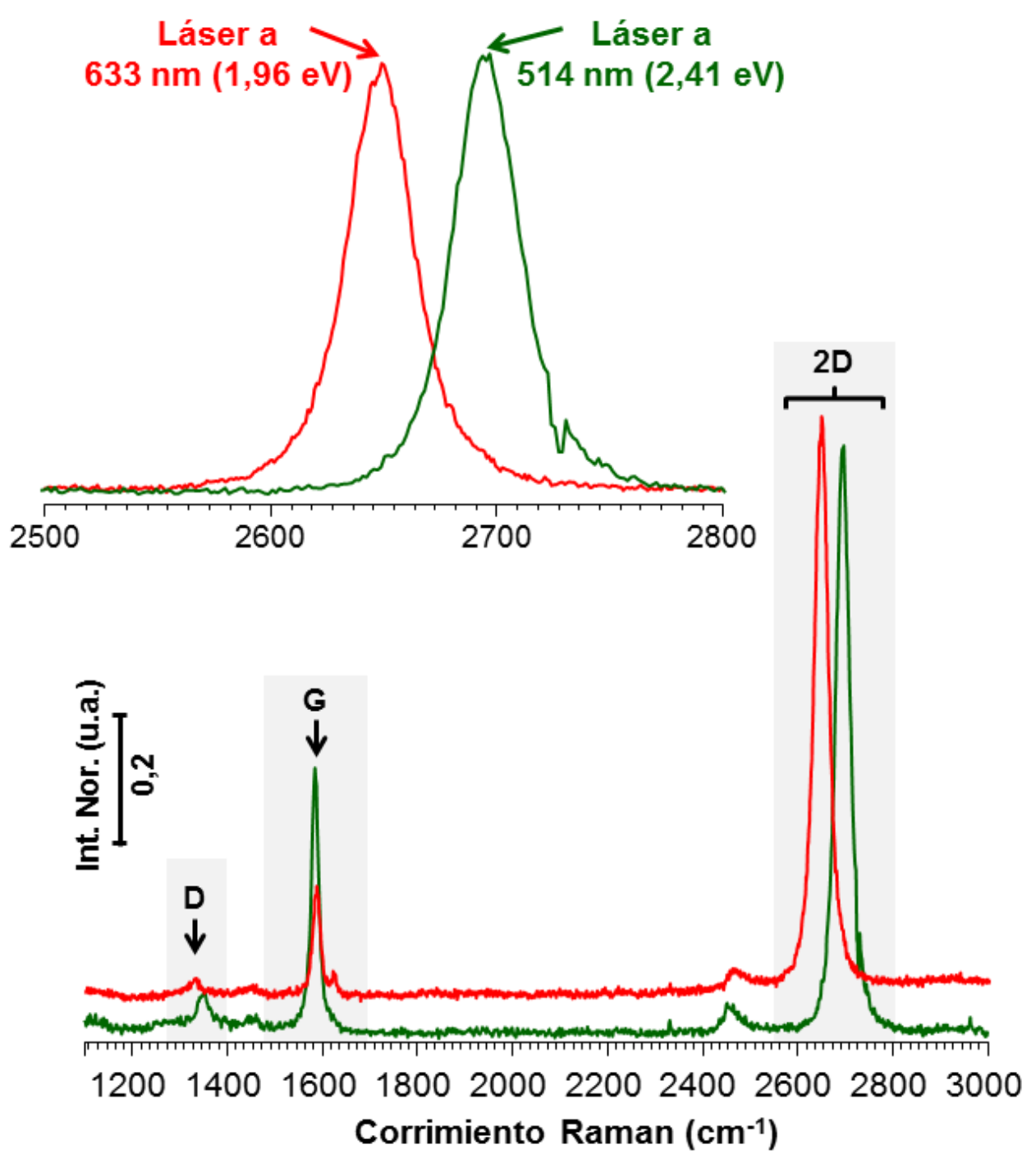

Figura 5.16 Espectros Raman de G as-transferred de una misma muestra adquiridos en la misma zona/spot, expuestos a 1,96 y 2,41 eV, mostrando los corrimientos en las bandas 2D y D (desorden), los cuales no se producen en la banda G. 
En éste contexto, conociendo que la banda 2D esta directamente asociada a la nube de electrones- $\pi$, los cuales controlan las propiedades electrónicas de grafeno, nos pareció interesante explorar los efectos de la luz UV en la corriente de las películas. La Figura 5.17 muestra un gráfico de corriente en función del tiempo (Cronoamperometría, CA) para varios sustratos sujetos a $-0,3 \mathrm{~V}$ y expuestos a $254 \mathrm{~nm}$ de luz UV durante periodos de "encendido/apagado" (on/off) de 100 segundos cada uno, como es indicado. La Figura muestra los experimentos llevados a cabo sobre sustratos de $\mathrm{SiO}_{\mathrm{x}} \mathrm{y}$ microelectrodos limpios $\left(\mathrm{Si} / \mathrm{SiO}_{\mathrm{x}} /\right.$ electrodos de $\left.\mathrm{Au}\right)$, debido a que éstos constituyen las plataformas en las cuales se ha depositado el grafeno. Como es notado en la mencionada figura, las películas de $\mathrm{G}$ as-transferred mostraron un decrecimiento en la corriente cuando fueron iluminadas y una incompleta recuperación de la corriente de base $\left(\mathrm{i}_{\mathrm{b}}\right)$ durante los ciclos de encendido ("on") y apagado ("off"), respectivamente. Como un experimento de control, se cubrió la lámpara para determinar los potenciales efectos causados por el $\mathrm{O}_{3}$ generado dentro de la cámara. ${ }^{9}$ Los resultados indicaron que la exposición transitoria a $\mathrm{O}_{3}$ no produjo mayores efectos en la corriente de las películas. A su vez, se obtuvo grafeno multicapas (few layers graphene, FLG) por medio de la exfoliación mecánica de HOPG, y se transfirieron dichas láminas (flakes) a microelectrodos, para evaluar su comportamiento. Sin embargo, si bien las películas de $\mathrm{G}$ obtenidas por exfoliación mecánica presentaron una corriente similar a la de $\mathrm{G}$ obtenido por CVD, no hubo en las primeras una respuesta detectable frente a la exposición a luz UV. Este experimento es muy importante, ya que resalta las propiedades de los materiales derivados del Carbono que presentan una dependencia con el tamaño. ${ }^{58}$ 


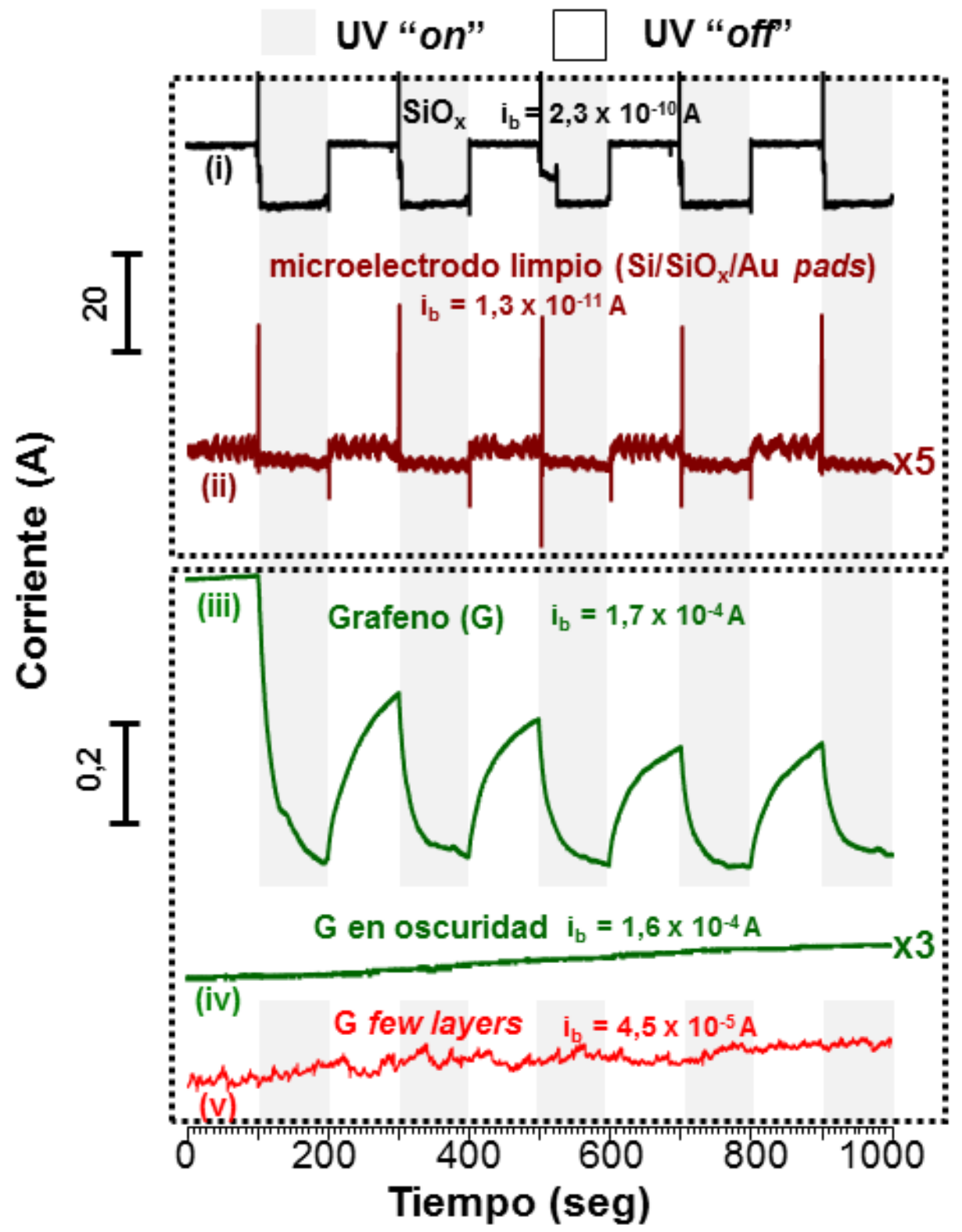

Figura 5.17 Gráficos de cronoamperometría, CA (corriente versus tiempo) de $\mathrm{SiO}_{\mathrm{x}}$ limpio (i), microelectrodos $\mathrm{Au}$ limpios ( $\mathrm{Si} / \mathrm{SiO}_{\mathrm{x}} / \mathrm{Au}$ pads) (ii), $\mathrm{G}$ astransferred sobre microelectrodos (iii), G en oscuridad (iv), y G multicapa (few layers graphene) transferido desde una cinta Scotch a microelectrodos (v), junto con sus correspondientes líneas de base $\left(i_{b}\right)$ como es indicado. Todos los gráficos están en offset para una mejor comparación. 
Si bien hasta el momento el mecanismo de sensado de luz UV por medio de grafeno permanece incierto, el mismo podría involucrar la foto-desorción de moléculas ya adsorbidas cuando la película es iluminada. ${ }^{59}$ En este sentido, ha sido determinado que tanto la humedad como el $\mathrm{O}_{2}$ que se encuentran adsorbidos sobre el carbono son capaces de tomar los electrones del material (fenómeno conocido como withdrawing electrons) y tornar así a la película en un material de tipo-p (en donde la mayoría de los portadores de cargas son huecos, (hole carriers). ${ }^{11,60}$ El mecanismo de sensado ha sido explicado por la desorción del $\mathrm{O}_{2}$ desde las películas cuando las mismas son expuestas a luz UV. El decrecimiento observado en la corriente de la película fue atribuido al decrecimiento del número de huecos (hole carriers) en la película causados por la desorción de las moléculas de $\mathrm{O}_{2}{ }^{61}$ Tan rápido como la lámpara de UV es apagada (off), las especies de $\mathrm{O}_{2}$ se re-adsorben sobre grafeno, llevando a un incremento en la corriente del sistema. Este comportamiento ha sido previamente observado en otros materiales del tipo de los nano-carbones, incluyendo los nanotubos de carbono de pared simple semiconductores (single-walled carbon nanotubes, SWNTs), ${ }^{59}$ los híbridos conformados por C60/nanopartículas de $\mathrm{Au},{ }^{62}$ y en $\mathrm{G}$ sintetizado por CVD. ${ }^{61,63}$ En términos generales, todas estas publicaciones tienen algo en común: una relativa rápida respuesta en la corriente frente a la iluminación y una lenta recuperación de la misma en la oscuridad. Nuestros resultados en la Figura 5.18 denotan una abrupta recuperación de la corriente y una alta sensibilidad a medida que la energía de la lámpara es incrementada. Por ejemplo, una comparación entre $365 \mathrm{~nm}(\sim 3,0 \mathrm{eV})$ y $180 \mathrm{~nm}(\sim 6,9$ $\mathrm{eV}$ ) exhibe un tiempo de respuesta de aproximadamente una vez mayor ( $\mathrm{t}_{90}$ desde $70 \mathrm{seg}$ a $6 \mathrm{seg}$ ) y una mejora en la sensibilidad desde -4 a -28 en el porcentaje de respuesta (\% $\mathrm{R}){ }^{64}$ para una misma película de $\mathrm{G}$ en donde sólo se incrementó al doble la energía aplicada. Pensamos que a la mayor energía de iluminación $\sim 6,9 \mathrm{eV}$, especies reactivas del $\mathrm{O}_{2}$ (reactive $\mathrm{O}_{2}$ species, $\mathrm{ROS}$ ) son preferencialmente formadas en la superficie. Es conocido que los radicales de oxígeno surgen a energías debajo de los $200 \mathrm{~nm}$, por lo tanto la alta sensibilidad (gran decrecimiento en la corriente) podría ser atribuido a las grandes cantidades de especies desorbidas. Durante la recuperación de la corriente, uno podría considerar el mismo paradigma en donde las especies altamente inestables requieren menor tiempo para ser readsorbidas sobre el grafeno. No obstante, se requieren más experimentos con el fin de comprender mayor el mecanismo de sensado. 


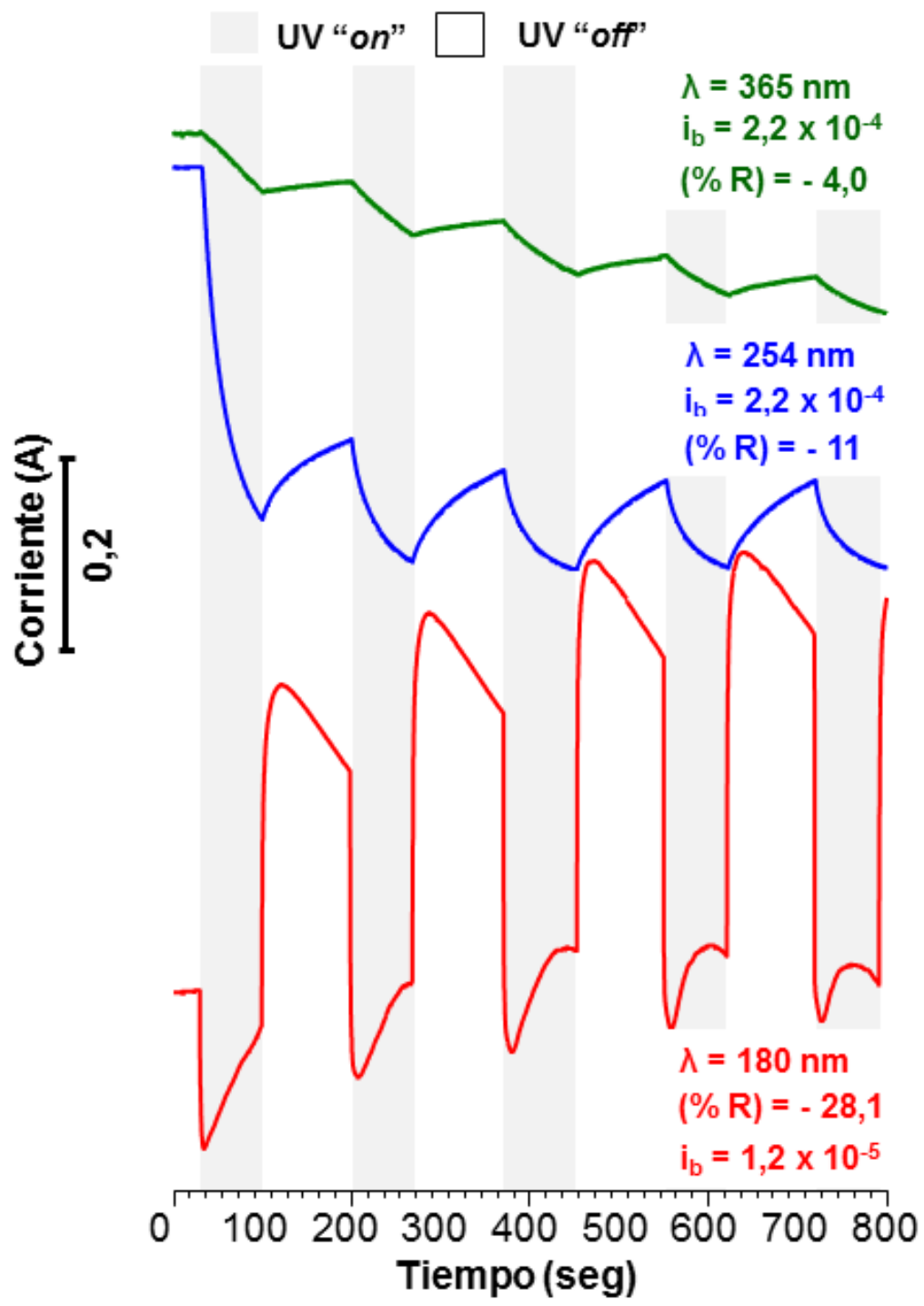

Figure 5.18 Gráficos de cronoamperometría (CA) normalizados de $\mathrm{G}$ astransferred sobre microelectrodos sujetos a la exposición a lámparas de UV con diferentes longitudes de onda $(365,254$, y $180 \mathrm{~nm})$, junto con el porcentaje de cambio en la corriente $(\% \mathrm{R})$ y la corriente de base $\left(\mathrm{i}_{\mathrm{b}}\right)$ de $\mathrm{G}$, como es indicado. Todos los gráficos están en offset para una mejor comparación. 
Finalmente, se realizaron experimentos de sensado de luz UV sobre ambos sistemas: a) una película de $\mathrm{G}$ previamente oxidada con $\mathrm{O}_{3}(\mathrm{OG})$ (ver Figura 5.19); y b) una película de G/NPs de Au (heterojunción) (ver Figura 5.20). De los resultados obtenidos se desprende que en ambos sistemas no se produjeron mayores efectos sobre el sensado de luz UV.

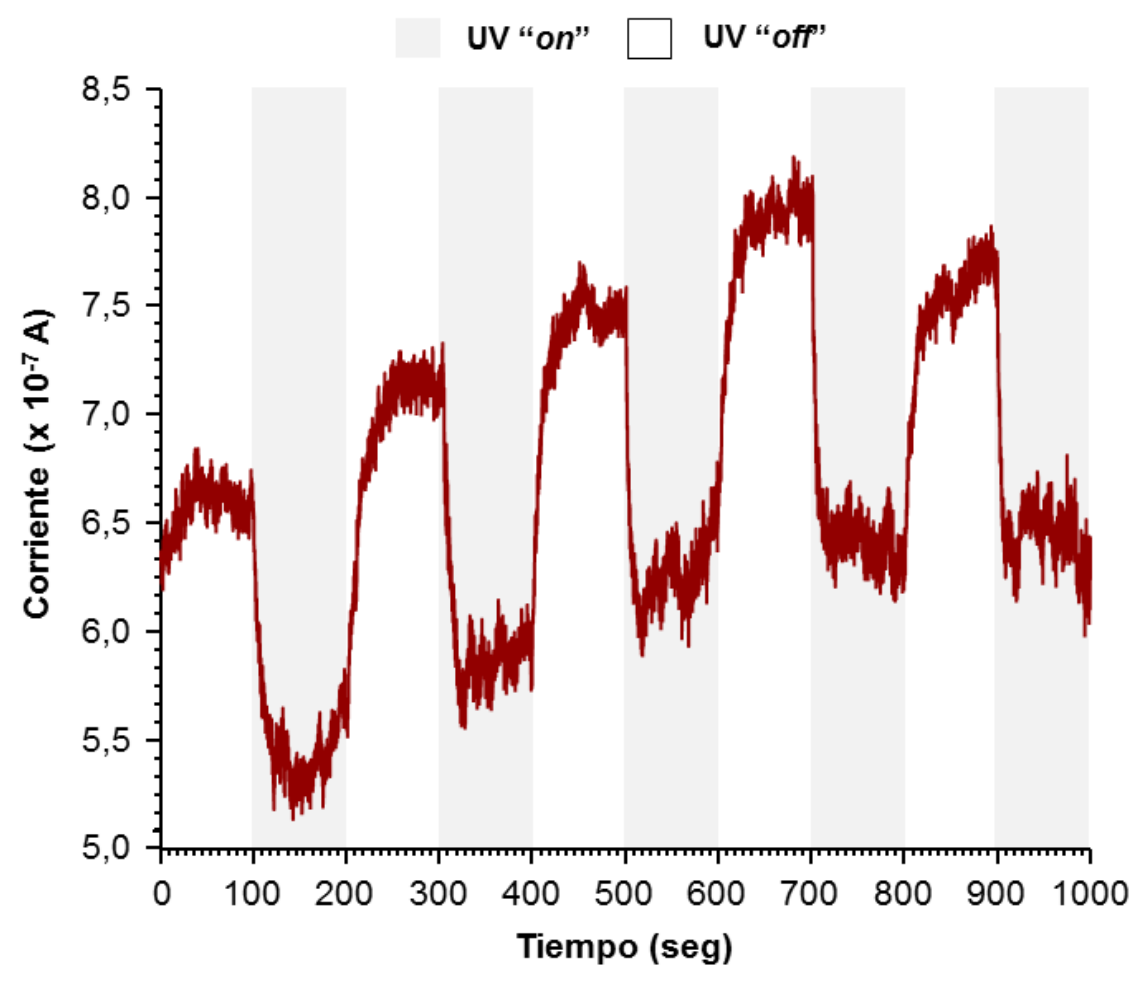

Figura 5.19 Cronoamperometría (CA) correspondiente al grafeno oxidado (OG), mostrando la respuesta a varios ciclos de radiación UV (a $180 \mathrm{~nm}$ ), indicando un comportamiento de sensado similar al del grafeno as-transferred. 


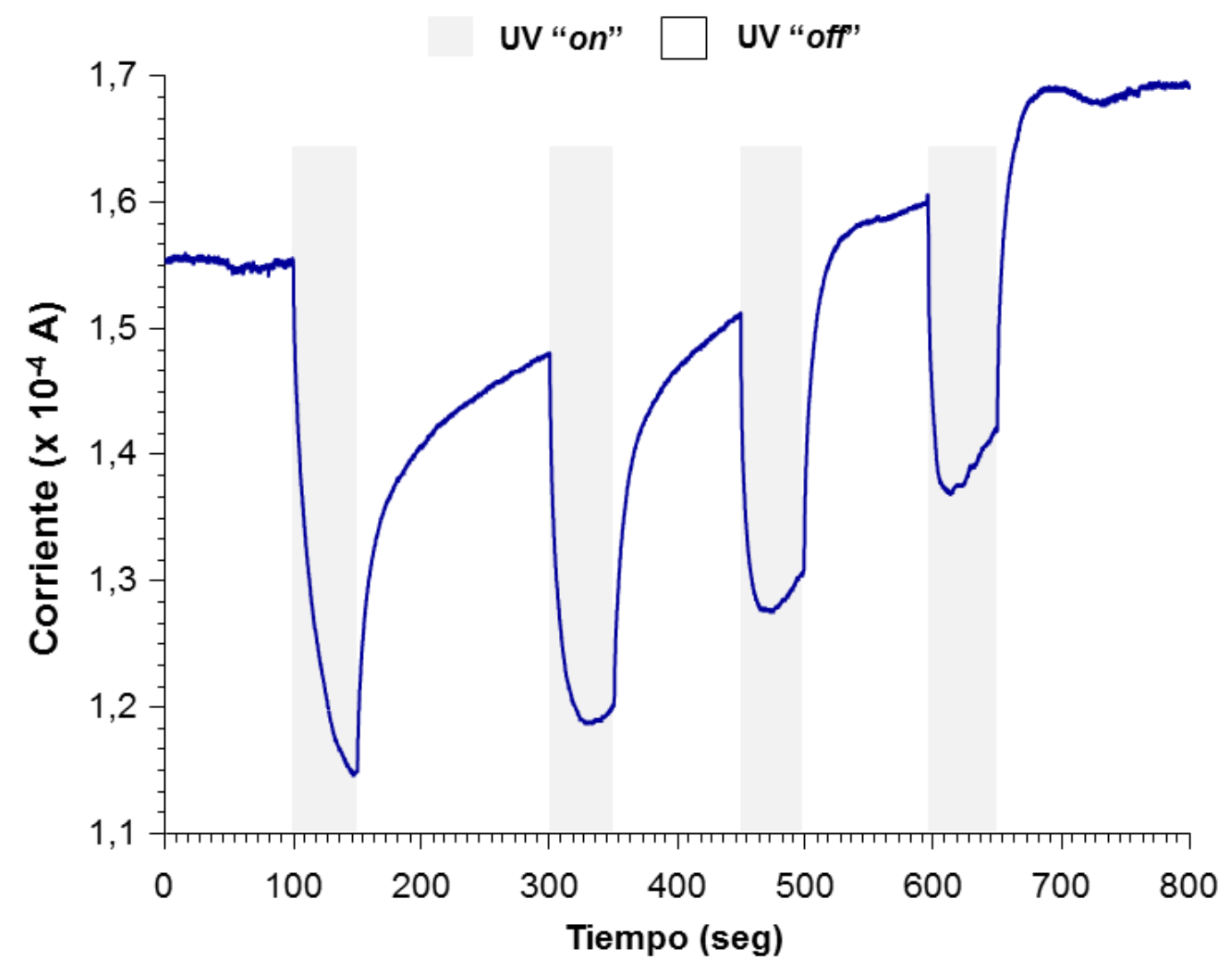

Figura 5.20 Cronoamperometría (CA) de la heterojunción mostrando la respuesta a varios ciclos de luz UV (a $180 \mathrm{~nm}$ ). 


\subsection{Conclusiones}

En conclusión, se demostró que el G sintetizado por la metodología de CVD permitió obtener monocapas de grafeno, como fue indicado por los espectros Raman. Las películas exhibieron una corriente comprendida entre $10^{-4}$ y $10^{-6} \mathrm{~A}$, sin embargo encontramos que el PMMA cambia las propiedades electrónicas de $\mathrm{G}$ y permanece como un residuo aún después de los procedimientos de limpieza convencionales. La película de $\mathrm{G}$ demostró la habilidad de poder ser espontáneamente decorada con NPs de $\mathrm{Au}$ cubiertas con un surfactante, lo cual permitió la caracterización de las heterojunciones por LSPR y su aplicación en plataformas Raman. Fue determinado que la heterojunción es una estupenda plataforma que apaga tanto la FL como la PL, y a su vez mejora la señal Raman de la RhB. Se demostró que grafeno es el mayor responsable del pagado de la PL y la FL, mientras que la heterojunción mejoró más de 3-veces la actividad Raman de la RhB. Finalmente, aunque los diferentes perfiles de sensado observados a diferentes energías de luz UV no fueron completamente entendidos, el mecanismo puede estar asociado con especies de oxígeno sobre la superficie de grafeno junto con por la distorsión de la nube de electrones- $\pi$. Planteamos explorar en el futuro la incorporación de nanoestructuras de Ag sobre grafeno, con el fin de mejorar la actividad SERS de varias moléculas Raman activas.

\subsection{Bibliografía}

(1) Schedin, F.; Geim, A. K.; Morozov, S. V.; Hill, E. W.; Blake, P.; Katsnelson, M. I.; Novoselov, K. S. Detection of Individual Gas Molecules Adsorbed on Graphene. Nat. Mater. 2007, 6 (9), 652-655.

(2) Bonaccorso, F.; Sun, Z.; Hasan, T.; Ferrari, A. C. Graphene Photonics and Optoelectronics. Nat. Photonics 2010, 4 (9), 611-622.

(3) Xu, W.; Mao, N.; Zhang, J. Graphene: A Platform for Surface-Enhanced Raman Spectroscopy. Small 2013, 9 (8), 1206-1224.

(4) Ferrari, A. C.; Meyer, J. C.; Scardaci, V.; Casiraghi, C.; Lazzeri, M.; Mauri, F.; Piscanec, S.; Jiang, D.; Novoselov, K. S.; Roth, S.; et al. Raman Spectrum of Graphene and Graphene Layers. Phys. Rev. Lett. 2006, 97 (18), 187401.

(5) Hummers, W. S.; Offeman, R. E. Preparation of Graphitic Oxide. J. Am. Chem. Soc. 1958, 80 (6), 1339-1339.

(6) Sidorov, A. N.; Sławiński, G. W.; Jayatissa, A. H.; Zamborini, F. P.; Sumanasekera, G. U. A Surface-Enhanced Raman Spectroscopy Study of Thin Graphene Sheets Functionalized with Gold and Silver Nanostructures by SeedMediated Growth. Carbon 2012, 50 (2), 699-705.

(7) Li, X.; Zhu, Y.; Cai, W.; Borysiak, M.; Han, B.; Chen, D.; Piner, R. D.; Colombo, L.; Ruoff, R. S. Transfer of Large-Area Graphene Films for HighPerformance Transparent Conductive Electrodes. Nano Lett 2009, 9 (12), 43594363. 
(8) Dan, Y.; Lu, Y.; Kybert, N. J.; Luo, Z.; Johnson, A. T. C. Intrinsic Response of Graphene Vapor Sensors. Nano Lett 2009, 9 (4), 1472-1475.

(9) Huh, S.; Park, J.; Kim, Y. S.; Kim, K. S.; Hong, B. H.; Nam, J.-M. UV/OzoneOxidized Large-Scale Graphene Platform with Large Chemical Enhancement in Surface-Enhanced Raman Scattering. ACS Nano 2011, 5 (12), 9799-9806.

(10) Sarantopoulou, E.; Kollia, Z.; Cefalas, A. C.; Manoli, K.; Sanopoulou, M.; Goustouridis, D.; Chatzandroulis, S.; Raptis, I. Surface Nano/micro Functionalization of PMMA Thin Films by $157 \mathrm{Nm}$ Irradiation for Sensing Applications. Appl. Surf. Sci. 2008, 254 (6), 1710-1719.

(11) Pirkle, A.; Chan, J.; Venugopal, A.; Hinojos, D.; Magnuson, C. W.; McDonnell, S.; Colombo, L.; Vogel, E. M.; Ruoff, R. S.; Wallace, R. M. The Effect of Chemical Residues on the Physical and Electrical Properties of Chemical Vapor Deposited Graphene Transferred to $\mathrm{SiO}_{2}$. Appl. Phys. Lett. 2011, 99 (12), 122108.

(12) Lim, Y.-D.; Lee, D.-Y.; Shen, T.-Z.; Ra, C.-H.; Choi, J.-Y.; Yoo, W. J. SiCompatible Cleaning Process for Graphene Using Low-Density Inductively Coupled Plasma. ACS Nano 2012, 6 (5), 4410-4417.

(13) Lin, Y.-C.; Lu, C.-C.; Yeh, C.-H.; Jin, C.; Suenaga, K.; Chiu, P.-W. Graphene Annealing: How Clean Can It Be? Nano Lett 2011, 12 (1), 414-419.

(14) Lin, Y.-C.; Jin, C.; Lee, J.-C.; Jen, S.-F.; Suenaga, K.; Chiu, P.-W. Clean Transfer of Graphene for Isolation and Suspension. ACS Nano 2011, 5 (3), 23622368.

(15) Fleischmann, M.; Hendra, P. J.; McQuillan, A. J. Raman Spectra of Pyridine Adsorbed at a Silver Electrode. Chem. Phys. Lett. 1974, 26 (2), 163-166.

(16) Stiles, P. L.; Dieringer, J. A.; Shah, N. C.; Van Duyne, R. P. Surface-Enhanced Raman Spectroscopy. Annu. Rev. Anal. Chem. 2008, 1 (1), 601-626.

(17) Jensen, L.; Aikens, C. M.; Schatz, G. C. Electronic Structure Methods for Studying Surface-Enhanced Raman Scattering. Chem. Soc. Rev. 2008, 37 (5), 1061-1073.

(18) Zrimsek, A. B.; Henry, A.-I.; Van Duyne, R. P. Single Molecule SurfaceEnhanced Raman Spectroscopy without Nanogaps. J. Phys. Chem. Lett. 2013, 4 (19), 3206-3210.

(19) Nie, S.; Emory, S. R. Probing Single Molecules and Single Nanoparticles by Surface-Enhanced Raman Scattering. Science 1997, 275 (5303), 1102-1106.

(20) Reents, B.; Plieth, W.; Macagno, V. A.; Lacconi, G. I. Influence of Thiourea on Silver Deposition: Spectroscopic Investigation. J. Electroanal. Chem. 1998, 453 (1-2), 121-127.

(21) Cortés, E.; Etchegoin, P. G.; Le Ru, E. C.; Fainstein, A.; Vela, M. E.; Salvarezza, R. C. Strong Correlation between Molecular Configurations and Charge-Transfer Processes Probed at the Single-Molecule Level by Surface-Enhanced Raman Scattering. J. Am. Chem. Soc. 2013, 135 (7), 2809-2815.

(22) Camden, J. P.; Dieringer, J. A.; Zhao, J.; Van Duyne, R. P. Controlled Plasmonic Nanostructures for Surface-Enhanced Spectroscopy and Sensing. Acc. Chem. Res. 2008, 41 (12), 1653-1661.

(23) Lee, K.; Irudayaraj, J. Correct Spectral Conversion between Surface-Enhanced Raman and Plasmon Resonance Scattering from Nanoparticle Dimers for SingleMolecule Detection. Small 2013, 9 (7), 1106-1115. 
(24) McLellan, J. M.; Siekkinen, A.; Chen, J.; Xia, Y. Comparison of the SurfaceEnhanced Raman Scattering on Sharp and Truncated Silver Nanocubes. Chem. Phys. Lett. 2006, 427 (1-3), 122-126.

(25) Brus, L. Noble Metal Nanocrystals: Plasmon Electron Transfer Photochemistry and Single-Molecule Raman Spectroscopy. Acc. Chem. Res. 2008, 41 (12), 17421749 .

(26) Malinsky, M. D.; Kelly, K. L.; Schatz, G. C.; Van Duyne, R. P. Chain Length Dependence and Sensing Capabilities of the Localized Surface Plasmon Resonance of Silver Nanoparticles Chemically Modified with Alkanethiol SelfAssembled Monolayers. J. Am. Chem. Soc. 2001, 123 (7), 1471-1482.

(27) Wilcoxon, J. P.; Martin, J. E.; Parsapour, F.; Wiedenman, B.; Kelley, D. F. Photoluminescence from Nanosize Gold Clusters. J. Chem. Phys. 1998, 108 (21), 9137-9143.

(28) Hasegawa, T.; Nishijo, J.; Umemura, J. Separation of Raman Spectra from Fluorescence Emission Background by Principal Component Analysis. Chem. Phys. Lett. 2000, 317 (6), 642-646.

(29) Yu, X.; Cai, H.; Zhang, W.; Li, X.; Pan, N.; Luo, Y.; Wang, X.; Hou, J. G. Tuning Chemical Enhancement of SERS by Controlling the Chemical Reduction of Graphene Oxide Nanosheets. ACS Nano 2011, 5 (2), 952-958.

(30) Liu, J.; Cai, H.; Yu, X.; Zhang, K.; Li, X.; Li, J.; Pan, N.; Shi, Q.; Luo, Y.; Wang, X. Fabrication of Graphene Nanomesh and Improved Chemical Enhancement for Raman Spectroscopy. J. Phys. Chem. C 2012, 116 (29), 15741-15746.

(31) Murphy, S.; Huang, L.; Kamat, P. V. Reduced Graphene Oxide-Silver Nanoparticle Composite as an Active SERS Material. J. Phys. Chem. C 2013, 117 (9), 4740-4747.

(32) Dutta, S.; Ray, C.; Sarkar, S.; Pradhan, M.; Negishi, Y.; Pal, T. Silver Nanoparticle Decorated Reduced Graphene Oxide (rGO) Nanosheet: A Platform for SERS Based Low-Level Detection of Uranyl Ion. ACS Appl. Mater. Interfaces 2013, 5 (17), 8724-8732.

(33) Chen, P.; Yin, Z.; Huang, X.; Wu, S.; Liedberg, B.; Zhang, H. Assembly of Graphene Oxide and $\mathrm{Au} 0.7 \mathrm{Ag} 0.3$ Alloy Nanoparticles on $\mathrm{SiO}_{2}$ : A New Raman Substrate with Ultrahigh Signal-to-Background Ratio. J. Phys. Chem. C 2011, 115 (49), 24080-24084.

(34) Kim, Y.-K.; Han, S. W.; Min, D.-H. Graphene Oxide Sheath on Ag Nanoparticle/Graphene Hybrid Films as an Antioxidative Coating and Enhancer of Surface-Enhanced Raman Scattering. ACS Appl. Mater. Interfaces 2012, 4 (12), 6545-6551.

(35) Saito, R.; Dresselhaus, G.; Dresselhaus, M. S. Physical Properties of Carbon Nanotubes; Imperial College Press, 1998.

(36) Fink, J.; Kiely, C. J.; Bethell, D.; Schiffrin, D. J. Self-Organization of Nanosized Gold Particles. Chem. Mater. 1998, 10 (3), 922-926.

(37) Dalfovo, M. C.; Salvarezza, R. C.; Ibañez, F. J. Improved Vapor Selectivity and Stability of Localized Surface Plasmon Resonance with a Surfactant-Coated Au Nanoparticles Film. Anal Chem 2012.

(38) Sidorov, A. N.; Sherehiy, A.; Jayasinghe, R.; Stallard, R.; Benjamin, D. K.; Yu, Q.; Liu, Z.; Wu, W.; Cao, H.; Chen, Y. P.; et al. Thermoelectric Power of 
Graphene as Surface Charge Doping Indicator. Appl. Phys. Lett. 2011, 99 (1), 013115.

(39) Wallace, P. R. The Band Theory of Graphite. Phys. Rev. 1947, 71 (9), 622-634.

(40) Jorio, A.; Saito, R.; Dresselhaus, M. S.; Dresselhaus, G. Raman Spectroscopy in Graphene Related Systems; Wiley Vch Verlag Gmbh, 2011.

(41) Costa, S. D.; Righi, A.; Fantini, C.; Hao, Y.; Magnuson, C.; Colombo, L.; Ruoff, R. S.; Pimenta, M. A. Resonant Raman Spectroscopy of Graphene Grown on Copper Substrates. Solid State Commun. 2012, 152 (15), 1317-1320.

(42) Eckmann, A.; Felten, A.; Mishchenko, A.; Britnell, L.; Krupke, R.; Novoselov, K. S.; Casiraghi, C. Probing the Nature of Defects in Graphene by Raman Spectroscopy. Nano Lett. 2012, 12 (8), 3925-3930.

(43) Casiraghi, C.; Hartschuh, A.; Qian, H.; Piscanec, S.; Georgi, C.; Fasoli, A.; Novoselov, K. S.; Basko, D. M.; Ferrari, A. C. Raman Spectroscopy of Graphene Edges. Nano Lett. 2009, 9 (4), 1433-1441.

(44) Basko, D. M. Theory of Resonant Multiphonon Raman Scattering in Graphene. Phys. Rev. B 2008, 78 (12), 125418.

(45) Venezuela, P.; Lazzeri, M.; Mauri, F. Theory of Double-Resonant Raman Spectra in Graphene: Intensity and Line Shape of Defect-Induced and Two-Phonon Bands. Phys. Rev. B 2011, 84 (3), 035433.

(46) Das, A.; Pisana, S.; Chakraborty, B.; Piscanec, S.; Saha, S. K.; Waghmare, U. V.; Novoselov, K. S.; Krishnamurthy, H. R.; Geim, A. K.; Ferrari, A. C.; et al. Monitoring Dopants by Raman Scattering in an Electrochemically Top-Gated Graphene Transistor. Nat. Nanotechnol. 2008, 3 (4), 210-215.

(47) $\sigma=(1 / \rho) x(A / d)$. Donde, $\sigma=$ conductividad $(1 / \Omega . m) ; \rho=\operatorname{resistividad}(\Omega . m) ; A=$ cross-section $\left(\mathrm{m}^{2}\right) ; \mathrm{D}=$ distancia entre los electrodos de $\mathrm{Au}$ ( $\left.\mathrm{m}\right)$.

(48) Ibañez, F. J.; Zamborini, F. P. Chemiresistive Sensing of Volatile Organic Compounds with Films of Surfactant-Stabilized Gold and Gold-Silver Alloy Nanoparticles. ACS Nano 2008, 2 (8), 1543-1552.

(49) Rechberger, W.; Hohenau, A.; Leitner, A.; Krenn, J. R.; Lamprecht, B.; Aussenegg, F. R. Optical Properties of Two Interacting Gold Nanoparticles. Opt. Commun. 2003, 220 (1-3), 137-141.

(50) Mie, G. Ann. Phys. 1908, 25, 377.

(51) Templeton, A. C.; Pietron, J. J.; Murray, R. W.; Mulvaney, P. Solvent Refractive Index and Core Charge Influences on the Surface Plasmon Absorbance of Alkanethiolate Monolayer-Protected Gold Clusters. J. Phys. Chem. B 2000, 104 (3), 564-570.

(52) Mooradian, A. Photoluminescence of Metals. Phys. Rev. Lett. 1969, 22 (5), 185187.

(53) Izquierdo-Lorenzo, I.; Kubackova, J.; Manchon, D.; Mosset, A.; Cottancin, E.; Sanchez-Cortes, S. Linking Ag Nanoparticles by Aliphatic A, $\omega$-Dithiols: A Study of the Aggregation and Formation of Interparticle Hot Spots. J. Phys. Chem. C 2013, 117 (31), 16203-16212.

(54) Liao, H.; Wen, W.; Wong, G. K. Photoluminescence from Au Nanoparticles Embedded in Au:oxide Composite Films. J. Opt. Soc. Am. B 2006, 23 (12), 2518.

(55) Smith, B. L.; Hutchison, J. E. Transformations during Sintering of Small (Dcore $<2 \mathrm{Nm}$ ) Ligand-Stabilized Gold Nanoparticles: Influence of Ligand Functionality and Core Size. J. Phys. Chem. C 2013, 117 (47), 25127-25137. 
(56) Maye, M. M.; Zhong, C.-J. Manipulating Core-Shell Reactivities for Processing Nanoparticle Sizes and Shapes. J. Mater. Chem. 2000, 10 (8), 1895-1901.

(57) Hoggard, A.; Wang, L.-Y.; Ma, L.; Fang, Y.; You, G.; Olson, J.; Liu, Z.; Chang, W.-S.; Ajayan, P. M.; Link, S. Using the Plasmon Linewidth To Calculate the Time and Efficiency of Electron Transfer between Gold Nanorods and Graphene. ACS Nano 2013, 7(12):11209-17

(58) Shi, Y.; Fang, W.; Zhang, K.; Zhang, W.; Li, L.-J. Photoelectrical Response in Single-Layer Graphene Transistors. Small 2009, 5 (17), 2005-2011.

(59) Chen, R. J.; Franklin, N. R.; Kong, J.; Cao, J.; Tombler, T. W.; Zhang, Y.; Dai, H. Molecular Photodesorption from Single-Walled Carbon Nanotubes. Appl. Phys. Lett. 2001, 79 (14), 2258-2260.

(60) Ryu, S.; Liu, L.; Berciaud, S.; Yu, Y.-J.; Liu, H.; Kim, P.; Flynn, G. W.; Brus, L. E. Atmospheric Oxygen Binding and Hole Doping in Deformed Graphene on a $\mathrm{SiO}_{2}$ Substrate. Nano Lett. 2010, 10 (12), 4944-4951.

(61) Luo, Z.; Pinto, N. J.; Davila, Y.; Johnson, A. T. C. Controlled Doping of Graphene Using Ultraviolet Irradiation. Appl. Phys. Lett. 2012, 100 (25), 253108-4.

(62) Dinh, T.; Shon, Y.-S. Direct Assembly of Photoresponsive C60-Gold Nanoparticle Hybrid Films. ACS Appl. Mater. Interfaces 2009, 1 (12), 26992702.

(63) Lin, J.; Zhong, J.; Kyle, J. R.; Penchev, M.; Ozkan, M.; Ozkan, C. S. Molecular Absorption and Photodesorption in Pristine and Functionalized Large-Area Graphene Layers. Nanotechnology 2011, 22 (35), 355701.

(64) $\%$ Respuesta $=\left(i_{r}-i_{b}\right) / i b \times 100 \%=\Delta i / i_{b} \times 100 \%$, donde $i_{r}$ es la corriente de respuesta; $i_{b}$ es la corriente de base del sistema. 


\section{Sección IV}

\section{Implicancias en la Formación de Heterojunciones}

(Grafeno + NPs Metálicas) 


\section{Capítulo 6}

\section{Diseño de Plataformas Sensibles con Heterojunciones. Caracterización por TERS y SERS}

\subsection{Introducción}

Las propiedades únicas de Grafeno combinadas con otros materiales con escalas nanométricas han superado las expectativas sobre las futuras aplicaciones en el área de la ciencia de los nanomateriales. Ejemplos de ello son la combinación de grafeno con nitruro de boro hexagonal en membranas separadoras de protones, ${ }^{1}$ el dopado de grafeno con iones de N y B para aumentar el band gap (energía prohibida) del mismo, ${ }^{2}$ la deposición de pequeñas cantidades de átomos de $\mathrm{Cu}$ para aplicaciones de water splitting, ${ }^{3}$ y la formación de hetero-estructuras con nanopartículas de $\mathrm{Au}, \mathrm{Ag}$ y $\mathrm{Cu}$ para mejorar dramáticamente la señal Raman de diferentes analitos por SERS (surfaceenhanced Raman scattering). ${ }^{4}$ Recientemente, se ha demostrado que grafeno combinado con sigo mismo, ${ }^{5,6}$ tanto en configuraciones de bicapas como multicapas, incrementa su energía prohibida (band gap), permitiendo que éste material sea más apropiado para la industria de los semiconductores. ${ }^{7}$ La adición/combinación de nanoestructuras metálicas a/con grafeno es una estrategia inteligente para la construcción de plataformas SERS, ya que grafeno provee de propiedades fisicoquímicas únicas mientras que los centros metálicos mejoran la señal Raman debido a sus plasmones. Existen varias configuraciones interesantes de grafeno con nanoestructuras metálicas ${ }^{8,9}$ empleadas para la detección altamente sensible de bajas concentraciones de analitos ${ }^{10-13}$ aún tan bajas como al nivel de una única molécula ${ }^{14}$ (plataformas SERS) y en el estudio de los llamados local strains en grafeno (ej.: estudiados mediante TERS) ${ }^{8}$.

Luego del trascendental aislamiento de grafeno desde grafito llevado a cabo por Novoselov y Geim, se han desarrollado algunos métodos relevantes para la obtención del mismo. ${ }^{15}$ En éste sentido, como se estudió en el Capítulo 5, la deposición química de vapores (chemical vapor deposition, CVD) es usualmente el método escogido debido a que produce una única capa de grafeno de un modo reproducible aun a grandes escalas. ${ }^{16}$ Sin embargo, el procedimiento de transferencia involucra el uso de polímeros de alto peso molecular tales como polimetilmetacrilato (PMMA), el cual no puede ser removido completamente desde la superficie de éste nanocarbón. ${ }^{17}$ La mayoría de las 
estrategias para la remoción del PMMA han fallado, ${ }^{13,18}$ mientras que las únicas que han sido exitosas requieren de protocolos poco prácticos en los que se emplea, por ejemplo, un bombardeo de iones en pulsos con energías controladas. ${ }^{19}$ En vistas de lo expuesto, nuestro grupo ha demostrado que empleando los procedimientos de limpieza convencionales, no fue posible la remoción completa de los residuos del polímero. Esto fue demostrado tanto por los cambios en la corriente como en la aparición de las bandas Raman localizadas en $\sim 1430 \mathrm{y} \sim 1550 \mathrm{~cm}^{-1}$, las cuales están asociadas con las impurezas del PMMA. ${ }^{20}$ La transferencia de grafeno sin el uso de polímeros conduce y produce heterojunciones "limpias", las cuales pueden ser directamente empleadas para aplicaciones en TERS (tip-enhanced Raman spectroscopy) y en SERS.

Desde el descubrimiento de grafeno, la espectroscopia Raman ha jugado un rol central en la caracterización de materiales $2 \mathrm{D}$ debido a que ésta provee de información precisa sobre el número de capas, el desorden de la película, la presencia de impurezas, y su estado electrónico. ${ }^{21}$ Sin embargo, la microscopia Raman convencional usada para mapear grafeno es una técnica que es restringida por el límite de difracción de la luz o el láser empleado." TERS, es una técnica que combina las microscopias de barrido por sondas (scanning probe microcopy, SPM) con la espectroscopia Raman, perimiendo obtener la misma información que un microscopio Raman confocal pero mejorando enormemente la resolución local obtenida. ${ }^{22}$ La resolución obtenida por TERS es el resultado de una combinación entre las dimensiones de la nanopartícula (NP) de Au (podría ser de otro metal) que determina la resolución espacial, y los plasmones superficiales localizados o confinados (localized surface plasmon) de la misma (la NP esta en el ápice de la punta de TERS) lo cual permite mejorar la sensibilidad cada vez que la punta se acerca a la superficie en estudio.

Por otro lado, existen unos pocos efectos que pueden causar cambios en la frecuencia de la banda 2D de grafeno los cuales incluyen: la energía del láser, ${ }^{13,23}$ el número de capas de grafeno, ${ }^{15}$ el dopado con cargas (electron or hole doping), ${ }^{6}$ la influencia del sustrato $^{24}$ o la ausencia del mismo (suspendido), ${ }^{25}$ y los esfuerzos

\footnotetext{
* En un microscopio óptico la resolución lateral va a estar limitada por la difracción óptica, lo cual puede explicarse con la siguiente ecuación:

$$
\Delta \mathrm{x}=0,61 \lambda / \mathrm{NA}
$$

siendo, " $\Delta \mathrm{x}$ " es la resolución lateral, " $\lambda$ " es la longitud de onda de la luz empleada para la excitación, $y$ "NA" la apertura numérica de las lentes objetivos. Por ende, la resolución lateral obtenida en los espectros colectados en un microscopio Raman van a presentar bajas resoluciones. Ver la Sección 2.19 del Capítulo 2 para más detalles.
} 
mecánicos (local strains) sobre grafeno. ${ }^{26,27}$ Particularmente, los local strains sobre grafeno pueden ser inducidos por la punta, ${ }^{27}$ detectados por ésta ${ }^{28}$ o ambas ${ }^{27}$ situaciones durante el sondeo por TERS en campo cercano (near-field scanning). Por ejemplo, una disminución en la frecuencia de la banda 2D ha sido observada durante sondeos con la punta TERS sobre "crestas" (ridges) de grafeno crecido sobre $\mathrm{SiC}^{29}$ sobre grafeno suspendido y soportado, ${ }^{25}$ y sobre grafeno depositado sobre una única nanopartícula de Au de $5 \mathrm{~nm}$ de diámetro. ${ }^{8}$ Todas estas publicaciones han demostrado que la banda $2 \mathrm{D}$ de grafeno disminuye su frecuencia y aumenta el ancho del pico a la altura media (full width at half máximum, FWHM) durante los experimentos de TERS.

En éste Capítulo, se reporta una metodología simple pero efectiva para transferir grafeno empleando NPs de Au recubiertas con un surfactante. La mencionada estrategia presenta beneficios en dos aspectos importantes: a) evita el uso de polímeros de alto peso molecular (ej.: PMMA); y b) las NPs de Au se asocian con grafeno para construir nanomateriales híbridos con una sensibilidad destacada. Estos nanomateriales permiten que se pueda explorar en los planos desparejos (mismatch planes) de grafeno, los efectos locales generados por las NPs de $\mathrm{Au}$ y la punta $\mathrm{Au}$, y finalmente estudiar la actividad SERS de la Rodamina 6G (Rh6G) tanto sobre diferentes áreas de un único nanoplate de $\mathrm{Au}$ como sobre redes de NPs de Au encontradas en las heterojunciones. Los experimentos de TERS llevados a cabo sobre redes de NPs mostraron cambios reversibles en la frecuencia y en el valor de FWHM de la banda 2D cada vez que la punta se aproxima/retrae a/desde la heterojunción. Resulta interesante que, la actividad SERS de la Rh6G adsorbida sobre un único nanoplate de Au con forma triangular, mostró que el mayor incremento corresponde a las áreas deprimidas sobre un borde en particular. Estos experimentos empleando TERS revelan información valiosa acerca del número de capas de grafeno, potenciales dislocaciones entre capas, dopado del material, junto con la determinación de los local strains sobre grafeno.

\subsection{Experimental}

\subsubsection{Síntesis de las Nanopartículas de Au Protegidas con TOABr (Au@TOABr)}

Las NPs de Au protegidas con TOABr (SNPs) fueron sintetizadas acorde a la reacción bifásica de Brust-Schiffrin, pero sin el agregado de tioles orgánicos. ${ }^{30}$ Los detalles de la síntesis se encuentran en el Capítulo 2 de ésta tesis. Las nanopartículas preparadas por éste método presentan un diámetro de 4,39 $\pm 1,25 \mathrm{~nm}$ y 2,96 $\pm 0,66 \mathrm{~nm}$ de acuerdo a los datos obtenidos por microscopia de transmisión de electrones (TEM) ${ }^{31}$ y por dispersión de rayos-X a bajo ángulo (SAXS), ${ }^{32}$ respectivamente. 


\subsubsection{Síntesis de Grafeno por CVD}

El grafeno fue crecido por chemical vapor deposition (CVD) sobre una lámina de $\mathrm{Cu}$ (espesor de $25 \mu \mathrm{m}, 5 \times 10 \mathrm{~cm}^{2},>99.99 \%$ MTI Corp.), previamente ultra-sonicada por 20 minutos en acetona (este procedimiento se repite 3 veces). La lámina de $\mathrm{Cu}$ fue colocada dentro de un tubo de cuarzo dispuesto en un horno tubular, al cual se le genera vacío por medio de una bomba $\left(8.0 \times 10^{-5}\right.$ Torr $)$. Después de alcanzar una presión estable, se permite el ingreso de $\mathrm{H}_{2}(24 \mathrm{~mL} / \mathrm{min})$ el cual está presente durante todo el proceso de síntesis. La muestra fue luego calentada a $1000{ }^{\circ} \mathrm{C}$ por 30 minutos y el grafeno fue crecido bajo un flujo de $75 \mathrm{~mL} / \mathrm{min}$ de $\mathrm{CH}_{4}$ corrido por 5 minutos. ${ }^{13,33}$ Después de la remoción del horno, el grafeno fue transferido a los diferentes sustratos ( $\mathrm{Si}$, vidrio y grillas para TEM) usando el protocolo descrito en la sección de formación de la heterojunción.

\subsubsection{Procedimiento para la Transferencia de Grafeno Libre de PMMA y Formación de la Heterojunción}

El grafeno crecido sobre láminas de $\mathrm{Cu}$ fue cortado en pequeñas piezas y las mismas fueron colocadas dentro de placas de Petri. Luego, a dichas piezas de $\mathrm{Cu}$ /grafeno se les depositó por la metodología de drop-casting una solución concentrada de NPs de Au@TOABr. Las muestras se secaron al aire, y las láminas de Cu fueron disueltas empleando una solución de etching compuesta de $\mathrm{CuCl}_{2} 2,0 \mathrm{M}(28 \% \mathrm{p} / \mathrm{v})$ en $\mathrm{HCl} 6 \mathrm{M}$ mezclado con alcohol isopropílico $(10 \% \mathrm{v} / \mathrm{v})$. Finalmente, la solución de etching fue removida y remplazada con una mezcla de alcohol isopropílico (IPA) en agua Milli-Q al 10\% v/v, la cual permite remover los residuos de $\mathrm{CuCl}_{2}$.

La mencionada metodología permite la obtención de heterojunciones conformadas por películas de NPs de Au@TOABr en la superficie de grafeno. Las muestras fueron luego transferidas a diferentes sustratos tales como $\mathrm{Si}$, vidrio y grillas de $\mathrm{Cu}$ (para ser usadas en microscopia TEM). Más detalles pueden encontrarse en el Capítulo 2 (Sección 2.4.3.2).

\subsubsection{Tratamiento Térmico}

Con el fin de remover el material orgánico de las NPs de Au, la heterojunción fue sujeta a un tratamiento térmico a $300{ }^{\circ} \mathrm{C}$ por 1 hora, el cual fue llevado a cabo en una mufla Barnstead/Thermolyne Small Benchtop Muffle Furnaces Type 1300 (Thermo Scientific).

\subsubsection{Caracterización Microscópica}

\subsubsection{Experimentos Raman}


Los espectros Raman fueron adquiridos en un microscopio Raman con sistema confocal LABRAM-HR Horiba Jobin-Yvon usando un láser de 632,8 nm (He-Ne). Los experimentos Raman fueron llevados a cabo con lentes de objetivo de 100x (0,9 NA) y una potencia de láser de 5,4 $\mathrm{mW}$. Para los experimentos de SERS, las muestras de heterojunciones (grafeno + nanopartículas de $\mathrm{Au}$ ) fueron inmersas en una solución acuosa de $\mathrm{Rh} 6 \mathrm{G}$ de $1,0 \times 10^{-3} \mathrm{M}(\mathrm{pH}=5)$ por 1 hora. Luego, las mismas fueron lavadas cuidadosamente con agua Milli-Q y secadas con $\mathrm{N}_{2}$, previo a su caracterización.

\subsubsection{Imagen Raman}

La imagen Raman fue construida con 64 espectros Raman colectados por el escaneo cada $0,5 \mu \mathrm{m}$ a lo largo del nanoplate triangular entero. El tiempo de adquisición fue de: 5 segundos por cada 5 espectros promediados. En éste caso, se empleó una baja potencia del láser $(0,05 \mathrm{~mW})$ con el fin de evitar el calentamiento de la muestra inducido por el mismo.

\subsubsection{Experimentos de TERS}

Los espectros de Tip-Enhanced Raman Spectroscopy (TERS) fueron colectados en un microscopio Nanonics Imaging Ltd. Multiview $2000^{\mathrm{TM}}$ Scan Head Assembly (con iluminación superior) con un lente objetivo de 100x (0,7 NA). Para cada experimento de TERS, el láser de 632,8 nm (He-Ne) fue cuidadosamente enfocado y fijado sobre la punta de AFM, y la muestra fue escaneada debajo de ambos. Las puntas con NPs de Au (Au NPs-tips) fueron compradas a Nanonics Imaging Ltd.

\subsubsection{Caracterización por AFM}

Las imágenes de microscopia de fuerza atómica (Atomic Force Microcopy, AFM) fueron adquiridas con el mismo microscopio usado en los experimentos de TERS, empleando una punta de Si operando en modo tapping.

\subsubsection{Caracterización por HRTEM}

Las imágenes de microscopía electrónica de transmisión de alta resolución (High Resolution Transmission Electron Microscopy, HRTEM) fueron adquiridas empleando un microscopio Phillips CM 200 UT operado a $200 \mathrm{keV}$.

\subsubsection{Caracterización Espectroscópica}

Los espectros de dispersión fueron colectados sobre un nanoplate de $\mathrm{Au}$ individual usando resonant Rayleigh dark-field scattering spectroscopy. Las imágenes de campo claro y oscuro fueron llevadas a cabo empleando un microscopio invertido Olympus con una fuente de luz de una lámpara halógena y un condensador de campo oscuro $(\mathrm{NA}=0,95-0,80)$ para la iluminación de la muestra. 


\subsection{Resultados}

\subsubsection{Transferencia de Grafeno Libre de PMMA}

El esquema en la Figura 6.1 describe los tres pasos requeridos para obtener películas de grafeno libres de PMMA. El Paso 1 muestra el crecimiento de grafeno sobre una lámina de $\mathrm{Cu}$, seguido por la deposición por drop-casting de las NPs de $\mathrm{Au}$ protegidas con surfactante (Paso 2), y la disolución (etching) del $\mathrm{Cu}$ (ver el Capítulo 2 para más detalles experimentales). Una vez que la heterojunción es transferida, esta es sujeta a un tratamiento térmico $\left(300^{\circ} \mathrm{C}\right.$ por 1 hora $)$, con el fin de remover las moléculas de surfactante adsorbidas sobre las NPs de Au. El tratamiento térmico causa un incremento en el diámetro de las NPs de Au as-synthesized desde $\sim 3-4 \mathrm{~nm}^{13,34} \mathrm{a} \sim 10$ $\mathrm{nm}$, junto con la formación de nuevas formas que incluyen: redes de nanopartículas, dímeros, y nanoplates (con formas de círculos, hexágonos y triángulos) como puede ser notado tanto en las imágenes ópticas de campo amplio (wide field) como en las de HRTEM mostradas en la Figura 6.2. Asimismo, en la Figura 6.3 se muestran las imágenes de HRTEM asociadas con el aumento de las NPs de Au durante el tratamiento térmico.

En la Figura 6.1 también se muestra la caracterización del sistema por microscopia Raman. Brevemente, cada espectro Raman fue colectado sobre un área selecta de grafeno antes (Paso 1) y después de haber sido transferido con las NPs de Au y tratado térmicamente (Paso 3). Una vez finalizada la transferencia, el espectro exhibe un incremento de $\sim 10$ veces en la intensidad de todas las bandas características de grafeno (D, G y 2D) y la aparición de nuevas bandas en 990 (D”), 1610 (D'), 2450 (D+D”), y $\sim 3220 \mathrm{~cm}^{-1}$ (2D'). ${ }^{35}$ Asimismo, es notoria la ausencia de las bandas localizadas en $\sim 1430, \sim 1530$, y $\sim 2900 \mathrm{~cm}^{-1}$ lo cual indica que el grafeno as-transferred esta libre de impurezas orgánicas provenientes tanto residuos poliméricos como de cadenas alquílicas. ${ }^{17,20,36}$ 


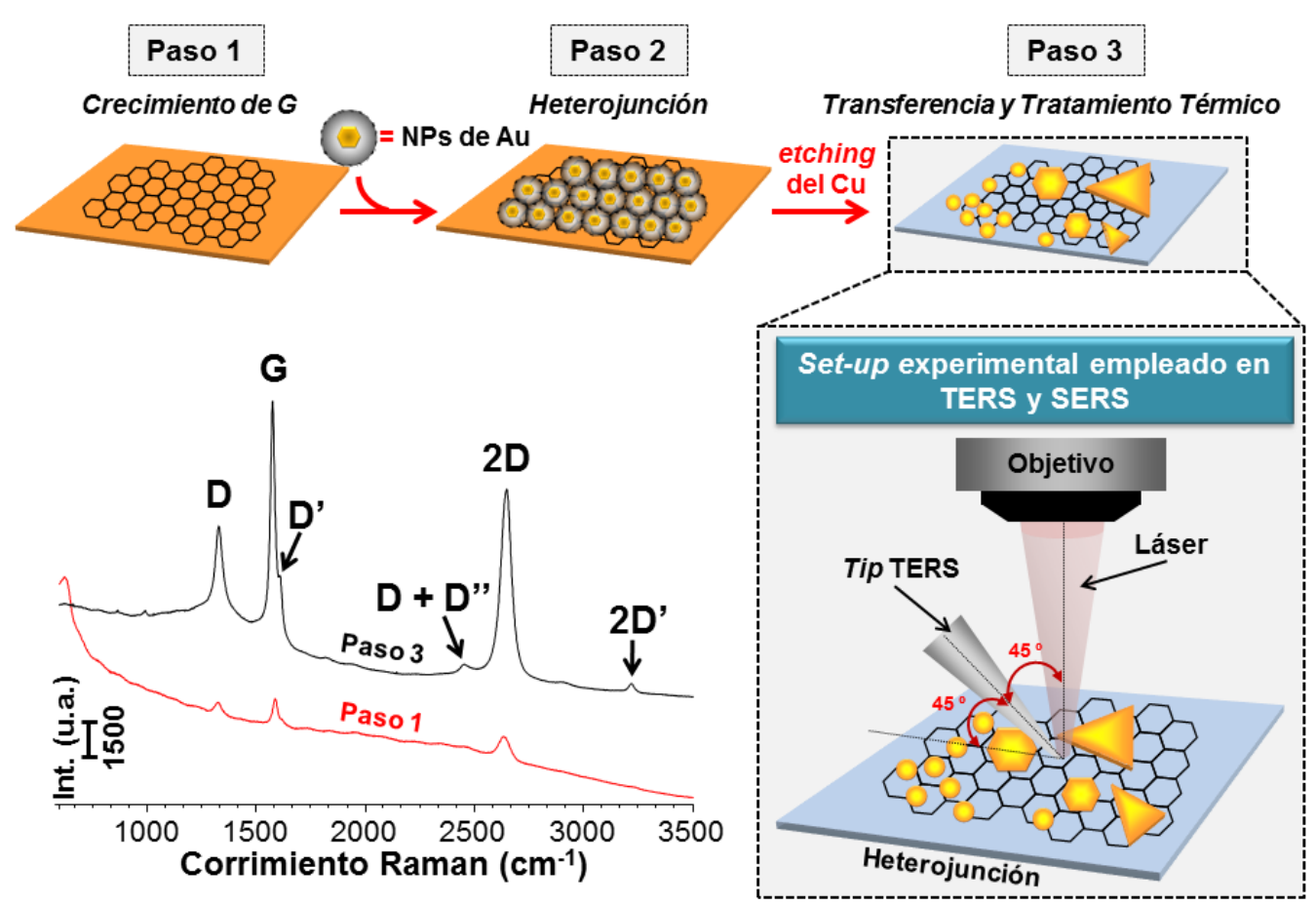

Figura 6.1 Esquema describiendo los pasos generales requeridos para obtener grafeno libre de PMMA, los cuales incluyen: el crecimiento de grafeno (G) sobre una lámina de $\mathrm{Cu}$ por la metodología de CVD (Paso 1); la formación de la heterojunción usando NPs de $\mathrm{Au}$ (Paso 2); y el etching de la lámina de $\mathrm{Cu}$ y transferencia de $\mathrm{G}$ a sustratos limpios seguida de un tratamiento térmico (Paso 3). El esquema muestra también el set-up experimental usado para las aplicaciones en TERS y SERS. Los espectros Raman de grafeno as-synthsized sobre una lámina de $\mathrm{Cu}$ (Paso 1) y la heterojunción en el Paso 3, como es indicado.

En la Figura 6.2 A, B se muestran las imágenes ópticas de áreas selectas de las heterojunciones as-transferred correspondientes a las diferentes formas de $\mathrm{Au}$ y a las redes de NPs de Au, respectivamente. La Figura 6.2 B exhibe una interesante red de pequeñas NPs de $\mathrm{Au}$, las cuales podrían estar alineadas preferencialmente sobre los bordes de grano de la película de grafeno. La Figura 6.2 C, D y el recuadro (zoom-in) exhiben imágenes de HRTEM de una heterojunción as-transferred luego del tratamiento térmico, notar que las NPs de Au están rodeadas por halos que poseen un contraste diferente al del centro metálico, los cuales podrían corresponder a regiones en las que predominan formas alotrópicas del Carbono. En tal sentido, en la Figura 6.2 D se exhiben franjas con ordenamiento atómico, junto con zonas sombreadas y brillantes las cuales podrían indicar la presencia de un patrón Moiré potencialmente causado por 
el mal apareamiento entre los planos de grafeno. ${ }^{37-39}$ Esto también podría ser atribuido a fragmentos de Carbono remanentes después del tratamiento térmico. El espectro Raman llevado a cabo sobre la heterojunción as-prepared no mostró evidencia de los modos de stretching de $\mathrm{R}-\mathrm{CH}_{2}$ y $-\mathrm{CH}_{3}$ (ver los espectros Raman en la Figura 6.1), los cuales habrían indicado la presencia de residuos orgánicos. Por otro lado, los experimentos Raman deberían haber mostrado la presencia de una nueva banda cercana a la banda $\mathrm{G}^{39}$ en el caso de patrones Moiré, la cual no es observada en este sistema. Como resultado de lo expuesto, una examinación cuidadosa dentro de las bandas Raman de grafeno y las imágenes de HRTEM del mismo, permiten obtener información valiosa respecto al número actual de capas y potenciales dislocaciones entre las mismas, respectivamente mientras que la presencia de nanoestructuras de Au acopladas a grafeno incrementa significativamente la sensibilidad Raman. 

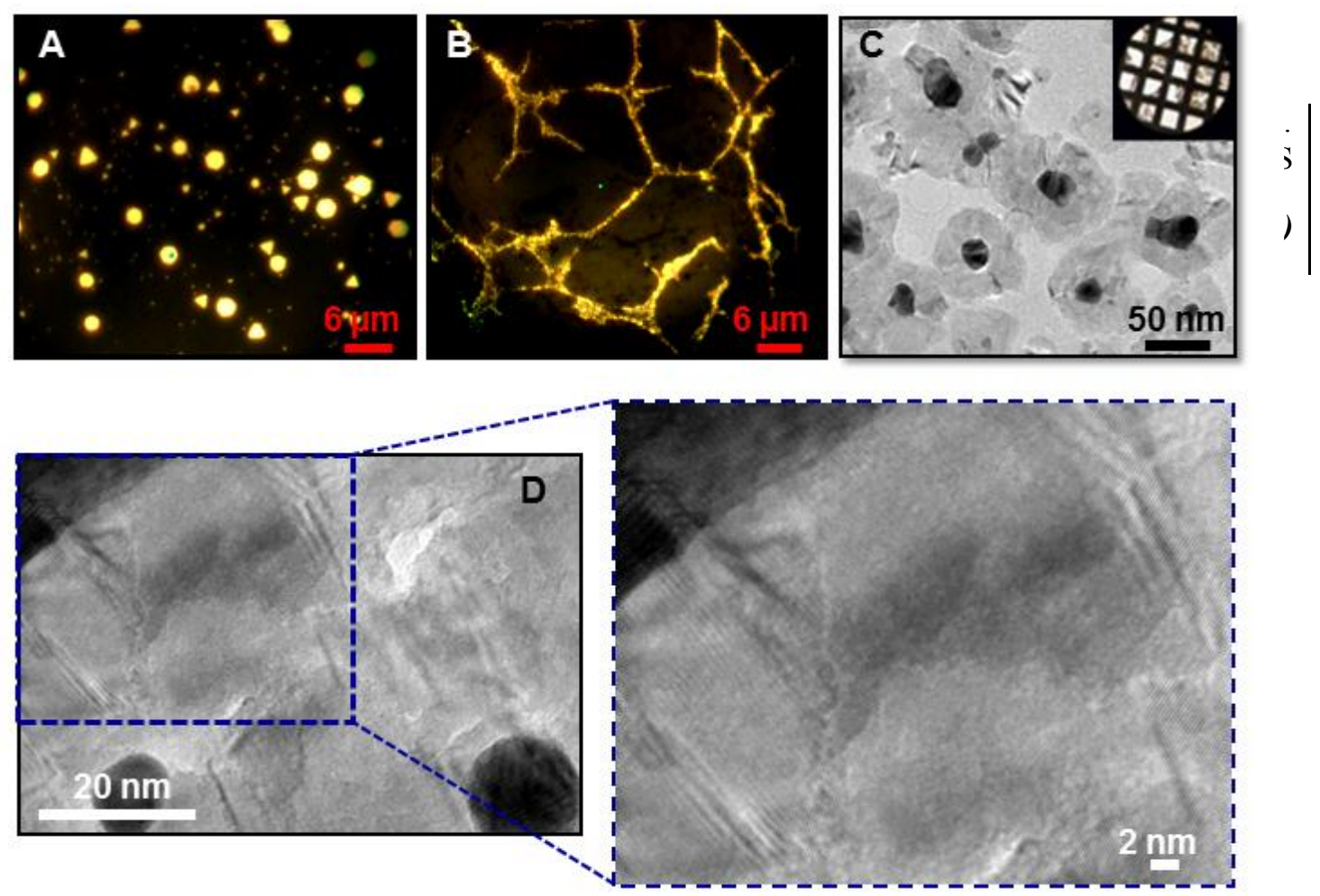

Figura 6.2 Imágenes ópticas de áreas selectas de una heterojunción as-transferred sobre vidrio (después del tratamiento térmico), las cuales corresponden a las diferentes formas de Au encontradas (A) y a las redes de NPs de Au (B). Imágenes de HRTEM de un área as-transferred de la heterojunción sobre una grilla de $\mathrm{Cu}$ (después del tratamiento térmico) mostrando las NPs de Au rodeadas por algunos halos sombreados $(\mathrm{C}, \mathrm{D})$. El recuadro corresponde a un zoom-in en un área de la imagen D. 

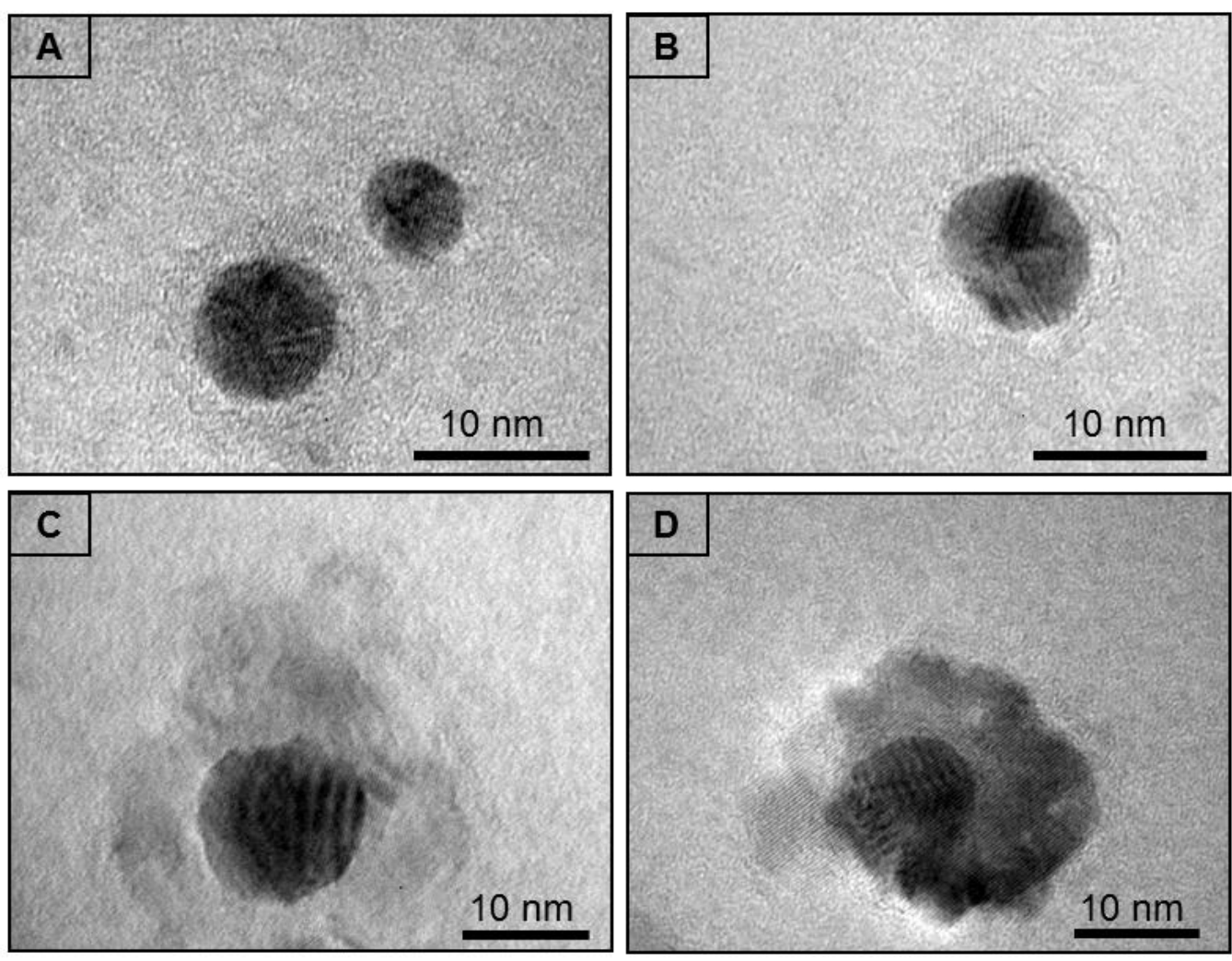

Figura 6.3 Imágenes de microscopía de transmisión de electrones de alta resolución (High Resolution Transmission Electron Microscopy, HRTEM) de las NPs de Au en una heterojunción (A-D). Notar que luego del tratamiento térmico las NPs han aumentado su tamaño (ver el texto para más detalles).

\subsubsection{Caracterización por Tip-Enhanced Raman Spectroscopy (TERS)}

El protocolo de transferencia libre de PMMA junto con la formación de las llamativas redes de NPs de Au, nos condujo a explorar en las propiedades mecánicas de grafeno. La Figura 6.4 muestra las medidas de TERS llevadas a cabo por los sucesivos 
movimientos de la punta en posición "tip up" y "tip down" sobre una red de NPs de Au selecta (en el área con NPs agregadas en el recuadro). Es necesario mencionar que todos los espectros y los datos mostrados fueron normalizados respecto a la intensidad de la banda $\mathrm{G}$ de grafeno. En el campo lejano (tip retracted), el espectro exhibe las bandas características de grafeno correspondientes a D, G y 2D en $\sim 1325, \sim 1585$, y $2648 \mathrm{~cm}^{-1}$, respectivamente. Es importante mencionar que dichas bandas son observadas aún a pesar de la gran concentración de NPs de Au en la heterojunción. Cada vez que la punta se aproxima a la muestra, es posible destacar algunos aspectos interesantes que aquí se detallan. Primero, todos los modos Raman cambian reversiblemente tanto sus números de onda $\left(\mathrm{cm}^{-1}\right)$ como el ancho del pico a la altura media (full width at half maximum, FWHM). El corrimiento Raman a grandes valores de número de onda (blue-shift) observados para las bandas D y 2D sugieren que el sistema requiere de mayor energía para excitar a los modos vibracionales (fonones) de grafeno (ver infra). Segundo, se observa una destacada resolución de las bandas de grafeno antes mencionadas (ej.: la banda D asociada al desorden de la película) junto con las bandas D' $\left(\sim 1620 \mathrm{~cm}^{-1}\right)$ y D + D' $\left(\sim 2921 \mathrm{~cm}^{-1}\right)$ con mayor resolución, las cuales no fueron observadas en la posición de la punta retraída (ver la Figura 6.5, correspondiente a otra zona de la muestra). La banda D' es activada por un proceso de dispersión intra-valle que implica un único

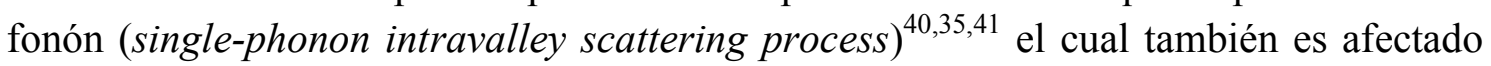
por los defectos o fallas presentes en grafeno, mientras que la banda $\mathrm{D}+\mathrm{D}$ ' es una combinación de ambos modos Raman. ${ }^{41}$ Finalmente, en la Figura 6.4B, C y D se muestran los gráficos de frecuencia/corrimiento Raman (y FWHM) versus el número de los sucesivos eventos realizados por la punta (tip up y tip down) medidos para las bandas D, G y 2D, respectivamente. El corrimiento Raman observado para la banda 2D $\left(8-10 \mathrm{~cm}^{-1}\right)$, como es esperado, es de aproximadamente dos veces el valor del corrimiento de la banda $\mathrm{D}\left(4-5 \mathrm{~cm}^{-1}\right)$ debido a que la primer banda es producida por un proceso de resonancia inter-valle de doble fonón (intervalley double-phonon resonance process $).{ }^{35}$ Asimismo, la frecuencia de la banda $\mathrm{G}$ también incrementa, pero en menor extensión (2-3 $\left.\mathrm{cm}^{-1}\right)$ que las otras dos bandas antes mencionadas. Se observan cambios en los valores de FWHM de todas las bandas involucradas en éste estudio, pero las mismas presentan diferentes tendencias. Por ejemplo, el FWHM de la banda 2D reversiblemente crece/decrece cuando la punta esta en posición up/down, mientras que las bandas G y D progresivamente incrementan el valor de el FWHM a pesar de la posición de la punta. La Figura 6.5 muestra los resultados de TERS correspondientes a otra área con redes de NPs de Au de la misma muestra, demostrando que los efectos descritos son reproducibles. 
A
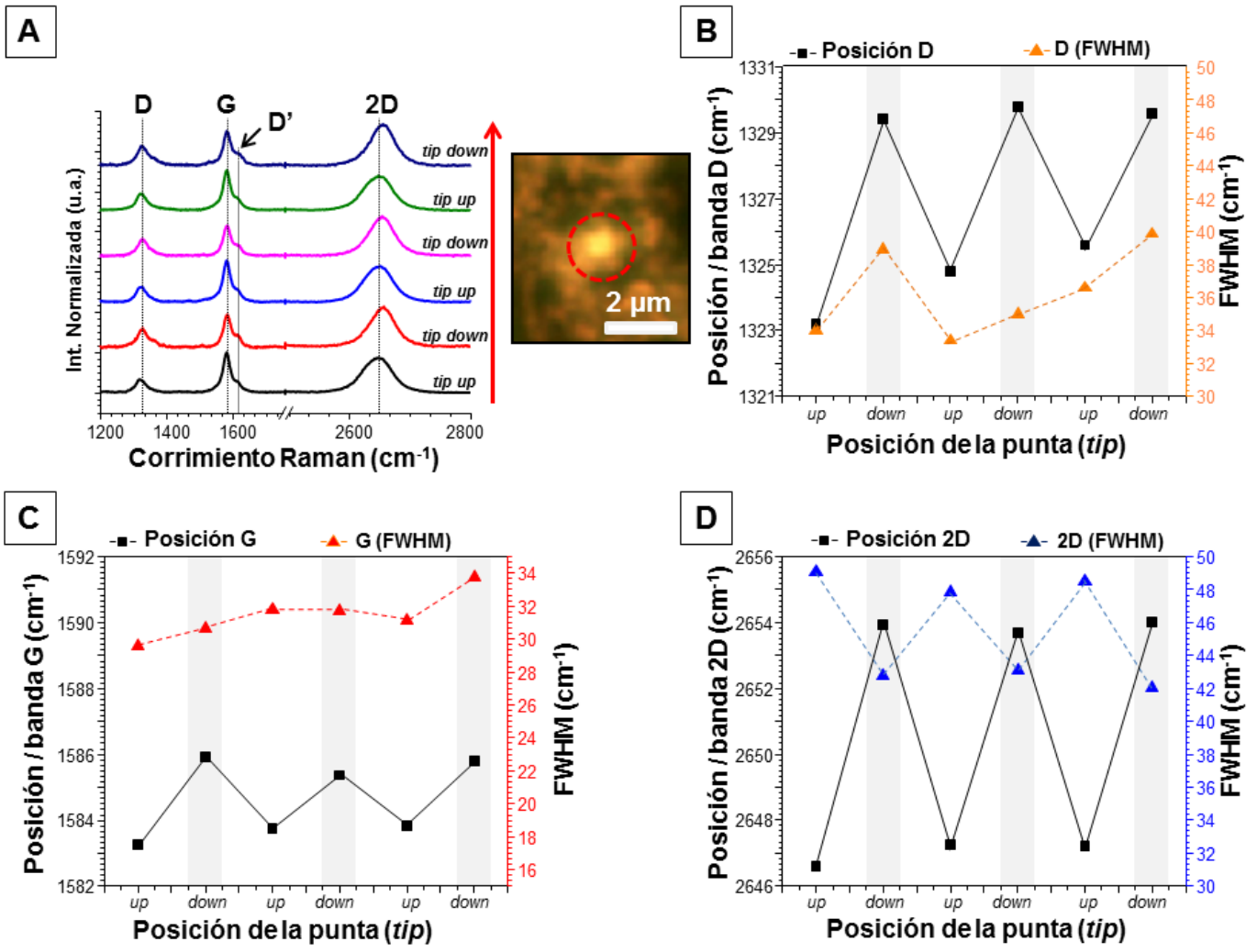

Figura 6.4 Caracterización TERS en condiciones de "tip up" y "tip down", llevadas a cabo sobre una red de NPs de Au como es indicado por la imagen óptica mostrada en el recuadro (A). Los gráficos están en off-set para una mejor comparación. Todos los espectros y los datos mostrados fueron normalizados respecto a la intensidad de la banda $G$ de grafeno. Cambios en la frecuencia y ancho del pico a la altura media (full width at half maximum, FWHM) de las bandas D (B), la G (C) y la 2D (D) durante los experimentos de "tip up/tip down" correspondientes a los gráficos mostrados en A, como es indicado. Las líneas negras y las sobras grises son guías visuales. 


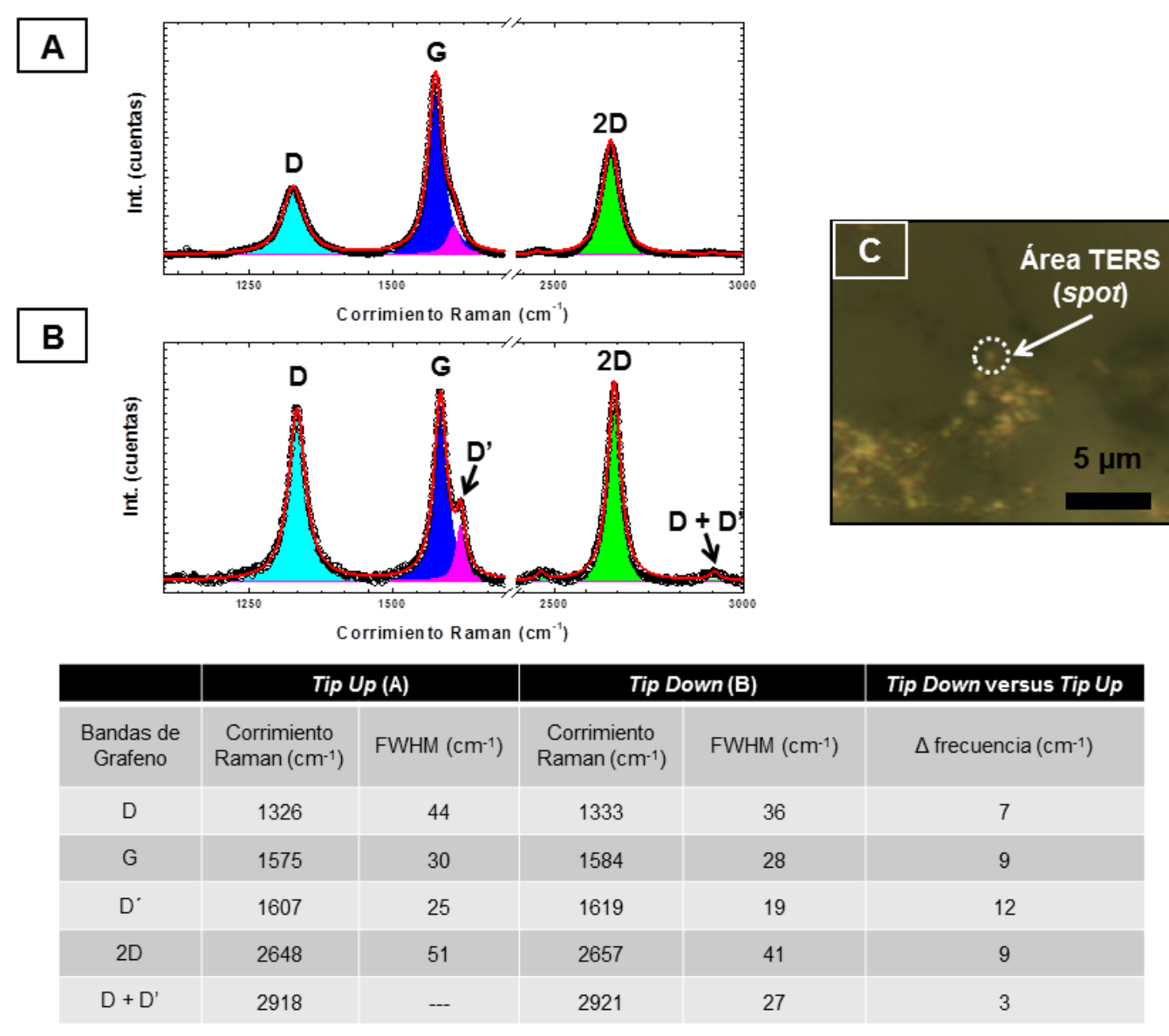

Figura 6.5 Caracterización TERS de una red de NPs de Au selecta en posición "tip up" (A) y "tip down" (B) junto con una tabla mostrando los ajustes Lorentzianos para todas las bandas de grafeno, como es indicado. Todos los espectros y los datos mostrados fueron normalizados a la intensidad de la banda $G$ de grafeno. Imagen óptica de una red de NPs de Au, donde se muestra el área en donde se caracterizó por TERS (spot) (C).

Recientemente, el grupo de Novotny ${ }^{8}$ reportó la caracterización TERS de una heterojunción (NPs + grafeno). Ellos sondearon sobre una única nanopartícula de Au 
colocada debajo de grafeno obtenido por exfoliación mecánica, y observaron un decrecimiento tanto en la frecuencia como en el valor del FWHM durante el sondeo por TERS. La mencionada heterojunción presenta un parecido a nuestro sistema en estudio, ya que combina NPs de Au y grafeno, sin embargo la configuración es diferente debido a que la punta se encuentra sondeando directamente sobre grafeno en vez de interactuar con las NPs de Au. Esta podría ser una de las razones por las cuales el comportamiento TERS se opone a nuestros resultados, en términos de frecuencia, por decrecimiento en vez de incremento. Pensamos que el corrimiento Raman de la banda 2D a grandes frecuencias puede estar asociado con la transferencia de electrones desde grafeno a las NPs de $\mathrm{Au}$ (o a la punta de $\mathrm{Au}){ }^{42}$

Respecto a lo expuesto, en la Figura 6.6 se muestra un experimento de control llevado acabo sobre un área de la muestra transferida, donde la imagen óptica no muestra ni redes con NPs ni los característicos nanoplates observados en otras zonas. La mencionada figura muestra los espectros TERS y una tabla indicando las posiciones de
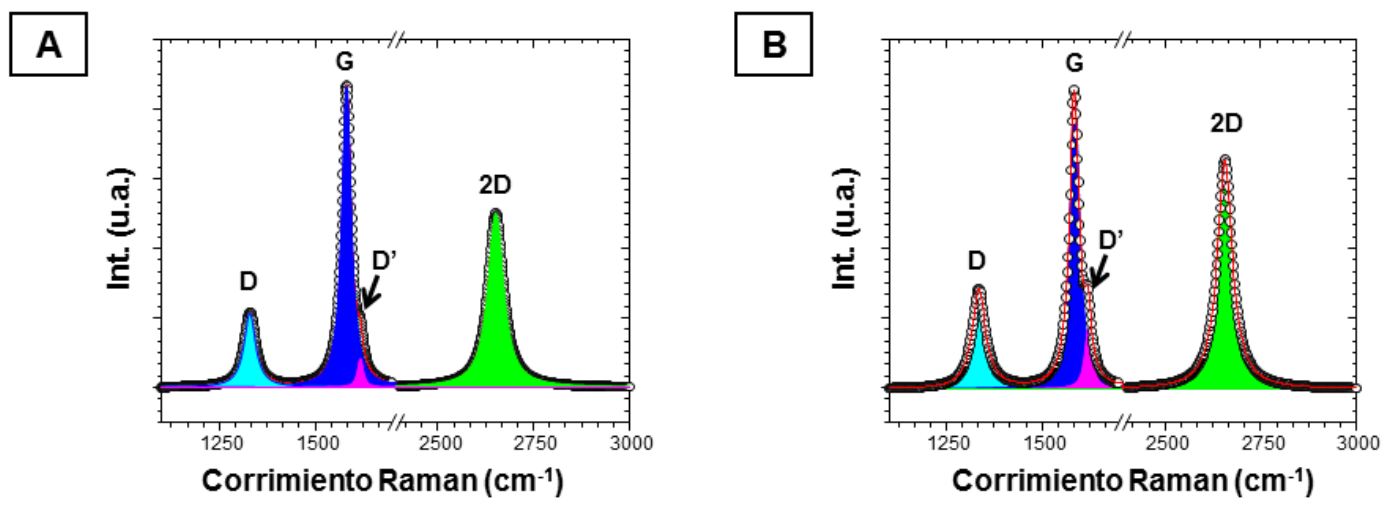

\begin{tabular}{|c|c|c|c|c|c|}
\hline & \multicolumn{2}{|c|}{ Tip Up (A) } & \multicolumn{2}{c|}{ Tip Down (B) } & Tip Down versus Tip Up \\
\hline $\begin{array}{c}\text { Bandas de } \\
\text { Grafeno }\end{array}$ & $\begin{array}{c}\text { Corrimiento } \\
\text { Raman }\left(\mathrm{cm}^{-1}\right)\end{array}$ & FWHM (cm-1) & $\begin{array}{c}\text { Corrimiento } \\
\text { Raman }\left(\mathrm{cm}^{-1}\right)\end{array}$ & FWHM $\left(\mathrm{cm}^{-1}\right)$ & Afrecuencia $\left(\mathrm{cm}^{-1}\right)$ \\
\hline D & 1330 & 38 & 1335 & 43 & 5 \\
\hline G & 1583 & 29 & 1584 & 29 & 1 \\
\hline D & 1619 & 18 & 1620 & 22 & 1 \\
\hline 2D & 2651 & 48 & 2657 & 48 & 6 \\
\hline
\end{tabular}

Figura 6.6 Caracterización TERS sobre un área selecta de la muestra donde se asume que no hay NPs de Au, en posición "tip up" (A) y "tip down" (B) junto con una tabla mostrando los ajustes Lorentzianos para todas las bandas de grafeno, como es indicado. Todos los espectros y los datos mostrados fueron normalizados a la intensidad de la banda $\mathrm{G}$ de grafeno.

las bandas de grafeno durante los eventos de "tip up" y "tip down". Del análisis de estos datos se desprende que, el comportamiento observado en las frecuencias de las bandas 
D, G y 2D presenta una tendencia similar (blue-shift) tal como fue observado en la Figura 6.5. Este efecto es equivalente a un dopado local (local doping) de grafeno hacia un estado tipo- $p$ ( $p$-type) observado en nanocarbones. ${ }^{43}$ Además, esto podría ser confirmado por cambios sistemáticos en la frecuencia de la banda G, la cual está asociada con los cambios en el nivel de Fermi. ${ }^{44}$ Actualmente, estamos realizando más experimentos con el fin de determinar conclusivamente las razones de los comportamientos observados.

\subsubsection{Actividad SERS Sobre un Único Nanoplate Triangular}

Con el fin de analizar la actividad SERS sobre una única nanoestructura, una

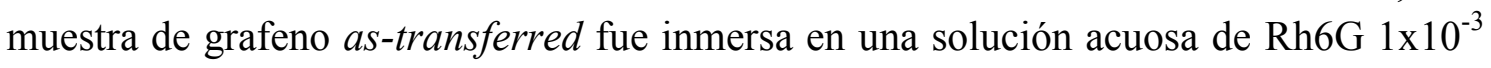
M por 60 minutos. Se adquirieron espectros Raman (SERS) sobre cada esquina, borde y centro de un único nanoplate triangular, medidos a $760 \mathrm{~cm}^{-1}$, el cual corresponde al modo de bending en el plano de los enlaces C-C-C del anillo de la Rh6G. ${ }^{45}$ La Figura 6.7 muestra una imagen de AFM (adquirida en modo tapping) de un nanoplate junto con su cross-section. La flecha blanca señala una nanopartícula usada como referencia, sin embargo es notorio que la mencionada nanopartícula podría haber sido barrida por la punta del AFM durante el sondeo de la muestra. La cross-section realizada a lo largo de un borde en particular, revela una significativa diferencia en el espesor en un rango comprendido desde $\sim 40$ a $\sim 120 \mathrm{~nm}$. Una correlación simple entre la rugosidad superficial de la muestra y la intensidad SERS de la misma es obtenida por una imagen Raman (a $760 \mathrm{~cm}^{-1}$ ) de las moléculas de Rh6G (Fig. 6.7B). Puede notarse una distribución variable (no uniforme) de las intensidades SERS sobre la superficie del nanoplate, equivalente a 1 orden de magnitud de diferencia entre el centro y el borde del mismo. Esta diferencia en la señal Raman puede ser asociada a campos electromagnéticos distribuidos de manera desigual a lo largo de la superficie del nanoplate. En éste sentido, existen en literatura variados reportes en los cuales el efecto SERS es causado por nanopartículas con tamaños menores a los $100 \mathrm{~nm}$, en los cuales el incremento en la señal esta asociado con los plasmones superficiales (localized surface plasmon resonance, LSPR). ${ }^{46}$ Sin embargo, las diferencias en la intensidad Raman no pueden ser determinadas experimentalmente en cada punto de las nanopartículas individuales debido a que la resolución lateral en SERS esta limitada por la difracción. Por otro lado, cuando se emplean como sustratos SERS estructuras de mayor tamaño, tales como nano-prismas, ${ }^{47}$ el incremento en la señal Raman es usualmente atribuida a las variaciones en la tortuosidad (roughness) superficial. 

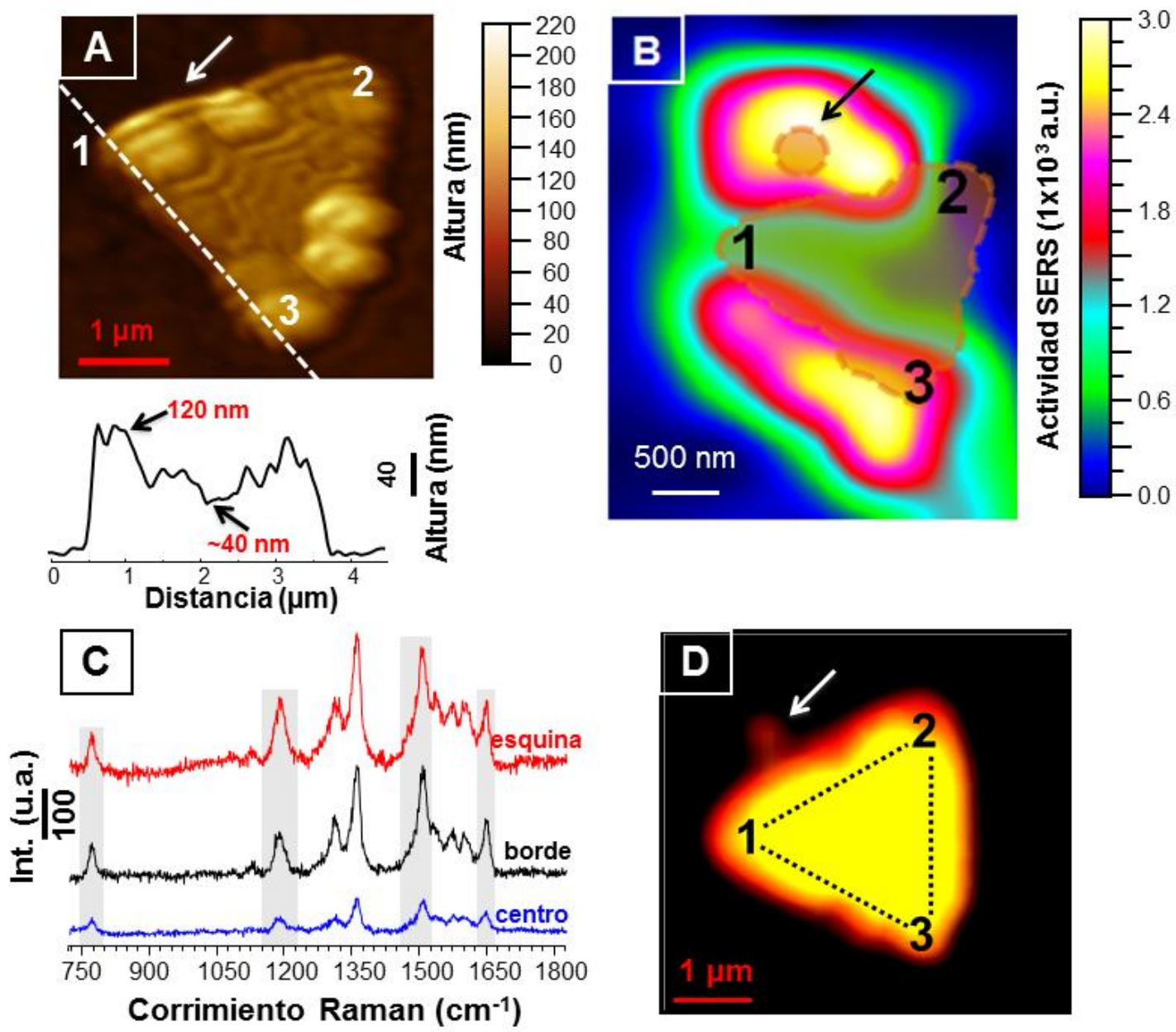

Figura 6.7 Imagen de AFM en modo tapping junto con una cross-section realizada sobre un borde de un nanoplate triangular, el cual exhibe NPs asentadas en su superficie (A). La flecha blanca indica una región en donde se observa una NP, la cual es usada como referencia. La imagen Raman muestra un gráfico de color construido por las medidas Raman adquiridas a $760 \mathrm{~cm}^{-1}$ (B). Los espectros Raman representativos de la Rh6G medidos en una esquina, un borde y el centro del nanoplate (C). Las bandas sombreadas representan cuatro de las bandas Raman características de la Rh6G. Imagen óptica correspondiente al mismo triángulo con colores exaltados, nombrando las esquinas con los números 1, 2, y 3 (D). 
Particularmente, en esta sección se estudió un único nanoplate con características intermedias entre sistemas de pequeñas partículas y superficies con un cierto grado de rugosidad. Como un ejemplo de lo expuesto, en la Figura 6.8 A, B, C se muestran las imágenes de microscopía de campo claro y oscuro, junto con el espectro de dispersión que corresponden al nanoplate en estudio, respectivamente. La línea roja punteada y la región sombreada en el gráfico de dispersión indican la energía del láser empleada y la región del fingerprint de la Rh6G, respectivamente. Estos resultados muestran que las bandas Stokes de la Rh6G caen dentro del rango de uno de los modos plasmónicos del nanoplate de $\mathrm{Au}$, lo cual podría indicar que el incremento en la señal
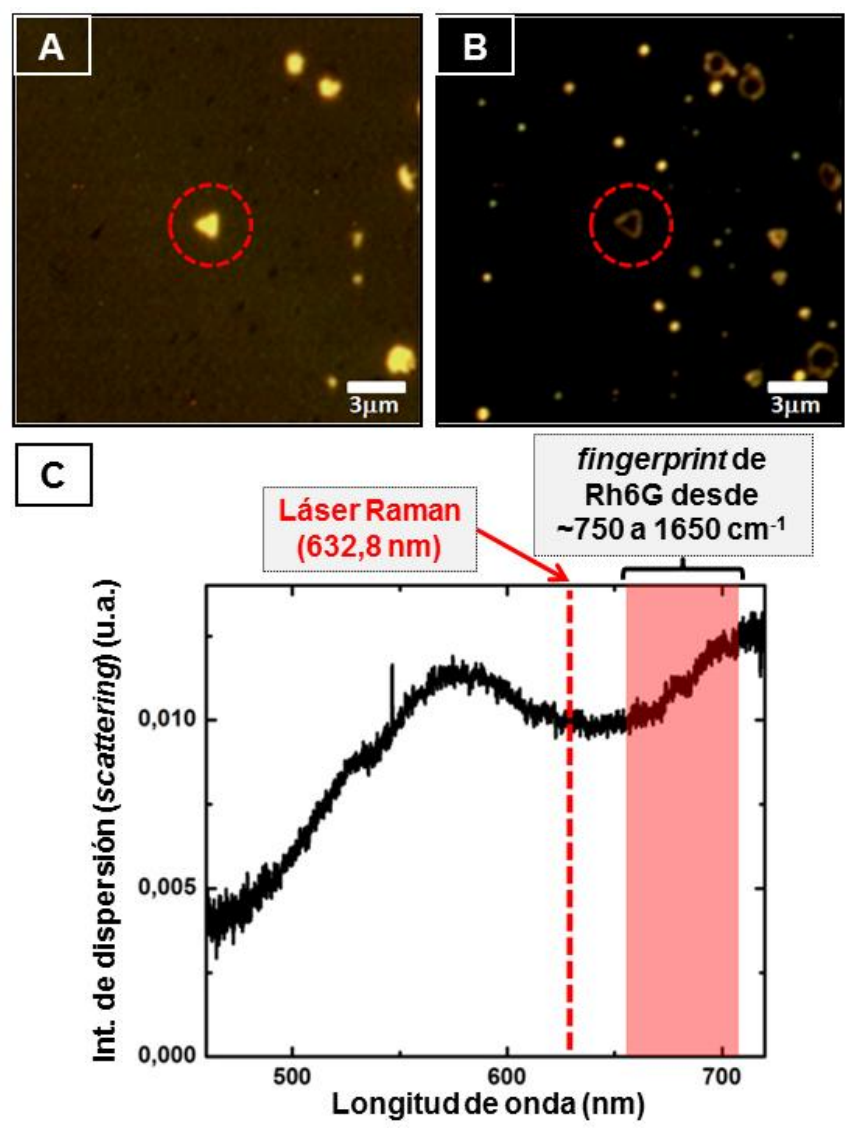

Figura 6.8 Imágenes de microscopia de campo claro (A) y oscuro (B) correspondientes a un único nanoplate de Au formado durante el annealing de una muestra de grafeno as-transferred (depositada sobre un sustrato de vidrio). Espectro de dispersión del nanoplate de Au mostrado en A y B (dentro del círculo con líneas punteadas rojas) (C). La línea roja punteada en el gráfico de dispersión indica la energía del laser (línea roja punteada a $633,8 \mathrm{~nm}, 1,90 \mathrm{eV}$ ) y la región del fingerprint de la Rodamina 6G (Rh6G) (área rosada sombreada desde $\sim 660 \mathrm{~nm}$ a $\sim 720 \mathrm{~nm}$ ). 
analítica de la misma es mayormente debido a los campos electromagnéticos en las inmediaciones de la nanoestructura. Sin embargo, el incremento en la señal Raman puede ser atribuido a las diferencias en la rugosidad superficial del nanoplate, tal como es evidenciado por la imagen de AFM y los valores correspondientes a la root-meansquare, mostrados en la Tabla 6.1

Tabla 6.1 Correlación entre los valores de Enhancement Factor (EF), Root Mean Square (RMS), y el rango en el espesor, medidos en las esquinas, bordes y en el centro del mismo nanoplate.

\begin{tabular}{|c|c|c|c|}
\hline $\begin{array}{c}\text { áreas del } \\
\text { nanoplate }\end{array}$ & $\mathbf{E F}\left(\mathbf{x} \mathbf{1 0}^{\mathbf{3}}\right)^{\mathbf{a}}$ & $\mathbf{R M S}(\mathbf{n m})^{\mathbf{b}}$ & ${\text { Rango del espesor }(\mathbf{n m})^{\mathbf{c}}}$ \\
\hline esquina 1 & 0,3 & $32,8^{\star}$ & --- \\
\hline esquina 2 & 0,4 & 11,9 & -- \\
\hline esquina 3 & 3,0 & 18,2 & --- \\
\hline borde 1-3 & 2,5 & 23,3 & $40-120$ \\
\hline borde 1-2 & 1,7 & 28,2 & $70-130$ \\
\hline borde 2-3 & 0,2 & 28,6 & $80-160$ \\
\hline centro & 0,6 & 4,9 & $90-120$ \\
\hline
\end{tabular}

Nota: ${ }^{a}$ Corresponde a los valores del Enhanced Factor (EF) de la Rh6G medidos a $760 \mathrm{~cm}^{-1}$ para las diferentes áreas del nanoplate con respecto a la intensidad de la misma medida fuera del nanoplate. ${ }^{\mathrm{b}}$ Corresponde a los valores de Root Mean Square (RMS). ${ }^{\mathrm{c}}$ Corresponde a el rango de espesores (thickness) obtenidos de las cross-sections realizadas en las diferentes áreas del nanoplate, tal como es indicado en las Figuras 6.7 A y 6.9. ${ }^{*}$ Notar que la esquina 3 presenta una nanopartícula en su superficie, lo cual es consistente con el mayor valor de RMS obtenido (más irregular) del nanoplate.

Pensamos que la NP de referencia, observada en la imagen óptica de la Figura 6.7, la cual esta situada en las inmediaciones del borde 1-2, podría influenciar la distribución del campo electromagnético en ésta área, lo cual es claramente evidenciado en la imagen Raman. Por esta razón, centramos el análisis en todas las áreas del nanoplate, excluyendo solamente el borde 1-2. En la Figura $6.7 \mathrm{C}$ se muestran tres espectros Raman de la Rh6G, correspondientes a tres regiones del mismo nanoplate. El espectro SERS con menor intensidad proviene de la región central, con un valor de Enhancement Factor (EF) de $\sim 0,6 \times 10^{3}$. Los valores de EF medidos en el borde 1-3 y la esquina 3 son de $2,5 \times 10^{3}$ y $3,0 \times 10^{3}$, respectivamente. Esto último es consistente 
con la gran intensidad Raman observada en las mencionadas zonas. Los referidos valores de EF pueden ser argumentados en términos de la diferencia en la rugosidad superficial de esas regiones del nanoplate. Finalmente, en la Tabla 6.1 se resumen las correlaciones entre los valores de EF, RMS y los rangos de espesor medidos en las esquinas, bordes y el centro del nanoplate. La tabla muestra que el valor del RMS en el centro es $4 \mathrm{x}$ menor que los valores correspondientes a los bordes y esquinas, mientras que los bordes y esquinas son muy similares entre ellos. En conclusión, la señal SERS modulada espacialmente, puede ser atribuida a las diferencias en la rugosidad superficial a lo largo del nanoplate.
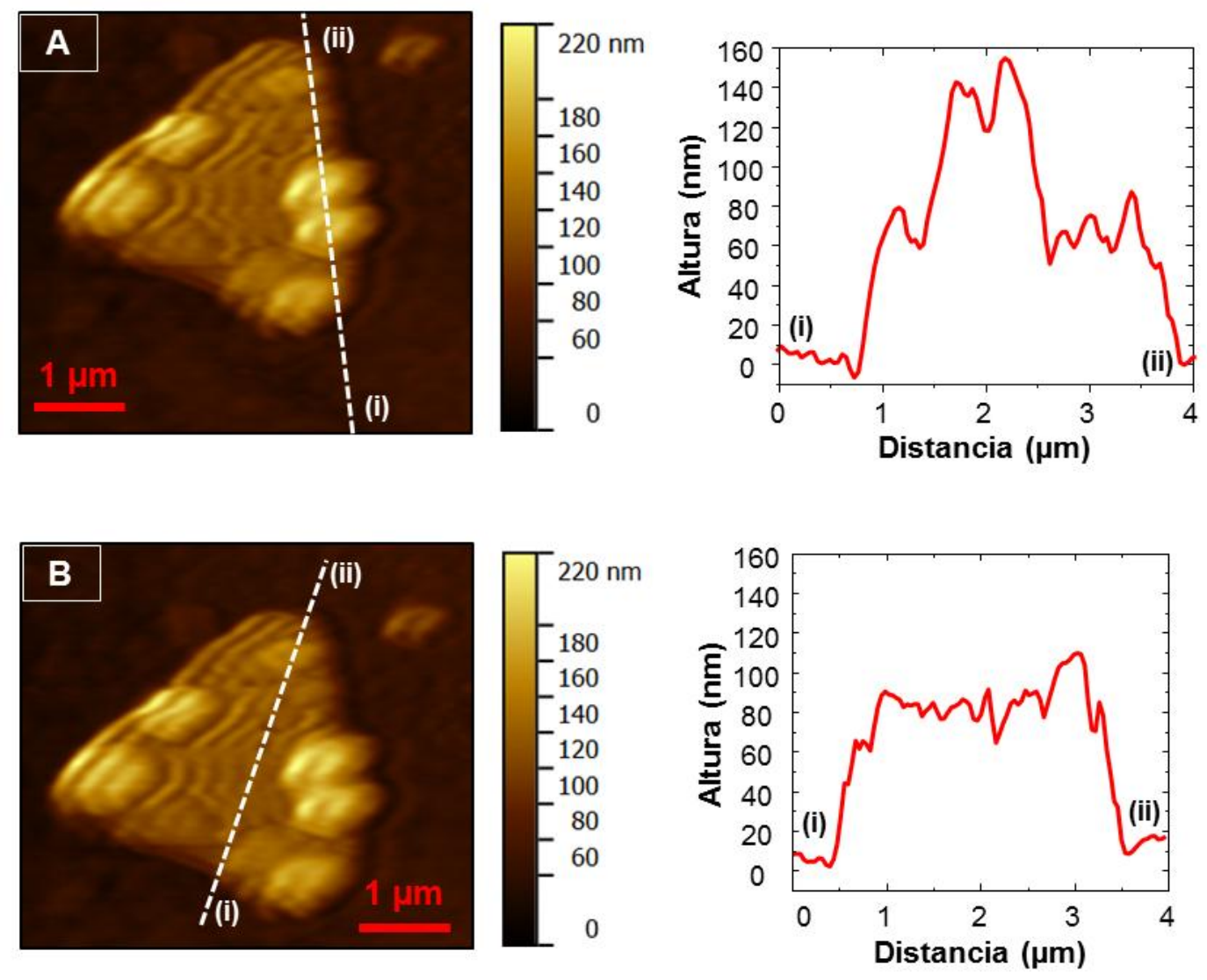

Figura 6.9 Imágenes de Microscopia de Fuerza Atómica (AFM) en modo tapping, junto con las cross-sections de un nanoplate triangular medidas a lo largo de un borde (A) y del centro (B) del mismo. 


\subsubsection{Actividad SERS sobre Redes de NPs de Au}

Se expandieron los estudios de la actividad SERS a otras configuraciones con NPs de Au sobre la muestra, tales como zonas con redes (Fig. 6.10 A y B) y regiones con un único nanoplate circular (Fig. 6.10 C). La comparación de la actividad SERS de dos redes de NPs indica una diferencia de al menos un orden de magnitud en la intensidad de la Rh6G entre la red en la Figura $6.10 \mathrm{~A}\left(\mathrm{EF}=1,7 \times 10^{3}\right)$ y la de la Figura $6.10 \mathrm{~B}\left(\mathrm{EF}=3,3 \times 10^{2}\right)$. La imagen óptica de la Figura $6.10 \mathrm{~A}$ muestra un área más poblada y NPs de Au bien definidas en comparación a la otra red estudiada, lo cual podría ser el factor responsable de mejorar la señal Raman. En éste sentido, es posible pensar en que el campo electromagnético entre las partículas es incrementado notablemente cuando la distancia entre las mismas disminuye, resultando en altos valores de EF. ${ }^{47}$ Por otro lado, es importante mencionar que la banda $2 \mathrm{D}$ aparece en ambas redes de NPs, sin embargo ésta tiende a desvanecerse a medida que los electrones del grafeno son encubiertos por las NPs de Au. Resulta particularmente llamativo que, en la Figura 6.10 iii se observa un pequeño pico (spike) correspondiente a la banda 2D, el cual persiste a pesar de la presencia del nanoplate de Au. De acuerdo a lo expuesto, es razonable pensar que el Au podría actuar como una antena para la propagación de la energía, tal como ha sido demostrado en sistemas con nanorods de Au colocados sobre grafeno. ${ }^{48}$ Finalmente, más experimentos deberían de realizarse con el fin de explorar en las habilidades y capacidades de las heterojunciones para propagar la energía en grandes longitudes de la muestra. 

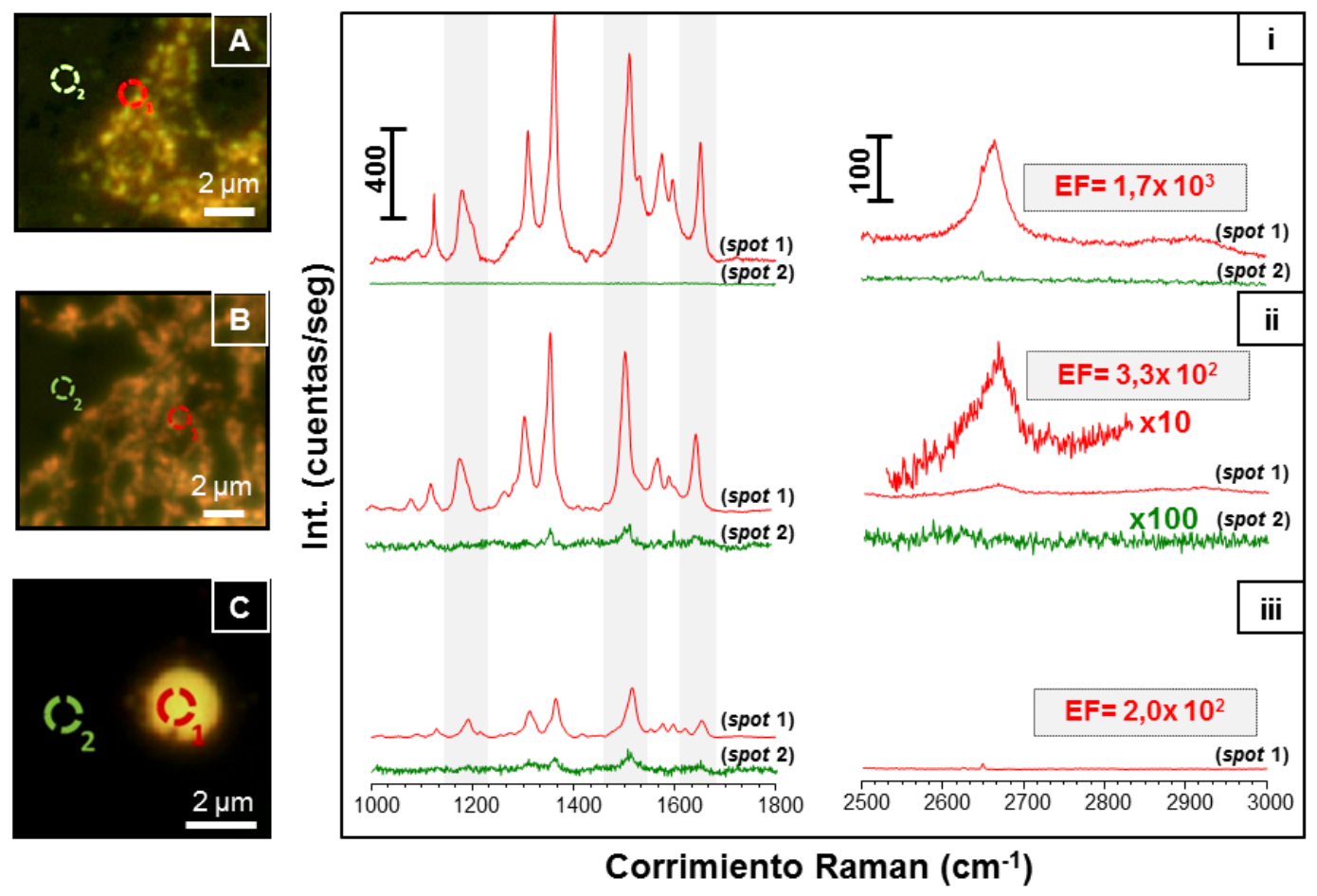

Figura 6.10 Imágenes ópticas (A, B, y C) y actividad SERS (i, ii y iii) de Rh6G adquirida sobre tres diferentes áreas de la misma heterojunción, incluyendo dos redes diferentes de NPs de $\mathrm{Au}$ (áreas con diferentes agregados) (A, i; B, ii) y un único nanoplate circular (C, iii). Los valores del factor de incremento de la señal (enhanced factor, EF) de la Rh6G fueron medidos a $1362 \mathrm{~cm}^{-1}$, como es indicado. Los círculos rojos (1) y verdes (2) indican el spot del láser enfocado dentro y fuera de la heterojunción, respectivamente. Para la claridad del lector, todos los espectros fueron separados dentro de dos paneles con diferentes escalas de intensidad, como es indicado. 


\subsection{Conclusiones}

En conclusión, la transferencia de grafeno remplazando el uso de polímeros por NPs de Au protegidas con un surfactante, presenta dos grandes beneficios. Primero, la heterojunción está libre de impurezas, una condición muy importante para el diseño de plataformas altamente sensibles en aplicaciones de SERS y TERS. Segundo, el proceso de annealing de la heterojunción produce estructuras de Au con formas diversas (redes de NPs, nanoplates triangulares y circulares, etc.) las cuales son ideales como plataformas TERS y SERS. Los resultados obtenidos por Raman y HRTEM denotan la presencia de grafeno bicapa y una potencial dislocación entre las mismas, respectivamente. El corrimiento de las bandas Raman de grafeno a altas energías, producido por la interacción entre la punta TERS y la muestra, sugiere que el sistema requiere de altas energías para excitar los fonones de grafeno. En el caso particular de las heterojunciones estudiadas aquí, los resultados de TERS sugieren que el Au podría ser el responsable de quitar (withdrawing) los electrones del grafeno, resultando en altas energías para excitar las bandas Raman. Los resultados de SERS llevados a cabo sobre un único nanoplate con forma triangular demostraron que, diferentes factores de incremento en la señal Raman de la Rh6G son detectados en los bordes, en las esquinas y en la región superficial del mismo. Una examinación cuidadosa dentro de los agregados de NPs de Au y un nanoplate circular demostró que las áreas más pobladas y con nanopartículas bien definidas sobre grafeno son mejores plataformas SERS en comparación a un nanoplate circular liso. Finalmente, planeamos continuar explorando tanto en la actividad como en el comportamiento TERS de nanopartículas individuales y la propagación de cargas dentro de las heterojunciones (metal + grafeno).

\subsection{Bibliografía}

(1) Hu, S.; Lozada-Hidalgo, M.; Wang, F. C.; Mishchenko, A.; Schedin, F.; Nair, R. R.; Hill, E. W.; Boukhvalov, D. W.; Katsnelson, M. I.; Dryfe, R. A. W.; et al. Proton Transport through One-Atom-Thick Crystals. Nature 2014, 516 (7530), 227-230.

(2) Telychko, M.; Mutombo, P.; Merino, P.; Hapala, P.; Ondráček, M.; Bocquet, F. C.; Sforzini, J.; Stetsovych, O.; Vondráček, M.; Jelínek, P.; et al. Electronic and Chemical Properties of Donor, Acceptor Centers in Graphene. ACS Nano 2015, 9 (9), 9180-9187.

(3) Fei, H.; Dong, J.; Arellano-Jimenez, M. J.; Ye, G.; Dong Kim, N.; Samuel, E. L. G.; Peng, Z.; Zhu, Z.; Qin, F.; Bao, J.; et al. Atomic Cobalt on Nitrogen-Doped Graphene for Hydrogen Generation. Nat Commun 2015, 6, 1-8.

(4) Wei, H.; Xu, H. Hot Spots in Different Metal Nanostructures for PlasmonEnhanced Raman Spectroscopy. Nanoscale 2013, 5 (22), 10794-10805. 
(12) Xu, S.; Man, B.; Jiang, S.; Wang, J.; Wei, J.; Xu, S.; Liu, H.; Gao, S.; Liu, H.; Li, Z.; et al. Graphene/Cu Nanoparticle Hybrids Fabricated by Chemical Vapor Deposition As Surface-Enhanced Raman Scattering Substrate for Label-Free Detection of Adenosine. ACS Appl. Mater. Interfaces 2015, 7 (20), 10977-10987.

(13) Dalfovo, M. C.; Lacconi, G. I.; Moreno, M.; Yappert, M. C.; Sumanasekera, G. U.; Salvarezza, R. C.; Ibañez, F. J. Synergy between Graphene and Au Nanoparticles (Heterojunction) towards Quenching, Improving Raman Signal, and UV Light Sensing. ACS Appl. Mater. Interfaces 2014, 6 (9), 6384-6391.

(14) Wang, P.; Liang, O.; Zhang, W.; Schroeder, T.; Xie, Y.-H. Ultra-Sensitive Graphene-Plasmonic Hybrid Platform for Label-Free Detection. Adv. Mater. 2013, 25 (35), 4918-4924.

(15) Ferrari, A. C.; Meyer, J. C.; Scardaci, V.; Casiraghi, C.; Lazzeri, M.; Mauri, F.; Piscanec, S.; Jiang, D.; Novoselov, K. S.; Roth, S.; et al. Raman Spectrum of Graphene and Graphene Layers. Phys. Rev. Lett. 2006, 97 (18), 187401.

(16) Li, X.; Zhu, Y.; Cai, W.; Borysiak, M.; Han, B.; Chen, D.; Piner, R. D.; Colombo, L.; Ruoff, R. S. Transfer of Large-Area Graphene Films for HighPerformance Transparent Conductive Electrodes. Nano Lett 2009, 9 (12), 43594363.

(17) Lin, Y.-C.; Lu, C.-C.; Yeh, C.-H.; Jin, C.; Suenaga, K.; Chiu, P.-W. Graphene Annealing: How Clean Can It Be? Nano Lett 2011, 12 (1), 414-419.

(18) Pirkle, A.; Chan, J.; Venugopal, A.; Hinojos, D.; Magnuson, C. W.; McDonnell, S.; Colombo, L.; Vogel, E. M.; Ruoff, R. S.; Wallace, R. M. The Effect of Chemical Residues on the Physical and Electrical Properties of Chemical Vapor Deposited Graphene Transferred to $\mathrm{SiO}_{2}$. Appl. Phys. Lett. 2011, 99 (12), 122108.

(19) Lim, Y.-D.; Lee, D.-Y.; Shen, T.-Z.; Ra, C.-H.; Choi, J.-Y.; Yoo, W. J. SiCompatible Cleaning Process for Graphene Using Low-Density Inductively Coupled Plasma. ACS Nano 2012, 6 (5), 4410-4417. 
(20) Lin, Y.-C.; Jin, C.; Lee, J.-C.; Jen, S.-F.; Suenaga, K.; Chiu, P.-W. Clean Transfer of Graphene for Isolation and Suspension. ACS Nano 2011, 5 (3), 23622368.

(21) Pimenta, M. A.; del Corro, E.; Carvalho, B. R.; Fantini, C.; Malard, L. M. Comparative Study of Raman Spectroscopy in Graphene and $\mathrm{MoS}_{2}$-Type Transition Metal Dichalcogenides. Acc. Chem. Res. 2015, 48 (1), 41-47.

(22) Stadler, J.; Schmid, T.; Zenobi, R. Developments in and Practical Guidelines for Tip-Enhanced Raman Spectroscopy. Nanoscale 2012, 4 (6), 1856-1870.

(23) Costa, S. D.; Righi, A.; Fantini, C.; Hao, Y.; Magnuson, C.; Colombo, L.; Ruoff, R. S.; Pimenta, M. A. Resonant Raman Spectroscopy of Graphene Grown on Copper Substrates. Solid State Commun. 2012, 152 (15), 1317-1320.

(24) Wang, Y. ying; Ni, Z. hua; Yu, T.; Shen, Z. X.; Wang, H. min; Wu, Y. hong; Chen, W.; Shen Wee, A. T. Raman Studies of Monolayer Graphene: The Substrate Effect. J. Phys. Chem. C 2008, 112 (29), 10637-10640.

(25) Reserbat-Plantey, A.; Kalita, D.; Han, Z.; Ferlazzo, L.; Autier-Laurent, S.; Komatsu, K.; Li, C.; Weil, R.; Ralko, A.; Marty, L.; et al. Strain Superlattices and Macroscale Suspension of Graphene Induced by Corrugated Substrates. Nano Lett. 2014, 14 (9), 5044-5051.

(26) Snitka, V.; Rodrigues, R. D.; Lendraitis, V. Novel Gold Cantilever for NanoRaman Spectroscopy of Graphene. Microelectron. Eng. 2011, 88 (8), 2759-2762.

(27) Wang, P.; Zhang, D.; Li, L.; Li, Z.; Zhang, L.; Fang, Y. Reversible Defect in Graphene Investigated by Tip-Enhanced Raman Spectroscopy. Plasmonics 2012, 7 (3), 555-561.

(28) Shiotari, A.; Kumagai, T.; Wolf, M. Tip-Enhanced Raman Spectroscopy of Graphene Nanoribbons on Au(111). J. Phys. Chem. C 2014, 118 (22), 1180611812.

(29) Vantasin, S.; Tanabe, I.; Tanaka, Y.; Itoh, T.; Suzuki, T.; Kutsuma, Y.; Ashida, K.; Kaneko, T.; Ozaki, Y. Tip-Enhanced Raman Scattering of the Local Nanostructure of Epitaxial Graphene Grown on 4H-SiC (0001). J. Phys. Chem. C 2014, 118 (44), 25809-25815.

(30) Fink, J.; Kiely, C. J.; Bethell, D.; Schiffrin, D. J. Self-Organization of Nanosized Gold Particles. Chem. Mater. 1998, 10 (3), 922-926.

(31) Dalfovo, M. C.; Salvarezza, R. C.; Ibañez, F. J. Improved Vapor Selectivity and Stability of Localized Surface Plasmon Resonance with a Surfactant-Coated Au Nanoparticles Film. Anal. Chem. 2012, 84 (11), 4886-4892.

(32) Dalfovo, M. C.; Giovanetti, L. J.; Ramallo-López, J. M.; Salvarezza, R. C.; Requejo, F. G.; Ibañez, F. J. Real-Time Monitoring Distance Changes in Surfactant-Coated Au Nanoparticle Films upon Volatile Organic Compounds (VOCs). J. Phys. Chem. C 2015, 119 (9), 5098-5106.

(33) Sidorov, A. N.; Sherehiy, A.; Jayasinghe, R.; Stallard, R.; Benjamin, D. K.; Yu, Q.; Liu, Z.; Wu, W.; Cao, H.; Chen, Y. P.; et al. Thermoelectric Power of Graphene as Surface Charge Doping Indicator. Appl. Phys. Lett. 2011, 99 (1), 013115.

(34) Fink, J.; Kiely, C. J.; Bethell, D.; Schiffrin, D. J. Self-Organization of Nanosized Gold Particles. Chem. Mater. 1998, 10 (3), 922-926. 
(35) Venezuela, P.; Lazzeri, M.; Mauri, F. Theory of Double-Resonant Raman Spectra in Graphene: Intensity and Line Shape of Defect-Induced and Two-Phonon Bands. Phys. Rev. B 2011, 84 (3), 035433.

(36) Schmid, T.; Opilik, L.; Blum, C.; Zenobi, R. Nanoscale Chemical Imaging Using Tip-Enhanced Raman Spectroscopy: A Critical Review. Angew. Chem. Int. Ed. 2013, 52 (23), 5940-5954.

(37) Tománek, D.; Louie, S. G.; Mamin, H. J.; Abraham, D. W.; Thomson, R. E.; Ganz, E.; Clarke, J. Theory and Observation of Highly Asymmetric Atomic Structure in Scanning-Tunneling-Microscopy Images of Graphite. Phys. Rev. B 1987, 35 (14), 7790-7793.

(38) N'Diaye, A. T.; Coraux, J.; Plasa, T. N.; Busse, C.; Michely, T. Structure of Epitaxial Graphene on $\operatorname{Ir}(111)$. New J. Phys. 2008, 10 (4), 043033.

(39) Carozo, V.; Almeida, C. M.; Ferreira, E. H. M.; Cançado, L. G.; Achete, C. A.; Jorio, A. Raman Signature of Graphene Superlattices. Nano Lett. 2011, 11 (11), 4527-4534.

(40) Basko, D. M. Theory of Resonant Multiphonon Raman Scattering in Graphene. Phys. Rev. B 2008, 78 (12), 125418.

(41) Eckmann, A.; Felten, A.; Mishchenko, A.; Britnell, L.; Krupke, R.; Novoselov, K. S.; Casiraghi, C. Probing the Nature of Defects in Graphene by Raman Spectroscopy. Nano Lett. 2012, 12 (8), 3925-3930.

(42) Wang, Y.; Ni, Z.; Hu, H.; Hao, Y.; Wong, C. P.; Yu, T.; Thong, J. T. L.; Shen, Z. $X$. Gold on Graphene as a Substrate for Surface Enhanced Raman Scattering Study. Appl. Phys. Lett. 2010, 97 (16), 163111-163111 - 3.

(43) Klusek, Z.; Dabrowski, P.; Kowalczyk, P.; Kozlowski, W.; Olejniczak, W.; Blake, P.; Szybowicz, M.; Runka, T. Graphene on Gold: Electron Density of States Studies by Scanning Tunneling Spectroscopy. Appl. Phys. Lett. 2009, 95 (11), 113114.

(44) Beams, R.; Gustavo Cançado, L.; Novotny, L. Raman Characterization of Defects and Dopants in Graphene. J. Phys. Condens. Matter 2015, 27 (8), 083002.

(45) Majoube, M.; Henry, M. Fourier Transform Raman and Infrared and SurfaceEnhanced Raman Spectra for Rhodamine 6G. Spectrochim. Acta Part Mol. Spectrosc. 1991, 47 (9-10), 1459-1466.

(46) Lin, W.-H.; Lu, Y.-H.; Hsu, Y.-J. Au Nanoplates as Robust, Recyclable SERS Substrates for Ultrasensitive Chemical Sensing. J. Colloid Interface Sci. 2014, 418, 87-94.

(47) Brus, L. Noble Metal Nanocrystals: Plasmon Electron Transfer Photochemistry and Single-Molecule Raman Spectroscopy. Acc. Chem. Res. 2008, 41 (12), 17421749.

(48) Alonso-González, P.; Nikitin, A. Y.; Golmar, F.; Centeno, A.; Pesquera, A.; Vélez, S.; Chen, J.; Navickaite, G.; Koppens, F.; Zurutuza, A.; et al. Controlling Graphene Plasmons with Resonant Metal Antennas and Spatial Conductivity Patterns. Science 2014, 344 (6190), 1369-1373. 


\section{Capítulo 7}

\section{Sensado de Hidrógeno con Heterojunciones: Grafeno + Nanopartículas de Pd, Pt y Aleaciones $\mathbf{P d} / \mathbf{P t}$}

\subsection{Introducción}

Las películas en estado sólido conformadas con nanopartículas (NPs) de Pd son frecuentemente utilizadas en diversas áreas tales como el sensado de $\mathrm{H}_{2}$, ${ }^{1,2}$ almacenamiento de $\mathrm{H}_{2} \quad\left(\mathrm{H}_{2} \text { storage }\right)^{3}$ y en catálisis heterogénea (reacciones de hidrogenación), ${ }^{4}$ sólo por mencionar algunas.

La importancia del estudio del $\mathrm{H}_{2}$ recae en la amplia gama de usos del mismo, tales como en procesamientos industriales, en el área de alimentos, en el área de almacenamiento de energía, etc. Sin embargo, el uso de éste en todos los procesos antes mencionados presenta la desventaja de que es explosivo en concentraciones mayores al $4 \%$ en atmósfera de aire. ${ }^{5 *}$ Esto último impone grandes desafíos e impulsa al desarrollo de nuevos materiales, particularmente nanomateriales, que puedan detectar la presencia de $\mathrm{H}_{2}$ en muy bajas concentraciones.

Por otro lado, tal como fue estudiado a lo largo de los Capítulos 5 y 6 de la presente Tesis, desde el descubrimiento de Grafeno (G) se han abierto nuevas avenidas hacia la construcción de plataformas sensibles. Conociendo las extraordinarias propiedades químicas y electrónicas de $\mathrm{G}$, es posible plantear y construir dispositivos los cuales se vean beneficiados por la presencia de este nanocarbón. En este sentido, las películas de $\mathrm{G}$ han demostrado la habilidad de poder ser espontáneamente decoradas con NPs protegidas con grupos orgánicos, ${ }^{6}$ formando así una nueva clase de nanomateriales conocidos como heterojunciones.

\footnotetext{
${ }^{*}$ Conocido como lower explosive limit (LEL). ${ }^{5}$
} 
En relación a lo expuesto, es conocido que la interacción $\mathrm{Pd}-\mathrm{H}_{2}$ constituye un sistema modelo para la compresión de aspectos fundamentales en diferentes áreas en las cuales se exploten las propiedades del $\mathrm{Pd}$, debido al carácter altamente selectivo de la misma. ${ }^{\dagger}$ En éste sentido, en una reciente publicación en la revista Nature Communications, el grupo de Ulvestad et al. ${ }^{8}$ empleó in-situ la técnica conocida como Coherent $X$-ray Diffractive Imaging (CXDI) para explorar las transformaciones de fases $(\alpha, \alpha-\beta$ y $\beta)$ que ocurren durante la interacción del $\mathrm{H}_{2}$ con nanocubos de $\mathrm{Pd}$. Dicho trabajo contribuye con un carácter enorme en aspectos fundamentales de la interacción $\mathrm{Pd}-\mathrm{H}_{2}$. Sin embargo, aún permanecen inciertos varios puntos respecto a ésta, sumado a que sería muy interesante inspeccionar sistemas que comprendan aleaciones con otros metales de transición como el Pt.

En éste Capítulo se muestran los resultados preliminares correspondientes a NPs de $\mathrm{Pd}$ y aleaciones $\mathrm{Pd} / \mathrm{Pt}$ protegidas con alquilaminas (sintetizadas químicamente) las cuales se ensamblaron como películas y se emplearon para la detección de $\mathrm{H}_{2}$. El objetivo principal del mismo fue, explorar dentro de las restructuraciones de las películas conformadas con NPs durante el sensado de $\mathrm{H}_{2}$, para luego poder correlacionar estos comportamientos con el mismo tipo de películas con NPs en sensores del tipo chemiresistivos. Particularmente, los resultados aquí mostrados contribuyen a la compresión básica en la interacción entre el $\mathrm{H}_{2}$ y los centros metálicos, lo cual es fundamental para interpretar con mayor profundidad cuestiones relacionadas al sensado, catálisis y potenciales usos de este sistema en almacenamiento de energía.

\footnotetext{
${ }^{\dagger}$ En el caso de ya sea un sensor constituido por Pd o por aleaciones del mismo con otros metales, la reacción entre el $\mathrm{H}_{2}$ y el $\mathrm{Pd}$ se basa en la formación de hidruros de $\mathrm{Pd}$, nombrados como $\mathrm{PdH}_{\mathrm{x}}$. Particularmente, cuando el $\mathrm{Pd}$ se expone a $\mathrm{H}_{2}$, el primero cataliza una reacción en donde el $\mathrm{H}_{2}$ se disocia en $\mathrm{H}$ atómico. Seguidamente, el $\mathrm{H}$ atómico se adsorbe en la superficie del Pd y difunde dentro de la estructura cristalina del mismo (lattice) para finalmente formar los $\mathrm{PdH}_{\mathrm{x}}$. La reacción puede, de manera general, describirse como:

$$
\begin{aligned}
& \mathrm{Pd}+\mathrm{H}_{2} \text { (gas) } \leftrightarrow \mathrm{Pd} / 2 \mathrm{H} \text { adsorbidos } \\
& \mathrm{Pd} / 2 \mathrm{H} \text { adsorbidos } \leftrightarrow \mathrm{PdH}_{\mathrm{x}} \text { masivo }
\end{aligned}
$$

Luego, el Pd sufre transiciones de fases desde una fase $\alpha$ a un estado intermedio conocido como $\alpha-\beta$, para finalmente alcanzar la fase $\beta$, a diferentes concentraciones o presiones parciales de $\mathrm{H}_{2}$. Como resultado de lo expuesto, se produce un incremento en el espaciamiento atómico entre los átomos de $\mathrm{Pd}(\mathrm{Pd}-\mathrm{Pd}), \mathrm{lo}$ cual se manifiesta con diferentes cambios estructurales del material, tales como: el volumen, la resistencia, la conducción, cambios ópticos, etc. Es necesario mencionar que, luego los sensores de hidrógeno van a poder diseñarse explotando algunos de los cambios antes mencionados. Valiosa información al respecto puede encontrarse en la siguiente referencia. ${ }^{7}$
} 


\subsection{Experimental}

\subsubsection{Síntesis de los Nanomateriales}

El grafeno fue sintetizado por deposición química de vapores (CVD) y transferido a diferentes sustratos siguiendo el protocolo reportado por Sumanasekera et $a l .{ }^{9}$ La síntesis de las NPs de Pd y aleaciones de Pd/Pt fueron realizadas de acuerdo al método de Leff ${ }^{10}$ (originalmente reportado para la síntesis de NPs de $\mathrm{Au}$ ) con algunas modificaciones. ${ }^{11}$ Más detalles experimentales respecto a las mencionadas síntesis, pueden encontrarse en el Capítulo 2 de esta Tesis.

\subsubsection{Ensamblado de las Películas: Formación de las Heterojunciones sobre Grafeno}

Esta etapa incluye la deposición de las NPs cubiertas con material orgánico sobre los sustratos con grafeno. Es esperado que dichas NPs se adhieran al grafeno por medio de interacciones hidrofóbicas, como ha sido previamente reportado para sistemas similares. $^{6}$

\subsubsection{Ensamblado de las Películas sobre Si/APTES: Experimentos de Control}

Primeramente se deben funcionalizar los sustratos de silicio y vidrio con aminopropiltrietoxisilano (APTES). ${ }^{12}$ Luego los mencionados sustratos se decoran con las NPs en estudio. Todas estas películas van a ser empleadas a modo de control y como comparación para evaluar la influencia del sustrato tanto en la estructura, la estabilidad y el comportamiento de las películas de $\mathrm{Pd}$ y Pd/Pt.

\subsubsection{Caracterización por SAXS}

Con el fin de determinar el tamaño y forma de las nanopartículas, se realizaron medidas de SAXS.

Las medidas de SAXS fueron realizadas en un equipo provisto por la empresa XENOCS modelo XEUSS 1.0, perteneciente al INIFTA. Este equipo cuenta con una microfuente de $\mathrm{Cu}-\alpha$ equipada con un sistema óptico tipo Monte ${ }^{13}$ que otorga un haz con una divergencia del orden de $0,4 \mathrm{mrad}$. El haz es colimado con un sistema de

\footnotetext{
* Equipamiento adquirido con financiamiento del Proyecto Nano-Pymes del Ministerio de Ciencia y Tecnología.
} 
rendijas de baja dispersión (scatterless slits) con las que se definió un tamaño final del haz de 0,5 x 0,5 mm. La intensidad de dispersión es colectada utilizando un detector bidimensional PILATUS 100K. La distancia muestra-detector fue calibrada utilizando behenato de plata $(521 \mathrm{~mm})$ lo que permite un rango en q comprendido entre 0,1 y 6 $\mathrm{nm}^{-1}$. Las muestras de NPs se dispersaron en tolueno y se midieron a temperatura ambiente $\left(\sim 25^{\circ} \mathrm{C}\right)$ en tubos capilares de cuarzo de $1,5 \mathrm{~mm}$ de diámetro y $0,1 \mathrm{~mm}$ de espesor de pared (CharlesSupper comp.).

\subsubsection{Caracterización por GISAXS}

Esta poderosa técnica provee de información cualitativa y cuantitativa de la estructura de las películas y de la separación entre las NPs, respectivamente. Ambas variables son crucialmente importantes en aplicaciones tales como el sensado de $\mathrm{H}_{2}$, el almacenamiento de $\mathrm{H}_{2}$, y en catálisis. Asimismo, a través de ésta técnica es posible explorar la correlación entre las NPs, la separación, la conformación, la forma, y el tamaño de las NPs tanto en las heterojunciones (NPs metálicas + grafeno) como en sustratos de Si/APTES.

\subsection{Resultados}

\subsubsection{Caracterización de las Nanopartículas en Solución por SAXS}

La caracterización mediante SAXS se realizó con el fin de determinar el tamaño inicial de las nanopartículas (NPs) en solución. Es sabido que, los sistemas conformados por NPs metálicas protegidas con grupos orgánicos (ej.: cadenas orgánicas o polímeros) pueden ser fácilmente explorados por dispersión de Rayos-X. Esto es debido a que los centros metálicos dominan la dispersión, mientras que tanto la cubierta orgánica como el solvente (en el cual están dispersas las NPs) presentan contribuciones mínimas en comparación a la mencionada dispersión. ${ }^{14}$

Debido a que muchos sistemas de catalizadores y sensores en general trabajan en estado sólido, tal es el caso de los catalizadores heterogéneos, ${ }^{\S}$ los cuales traen aparejada la ventaja de que luego de catalizada una reacción particular, los mismos pueden re-utilizarse, tal como fue demostrado por El-Sayed et al. ${ }^{15}$ En éste contexto, existen numerosos estudios es los cuales correlacionan la estructura de las NPs con su reactividad, debido a que en la mayoría de los casos el sustrato empleado para soportar a las NPs puede inducir cambios en la estructura de las mismas. Por ende, esos cambios

\footnotetext{
$\S$ En el área de catálisis heterogénea, las nanopartículas metálicas han sido empleadas, debido a que las mismas pueden anclarse a un sustrato determinado.
} 
van a ser manifestados como diferentes reactividades del sistema frente a un compuesto $\mathrm{u}$ analito dado. En éste sentido, Giovanetti et al. ${ }^{16}$ reportó el estudio de NPs de Pt protegidas con PVP, las cuales en solución presentan un tamaño y forma determinados, sin embargo luego de que entran en contacto con un sustrato de sílica mesoporosa (SBA-15) se produce un cambio notorio tanto en la forma como en el tamaño de las mismas. Ellos informaron que las NPs luego de ensambladas sobre la SBA-15 presentan un valor promedio del radio de giro de un $22 \%$ mayor que el de las mismas NPs en solución, de acuerdo a experimentos empleando SAXS.

En éste contexto, se brindará una breve descripción de la ecuación de Guinier, con el fin de facilitar la compresión de los datos analizados en este Capítulo.

\subsubsection{Breve Descripción de la Ecuación de Guinier}

Tal como fue introducido en el Capítulo 4 (Sección 4.3.2), en aquellos casos en los cuales el sistema en estudio se encuentre lo suficientemente diluido y los nanoobjetos no presenten correlación, la dispersión de los mismos no va a ser influida por los nano-objetos vecinos (sin interferencias). Dadas estas condiciones y considerando un sistema ideal en el cual todos los objetos son idénticos $(N)^{* *}$ y se encuentran azarosamente orientados, la intensidad total de dispersión del sistema puede ser expresada como:

$$
I(q)=N \cdot<I(\vec{q})>
$$

siendo, "I $(q)$ " la intensidad total de dispersión; $\mathrm{y}$ “ $<>$ " indica el promedio angular para todas las posibles orientaciones del objeto.

Luego, de la resolución de la ecuación 7.1 para una función de correlación $\gamma(\vec{r})$ arbitraria, Guinier ${ }^{17}$ demostró que la intensidad para pequeños valores de $q$ puede ser expresada como:

$$
I(q)=N \cdot \Delta n^{2} \cdot e^{-\frac{R g^{2} \cdot q^{2}}{3}} q \rightarrow 0
$$

\footnotetext{
** Donde " $N$ " denota la concentración de los objetos en estudio.
} 
siendo, “ $R_{g}$ ” el Radio de Giro, el cual es expresado por la siguiente ecuación:

$$
R_{g}=\left\{\frac{\int_{V_{1}} \rho(\vec{r}) \cdot r^{2} d v}{\int_{V_{1}} \rho(\vec{r}) d v}\right\}^{1 / 2}
$$

donde, " $V_{1}$ " es el volumen del objeto; y " $\Delta n$ " corresponde al exceso en el número de electrones dentro del objeto.

Luego, en el caso particular de objetos con una densidad electrónica constante $\rho_{1}$ embebida en una matriz ${ }^{\dagger \dagger}$ de densidad electrónica $\rho_{2}$, el exceso de electrones dentro del objeto puede ser escrito como $\Delta n=\left(\rho_{1}-\rho_{0}\right) \cdot V_{1}$. En esta condición, la ecuación 7.2 se denomina Ley de Guiner. ${ }^{18}$

\subsubsection{SAXS de las Nanopartículas en Solución}

La Figura 7.1 se muestran los perfiles SAXS correspondientes a las suspensiones coloidales (tolueno) de los cuatro tipos de NPs metálicas en estudio. Para mayor simplicidad, las mismas se han nombrado de acuerdo a sus centros metálicos: i) Pd; ii) PdPt (3:1); iii) PdPt (1:1); y iv) Pt. Además, se muestra el perfil SAXS correspondiente al tolueno, debido a que el mismo es el solvente empleado como medio para suspender a todas las NPs.

\footnotetext{
${ }^{\dagger}$ Asumiendo como "matriz" al medio en el que están suspendidos, disueltos o embebidos lo objetos en estudio.
} 


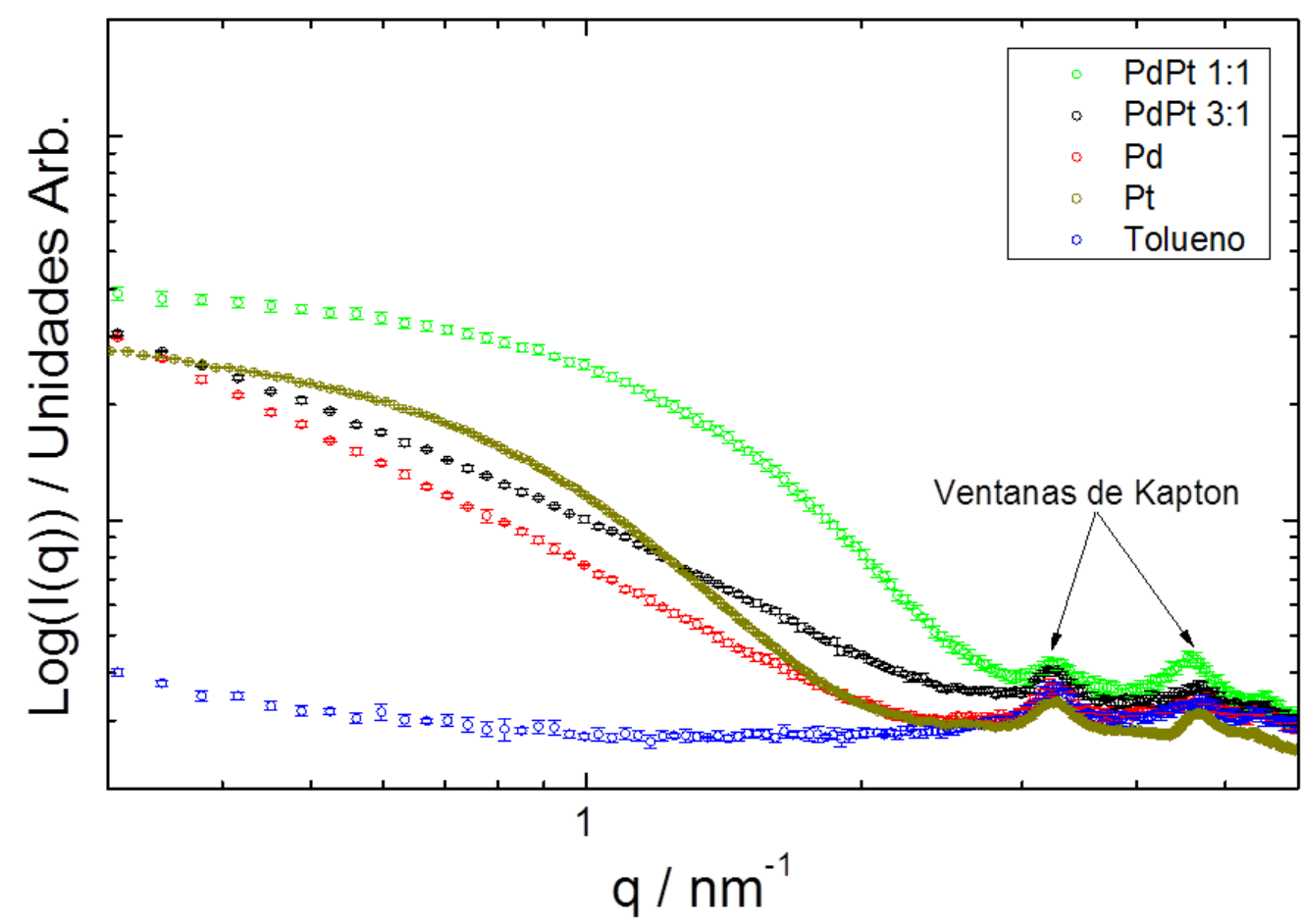

Figura 7.1 Perfiles SAXS correspondientes a las suspensiones coloidales (tolueno) de los cuatro tipos de NPs metálicas de: i) Pd; ii) PdPt 3:1; iii) PdPt 1:1; y iv) Pt, junto con el perfil SAXS correspondiente al tolueno (empleado como background). Notar que están presentes en todos los perfiles las señales correspondientes a las ventanas de Kapton.

Es conocido que, el valor del radio de giro $\left(R_{g}\right)$ provee una buena aproximación al tamaño de las NPs u objetos en estudio. Por lo tanto, para determinar el valor del radio $R_{g}$ se realizó un grafico de Guinier $\left(\log \left(I(q) v s q^{2}\right)\right.$, en donde se espera encontrar una región lineal parcialmente extendida en $q^{2}$, cuyo valor depende del tamaño y forma del objeto en estudio. De acuerdo a lo expuesto, a partir de la pendiente obtenida del ajuste con una función lineal $\left(\alpha_{g}\right)$ se puede conseguir una estimación del radio de giro $\left(R_{g}=\sqrt{3 \cdot \alpha_{g}}\right) \cdot{ }^{18,19}$ En la Figura 7.2 se muestran expresados como un gráfico de Guinier los mismos datos de la Figura 7.1. Como puede notarse, la curva correspondiente a las NPs de PdPt 1:1 presenta un comportamiento lineal de $q^{2}$ desde $\sim 0,15$ hasta $\sim 1,2 \mathrm{~nm}^{-2}$. Asimismo, pero con un menor rango de valores, las NPs de Pt 
presentan un comportamiento lineal comprendido de $q^{2}$ desde $\sim 0,15$ hasta $\sim 0,9 \mathrm{~nm}^{-2}$.

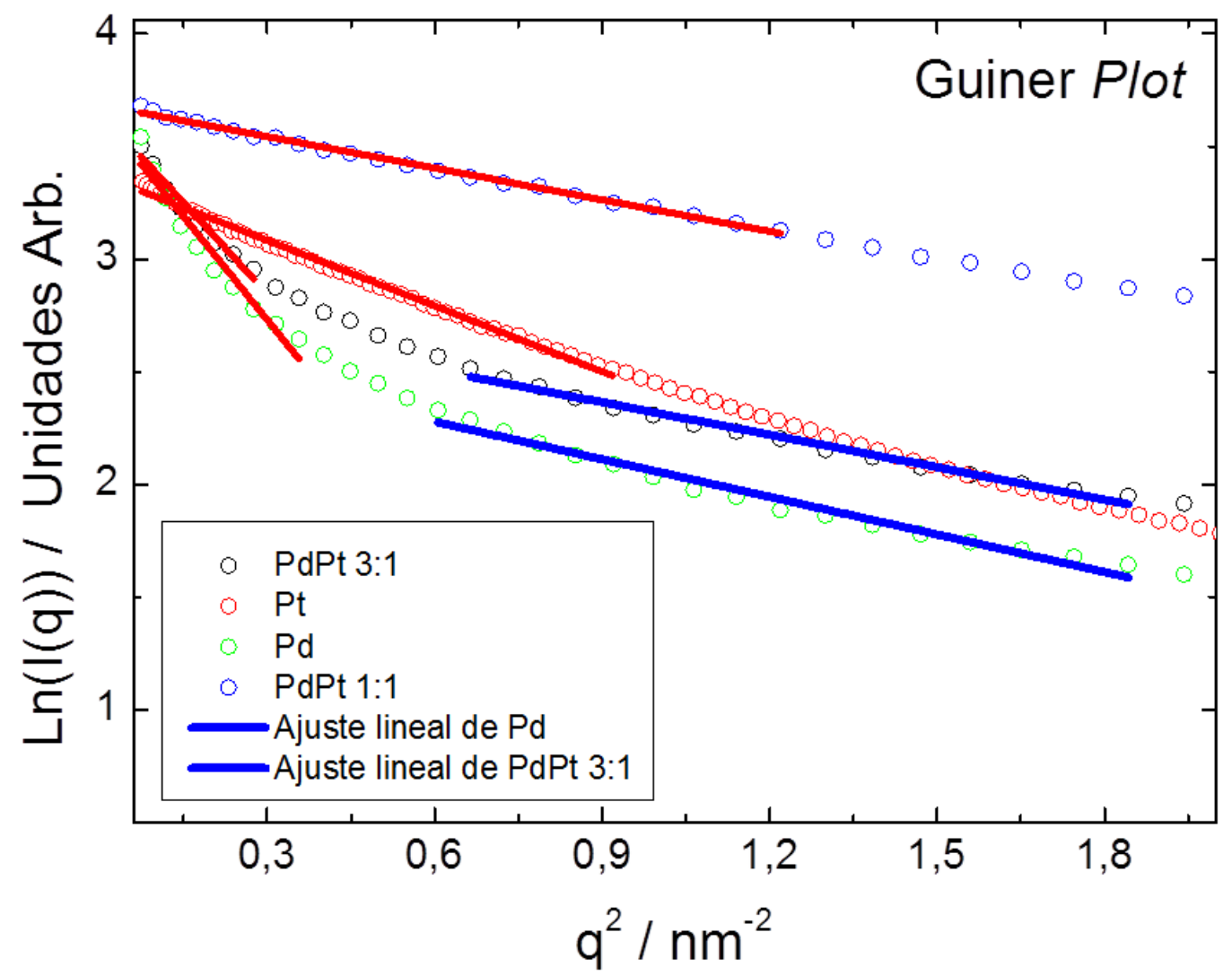

Figura 7.2 Gráficos de Guinier $\left(\operatorname{Ln}\left(I(q) v s q^{2}\right)\right.$ correspondientes a los datos mostrados en la Figura 7.1. Notar que las líneas color rojo y azul corresponden a la función Gaussiana de la ecuación de Guinier que mejor se ajusta a los datos experimentales.

Sin embargo, las NPs de Pd y PdPt 3:1 presentan dos regiones con comportamiento lineal (denotadas en colores rojo y azul en el mencionado gráfico). Esto último denota que en éstos tipos de NPs existe una gran dispersión de tamaños, lo que da lugar a dos poblaciones de NPs. Estas poblaciones pueden surgir ya sea porque las muestras naturalmente presentan dos rangos de tamaños y/o debido a que existe un cierto grado de aglomeración entre las mismas, lo cual produce un segundo grupo de mayor tamaño.

Finalmente, en la Tabla 7.1 se muestran los parámetros obtenidos de los ajustes de los perfiles de SAXS de las NPs en estudio. Además, puede encontrarse una comparación entre el radio de Guinier y el radio de la esfera de Guinier, correspondiendo éste último al cálculo que considera que todas las NPs en la suspensión poseen forma esférica. 
Tabla 7.1 Tabla mostrando los ajustes correspondientes a los datos de SAXS de las diferentes nanopartículas metálicas protegidas con octilamina $\left(\mathrm{NH}_{2} \mathrm{C}_{8}\right)$.

\begin{tabular}{cccc}
$\begin{array}{c}\text { NPs en } \\
\text { solución }\end{array}$ & $\begin{array}{c}\text { Pendiente de } \\
\text { Guinier(u.a.) }\end{array}$ & $\begin{array}{c}\text { Radio de } \\
\text { GuinierRg(nm) }\end{array}$ & $\begin{array}{c}\text { Radio de la Esfera } \\
\text { de Guinier (nm) }\end{array}$ \\
\hline $\mathrm{Pd}^{*}$ & $-3,061 \pm 0,246$ & $3,030 \pm 0,244$ & $3,912 \pm 0,315$ \\
\hline $\mathrm{Pd}^{\dagger}$ & $-0,556 \pm 0,022$ & $1,292 \pm 0,052$ & $1,668 \pm 0,067$ \\
\hline $\mathrm{PdPt} 3: 1^{*}$ & $-2,692 \pm 0,203$ & $2,842 \pm 0,214$ & $3,669 \pm 0,276$ \\
\hline $\mathrm{PdPt} 3: 1^{\dagger}$ & $-0,480 \pm 0,013$ & $1,201 \pm 0,034$ & $1,550 \pm 0.043$ \\
\hline $\mathrm{PdPt} 1: 1$ & $-0,468 \pm 0,007$ & $1,185 \pm 0,017$ & $1,530 \pm 0,022$ \\
\hline $\mathrm{Pt}$ & $-0,970 \pm 0,009$ & $1,706 \pm 0,016$ & $2,202 \pm 0,020$ \\
\hline
\end{tabular}

Nota: ( $\left.{ }^{*}\right)$ y (†) corresponden a los datos de los ajustes marcados en color rojo y color azul, respectivamente, ambos indicados en la Figura 7.2.

Es posible notar que, de los datos expresados en la Tabla 7.1, las NPs de Pd son las que presentan una pendiente de Guinier con mayor valor absoluto. Asimismo, éstas muestran una segunda población de NPs con menor valor absoluto en la citada pendiente. Dichos resultados son indicadores de la polidispersidad en el tamaño de las mismas. Sin embargo, las NPs de PdPt 1:1 presentan el menor valor absoluto en la pendiente de Guinier, indicando así que éstas poseen una distribución de tamaños mucho menor que los otros tipos de NPs analizadas.

Por otro lado, a modo introductorio a los sistemas de heterojunciones y sus posibles áreas de desarrollo, en la Figura 7.3 se muestra un esquema general de la preparación de los dispositivos por medio del ensamblado de las NPs sobre grafeno $(G)$, además se detalla el amplio espectro de aplicaciones de las mismas. Se planteó el uso de GISAXS con el fin de explorar dentro de aspectos fundamentales tales como la formación de la heterojunción, el ensamblado de las NPs para formar las películas, la distancia inter-nanopartículas (inter-NPd), la restructuración de la película con NPs durante el sensado de $\mathrm{H}_{2}$, y finalmente poder correlacionar todos estos estudios y caracterizaciones con el mismo tipo de películas con NPs en sensores de $\mathrm{H}_{2}$ del tipo chemiresistivos. 


\section{Películas de NPs sobre Grafeno / Aplicaciones}

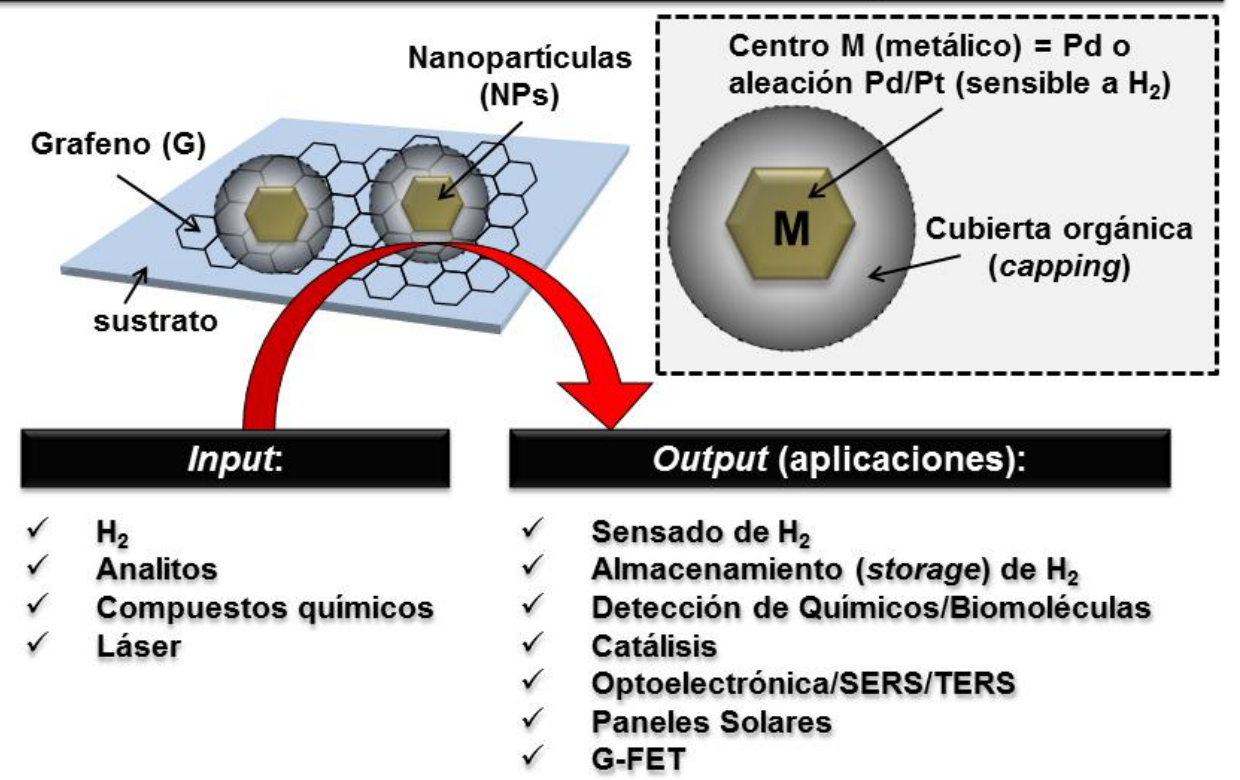

Figura 7.3 Esquema general mostrando la preparación de las películas sensibles, por medio del ensamblado de las nanopartículas (NPs) sobre grafeno (G) y sus posibles aplicaciones en diferentes áreas. 


\subsubsection{Sensado de Hidrógeno con Películas de Grafeno/Pd@ $@ \mathrm{NH}_{2} \mathrm{C}_{8}$}

Con el fin de explorar el comportamiento de heterojunciones conformadas con nanopartículas (NPs) metálicas sobre grafeno, se comenzó ensamblando las NPs de Pd cubiertas con octilamina $\left(\mathrm{Pd} @ \mathrm{NH}_{2} \mathrm{C}_{8}\right)$ sobre sustratos de Si/grafeno (22 horas de incubación del sustrato con NPs en solución). Para evitar confusiones al lector, a éste sistema le llamaremos grafeno/ $\mathrm{Pd} @ \mathrm{NH}_{2} \mathrm{C}_{8}$. La Figura 7.4 muestra los patrones GISAXS in-situ correspondientes a la heterojunción de grafeno/ $\mathrm{Pd} @ \mathrm{NH}_{2} \mathrm{C}_{8}$, durante el sensado de $\mathrm{H}_{2}$ en el estado inicial/sin $\mathrm{H}_{2}$ (A), 15' (B), 30' (C), 45' (D), 60' (E) y 75' (F) en $\mathrm{H}_{2}$ como es indicado. Todos los datos fueron adquiridos empleando un ángulo de incidencia de $(\alpha)$ de $0,3^{\circ}$ y una energía $\left(\mathrm{E}^{\circ}\right)$ de $8,0 \mathrm{keV}$.
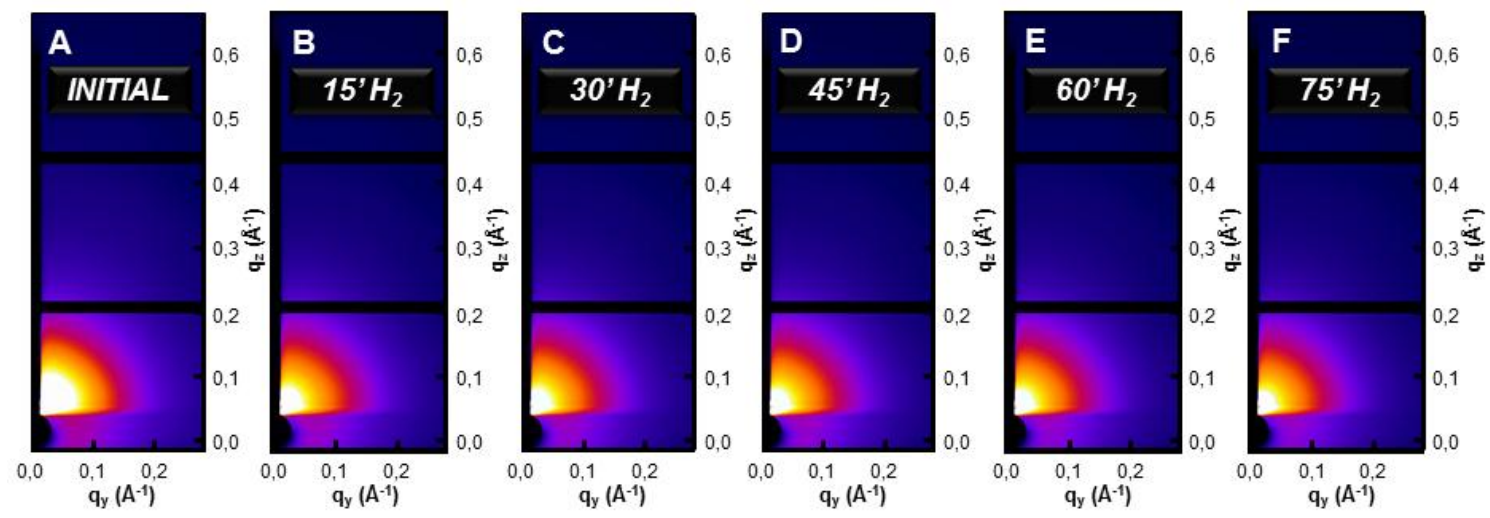

Figura 7.4 Patrones GISAXS in-situ correspondientes a la heterojunción de grafeno/Pd@ $\mathrm{NH}_{2} \mathrm{C}_{8}$, durante el sensado de $\mathrm{H}_{2}$ en el estado inicial/sin $\mathrm{H}_{2}$ (A), 15' (B), 30' (C), 45' (D), 60' (E) y 75' (F) en $\mathrm{H}_{2}$, como es indicado.

Resulta particularmente interesante que, la integración angular de los mencionados patrones GISAXS fue cambiando durante la exposición a $\mathrm{H}_{2}$, tal como es mostrado en la Figura 7.5. Por otro lado, es importante mencionar que las NPs de Pd no presentan correlación ${ }^{+5}$ entre ellas (ver los patrones GISAXS de la Figura 7.4).

\footnotetext{
\# El término "correlación" se refiere a la probabilidad de encontrar una distribución espacial de objetos en un volumen dado. La distancia entre los objetos (vecino-a-vecino) es definida como "d". Como resultado de lo expuesto, a medida que incrementa la cantidad de objetos separados por una distancia "d" particular, se produce un incremento en la intensidad del vector de dispersión q (scattering), produciendo así un incremento en la correlación del sistema.
} 


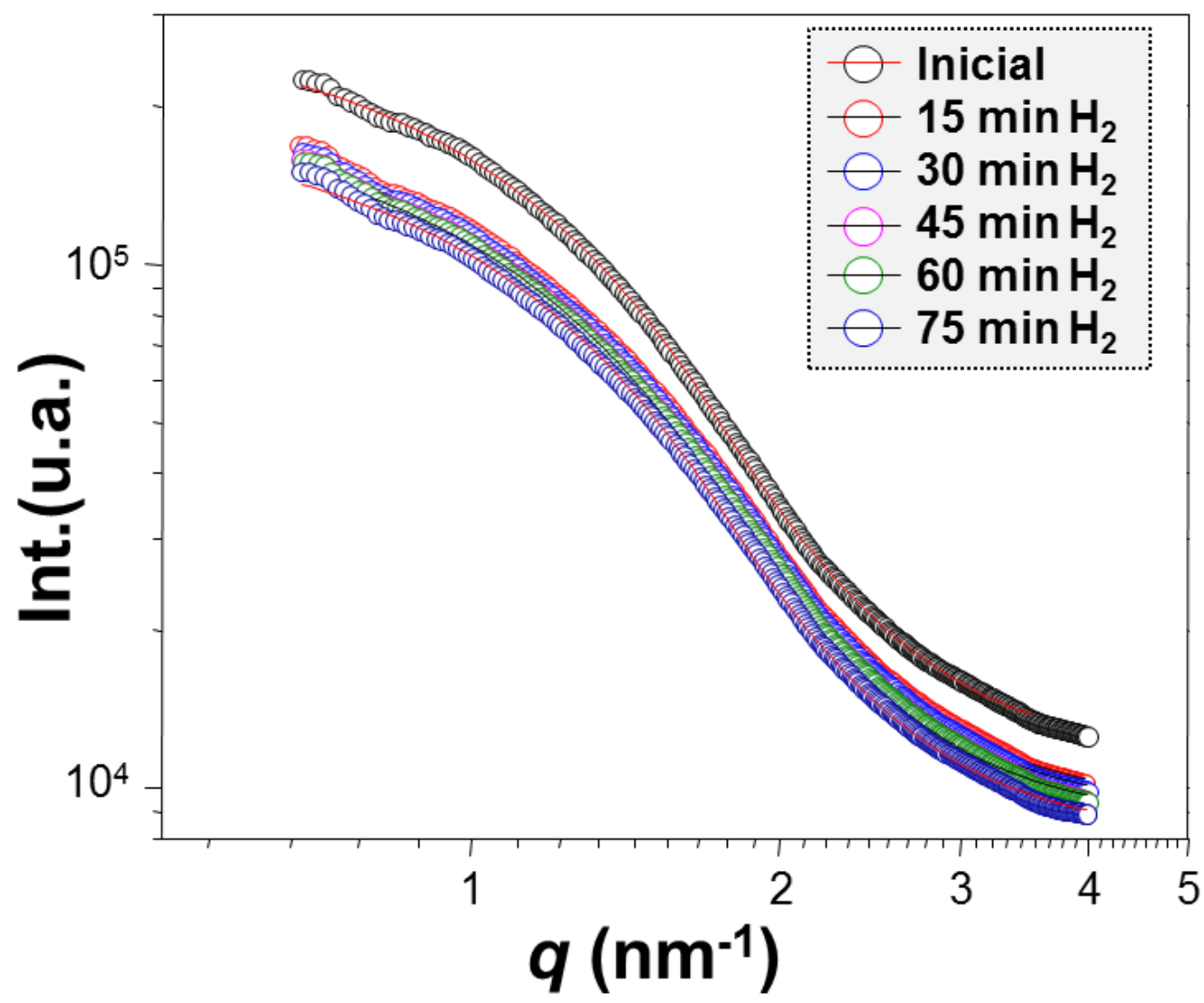

Figura 7.5 Cambios en la integración angular (con sus respectivos ajustes) de la misma heterojunción mostrada en la Fig. 7.4 (grafeno/Pd@ $\mathrm{NH}_{2} \mathrm{C}_{8}$ ) durante el sensado de $\mathrm{H}_{2}$ en el estado inicial/sin $\mathrm{H}_{2}$ (A), 15' (B), 30' (C), 45' (D), 60' (E) y 75' (F) en $\mathrm{H}_{2}$, como es indicado.

En vistas de que el sistema no presenta correlación (lo cual en principio limita las posibilidades de determinar la estructura de las películas) se procedió a calcular el radio de giro $\left(\mathrm{R}_{\mathrm{g}}\right)$ de los diferentes patrones GISAXS de éste sistema. Tal como fue mencionado anteriormente, el $\mathrm{R}_{\mathrm{g}}$ provee una buena estimación del tamaño de las nanopartículas. ${ }^{20}$ La Figura 7.6 muestra los cambios en el $\mathrm{R}_{\mathrm{g}}$ de la misma heterojunción mostrada en la Figura 7.4, durante el sensado de $\mathrm{H}_{2}$ en el estado inicial/sin $\mathrm{H}_{2}, 15$ ', 30', 45', 60' y 75' en $\mathrm{H}_{2}$ como es indicado. El $\mathrm{R}_{\mathrm{g}}$ (Guinier-Porod) fue calculado empleando el programa SaSView. Los parámetros empleados fueron: d (slop) fue fijada en 4; $\mathrm{R}_{\mathrm{g}}$ se mantuvo variable durante el análisis; y s (slop en la zona de Guinier) fue fijada en $\mathrm{s}=0 .{ }^{20}$ 
A primera vista, se denotan dos comportamientos diferentes para la misma muestra durante el sensado de $\mathrm{H}_{2}$. En el primer estadio (desde el estado inicial a los 15 'en $\mathrm{H}_{2}$ ) se produce un decrecimiento en el valor del $\mathrm{R}_{\mathrm{g}}$. Esto puede ser explicado por la pérdida de parte de los ligandos orgánicos $\left(\mathrm{C}_{8} \mathrm{NH}_{2}\right)$ de la superficie de los clusters metálicos (nanopartículas). ${ }^{11}$ Después de la remoción parcial de los ligandos orgánicos, probablemente el progresivo incremento en el valor del $\mathrm{R}_{\mathrm{g}}$ (desde $30^{\prime}$ a $75^{\prime}$ ' en $\mathrm{H}_{2}$ ) pueda deberse a la formación de $\mathrm{PdH}_{\mathrm{x}}$, el cual causa un incremento en el tamaño de la red cristalina (lattice) de las NPs de Pd. Sin embargo, son necesarios más experimentos para determinar conclusivamente la naturaleza de la interacción del H2 con las películas de NPs de Pd ensambladas sobre grafeno.

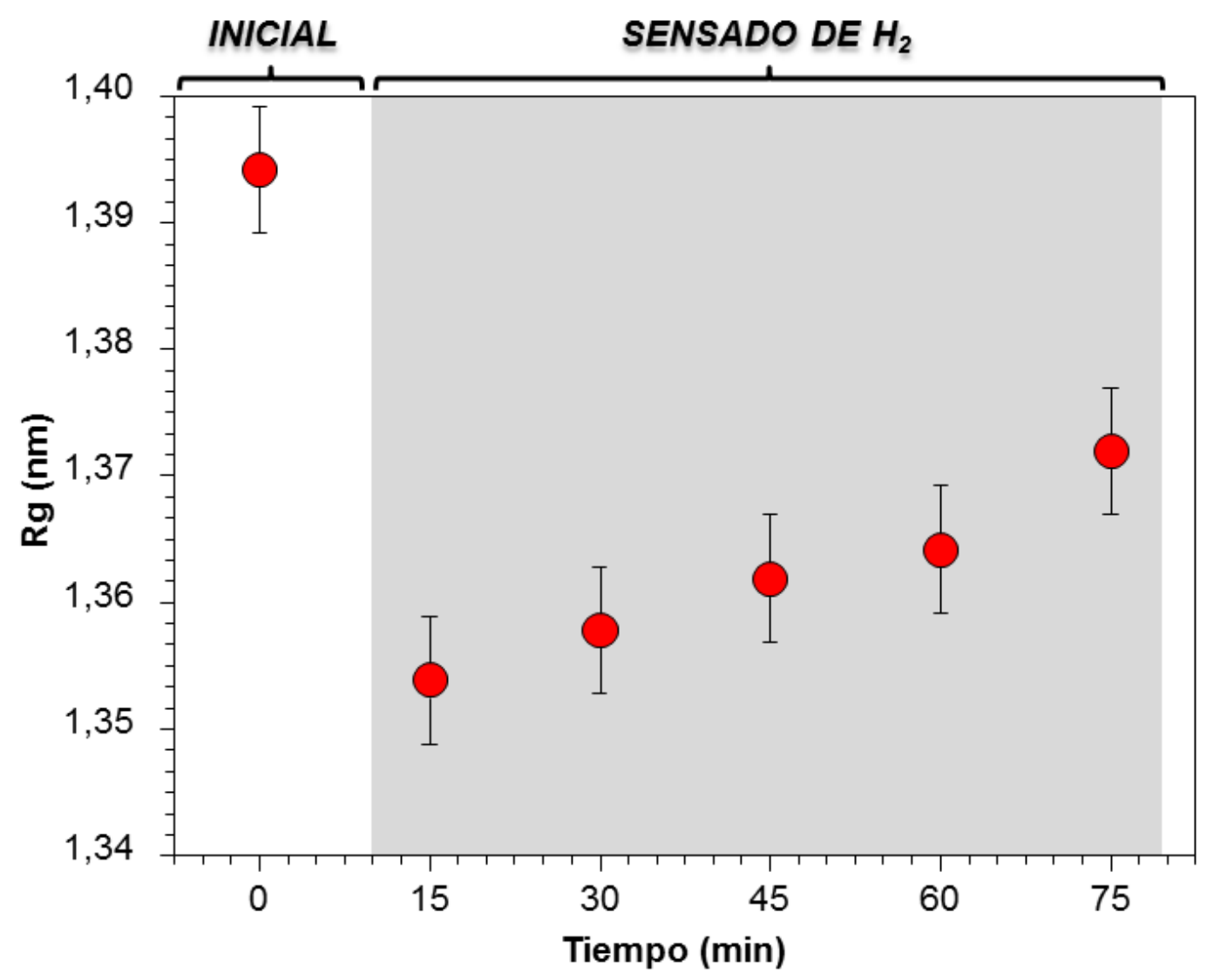

Figura 7.6 Cambios en el radio de giro $\left(\mathrm{R}_{\mathrm{g}}\right)$ de la misma heterojunción mostrada en la Fig. 7.4 (grafeno/ $\mathrm{Pd} @ \mathrm{NH}_{2} \mathrm{C}_{8}$ ) durante el sensado de $\mathrm{H}_{2}$ en el estado inicial/sin $\mathrm{H}_{2}, 15^{\prime}, 30^{\prime}$, 45', 60' y 75' en $\mathrm{H}_{2}$ como es indicado. El $\mathrm{R}_{\mathrm{g}}$ (GuinierPorod) fue calculado usando el programa SaSView (ver más detalles del ajuste en el texto). 


\subsubsection{Sensado de Hidrógeno con Películas de Grafeno/Pd/Pt $(1: 1) @ \mathrm{NH}_{2} \mathrm{C}_{8}$}

Debido a las excelentes propiedades catalíticas del Pt, se decidió explorar la formación de nanopartículas (NPs) conformadas por diferentes relaciones molares entre Pd y Pt (aleaciones). Cabe mencionar que, las síntesis de las NPs de Pd/Pt cubiertas con octilaminas aún no han sido reportadas en la literatura (ver más detalles en el Capítulo 2).

Para la formación de las heterojunciones, se siguieron los mismos pasos descritos en la sección anterior. Brevemente, se comenzó ensamblando NPs de $\mathrm{Pd} / \mathrm{Pt}$ (1:1) cubiertas con octilamina $\left(\mathrm{Pd} @ \mathrm{NH}_{2} \mathrm{C}_{8}\right)$ sobre sustratos de $\mathrm{Si} /$ grafeno (22 horas de incubación del sustrato con NPs en solución). Para evitar confusiones al lector, a éste sistema le llamaremos grafeno/Pd/Pt (1:1)@ $\mathrm{NH}_{2} \mathrm{C}_{8}$. La Figura 7.7 muestra los patrones GISAXS in-situ correspondientes a la heterojunción de grafeno/Pd/Pt (1:1)@ $\mathrm{NH}_{2} \mathrm{C}_{8}$, durante el sensado de $\mathrm{H}_{2}$ en el estado inicial/sin $\mathrm{H}_{2}$ (A), paso 1 (B), paso 2 (C), paso 3 (D), paso $4(\mathrm{E})$, paso $5(\mathrm{~F})$, paso $6(\mathrm{G})$, paso $7(\mathrm{H})$, paso $8(\mathrm{I})$, paso $9(\mathrm{~J})$, paso $10(\mathrm{~K})$ en $\mathrm{H}_{2}$ y estado final/purga en He (L) como es indicado. Todos los datos fueron adquiridos empleando un ángulo de incidencia de $(\alpha)$ de $0,3^{\circ}$ y una energía $\left(\mathrm{E}^{\circ}\right)$ de $8,0 \mathrm{keV}$. Resulta llamativo que, en éste sistema se encontró correlación entre las NPs, algo que no fue observado en el sistema de grafeno/ $\mathrm{Pd} @ \mathrm{NH}_{2} \mathrm{C}_{8}$ (ver Figura 7.2). Dicha correlación entre las NPs implica que éstas presentan un cierto orden a nivel espacial, y que el mismo puede tener su origen en la presencia del Pt en las NPs. Es posible pensar que dicho comportamiento puede estar asociado a la propia estructura cristalina (lattice) del Pt, como así también en la interacción/enlace entre el Pt y las aminas. Por otro lado, tal como fue estudiado en la sección de SAXS (ver Tabla 7.1) las mencionadas NPs son las que presentaron mayor homogeneidad en sus tamaños, lo cual explica la facilidad de éstas para ensamblarse con un cierto orden.

Debido a lo expuesto anteriormente, para las heterojunciones con $\mathrm{Pd} / \mathrm{Pt}$ (con correlación) no fue posible emplear los mismos criterios para el análisis de datos realizados para las heterojunciones de Pd (sin correlación), como el radio de giro $\left(\mathrm{R}_{\mathrm{g}}\right) \mathrm{y}$ la integración angular. Por otro lado, si se observan detenidamente los halos intensos cercanos al beam-stopper en la Figura 7.7, la intensidad de los mismos varía débilmente en la presencia de $\mathrm{H}_{2}$. Sin embargo, si se sigue alguno de los spots de difracción como el seleccionado en el cuadrado blanco punteado de la Figura 7.8, es notoria la disminución en la intensidad del mismo en función del tiempo de exposición a $\mathrm{H}_{2}$.

La Figura 7.8 muestra los patrones GISAXS in-situ correspondientes a la heterojunción de grafeno/Pd/Pt (1:1)@ $\mathrm{NH}_{2} \mathrm{C}_{8}$, (mostrada en la Figura 7.7) durante el sensado de $\mathrm{H}_{2}$ en el estado inicial/sin $\mathrm{H}_{2}$ (A), paso 1 en $\mathrm{H}_{2}$ (B) y estado final/purga en $\mathrm{He}$ (C) como es indicado. Notar que todas las imágenes corresponden al cuadrante 
superior del detector Pilatus 300K, y los recuadros (línea punteada blanca) muestran una zona aumentada para enfatizar en los cambios observados durante la exposición a $\mathrm{H}_{2}$. Para mayor claridad al lector, sólo se muestran tres de los estadios de la película.
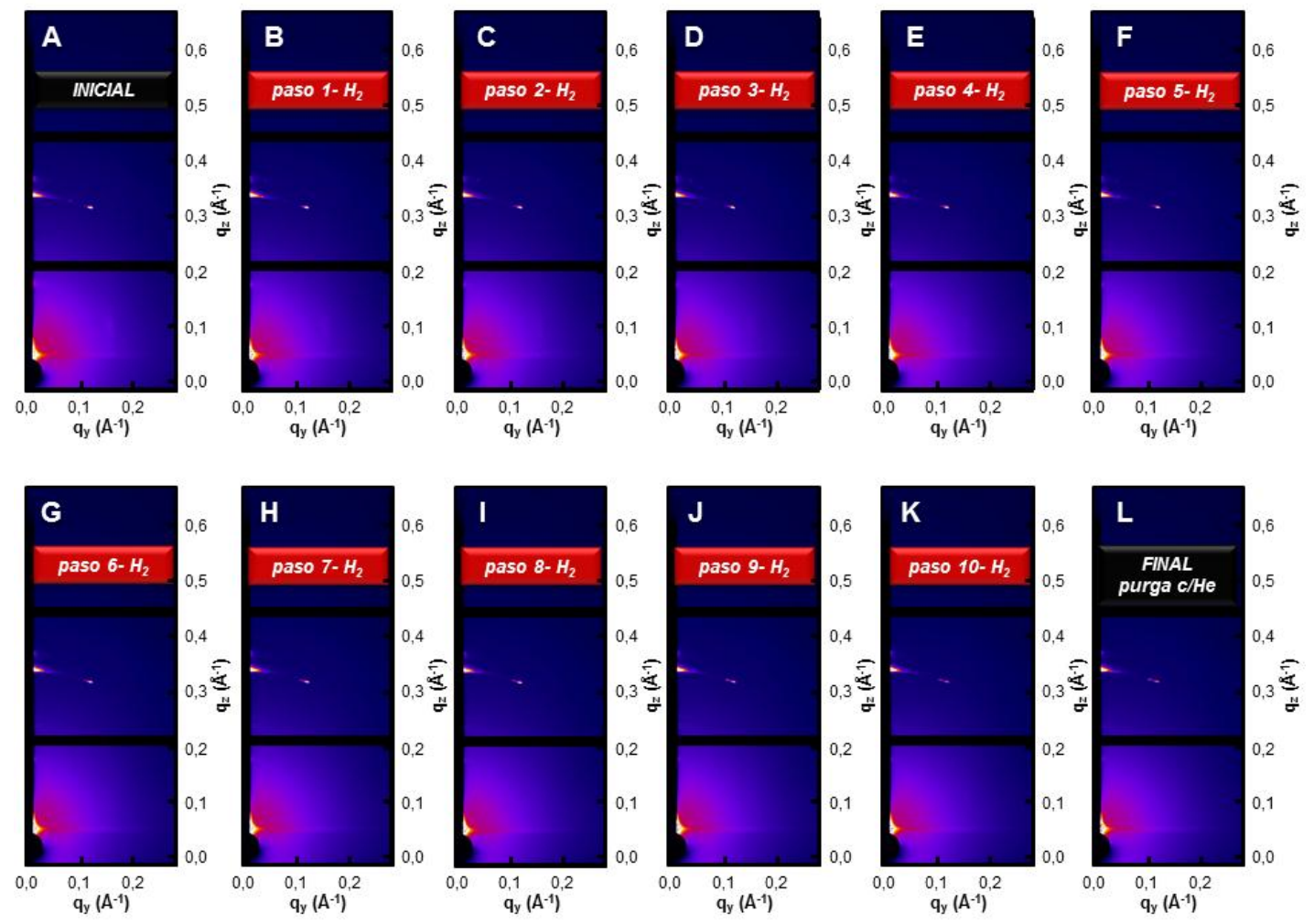

Figura 7.7 Patrones GISAXS in-situ correspondientes a la heterojunción de grafeno/Pd/Pt (1:1)@ $\mathrm{NH}_{2} \mathrm{C}_{8}$, durante el sensado de $\mathrm{H}_{2}$ en el estado inicial $/ \mathrm{sin} \mathrm{H}_{2}(\mathrm{~A})$, paso $1(\mathrm{~B})$, paso $2(\mathrm{C})$, paso $3(\mathrm{D})$, paso $4(\mathrm{E})$, paso $5(\mathrm{~F})$, paso $6(\mathrm{G})$, paso $7(\mathrm{H})$, paso $8(\mathrm{I})$, paso $9(\mathrm{~J})$, paso $10(\mathrm{~K})$ en $\mathrm{H}_{2}$ y estado final/purga en $\mathrm{He}(\mathrm{L})$ como es indicado.

Como una primera aproximación al análisis de datos del mencionado sistema, se realizaron cortes a los largo del eje $q_{z}$. La Figura 7.9 muestra gráficos correspondientes a la evolución temporal de un corte a lo largo del eje $q_{z}\left(0,3038 \AA^{-1}\right)$ de la heterojunción de grafeno/Pd/Pt (1:1)@ $\mathrm{NH}_{2} \mathrm{C}_{8}$, (mostrada en la Figura 7.7), correspondientes al spot de difracción seleccionado con el cuadrado blanco punteado en la Figura 7.8. Notar que se produce una disminución en la intensidad de la señal de los gráficos durante la exposición a $\mathrm{H}_{2}$, y la misma no retorna a su valor inicial aún después de una purga en He por 30 minutos. Dichos resultados indican que los cambios a nivel estructural 
inducidos por la presencia de $\mathrm{H}_{2}$ son irreversibles. Es importante tener en cuenta que las técnicas derivadas de la dispersión de rayos-X (particularmente Surface X-Ray Diffraction (SXRD) y GISAXS) son altamente sensibles a los cambios superficiales. ${ }^{21}$ Esto último implica que, la irreversibilidad observada por GISAXS puede que no sea detectada por otras técnicas con menor sensibilidad a los cambios estructurales tales como la Cronoamperometría (CA), la espectroscopia UV-vis (en estudios de estabilidad frente a $\mathrm{H}_{2}$ ) o la microscopía electrónica de transmisión (TEM), entre otras. ${ }^{11}$

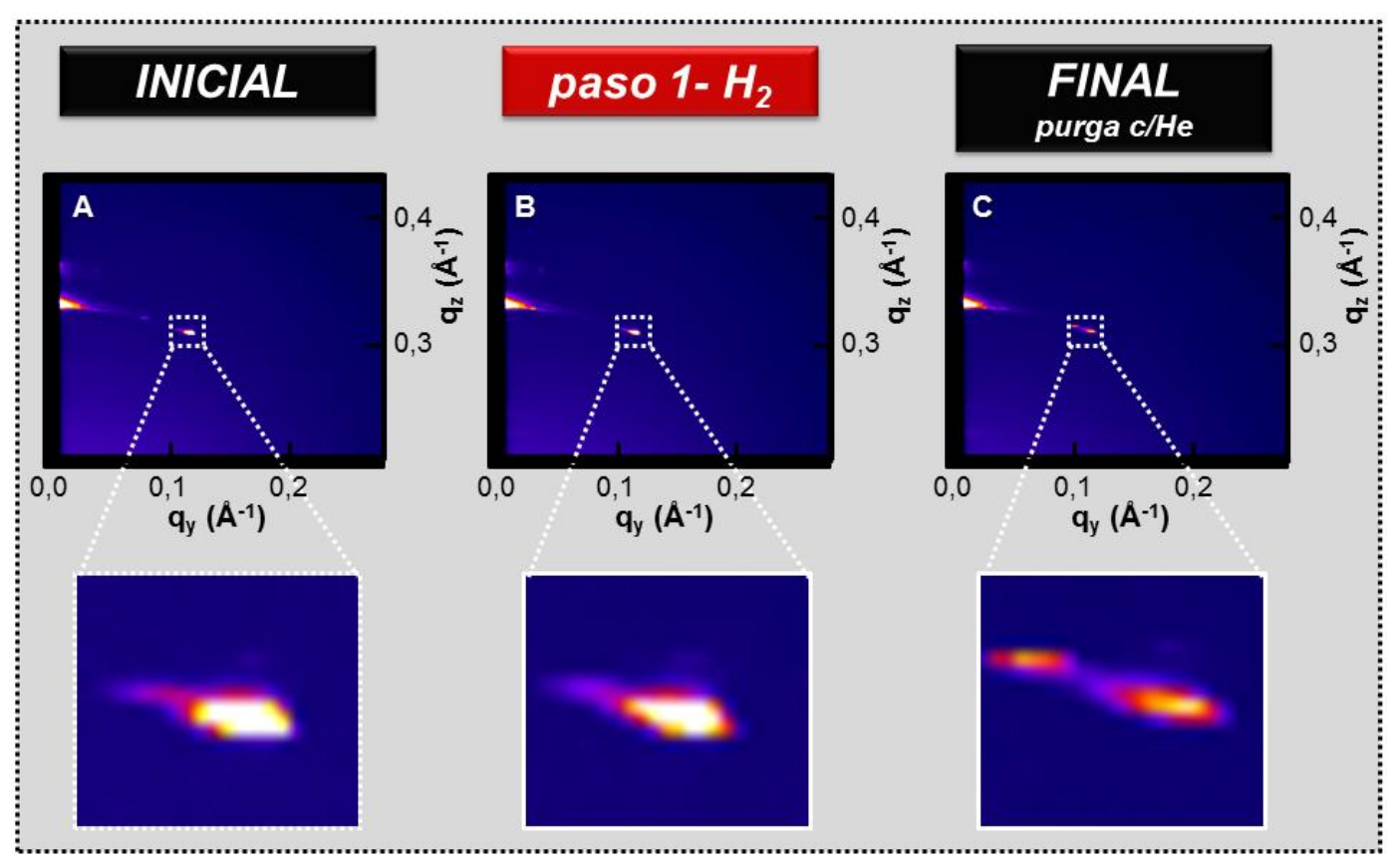

Figura 7.8 Patrones GISAXS in-situ correspondientes a la heterojunción de grafeno/Pd/Pt (1:1)@ $\mathrm{NH}_{2} \mathrm{C}_{8}$, (mostrada en la Figura 7.7) durante el sensado de $\mathrm{H}_{2}$ en el estado inicial/sin $\mathrm{H}_{2}$ (A), paso 1 en $\mathrm{H}_{2}$ (B) y estado final/purga en $\mathrm{He}$ (C), como es indicado. Notar que todas las imágenes corresponden al cuadrante superior del detector, y los recuadros (línea punteada blanca) muestran una zona aumentada para enfatizar en los cambios observados durante la exposición a $\mathrm{H}_{2}$. Ver la sección de $\mathrm{Pd} / \mathrm{Pt}$ para más detalles del análisis de datos. 
Con el fin de incrementar la estadística de los datos analizados, se realizaron integraciones totales del área de cada spot de difracción seleccionado en la Figura 7.8. La Figura 7.10 muestra un gráfico correspondiente a la integración de cada spot de difracción seleccionado con el cuadrado blanco punteado en la Figura 7.8 de la heterojunción de grafeno/Pd/Pt (1:1)@ $\mathrm{NH}_{2} \mathrm{C}_{8}$, (mostrada en la Figura 7.7) en su estado inicial, durante la exposición a $\mathrm{H}_{2}$ y luego de una purga en $\mathrm{He}$, como es indicado. Se observan dos estadios aparentes durante la exposición a $\mathrm{H}_{2}$ en los cuales se produce una disminución de la intensidad de correlación (recordar que es un área), como aquí se detallan: a) el primero esta comprendido entre los paso 1 al 7 , en el cual se denota una disminución en la intensidad de difracción de $20 \%$ (respecto a la intensidad inicial); y b) el segundo está comprendido entre los pasos 8 al 10 con una disminución en la intensidad de $\sim 30 \%$ (respecto a la intensidad inicial). Finalmente, luego de la purga en $\mathrm{He}$, la intensidad del área de difracción estudiada no retorna a su valor original. Dichos resultados concuerdan con los datos mostrados en la Figura 7.9.

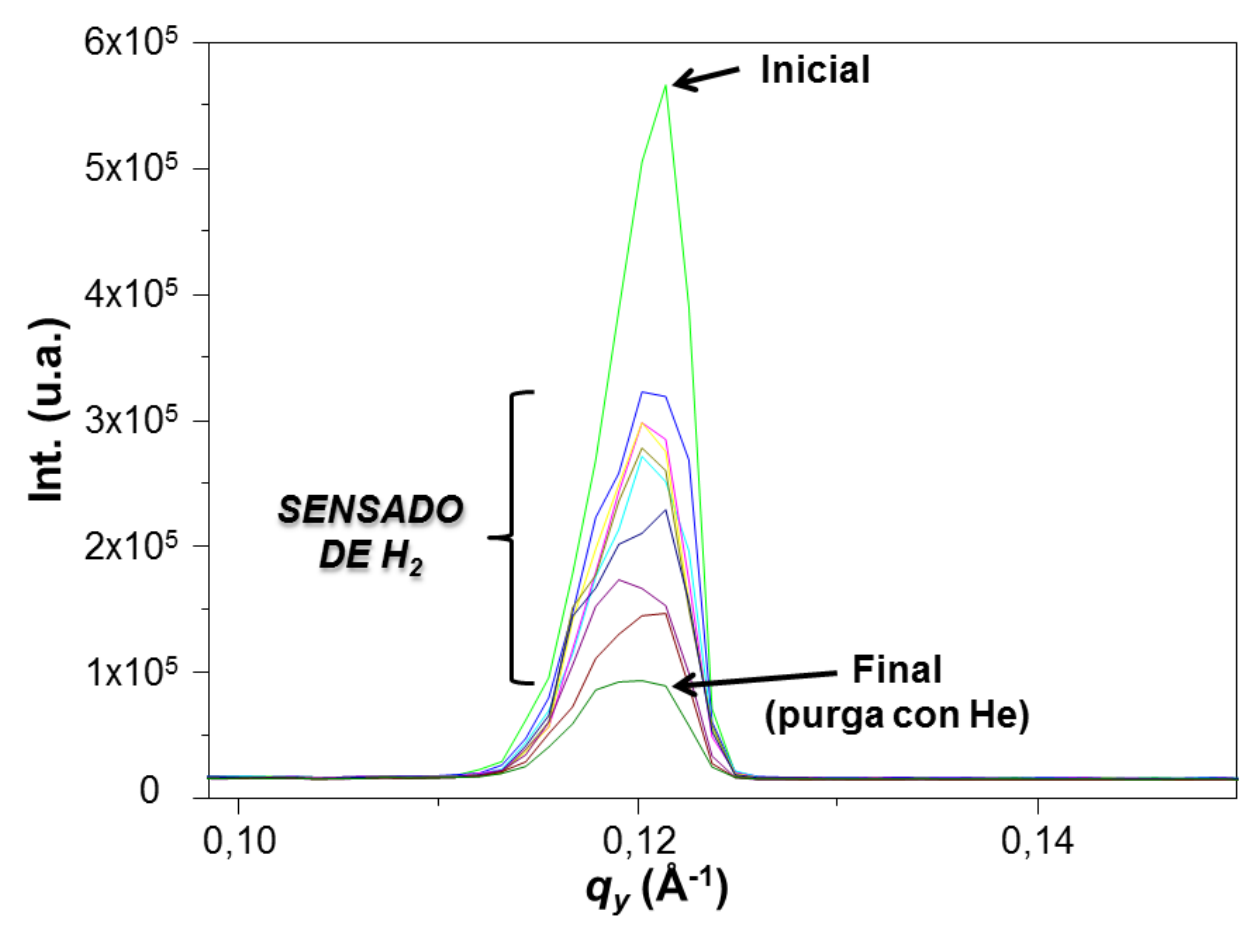

Figura 7.9 Gráficos mostrando la evolución temporal de un corte a lo largo del eje $\mathrm{q}_{\mathrm{z}}\left(0,3038 \AA^{-1}\right)$ de la heterojunción de grafeno/ $\mathrm{Pd} / \mathrm{Pt}(1: 1) @ \mathrm{NH}_{2} \mathrm{C}_{8}$, (mostrada en la Figura 7.7), correspondientes al spot de difracción seleccionado con el cuadrado blanco punteado en la Figura 7.8. Notar que se produce una disminución en la intensidad los gráficos durante la exposición a $\mathrm{H}_{2}$, y la intensidad no retorna a su valor inicial aún después de una purga en $\mathrm{He}$. 


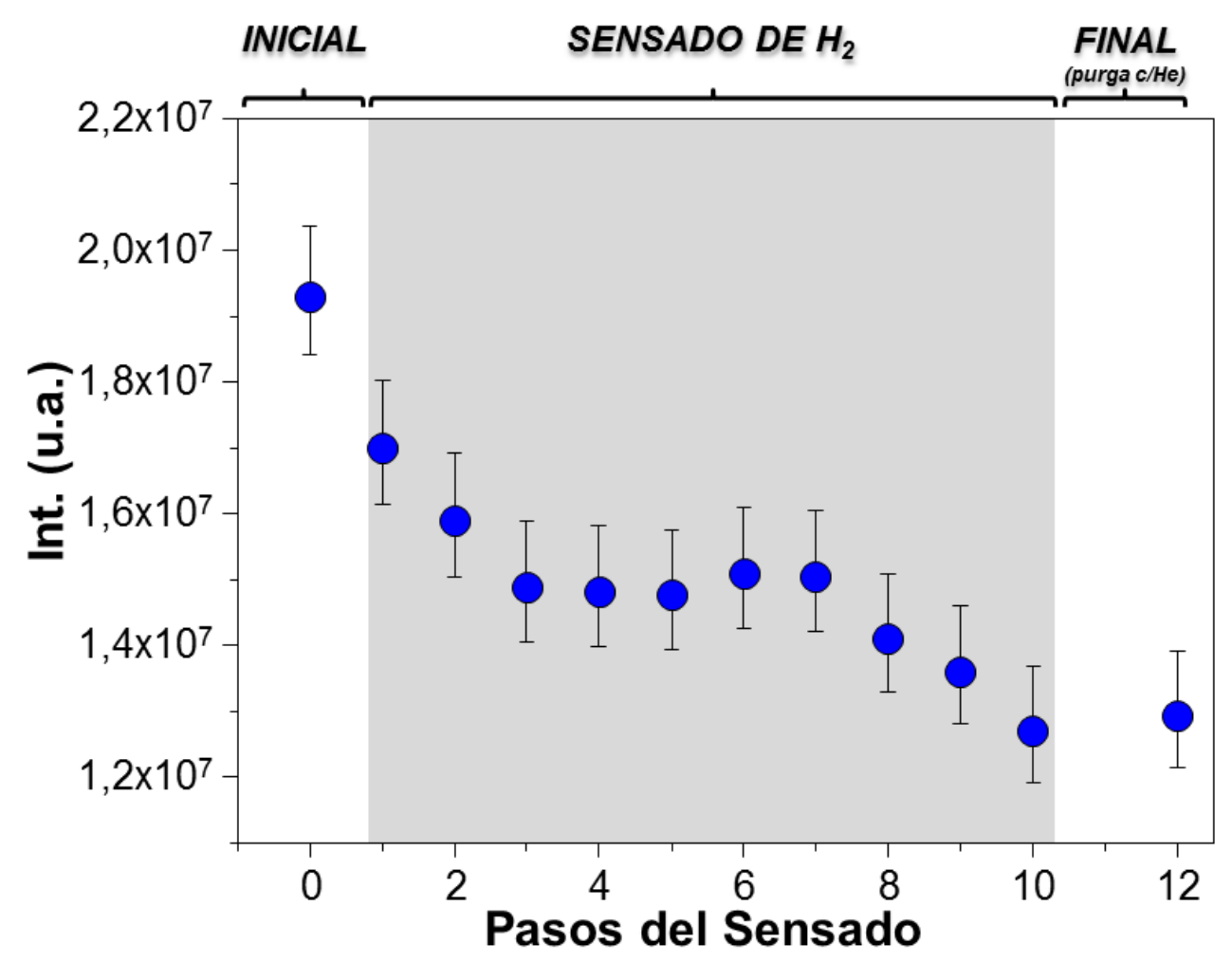

Figura 7.10 Gráfico mostrando la integración de cada spot de difracción seleccionado con el cuadrado blanco punteado en la Figura 7.8 de la heterojunción de grafeno/Pd/Pt (1:1)@ $\mathrm{NH}_{2} \mathrm{C}_{8}$, (mostrada en la Figura 7.7) en su estado inicial, durante la exposición a $\mathrm{H}_{2}$ y luego de una purga en $\mathrm{He}$, como es indicado. Notar que se produce una disminución en la intensidad de correlación durante la exposición a $\mathrm{H}_{2}$, y que el proceso es irreversible. Ver la sección de $\mathrm{Pd} / \mathrm{Pt}$ para más detalles.

\subsection{Conclusiones}

En éste Capítulo se presentaron los resultados preliminares correspondientes a las NPs de $\mathrm{Pd}$ y aleaciones de $\mathrm{Pd} / \mathrm{Pt}$ cubiertas con octilamina, las cuales fueron ensambladas como películas sobre grafeno crecido por CVD. En primer lugar, las NPs fueron caracterizadas por SAXS, determinando así sus tamaños promedio. Seguidamente, las mismas se ensamblaron espontáneamente sobre las películas de grafeno, lo cual fue facilitado por las interacciones hidrofóbicas entre las cadenas orgánicas de las NPs y el G. Por lo tanto, es importante enfatizar en que grafeno no necesita ser funcionalizado para poder formar este tipo de heterojunciones, lo cual es una ventaja para el ensamblado de los dispositivos. 
Los resultados obtenidos demuestran que la heterojunción comprendida por grafeno/ $\mathrm{Pd} @ \mathrm{NH}_{2} \mathrm{C}_{8}$ responde a la presencia del $\mathrm{H}_{2}$ con cambios tanto en el ángulo de giro $\left(\mathrm{R}_{\mathrm{g}}\right)$ como en la integración angular. Pensamos que el decrecimiento en el $\mathrm{R}_{\mathrm{g}}$ durante la primera exposición a $\mathrm{H}_{2}$, puede deberse a la formación de $\mathrm{PdH}_{\mathrm{x}}$ en la superficie de las NPs, lo que provocaría que las aminas (que se encuentran sorbidas débilmente al $\mathrm{Pd}$ ) tiendan a desprenderse de la superficie. Por otro lado, la heterojunción conformada por grafeno/PdPt (1:1)@ $\mathrm{NH}_{2} \mathrm{C}_{8}$ mostró correlación, lo cual permitió realizar un análisis diferente del realizado para las NPs sin correlación. Particularmente, para la película de grafeno/PdPt (1:1)@ $\mathrm{NH}_{2} \mathrm{C}_{8}$ durante la exposición a $\mathrm{H}_{2}$ se observó un decrecimiento en la intensidad de correlación. Además, después de un periodo de purga (flujo de He), la intensidad de correlación nunca retornó a su posición inicial, indicando la irreversibilidad de la película. Es necesario mencionar que, también se realizaron experimentos de control en los cuales se ensamblaron las NPs sobre sustratos de Si/APTES con el fin de dilucidar lo efectos de los mismos en la estructura, la estabilidad y orden de las NPs (datos no mostrados).

Finalmente, se plantean más experimentos empleando otras técnicas complementarias, tales como microscopía TEM y espectroscopia XANES con motivo de profundizar en el conocimiento de la interacción entre el $\mathrm{H}_{2}$ y los centros metálicos de las NPs.

\subsection{Bibliografía}

(1) Ibañez, F. J.; Zamborini, F. P. Reactivity of Hydrogen with Solid-State Films of Alkylamine- and Tetraoctylammonium Bromide-Stabilized Pd, PdAg, and PdAu Nanoparticles for Sensing and Catalysis Applications. J. Am. Chem. Soc. 2008, $130(2), 622-633$.

(2) Moreno, M.; Ibañez, F. J.; Jasinski, J. B.; Zamborini, F. P. Hydrogen Reactivity of Palladium Nanoparticles Coated with Mixed Monolayers of Alkyl Thiols and Alkyl Amines for Sensing and Catalysis Applications. J. Am. Chem. Soc. 2011, 133 (12), 4389-4397.

(3) Yamauchi, M.; Kobayashi, H.; Kitagawa, H. Hydrogen Storage Mediated by Pd and Pt Nanoparticles. ChemPhysChem 2009, 10 (15), 2566-2576.

(4) Sadeghmoghaddam, E.; Gu, H.; Shon, Y.-S. Pd Nanoparticle-Catalyzed Isomerization vs Hydrogenation of Allyl Alcohol: Solvent-Dependent Regioselectivity. ACS Catal. 2012, 2 (9), 1838-1845.

(5) Korotcenkov, G.; Han, S. D.; Stetter, J. R. Review of Electrochemical Hydrogen Sensors. Chem. Rev. 2009, 109 (3), 1402-1433.

(6) Dalfovo, M. C.; Lacconi, G. I.; Moreno, M. A.; Yappert, M. C.; Sumanasekera, G. U.; Salvarezza, R. C.; Ibañez, F. J. Synergy between Graphene and Au Nanoparticles (Heterojunction) Towards Quenching, Improving Raman Signal, and UV Light Sensing. ACS Appl. Mater. Interfaces 2014, 6 (9), pp 6384-6391 
(7) Moreno, Monica. Doctoral Thesis. Title: Hydrogen $\left(\mathrm{H}_{2}\right)$ Sensing and Catalysis with Organic-Stabilized Pd and Pd Alloy Nanoparticles. Department of Chemistry, University of Louisville, KY, USA. (2013). Director: Francis Zamborini.

(8) Ulvestad, A.; Welland, M. J.; Collins, S. S. E.; Harder, R.; Maxey, E.; Wingert, J.; Singer, A.; Hy, S.; Mulvaney, P.; Zapol, P.; et al. Avalanching Strain Dynamics during the Hydriding Phase Transformation in Individual Palladium Nanoparticles. Nat Commun 2015, 6, Article number: 10092

(9) Sidorov, A. N.; Sherehiy, A.; Jayasinghe, R.; Stallard, R.; Benjamin, D. K.; Yu, Q.; Liu, Z.; Wu, W.; Cao, H.; Chen, Y. P.; et al. Thermoelectric Power of Graphene as Surface Charge Doping Indicator. Appl. Phys. Lett. 2011, 99 (1), 013115.

(10) Leff, D. V.; Brandt, L.; Heath, J. R. Synthesis and Characterization of Hydrophobic, Organically-Soluble Gold Nanocrystals Functionalized with Primary Amines. Langmuir 1996, 12 (20), 4723-4730.

(11) Moreno, M.; Ibañez, F. J.; Jasinski, J. B.; Zamborini, F. P. Hydrogen Reactivity of Palladium Nanoparticles Coated with Mixed Monolayers of Alkyl Thiols and Alkyl Amines for Sensing and Catalysis Applications. J. Am. Chem. Soc. 2011, 133 (12), 4389-4397.

(12) Dalfovo, M. C.; Salvarezza, R. C.; Ibañez, F. J. Improved Vapor Selectivity and Stability of Localized Surface Plasmon Resonance with a Surfactant-Coated $\mathrm{Au}$ Nanoparticles Film. Anal. Chem. 2012, 84 (11), 4886-4892.

(13) Montel, M. X-Ray Microscopy with Catamegonic Roof Mirrors, X-Ray Microscopy and Microradiography. Academic Press, New York, 1957, 177-185.

(14) Hostetler, M. J.; Wingate, J. E.; Zhong, C.-J.; Harris, J. E.; Vachet, R. W.; Clark, M. R.; Londono, J. D.; Green, S. J.; Stokes, J. J.; Wignall, G. D.; et al. Alkanethiolate Gold Cluster Molecules with Core Diameters from 1.5 to $5.2 \mathrm{Nm}$ : Core and Monolayer Properties as a Function of Core Size. Langmuir 1998, 14 (1), 17-30.

(15) Narayanan; El-Sayed, M. A. Carbon-Supported Spherical Palladium Nanoparticles as Potential Recyclable Catalysts for the Suzuki Reaction. J. Catal. 2005, 234, 348-355.

(16) Giovanetti, L. J.; Ramallo-López, J. M.; Foxe, M.; Jones, L. C.; Koebel, M. M.; Somorjai, G. A.; Craievich, A. F.; Salmeron, M. B.; Requejo, F. G. Shape Changes of Pt Nanoparticles Induced by Deposition on Mesoporous Silica. Small 2012, 8 (3), 468-473.

(17) Guinier, A.; Fournet, G. Small-Angle Scattering of X-Rays; Wiley, 1955.

(18) Giovanetti, Lisandro. Tesis Doctoral: Efectos de Superficies En Nanopartículas Metálicas Estudiados Mediante Técnicas de Luz Síncrotron. Facultad de Ciencias Exactas, Universidad Nacional de La Plata. (2008). Director: Félix G. Requejo.

(19) Sakka, S. Handbook of Sol-Gel Science and Technology: Processing, Characterization and Applications, V. I - Sol-Gel Processing/Hiromitsu Kozuka, Editor, V. II - Characterization of Sol-Gel Materials and Products/Rui M. Almeida, Editor, V. III - Applications of Sol-Gel Technology/Sumio Sakka, Editor; Springer, 2004.

(20) B. Hammouda. A New Guinier-Porod Model. J. Appl. Cryst. 2010, 716-719. 
CAPÍTULO 7. SENSADO DE $\mathrm{H}_{2}$ CON HETEROJUNCIONES: GRAFENO + NPs DE $\mathrm{Pd}, \mathrm{Pt}$ Y ALEACIONES Pd/Pt

Sensores en Estado Sólido

(21) Willmott, P. An Introduction to Synchrotron Radiation: Techniques and Applications, 1 edition.; Wiley, 2011. 
Sección V

Parte Final 


\section{Capítulo 8}

\section{Conclusiones Generales}

A lo largo de ésta Tesis se exploró en el uso de nanomateriales para el diseño de sensores y plataformas sensibles.

En el Capítulo 3 se emplearon nanopartículas (NPs) de Au protegidas con bromuro de tetraoctilamonio (TOABr), ensambladas como películas, para el sensado óptico de compuestos orgánicos volátiles (volatile organic compounds, VOCs). Dichas películas respondieron selectivamente a la presencia de vapores polares y no-polares manifestando cambios en la longitud de onda máxima $\left(\lambda_{\text {máx }}\right)$ hacia altos y bajos valores, respectivamente, como fue demostrado por espectroscopia UV-vis. Se observó por FTIR que cuando los vapores de los analitos se particionan en la cubierta orgánica, ésta se reorganiza. Además, la película se contrae en la presencia de agua, como fue demostrado por las imágenes de SEM.

Por otro lado, cuando las películas de Au@TOABr (SNPs) se compararon a los sistemas modelo/control (conformados con NPs de Au protegidas con citrato), se encontró que las primeras son más sensibles frente a los vapores polares y no-polares. A su vez, las películas de Au@TOABr fueron fácilmente ensambladas sobre sustratos transparentes y demostraron ser más estables que las NPs de Au y Ag protegidas con citrato.

Todos estos resultados permitieron una comprensión fundamental de los sensores del tipo localized surface plasmon resonance (LSPR) constituidos con los tipos de NPs antes mencionadas.

En el Capítulo 4, con el fin de comprender e indagar en la importancia de la cubierta orgánica (capping agent) de las NPs para la detección de VOCs, se emplearon técnicas de luz sincrotrón para dilucidar tal mecanismo de sensado.

Se realizaron cinéticas (real time) empleando GISAXS in-situ mientras se expuso a las películas de Au@TOABr (SNPs) a la presencia de analitos en fase vapor. Se observaron diferentes cambios en la distancia centro-a-centro (core-to-core) y la restructuración de la película cuando la misma fue expuesta a concentraciones conocidas de vapores tanto polares como no polares. De los resultados obtenidos, se desprende el interesante comportamiento de las películas de SNPs as-prepared frente al vapor de Tolueno (Tol), ya que la distancia inter-nanopartículas (inter-NPd) incrementa en la presencia de Tol al mismo tiempo que se mejora la correlación (incremento en la 
intensidad del vector $q$ ) de la misma. Por el contrario, en la presencia de Etanol (EtOH) la inter-NPd no cambió y la correlación entre las mismas disminuyó dramáticamente.

A su vez, con el fin de ahondar tanto en la composición orgánica, la estructura y la flexibilidad de la cubierta orgánica de dichos sistemas, se realizó un intercambio de ligandos (tanto en fase vapor como en fase líquida) de las películas de SNPs con nonanotiol (NT) y nonanoditiol (NDT). Luego, dichas muestras fueron expuestas a un $100 \%$ de vapor de Tol y se caracterizaron por GISAXS en tiempo real. Resulta interesante que, la incorporación de NDT reduce la flexibilidad de las películas y produce un incremento en la distancia inter-nanopartículas (indicado por GISAXS). Además, fue determinado que sólo un pequeño número de átomos de $\mathrm{S}$ se enlazan a las NPs de Au y se evidenció la formación de una conformación con la forma de asa (loop) para las cadenas de alcanoditioles, como fue indicado por los espectros de XANES y los defectos de tipo vuelta (kink defects) evidenciados por FT-IR, respectivamente.

Finalmente, se correlacionaron los resultados obtenidos por GISAXS con los de el mismo tipo de películas de SNPs en sensores del tipo chemiresitivos (Ibañez et al. ${ }^{1}$ ), proporcionando resultados muy interesantes.

Todos estos resultados demostraron que las películas de SNPs constituyen plataformas sensibles a compuestos orgánicos volátiles (VOCs) tanto polares como nopolares. Cabe mencionar que las mismas constan de los siguientes atributos: son de fácil ensamblado, bajo costo y estables en largos periodos de tiempo (expuestas a condiciones de presión y temperatura ambiente).

En el Capítulo 5, se empleó grafeno $(\mathrm{G})$ monocapa obtenido por CVD, el cual luego fue transferido a diferentes sustratos utilizando el polímero PMMA. Seguidamente, el G fue combinado con nanopartículas (NPs) de Au protegidas con $\mathrm{TOABr}$ (SNPs) para formar heterojunciones. Estas últimas fueron empleadas para medir la conducción de la película (evaluando el efecto de la presencia de las NPs en la corriente del sistema) y como plataformas SERS para la detección de bajas concentraciones de Rodamina B.

Con el fin de explorar el comportamiento del grafeno obtenido, se realizaron tratamientos post-síntesis a las muestras de $\mathrm{G}$ tanto con PMMA como con ozono $\left(\mathrm{O}_{3}\right)$, los cuales mostraron un decrecimiento en la corriente de las películas estudiadas. Cabe mencionar que, las heterojunciones $(\mathrm{G}+\mathrm{NPs}$ de $\mathrm{Au})$ no mostraron efectos significativos en la corriente respecto a las películas de G sin NPs (as-transferred).

Un aspecto central de éste Capítulo es que, se demostró que G es capaz de apagar (quenching) más del $90 \%$ de una combinación de fotolumiscencia (PL) y fluorescencia (FL) pertenecientes a las NPs de Au y la Rodamina B (RhB), respectivamente. Uno de los beneficios de éste comportamiento radica en que moléculas 
que presentan fluorescencia van a poder ser detectadas y caracterizadas por SERS sobre plataformas que contengan grafeno (ej.: G "as-transferred", grafeno oxidado (OG) y heterojunciones). Además, se demostró que $\mathrm{G}$ es el mayor responsable del pagado de la PL y la FL, mientras que la heterojunción mejoró más de 3-veces la actividad Raman de la RhB.

Finalmente, durante los experimentos de sensado de luz UV fue posible correlacionar los cambios en la corriente de las películas. En éste aspecto, se observaron peculiares perfiles de sensado cuando se emplearon diferentes energías de luz UV.

En el Capítulo 6, se planteó el desafío de poder transferir el grafeno (G) obtenido por CVD evitando el uso del polímero PMMA, debido a que este último aún luego de rigurosos procedimientos de limpieza permanece como una impureza en la superficie del G (alterando las propiedades intrínsecas de este nanocarbón). Para resolver este dilema, se transfirió el G empleando las nanopartículas (NPs) de Au protegidas con TOABr (SNPs), lo cual conduce a la formación de una heterojunción que sirve tanto de plataforma TERS como SERS.

Se descubrió que, luego de que el G es transferido empleando las SNPs y es sometido a un tratamiento térmico (para remover los residuos orgánicos provenientes de las NPs) se forman redes con NPs de $\mathrm{Au}$, dímeros y nanoplates de variadas formas (discos, hexágonos y triángulos). Dichas estructuras fueron extensivamente estudiadas por HRTEM, Raman, SERS y TERS.

Uno de los puntos más importantes de éste Capítulo radica en que, se lograron por primera vez en nuestro país estudiar plataformas constituidas con G y NPs empleando técnicas tan novedosas como TERS, permitiendo éste último obtener una alta resolución a nivel local.

Finalmente, las contribuciones más importantes de este Capítulo fueron: a) el aporte de nuevas metodologías para la transferencia de grafeno; b) el estudio fundamental de los "local strains" en las heterojunciones; y c) el estudio de la actividad SERS realizado tanto en el nanoplate de Au como en las "Au networks".

En el Capítulo 7, se sintetizaron nanopartículas (NPs) de Pd y aleaciones de $\mathrm{Pd} / \mathrm{Pt}$ cubiertas con octilamina (sintetizadas químicamente), las cuales luego se ensamblaron como películas sobre grafeno crecido por CVD para aplicaciones en sensado de $\mathrm{H}_{2}$ (sensores en estado sólido).

Con el fin de explorar la forma, el orden y el tamaño de las NPs tanto en suspensión como en películas en estado sólido, se llevaron a cabo caracterizaciones utilizando SAXS y GISAXS, respectivamente. 
Además, se realizaron experimentos de GISAXS en tiempo real, lo cual permitió ahondar en: a) las restructuraciones de las películas conformadas con NPs durante el sensado de $\mathrm{H}_{2}$; b) los efectos e influencia del sustrato en la formación y estabilidad; y c) la estructura de las películas.

Finalmente, se encontró que las películas se comportan de manera diferente dependiendo de: a) el tipo de NPs (Pd versus aleaciones $\mathrm{Pd} / \mathrm{Pt}$ ); y b) la naturaleza de los sustratos empleados.

\section{Perspectivas}

Durante esta Tesis se investigaron diferentes tipos de plataformas sensibles, desde la detección de VOCs, incrementando la señal analítica de moléculas orgánicas de mayor tamaño (colorantes altamente fluorescentes), hasta la detección de $\mathrm{H}_{2}$.

Por otro lado, de los sistemas estudiados surgen las siguientes preguntas y cuestiones que no fueron completamente respondidas, es por ello que se plantean los siguientes experimentos para poder resolverlos.

- En el Capítulo 3 se planteó la mejora de los sensores para VOCs, constituidos con NPs, remplazando las nanopartículas de Au ya sea por Ag y/o aleaciones entre ambos elementos (para mejorar la sensibilidad de los sensores). Este tipo de NPs (Ag@TOABr y AuAg@TOABr) han sido ya reportadas por Ibañez et $a l{ }^{1}$ en sensores del tipo chemiresistores para la detección de un amplio espectro de VOCs. Es por ello que sería viable el uso de éste tipo de NPs en sensores del tipo LSPR.

- En estudios preliminares, el mismo tipo de NPs que se estudiaron a lo largo de los Capítulos 3 y 4, fueron ensambladas de manera tal de obtener películas con concentraciones mayores y menores a las estudiadas, lo cual permite el diseño de arreglos de multisensores. El objetivo de obtener multisensores radica en que éstos pueden ya sea detectar diferentes familias de compuestos químicos y/o que según el ensamblado de las NPs se puedan obtener sistemas con diferentes sensibilidades frente a diferentes analitos. Dichos resultados no fueron mostrados en éste reporte.

- Por otro lado, sería muy interesante remplazar la cubierta orgánica de las NPs, por ejemplo con moléculas con cabezas de grupo polares, lo cual permitiría el diseño de plataformas con mayor selectividad frente a una familia determinada de compuestos. 
- En el Capítulo 4 se exploró el mecanismo de sensado de las películas de $\mathrm{Au} @ \mathrm{TOABr}$ frente a VOCs, mediante GISAXS, XANES y FT-IR, entre otras técnicas. En dicho estudio, se emplearon como sistema de control películas de SNPs tratadas con ditioles (NDT), los cuales limitan la movilidad entre las NPs cuando éstas se enfrentan a la presencia de los analitos en fase vapor. Como resultado de los sistemas estudiados se determinó que, las cadenas orgánicas en el sistema de control (con NDT) se encuentran en una conformación en forma de asa (loop). Es por ello que planteamos realizar experimentos utilizando RMN en estado sólido (solid-state NMR) con el fin de poder explorar en mayor detalle cada Carbono a lo largo de la cadena del alcanoditiol.

- En el Capítulo 5 se introdujo al primer cristal bidimensional aislado, el grafeno. El mismo fue obtenido por CVD sobre láminas de $\mathrm{Cu}$ y transferido a diferentes sustratos. Luego, el mismo fue empleado (y combinado con NPs) en la formación de plataformas SERS para la detección de el analito Rodamina B en bajas concentraciones.

- En el futuro, sería interesante explorar en la incorporación de nanoestructuras de Ag y/o aleaciones $\mathrm{Au} / \mathrm{Ag}$ sobre grafeno, con el fin de mejorar la actividad SERS de otras moléculas Raman activas.

- Cabe mencionar que, durante esta Tesis se logró sintetizar grafeno por CVD sobre sustratos de espuma de $\mathrm{Ni}$ (Ni foam). El interés en la obtención de grafeno tridimensional (G-3D) radica en que se pueden plantear plataformas en las cuales se conserven las propiedades innatas de grafeno y al mismo tiempo se obtenga una gran área superficial específica (lo cual lo convierte en un material más activo desde el punto de vista catalítico). Esto permitirá emplear el G-3D en el desarrollo y estudio desde ánodos para celdas solares ${ }^{2,3}$ hasta supercapacitores y baterías. ${ }^{4}$

- Respecto al sensado de luz UV por parte del grafeno, sería interesante explorar en el mecanismo por el cual las especies de Oxígeno (que están adsorbidas en la superficie del grafeno) interactúan para generar cambios en la corriente del sistema cuando el mismo es iluminado con luz UV.

- En el Capítulo 6, se reportó una nueva metodología para la transferencia de grafeno empleando NPs de Au, evitando el uso del PMMA. Como resultado de dicha transferencia, se obtuvieron heterojunciones que se emplearon como plataformas SERS y TERS.

- Respecto a las plataformas SERS/TERS estudiadas a lo lago del Capítulo 6, sería muy importante la mejora del tamaño de los flakes de las heterojunciones obtenidas $(\mathrm{G}+\mathrm{NPs})$, ya que la metodología de transferencia libre del polímero 
PMMA (sólo empleando NPs como agente de transferencia) trae aparejado un bajo rendimiento. Es por ello que, proponemos mejorar éste nuevo método de transferencia de grafeno empleando por ejemplo la combinación de las NPs con algún polímero de menor peso molecular, el cual luego pueda ser removido con facilidad.

- Sería interesante explorar tanto en la actividad como en el comportamiento TERS de las nanopartículas individuales y en la propagación de cargas dentro de las heterojunciones (metal + grafeno), para poder determinar así el mecanismo/fenómeno por el cual los espectros TERS de grafeno están desplazados hacia mayores frecuencias (blue-shift).

- En el Capítulo 7, exploró en el comportamiento básico de sensores de $\mathrm{H}_{2}$ en estado sólido constituidos por NPs de Pd y aleaciones de Pd/Pt cubiertas con octilamina, las cuales se ensamblaron como películas sobre grafeno. Para ello se emplearon las técnicas de luz sincrotrón SAXS y GISAXS.

- Si bien en el mencionado Capítulo se estudiaron las restructuraciones de las películas conformadas con NPs durante el sensado de $\mathrm{H}_{2}$, sería muy interesante poder correlacionar estos comportamientos con el mismo tipo de películas con NPs en sensores del tipo chemiresistivos.

- Finalmente, en el área de energías renovables es importante mencionar que se diseñaron y sintetizaron estructuras tridimensionales de $\mathrm{Cu}$, las cuales se depositaron sobre sustratos de FTO (fluorine-doped tin oxide) y se combinaron con $\mathrm{TiO}_{2}$ y colorantes orgánicos que absorben la luz solar (dye) para la construcción de fotoánodos empleados en celdas solares del tipo dye-sensitized solar cells (DSSCs). Dicho trabajo actualmente esta siendo ejecutado en colaboración con el Conn Center for Renewable Energy Research, Kentucky, Estados Unidos. Si bien éstos resultados no se mostraron en esta Tesis, los mismos corresponden a parte del desarrollo científico logrado en la misma. 


\section{Bibliografía}

(1) Ibañez, F. J.; Zamborini, F. P. Chemiresistive Sensing of Volatile Organic Compounds with Films of Surfactant-Stabilized Gold and Gold-Silver Alloy Nanoparticles. ACS Nano 2008, 2 (8), 1543-1552.

(2) Bernardi, M.; Lohrman, J.; Kumar, P. V.; Kirkeminde, A.; Ferralis, N.; Grossman, J. C.; Ren, S. Nanocarbon-Based Photovoltaics. ACS Nano 2012, 6 (10), 88968903.

(3) Roy-Mayhew, J. D.; Aksay, I. A. Graphene Materials and Their Use in DyeSensitized Solar Cells. Chem. Rev. 2014, 114 (12), 6323-6348.

(4) Cao, X.; Shi, Y.; Shi, W.; Lu, G.; Huang, X.; Yan, Q.; Zhang, Q.; Zhang, H. Preparation of Novel 3D Graphene Networks for Supercapacitor Applications. Small 2011, 7 (22), 3163-3168. 


\title{
A.1 Abreviaturas, Siglas y Acrónimos
}

\author{
AFM Atomic Force Microscopy \\ CNPs Citrate coated nanoparticles, nanopartículas protegidas con citrato \\ CVD Chemical vapor Deposition, deposición química de vapores \\ EtOH Etanol \\ FL Fluorescence, fluorescencia \\ FTIR Fourier transform infrared spectroscopy \\ GERS Graphene-enhanced Raman scattering \\ G Graphene, grafeno
}

GISAXS Grazing-incidence small-angle X-ray scattering, dispersion de rayos X a bajo ángulo con incidencia rasante.

HSC $_{6} \quad$ Hexanotiol (HT)

$\mathbf{H S C}_{12} \quad$ Dodecanotiol

HSC9 Nonanotiol (NT)

$\mathbf{H}_{2} \mathbf{S}_{\mathbf{2}} \mathbf{C}_{\mathbf{9}} \quad$ Nonanoditiol (NDT)

HOPG Highly oriented pyrolytic graphite

HRTEM High-resolution transmission electron microscopy

inter-NPd Distancia inter-nanopartículas (puede ser determinada de borde-a-borde o de centro-a-centro)

LSPR Localized surface plasmon resonance

NPs Nanopartículas

OG Oxidazed graphene, grafeno oxidado (G obtenido por CVD)

PL Photoluminiscence, fotoluminiscencia

RhB Rhodamine B, rodamina B

Rho6G Rhodamine 6G, rodamina 6G 
RMS desviación cuadrática media de la rugosidad

SAMs Monolayer protected-clusters

SAXS Small-angle X-ray scattering, dispersion de rayos $\mathrm{X}$ a bajo ángulo con incidencia normal

SEM Scanning electron microscopy

SERS Surface-enhanced Raman scattering, espectroscopia Raman amplificada por superficie

SNPs Surfactant coated nanoparticles, nanopartículas protegidas con un surfactante

TEM Transmission electron microscopy

TERS Tip-enhanced Raman spectroscopy

TGA Thermogravimetric analysis

TOABr Tetraoctylammonium bromide, bromuro de tetraoctilamonio

Tol Tolueno

UV-Vis Espectroscopia ultravioleta-visible

XANES X-ray absorption near edge structure,

XPS X-ray photoelectron spectroscopy, espectroscopía de fotoelectrones

generados por rayos $\mathrm{X}$ 


\section{A.2 Constantes Físicas}

\section{Índices de Refracción ${ }^{1}$}

\begin{tabular}{lc}
\hline \multicolumn{1}{c}{ Sustancia } & Índice de Refracción $(\boldsymbol{\eta})$ \\
\hline Aire & 1,00030 \\
Etanol (EtOH) & 1,36168 \\
Tolueno (Tol) & 1,49690 \\
\hline
\end{tabular}

(1) CRC Handbook of Chemistry and Physics, 96th Edition, 96 edition.; CRC Press, 2015. 


\section{B.1 Cambios Esperados en el Valor de LSPR Calculados Empleando la Teoría de Mie}

Es importante comparar los corrimientos en el plasmón causados por los cambios en el índice de refracción (RI) tanto para las nanopartículas cubiertas (con material orgánico) como para las nanopartículas desnudas (no cubiertas) dispersas en solventes puros, con aquellos corrimientos producidos por las películas de nanopartículas cubiertas ensambladas sobre sustratos y expuestas a vapores. siguiente, ${ }^{2}$

Usando la teoría de Mie para nanopartículas desnudas, la ecuación es la

$$
\lambda_{\text {máx }}^{2}=\lambda_{p}^{2}\left(\varepsilon^{\infty}+2 \varepsilon_{\mathrm{m}}\right)
$$

donde " $\lambda_{\text {máx }}$ " es la posición del pico del plasmón superficial, " $\lambda_{\mathrm{p}}$ " es la longitud de onda correspondiente a la frecuencia plasma del metal masivo (para el Au es, $131 \mathrm{~nm}$ ), " $\varepsilon$ ", es la función dieléctrica óptica del metal $(12,2)$, y " $\varepsilon_{\mathrm{m}}$ " es la función dieléctrica óptica del medio.

Luego de resolver la ecuación 1 para determinar el $\lambda_{\text {máx }}$ en diferentes medios, se obtuvieron los siguientes valores: 493,6, 522,3, y 534,4 nm para aire, EtOH, y Tol, respectivamente.

Por otro lado, para las nanopartículas de Au cubiertas con material orgánico, la ecuación involucra un segundo término, como aquí se describe:

$$
\lambda_{\text {máx }}^{2}=\lambda_{\mathrm{p}}^{2}\left[\left(\varepsilon^{\infty}+2 \varepsilon_{\mathrm{m}}\right)-2 \mathrm{~g}\left(\varepsilon_{\mathrm{m}}-\varepsilon_{\mathrm{s}}\right) / 3\right]
$$

donde " $\varepsilon_{\mathrm{s}}$ " es la función dieléctrica óptica del capping (cubierta orgánica) y "g" es un valor dado correspondiente a la fracción de volumen comprendida entre el core y la shell, obtenido por la siguiente ecuación:

$$
\mathrm{g}=\left[\left(\mathrm{R}_{\text {core }}+\mathrm{R}_{\text {shell }}\right)^{3}-\left(\mathrm{R}_{\text {core }}\right)^{3}\right] /\left(\mathrm{R}_{\text {core }}+\mathrm{R}_{\text {shell }}\right)^{3}
$$




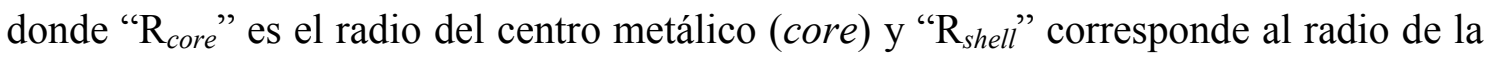
cubierta orgánica (organic shell). Para el caso de las nanopartículas de Au cubiertas con TOABr, consideramos que el $\mathrm{R}_{\text {core }}=2,2 \mathrm{~nm}, \mathrm{R}_{\text {shell }}=0,5 \mathrm{~nm}, \mathrm{y} \varepsilon_{\mathrm{s}}=1,6^{2}$ el cual es la función dieléctrica asumiendo una monocapa compuesta de 8 unidades de metilenos.

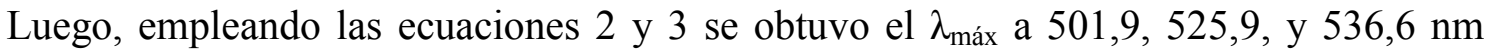
para aire, EtOH, y Tol, respectivamente. Las constantes de índice de refracción usadas aquí fueron: $\eta_{\text {aire }}=1,0003 ; \eta_{\mathrm{EtOH}}=1,36168 ; \eta_{\mathrm{Tol}}=1,4969$ (las mismas están detalladas en el Apéndice A). De acuerdo a los cálculos, una comparación entre las nanopartículas de Au desnudas y las cubiertas indica un decrecimiento en el corrimiento del plasmón para las últimas. Por ejemplo, el corrimiento en el plasmón producido entre aire y EtOH es de 29 y $24 \mathrm{~nm}$ para las NPs de Au desnudas y las cubiertas dispersas en EtOH, respectivamente. Finalmente, la siguiente Tabla resume los cálculos de los $\lambda_{\text {máx }}$ tanto para las NPs desnudas (CNPs) como para las NPs cubiertas (SNPs) aquí realizados.

\begin{tabular}{lcc}
\hline \multicolumn{1}{c}{ Sustancia } & CNPs (desnudas) & SNPs (cubiertas) \\
\hline Aire & 493,6 & 501,9 \\
Etanol (EtOH) & 522,3 & 525,9 \\
Tolueno (Tol) & 534,4 & 536,6 \\
\hline
\end{tabular}

(2) Templeton, A. C.; Pietron, J. J.; Murray, R. W.; Mulvaney, P. Solvent Refractive Index and Core Charge Influences on the Surface Plasmon Absorbance of Alkanethiolate Monolayer-Protected Gold Clusters. The Journal of Physical Chemistry B 1999, 104 (3), 564-570. 


\section{C.1 Trabajos Publicados}

(1) Dalfovo, M. C.; Salvarezza, R. C.; Ibañez, F. J. Improved Vapor Selectivity and Stability of Localized Surface Plasmon Resonance with a Surfactant-Coated Au Nanoparticles Film. Anal. Chem. 2012, 84 (11), 4886-4892.

(2) Dalfovo, M. C.; Lacconi, G. I.; Moreno, M.; Yappert, M. C.; Sumanasekera, G. U.; Salvarezza, R. C.; Ibañez, F. J. Synergy between Graphene and Au Nanoparticles (Heterojunction) towards Quenching, Improving Raman Signal, and UV Light Sensing. ACS Appl. Mater. Interfaces 2014, 6 (9), 6384-6391.

(3) Dalfovo, M. C.; Giovanetti, L. J.; Ramallo-López, J. M.; Salvarezza, R. C.; Requejo, F. G.; Ibañez, F. J. Real-Time Monitoring Distance Changes in Surfactant-Coated Au Nanoparticle Films upon Volatile Organic Compounds (VOCs). J. Phys. Chem. C 2015, 119 (9), 5098-5106.

(4) Pérez, L. A.; Dalfovo, M. C.; Troiani, H. E.; Soldati, A. L.; Lacconi, G. I.; Ibañez, F. J. CVD Graphene Transferred with Au Nanoparticles: An Ideal Platform for TERS and SERS on a Single Triangular Nanoplate. J. Phys. Chem. C 2016. 


\section{C.2 Premios/Menciones}

* 2014. Premios Innovar. Preselección. Proyecto ID: 17182. Título: Nanopartículas de Oro Utilizadas como Sensores Colorimétricos. Categoría: Investigación Aplicada. Link: http://www.innovar.mincyt.gob.ar/catalogointeractivo/\#

* 2013. Premios Innovar. Preselección. Proyecto ID: 14950. Título: Grafeno como Plataforma de Sensado: Detección de Luz Ultravioleta (UV) y Otros Analitos de Interés. Categoría: Investigación Aplicada. Link: http://www.innovar.mincyt.gob.ar/catalogo-interactivo/\# 